6.

7.

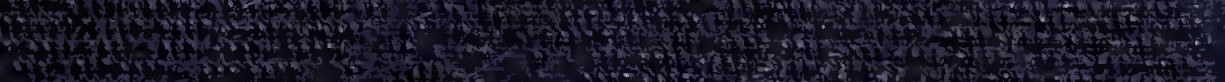

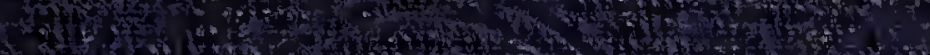

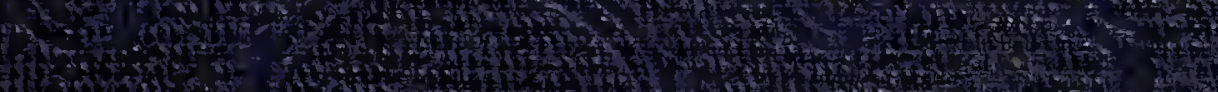
5. - 45 - 20 .

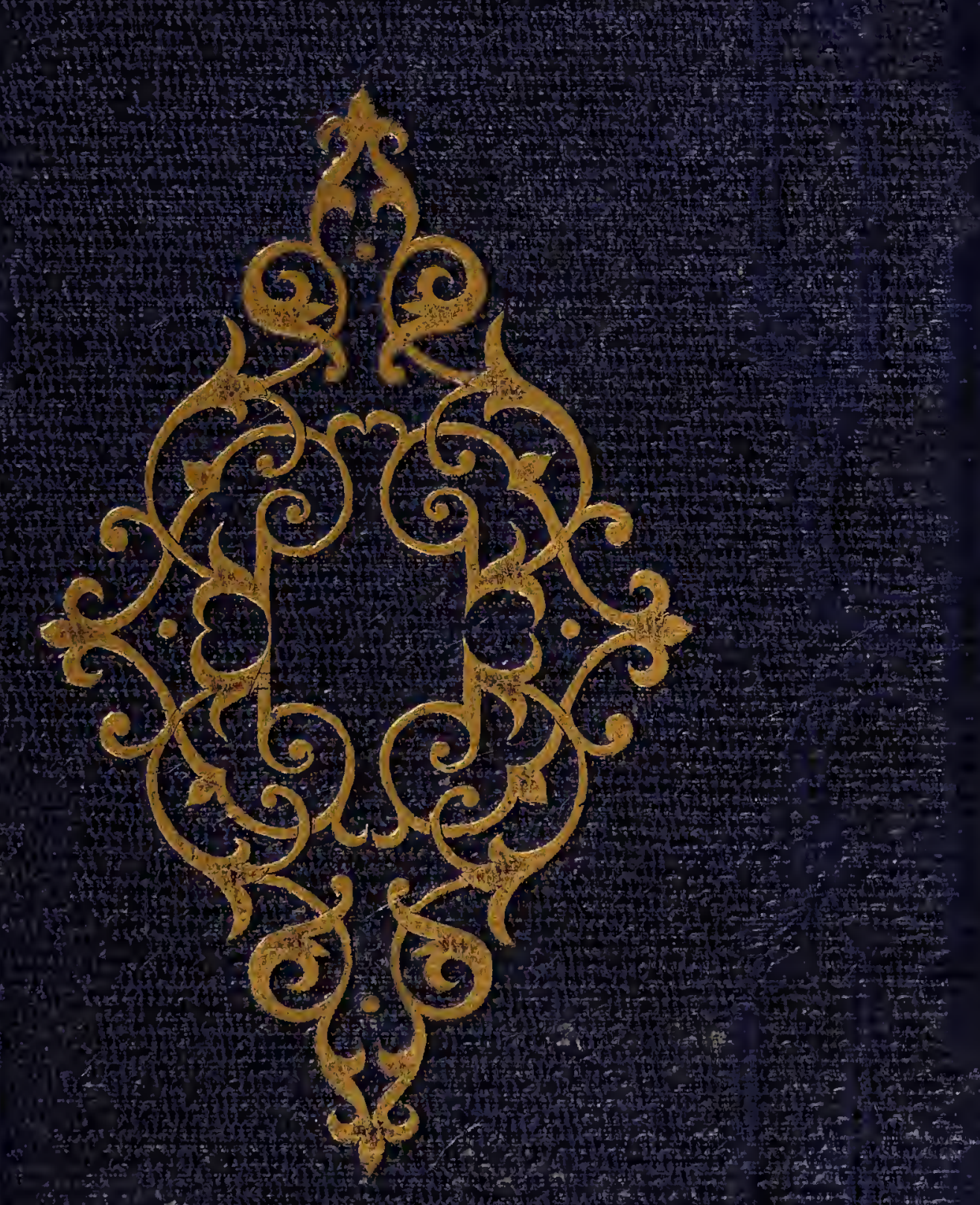

$17 x^{2}$

M. 


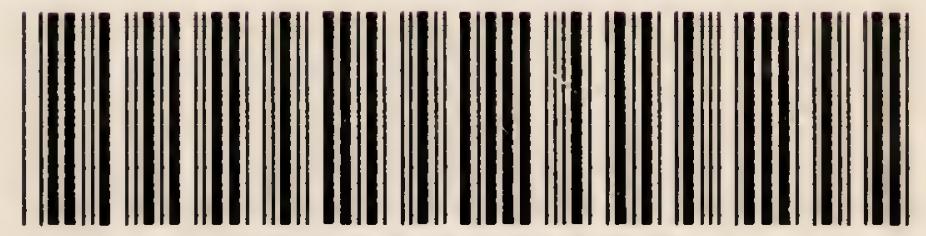

22101438878 
- Hautes leciuat lezedall

Hest isege on

cladiedate. Lanis and

- lood lendert

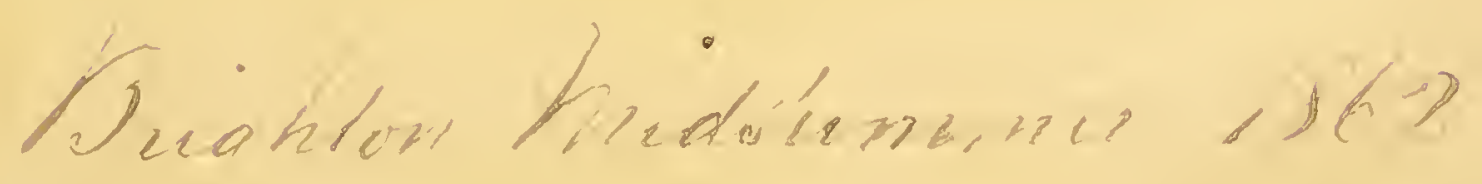



Digitized by the Internet Archive in 2017 with funding from Wellcome Library 


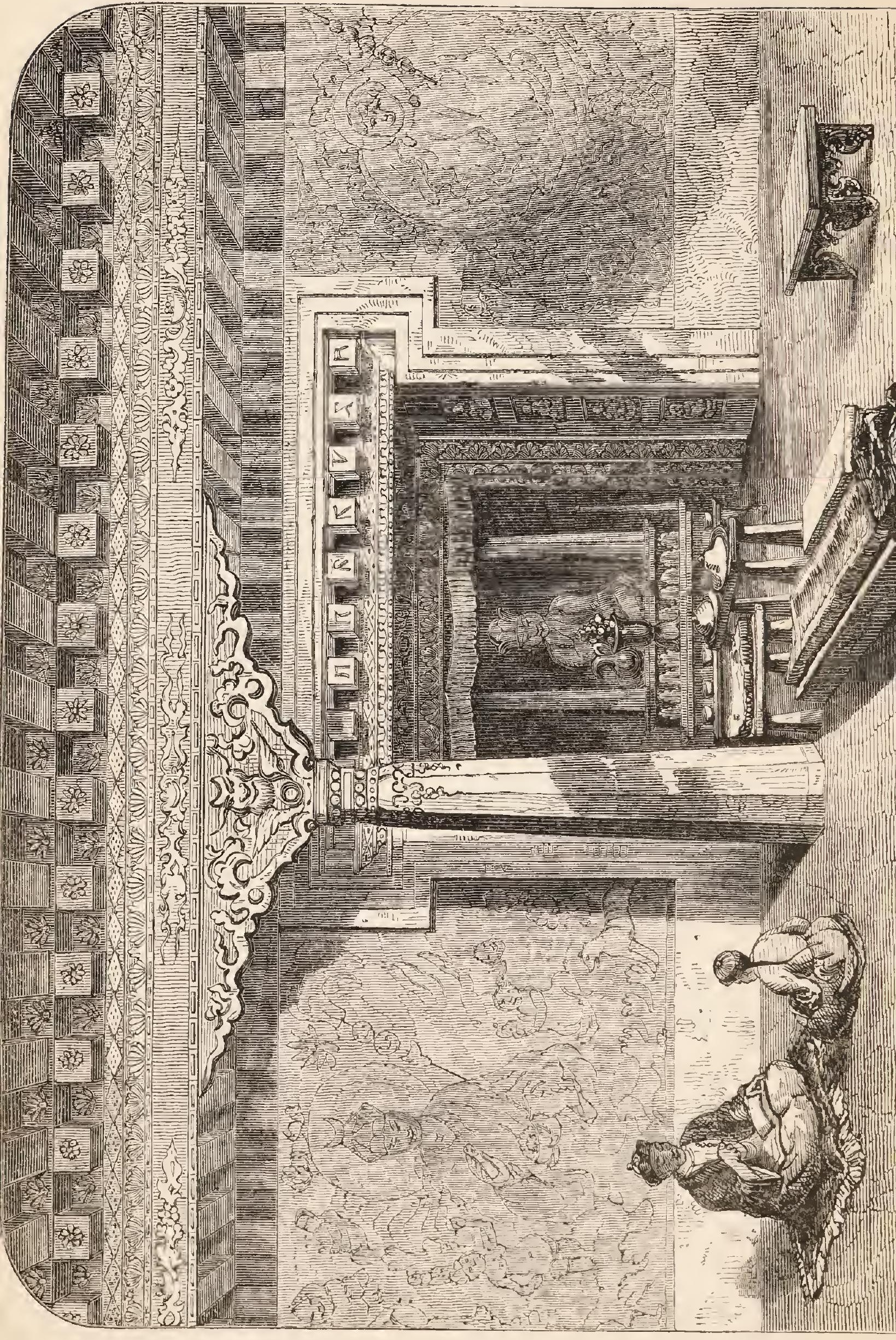




\title{
HIMALAYAN JOURNALS.
}

\author{
NOTES OF A NATURALIST
}

IN BENGAL, THE SIKKIM AND NEPAL HIMALAYAS, THE KHASIA MOUNTAINS, \&c.

By JOSEPH DALTON HOOKER, M.D. R.N. F.R.S.

A NEW EDITION, CAREFULLY REVISED AND CONDENSED.

IN TWO VOLUMES.-VOL. I.

WITH WOODCUTS.

LONDON :

JOHN MURRAY, ALBEMARLE STREET. 1855. 
LONDON :

BRADBURY AND EVANS, PRINTERS, WHITEFRIAPS,
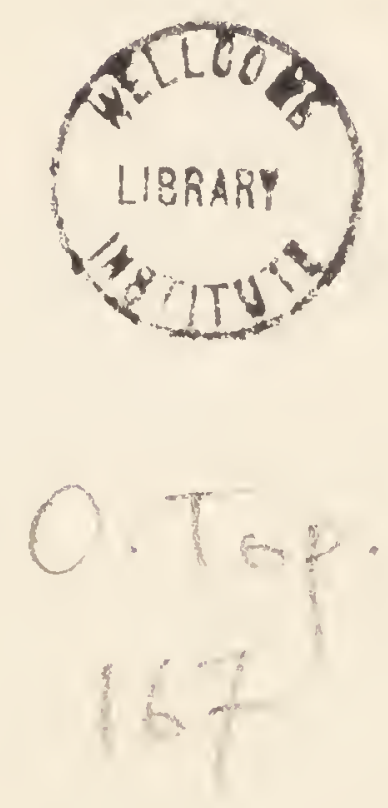


\section{PREFACE.}

Having accompanied Sir James Ross on his voyage of discovery to the Antarctic regions, where botany was my chief pursuit, I was anxious to add to my acquaintance with the natural history of the temperate zones, more knowledge of that of the tropics than I had hitherto had the opportunity of acquiring. My choice lay between India and the Andes, and I decided upon the former, being principally influenced by Dr. Falconer, the Superintendent of the H. E. I. C. Botanic Garden at Calcutta. He drew my attention to the fact that we were ignorant even of the geography of the central and eastern parts of these mountains, while all to the north was involved in a mystery equally attractive to the traveller and the naturalist.

The portion of the Himalaya best worth exploring, was selected for me both by Lord Auckland and Dr. Falconer, who each recommended Sikkim, as being ground untrodden by traveller or naturalist. Its ruler 
was, moreover, all but a dependant of the British government, and it was supposed, would therefore be glad to facilitate my researches.

No part of the snowy Himalaya eastward of the north-west extremity of the British possessions had been visited since Turner's embassy to Tibet in 1789 ; and hence it was highly important to explore scientifically a part of the chain which from its central position might be presumed to be typical of the whole range. The possibility of visiting Tibet, and of ascertaining particulars respecting the great mountain Chumulari, which was only known from Turner's account, were additional inducements to a student of physical geography; but it was not then known that Kinchinjunga, the loftiest known mountain on the globe, was situated on my route, and formed a principal feature in the physical geography of Sikkim.

My passage to Egypt was provided by the Admiralty in H. M. steam-ressel "Sidon," destined to convey the Marquis of Dalhousie, Governor-General of India, thus far on his way. On his arrival in Egypt, his Lordship did me the honour of desiring me to consider myself in the position of one of his suite, for the remainder of the voyage, which was performed in the "Moozuffer," a steam frigate belonging to the Indian Navy.

During the passage out, some days were spent in 
Egypt, at Aden, Ceylon, and Madras. I have not thought it necessary to give here the observations made in those well-known countries; they are detailed in a series of extracts published in the "London Journal of Botany," from letters written to my private friends. Arriving at Calcutta in January, I passed the remainder of the cold season in making myself acquainted with the vegetation of the plains and hills of Western Bengal, south of the Ganges, by a journey across the mountains of Birbhoom and Behar to the Soane valley, and thence over the Vindhya range to the Ganges, at Mirzapore, whence I descended that stream to Bhaugulpore; and leaving my boat, I then struck north to the Sikkim Himalaya.

In the course of this narrative, I shall give a sketch of the rise, progress, and prospects of the Sanatarium, or Health-station of Dorjiling, and of the anomalous position held by the Sikkim Rajah. The latter circumstance led indirectly to the detention of Dr. Campbell, the superintendent of Dorjiling (who joined me in one of my journeys), and myself, by a faction of the Sikkim court, for the purpose of obtaining from the Indian Government a more favourable treaty than that then existing. This mode of enforcing a request by douce violence and detention, is common with the turbulent tribes east of Nepal, but was in this instance aggravated by violence towards my fellow-prisoner, 
through the ill will of the persons who executed the orders of their superiors, and who had been punished by Dr. Campbell for crimes committed against the British and Nepalese governments. The circumstances of this outrage were misunderstood at the time; its instigators were supposed to be Chinese; its perpetrators Tibetans; and we, the offenders, were assumed to have thrust ourselves into the country, without authority from our own government, and contrary to the will of the Sikkim Rajah; who was imagined to be a tributary of China, and protected by that nation, and to be under no obligation to the East Indian government.

Dr. T. Thomson joined me in Dorjiling towards the end of 1849, after the completion of his arduous journeys in the North-West Himalaya and Tibet, and we spent the year 1850 in travelling and collecting in the Khasia mountains; returning to England together in 1851 . 


\section{LIST OF ILLUSTRATIONS.}

INTERIOR OF THE tEMPLE AT PEMiONgChi • . Fiontispiece. Page OLD TAMARIND TREES • • • . • • • • . . 15

CROSSING THE SOANE, WITH THE KYMORE HILLS IN THE DISTANCE 40

EQUATORIAL SUN-DIAL • • • • • • • • . 68

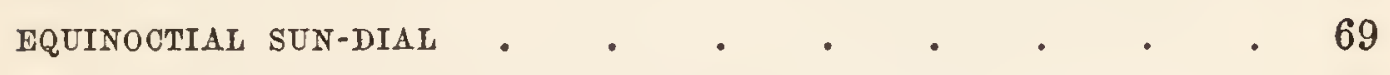

BRASS AZIMUTH CIRCLE $. \quad . \quad . \quad . \quad . \quad .70$

MONGHYR ON THE GANGES, WITH THE CURRUCKPORE HILLS IN THE DISTANCE

PUNKABAREE BUNGALOW AND BASE OF THE HIMALAYA • • . 94

LEPCHA GIRL AND BOODHIST LAMA • • • • • . 119

LEPCHA AHCLET

PINES (PINUS LONGIFOLIA), RUNGEET VALLEY • • • • . 139

CANF BRIDGE

LEPCHA WATER-CARRIER WITH A BAMBOO CHUNGI • • . 147

CLASPING ROOTS OF WIGHTIA • • • • . • . 155

SIMONBONG TEMPLE

TRUMPET MADE OF A HUMAN THIGH-BONE • • • • • . 163

TIBETAN AMULET • • • • . . . . . . . . 166

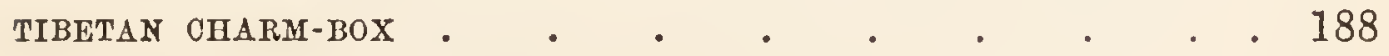

TAMBUR RIVER AT THE LOWER LIMIT OF FIRS . . . . 197

WALLANCHOON VILLAGE • . . . . . . . 200

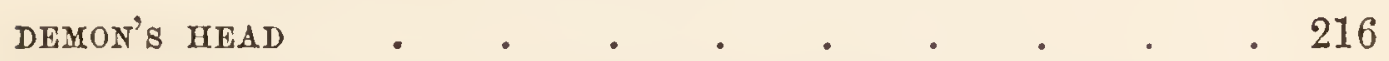

ANCIENT MORAINES IN THE YANGMA VALLEY . . . . 224

LOOKING ACROSS THE YANGMA VALLEY . . . • . 227 


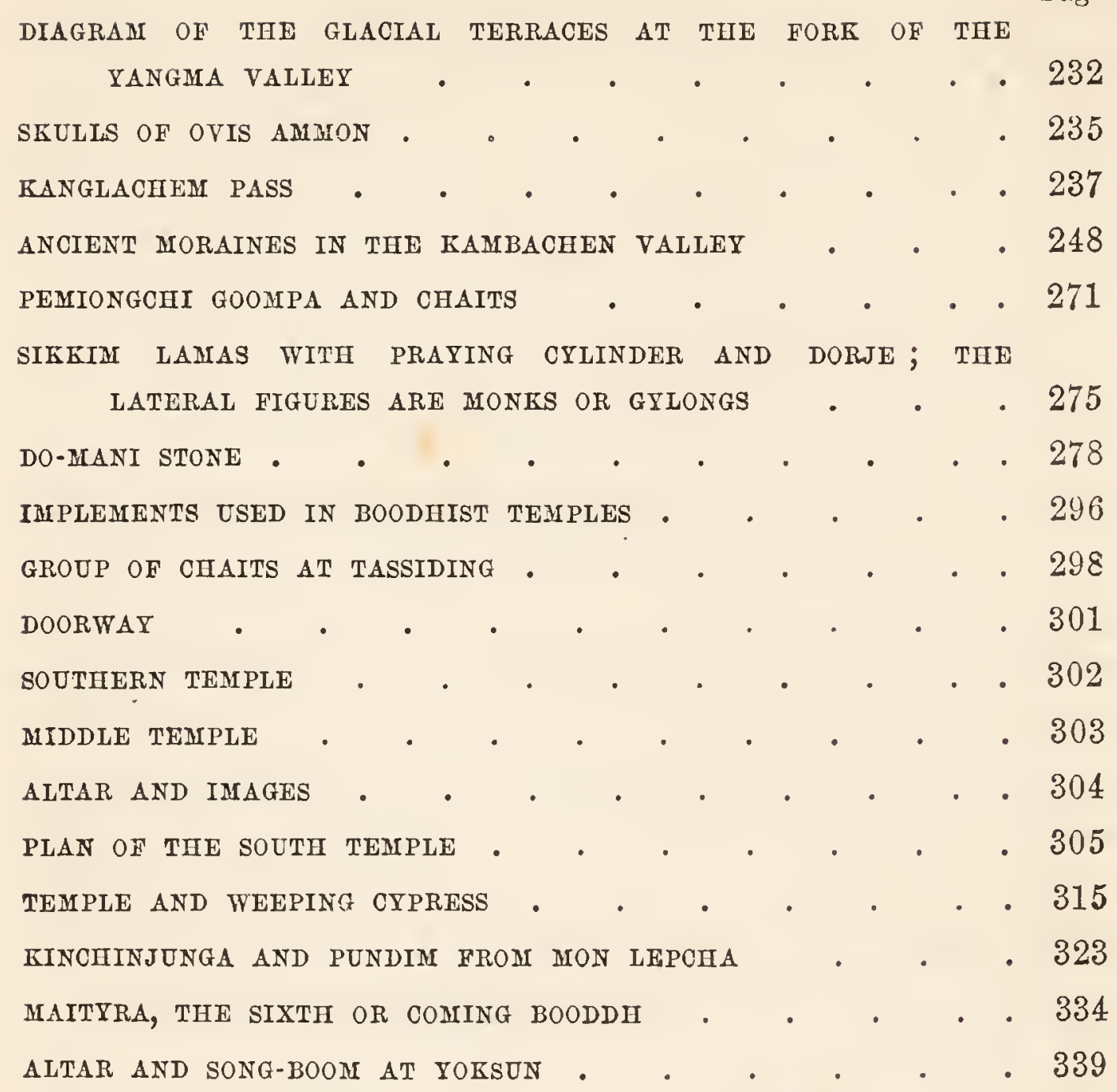




\section{CONTENTS.}

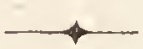

\section{CHAPTER I.}

Sunderbunds vegetation-Calcutta Botanic Garden-Leave for Burdwan-Rajah's gardens and menagerie-Coal-beds, geology, and plants of-Lac insect and plant-Kunker-Cowage-Effloresced soda on soil-Glass, manufacture of-Atmospheric vapoursTemperature, \&c.-Mahowa oil and spirits-Maddaobund-Jains -Ascent of Parasnath-Vegetation of that mountain

\section{CHAPTER II.}

Doomree-Vegetation of table-land-Birds-Lieutenant BeadleHot springs of Soorujkoond-Plants near them-Cholera-treeOlibanum-Palms, form of-Dunwah Pass-Trees, native and planted-Wild peacock-Poppy fields-Geography and Geology of Behar and Central India-Toddy-palm - Baroon-LizardAurora Borealis-Cross the Soane-Sand, ripple-marks onKymore hills-Rotas fort and palace-Nitrate of lime-Change of climate-Lime stalagmites, enclosing leaves--Spiders, \&c.Scenery and natural history of upper Soane valley-Bhel fruit -Dust-storm - Alligator - Catechu - Cochlospermum - Leafbellows-Scorpions-Tortoises-Florican-Limestone spheresColes-Tiger-hunt-Robbery . . . . . .

CHAPTER III.

Ek-powa Ghat - Sandstones - Shahgunj - Gum-arabic - MangoFair-Rujubbund-Storm-False sunset and sunrise-Bind hills 
-Mirzapore-Manufactures, imports, \&c.-Climate of-Thuggee

- Chunar - Benares - Mosque - Observatory - Sar-nath Ghazepore - Rose-gardens-Manufactory of Attar-Lord Cornwallis' tomb-Ganges, scenery and natural history of-Pelicans - Vegetation-Insects-Dinapore-Patna-Opium godowns and manufacture-Monghyr-Hot Springs of Seetakoond-Rocks of Sultan-gunj-Bhagulpore-Temples of Mt. Manden-Coles and native tribes-Bhagulpore rangers-Horticultural gardens. .

\section{CHAPTER IV.}

Leave Bhagulpore-Colgong-Himalaya, distant view of - Cosi, mouth of-Difficult navigation-Sand-storms-Caragola-GhatPurnea - Ortolans - Mahanuddee, transport of pebbles, \&c.Betel-pepper, cultivation of-Titalya-Siligoree-View of outer Himalaya-Terai-Mechis-Punkabaree-Foot of mountainsAscent to Dorjiling - Cicadas - Leeches - Animals - Kursiong, spring vegetation of-Pacheem-Arrive at Dorjiling-Dorjiling, origin and settlement of-Grant of land from Rajah-Dr. Campbell appointed superintendent-Dewan, late and present-Aggressive conduct of the latter-Increase of the station-Trade-Titalya fair-Healthy climate for Europeans and children-Invalids, diseases prejudicial to . . . . . . . . .

\section{CHAPTER V.}

View from Mr. Hodgson's of the snowy mountains-Their extent and elevation-Deceptive appearance of elevation-Sinchul, view from and vegetation of-Chumulari-Magnolias, white and purple -Rhododendron Dalhousix, arboreum and argenteum-Natives of Dorjiling-Lepchas, origin, tradition of flood, morals, dress, arms, ornaments, diet-cups, origin and value-MarriagesDiseases-Burial-Worship and religion-Bijooas-Kampa Rong, or Arratt-Limboos, origin, habits, language, \&c.-MoormisMagras - Mechis - Comparison of customs with those of the natives of Assam, Khasia, \&c.

\section{CHAPTER VI.}

Excursion from Dorjiling to Great Rungeet-Zones of regetationTree-ferns-Palms-Leebong, tea plantations-Ging-Boodhist 
remains-Tropical vegetation-Pines-Lepcha clearances-Forest fires-Boodhist monuments-Fig-Cane bridge and raft over Rungeet-India-rubber-Yel Pote-Butterflies and other insects -Snakes-Camp-Junction of Teesta and Rnngeet-Return to Dorjiling-Tonglo, excursion to - Bamboo flowering - OaksPeepsa-Simonbong, cultivation at-European fruits at Dorjiling -Plains of India

\section{CHAPTER VII.}

Continue the ascent of Tonglo-Trees-Lepcha construction of hutSimsibong-Climbing-trees-Frogs-Ticks-Leeches-Summit of Tonglo-Rhododendrons-Yew-Rose-Aconite-Bikh poisonEnglish genera of plants-Ascent of tropical orders-Comparison with south temperate zone-Heary rain-Temperature, \&c.Descent - Simonbong temple - Furniture therein - Prayingcylinder-Thigh-bone trumpet-Morning orisons-Present of Murwa beer, \&c.

\section{CHAPTER VIII.}

Difficulty in procuring leave to enter Sikkim-Obtain permission to travel in East Nepal-Arrangements-Coolies-Stores-Servants -Personal equipment-Mode of travelling-Leave DorjilingGoong ridge-Behaviour of Bhotan coolies-Nepal frontierMyong valley-Ilam-Sikkim massacre-Cultivation-NettlesCamp at Nanki on Tonglo-Bhotan coolies run away-View of Chumulari-Nepal peaks-Sakkiazung-Hornbills-Road to Wallanchoon-Scarcity of water-Singular view of mountainvalleys - Encampment-My tent and its furniture-Evening occupations-Dunkotah-Cross ridge of Sakkiazung-Yews-Silver-firs-View of Tambur valley-Pemmi river-Pebbly terraces-Holy springs-Enormous trees-Lucnlia gratissimaKhawa river-Arrive at Tambur-Shingle and gravel terracesNatives, indolence of-Canoe ferry-Votive offerings-Bad road - Teinperature, \&c. —Chingtam village, view from-Mywa river and Guola-House-Boulders-Chain-bridge-Meepo, arrival of - Fevers . 


\section{CHAPTER IX.}

Leave Mywa - Suspension bridge - Landslips - Vegetation - Bees' nests-Glacial phenomena-Tibetans, clothing, ornaments, amulets, salutation, children, dogs-Last Limboo village, Taptiatok - Beautiful scenery-Tibet village of Lelyp-EdgeworthiaCrab-apple-Chameleon and porcupine-Praying machineAbies Brunoniana-European plants-Grand scenery-Arrive at Wallanchoon-Scenery around-Trees-Tibet houses-Manis and Mendongs-Tibet household-Food-Tea-soup-Hospitality - Yaks and Zobo, uses and habits of-Bhoteas-Yak-hair tents - Guobah of Walloong - Jhatamansi-Obstacles to proceedingClimate and weather-Proceed-Rhododendrons, \&c.-Lichens -Poa annua and Shepherd's purse-Tibet camp-Tuquoroma - Scenery of pass - Glaciers and snow - Summit-Plants, woolly, \&c. . . . . . . . . . .

\section{CHAPTER X.}

Return from Wallanchoon pass-Procure a bazaar at village-Dance of Lamas-Temple and convent-Leave for Kanglachem passSend part of party back to Durjiling-Yangma Guola-Drunken Tibetans-Guobah of Wallanchoon-Camp at foot of Great Moraine-View from top-Geological speculations-Height of moraines-Cross dry lake-bed-Glaciers-More morainesTerraces-Yangma temples-Jos, books and furniture-Peak of Nango-Arrive at village-Cultivation-Scenery-Potatos-State of my provisions-Pass through village-Gigantic bouldersTerraces-Wild sheep-Lake-beds--Sun's power-Piles of gravel and detritus-Glaciers and moraines-Pabuk, elevation ofMoonlight scene-Return to Yangma-Temperature, \&c. - Geological causes of phenomena in valley-Scenery of valley on descent

\section{CHAPTER XI.}

Ascend Nango mountain - Moraines - Vegetation - Honey-combed surface of snow-Perpetual snow-Top of pass-View-Elevation-Distance of sound-Plants-Temperature-Scenery-Cliffs 
of granite and hurled boulders-Camp-Descent-Pheasants-

Larch-Distribution of Deodar-Kambachen village-Cultivation-Moraines in valley, distribution of-Picturesque lake-beds, and their vegetation-Tibetan sheep and goats-Cryptogramma crispa-Ascent to Choonjerma pass-View of Junnoo-Rocks of its summit-Misty ocean-Nepal peaks-Top of pass-Temperature, and observations-Gorgeous sunset-Descent to Yalloong valley-Lose path-Night scenes-Musk deer . . . .

\section{CHAPTER XII.}

Yalloong valley-Find Kanglanamo pass closed-Change route for the southward - Picrorhiza-Cross Yalloong range-ViewDescent-Yew-Vegetation-Misty weather-Tonghem village - Khabang-Tropical vegetation-Sidingbah Mountain-View of Kinchinjunga-Khabili valley-Ghorkha Havildar's bad conduct -Ascend Singalelah-Plague of ticks-Short commons-Cross Islumbo pass-Boundary of Sikkim-Kulhait valley-Lingcham - Reception by Kajee-Hear of Dr. Campbell's going to meet Rajah-Views in valley-Leave for Teesta river-Tipsy KajeeHospitality-Murwa beer-Temples-Long Mendong-Burning of dead-Superstitions-Cross Great Rungeet-Purchase of a dog-Marshes - Lamas - Dismiss Gliorkhas-Bhotea houseNurwa beer

\section{CHAPTER XIII.}

Raklang pass-Uses of nettles-Edible plants-Lepcha war-Domani stone-Neongong-Teesta valley-Pony, saddle, \&c.-Meet Campbell-Vegetation and scenery-Presents-Visit of DewanCharacters of Rajal and Dewan-Accounts of Tibet-LhassaSiling-Tricks of Dewan-Walk up Teesta--Audience of Rajah -Lamas - Kajees-Tchebu Lama, his character and positionEffects of interview-Heir-apparent-Dewan's house-GuitarTibet officers-Gigantic trees-Neongong lake-Mainom, ascent of-Vegetation-Camp on snow-View from top-Kinchin, \&c. -Vapours-Sunset effect-Temperature, \&c.-Lamas of Neongong-Temples-Religious festival-Bamboo, flowering-Recross pass of Raklang-Numerous temples, villages, \&c.-Domestic animals-Descent to Great Rungeet 


\section{CHAPTER XIV.}

Tassiding, view of and from-Funereal cypress-Camp at Sunnook - Hot vapours-Lama's house-Temples, decorations, altars, idols, general effect-Chaits-Date of erection-Plundered by Ghorkas-Cross Ratong-Ascend to Pemiongchi-Pemiongchi, view from - Vegetation - Temple, decorations, \&c. - Former capital of Sikkim-History of Sikkim - Nightingales-Campbell departs - T'chonpong-Edgeworthia_Cross Rungbee and Ratong - Yoksun - Walnuts - View - Funereal cypresses - DoobdiGigantic cypresses -Temples-Snowfall-Sikkim, \&c.-Toys .

\section{CHAPTER XV.}

Leave Yoksun for Kinchinjunga-Ascend Ratong valley-Saltsmuggling over Ratong-Plants-Buckeem-Blocks of gneissMon Lepcha-View-Weather-View from Gubroo-Kinchinjunga, tops of-Pundim cliff-Nursing - Vegetation of Himalaya -Coup d'oil of Jongri-Route to Yalloong-Arduous route of salt-traders from Tibet-Kinchin, ascent of-Lichens-Surfaces sculptured by snow and ice-Weather at Jongri-Snow-Shades for eyes

\section{CHAPTER XVI.}

Ratong river below Mon Lepcha-Ferns-Vegetation of Yoksun, tropical-A raliacece, fodder for cattle-Rice-paper plant-Lake -Old temples-Funereal cypresses-Gigantic chait-AltarsSongboom-Catsuperri-Worship at Catsuperri lake-Scenery -Willow_Lamas and ecclesiastical establishments of SikkimTengling-Changachelling temples and monks-Portrait of myself on walls-Lingcham Kajee asks for spectacles-Arrive at Little Rungeet-At Dorjiling-Its deserted and wintry appearance 


\section{HIMALAYAN JOURNALS.}

\section{CHAPTER T.}

Sunderbunds vegetation-Calcutta Botanic Garden-Leave for Burdwan - Rajah's gardens and menagerie-Coal-beds, geology, and plants of - Lac insect and plant-Kunker-Cowage-Effloresced soda on soilGlass, manufacture of-Atmospheric vapours-Temperature, \&c.Mahowa oil and spirits-Maddaobund-Jains-Ascent of Parasnath - Vegetation of that mountain.

I LEFT England on the 11th of November, 1847, and performed the voyage to India under circumstances which have been detailed in the Introduction. On the 12th of January, 1848, the "Moozuffer" was steaming amongst the low swampy islands of the Sunderbunds. These exhibit no tropical luxuriance, and are, in this respect, exceedingly disappointing. A low vegetation covers them; growing in brackish swamps, chiefly made up of a dwarf-palm and small mangroves, with a few scattered trees on the higher bank that rums along the water's edge, consisting of fan and toddy-palms. Every now and then, the paddles of the steamer tossed up the large fruits of Nipa fruticans, a low stemless palm that grows in the tidal waters of the Indian ocean, 
and bears a large head of nuts. It is a plant of no interest to the common observer, but of much to the geologist, from the nuts of a similar plant abounding in the tertiary formations at the mouth of the Thames, having floated about there in as great profusion as here, till buried deep in the silt and mud that now form the island of Sheppey.*

Higher up, the river Hoogly is entered, and large trees, with villages and cultivation, replace the sandy spits and marshy jungles of the great Gangetic delta. A few miles below Calcutta, the scenery becomes beautiful, beginning with the Botanic Garden, once the residence of Roxburgh and Wallich, and now of Falconer,-classical ground to the naturalist. Opposite are the gardens of Sir Lawrence Peel; unrivalled in India for their beauty and cultivation, and fairly entitled to be called the Chatsworth of Bengal. A little higher up, Calcutta opened out, with the batteries of Fort William in the foreground, thundering forth a salute, and in a few minutes more all other thoughts were absorbed in watching the splendour of the arrangements made for the reception of the GovernorGeneral of India.

During my short stay in Calcutta, I was principally occupied in preparing for an excursion with Mr. Williams of the Geological Survey, who was about to move his camp from the Damooda valley coal-fields, near Burdwan, to Beejaghur on the banks of the Soane, where coal was reported to exist, in the immediate

* Bowerbank "On the Fossil Fruits and Seeds of the Isle of Sheppey," and Lyell's "Elements of Geology," 3rd ed. p. 201. 
vicinity of water-carriage, the great desideratum of the Burdwan fields.

My time was spent partly at Government-House, and partly at Sir Lawrence Peel's residence. The former I was kindly invited to consider as my Indian home, an honour which $I$ appreciate the more highly, as the invitation was accompanied with the assurance that I should have entire freedom to follow my own pursuits; and the advantages which such a position afforded me, were, I need not say, of no ordinary kind.

At the Botanic Gardens I received every assistance from Dr. McLelland, who was very busy, superintending the publication of the botanical papers and drawings of his friend, the late Dr. Griffith, for which native artists were preparing copies on lithographic paper.

I was surprised to find the Botanic Gardens looked upon by many of the Indian public, and even by some of the better informed official men, as rather an extravagant establishment, more ornamental than useful. These persons seemed astonished to learn that its name was renowned throughout Europe, and that during the first twenty years especially of Dr. Wallich's superintendence, it had contributed more useful and ornamental tropical plants to the public and private gardens of the world than any other establishment before or since. I speak from a personal knowledge of the contents of our English gardens, and our colonial ones at the Cape, and in Australia, and from an inspection of the ponderous volumes of distribution lists, to which Dr. Falconer is daily adding. The botanical public of Europe and India is no less indebted than the 
horticultural to the liberality of the Hon. East India Company, and to the energy of the several eminent men who have carried their views into execution. The Indian government itself, has already profited largely by this garden, directly and indirectly, and might have done so still more, had its efforts been better seconded either by the European or native population of the country. Amongst its greatest triumphs may be considered the introduction of the tea-plant from China, a fact I allude to, as many of my English readers may not be aware that the establishment of the tea-trade in the Himalaya and Assam is almost entirely the work of the superintendents of the gardens of Calcutta and Seharumpore.

From no one did I receive more kindness than from Sir James Colvile, President of the Asiatic Society, who not only took care that $\mathrm{I}$ should be provided with every comfort, but presented me with a completely equipped palkee, which, for strength and excellence of construction, was everything that a traveller could desire. Often en route did I mentally thank him when I saw other palkees breaking down, and traveller's bewailing the loss of those forgotten necessaries, with which his kind attention had furnished me.

I left Calcutta to join Mr. Williams' camp on the 28th of January, driving to Hoogly on the river of that name, and thence following the grand trunk-road westward towards Burdwan. The novelty of palkee-travelling at first renders it pleasant: the neatness with which everything is packed, the good-humour of the bearers, their merry pace, and the many more comforts 
than could be expected in a conveyance horsed by men, the warmth when the sliding door's are shut, and the breeze when they are open, are all fully appreciated on first starting; but soon the novelty wear's off, and the discomforts are so numerous, that it is pronounced, at best, a barbarous conveyance. The greedy cry and gestures of the bearer's, when, on changing, they break a fitful sleep by poking a torch in your face, and vociferating "Bucksheesh, Sahib;" their discontent at the most liberal largesse, and the sluggishness of the next set who want bribes, put the traveller out of patience with the natives. The dust when the slides are open, and the stifling heat when shut during a shower, are conclusive against the vehicle; and on getting out with aching bones and giddy head at my journey's end, I shook off the dust, and wished never to see a palkee again.

On the following morning I was passing through the straggling villages close to Burdwan, consisting of native hovels by the road side, with mangos and figs planted near them, and palms waving over their roofs. Crossing the nearly dry bed of the Damooda, I was set down at Mr. M'Tntosh's (the magistrate of the district), and never more thoroughly enjoyed a hearty welcome and a breakfast.

In the evening we visited the Rajah of Burdwan's palace and pleasure-grounds, where I had the first glimpse of oriental gardening: the roads were generally raised, running through rice fields, now dry and hard, and bordered with trees of Jack, Bamboo, "Pride of India," \&c. Tanks were the prominent features: chains 
of them, full of Indian water-lilies, being fringed with rows of the fan-palm, and occasionally the Indian date. Close to the house was a rather good menagerie, where I saw, amongst other animals, a pair of kangaroos in high health and condition, the female with young in her pouch. Before dark I was again in my palkee, and hurrying onwards, refreshed by the cool and clear night air, so different from the damp and foggy atmosphere I had left at Calcutta. On the following morning I found myself travelling over a flat and apparently rising country, along an excellent road, with groves of bamboos and stunted trees on either hand, few villages or palms, a sterile soil, with stunted grass and but little cultivation; altogether a country as unlike what I had expected to find in India as well might be. All around was a dead flat or table-land, out of which a few conical hills rose in the west, about 1000 feet high, covered with a low forest of dusky green or yellow, from the prevalence of bamboo. The lark was singing merrily at sumrise, and the accessories of a fresh air and dewy grass more reminded me of some moorland in the north of England than of the torrid regions of the East.

At 10 p.s. I arrived at Mr. Williams' camp, near the western limit of the coal basin of the Damooda valley. His operations being finished, he was prepared to start, haring kindly waited a couple of days for my arrival.

Early on the morning of the last day of January, a motley group of natives was busy striking the tents, and loading the bullocks, bullock-carts and elephants; 
which then proceeded on the march, occupying in straggling groups nearly three miles of road.

The coal crops out at the surface; but the shafts worked are sunk through thick beds of alluvium. The age of these coal-fields is quite unknown, and I regret to say that my examination of their fossil plants throws no material light on the subject. Upwards of thirty species of these have been procured from them, the majority of which are referred by $\mathrm{Dr}_{\mathrm{r}}$. McLelland * to the inferior oolite epoch of England: most of these are ferns, some of which are supposed to be the same as occur in the coal-fields of Sind and of Australia. I cannot, however, think that botanical evidence of such a nature is sufficient to warrant a satisfactory reference of these Indian coal-fields to the same epoch as those of England or of Australia: in the first place the outlines of the fronds of ferns and their nervation are frail characters if employed alone for the determination of existing genera, and much more so of fossil fragments: in the second place recent ferns are so widely distributed, that an inspection of the majority affords little clue to the region or locality they come from: and in the third place, considering the wide difference in latitude and longitude of Yorkshire, India, and Australia, the natural conclusion is that they could not have supported a similar vegetation at the same epoch. In fact, finding similar fossil plants at places widely different in latitude, and therefore in climate, is, in the present state of our knowledge, rather an argument against than for their having existed cotemporaneously.

* Reports of the Geological Survey of India. Calcutta, 1850. 
But, even supposing that specific identity of their contained fossils be considered as fair evidence of the cotemporaneous origin of beds; amongst the many collections of fossil plants that I have examined, there is hardly a specimen, belonging to any epoch, sufficiently perfect to warrant the assumption that the species to which it belonged can be recognised. The botanical evidences which geologists too often accept as proofs of specific identity, are such as no botanist would attach any importance to in the investigation of existing plants.

A number of women were here employed in making gunpowder, grinding the usual materials on a stone, with the addition of water from the Hookah; a custom for which they have an obstinate prejudice. The charcoal here used is made from an Acacia: the Seiks, I believe, employ Justicia Adhatoda, which is also in use all over India: at Aden the Arabs prefer the Calotropis, probably because it is most easily procured. The grain of all these plants is open, whereas in England, closergrained and more woody trees, especially willows, are preferred.

The jungle I found to consist chiefly of thomy bushes, Jujube of two species, an Acacia and Butea frondosa, the twigs of the latter often covered with lurid red tears of Lac, which is here collected in abundance. As it occurs on the plants and is collected by the natives it is called Stick-lac, but after preparation Shell-lac. In Mirzapore, a species of Celtis yields it, and the Peepul rery commonly in various parts of India. 'The elaboration of this dye, whether by the 
same or many species of insect, from plants so widely different in habit and characters, is a very curious fact; the more so since none of these plants have red, but some have milky and others limpid juices.

After breakfast, Mr. Williams and I started on an elephant, following the camp. The docility of these animals is an old story, but it loses so much in the telling, that their gentleness, obedience, and sagacity seemed as strange to me as if I had never heard or read of these attributes. The swinging motion, under a hot sun, is very oppressive, but compensated for by being so high above the dust. The mahout or driver' guides by poking his great toes under either ear, enforcing obedience with an iron goad, with which he hammers the animal's head with quite as much force as would break a cocoa-nut, or drives it through his thick skin down to the quick. Our elephant was an excellent one, when he did not take obstinate fits, and so intelligent as to pick up pieces of stone when desired, and with a jerk of the trunk throw them over his head for the rider to catch, thus saving the trouble of dismounting to geologise!

We met many pilgrims to Juggernath, most of whom were on foot, while a few were in carts or pony gigs of rude construction. The vehicles from the upper' country are distinguished by a far superior build, their hor'ses are caparisoned with jingling bells, and the wheels and other parts are bound with brass. The kindness of the people towards animals, and in some cases towards their suffering relations, is very remarkable, and may in part have given rise to the prevalent 
idea that they are less cruel and stern than the majority of mankind; but that the "mild" Hindoo, however" gentle on occasion, is cruel and vindictive to his brother man and to animals, when his indolent temper is roused or his avarice stimulated, no one can doubt who reads the accounts of Thuggee, Dacoitee, and poisoning, and witnesses the cruelty with which beasts of burthen are treated. A child carrying a bird, kid, or lamb, is not an uncommon sight, and a woman with a dog in her arms is still more frequently seen. Occasionally too, a group will bear an old man to see Juggemath before he dies, or a poor creature with elephantiasis, who hopes to be allowed to hurry himself to his paradise, in preference to lingering in helpless inactivity, and at last crawling up to the second heaven only. The costumes are as various as the religious castes, and the many countries to which the travellers belong. The most thriving-looking wanderer is the bearer of Ganges' holy water, who drives a profitable trade, his gains increasing as his load lightens, since the further he wanders from the sacred stream, the more he gets for the contents of his jar.

The Ganges being still the main channel of communication between north-west India and Bengal, we passed very little merchandise; such as there was, principally consisted of cotton, which, clumsily packed in ragged bags, dirty, and deteriorating every day, even at this dry season, proved in how bad a state it must arrive at the market during the rains, when the low waggons are dragged through the streams.

Occasionally a string of camels was seen, but, owing 
to the damp climate, these are rare, and east of the meridian of Calcutta altogether unknown. The roads here are all mended with a curious stone, called Kunker, which is a nodular concretionary deposit of limestone, abundantly imbedded in the alluvial soil of a great part of India; and often occurring in strata, like flints. It resembles a coarse gravel, each pebble being often as large as a walnut, and tuberculated on the surface: it binds admirably, and forms excellent roads, but pulverises into a most disagreeable impalpable dust.

The vegetation of this part of the country was very poor, consisting of a low stunted jungle, and no goodsized trees being risible: even grasses were few, and dried up, except in the beds of the rivulets. Bambôos were however common, and the Cowage plant, now with orer-ripe pods, by shaking which, in passing, there often falls such a shower of its irritating microscopic hairs, as to make the skin tingle for an hour.

On the 1st of February, we moved on to Gyra, an insignificant village. The air was cool, and the atmosphere clear; the temperature, at three in the morning, being $65^{\circ}$. As the sun rose, Parasnath appeared against the clear grey sky, in the form of a beautiful broad cone, with a rugged peak, of a deeper grey than the sky. It is a remarkably handsome mountain, sufficiently lofty to be imposing, rising out of an elevated country, the slope of which, upward to the base of the mountain, though imperceptible, is really considerable; and it is surrounded by lesser hills 
of just sufficient elevation to set it off. The atmosphere, too, of these regions is peculiarly favourable for views: it is very dry at this season; but still the hills are clearly defined, without the harsh outlines so characteristic of a moist air. The skies are bright, the sun powerful; and there is an almost imperceptible haze that seems to soften the landscape, and keep every object in true perspective.

Our route led towards the picturesque hills and valleys in front. There was little cultivation, and that little of the most wretched kind; even rice-fields were few and scattered; there was no corn, nor lentiles, nor Castor-oil, no Poppy, Cotton, Safflower, nor other crops of the richer soils that flank the Ganges and Hoogly; a very little Sugar-cane, Dhal (a small pea), Mustard, Linseed, and Rape, the three latter cultivated for their oil. Hardly a Palm was to be seen; and it was seldom that the cottages could boast of a Banana, Tamarind, Orange, Cocoa-nut, or Date. The Mahowa (Bassia latifolia) and Mango were the commonest trees. There being no Kunker in the soil here, the roads were mended with angular quartz, much to the elephant's annoyance.

The country around the base of Parasnath is rather pretty, the hills covered with bamboo and brushwood, and as usual, rising rather suddenly from the elevated plains. The jungle affords shelter to a fer bears and tigers, jackals in abundance, and occasionally foxes; the birds seen are chiefly pigeons. Insects are very scarce; those of the locust tribe being most prevalent, indicative of a dry climate. 
The temperature varied from $65^{\circ}$ at night, to $82^{\circ}$ at :3 P.ar., from which there was no great variation during the whole time we spent at these elevations. The clouds were rare, and always light and high, except a little fleecy spot of rapour condensed close to the summit of Parasnath. Though the nights were clear and starlight, no dew was deposited, owing to the great dryness of the air.

On the 2nd of February we proceeded to TofeChoney, the hills increasing in height to nearly 1000 feet, and the country becoming more picturesque. We passed some tanks covered with Villarsia, and frequented by flocks of white egrets. The existence of artificial tanks so near a lofty mountain, from whose sides innumerable water-courses descend, indicates the great natural dryness of the country during one season of the year. 'The hills and valleys were richer' than I expected, though far from luxuriant.

This being the most convenient station whence to ascend Parasnath, we started at 6 A.M. for the village of Maddaobund, at the north base of the mountain, or opposite side from that on which the grand trunk-road runs. After following the latter for a ferw miles to the west, we took a path through beautifully wooded plains, with scattered trees of the Mahowa, resembling good oaks: the natives distil a kind of arrack from its fleshy flowers, which are also eaten raw. The seeds, too, yield a concrete oil, by expression, which is used for lamps and occasionally for frying.

Some villages at the west base of the mountain occupy a better soil, and are surrounded with richer 
cultivation; palms, mangos, and the tamarind, the first and last rare features in this part of Bengal, appeared to be common, with fields of rice and broad acres of flax and rape, through the latter of which the blue Indian Broom rape (Orobanche indica) swarmed. The short route to Maddaobund, through narrow rocky valleys, was impracticable for the elephant, and we had to make a ver'y considerable détour, only reaching that village at 2 P.r. All the hill people we observed were a fine-looking athletic race; they disclaimed the tiger being a neighbour, which every palkee-bearer along the road declares to carry off the torch-bearers, torch and all. Bears they said were scarce, and all other wild animals, but a natural jealousy of Europeans often leads the natives to deny the existence of what they know to be an attraction to the proverbially sporting Englishman.

The site of Maddaobund, elevated 1230 feet, in a clearance of the forest, and the appearance of the snowwhite domes and bannerets of its temples through the fine trees by which it is surrounded, are rery beautiful; and the situation is so sheltered that the tamarind, peepul, and banyan trees are superb. A fine specimen of the latter stands at the entrance to the village, not a broad-headed tree, as is usual in the prime of its existence, but a mass of trunks irregularly throwing out immense branches in a most picturesque manner; the original trunk is apparently gone, and the principal mass of root-stems is fenced in. This, with two magnificent tamarinds, forms a grand clump. The ascent of the mountain is immediately from the 
village up a pathway worn by the feet of many a pilgrim from the most remote parts of India.

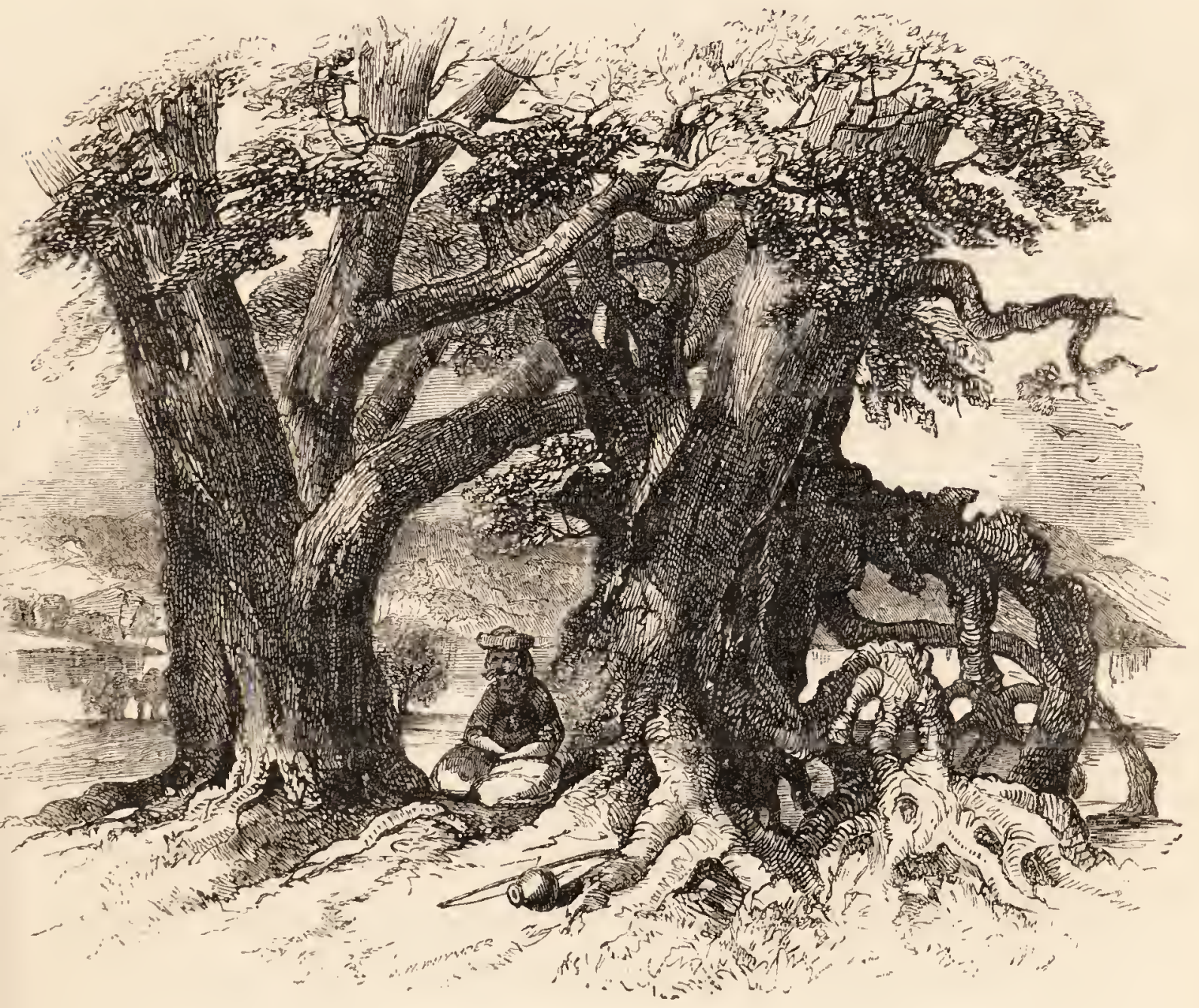

OLD TAMARIND TREES.

Parasmath is a mountain of peculiar sanctity, to which circumstance is to be attributed the flowishing: state of Maddaobund. The name is that of the twentythird incarnation of Jimna (Sanscrit "Conqueror"), who was born at Benares, lived one hundred years, and was buried on this mountain, which is the eastern metropolis of Jain worship, as Mount Aboo is the western (where are their libraries and most splendid temples). The origin of the Jain sect is obscure, 
though its rise appears to correspond with the wreck of Boodhism throughout India in the eleventh century. The Jains form in some sort a transition-sect between Boodhists and Hindoos, differing from the former in acknowledging castes, and from both in their worship of Parasnath's foot, instead of that of Munja-gosha of the Boodhs, or Vishnoo's of the Hindoos. As a sect of Boodhists their religion is considered pure, and free from the obscenities so conspicuous in Hindoo worship; whilst, in fact, perhaps the reverse is the case; but the symbols are fewer, and indeed almost confined to the feet of Parasnath, and the priests jealously conceal their esoteric doctrines.

The temples, though small, are well built, and carefully kept. No persuasion could induce the Brahmins to allow us to proceed beyond the vestibule without taking off our shoes, to which we were not inclined to consent. The bazaar was for so small a village large, and crowded to excess with natives of all castes, colours, and provinces of India, very many from the extreme W. and N. W., Rajpootana, the Madras Presidency, and Central India. Numbers had come in good cars, well attended, and appeared men of wealth and consequence; while the quantities of conveyances of all sorts standing about, rather reminded me of an election, than of anything I had seen in India.

The natives of the place were a more Negro-looking race than the Bengalees to whom I had previously been accustomed; and the curiosity and astonishment they displayed at seeing (probably many of them for the first time) a party of Englishmen, were sufficiently 
amusing. Our coolies not having come up, and it being two o'clock in the afternoon, I having had no breakfast, and being ignorant of the exclusively Jain population of the village, sent my servant to the bazaar, for some fowls and eggs; but he was mobbed for asking for these articles, and parched rice, beaten flat, with some coarse sugar, was all he could obtain; together with sweetmeats so odiously flavoured with various herbs, and sullied with such impurities, that we quickly made them over to the elephants.

In the evening a very gaudy poojah was performed. The car, filled with idols, was covered with gilding and silk, and drawn by noble bulls, festooned and garlanded. A procession was formed in front; and it opened into an avenue, up and down which gaily dressed dancingboys paced or danced, shaking castanets, the attenlant worshippers singing in discordant voices, beating tomtoms, cymbals, \&c. Images (of Boodh apparently) abounded on the car, in front of which a child was placed. The throng of natives was very great and perfectly orderly, indeed, sufficiently apathetic: they were remarkably civil and willing to explain what they understood of their own worship.

Having provided doolies, or little bamboo chairs slung on four men's shoulders, in which I put my papers and boxes, we next morning commenced the ascent; at first through woods of the common trees, with large clumps of bamboo, over slaty rocks of gneiss, much inclined and sloping away from the mountain. The view from a ridge 500 feet high was superb, of the village, and its white domes half buried 
in the forest below, the latter of which continued in sight for many miles to the northward. Descending to a valley some ferns were met with, and a more luxuriant vegetation, especially of the nettle tribe. Wild bananas formed a beautiful, and to me a novel feature in the woods.

The conical hills of the white ants were very abundant. The structure appears to me not an independent one, but the débris of clumps of bamboos, or of the trunks of large trees, which these insects have destroyed. As they work up a tree from the ground, they coat the bark with partieles of sand glued together, carrying up this artificial sheath or covered way as they ascend. A clump of bamboos is thus speedily killed; and the dead stems fall away, leaving the mass of stumps coated with sand, which the action of the weather soon fashions into a cone of earthy matter.

Ascending again, the path struck through a thick forest of Sal (Vateria robusta) and other trees, spanned with cables of scandent Bautinia stems. At about 3000 feet above the sea, the vegetation became more luxuriant, and by a little stream I collected five species of ferns and some mosses, - all in a dry state, however. The white ant apparently does not enter this cooler. region. At 3500 feet the regetation again changed, the trees all becoming gnarled and scattered; and as the dampness also increased, more mosses and ferns appeared. We emerged from the forest at the foot of the great ridge of rocky peaks, stretching $\mathrm{E}$. and W. three or four miles. Abundance of a species of 
berberry and an Osbeckia marked the change in the vegetation most decidedly, which were frequent over the whole summit, with coarse grasses, and various bushes.

At noon we reached the saddle of the crest (alt. 4230 feet), where was a small temple, one of five or six which occupy various prominences of the ridge. The wind, N. W., was cold, the temp. $56^{\circ}$. The atmosphere was unfortmately hazy, nevertheless the view was beautiful. To the north were ranges of low wooded hills, and the course of the Barakah and Adji rivers; to the south lay a more level country, with lower ranges, and the Damooda river, its all but waterless bed snowywhite from the exposed granite blocks with which its course is strewn. East and west rose sereral sharp ridges of the mountain itself; the western considerably the highest. Immediately below, the mountain flanks appeared clothed with impenetrable forest, here and there interrupted by rocky eminences; while to the north the grand trunk-road crossed the plains, like a white thread, as straight as an arrow, spanning the beds of the mountain torrents with picturesque bridges.

On the south side the vegetation was more luxuriant than on the north, though, from the heat of the sum, the reverse might have been expected. This is owing partly to the curve taken by the ridge being open to the south, and partly to the winds from that quarter being the moist ones. Accordingly, trees which I had left 3000 feet below on the north flank, here ascended to near the summit, such as figs and bananas. A shortstemmed palm was tolerably abundant, and a small 
tree (Pterospermum) on which a species of grass grew epiphytically; forming a curious feature in the landscape.

The situation of the principal temple is very fine, below the saddle in a hollow facing the south, surrounded by jungles of plantain and banyan. It is small, and contains little worthy of notice but the sculptured feet of Parasnath, and some marble Boodh idols; cross-legged figures, with crisp hair and the Brahminical cord. These, a leper covered with ashes in the vestibule, and an officiating priest, were all we saw." Pilgrims were seen on various parts of the mountain in considerable numbers, passing from one temple to another, and generally leaving a few grains of dry rice at each.

The culminant rocks were very dry, but in the rains may possess many curious plants; a fine Kalanchoe was common, with a berberry, and various other shrubs; a Bolbophyllum grew on the rocks, with a small Begonia, and some ferms. There were no birds, and very few insects, a beautiful small Pontia being the only butterfly. The striped squirrel was very busy amongst the rocks; and I saw a few mice, and the traces of bears.

At 3 P.x., the temperature ras $54^{\circ}$, and the air deliciously cool and pleasant. I tried to reach the western peak (perhaps 300 feet above the saddle), by keeping along the ridge, but was cut off by precipices, and ere I could retrace my steps it was time to descend. This I was glad to do in a doolie, and I was carried to the bottom, with only one short rest, in an hour and 
three quarters. The descent was very steep the whole way, partly down steps of sharp rock, where one of the men cut his foot severely. The pathway at the bottom was lined for nearly a quarter of a mile with sick, halt, maimed, lame, and blind beggars, awaiting us. It was truly a fearful sight, especially the lepers, and numerous unhappy victims to elephantiasis.

Though the botany of Parasnath proved interesting, its elevation was not accompanied by such a change from the flora of its base as I had expected. This is no doubt due to its dry climate and sterile soil; characters which it shares with the extensive elevated area of which it forms a part, and upon which I could not detect above 300 species of plants. 


\section{CHAPTER II.}

Doomree-Vegetation of table-land-Birds-Lieutenant Beadle - Hot springs of Soorujkooud-Plants near them-Cholera-tree-Olibanum -Palms, form of-Dunwah Pass-Trees, native and planted-Wild peacock-Poppy fields-Geography and Geology of Behar and Central India-Toddy-palm-Baroon-Lizard-Aurora Borealis-Cross the Soane-Sand, ripple-marks on-Kymore hills-Rotas fort and palace -Nitrate of lime-Change of climate-Lime stalagmites, enclosing leaves-Spiders, \&c.-Scenery and natural history of upper Soane valley-Bhel fruit -Dust-storm-Alligator-Catechu-Cochlospermum - Leaf-bellows - Scorpions - Tortoises - Florican — Limestone spheres-Coles-Tiger-hunt-Robbery.

In the evening we returned to our tamarind tree, and the next morning regained the trunk-road, following it to the dawk bungalow of Doomree. On the way I found the Cesalpinia paniculata, a magnificent climber, festooning the trees with its dark glossy foliage and gorgeous racemes of orange blossoms. Receding from the mountain, the country again became barren; and no palms or large trees of any kind appeared. The spear'-grass abounded, and a detestable nuisance it was, its long awns and husked seed working through trowsers and stockings.

Having rested the tired elephant, we pushed on in the evening to the next stage, Baghoda, arriving there at 3 A.M. and after a few hour's' rest, I walked to the 
bungalow of Lieutenant Beadle, the surveyor of roads, sixteen miles further.

At 10 A.x. the sum became uncomfortably hot, the thermometer being $77^{\circ}$. I had lost my hat, and possessed no substitute but a silken nightcap; so I had to tie a handkerchief over my head, to the astonishment of the passers-by. Holding my head down, I had little source of amusement but in examining the footmarks on the road; and these were strangely diversified to an English eye. Those of the elephant, camel, buffalo and bullock, horse, ass, pony, dog, goat, sheep and kid, lizard, wild-cat and pigeon, with men, women, and children's, naked and shod, were all recognisable.

It was noon ere I arrived at Lieutenant Beadle's, at Belcuppee (alt. 1219 feet), glad enough of the hearty welcome I received, being very hot, dusty, and hungry. The country about his bungalow is very pretty, from the number of wooded hills and large trees, especially of banyan and peepul, noble oak-like Mahowas, Mangos, and Figs. These are all scattered, however, and do not form forest, such as in a stunted form clothes the hills. Insects and birds are numerous, the latter consisting of jays, crows, doves, sparrows, and maina (Pastor); also the Phocnicopluaus tristis " Mahoka" of the natives), with a note like that of the English cuckoo, as heard late in the season.

I remained two days with Lieutenant Beadle, enjoying in his society several excursions to some hot springs, and other places of interest, in the neighbourhood. These springs (called Soorujkoond) are situated 
close to the road, near the mouth of a valley, in a remarkably pretty spot. They are, of course, objects of worship; and a ruined temple stands close behind them, with three very conspicuous trees - a peepul, a banyan, and a white, thick-stemmed, leafless Sterculia, whose branches bore dense clusters of greenish foetid flowers. The hot springs are four in number, and rise in as many ruined brick tanks, each about two yards across. Another tank, fed by a cold spring, about twice that size, flows between two of the hot, only two or three paces distant from one of the latter on either hand. All meet in one stream after a few yards, and are conducted by bricked canals to a pool about eighty yards off.

The water of the cold spring is sweet but not good, and emits gaseous bubbles; it was covered with a green floating Conferva. Of the four hot springs, the most copious is about three feet deep, bubbles constantly, boils eggs, and though brilliantly clear, has an exceedingly nauseous taste.

Conferva abound in the warm stream from the springs, and two species, one ochreous brown, and the other green, occur on the margins of the tanks themselves, and in the bottest water ; the brown is the best salamander, and forms a belt in deeper water than the green; both appear in broad luxuriant strata, wherever the temp. is cooled down to $168^{\circ}$, and as low as $90^{\circ}$. Of flowering plants, three showed in an eminent degree a constitution capable of resisting the heat, if not a predilection for it; these were all Cyperacea, having their roots in water of $100^{\circ}$, and where they are 
probably exposed to greater heat; all were very luxuriant. From the margins of the four hot springs I gathered sixteen species of flowering plants, and from the cold tank five, which did not grow in the hot. A water-beetle abounded in water at $112^{\circ}$, with quantities of dead shells; at $90^{\circ}$ frogs were very lively, with live shells, and various water-beetles.

I left Belcuppee on the 8th of February, following Mr. Williams' camp: the morning was clear and cold, the temperature being only $56^{\circ}$. I crossed the nearly dry broad bed of the Burkutta river, a noble stream during the rains, carrying along huge boulders of granite. Near this I passed the Cholera-tree, a famous peepul, so called from a detachment of infantry having been attacked and decimated at the spot by that fell disease: it was covered with inscriptions and votive tokens in the shape of rags, \&c. The road continued to ascend to 1360 feet, where I came upon a small forest of the Indian Olibanum (Boswellia thurifera), conspicuous from its pale bark, and spreading curved branches, leafy at their tips; its general appearance is a good deal like that of the mountain ash. The very fragrant and transparent gum, celebrated throughout the East, was flowing abundantly from the trunks.

Descending to the village of Burshoot, we lost sight of the Olibanum, and came upon a magnificent tope of mango, banyan, and peepul, so far superior to anything hitherto met with, that we were glad to choose such a pleasant halting-place for breakfast. There were a few lofty fan-palms here too, great rarities in this soil and at this elevation: one, about eighty feet high, towered

VOL, I. 
above some wretched hovels, displaying the curious proportions of this tribe of palms; namely, first, a short cone, tapering to one-third the height of the stem, the trunk then swelling to two-thirds, and again tapering to the crown.

So little was there to observe, that I again amused myself by examining footsteps, the precision of which in the sandy soil was curious. Looking down from the elephant, I was interested by seeing them all in relief, instead of depressed, the slanting rays of the sun in front producing this kind of mirage.

Chorparun, at the top of the Dunwah pass, is situated on an extended barren flat, 1320 feet above the sea, and from it the descent from the table-land to the level of the Soane valley, a little above that of the Ganges at Patna, is very sudden. The road is carried zigzag down a rugged hill, with a descent of nearly 1000 feet in six miles, of which 600 are exceedingly steep. The pass is well wooded, with abundance of bamboo, Bombax, Cassia, Acacia, and Butea, with Calotropis, the purple Mudar, a very handsome road-side plant, which I had not seen before, but which, with the Argemone Mexicana, was to be a companion for hundreds of miles farther. All the views in the pass are very picturesque, though wanting in good foliage, such as Figs would afford, of which I did not see one tree. The banyan and peepul always appeared to be planted, as did the tamarind and mango.

Dunwah, at the foot of the pass, is 620 feet above the sea, and nearly 1000 below the mean level of the highland we had been traversing. Every thing bears 
here a better aspect; the woods at the foot of the hills afforded many plants; the bamboo (B. stricta) is green instead of yellow and white; a little castor-oil is cultivated, and the Indian date (low and stunted) appears about the cottages.

In the woods I heard and saw the wild peacock for the first time. Its voice is not to be distinguished from that of the tame bird in England; a curious instance of the perpetuation of character under widely different circumstances, and contrasting with the wild junglefowl, whose crow by no means rivals that of the farmyard cock.

In the evening we left Dunwah for Barah (alt. 480 feet), passing over very barren soil, covered with low jungle, the original woods having apparently been cut for fuel. Our elephant, a timid animal, came on a drove of camels in the dark by the road-side, and in his alarm insisted on doing battle, tearing through the thorny jungle, regardless of the mahout, and still more of me; the uproar raised by the camel-drivers was ridiculous, and the danger to my barometer imminent.

We proceeded on the 11th of February to Sheergotty, where Mr. Williams and his camp were awaiting our arrival. Wherever cultivation appeared the crops were tolerably luxuriant, of poppy (which I had not seen before), sugar-cane, wheat, barley, mustard, rape, and flax. At a distance a field of poppies looks like a green lake, studded with white water-lilies. The houses, too, are better, and have tiled roofs; while, in such situations, the road is lined with trees. 
A retrospect of the ground passed over is unsatisfactory, as far as botany is concerned, except as showing how potent are the effects of a dry soil and climate during one season of the year upon a vegetation which has no desert types. During the rains probably many more species would be obtained, for of annuals I scarcely found twenty: at that season, however, the jungles of Behar and Birbhoom, though far from tropically luxuriant, are singularly unhealthy.

In a geographical point of view the range of hills between Burdwan and the Soane is interesting, as being the north-east continuation of a chain which crosses the broadest part of the peninsula of India, from the gulf of Cambay to the junction of the Ganges and Hoogly at Rajmahal. This range rums south of the Soane and Kymore, which it meets I believe at Omerkuntuk:* further west again, they separate, the southern forming the Satpur range, which divides the valley of the Taptee from that of the Nerbudda. The Parasnath range is, though the most difficult of definition, the longer of the two parallel ranges; the Vindhya, continued as the Kymore, terminating abruptly, at the Fort of Chunar on the Ganges. The general and geological features of the two, especially along their eastern course, are very different. 'This range consists of gneiss, through which granite hills protrude, the loftiest of which is Parasnath. The northeast Vindhya (called Kymore), on the other hand, consists of nearly horizontal beds of sandstone, overlying inclined beds of limestone. Between the latter

\footnotetext{
* A lofty mountain said to be $7000-8000$ feet high.
} 
and the Parasnath gneiss, come (in order of superposition) beds of quartz, hornstone, jaspers, \&c. These are thrown up, by greenstone I believe, along the north and north-west boundary of the gneiss range, and form the rocks of Colgong, of Sultangunj, and of Monghyr, on the Ganges, as also various detached hills near Gyah, and along the upper course of the Soane. From these are derived the beautiful agates and cornelians, so famous under the name of Soane pebbles, and they are equally common on the Curruckpore range, as on the south bank of the Soane, so much so as to have been used in the decoration of the walls of the now ruined palaces near Bhagulpore.

In the route I had taken, I had crossed the eastern extremity alone of the range, commencing with a very gradual ascent to the table-land, properly so called. A little beyond the coal fields, this table-land reaches an average height of 1130 feet, which is continued for upwards of 100 miles, to the Dunwah pass. Here the descent is sudden to plains, which, continuous with those of the Ganges, run up the Soane till beyond. Rotasghur. Except for the occasional ridges mentioned above, and some hills of greenstone, the lower plain is stoneless, its subjacent rocks being covered with a thicker stratum of the same alluvium which is thinly spread over the higher table-land above. This range is of great interest from its being the source of many important rivers, and of all those which water the country between the Soane, Hoogly, and Ganges; as well as from its deflecting the course of the latter river, which washes its base at Rajmahal, and forcing it to 
take a sinuous course to the sea. In its climate and botany it differs equally from the Gangetic plains to the north, and from the hot, damp, and exuberant forests of Orissa to the south. Nor are its geological features less different, or its concomitant and in part resultant characters of agriculture and native population.

On the 12th of February, we left Sheergotty (alt. 463 feet), crossing some small streams, which flow $\mathrm{N}$. to the Ganges. Between Sheergotty and the Soane, occur many isolated hills of greenstone, better known to the traveller from having been telegraphic stations.

The road-sides being highly cultivated, and the Datepalm becoming more abundant, we encamped in a grove of these trees. All were curiously distorted; the trunks growing zigzag, from the practice of yearly tapping the alternate sides for toddy. The incision is just below the crown, and slopes upwards and inwards: a vessel is hung below the wound, and the juice conducted into it by a little piece of bamboo. This operation spoils the fruit, which, though eaten, is small, and much inferior to the African date.

The following day we marched to Baroon on the alluvial banks of the Soane, crossing a deep stream by a pretty suspension bridge, of which the piers were visible two miles off, so level was the road. The Soane was here three miles wide, its nearly dry bed being a desert of sand, resembling a vast arm of the sea when the tide is out: the banks were very barren, with no trees near, and but very few in the distance. The houses were scarcely visible on the opposite side, behind which the Kymore mountains rise. The Soane 
is a classical river, being now satisfactorily identified with the Eranoboas of the ancients.**

Mr. Theobald (my companion in this and many other rambles) pulled a lizard from a hole in the bank. Its throat was mottled with scales of brown and yellow. Three ticks had fastened on it, each of a size covering three or four scales: the first was yellow, corresponding with the yellow colour of the animal's belly, where it lodged; the second brown, from the lizard's head; but the third, which was clinging to the parti-coloured scales of the neck, had its body parti-coloured, the hues corresponding with the individual scales covered. The adaptation of the two first specimens in colour to the parts to which they adhered, was sufficiently remarkable; but the third case was certainly most extraordinary.

During the night of the 14th of February, I observed a beautiful display of the Aurora borealis. It commenced at 9 P.M., with about thirty lancet beams rising in the north-west from a low luminous arch, which crossed the zenith, and converged towards the opposite quarter of the heavens. All moved and flashed slowly, occasionally splitting and forking, fading and brightening; they were clearly defined, though the milky way and zodiacal light could not be discerned, and the stars and planets were very pale. When this display had lasted about an hour, the light

* The etymology of Eranoboas is undoubtedly Hievrinia Vahu (Sanskrit), the golden-armed. Sona is also the Sanskrit for gold. The stream is celebrated for its agates (Soane pebbles), whicli are common, but gold is not now obtained from it. 
became more diffused, the beams lessened by degrees, and a dark belt appeared in the luminous arch, gradually breaking it up, and appearing to disperse the beams, of which, however, a few faint ones continued to appear occasionally until midnight.

Our passage through the Soane sands was very tedious, though accomplished in excellent style, the elephants pushing forward the heavy waggons of mining tools with their foreheads. The wheels were sometimes buried to the axles in sand, and the draught bullocks were rather in the way than otherwise.

The body of water over which we were ferried, was not above 80 yards wide. In the rains, when the whole space of three miles is one rapid flood, 10 or 12 feet deep, charged with yellow sand, this river must present an imposing spectacle. I walked across the dry portion, observing the sand-waves, all ranged in one direction, perpendicular to that of the prevailing wind, and accurately representing the undulations of the ocean, as seen from a mast-head or high cliff. As the sand was finer or coarser, so did the surface resemble a gentle ripple, or an ocean-swell. The progressive motion of the waves was curious, and caused by the lighter particles being blown over the ridges, and filling up the hollows to leeward. There were a few islets in the sand, oases of mud and clay, in lamina no thicker than paper, and these were at once denizened by various weeds. Some large spots were green with wheat and barley-crops, both suffering from smut.

We encamped close to the westem shore, at the village of Dearee (alt. 330 feet): it marks the termi- 
nation of the Kymore Hills, along whose S.E. base our cour'se now lay, as we here quitted the grand trunk road for a country rarely visited.

On the 16th we marched south up the river to Tilotho (alt. 395 feet), through a rich and highly cultivated country, covered with indigo, cotton, sugarcane, safflower, castor-oil, poppy, and various grains. Dodders covered even tall trees with a golden web, and the Capparis acuminata was in full flower along the road side. Tilotho, a beautiful village, was situated in a superb grove of Mango, Banyan, Peepul, Tamarind, and Bassia. The Date or toddy-palm and fan-palm were very abundant and tall: each had a pot hung under the crown. The natives climb their trunks with a hoop or cord round the body and both ancles, and a bottle-gourd or other vessel hanging round the neck to receive the juice from the stock-bottle, in this aerial wine-cellar. These palms were so lofty that the climbers, as they paused in their ascent to gaze with wonder at our large retinue, resembled monkeys rather than men. Both trees yield a toddy, but in this district that from the Date alone ferments, and is distilled; while in other parts of India, the fan-palm is chiefly employed. I walked to the hills, over a level cultivated country interspersed with occasional belts of low wood; in which the pensile nests of the weaverbird were abundant, but generally hanging out of reach, in prickly Acacias.

The hills here present a straight precipitous wall of sandstone, very like the rocks at the Cape of Good Hope, with occasionally a shallow valley, and a slope 
of débris at the base, densely clothed with dry jungle. The cliffs are about 1000 feet high, and the plants similar to those at the foot of Parasnath, but stunted: I climbed to the top, the latter part by steps or ledges cut in the sandstone. The summit was clothed with long grass, trees of Diospyros and Terminalia, and here and there the Boswellia. On the precipitous rocks the curious white-barked Sterculia foetida "flung its arms abroad," leafless, and looking as if blasted by lightning.

On the 17 th we marched to Akbarpore, a village overhung by the rocky precipice of Rotasghur. Passing between the river and a detached conical hill of limestone, capped with a flat mass of sandstone, the spur of Rotas broke suddenly on the view, and very grand it was, quite realising my anticipations of the position of these eyrie-like hill-forts of India. To the left of the spur winds the valley of the Soane, with low wooded hills on its opposite bank, and a higher range, comnected with that of Behar, in the distance. To the right, the hills sweep round, forming an immense and beautifully wooded amphitheatre, about four miles deep, bounded by a continuation of the escarpment. At the foot of the crowned spur is the village of Akbarpore, where we encamped in a Mango tope; ${ }^{*}$ it occupies some pretty undulating limestone hills, amongst which sereral streams flow from the amphitheatre to the Soane.

During our two days, stay here, I had the advantage of the society of Mr. C. E. Daris, who was our guide

* On the 24th of June, 1848, the Soane rose to an unprecedented height, and laid this grove of Mangos three feet under water. 
during some rambles in the neighbourhood, and to whose experience, founded on the best habits of observation, I am indebted for much information. At noon we started to ascend to the palace, on the top of the spur. On the way we passed a beautiful well, sixty feet deep, and with a fine flight of steps to the bottom. Now neglected, and overgrown with flowering weeds and creepers, I found there many of the plants I had only previously obtained in a withered state; it was curious to observe there some of the species of the hilltops, whose seeds are doubtless scattered abundantly over the surrounding plains, but only vegetate where they find a coolness and moisture resembling that of the altitude they elsewhere affect. A fine fig-tree growing out of the stone-work spread its leafy green branches over the well mouth, which was about twelve feet square; its roots assumed a singular form, enveloping two sides of the walls with a beautiful net-work, which at high-water mark (rainy season), abruptly divides into thousands of little brushes, dipping into the water which they fringe. It was a pretty cool place to descend to, from a temperature of $80^{\circ}$ above, to $74^{\circ}$ at the bottom, where the water was $60^{\circ}$; and most refreshing to look, either up the shaft to the green fig-tree shadowing the deep profound, or along the sloping steps through a vista of flowering herbs and climbing plants, to the blue heaven of a burning sky.

The ascent to Rotas is over the dry hills of limestone, covered with a scrubby brushwood, to a crest where are the first rude and ruined defences. The limestone 
is succeeded by the sandstone cliff cut into steps, which led from ledge to ledge and gap to gap, well guarded with walls and an archway of solid masonry. Through this we passed on to the flat summit of the Kymore hills, covered with grass and forest, and intersected by paths in all directions. The ascent is about 1200 feet-a long pull in the blazing sun of February. 'The turf consists chiefly of spear-grass and Andropogon muricatus, the kus-kus, which yields a favourite fragrant oil, used as a medicine in India. A pretty octagonal summer-house, with its roof supported by pillars, occupies one of the highest points of the plateau, and commands a superb view. From this a walk of three miles leads through the woods to the palace. The buildings are very extensive, and though now ruinous, bear evidence of great beauty in the architecture: light galleries, supported by slender columns, long cool arcades, screened squares and terraced walks, are the principal features. The rooms open out upon flat roofs, commanding views of the long endless table-land to the west, and a sheer precipice of 1000 feet on the other side, with the Soane, the amphitheatre of hills, and the village of Akbarpore below.

This and Beejaghur, higher up the Soane, were amongst the most recently reduced forts, and this was further the last of those wrested from Baber in 1542 . Some of the rooms are still habitable, but the greater part are ruinous, and covered with climbers, both of wild flowers and of the naturalised garden plants of the adjoining shrubbery; the Arbor-tristis, with Hibiscus, 
Abutilon, \&c., and above all, the little yellow-flowered Linaria ramosissima, crawling over every ruined wall, as we see the walls of our old English castles clothed with its congener L. Cymbalaria.

In the old dark stables I observed the soil to be covered with a copious evanescent efflorescence of nitrate of lime, like soap-suds scattered about.

I made Rotas Palace 1490 feet above the sea, so that this table-land is here only fifty feet higher than that we had crossed on the grand trunk road, before descending at the Dunwah pass. Its mean temperature is below that of the valley, but though so cool, agues prevail after the rains. The extremes of temperature are less marked than in the valley, which becomes excessively heated, and where hot winds sometimes last for a week, blowing in furious gusts.

The climate of the whole neighbourhood has of late changed materially; and the fall of rain has much diminished, consequent on felling the forests; even within six years the hail-storms have been far less frequent and violent. The air on the hills is highly electrical, owing, no doubt, to the dryness of the atmosphere, and to this the frequent recurrence of hailstorms may be due.

The zoology of these regions is tolerably copious, but little is known of the natural history of a great part of the plateau; a native tribe, prone to human sacrifices, is talked of. Tigers are common, and bears are numerous; they have, besides, the leopard, panther, viverine cat, and civet; and of the dog tribe the pariah, jackal, fox, and wild dog, called Koa. Deer are very 
numerous, of six or seven kinds. A small alligator inhabits the hill streams, said to be a very different animal from either of the Soane species.

On the following day we visited Rajghat, a steep ghat or pass leading up the cliff to Rotas Palace, a little higher up the river. We took the elephants to the mouth of the glen, where we dismounted, and whence we followed a stream abounding in small fish and aquatic insects (Dytisci and Gyrini), through a close jungle, to the foot of the cliffs, where there were indications of coal. The woods were full of monkeys, but though dense, were very dry, containing no Palm, Arums, Peppers, Orchids, or Ferns. The springs were charged with lime, of which enormous tuff beds were deposited on the sandstone, full of impressions of the leaves and stems of the surrounding trees, which, however, I found it very difficult to recognize; and I could not help contrasting this circumstance with the fact that so many geologists, unskilled in botany, see no difficulty in referring equally imperfect remains of extinct regetables to existing genera. In some parts of their course the streams take up quantities of the efflorescence, which they scatter over the sandstones in a singular manner.

On the 19th of February we marched up the Soane to Tura, passing some low hills of limestone, between the cliffs of the Kymore and the river. On the shaded river-banks grew abundance of English genera-Cynoglossum, Veronica, Potentilla, Ranuinculus sceleratus, Rumex, several herbaceous Compositce and Labiata; Tamarix formed a small bush in rocky hillocks in the 



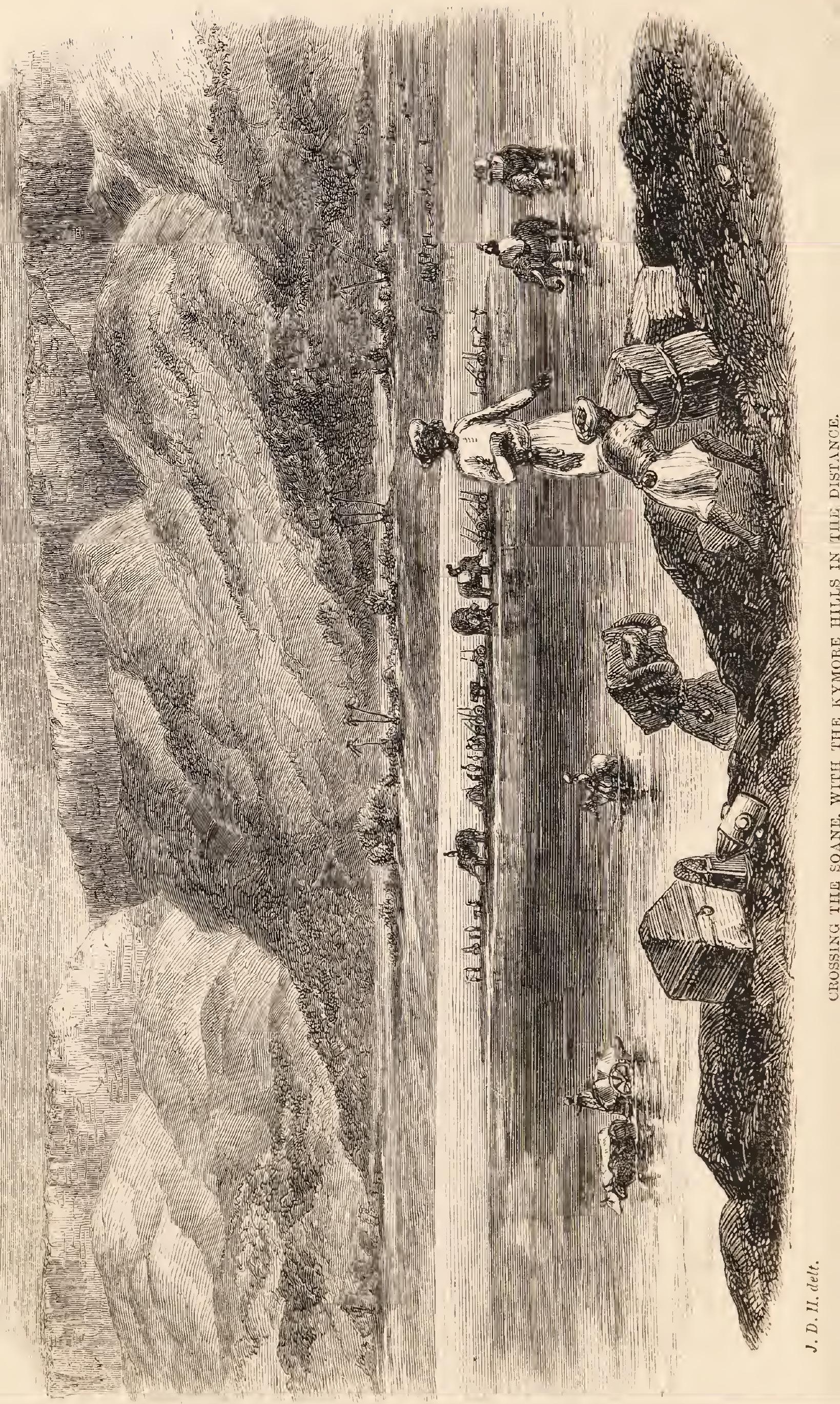


bed of the river, and in pools were several aquatic plants, Zannichellia, Chara, a pretty little Vallisneria, and Potamogeton. The Brahminee goose was common here, and we usually saw in the morning immense flocks of wild geese overhead, migrating northward.

From Tura our little army again crossed the Soane, the scarped cliffs of the Kymore approaching close to the river on the west side. The bed was very sandy, and about one mile and a half across. The stream was very narrow, but deep and rapid, obstructed with beds of coarse agate, jasper, cornelian and chalcedony pebbles. A clumsy boat took us across to the village of Soanepore, a wretched collection of hovels. The crops were thin and poor, and I saw no palms or good trees. Squirrels however abounded, and were busy laying up their stores; descending from the trees they scoured across a road to a field of tares, mounted the hedge, took an observation, foraged and returned up the trees with their booty, quickly descended, and repeating the operation of reconnoitring and plundering.

Near this the sandy banks of the Soane were full of martins' nests, each containing a pair of eggs. The deserted ones were literally crammed full of longlegged spiders (Opilio), which could be raked out with a stick, when they came pouring down the cliff like corn from a sack, in quantities quite inconceivable. I did not observe the martin feed on them.

The entomology here resembled that of Europe, more than I had expected in a tropical country, where predaceous beetles, at least Carabidec and Staphylinidere, are generally considered rare. The latter 
tribes swarmed under the clods, of many species, but all small, and so singularly active that I could not give the time to collect many. In the banks again, the round egg-like earthy chrysalis of the Death's-head Sphynx, and the many-celled nidus of the leaf-cutter bee, were very common.

A large columnar Euphorbia (E. ligulata) is common all along the Soane, and I observed it to be used everywhere for fencing. I had not remarked the $E$. neriffolia; and the $E$. tereticaulis had been very rarely seen since leaving Calcutta. The Cactus is nowhere found; it is abundant in many parts of Bengal, but certainly not indigenous.

From this place onwards up the Soane, there was no road of any kind, and we were compelled to be our own engineers. The sameness of the regetation and the lateness of the season made me regret this the less, for I was disappointed in my anticipations of finding luxuriance and novelty in these wilds. Before us the valley narrowed considerably, the forest became denser, the country on the south side was broken with rounded hills, and on the north the noble cliffs of the Kymore dipped down to the river. 'The villages were smaller', more scattered and poverty-stricken, with the Mahowa and Mango as the usual trees; the banyan, peepul, and tamarind being rare. The natives are of an aboriginal jungle race; and are tall, athletic, erect, much less indolent, and more spirited than the listless natives of the plains.

So slow and difficult was our progress through fields and woods, and across deep gorges from the hills, that 
we advanced but a few miles each day; the elephant's head too frequently ached too badly to let him push, and the cattle would not proceed when the draught was not equal. What was worse, it was impossible to get them to pull together up the inclined planes we cut, except by placing a man at the head of each of the six, eight, or ten in a team, and simultaneously screwing round their tails; when one tortured animal sometimes capsized the vehicle. The small carts got on better, though it was most nervous to see them rushing down the steeps, especially those with our fragile instruments, \&c.; and I was not surprised when one of my carts was hopelessly broken down; advancing on the spokes instead of the tire of the wheels.

On the 23rd and 24th we continued to follow up the Soane, the country becoming densely wooded, very wild, and picturesque; the woods being full of monkeys, peacocks, hornbills, and wild animaIs. Strychnos potatorum, whose berries are used to purify water, forms a dense foliaged tree, 30 to 60 feet high, some individuals pale yellow, others deep green, though both in apparent health. Feronia elephantum and AEgle marmelos* were very abundant, with Sterculia, and the dwarf date-palm.

A spur of the Kymore, like that of Rotas, here projects to the bed of the river, and was blazing at night with the beacon-like fires of the natives, lighted to scare the tigers and bears from the spots where they cut wood and bamboo; they afforded a splendid spectacle, the flames in some places leaping zig-zag from hill to hill

* The Bhel fruit, lately introduced into English medical practice, as an astringent of great effect, in cases of diarrhoa and dysentery. 
in front of us, and looking as if a gigantic letter W were written in fire.

The night was bright and clear, with much lightning, which was attracted to the spur, and darted down as it were to mingle its fire with that of the forest; so many flashes appeared to strike on the flames, that it is probable the heated air attracted them. We were awakened between 3 and 4 A.M. by a violent dust-storm, which threatened to carry away the tents: this was no doubt owing to our position at the mouth of the gully formed by the opposite hills. The gusts were so furious that it was impossible to observe the barometer, which I returned to its case on ascertaining that any indications of a rise or fall in the column must have been quite trifling. The night had been oppressively hot, with many insects flying about; amongst which I noticed earwigs, a genus erroneously supposed rarely to take to the wing in Britain.

At $8 \frac{1}{2}$ A.n. it suddenly fell calm, and we proceeded to Chanchee (alt. 500 feet), many of the native carts breaking down in their passage over the projecting beds of flinty rocks, or as they hurried down the inclined planes, we cut through the precipitous clay banks of the streams. Near Chanchee we passed an alligator, just killed by two men, a foul beast, about nine feet long, of the mugger kind. Nore absorbing than its natural history was the circumstance of its having swallowed a child, which was playing in the water as its mother was washing her utensils in the river. 'T'he brute was harily dead, much distended by the prey, and the mother was standing beside it with her hands clasped in agony, 
mable to withdraw her eyes from the cursed reptile, which still clung to life with that tenacity for which its tribe are so conspicuous; besides these the two athletes leaned on the bloody bamboo staffs, with which they had all but despatched the animal.

This poor woman earned a scanty maintenance by making catechu ; inhabiting a little cottage, and having no property but two cattle to bring wood from the hills, and a very few household chattels; and how few of these they only know who have seen the meagre furniture of Danga hovels. Her husband cut the trees in the forest and dragged them to the hut, but at this time he was sick, and her only boy, her future stay, it was, whom the beast had devoured.

This province is famous for the quantity of catechu its dry forests yield. The plant (Acacia) is a little thorny tree, erect, and bearing a rounded head of well remembered prickly branches. Itss wood is yellow, with a dark brick-red heart, most profitable in January for yielding the extract.

The Dhat was abundantly in flower here, and a gorgeous sight. In mass the inflorescence resembles sheets of flame, and individually the flowers are eminently beautiful, the bright orange-red petals contrasting brilliantly against the jet-black velrety calyx. 'I'he nest of the leaf-cutter' bee was in thousands in the cliff's, with Mayflies, caddis-worms, spider's, and many predaceous beetles.

We marched on the 28th to Kota, at the junction of the river of that name with the Soane, over hills of flinty rock, which projected everywhere, to the utter 
min of the elephant's feet, and then over mdulating hills of limestone; on the latter I found trees of Cochlospermum, whose curious thick branches spread out somewhat awkwardly, each tipped with a cluster of golden yellow flowers, as large as the palm of the hand, and very beantiful: it is a tropical Gum-Cistus in the appearance and texture of the petals, and their frail nature. The bark abounds in a transparent gum, of which the white ants seem fond, for they had killed many trees. Of the leaves a curious sort of rude bellows are made, with which the natives of these hills smelt iron. Scorpions appeared very common here, of a small kind, $1 \frac{1}{2}$ inch long; several were captured, and one of our party was stung on the finger; the smart was burning for an hour or two, and then ceased.

At Kota we were nearly opposite the cliffs at Beejaghur, where coal is reported to exist; and here we again crossed the Soane, and for the last time. The ford was three miles up the river, and we marched to it through deep sand. The bed of the river is here 500 feet above the sea, and about three-quarters of a mile broad, the rapid stream being 50 or 60 yards wide, and breast deep. The sand is firm and siliceous, with no mica; nodules of coal are said to be washed down thus far from the coal-beds of Burdee, a good deal higher up, but we saw none.

The cliffs come close to the river on the opposite side, their bases clothed with woods which teemed with birds. The soil is richer, and many individual trees were very fine; one tree of the Hardwickia, about 120 feet high, was as handsome a monarch of the forest as 
I ever saw, and it is not often that one sees trees in the tropics, which for a combination of beauty in outline, harmony of colour, and arrangement of branches and foliage, would form so striking an addition to an English park.

There is a large break in the Kymore hills here, beyond the village of Kunch, through which our route lay to Beejaghur, and the Ganges at Mirzapore; the cliffs leaving the river, and trending to the north in a continuous escarpment flanked with low ranges of rounded hills, and terminating in an abrupt spur (Mungeesa Peak) whose summit was covered with a ragged forest. At Kunch we saw four alligators sleeping in the river, looking at a distance like logs of wood: all were of the short-nosed or mugger kind, dreaded by man and beast; I saw none of the sharp-snouted (or gavial), so common on the Ganges, where their long bills, with a garniture of teeth and prominent eyes peeping out of the water, remind one of geological lectures and visions of Ichthyosauri. T'ortoises were frequent in the river, basking on the rocks, and popping into the water when approached.

On the 1st of March we left the Soane, and struck inland over a rough hilly country, covered with forest, fully 1000 feet below the top of the Kymore table-land, which here recedes from the river and surrounds an undulating plain, some ten miles either way, facing the south. The roads, or rather pathways, were very bad, and quite impassable for the carts, without much engineering, cutting through forest, smoothing down the banks of the water-courses to be crossed, and clearing 
away the rocks as we best might. We traversed the empty bed of a mountain torrent, with perpendicular banks of alluvium 30 feet high, and thence plunged into a dense forest. Our course was directed towards Mungeesa Peak, between which and a conical hill the path led. Whether on the elephants or on foot, the thorny jujubes, Acacias, \&c. were most troublesome, and all our previous scratchings were nothing to this. Peacocks and jungle-fowl were very frequent, the squabbling of the former and the hooting of the monkeys constantly grating on the ear. There were innumerable pigeons and a few Floricans; a kind of bustard-considered the best eating game-bird in India. From the defile we emerged on an open flat, halting: at Sulkun, a scattered village (alt. 684 feet), peopled by a bold-looking race (Coles)* who habitually carry the spear and shield. We had here the pleasure of meeting Mr. Felle, an English gentleman employed in the Revenue department; this being one of the roads along which the natives transport their salt, sugar, \&c., from one province to another.

In the afternoon, I examined the conical hill, which, like that near Rotas, is of stratified beds of limestone, capped with sandstone. A stream runs round its base, cutting through the alluvium to the subjacent rock, which is exposed, and contains flattened spheres of limestone. These spheres are from the size of a fist

* The Coles, like the Dangas of the Rajmahal and Behar hills, and the natives of the mountains of the peninsula, form one of the aboriginal tribes of British India, and are widely different people from either the Hindoos or Mussulmen. 
to that of a child's head, or even much larger; they are excessively hard, and neither laminated nor formed of concentric layers. At the top of the hill the sandstone cap was perpendicular on all sides, and its dry top covered with small trees, especially of Cochlospermum. A few large fig-trees clung to the edge of the rocks, and by forcing their roots into the interstices had detached enormous masses, affording good dens for bears and other wild animals. From the top, the view of rock, river, forest, and plain, was very fine, the eye ranging over a broad flat, girt by precipitous hills;West, the Kymore or Vindhya range rose in rugged elevations;- - South, flowed the Soane, backed by ranges of wooded hills, smoking like volcanos with the fires of the natives;- -below, lay the bed of the stream we had left at the foot of the hills, cutting its way through the alluvium, and following a deep gorge to the Soane, which was there hidden by the rugged heights we had crossed, on which the greater part of our camp might be seen still straggling onwards; - east, and close above us, the bold spur of Mungeesa shot up, terminating a continuous stretch of red precipices, clothed with forest along their bases, and over their horizontal tops.

From Sulkun the view of the famed fort and palace of Beejaghur is very singular, planted on the summit of an isolated hill of sandstone, about ten miles off. A large tree by the palace marks its site; for, at this distance, the buildings are themselves undistinguishable.

There are many tigers on these hills; and as one was close by, and had lilled several cattle, Mir. Felle VOL. I. 
kindly offered us a chance of slaying him. Bullocks are tethered out, over-night, in the places likely to be visited by the brute; he kills one of them, and is from the spot tracked to his haunt by natives, who visit the stations early in the morning, and report the whereabouts of his lair. The sportsman then goes to the attack mounted on an elephant, or having a roost fixed in a tree, on the trail of the tiger, when he employs some hundred natives to drive the animal past the lurking-place.

On the present occasion, the locale of the tiger was doubtful; but it was thought that by beating over several miles of country, he (or at any rate, some other game) might be driven past a certain spot. Thither, accordingly, natives were sent, who built machans (stages) in the trees, high out of danger's reach; Mr. Theobald and myself occupied one of these perches in a Mardwickic tree, and Mr. Felle another, close by, both on the slope of a steep hill, surrounded by jungly valleys. We were also well thatched in with leafy boughs to prevent the wary beast from espying the ambush, and had a whole stand of small arms ready for his reception.

When roosted aloft, and duly charged to keep profound silence (which I obeyed to the letter, by falling sound asleep), the word was passed to the beaters, who surrounded our post on the plain-side, extending some miles in line, and full two or three distant from us. They entered the jungle, beating tom-toms, singing and shouting as they advanced, and converging towards our position. In the noonday 
solitude of these vast forests, our situation was romantic enough: there was not a breath of wind, an insect or bird stirimg; and the wild cries of the men, and the hollow sound of the drums, broke upon the ear from a great distance, gradually swelling and falling, as the natives ascended the heights or crossed the valleys. After about an hour and a half, the beaters emerged from the jungle beneath our retreat; one by one, two by two, but preceded by no single living thing; either mouse, bird, deer, or bear, and much less tiger. They received about a penny a-piece for the day's work; a rich guerdon for these poor wretches, whom necessity sometimes drives to feed on rats and offal.

We were detained three days at Sulkum, from inability to get on with the carts; and as the pass over the Kymore to the north (on the way to Mirzapore) was to be still wor'se, I took adrantage of Mr. Felle's kind offer of camels and elephants to make the best of my way forward, accompanying that gentleman, on route, to his residence at Shahgunj, on the table-land.

Both the climate and natural history of this flat on which Sulkun stands, are similar to those of the banks of the Soane; the crops are wretched. At this season the dryness of the atmosphere is excessive: our nails cracked, and skins peeled, whilst all articles of wood, tortoiseshell, \&c., broke on the slightest blow. The air, too, was always highly electrical, and the dew-point was frequently $40^{\circ}$ below the temperature of the air.

The natives are far from honest: they are, moreover', dexterous thieves; of which we had a proof in their robbing one of the tents placed between two others, 
wherein a light was burning. One gentleman in it was awake, and on turning saw five men at his bedside, who escaped with a bag of booty, in the shape of clothes, and a tempting strong brass-bound box, containing private letters. The clothes they dropped outside, but the box of letters was carried off. There were about a hundred people asleep outside the tents, between whose many fires the rogues must have passed, eluding also the guard, who were, or ought to have been, awake. 


\section{CHAPTER III.}

Ek-powa Ghat-Sandstones - Shahgunj-Gum-arabic-Mango-FairRujubbund-Storm-False sunset and sunrise-Bind hills-Mirzapore-Manufactures, imports, \&c.-Climate of-Thuggee-ChunarBenares - Mosque - Observatory - Sar-nath - Ghazepore - Rosegardens-Manufactory of Attar-Lord Cornwallis' tomb-Ganges, scenery and natural history of - Pelicans-Vegetation-InsectsDinapore-Patna-Opium godowns and manufacture-Monghyr-Hot Springs of Seetakoond-Rocks of Sultan-gunj-Bhagulpore-Temples of Mt. Manden-Coles and native tribes-Bhagulpore rangersHorticultural gardens.

ON the 3rd of March I bade farewell to Mr. Williams and his kind party, and rode over a plain to the village of Markunda, at the foot of the Ghat. There the country becomes rery rocky and wooded, and a stream is crossed, which runs over a flat bed of limestone, cracked into the appearance of a tesselated pavement. For many miles there is no pass over the Kymore range, except this, significantly called "Ek-powa Ghat" (one-foot Ghat). It is evidently a fault, or shifting of the rocks, producing so broken a cliff as to admit of a path winding over the shattered crags. On either side, the precipices are extremely steep, and continued in an umbroken line; and the views across the plain and Soane valley, over which the sun was now setting, were 
superb. At the summit we entered on a dead flat plain or table-land, with no hills, except along the brim of the valley we had left, where are some curious broad pyramids, formed of slabs of sandstone arranged in steps. By dark we reached the village of Roump (alt. 1090 feet), beyond the top of the pass.

On the next day I proceeded on a small, fast, and wofully high trotting elephant, to Shahgunj, where I enjoyed Mr. Felle's hospitality for a few days. The country here, though elevated, is, from the nature of the soil and its formation, much more fertile than that I had left. Water is abundant, both in tanks and wells, and rice-fields, broad and productive, cover the ground; while groves of tamarinds and mangos, now loaded with blossoms, occur at every village.

The gum-arabic Acacia is abundant here, though not seen lower, and very rare to the eastward of this meridian, for I saw but little of it in Behar. It is a plant partial to a dry climate, and rather prefers a good soil. In its distribution it in some degree follows the range of the camel, which is its constant companion over thousands of leagues. In the valley of the Ganges I was told that neither the animal nor plant flourish east of the Soane, where I experienced a marked change in the humidity of the atmosphere on my passage down the Ganges. It was a circumstance I was interested in, having first met with the camel at Teneriffe and the Cape Verd Islands, the westermmost limit of its distribution; imported thither, howerer, as it now is into Australia, where, though there is no Acacia Arabica, four hundred other species of the genus are knorm. 
The mango, which is certainly the fiuit of India, (as the pine-apple is of the West Indies,) was now blossoming, and a superb sight. The young leaves are purplish-green, and form a curious contrast to the deep lurid hue of the older foliage; especially when the tree is (which often occurs) dimidiate, one half the green, and the other the red shades of colours; when in full blossom, all forms a mass of yellow, diffusing a fragrance rather too strong and peculiar to be pleasant.

We passed a village where a large fair was being held, and singularly familiar its arrangements were to my early associations. The women and children were the principal customers; for the latter whirl-you-gorounds, toys, and sweetmeats were destined; to tempt the former, little booths of gay ornaments, patches for the forehead, ear-rings of quaint shapes, bugles and beads. Here, as at home, I remarked that the vendors of these superfluities occupied the approaches to this Vanity-Fair. As, throughout the East, the trades are congregated into particular quarter's of the cities, so here the itinerants grouped themselves into little bazaars for each class of commodity. Whilst I was engaged in purchasing a few articles of native workmanship, my elephant made an attack on a sweetmeat stall, demolishing a magnificent erection of barley-sugar, before his proceedings could be put a stop to.

I here visited a small tarn, or more properly the expanded bed of a stream, art haring aided nature in its formation: it is called Rujubbund (the pleasant spot), and is edged by rocks and cliffs fringed with the 
usual trees of the neighbourhood; it is a wild and pretty spot, not unlike some birch-bordered pool in the mountains of Wales or Scotland, sequestered and picturesque. It was dark before I got back, with heavy clouds and lightning approaching from the south-west. The day had been very hot (3 P.r., 909), and the evening the same; but the barometer did not foretell the coming tempest, which broke with fury at 7 P.r., blowing open the doors, and accompanied with vivid lightning and heary thunder, close by and all round, though no rain fell.

In the clear dry mornings of these regions, a curious optical phenomenon may be observed, of a sunvise in the west, and sunset in the east. In either case, bright and well-defined beams rise to the zenith, often crossing to the opposite horizon. It is a beautiful feature in the firmament, and equally visible whether the horizon be cloudy or clear, the white beams being projected indifferently against a dark rapour or the blue serene. The zodiacal light shines from an hour or two after sunset till midnight, with singular biightness, almost equalling the milky way.

On the rth of March I left Shahgunj for Mirzapore, the road leading over a dead allurial flat to Amowee, about fifteen miles from the Ganges, which is seen flowing among trees, with the white houses, domes, and temples of Mirzapore scattered around, and high above which the dust-clouds were coursing along the horizon.

Mr. Money, the magistrate of Mirzapore, kindly sent a mounted messenger to meet me here, who had 
vast trouble in getting bearers for my palkee. In it I proceeded the next day to Mirzapore, descending a steep ghat of the Bind hills by an excellent road, to the level plains of the Ganges. Unlike the Dunwah pass, this is wholly barren. At the foot the sun was intensely hot, the roads alternately rocky and dusty, the villages thronged with a widely different looking race from those of the hills, and the whole air of the outskirts, on a sultry afternoon, far from agreeable.

Mirzapore is a straggling town, said to contain 100,000 inhabitants. It flanks the river, and is built on an undulating alluvial bank, full of kunker, elevated 360 feet above the sea, and from 50 to 80 above the present level of the river. The vicinity of the Ganges and its green bank, and the numbers of fine trees around, render it a pleasing, though not a fine town. It presents the usual Asiatic contrast of squalor and gaudiness; consisting of large squares and broad streets, interspersed with acres of low huts and groves of trees. It is celebrated for its manufactory of carpets, which are admirable in appearance, and, save in durability, equal to the English. Indigo seed from Bundelkund is also a most extensive article of commerce, the best coming from the Doab. For cotton, lac, sugar and saltpetre, it is one of the greatest marts in India. The articles of native manufacture are brass washing and cooking utensils, and deities carved from the sandstone.

There is little native regetation, the country being covered with cultivation and extensive groves of mango, and occasionally of guava. English vegetables are 
abundant and excellent, and the strawberries, which ripen in March, rival the European fruit in size, though hardly in flavour.

During the few days spent at Mirzapore, in the house of my friend C. Hamilton, Esq., I was surprised to find the temperature of the day cooler by nearly $4^{\circ}$ than that of the hills above, or of the upper part of the Soane valley; while on the other hand the nights were decidedly warmer. The atmosphere was extremely dry and electrical, the hair constantly crackling when combed. Further rest, where the climate becomes still drier, the electricity of the air is even greater; Mr. Griffith mentions in his journal that in filling barometer tubes in Affghanistan, he constantly experienced a shock.

Here I had the pleasure of meeting Lientenant Ward, one of the suppressor's of Thuggee (Thuggee, in Hindostan, signifies a deceiver; fraud, not open force, being employed). This gentleman kindly showed me the approvers or king's evidence of his establishment, belonging to those three classes of human scourges, the 'Thug, Dakoit, and Poisoner. Of these the first was the Thug, a mild-looking man, who had been bor'u and bred to the profession: he had committed many murder's, saw no harm in them, and felt neither shame nor remorse. His organs of observation and destructiveness were large, and the cerebellum small. Ho explained to me how the gang waylay the unwary traveller, enter into conversation with him, and have him suddenly seized, when the superior throws his own girdle round the victim's neck and strangles him, press- 
ing the knuckles against the spine. Taking off his own girdle, he passed it round my arm, and showed me the turn as coolly as a sailor once taught me the hangman's knot. The Thug is of any caste, and from any part of India. The profession have particular stations, which they generally select for murder, throwing the body of their rictim into a well.

The Dakoit (dakhee, a robber) belongs to a class who rob in gangs, but never commit murder-arson and housebreaking also forming part of their profession. These are all high-class Rajpoots, originally from Guzerat; who, on being conquered, vowed vengeance on mankind. They speak both Hindostanee and the otherwise extinct Guzerat language ; this is guttural in the extreme, and very singular in sound. They are a very remarkable and cowardly people, found throughout India, and called by various names; their women dress peculiarly, and are utterly devoid of modesty. The man I examined was a short, square, but far from powerful Nepalese, with high arched eyebrows, and no organs of observation.

The Poisoners all belong to one caste, of Pasie, or dealers in toddy: they go singly or in gangs, haunting the travellers' resting-places, where they drop half a rupee weight of pounded or whole Datura seeds into his food, producing a twenty-hours' intoxication, during which he is robbed, and left to recover or sink under the stupifying effects of the narcotic. The one whom I saw told me that the Daturce seed is gathered without ceremony, and at any time, place, or age of the plant. He was a dirty, ill-conditioned looking fellow, with no 
bumps behind his ears, or prominence of eyebrow region, but a remarkable cerebellum.

Though now all but extinct (except in Cuttack), through ten or fifteen years of unceasing vigilance on the part of Government, and incredible activity and acuteness in the officers employed, the Thugs were formerly a wonderfully numerous body, who abstained from their vocation solely in the immediate neighbourhood of their own villages; which, however, were not exempt from the visits of other Thugs; so that, as Major Sleeman says,- "The annually returning tide of murder swept unsparingly orer the whole face of India, from the Sutlej to the sea-coast, and from the Himalaya to Cape Comorin. One narrow district alone was free, the Concan, beyond the ghats, whither they never penetrated." Candeish and Rohilkund alone harboured no Thugs as residents, but they were nevertheless haunted by the gangs.

Their origin is uncertain, but supposed to be very ancient, soon after the Mahommedan conquest. They now claim a divine original, and are supposed to have supernatural powers, and to be the emissaries of the divinity, like the wolf, the tiger, and the bear. It is only lately that they have swarmed so prodigiously,seven original gangs having migrated from Delhi to the Gangetic provinces about 200 years ago, from which all the rest have sprung. Many belong to the most amiable, intelligent, and respectable classes of the lower and even middle ranks: they love their profession, regard murder as sport, and are never haunted with dreams, nor troubled with pangs of conscience 
during hours of solitude, or in the last moments of life. The victim is an acceptable sacrifice to the goddess Davee, who by some classes is supposed to eat the lifeless body, and thus save her votaries the necessity of concealing it.

They are extremely superstitious, always consulting omens, such as the direction in which a hare or jackal crosses the road; and even far more trivial circumstances will determine the fate of a dozen of people, and perhaps of an immense treasure. All worship the pickaxe, which is symbolical of their profession, and an oath sworn on it binds closer than on the Koran. The consecration of this weapon is a most elaborate ceremony, and takes place only under certain trees. The Thugs rise through various grades: the lowest are scouts; the second, sextons; the third are holders of the victim's hands; the highest, stranglers.

Though all agree in never practising cruelty, or robbing previous to murder, - never allowing any but infants to escape (and these are trained to Thuggee), and never leaving a trace of such goods as may be identified,--there are several variations in their mode of conducting operations: some tribes spare certain castes, others none; murder of woman is against all rules; but the practice crept into certain gangs, and this it is which led to their discountenance by the goddess Davee, and the consequent downfall of the system. Davee, they say, allowed the British to punish them, because a certain gang had murdered the mothers to obtain their daughters to be sold to prostitution.

IIajor Sleeman has constructed a map demonstrating 
the number of "Bails," or regular stations for committing murder, in the kingdom of Oude alone, which is 170. miles long by 100 broad, and in which are 274, which are regarded by the Thug with as much satisfaction and interest as a game preserre is in England: nor are these "bails" less numerous in other parts of India. Of twenty assassins who were examined, one frankly confessed to having been engaged in 931 murders, and the least guilty of the number in 24 . Sometimes 150 persons collected into one gang, and their profits have often been immense, the murder of six persons on one occasion yielding 82,000 rupees; upwards of $8000 l$.

Of the various facilities for keeping up the system, the most prominent are, the practice amongst the natives of travelling before dawn, of travellers mingling freely together, and taking their meals by the way-side instead of in villages; in the very Bails, in fact, to which they are inveigled by the Thug in the shape of a fellow-traveller'; money remittances are also usually made by disguised travellers, whose treasure is exposed at the custom-houses; and, worst of all, the bankers will nevel own to the losses they sustain, which, as a visitation of God, would, if avenged, lead, they think, to future, and perhaps heavier punishment. Had the Thugs destroyed Englishmen, they would quickly have been put down; but the system being invariably practised on a class of people acknowledging the finger of the Deity in its execution, its glaring enormities were long in rousing the attention of the Indian Government. 
A few examples of the actirity exercised by the suppressor's may be interesting. They act wholly through the information given by approvers, who are simply king's evidences. Of 600 'Thugs, all except serenty were captured in ten years, though separated into six gangs, and their operations continued from 1826 to 1830 : the last party was taken in 1836 . And again between the years 1826 and 1835, 1562 Thugs were seized, of whom 382 were hanged, and 909 transported; so that now it is but seldom these wretches are ever heard of.

To show the extent of their operations I shall quote an anecdote from Sleeman's Reports (to which I am indebted for most of the above information). He states that he was for three years in charge of a district on the Nerbudda, and considered himself acquainted with every circumstance that occurred in the neighbourhood; yet, during that time, 100 people were murdered and buried within less than a quarter of a mile of his own residence!

Two hundred and fifty boats full of river Thugs, in crews of fifteen, infested the Ganges between Benares and Calcutta, during five months of every year, under pretence of conveying pilgrims. Traveller's along the banks were tracked, and offered a passage, which if refused in the first boat was probably accepted in some other. At a giren signal the crews rushed in, doubled up the decoyed rictim, broke his back, and threw him into the river, where floating corpses are too numerous to elicit even an exclamation.

At Mirzapore I engaged a boat to carry me down 
the river to Bhagulpore, whence I was to proceed to the Sikkim-Himalaya. The sketch at p. 80 will give some idea of this vessel, which, though slow and very shabby, had the advantage of being cooler and more commodious than the handsomer craft. Its appearance was not unlike that of a floating haystack, or thatched cottage: its length was 40 feet, and breadth 15, and it drew a foot and a half of water: the deck, on which a kind of house, neatly framed of matting, was erected, was but a little above the water's edge. My portion of this floating residence was lined with a kind of reed-work formed of long culms of Saccharum. The crew and captain consisted of six naked Hindoos, one of whom steered by the huge rudder, sitting on a bamboo-stage astern; the others pulled four oars in the very bows opposite my door, or tracked the boat along the riverbank.

In my room (for cabin I cannot call it) stood my palkee, fitted as a bed, with musquito curtains; a chair and table. On one side were placed all my papers and plants, under arrangement to go home; on the other, my provisions, rice, sugar, curry-powder, a preserved ham, and cheese, \&c. Around hung telescope, botanical box, dark lantern, barometer, and thermometer, \&c., \&c. Our position was often ashore, and, Hindoo-like, on the lee-shore, going bump, bump, bump, so that I could scarcely write. I considered myself fortunate in having to take this slow convey. ance down, it enabling me to write and arrange all day long. 
On the afternoon of the 15th of March I passed Chmar.* This is a tabular mass of sandstone, projecting into the river, and forming the eastern termination of the Kymore range. There is not a rock between this and the Himalaya, and barely a stone all the way down the Ganges, till the granite and gneiss rocks of the Behar range are again met with. The current of the Ganges is here very strong, and its breadth much lessened: the river runs between high banks of alluvium, containing much kunker. At Benares it expands into a broad stream, with a current which during the rains is said to flow eight miles an hour, when the waters rise 43 feet.

Benares is the Athens of India. The variety of buildings along the bank is incredible. There are temples of every shape, in all stages of completion and dilapidation, and at all angles of inclination; for the banks give way so much that many of these edifices are fearfully out of the perpendicular.

The famed mosque, built by Aurungzebe on the site of a Hindoo temple, is remarkable for its two octagonal minarets, 232 feet above the Ganges. The building. itself is deficient in beauty or ornament, but the view from it over the town, especially of the European Residents' quarter, is fine; it commands the muddy river with its thousands of boats, its waters peopled with swimmers and bather's, who spring in from the many temples, water-terraces, and ghats on the city side; while opposite is a great sandy plain. The town below appears a mass of poor, square, flat-roofed houses,

* The first station at which Henry Martyn laboured in India. 
through the crowd of which, and of small temples, the eye wanders in vain for some attractive feature, or evidence of the wealth, the devotion, the science, or the grandeur of a city celebrated throughout the East for all these attributes. Green parrots and pigeons people the air.

The general appearance of an oriental town is always more or less ruinous; and here the eye is fatigued with bricks and crumbling edifices, and the ear with prayerbells. The streets are so narrow that it is difficult to ride a horse through them; and the houses are often six stories high, with galleries crossing above from house to house. Enormous spiders' webs hang from the crumbling walls, resembling curtains of coarse muslin, being often some yards across, and not arranged in radii and ares, but spun like weaver's woofs. Paintings, remarkable only for their hideous proportions and want of perspective, are daubed on the walls in vermilion, ochre, and indigo. The elephant, camel, and porpoise of the Ganges, dog, shepherd, peacock, and horse, are especially frequent, and so is a running: pattern of a hand spread open, with a blood-red spot on the palm. A still less elegant but frequent object is the fuel, which is composed of the manure collected on the roads of the city, moulded into flat cakes, and stuck by the women on the walls to dry, retaining the sign-manual of the artist in the impressed form of her outspread hand. The cognizance of the Rajah, two fish chained together, appears over the gates of public buildings.

The hundreds of temples and shrines throughout the 
city are its most remarkable features: sacred bulls, and lingams of all sizes, strewed with flowers and grains of rice, meet the eye at every turm; and the city's boast is the possession of one million idols, which, of one kind and another, I can well beliere.

Through the kindness of Mr. Reade (the Commissioner), I obtained admission to the Bishishar-Kumardil, the "holiest of holies." It was a small, low, stone building, daubed with red inside, and swarming with stone images of Brahminee bulls, and various disgusting emblems. A fat old Brahmin, naked to the waist, took me in, but allowed no followers; and what with my ignorance of his phraseology, the clang of bells and din of voices, I gained but little information. I emerged, adorned with a chaplet of magnolia flowers, and with my hands full of Calotropis and Nyctanthes blossoms. It was a horrid place for moise, smell, and sights. Thence I went to a holy well, rendered sacred because Sira, when stepping from the Himalaya to Ceylon, accidentally let a medicine-chest fall into it. The natives frequent it with little basins or baskets of rice, sugar, \&c., dropping in a little of each while they mutter prayer's.

The observatory at Benares, and those at Delhi, Matra on the Jumna, and Oujein, were built by JeySing, Rajah of Jayanagar, upwards of 200 years ago; his skill in mathematical science was so well known, that the Emperor Mahommed Shah employed him to reform the calendar.

Of the more important instruments I took sketches; No. 1 is the Naree-wila, or Equatorial dial; No. 2, the 
Semrat-yunta, or Equinoctial dial; No. 3, an Equatorial dial, probably a Kranti-urit, or Azimuth circle.* Jey-Sing's genius and love of science seem, according

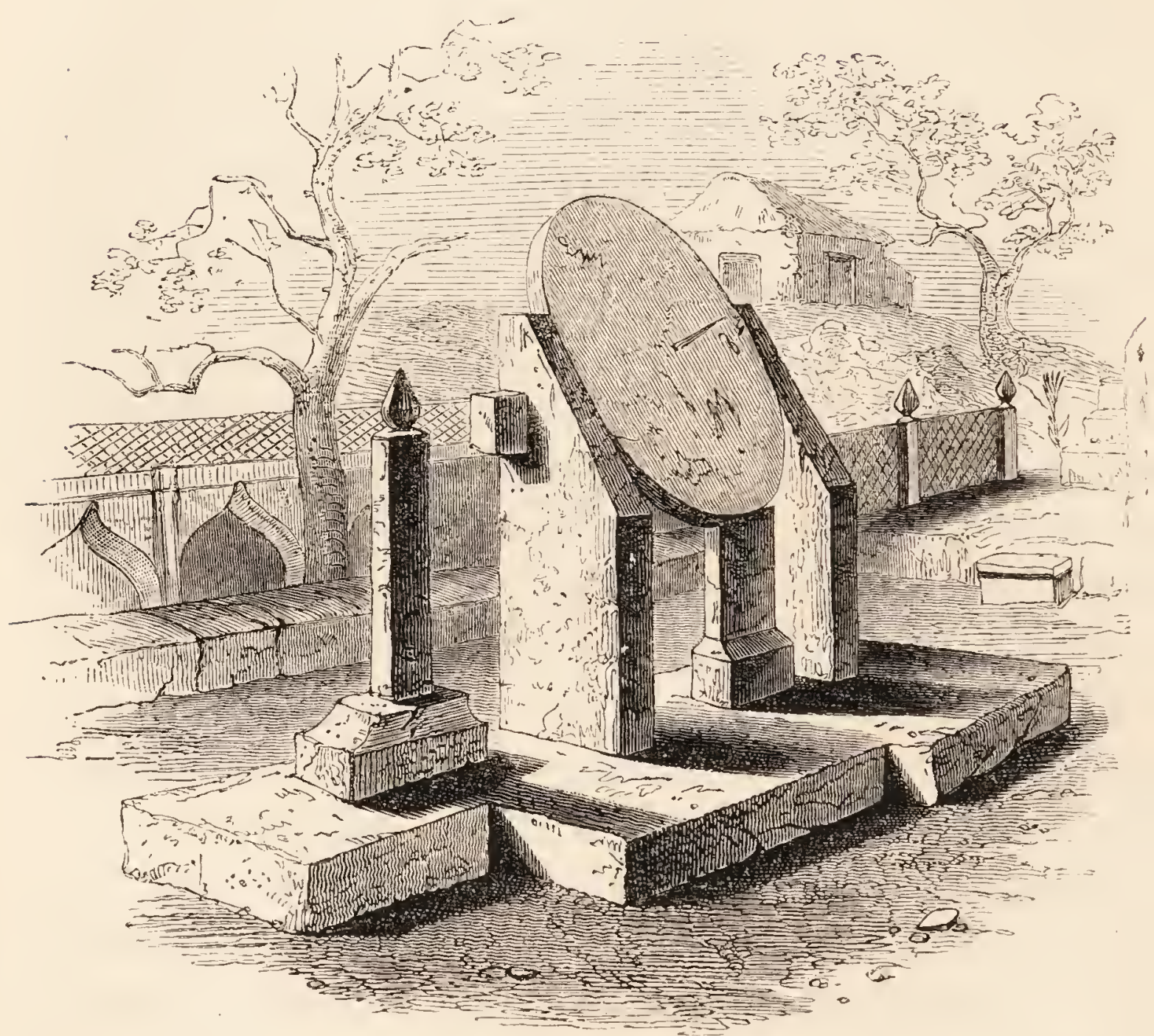

1. EQUATORIAL SUN-DIAL.

(DIAMETER OF FACE OF DIAL, 2 FEET 2 INCHES.)

to Hunter, to have descended to some of his family, who died early in this century, when "Urania fled before the brazen-fronted Mars, and the best of the

* Hunter, in As. Soc. Researches, 177 (Calcutta); Sir R. Barker, in Phil. Trans., lxvii. 608 (1777); J. L. Williams, Phil. Trans., 1xxxiii. 45 (1793). 
observatories, that of Oujein, was turned into an arsenal and cannon foundry."

The observatory is still the most interesting object

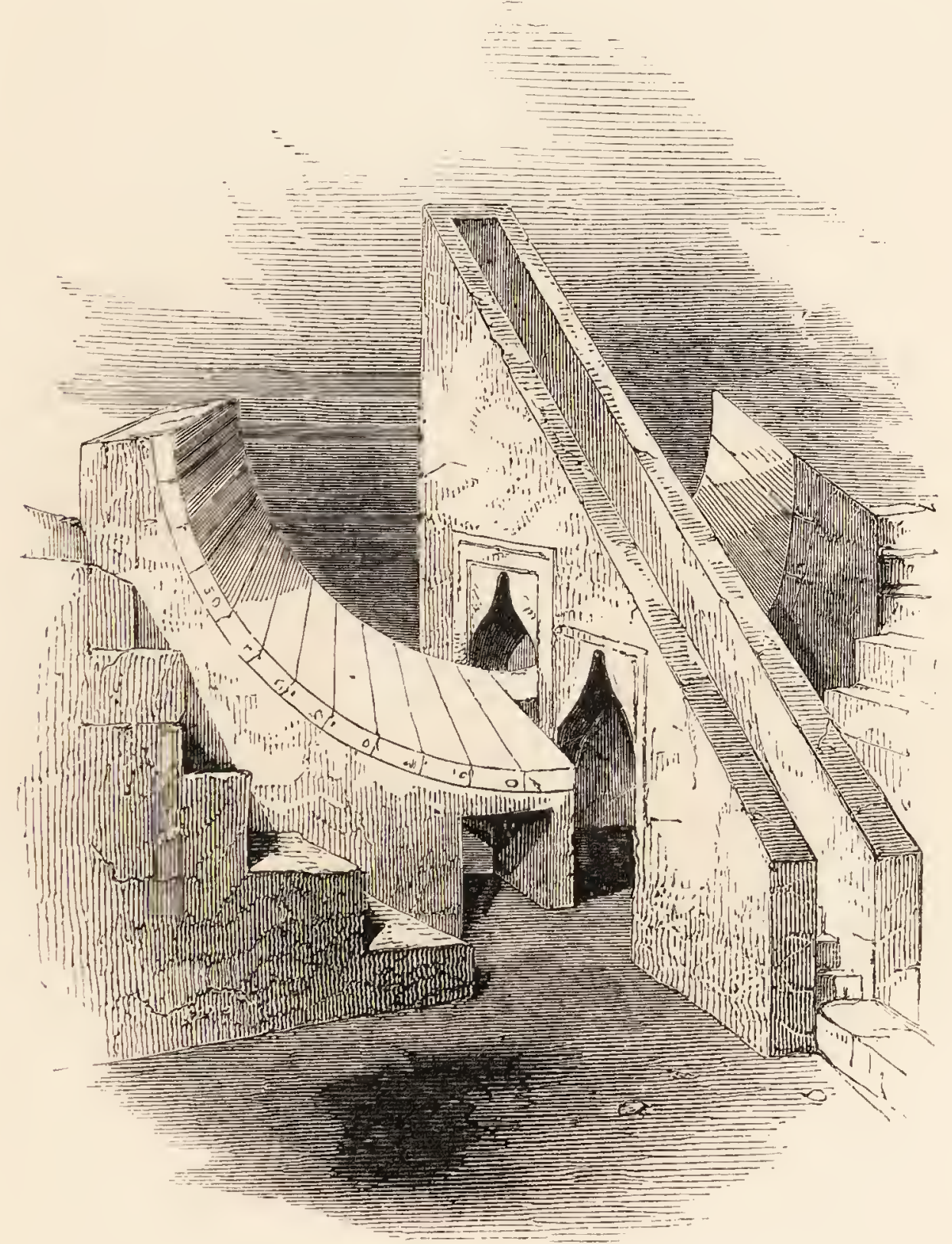

2. EQUIYOCTIAL SUN-DIAL.

(LENGTH OF GNOMON, 39 FEET; OF EACI QUADRANT, 9 FEeT.)

in Benares, though it is now dirty and ruinous, and the great stone instruments are rapidly crumbling away. 'The building is square, with a central court and flat 
roof, round which the astrolabes, \&c. are arranged. A half-naked Astronomer-Royal, with a large sore on his stomach, took me round-he was a pitiful object, and

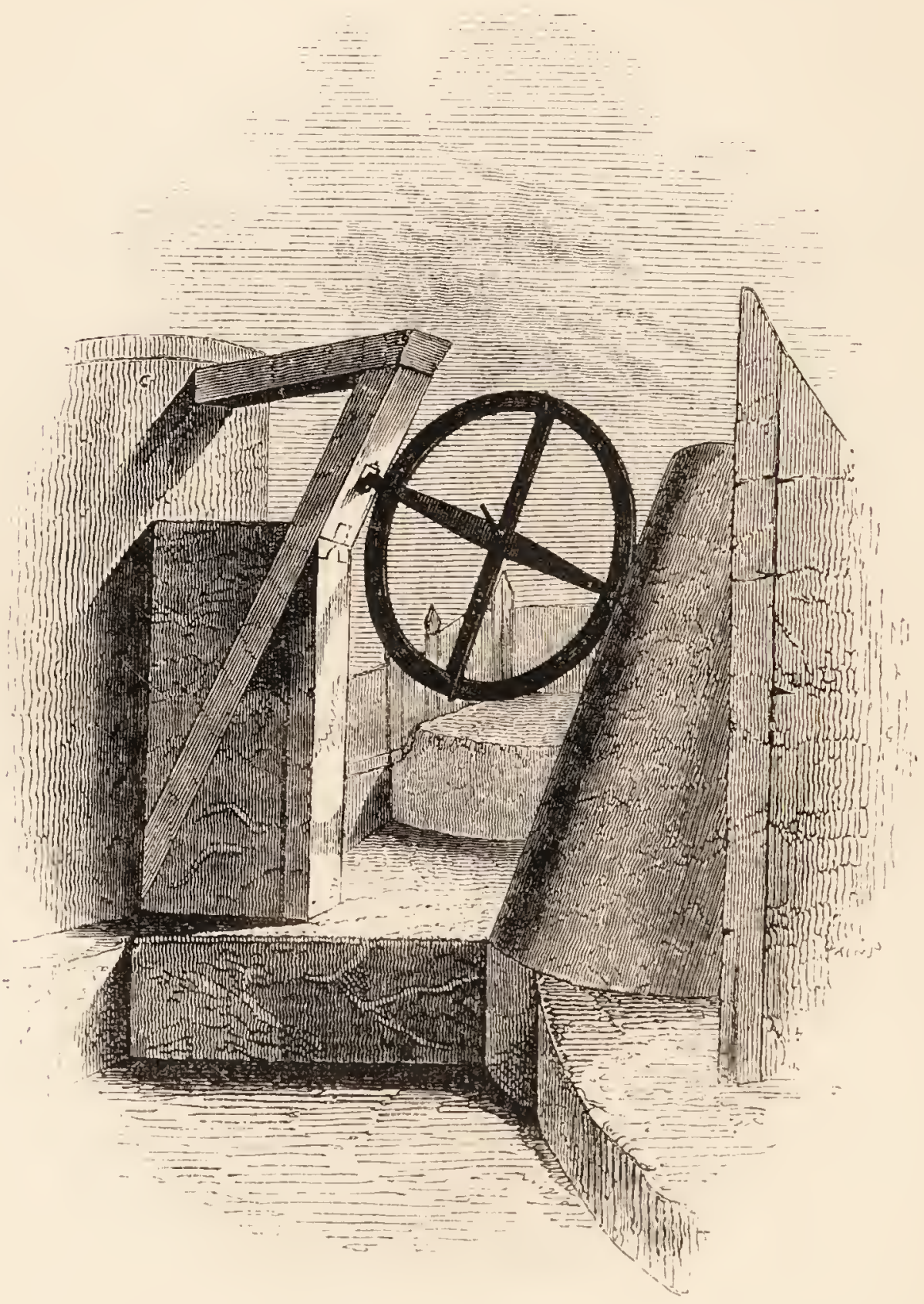

3. BRASS AZIMUTH CIRCLE.

(DIAMETER, 2 FEET.)

told me he was very hungry. The observatory is nominally supported by the Rajah of Jeypore, who doles out a too scanty pittance to his scientific corps. 
In the afternoon I visited the Sar-nath, a singular Boodhist temple, a cylindrical mass of brickwork, faced with stone, the scrolls on which were rery beautiful, and as sharp as if freshly cut: it is surmounted by a tall dome, and is altogether about seventy or a hundred feet high. Of the Boodh figures only one remains, the others having been used by a recent magistrate of Benares in repairing a bridge over the Goomtee!

Benares is the Mecca of the Hindoos, and the number of pilgrims who visit it is incalculable. Casi (its ancient name, signifying splendid) is alleged to be no part of this world, which rests on eternity, whereas Benares is perched on a prong of Sira's trident, and is hence beyond the reach of earthquakes.* Originally built of gold, the sins of the inhabitants were punished by its transmutation into stone, and latterly into mud and thatch: whoever enters it, and especially risits its principal idol (Siva fossilised), is secure of heaven.

On the 18th I left Benares for Gliazepore, a pretty town situated on the north bank of the river, celebrated for its manufacture of rose-water, the tomb of Lord Cornwallis, and a site of the Company's stud. The Rose gardens surround the town : they are fields, with low bushes of the plant grown in rows, red with blossoms in the morning, all of which are, however, plucked long before midday. The petals are put into clay stills, with twice their weight of water, and the produce exposed to the fresh air, for a night, in open

* Probably an allusion to the infrequency of these phenomena in this meridian; they being common both in Eastern Bengal, and in Western India beyond the Ganges. 
vessels. The unskimmed water affords the best, and it is frequently twice and eren oftener distilled; but the fluid deteriorates by too much distillation. The Attar is skimmed from the exposed pans, and sells at 10l. the rupee weight, to make which 20,000 flowers are required. It is frequently adulterated with sandalwood oil.

Lord Cornwallis' mausoleum is a liandsome building, modelled by Flaxman after the Sibyl's Temple. The allegorical designs of Hindoos and sorrowing soldiers with reversed arms, which decorate two sides of the enclosed tomb, though perhaps as good as can be, are under any treatment unclassical and uncouth. The simple laurel and oak-leaf chaplets on the alternating faces are far more suitable and suggestive.

On the 21st March I left Ghazepore, and dropped down the Ganges; the general features of which are soon described. A strong current, four or fire miles broad, of muddy water, flows between a precipitous bank of allurium or sand on one side, and a flat shelring one of sand or more rarely mud, on the other. Sand-banks are frequent in the river, especially where the great affuents débouche; and there generally are formed vast expanses of sand, small "Saharas," studded with stalking pillar's of sand, raised $70 \mathrm{or}^{\circ}$ 80 feet high by gusts of wind, erect, stately, fgravelooking columns, all shaft, with neither basement nor' capital, the genii of the "Arabian Nights." The river' is always dotted with boats of all shapes, mine being perhaps of the most common description, and the great square, Yankee-like steamers, towing their 
accommodation-boats (as the passengers' floating hotels are called), being the rarest. Trees are scarce on the banks, except near villages, and there is hardly a palm to be seen above Patna. Towns are unfrequent, such as there are being mere collections of huts, with the invariable ghat and boats at the bottom of the bank; and at a respectful distance from the bazaar, stand the neat bungalows of the European residents, with their smiling gardens, hedgings and fencings, and loitering servants at the door. A rotting charpoy (or bedstead) on the banks is a common sight,- the "sola reliqua" of some poor Hindoo, who departs this life by the side of the stream, to which his body is afterwards committed.

Shoals of small goggled-eyed fish are seen, that spring clear out of the water, and are preyed upon by terns and other birds; a few insects skim the surface, and turtle and porpoises tumble along; all forming a very busy contrast to the lazy alligator, sumning his green and scaly back near the shore, with his ichthyosaurian snout raised high above the water. Birds are numerous, especially early and late in the day. Along the silent shore the hungry Pariah dog may be seen tearing his meal from some stranded corpse, whilst the adjutant-bird, with his head sunk on his body and one leg tucked up, patiently awaits his turn. At night the beautiful Brahminee geese alight, one by one, and seek total solitude; ever since having disturbed a god in his slumbers, these birds are fated to pass the night in single blessedness. The gulls and terns, again, roost in flocks, as do the wild geese and pelicans, - the 
latter, not till after making a hearty and very noisy supper. These birds congregate by the sides of pools, and violently beat the water with their wings, so as to scare the fish, which thus become an easy prey; a fact which was, I believe, first indicated by Pallas, during his residence on the banks of the Caspian Sea. Shells are scarce, and consist of a few small bivalves; their comparative absence is probably due to the paucity of limestone in the mountains whence the many feeders flow.

Flies and mosquitos are terrible pests; and so are odious flying-bugs, ${ }^{*}$ which insinuate themselves between one's skin and clothes, diffusing a dreadful vdour, which is increased by any attempt to touch or remove them. In the evening it was impossible to keep insects out of the boat, or to hinder their putting the lights out; and of these the most intolerable was the above-mentioned flying-bug. Saucy crickets, too, swarm, and spring up at one's face, whilst mosquitos maintain a constant guerilla warfare, trying to the patience no less than to the nerves. Thick webs of the gossamer spider float across the river during the heat of the day, as coarse as fine thread, and being inhaled keep tickling the nose and lips.

On the 18th, the morning commenced with a duststorm; the horizon was about 20 yards off, and ashy white with clouds of sand, the trees were scarcely visible, and everything in my boat was covered with a fine coat of impalpable powder, collected from the boundless alluvial plains through which the Ganges 
flows. Trees were scarcely discernible, and so dry was the wind that drops of water vanished like magic.

On the 25th of March I reached Dinapore, a Iarge military station, sufficiently insalubrious, particularly for European troops, the barracks being so misplaced that the inmates are suffocated: the buildings run east and west instead of north and south, and therefore lose all the breeze in the hottest weather. From this place I sent the boat down to Patna, and proceeded thither by land to the house of Dr. Irvine, an old acquaintance and botanist, from whom I received a most kind welcome. On the road, Bengal forms of vegetation, to which I had been for three months a stranger', reappeared; likewise groves of fan and toddy palms, which are both very rare higher up the river. In the gardens, Papaw, Croton, Jatropha, Buddleia, Cookia, Loquat, Litchi, Longan, all kinds of the orange tribe, and the cocoa-nut, some by their presence, and many by their profusion, indicated a recided change of climate, a receding from the desert north-west of India, and its dry winds, and an approach to the damper regions of the many-mouthed Ganges.

My main object at Patna being to see the opium Godowns (stores), I waited on Dr. Corbett, the AssistantAgent, who kindly explained everything to me.

The E. I. Company grant licences for the cultivation of the poppy, and contract for all the produce at certain rates, varying with the quality. The produce is made over to district collector's, who approximately fix the worth of the contents of each jar, and forward it to Patna, where rewards are given for the best samples, 
and the worst are condemned without payment; but all are turned to some account in the reduction of the drug to a state fit for market.

The poppy flowers in the end of January and beginning of February, and the capsules are sliced in February and March with a little instrument like a saw, made of three iron plates with jagged edges, tied together. The cultivation is very carefully conducted, nor are there any apparent means of improving this branch of commerce and revenue. During the N. W. or dry winds, the best opium is procured, the worst during the moist, or E. and N. E., when the drug imbibes moisture; and a watery bad solution of opium collects in cavities of its substance, called Passewa.

At the end of March the opium jars arrive at the stores, and continue accumulating for some weeks. Every jar is labelled and stowed in a proper place, separately tested with extreme accuracy, and valued. When the whole quantity has been received, the contents of all the jars are thrown into great vats, whence the mass is distributed to be made up into balls for the markets. This operation is carried on in a long paved room, where every man is ticketed, and many overseers are stationed to see that the work is properly conducted. Each workman sits on a stool, with a double stage and a tray before him. On the top stage is a tin basin, containing opium sufficient for three balls; in the lower another basin, holding water: in the tray stands a brass hemispherical cup, in which the ball is worked. 'To the man's right hand is another' tray, with two compartments, one containing thin pan- 
cakes of poppy petals presserl together, the other a cupful of sticky opium-water, made from refuse opium. The man takes the brass cup, and places a pancake at the bottom, smears it with opium-water, and with many plies of the pancake, makes a coat for the opium. Of this he takes about one-third of the mass before him, puts it inside the petals, and agglutinates many other coats over it: the balls are then again weighed, and reduced or increased to a certain weight. At the end of the clay each man takes his work to a rack with numbered compartments, and deposits it in that which answers to his own number: thence the balls (each in a clay cup) are carried to an enormous drying-room, where they are exposed in tiers, and constantly examined and turned, to prevent their being attacked by weevils, which are very prevalent during the moist winds; little boys creep along the racks all day long for this purpose. When clry, the balls are packed in two layers of six each in chests, with the stalks, dried leaves, and capsules of the plant, and sent down to Calcutta. A gook workman will prepare from thirty to fifty balls a clay, working for ten hours; and the total produce is 10,000 to 12,000 a day; during the working season 1,353,000 balls are manufactured for the Chinese market alone.

The poppy-petal pancakes, each about a foot radius, are made in the fields by women, by the simple operation of pressing the fresh petals together. They are brought in large baskets, and purchased at the commencement of the season. The liquor with which the pancakes are agghtinated together by the ball- 
maker, and worked into the ball, is merely inspissated opium-water, the material for which is derived from the condemned opium (Passewa), the washing of the utensils, and of the workmen, erery one of whom is nightly laved before he leares the establishment, and the water is inspissated. Thus not a particle of opium is lost.

A powerful smell of opium pervaded these vast buildings, which Dr. Corbett assured me did not affect himself or the assistants.

Even the best East Indian opium is inferior to the Turkish, and, owing to peculiarities of climate, will probably always be so. It nerer yields more than fire per cent. of morphia, whence its inferiority, but is as good in other respects, and eren richer in narcotine.

The care and attention deroted to every department of collecting, testing, manipulating, and packing, is quite extraordinary; and the result lias been an impulse to the trade, beyond what was anticipated. The natives have been quick at apprehending and supplying the wants of the market, and now there are more demands for licences to grow opium than can be granted. All the opium eaten in India is given out with a permit to licensed dealers, and the drug is so adulterated before it reaches the retailers in the bazaars, that it does not contain one-thirticth part of the intoxicating porrer that it did when pure.

Patna is the stronghold of Mahommedanism, and from its central position, its command of the Ganges, and its proximity to Nepal (which country has been aptly compared to a dramn dagger, pointed at the lieart 
of India), it is an important place. For this reason there are always a European and several Native Regiments stationed there. In the neighbourhood there is little to be seen, and the highly cultivated flat country is unfavourable to native regetation.

During the remainder of my voyage down the river, I experienced a succession of east and north-east winds: such are very prevalent throughout the month of March, and they rendered the passage in my sluggish boat extremely tedious. In other respects I had but little bad weather to complain of: only one shower of rain occurred, and but few storms of thunder and lightning. The stream is very strong, and its action on the sand-banks conspicuous. All night I used to hear the falling cliffs precipitated with a dull heavy splash into the water, - a pretty spectacle in the daytime, when the whirling current is seen to carry a cloud of white dust, like smoke, along its course.

On the 1st of April I arrived at Monghyr, by far the prettiest town I had seen on the river, backed by a long range of wooded hills. The banks are steep, and appear even more so, owing to the fortifications, which are extensive. A number of large, white, two-storied houses, some very imposing, and perched on rounded or conical hills, give a European aspect to the place.

Monghyr is celebrated for its iron manufactures, especially of muskets, in which respect it is the Birmingham of Bengal. Generally speaking, these weapons are inferior, though stamped with the first English names. A native workman will, however, if time and sufficient reward be given, turn out a first-rate fowling-piece. 
The inhabitants are reported to be sad drunkards, and the abundance of toddy palms was quite remarkable. In the morning of the following day I went to the hot springs of Seeta-koond (wells of Seeta), a few miles south of the town.

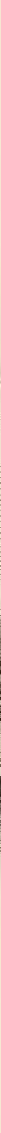

MONGHYR ON TIIE GANGES, WITH THE CURRUCKIORE IILLS IN THE DINTANCE.

Unlike the Soortijkoond hot-springs, these rise in a plain, and were once covered by a handsome temple. All the water is collected in a tank, some yards square, with steps leading down to it. It is clear and tasteless (temp. $104^{\circ}$ ), and so pure as to be exported copiously; whilst at Monghyr itself they manufacture from it soda-water, which presents the anomaly of owing its purity to Seeta's ablutions. 
On my passage down the river I passed the picturesque rocks of Sultangunj; they are similar to those of Monghyr, but very much larger and loftier. One, a round-headed mass, stands on the bank, capped with a triple-domed Mahommedan tomb, palms, and figs. The other, which is far more striking, rises isolated in the bed of the river, and is crowned with a Hindoo temple, its pyramidal cone surmounted with a curious pile of weathercocks, and two little banners. The temple is dedicated to Naragur, and inhabited by Fakirs; it is the most holy on the Ganges.

At Bhagulpore, where I arrived on the 5th, I took up my quarters with my friend Dr. Grant, till he should arrange my dawk for Sikkim.

The town has been supposed to be the much-sought Palibothra, and a dirty stream hard by (the Chundrm), the Eranoboas; but $\mathrm{Mr}$. Ravenshaw has now brought all existing proofs to bear on Patna and the Soane. It is, like most hilly places in India, S. of the Himalaya, the seat of much Jain worship; and the temples on Mount Manden, a few miles off, are said to have been 540 in number. At the assumed summer-palaces of the kings of Palibothra the ground is covered with agates, brought from the neighbouring hills, which were, in a rough state, let into the walls of the buildings.

Again, near the hills, the features of interest are very numerous. The neighbouring mountains of Curruckpore, which are a portion of the Rajmahal and Parasnath range, are peopled by tribes representing the earliest races of India, prior to the invasion of young Rama, prince of Oude, who, according to the legend, 
spread Brahminism with his conquests, and won the hand of King Jannulis daughter, Seeta, by bending: her father's bow. 'These people are called Coles, a middle-sized, strong, very dark, and black-haired race, with thick lips: they have no occupation but collecting iron from the soil, which occurs abundantly in nodules. They eat flesh, whether that of animals killed by themselves, or of those which have died a natural death; and mix with Hindoos, but not with Mussulmen.

The hill-rangers, or Bhagulpore-rangers, are all natives of the Rajmahal hills, and form a local corps maintained by the Company for the protection of the district. For many years these people were engaged in predatory excursions, which, owing to the nature of the country, were checked with great difficulty. The plan was therefore conceived, by an active magistrate in the district, of embodying a portion into a military force, for the protection of the country from invasions of their own tribes; and this scheme has answered perfectly.

To me the most interesting object in Bhagulpore was the Horticultural Gardens, whose origin and flourishing condition are due to the activity and enterprise of the late Major Napleton, commander of the hill-rangers. The site is good, consisting of fifteen acres, that were, four year's ago, an indigo field, but now form a smiling garden. About fifty men are employed; and the number of seeds and regetables annually distributed is very great. Of trees the most conspicuous are the tamarind, Tecoma jasminoides, Erythrina, Adansonia, Bombax, teak, banyan, peepul, Sissoo, Casuarina, Terminalia, Melia, Bauhinia. Of introduced species there 
are English and Chinese flat peaches (pruned to the centre to let the sun in), Mangos of various sorts, Eugenia Jambos, various Anonas, Litchi, Loquat and Longan, oranges, Sapodilla; apple, pear, both succeding tolerably; various Cabool and Persian varieties of fruit-trees; figs, grapes, guava, apricots, and jujube. The grapes looked extremely well, but their management requires great skill and care. They form a long corered walk, with a row of plantains on the W. side, to diminish the effects of the hot winds, but even with this screen, the fruit on that side is inferior to that on the opposite trellis. Easterly winds, again, being moist, blight the vines and other plants, by favouring the abundant increase of insects, and by causing the leaves to curl and fall off; and against this evil there is no remedy. The white ant sometimes attacks the stems, and is best checked by washing the roots with limewater, yellow arsenic, or tobacco-water. Numerous Cerealia, and the varieties of cotton, sugar-cane, \&c., all thrive extremely well; so do many of our English vegetables. Cabbages, peas, and beans are much injured by the caterpillars of a Pontia, like our English "White;" raspberries, currants, and gooseberries will not grow at all.

The manufacture of economic products is not neglected. Excellent coffee is grown; and arrow-root, equal to the best West Indian, is prepared, at $1 s .6 d$. per bottle of twenty-four ounces,-about a fourth of the price of that article in Calcutta.

In most respects the establishment is a model of what such institutions ought to be in India; not only 
of real practical value, in affording a good and cheap supply of the best culinary and other vegetables that the climate can produce, but as showing to what departments efforts are best directed. Such gardens diffuse a taste for the most healthful employments, and offer an elegant resource for the many unoccupied hours which the Englishman in India finds upon his hands. They are also schools of gardening; and a simple inspection of what has been done at Bhagulpore is a valuable lesson to any person about to establish a private garden. 


\section{CHAPTER IV.}

Leave Bhagulpore-Colgong-Himalaya, distant view of-Cosi, mouth of -Difficult navigation-Sand-storms-Caragola-Ghat-Purnea-Ortolans-Mahanuddee, transport of pebbles, \&c.-Betel-pepper, cultivation of-Titalya-Siligoree-View of outer Himalaya-Terai-Mechis -Punkabaree-Foot of mountains-Ascent to Dorjiling-CicadasLeeches-Animals-Kursiong, spring vegetation of - Pacheem-Arrive at Dorjiling-Dorjiling, origin and settlement of-Grant of land from Rajah-Dr. Campbell appointed superintendent-Dewan, late and present-Aggressive conduct of the latter-Increase of the stationTrade-Titalya fair-Healthy climate for Europeans and childrenInvalids, diseases prejudicial to.

I Took as it were a new departure, on Saturday, April the 8th, my dawk being laid on that day from Caragola-Ghat, about thirty miles down the river, for the foot of the Himalaya range and Dorjiling.

Passing the pretty villa-like houses of the. English residents, the river-banks re-assumed their wonted features: the hills receded from the shore; and steep clay cliffs, twenty to fifty feet high, on one side, opposed long sandy shelves on the other.

At Colgong, conical hills appear, and two remarkable sister-rocks start out of the river, the same in structure with those of Sultangunj. A boisterous current swirls round them, strong even at this season, and very dangerous in the rains, when the swollen river is 
from twenty-eight to forty feet deeper than now. We landed opposite the rocks, and proceeded to the residence of Mr: G. Barnes, prettily situated on one of the conical elevations characteristic of the district.

The village we passed through had been recently destroyed by fire; and nothing but the clay outer walls and curious-looking partition walls remained, often white-washed and daubed with figures in red of the palm of the hand, elephant, peacock, and tiger,- - a sort of rude fresco-painting. We did not arrive till past mid-day, and the boat, with my palkee and servant, not having been able to face the gale, I was detained till the middle of the following day.

The view from Mr. Barnes' house is very fine: it commands the river and its rocks; the Rajmahal hills to the east and south; broad acres of indigo and other crops below; long lines of palm-trees, and groves of mango, banana, tamarind, and other tropical trees, scattered close around and in the distance. In the rainy season, and immediately after, the snowy Himalaya are distinctly seen on the horizon, fully 170 miles off. Nearly opposite, the Cosi river enters the Ganges, bearing (considering its short course) an enormous volume of water, comprising the drainage of the whole Himalaya between the two giant peaks of Kinchinjunga in Siklim, and Gossain-Than in Nepal. Even at this season, looking from Mr. Barnes' eyrie over the bed of the Ganges, the enormous expanses of sand, the numerous shifting islets, and the long spits of mud indicate the proximity of some rery restless and resistless power. During the rains, the scene 
must indeed be extraordinary, when the Cosi lays many miles of land under water, and pours so vast a quantity of detritus into the bed of the Ganges that long islets are heaped up and swept away in a few hours; and the latter river becomes all but unnavigable. Boats are caught in whirlpools formed without a moment's rarning, and sunk ere they have spun round thrice in the eddies; and no part of the inland mavigation of India is so dreaded or dangerous, as the Ganges at its junction with the Cosi.

Pain generally falls in partial showers at this season, and is essential to the well-being of the spring crops of indigo. The stormy appearance of the sky, though it proved fallacious, was hailed by my hosts as predicting a fall, which was much wanted. The wind however seemed but to aggravate the drought, by the great body of sand it lifted and swept up the valleys, obscuring the near horizon, and especially concealing the whole delta of the Cosi.

All night the gale blew on, accompanied with much thunder and lightning; and it was not till noon of the 9th that I descried my palkee-boat toiling down the stream. Then I again embarked, taking the lagging boat in tow of my own. Passing the mouths of the Cosi, the gale and currents were so adverse that we had to bring up on the sand, when the quantity which drifted into the boat rendered the delay as disagreeable as it was tedious. The particles penetrated every where, up my nose and down my back, drying my eyelids, and gritting between my teeth. 'The craft kept bumping on the banks, and being both crazy and 
leaky, the little comfortless cabin became the refuge of scared rats and cockroaches. In the evening I shared a meal with these creatures, on some provisions my kind friends had put into the boat, but the food was so sandy that I had to bolt my supper!

At night the storm lulled a little, and I proceeded to Caragola-Ghat and took up my dawk, which had been twenty-eight hours expecting me, and was waiting, in despair of my arrival, for another traveller on the opposite bank, who however could not cross the river.

Having accomplished thirty miles, I halted at 9 A.Mr. on the following morning at Purnea, a large station, considered very unhealthy during and after the rains. I quitted it at noon for Kishengunj, passing through some pretty lanes, with groves of planted Guava and a rattan palm (Calamus), the first I had seen. The whole country wore a greener garb than I had seen anywhere south of the Ganges: the climate was evidently more humid, and had been gradually becoming so from Mirzapore. I was glad to feel myself within the influence of the long-looked-for Himalaya; and I narrowly watched every change in the character of the regetation. A fern, growing by the road-side, was the first and most tangible evidence of this; together with the rarity or total absence of Butea, Boswellia, Catechu, Gristea, Carissa, and all the companions of my previous excursion.

Though no hills are nearer than the Himalaya (distant 100 miles), yet from the constant alteration of the river-beds, the road undulates remarkably for this 
part of India, and a jungly vegetation ensues, consisting of the above plants, with the yellow-flowered Cactus replacing the Euphorbias, which were previously much more common.

Thirty-six miles from Purnea brought me to Kishengunj, when I found that no arrangements whatever had been made for my dawk, and I was fairly stranded. Luckily a thoughtful friend had provided me with letter's to the scattered residents along the road, and I proceeded with one to $\mathrm{Mr}$. Perry, the assistant magistrate of the district, $-a$ gentleman well known for his urbanity, and the many aids he affords to traveller's on this neglected line of road. Owing to this being some festival or holiday, it was impossible to get palkee-bearers; the natives were busy catching fish in all the muddy pools around. Some of Mr. Perry's own family also were about to proceed to Dorjiling, so that I had only to take patience, and be thankful for having to exercise it in such pleasant quarters. The Mahanuddee, a large stream from the hills, flows near this place, strewing the surrounding neighbourhood with sand, and from the frequent alterations in its course, causing endless disputes amongst the landholders. A kind of lark called an Ortolan was abundant: this is not, however, the European delicacy of that name, though a migratory bird; the flocks are large, and the birds so fat, that they make excellent table game. At this time they were rapidly disappearing; to return from the north in September.

I had just got into bed at night, when the bearers 
arrived; so bidding a hurried adieu to my kind host, I proceeded on my joumey.

April 12.-I awoke at 4 A.M., and found my palkee on the ground, and the bearer's coolly smoking their hookahs under a tree (it was raining hard): they had carried me the length of their stage, twelve miles, and there were no others to take me on. I had paid twentyfour pounds for my dawk, from Caragola to the hills, to which I had been obliged to add a handsome douceur; so I lost all patience. After waiting and entreating during several hours, I found the head-man of a neighbouring village, and by a further disbursement induced six out of the twelve bearers to carry the empty palkee, whilst I should walk to the next stage; or till we should meet some other's. They agreed, and cutting the thick and spongy sheaths of the banana, used them for shoulder-pads: they also wrapped them round the palkee-poles, to ease their aching clavicles. Walking along I picked up a few plants, and fourteen miles further on came again to the banks of the Mahanuddee, whose bed was strewn with pebbles and small boulders, brought thus far from the mountains (about thirty miles distant). Here, again, I had to apply to the head-man of a village, and pay for bearer's to take me to Titalya, the next stage (fourteen miles). Some curious long low sheds puzzled me very much, and on examining them they proved to be for the growth of Pawn or Betel-pepper, another indication of the moisture of the climate. These sheds were twenty to fifty yards long, eight or twelve broad, and scarcely five feet high; they were made of bamboo, 
wattled all round and over the top. Slender rods were placed a few feet apart, inside, up which the Pepper Vines climb, and quickly fill the place with their deep green glossy foliage. The owner enters every morning by a little door, and carefully cleans the plants. Constant heat, damp, and moisture, shelter from solar beams, from scorching heat, and from nocturnal radiation, are thus all procured for the plant, which would certainly not live twenty-four hours, if exposed to the climate of this treeless district. Great attention is paid to the cultivation, which is very profitable. Snakes frequently take up their quarters in these hot-houses, and cause fatal accidents.

Titalya was once a military station of some importance, and, from its proximity to the hills, has been selected by Dr. Campbell (the Superintendent of Dorjiling) as the site for an annual fair, to which the mountain tribes resort, as well as the people of the plains. The Calcutta road to Dorjiling by Dinajpore meets, near here, that by which I had come; and I found no difficulty in procuring bearer's to proceed to Siligoree, where $I$ arrived at 6 A.Mr. on the 13 th. Hitherto I had not seen the mountains, so uniformly had they been shrouded by dense wreaths of vapour: here, however, when within eight miles of their base, I caught the first glimpse of the outer range-sombre masses of far from picturesque outline, clothed everywhere with a dusky forest.

Siligoree stands on the verge of the 'Terai, that low malarious belt which skirts the base of the Himalaya, from the Sutlej to Brahma-koond in Upper Assam. 
Every feature, botanical, geological, and zoological, is new on entering this district. The change is sudden and immediate: sea and shore are hardly more conspicuously different; nor from the edge of the Terai to the limit of perpetual snow is any botanical region more clearly marked than this, which is the commencement of Himalayan vegetation. A sudden descent leads to the Mahanuddee, flowing in a shallow valley, over a pebbly bottom: it is a rapid river, even at this season; its banks are fringed with bushes, and it is as clear and sparkling as a trout stream in Scotland. Beyond it the road winds through a thick brush-wood, choked with long grasses, and with but few trees, chiefly of Acacia, Dalbergia Sissoo, and a scarlet-fruited Sterculia. At this season only a few spring plants were in flower; leaves of terrestrial Orchids appeared, with ferns and weeds of hot damp regions. I crossed the beds of many small streams: some were dry, and all very tortuous; their banks were richly clothed with brush-wood and climbers of Convolvulus, Vines, Bignonias, \&c.

Fatal as this district is, and especially to Europeans, a race inhabit it with impunity, who, if not numerous, do not owe their paucity to any climatic causes. These are the Mechis, often described as a squalid, unhealthy people, typical of the region they frequent; but who are, in reality, more robust than Europeans in India, and whose disagreeably sallow complexion is deceptive as indicating a sickly constitution. They are a mild, inoffensive people, industrious for Orientals, living by annually burning the Terai jungle and cultivating the 

de

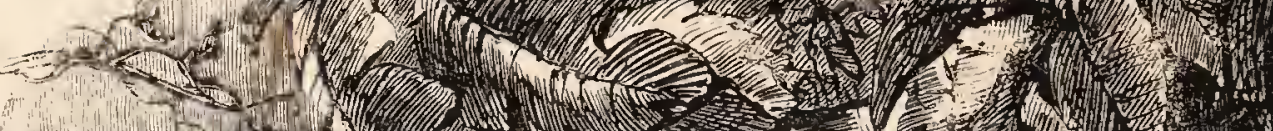

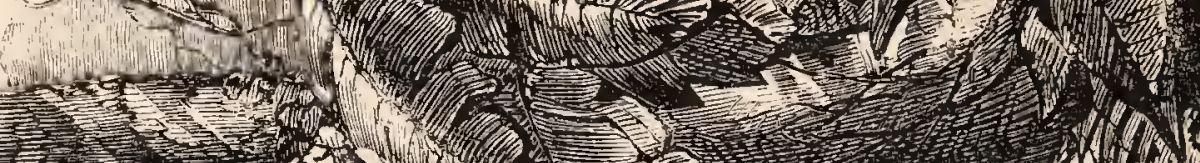
.

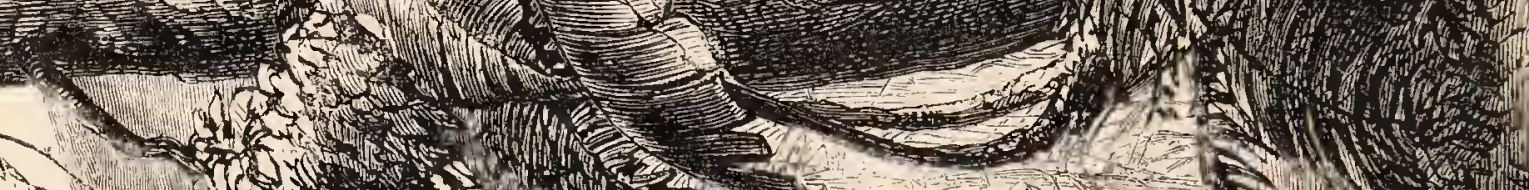

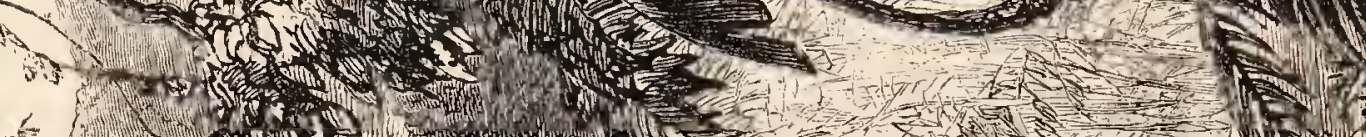

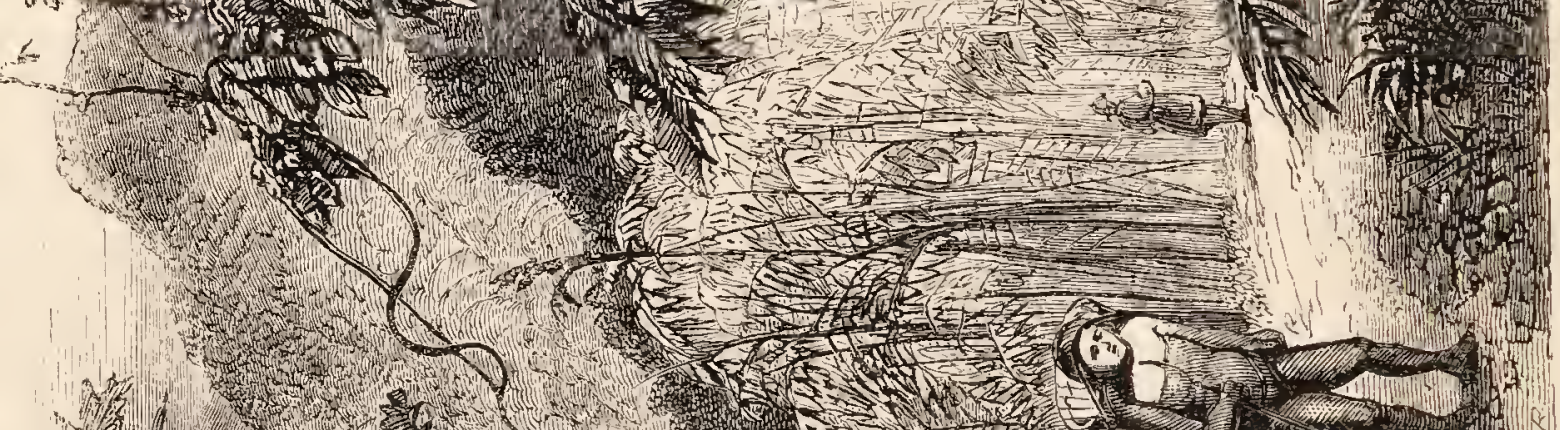

3.

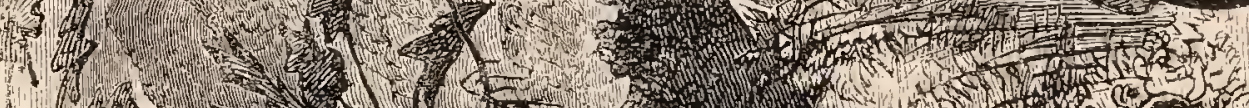
B

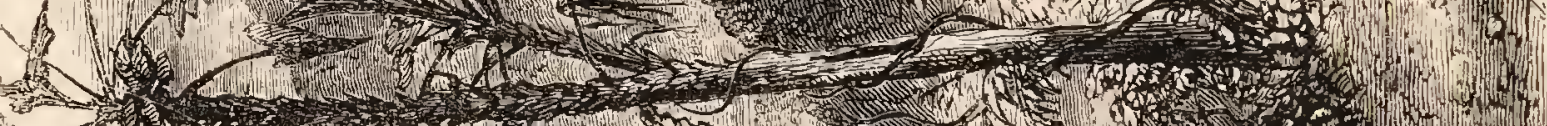

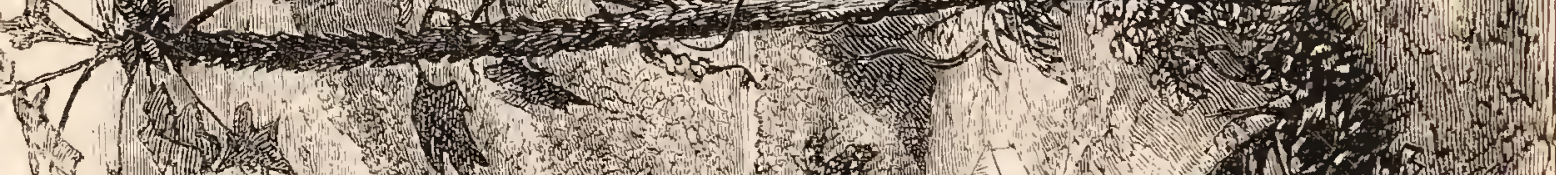
7. a (2) 1.r.

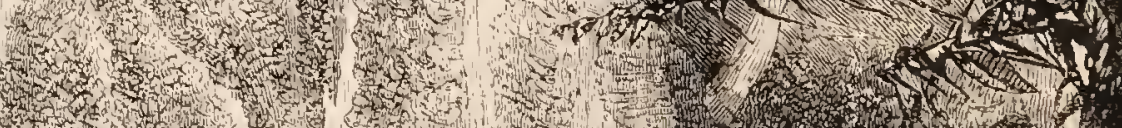

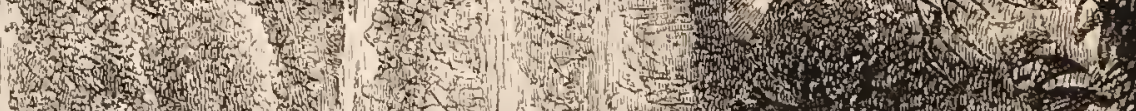

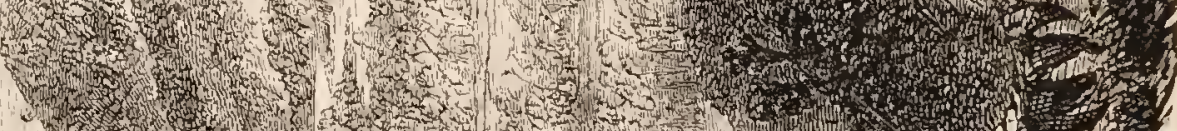

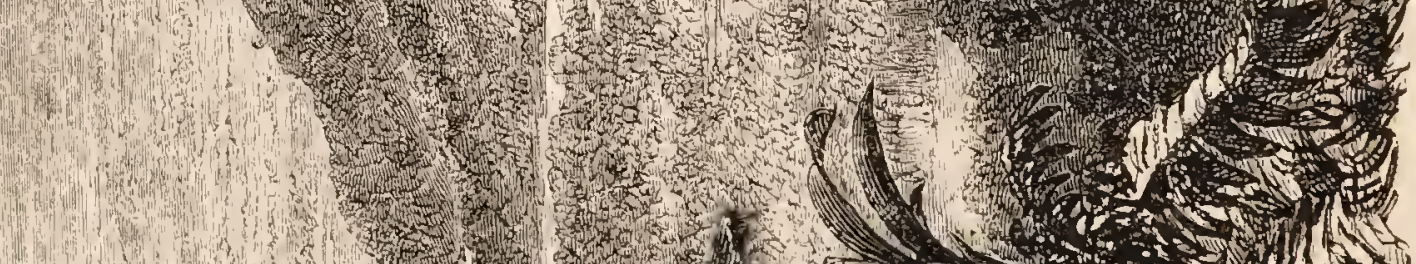

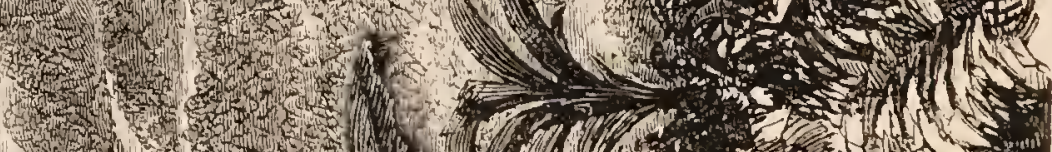

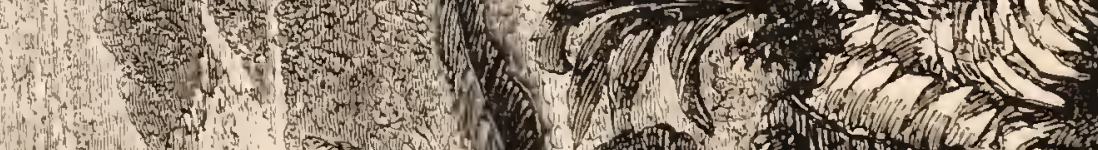

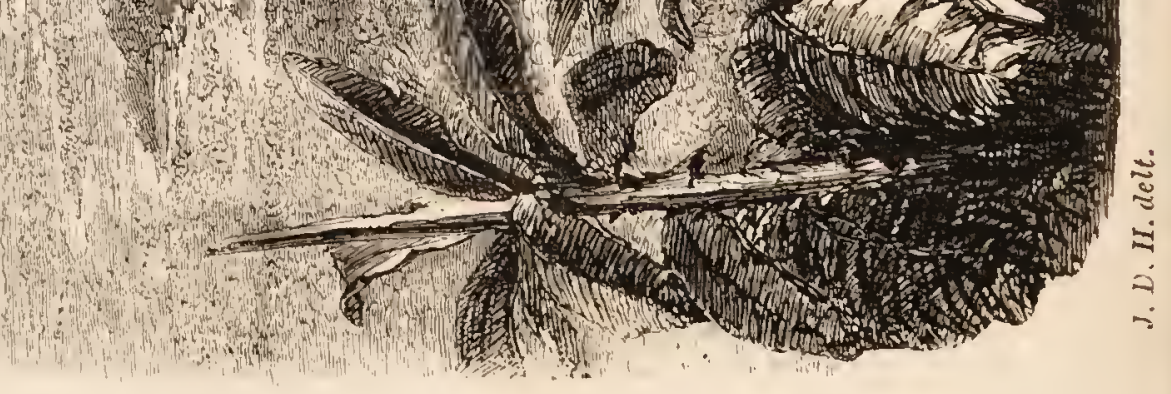


cleared spots; and, though so sequestered and isolated, they rather court than avoid intercourse with those whites whom they know to be kindly disposed.

After proceeding some six miles along the gradually ascending path, I came to a considerable stream, cutting its way through stratified gravel, with cliffs on each side fifteen to twenty feet high, here and there covered with ferns, the little Oxalis sensitiva, and other herbs. The road here suddenly ascends a steep gravelly hill, and opens out on a short flat, or spur, from which the Himalaya rise abruptly, clothed with forest from the base; the little bungalow of Punkabaree, my immediate destination, nestled in the woods, crowning a lateral knoll, above which, to east and west, as far as the eye could reach, were range after range of wooded mountains, 6000 to 8000 feet high.

From this steppe, the ascent to Punkabaree is sudden and steep, and accompanied with a change in soil and regetation. A giant forest replaces the stunted and bushy timber of the Terai Proper; of which the Duabanga and Terminalias form the prevailing trees, with Cedrela and the Gordonia Warlichii. Smaller timber and shrubs are innumerable; whilst a succulent character pervades the bushes and herbs, occasioned by the prevalence of the nettle tribe. Large bamboos rather crest the hills than court the deeper' shade, and of the latter there is abundance, for the torrents cut a straight, deep, and steep course down the hill flanks: the gulleys they traverse are choked with vegetation and bridged by fallen trees, whose 
trunks are richly clothed with epiphytical Orchids, pendulous Lycopodia and many ferms, and similar types of the hottest and dampest climates.

The bungalow at Punkabaree was good-which was fortunate, as my luggage-bearers were not come up, and there were no signs of them along the Terai road, which I saw winding below me. My scanty stock of paper being full of plants, I was reduced to the strait of gathering, and throwing away my specimens. The forest was truly magnificent along the steep mountain sides. The apparently large proportion of deciduous trees was far more considerable than I had expected; partly, probably, due to the abundance of the Dillenia, Cassia, and Sterculia, whose copious fruit was all the more conspicuous from the leafless condition of the plant. The white or lilac blossoms of the convolvuluslike Thunbergia, and other Acanthaces, were the predominant features of the shrubby regetation, and very handsome.

All around, the hills rise steeply five or six thousand feet, clothed with a dense deep-green dripping forest. Torrents rush down the slopes, their position indicated by the dipping of the forest into their beds, or the occasional cloud of spray rising above some more boisterous part of their course. From the road, at and a little above Punkabaree, the view is really superb, and very instructive. Behind (or north) the Himalaya rise in steep confused masses. Below, the hill on which I stood, and the ranges as far as the eye can reach east and west, throw spurs on to the plains of India. These spurs are very thickly wooded, and enclose 
broad, dead-flat, hot and damp valleys, apparently covered with a dense forest. The Terai district forms a very irregular belt, scantily clothed, and intersected by innumerable rivulets from the hills, which unite and divide again on the flat, till, emerging from the region of trees, they enter the plains, following devious courses, which glisten like silver threads. The whole horizon is bounded by the sea-like expanse of the plains, which stretch away into the region of sunshine and fine weather, in one boundless flat.

In the distance, the courses of the Teesta and Cosi, the great drainers of the snowy Himalayas, and the recipients of innumerable smaller rills, are with difficulty traced at this, the dry season. The oceanlike appearance of this southern view is even more conspicuous in the heavens than on the land, the clouds arranging themselves after a singularly sea-scape fashion. The breezes are south-easterly, bringing that vapour from the Indian Ocean, which is rarefied and suspended aloft over the heated plains, but condensed into a drizzle when it strikes the cooler flanks of the hills, and into heavy rain when it meets their still colder summits. Upon what a gigantic scale does nature here operate! Vapours, raised from an ocean whose nearest shore is more than 400 miles distant, are safely transported without the loss of one drop of water, to support the rank luxuriance of this far distant region. This and other offices fulfilled, the waste waters are returned, by the Cosi and Teesta, to the ocean, and again exhaled, imported, expended, re-collected, and returned. 
The soil and bushes everywhere swarmed with large and troublesome ants, and enormous earthworms. In the evening, the noise of the great Cicadce in the trees was almost deafening. They burst suddenly into full chorus, with a voice so harshly croaking, so dissonant, and so unearthly, that in these solitary forests I could not help being startled; and they cease as suddenly as they commence. In general character the note was very similar to that of other Cicadce. On the following morning my baggage arrived, and, leaving my palkee, I mounted a pony kindly sent for me from Dorjiling by Mr. Hodgson, and commenced a very steep ascent of about 3000 feet winding along the face of a steep, richly-wooded valley. The road zigzags extraordinarily in and out of the innumerable lateral ravines, each with its water-course, dense jungle, and legion of leeches; the bite of these blood-suckers gives no pain, but is followed by considerable effusion of blood. They puncture through thick worsted stockings, and even trousers, and, when full, roll in the form of a little soft ball into the bottom of the shoe, where their presence is hardly felt in walling.

Not only are the roadsides rich in plants, but native paths, cutting off all the zigzags, rum in straight lines up the steepest hill-faces, and thus double the available means for botanising; and it is all but impossible to leave the paths of one kind or other, except for a yard or two up the rocky ravines. Elephants, tiger's, and occasionally the rhinoceros, inhabit the foot of these hills, with wild boars, leopards, \&c.; but none are numerous. The elephant's path is an excellent 
specimen of engineering-the reverse of the native track, for it winds judiciously.

At about 1000 feet above Punkabaree, the vegetation is very rich, and appears all the more so from the many turnings of the road, which afford glorious prospects of the foreshortened tropical forests. The prevalent timber is gigantic, and scaled by climbing Leguminose, which sometimes sheath the trunks, or span the forest with huge cables, binding tree to tree. Their trunks are also clothed with parasitical Orchids, climbing Pothos, 'Peppers, Vines, Convolvulus, and Bignonias. The beauty of the drapery of the Pothosleaves is pre-eminent, whether for the graceful folds the foliage assumes, or for the liveliness of its colour. Of the more conspicuous smaller trees, the wild banana is the most abundant, its crown of very beautiful foliage contrasting with the smaller-leaved plants amongst which it nestles; next comes a screw-pine (Pandanus) with a straight stem and a tuft of leaves, each eight or ten feet long, waving on all sides. Bamboo abounds everywhere : its dense tufts of culms, 100 feet and upwards high, are as thick at the base as a man's thigh. Twenty or thirty species of ferns (including a tree-fern) were luxuriant and handsome; while foliaceous lichens and a few mosses appeared at 2000 feet. Such is the vegetation of the roads through the tropical forests of the Outer Himalaya.

At about 4000 feet a great change took place in the vegetation,-marked first by the appearance of a very English-looking bramble, which, however, by way of proving its foreign origin, bore a very good yellow fruit, 
called here the "yellow raspberry." Scattered oaks of a noble species, with large lamellated cups and magnificent foliage, succeeded; and along the ridge of the mountain to Kursiong (a dawk bungalow at about 4800 feet), the change in the flora was complete.

The spring of this region and elevation most vividly recalled that of England. The oak flowering, the birch bursting into leaf, the violet, Stellaria, and Arum, Vaccinium, wild strawberry, maple, geranium, bramble. A colder wind blew here: mosses and lichens carpeted the banks and roadsides: the birds and insects were very different from those below; and everything proclaimed the marked change in elevation, and not only in this, but also in the season, for I had left the winter of the tropics and here encountered the spring of the temperate zone.

These flowers are so notoriously the harbingers of a European spring that their presence carries one home at once: but, as species, they differ from their European prototypes, and are accompanied at this elevation, and for 2000 feet higher up, with tree-ferms, Pothos, bananas, palms, figs, peppers, numbers of epiphytal Orchids, and similar genuine tropical genera. The uniform temperature and humidity of the climate here favour the extension of tropical plants into a temperate region ; exactly as the same conditions cause similar forms to attain higher latitudes in the southern hemisphere (as in New Zealand, Tasmania, South Chili, \&c.) than they do in the northern.

Kursiong bungalow, where I stopped for a few hours, is superbly placed, on a narrow mountain ridge. The 
west window looks down the valley of the Balasun, the east into that of the Mahanuddee: both of these rivers rise from the outer range, and flow in broad, deep, and steep valleys (about 4000 feet deep) which are richly wooded from the Terai to their tops.

From Kursiong a very steep zigzag leads up the mountain, through a magnificent forest of chesnut, walnut, oaks, and laurels. It is difficult to conceive a grander mass of vegetation:-the straight shafts of the timber-trees shooting aloft, some naked and clean, with grey, pale, or brown bark; others literally clothed for yards with a continuous garment of epiphytes, one mass of blossoms, especially the white Orchids, which bloom in a profuse manner, whitening their trunks like snow. More bulky trunks were masses of interlacing climbers, enclosing a hollow, once filled by the strangled tree, which had long ago decayed away. From the sides and summit of these, supple branches hung forth, either leafy or naked; the latter resembling cables flung from one tree to another, swinging in the breeze, their rocking motion increased by the weight of great bunches of ferns or Orchids, which were perched aloft in the loops. Perpetual moisture nourishes this dripping forest; and pendulous mosses and lichens are met with in profusion.

It was very late before I arrived at Pacheem bungalow, the most sinister-looking rest-house I ever saw, stuck on a little cleared spur of the mountain, surrounded by dark forests, overhanging a profound valley, enveloped in mists and rain, and hideous in architecture, being a miserable attempt to unite the Swiss cottage with the 
suburban gothic;-it combined a maximum of discomfort with a minimum of good looks or good cheer. I was some time in finding the dirty housekeeper, in an outhouse hard by, and then in waking him. As he led me up the crazy verandah, and into a broad ghostly room, without glass in the windows, or fire, or any one comfort, my mind recurred to the stories told of the horrors of the Hartz forest, and of the benighted traveller's situation therein. Cold sluggish beetles clung to the damp walls,-and these I immediately secured. After due exertions and persererance with the wet wood, a fire smoked lustily, and, by cajoling the gnome of a housekeeper, I procured the usual roast fowl and potatoes, with the accustomed sauce of a strong smoky and singed flavour.

Pacheem stands at an elevation of nearly 7300 feet, and as I walked out on the following morning I met with English-looking plants in abundance, but was too early in the season to get aught but the foliage of most. Epiphytes were rare, still I found some white and purple Cologynes, and other Orchids, and a most noble white rhododendron, whose enormous and delicious lemon-scented blossoms strewed the ground. The trees were one half oaks, one quarter Magnolias, and nearly another quarter laurels, amongst which grew Himalayan kinds of birch, alder, maple, holly, birdcherry, common cherry, and apple. The absence of leguminous plants was remarkable, and the most prominent botanical feature in the vegetation of this region: it is too high for the tropical tribes of the warmer elevations, too low for the Alpines, and probably too 
moist for those of temperate regions; cool, equable, humid climates being generally unfarourable to these plants. I found very few native species of grasses; though both Poa annua and white Dutch clover flourished where accidentally disseminated, but only in artificially cleared spots. Of ferns I collected about sixty species, chiefly of temperate genera. The supremacy of this temperate region consists in the infinite number of forest trees, in the absence (in the usual proportion at any rate) of such common orders as Composita, Leguminose, Crucifere, Ranunculacee, and Grasses; and in the predominance of rarer and more local families, as those of Rhododendron, Camellia, Magnolia, Ivy, Cornel, Honeysuckle, Hydrangea, Begonia, and Epiphytic Orchids.

From Pacheem, the road runs in a northerly direction to Dorjiling, still along the Balasun valley, till the saddle of the great mountain Sinchul is crossed. This is narrow, and stretches east and west, and from it a spur projects northwards for five or six miles, amongst the many mountains still intervening between it and the snows. This saddle (alt. 7,400 feet) crossed, one is fairly amongst the mountains: the plains behind are cut off by it; and in front, the snows may be seen when the weather is propitious. The valleys on the inner side of the mountain run northwards, and discharge their streams into great rivers, which, coming from the snow, wind amongst the hills, and débouche into the Teesta, to the east, where it divides Sikkim from Bhotan.

Dorjiling station occupies a narrow ridge, which divides into two spurs, and descends steeply to the bed 
of the Great Rungeet river, up whose course the eye is carried to the base of the great snowy mountains. The ridge itself is very narrow at the top, along which most of the houses are perched, while others occupy positions on its flanks, where narrow locations on the east, and broader ones on the west, are cleared from wood. The valleys on either side are at least 6000 feet deep, forest-clad to the bottom, with very few and small level spots, and no absolute precipice; from their flanks project innumerable little spurs, occupied by native clearings.

My route lay along the east flank, overhanging the valley of the Rungmo river. To my right the amphitheatre of hills was very fine: it enclosed an area some four miles across and 4000 feet deep, clothed throughout with an impenetrable, dark forest: there was not one clear patch except near the very bottom, where were some seattered hamlets, each consisting of two or three huts. A wooded slope descends suddenly from the edge of the road, while, on the other hand, a bank rises abruptly to the top of the ridge, alternately mossy, rocky, and clayey.

I arrived atDorjiling on the 16th of April; a showery, cold month at this elevation. I was so fortunate as to find Mr. Charles Barnes (brother of my friend at Colgong), the sole tenant of a long, cottage-like building, divided off into pairs of apartments, which are hired by visitors. It is usual for Europeans to

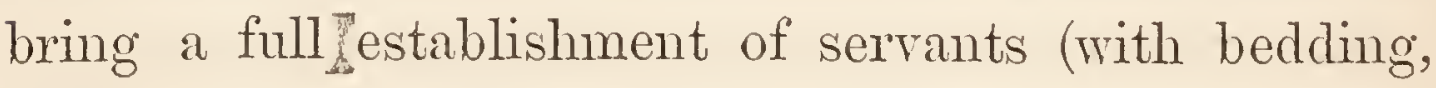
\&e.) to such stations, but I had not done so, having been told that there was a furnished hotel in Dorjiling; 
and I was, therefore, not a little indebted to $\mathrm{Mr}$. Barnes for his kind invitation to join his mess. As he was an active mountaineer, we enjoyed many excursions together, in the two months and a half during which we were companions.

Dr. Campbell procured me several active native (Lepcha) lads as collectors, at wages varying from eight to twenty shillings a month; these either accompanied me on my excursions, or went by themselves into the jungles to collect plants, which I occupied myself in drawing, dissecting, and ticketing, while the preserving of the specimens fell to the Lepchas, who, after a little training, became, with constant superintendence, good plant-driers. Even at this season (four weeks before the setting in of the rains) the weather was very uncertain, so that the papers had generally to be dried by the fire.

The hill-station or Sanatarium of Dorjiling owes its origin (like Simla, Mussooree, \&c.) to the necessity that exists in India, of providing places where the health of Europeans may be recruited by a temperate climate. Sikkim proved an eligible position for such an establishment, owing to its proximity to Calcutta, which lies but 370 miles to the southward; whereas the north-west stations mentioned above are upwards of a thousand miles from that city. Dorjiling ridge varies in height from 6,500 to 7,500 feet above the level of the sea; 8000 feet being the elevation at which the mean temperature most nearly coincides with that of London, viz., $50^{\circ}$.

Sikkim was, further, the only available spot for a Sanatarium throughout the whole range of the 
Himalaya, east of the extreme western frontier of Nepal ; being a protected state, and owing no allegiance, except to the British government; which, after the Rajah had been driven from the country by the Ghorkas, in 1817, replaced him on his throne, and guaranteed him the sovereignty. Our main object in doing this was to retain Siklim as a fender between Nepal and Bhotan: and but for this policy, the aggressive Nepalese would, long ere now, have possessed themselves of Sikkim, Bhotan, and the whole Himalaya, eastwards to the borders of Burmah.**

From 1817 to 1828 no notice was taken of Sikkim, till a frontier dispute occurred between the Lepchas and Nepalese, which was referred (according to the terms of the treaty) to the British Government. During the arrangement of this, Dorjiling was visited by a gentleman of high scientific attainments, Mr. J. W. Grant, who pointed out its eligibility as a site for a Sanatarium to Lord William Bentinck, then GovernorGeneral; dwelling especially on its climate, proximity to Calcutta, and accessibility; on its central position between Tibet, Bhotan, Nepal, and British India; and on the good example a peaceably-conducted and wellgoverned station would be to our turbulent neighbour's in that quarter. The suggestion was cordially received, and Major Herbert (the late eminent Surveyor-General

* Of this being their wish the Nepalese have never made any secret, and they are said to have asked permission from the British to march an army across Sikkim for the purpose of conquering Bhotan, promising to become more peaceable neighbours to us than the Bhotanese are. Such they would doubtless have proved, but the Nepal frontier is considered broad enough already. 
of India) and $\mathrm{Mr}$. Grant were employed to report further on the subject.

The next step taken was that of requesting the Rajah to cede a tract of country which should include Dorjiling, for an equivalent in money or land. His first demand was unreasonable; but on further consideration he surrendered Dorjiling unconditionally, and a sum of 300l. per annum was granted to him as an equivalent for what was to him a worthless uninhabited mountain. In 1840 Dr. Campbell was removed from Nepal to be superintendent of the new station, and was entrusted with the charge of the political relations between the British and Sikkim governments.

Once established, Dorjiling made rapid progress. Allotments of land were purchased by Europeans for building dwelling-houses; barracks and a bazaar were formed, with accommodation for invalid European soldiers; a few official residents, civil and military, formed the nucleus of a community, which was increased by retired officers and their families, and by temporary visitors in search of health, or the luxury of a cool climate and active exercise.

For the first few years matters went on smoothly with the Rajah, whose minister (or Dewan) was upright and intelligent; but the latter, on his death, was succeeded by the present Dewan, a Tibetan, and a relative of the Ranee (or Rajah's wife); a man unsurpassed for insolence and avarice, whose aim was to monopolise the trade of the country, and to enrich himself at its expense. Every obstacle was thrown by him in the way of a good understanding between 
Sikkim and the British government. British subjects were rigorously excluded from Sikkim; every liberal offer for free trade and intercourse was rejected, generally with insolence; merchandise was taxed, and notorious offenders, refugees from the British territories, were harboured; despatches were detained; and the Vakeels, or Rajah's representatives, were chosen for their overbearing manners and incapacity. The conduct of the Dewan throughout was Indo-Chinese; assuming, arrogant, aggressive, never perpetrating open violence, but by petty insults effectually preventing all good understanding. He was met by neglect or forbearance on the part of the Calcutta government; and by patience and passive resistance at Dorjiling. Such has been our policy in China, Siam, and Burmah, and in each instance the result has been the same: our inaction and long-suffering have been taken for weakness, and our concessions for timidity. Had it been insisted that the terms of the treaty should be strictly kept, and had the first act of insolence been noticed, we should have maintained the best relations with Silkkim, whose people and rulers (with the exception of the Dewan and his faction) have proved themselves friendly throughout, and most anxious for unrestricted communication.

These political difficulties have not, however, prevented the rapid increase of Dorjiling; the progress of which, during the two years I spent in Sikkim, resembled that of an Australian colony, not only in amount of building, but in the accession of native families from the surrounding countries. There were not a hundred 
inhabitants under British protection when the ground was transferred; there are now four thousand. At the former period there was no trade whatever; there is now a very considerable one, in musk, salt, gold-dust, borax, soda, woollen cloths, and especially in ponies, of which the Dewan in one year brought on his own account upwards of fifty into Dorjiling.* The trade has been greatly increased by the annual fair which Dr. Campbell has established at the foot of the hills, to which many thousands of natives flock from all quarters, and which exercises a most beneficial influence throughout the neighbouring territories. At this, prizes (in medals, money, and kind) are given for agricultural implements and produce, stock, \&c., by the originator and a few friends; a measure attended with eminent success.

When estimating in a sanatory point of view the value of any health-station, little reliance can be placed on the general impressions of invalids, or even of residents; the opinion of each varies with the nature and state of his complaint, if ill, or with his idiosyncracy and disposition, if well. I have seen prejudiced individuals rapidly recovering, in spite of themselves, and all the while complaining in unmeasured terms of the climate of Dorjiling, and abusing it as killing them. There are others who languish under the heat of the plains at one season, and the damp at another; and who, though

* The Tibetan pony, though born and bred 10,000 to 14,000 feet above the sea, is one of the most active and useful animals in the plains of Bengal, powerful and hardy, and when well trained early, docile, although by nature vicious and obstinate. 
sickening and dying under its influence, yet consistently praise a tropical climate to the last. The opinions of those who resort to Dorjiling in health, differ equally; those of active minds invariably thoroughly enjoy it, while the mere lounger or sportsman mopes. The statistical tables afford conclusive proofs of the value of the climate to Europeans suffering from acute diseases, and they are corroborated by the returns of the medical officer in charge of the station. With respect to its suitability to the European constitution I feel satisfied, and that much saving of life, health, and money would be effected were European troops drafted thither on their arrival in Bengal, instead of being stationed in Calcutta, exposed to disease, and temptation to those vices which prove fatal to so many hundreds. This, I have been given to understand, was the view originally taken by the Court of Directors, but it has never been carried out.

I believe that children's faces afford as good an index as any to the healthfulness of a climate, and in no part of the world is there a more active, rosy, and bright young community, than at Dorjiling. It is incredible what a ferw weeks of that mountain air will do for the India-born children of European parents: they are taken there sickly, pallid or yellow, soft and flabby, to become transformed into models of rude health and activity.

There are, however, disorders to which the climate (in common with all damp ones) is not at all suited; such are especially dysentery, bowel and liver complaints of long standing; which are not benefited by a residence on these hills, though how much wor'se they 
might have become in the plains is not shown. I cannot hear that the climate aggravates, but it certainly does not remove them. Whoever, on the contrary, is suffering from the debilitating effects of any of the multifarious acute maladies of the plains, finds immediate relief, and acquires a stock of health that enables him to resist fresh attacks, under circumstances similar to those which before engendered them.

Natives of the low country, and especially Bengalees, are far from enjoying the climate as Europeans do, being liable to sharp attacks of fever and ague, from which the poorly clad natives are not exempt. It is, however, difficult to estimate the effects of exposure upon the Bengalees, who sleep on the bare and often damp ground, and adhere, with characteristic prejudice, to the attire of a torrid climate, and to a vegetable diet, under skies to which these are least of all adapted.

It must not be supposed that Europeans who have resided in the plains can, on their first arrival, expose themselves with impunity to the cold of these elevations; and this was shown in the winter of 1848-9, when troops brought up to Dorjiling were cantoned in newly-built dwellings, on a high exposed ridge 8000 feet above the sea, and lay, insufficiently protected, on a floor of loosely laid planks, exposed to the cold wind, when the ground without was covered with snow. Rheumatisms, sharp febrile attacks, and dysenteries ensued, which were attributed, in the public papers, to the unhealthy nature of the climate of Dorjiling. 


\section{CHAPTER V.}

View from Mr. Hodgson's of the snowy mountains-Their extent and elevation-Deceptive appearance of elevation-Sinchul, view from and vegetation of-Chumulari-Magnolias, white and purple-Rhododendron Dalhousiæ, arboreum and argenteum-Natives of DorjilingLepchas, origin, tradition of flood, morals, dress, arms, ornaments, diet-cups, origin and value-Marriages-Diseases-Burial-Worship and religion-Bijooas-Kampa Rong, or Arratt-Limboos, origin, habits, language, \&c.-Moormis-Magras-Mechis-Comparison of customs with those of the natives of Assam, Khasia, \&c.

THE summer, or rainy season of 1818 , was passed at or near Dorjiling, during which period I chiefly occupied myself in forming collections, and in taking meteorological observations. I resided at $\mathrm{Mr}$. Hodgson's for the greater part of the time, in consequence of his having given me a hospitable invitation to consider his house my home. The view from his windows is quite unparalleled for the scenery it embraces, commanding confessedly the grandest known landscape of snowy mountains in the Himalaya, and hence in the world. Kinchinjunga (forty-five miles distant) is the prominent object, rising 21,000 feet above the level of the observer out of a sea of intervening wooded hills; whilst, on a line with its snows, the eye descends below the horizon, to a 
marrow gulf 7000 feet deep in the mountains, where the Great Rungeet, white with foam, threads a tropical forest with a silver line.

To the north-west towards Nepal, the snowy peaks of Kubra and Junnoo (respectively 24,005 feet and 25,312 feet) rise over the shoulder of Singalelah; whilst eastward the snowy mountains appear to form an unbroken range, trending north-east to the great mass of Donkia (23,176 feet) and thence south-east by the fingered peaks of Tunkola and the silver cone of Chola (17,320 feet), gradually sinking into the Bhotan mountains at Gipmoochi (14,509 feet).

'The most eloquent descriptions I have read fail to convey to my mind's eye the forms and colours of snowy mountains, or to my imagination the sensations and impressions that rivet my attention to these sublime phenomena when they are present in reality; and I shall not therefore obtrude any attempt of the kind upon my reader. The latter has probably seen the Swiss Alps, which, though barely possessing half the sublimity, extent, or height of the Himalaya, are yet far more beautiful. In either case the observer is struck with the precision and sharpness of their outlines, and still more with the wonderful play of colours on their snowy flanks, from the glowing hues reflected in orange, gold and ruby, from clouds illumined by the sinking or rising sun, to the ghastly pallor that succeeds with twilight, when the red seems to give place to its complementary colour, green. Such dissolving-views elude all attempts at description, they are far too aërial to be chained to the memory, and 
fade from it so fast as to be gazed upon day after day, with undiminished admiration and pleasure, long after the mountains themselves have lost their sublimity and apparent height.

The actual extent of the snowy range seen from Mr. Hodgson's windows is comprised within an are of $80^{\circ}$ (from north $30^{\circ}$ west to north $50^{\circ}$ east), or nearly a quarter of the horizon, along which the perpetual snow forms an unbroken girdle or crest of frosted silver; and in winter, when the mountains are covered down to 8000 feet, this white ridge stretches uninterruptedly for more than $160^{\circ}$. No known view is comparable with this in extent, when the proximity and height of the mountains are considered; for within the $80^{\circ}$ above mentioned more than twelve pealss rise above 20,000 feet, and there are none below 15,000 feet, while Kinchin is 28,178, and seven others above 22,000. The nearest perpetual snow is on Nursing, a beautiful sharp conical peak 19,139 feet high, and thirty-two miles distant; the most remote mountain seen is Donkia, 23,176 feet high, and seventy-three miles distant; whilst Kinchin, which forms the principal mass both for height and bulk, is forty-five miles distant.

On first viewing this glorious panorama, the impression produced on the imagination by their prodigious elevation is, that the peaks tower in the air and pierce the clouds, and such are the terms generally used in descriptions of similar alpine scenery; but the observer, if he look again, will find that even the most stupendous occupy a very low position on the horizon, the top of Kinchin itself 
measuring only $4^{\circ} 31^{\prime}$ above his own level! Donkia again, which is about 15,700 feet above Mr. Hodgson's, rises only $1^{\circ} 55^{\prime}$ above the horizon; an angle which is quite inappreciable to the eye, when unaided by instruments.

This view may be extended a little by ascending Sinchul, which rises a thousand feet above the elevation of Mr. Hodgson's house, and lies a few miles to the south-east of Dorjiling: from its summit Chumulari (23,929 feet) is seen to the nortl-east, at eighty-four miles distance, rearing its head as a great rounded mass over the snowy Chola range, out of which it appears to rise, although in reality lying forty miles beyond;-so deceptive is the perspective of snowy mountains. To the north-west again, at upwards of 100 miles distance, a beautiful group of snowy mountains rises above the black Singalelah range, the chief being, perhaps, as high as Kinchinjunga, from which it is fully eighty miles distant to the westward; and between them no mountain of considerable altitude intervenes; the Nepalese Himalaya in that direction sinking remarkably towards the Arun river, which there enters Nepal from Tibet.

The top of Sinchul is a favourite excursion from Dorjiling, being very easy of access, and the path abounding in rare and beautiful plants, and passing through magnificent forests of oak, magnolia, and rhododendron; while the summit, besides embracing this splendid view of the snowy range over the Dorjiling spur, commands also the plains of India, with the courses of the Teesta, Mahanuddee, Balasun 
and Mechi rivers. In the months of April and May, when the magnolias and rhododendrons are in blossom, the gorgeous vegetation is, in some respects, not to be surpassed by anything in the tropics; but the effect is much marred by the prevailing gloom of the weather. The white-flowered magnolia ( $M$. excelsa) is the predominant tree at 7000 to 8000 feet; and in 1848 it blossomed so profusely, that the forests on the broad flanks of Sinchul, and other mountains of that elevation, appeared as if sprinkled with snow. The purple-flowered kind again (M. Campbellii) hardly occurs below 8000 feet, and forms an immense, but very ugly, black-barked, sparingly branched tree, leafless in winter and also during the flowering season, when it puts forth from the end of its branches great rose-purple cup-shaped flowers, whose fleshy petals strew the ground. On its branches, and on those of oaks and laurels, Rhododendron Dalhousice grows as an epiphyte, a slender shrub, bearing from three to six white lemon-scented bells, four and a half inches long and as many broad, at the end of each branch. In the same woods the scarlet rhododendron ( $R$. arboreum) is very scarce, and is outvied by the great R. argenteum, which grows as a tree forty feet high, with magnificent leaves twelve to fifteen inches long, deep green, wrinkled above and silvery below, while the flowers are as large as those of $R$. Dalloousice, and grow more in a cluster. I know nothing of the kind that exceeds in beauty the flowering branch of $R$. argenteum, with its wide-spreading foliage and glorious mass of flowers. 
Oaks, laurels, maples, birch, chesnut, hydrangea, a species of fig (which is found on the very summit), and three Chinese and Japanese genera, are the principal features of the forest. In spring immense broad-leaved arums spring up, with green or purplestriped hoods, that end in tail-like threads, eighteen inches long, which lie along the ground; and there are various kinds of beautiful flowering herbs. Nearly thirty ferns may be gathered on this excursion, including many of great beauty and rarity, but the tree-fern does not ascend so high. Grasses are very rare in these woods, excepting the dwarf bamboo; a plant now cultivated in the open air in England.

Before proceeding to narrate my different expeditions into Sikkim and Nepal from Dorjiling, I shall give a sketch of the different peoples and races composing the heterogeneous population of Sikkim and the neighbouring mountains.

The Lepcha is the aboriginal inhabitant of the country, and the prominent character in Dorjiling, where he undertakes all sorts of out-door employment. The race to which he belongs is a very singular one; markedly Mongolian in features, and a good deal too, in habit; still he differs from his Tibetan prototype, though not so decidedly as from the Nepalese and Bhotanese, between whom he is hemmed into a tract of mountain country, barely 60 miles in breadth. The Lepchas possess a tradition of the flood, during which a couple escaped to the top of a mountain (Tendong) near Dorjiling. The earliest traditions which they have of their history date no further back than some three 
hundred years, when they describe themselves as having been long-haired, half-clad savages. At about that period they were visited by Tibetans, who introduced Boodh worship, the plaiting of their hair into pig-tails, and many of their own customs. Their physiognomy is however so Tibetan in its character, that it cannot be supposed that this was their earliest intercourse with the trans-nivean races: whether they may have wandered from beyond the snows before the spread of Boodhism, or whether they are a cross between the Tamulian of India and the Tibetan, has not been decided. Their language, though radically identical with Tibetan, differs from it in many important particulars. They, or at least some of their tribes, call themselves Rong, and Arratt, and their country Dijong: they once possessed a great part of East Nepal, as far west as the Tambur river, and at a still earlier period they penetrated as far west as the Arun.

An attentive examination of the Lepcha in one respect entirely contradicts our preconceived notions of a mountaineer, as he is timid, peaceful, and no brawler; qualities which are all the more remarkable from contrasting so strongly with those of his neighbours to the east and west: of whom the Ghorkas are brave and warlike to a proverb, and the Bhotanese quarrelsome, cowardly, and crtel. A group of Lepchas is exceedingly picturesque. They are of short stature-four feet eight inches to five feet-rather broad in the chest, and with muscular arms, but small hands and slender wrists. The face is broad, flat, and of eminently Tartar character, flat-nosed and oblique-eyed, with no beard, 
and little moustache; the complexion is sallow, or often a clear olive; the hair is collected into an immense tail, plaited flat or round. The lower limbs are powerfully developed, befitting genuine mountaineers: the

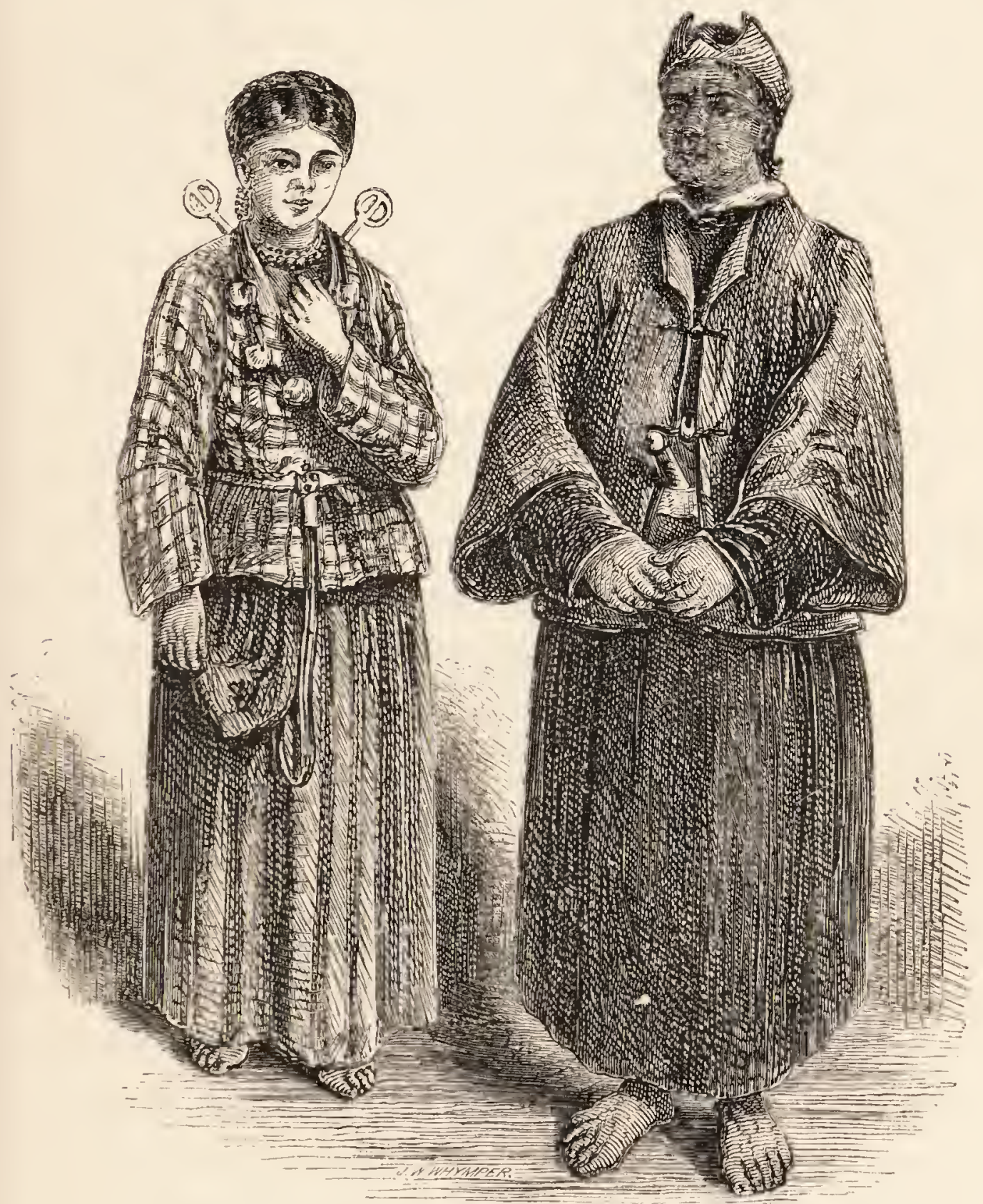

LEPCHA GIRL AND BHOODIST LAMA.

feet are small. Though never really handsome, and very womanish in the cast of countenance, they have invariably a mild, frank, and even engaging expression, 
which is perhaps due more to the absence of anything umpleasing, than to the presence of direct grace or beauty. In like manner, the girls are often very engaging to look upon, though without one good feature: they are all smiles and good nature; and the children are frank, lively, laughing urchins. The old women are thorough hags. Indolence is their besetting sin; they detest any fixed employment, and their foulness of person and garments renders them disagreeable inmates: in this rainy climate they are supportable out of doors. Though fond of bathing when they come to a stream in hot weather, and expert, even admirable swimmers, these people never take to the water for the purpose of ablution. In disposition they are amiable and obliging, frank, humorous, and polite, without the servility of the Hindoos; and their address is free and unrestrained. Their intercourse with one another and with Europeans is scrupulously honest; a present is divided equally amongst a party, without a syllable of discontent or grudging look or word; each, on receiving his share, coming up and giving the donor a brusque bow and thanks. They have learnt to overcharge already, and to use extortion in dealing, as is the custom with the people of the plains; but it is clumsily done, and never accompanied with the grasping air and insufferable whine of the latter. They are constantly armed with a long, heavy, straight knife, ${ }^{*}$ but never draw it on one another: family and political feuds are alike unheard of amongst them.

* It is called "Ban," and serves equally for plough, toothpick, tableknife, hatchet, hammer, and sword. 
The Lepcha is in morals far superior to his Tibet and Bhotan neighbour's, polyandry being unknown, and polygany rare. This is no doubt greatly due to the conventual system not being carried to such an excess as in Bhotan, where even the ties of relationship are disregarded.

Like the New Zealander, Tasmanian, Fnegian, and the natives of other climates, which, though cold, are moist and equable, the Lepcha's dress is very scanty, and when we are wearing woollen under-garments and hose, he is content with one cotton vestment, which is loosely thrown round the body, leaving one or both arms free; it reaches to the knee, and is gathered round the waist: its fabric is close, the ground colour white, ornamented with longitudinal blue stripes, two or three fingers broad, prettily worked with red and white. When new and clean, this garb is remarkably handsome and gay, but not showy. In cold weather an upper garment with loose sleeves is added. A long knife, with a common wooden handle, hangs by his side, stuck in a sheath; he has often also a quirer of poisoned arrows and a bamboo bow across his back. On his left wrist is a curious wooden guard for the borstring; and a little pouch containing aconite poison and a few common implements is suspended to his girdle. He seldom wear's a hat, and when he does, it is often extravagantly broad and flat-brimmed, with a small hemispherical crown. It is made of the leaves of Scitaminece, between two thin plates of bamboo-work, clumsy and heavy; this is generally used in rainy weather, while in dry a conical one is worn, also of platted slips of bamboo, YOL. I. 
with broad flakes of talc between the layers, and a peacock's feather at the side. The umbrella consists of a large hood much like the ancient boat called a coracle, which being placed over the head reaches to the thighs behind. It is made of platted bamboo, enclosing broad leaves of Phrynium. Lepchas running along in the pelting rain, with these on, are very droll figures ; they look like snails with their shells on their backs.

The Lepchas are fond of ormaments, wearing silver hoops in their ears, necklaces of cornelian, amber and turquoise, brought from Tibet, and pearls and corals from the south, with curious silver and golden charmboxes or amulets attached to their necks or arms. These are of Tibetan workmanship, and often of great value: they contain little idols, charms of written prayers, or the bones, hair, or nail-parings of a Lama: some are of great beauty and highly ornamented. In these decorations, and in their hair, they take some pride, the ladies frequently dressing the latter for the gentlemen: thus one may often see, the last thing at night, a damsel of discreet port, demurely go behind a young man, unplait his pig-tail, tease the hair, thin it of some of its lively inmates, braid it up for him and retire. The women always wear two braided pig-tails, and it is by this they are most readily distinguished from their effeminate-looking partners, who wear only one. When in full dress, the woman's costume is extremely ornamental and picturesque; besides the shirt and petticoat, she wear's a small sleeveless woollen cloak, of gay pattern, usually covered with crosses, and 
fastened in front by a girdle of silver chains. Her neck is loaded with silver chains, amber necklaces, \&c., and her head adorned with a coronet of scarlet cloth, studded with seed-pearls, jewels, glass beads, \&c. The common dress is a long robe of indi, a cloth of coarse silk, spun from the cocoon of a large caterpillar that is found wild at the foot of the hills, and is also cultivated : it feeds on many different leares, Sal, castor oil, \&c.

These people are gross feeder's; * rice, however, forming their chief sustenance; it is grown without irrigation, and produces a large, flat, coarse grain, which becomes gelatinous, and often pink, when cooked. Pork is a staple dish; and they also eat elephant, and all kinds of animal food. When travelling, they live on whatever they can find, whether animal or vegetable. Fern-tops, roots of Scitaminee, and their flower-buds, various leaves, and fungi, are chopped up, fried with a little oil, and eaten. Their cooling is coarse and dirty. Salt is costly, but prized; pawn (Betel pepper) is never eaten. Tobacco they are too poor to buy, and too indolent to grow and cure. Spices, oil, \&c., are relished.

They drink out of little wooden cups, turned from knots of maple or other woods; these are curious on several accounts; they are very pretty, often polished, and mounted with silver. Some are supposed to

* Dr. Campbell's definition of the Lepcha's Flora cibaria is, that he cats, or must have eaten, everything soft enough to be chewed; for, as he knows whatever is poisonous, he must have tried all ; lis knowlerge being wholly empirical. 
be antidotes against poison, and hence fetch an enormous price; they are of a peculiar wood, rarer and paler-coloured. I have paid a guinea for one such, hardly different from the common sort, which cost but $4 d$. or $6 d$. MMY. Huc and Gabet graphically allude to this circumstance, when describing the purchase of cups at Lhassa, where their price is higher, as they are all imported from the Himalaya. The knots from which they are formed, are produced on the roots of oaks, maples, and other mountain forest trees, by a parasitical plant, known to botanists as Balanophora.

Their intoxicating drink, which seems more to excite than to debauch the mind, is partially fermented Murwa grain (Eleusine Coracana). Spirits are rather too strong to be relished raw, and when a glass of wine is given to one of the party, he sips it, and hands it round to all the rest. A long bamboo flute, with four or six burnt holes far below the mouth-hole, is the only musical instrument I have seen in use among them. When travelling, and the fatigues of the day are orer, the Lepchas will sit for hours, chatting, telling stories, singing in a monotonous tone, or blowing the flute. I have often listened with real pleasure to the simple. music of this rude instrument; its low and sweet tones are singularly Eolian, as are the airs usually played, which fall by octaves: the sound seems to harmonise with the solitude of their primreval forests, and he must have a dull ear who cannot draw from it the indication of a contented mind, whether he may relish its soft musical notes or not. 
Their marriages are contracted in childhood, and the wife purchased by money, or by service rendered to the future father-in-law, the parties being often united before the woman leaves her parents' roof, in cases where the payment is not forthcoming, and the bridegroom prefers giving his and his wife's labour to her father for a stated period in lieu. On the time of service expiring, or the money being paid up, the marriage is publicly celebrated by feasting and riot. The females are generally chaste, and the marriage-tie is strictly kept, its violation being heavily punished by divorce, beating, slavery, \&c. In cases of intermarriage with foreigners, the children belong to the father's country. All the labours of the house, the field, and march, devolve on the.women and children, or slaves if they have them.

Small-pox is dreaded, and infected persons often cruelly shunned; a suspicion of this or of cholera frequently emptying a village or town in a night. Vaccination has been introduced by Dr. Pearson, and it is much practised by Dr. Campbell, it being eagerly sought. Cholera is scarcely known at Dorjiling, and when it has been imported thither has never spread. Disease is very rare amongst the Lepchas; and ophthalmia, elephantiasis, and leprosy, the scourges of hot climates, are rarely known. Goître prevails, though not so conspicuously as amongst Tibetans, Bhotanese, and others. Rheumatism is frequent, and intermittent fevers, with ague; also violent and often fatal remittents, almost invariably induced by sleeping in the hot valleys, especially at the beginning and end of the 
rains. The European complaints of liver and bowel disease are all but unknown. Death is regarded with horror. The dead are burnt or buried, sometimes both; much depending on custom and rank. Omens are sought in the entrails of fowls, \&c., and other vestiges of a savage origin are still preserved, though now gradually disappearing.

The Lepchas profess no religion, though acknowledging the existence of good and bad spirits. To the good they pay no heed; "Why should we?" they say, "the good spirits do us no harm; the evil spirits, who dwell in every rock, grove, and mountain, are constantly at mischief, and to them we must pray, for they hurt us." Every tribe has a priest-doctor'; he neither knows nor attempts to practise the healing art, but is a pure exorcist; all bodily ailments being deemed the operations of devils, who are cast out by prayer's and invocations. Still they acknowledge the Lamas to be very holy men, and were the latter only moderately active, they would soon convert all the Lepchas. Their' priests are called "Bijooas:" they profess mendicancy, and seem intermediate between the begging friar's of Tibet, whose dress and attributes they assume, and the exorcists of the aboriginal Lepchas: they sing, dance (masked and draped like harlequins), beg, bless, curse, and are merry mountebanks; those that affect more of the Lama Boodhist carry the "Mani," or revolving praying-machine, and wear rosaries and amulets; other's again are all tatter's and rags. They are often employed to carry messages, and to transact little knaveries. The natives stand in some awe of them, 
and being besides of a generous disposition, keep the wallet of the Bijooa always full.

Such are some of the prominent features of this people, who inhabit the sub-Himalayas, between the Nepalese and Bhotan frontiers, at elevations of 3000 to 6000 feet. In their relations with us, they are conspicuous for their honesty, their power as carriers and mountaineers, and especially for their skill as woodsmen; for they will build a waterproof house with a thatch of banana leaves in the lower, or of bamboo in the elevated regions, and equip it with a table and bedstead for three persons, in an hour, using no implement but their heavy knife. Kindness and good humour soon attach them to your person and service. A gloomy-tempered or morose master they avoid, an unkind one they flee. If they serve a good hills-man like themselves, they will follow him with alacrity, sleep on the cold, bleak mountain, exposed to the pitiless rain, without a murmur, lay down the heavy burden to carry their. master over a stream, or give him a helping hand up a rock or precipice-do anything, in short, but encounter a foe, for I believe the Lepcha to be a veritable coward. It is well, perhaps, he is so: for if a race, numerically so weak, were to embroil itself by resenting the injuries of the warlike Ghorkas, or dark Bhotanese, the folly would soon lead to destruction.

Before leaving the Lepchas, it may be worth mentioning that the northern parts of the country, towards the Tibet frontier, are inhabited by Sikkim Bhoteas *

* Bhote is the general name for Tibet (not Bhotan), and Kumpa is a large province, or district, in that country. The Bhotanese, natives of 
(or Kumpas), a mixed race calling themselves Kumpa Rong, or Kumpa Lepchas; but they are emigrants from Tibet, having come with the first rajah of Sikkim. These people are more turbulent and bolder than the Lepchas, and retain much of their Tibetan character, and even of that of the very province from which they came; which is north-east of Lhassa, and inhabited by robbers. All the accounts I have received of it agree with those given by MM. Huc and Gabet.

Next to the Lepchas, the most numerous tribe in Sikkim is that of the Limboos (called "Chung" by the Lepchas); they abound also in East Nepal, which they once ruled, inhabiting elevations from 2000 feet to 5000 feet. They are Boodhists, and though not divided into castes, belong to several tribes. All consider themselves as the earliest inhabitants of the Tambur Valley, though they have a tradition of having originally emigrated from Tibet, which their 'Tartar countenance confirms. They are more slender and sinewy than the Lepchas, and neither plait their hair nor wear ornaments; instead of the ban they use the Nepal curved knife, called "cookree," while for the striped kirtle of the Lepcha are substituted loose cotton trousers and a tight jacket; a sash is worn round the middle, and on the head a small cotton cap. When they ruled over East Nepal, their system was feudal; and on their uniting against the Nepalese, they were

Bhotan, or of the Dhurma country, are called Dhurma people, in allusion to their spiritual chief, the Dhurma Rajah. They are a darker and more powerful race, rude, turbulent, and Tibetan in language and religion, with the worst features of those people exaggerated. 
with difficulty dislodged from their strongholds. They are said to be equally brave and cruel in battle, putting the old and weak to the sword, carrying the younger into slavery, and killing on the march such captives as are unable to proceed. Many enlist at Dorjiling, which the Lepchas never do ; and the rajah of Nepal employs them in his army, where, however, they seldom obtain promotion, this being reserved for soldiers of Hindoo tribes. Latterly Jung Bahadur levied a force of 6000 of them, who were cantoned at Katmandoo, where the cholera breaking out, carried off some hundreds, causing many families who dreaded conscription to flock to Dorjiling. Their habits are so similar to those of the Lepchas, that they constantly intermarry with them. They mourn, burn, and bury their dead, raising a mound over the corpse, erecting a headstone, and surrounding the grave with a little paling of sticks; they then scatter eggs and pebbles over the ground. In these offices the Bijooa of the Lepchas is employed, but the Limboo has also priests of his own, called "Phedangbos," who belong to rather a higher order than the Bijooas. They officiate at marriages, when a cock, is put into the bridegroom's hands, and a hen into those of the bride; the Phedangbo then cuts off the birds' heads, when the blood is caught on a plantain leaf, and runs into pools from which omens are drawn. At death, guns are fired, to announce to the gods the departure of the spirit; of these there are many, having one supreme head, and to them offerings and sacrifices are made. They do not believe in metempsychosis. 
The Moormis are the only other native tribe remaining in any numbers in Sikkim, except the Tibetans of the loftier mountains (whom I shall mention at a future period), and the Mechis of the pestilential Terai, the forests of which they never leave. The Moormis are a scattered people, of Tibetan origin, and called "Nishung," from being composed of two branches, respectively from the districts of Nimo and Shung, both on the road between Sikkim and Lhassa. They are now most numerous in central and eastern Nepal, and are a pastoral and agricultural people, inhabiting elerations of 4000 to 6000 feet, and living in stone houses, thatched with grass. They are a large, powerful, and active race, grave, very plain in features, with little hair on the face. Both their language and religion are purely Tibetan.

The Magias, a tribe now confined to Nepal west of the Arun, are aborigines of Siklim, whence they were driven by the Lepchas westward into the country of the Limboos, and by these latter further west still. They are said to have been savages, and not of Tibetan origin, and are now converted to Hindooism.

It is curious to observe that these mountains do not appear to have afforded refuge to the Tamulian* aborigines of India proper: all the Himalayan tribes of Sikkim being markedly Mongolian in origin. It does not, howerer, follow that they are all of Tibetan

* The Tamulians are the Coles, Dangas, \&c., of the mountains of Ceutral India and the peninsula, who retired to mountain fastnesses, on the invasion of their country hy the Indo-Germanic conquerors, who are now represented by the Hindoos. 
extraction ; perhaps, indeed, none but the Moormis are so. The Mechi of the Terai is decidedly Indo-Chinese, and of the same stock as the sarage races of Assam. the north-east and east frontier of Bengal, Arracan, Burmah, \&c.

The laws affecting the distribution of plants, and the lower animals, materially influence the migrations of man also; and as the botany, zoology, and climate of the Malayan and Siamese peninsula advance far westwards into India, along the foot of the Himalaya, so do also the varieties of the human race. These features are most conspicuously displayed in the natives of Assam, on both sides of the Burrampooter, as far as the great bend of that river, beyond which they gradually disappear; and none of the Himalayan tribes west of that point practise the bloody and brutal rites in war that prevail amongst the Cookies, Khasias, Garrows, and other Indo-Chinese tribes of the mountain forests of Assam, Eastern Bengal, and the Malay peninsula.

That six or seven different tribes, without any feudal system or coercive head, with different languages and customs, should dwell in close proximity and in peace and unity, within the confined territory of Sikkim, even for a limited period, is an anomaly; the more especially when it is considered that with the exception of a tincture of the Boodhist religion among some few of the people, they are all but sarages, as low in the scale of intellect as the New Zealander or the Tahitian, and beneath those races in ingenuity and skill as craftsmen. Wars have been wrged 
amongst them, but they were neither sanguinary nor destructive, and the fact remains no less remarkable, that at the period of our occupying Dorjiling, friendship and unanimity reigned amongst all these tribes; from the Tibetan at 14,000 feet, to the Mechi of the plains; under a sovereign whose temporal power was wholly unsupported by even the semblance of arms, and whose spiritual supremacy was acknowledged by very few.

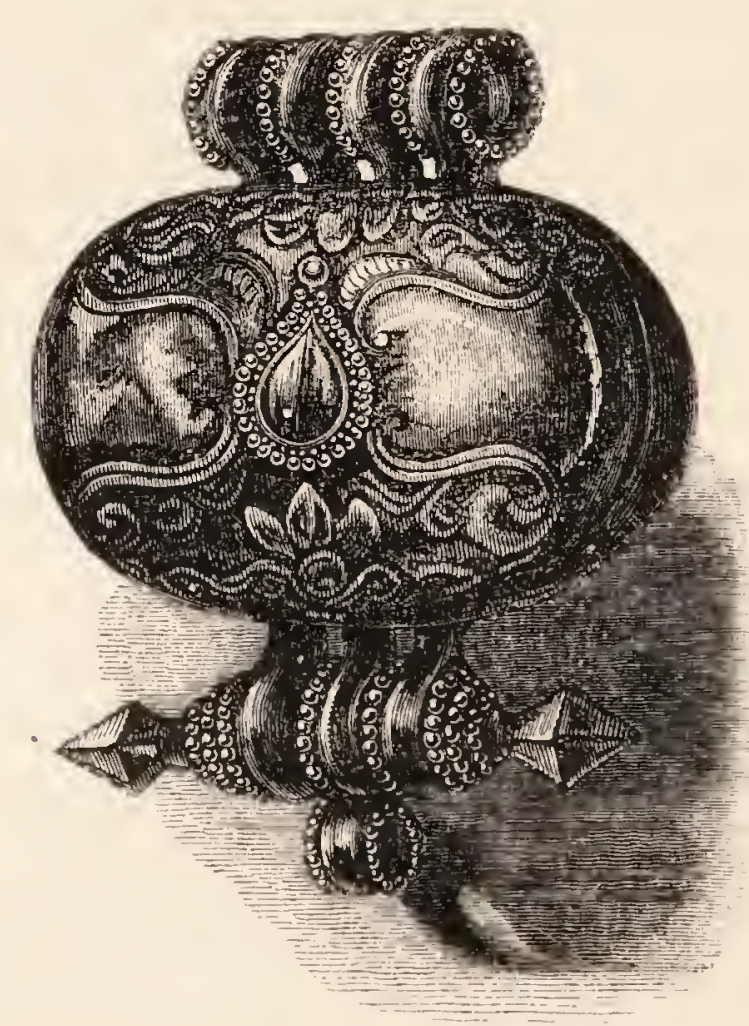




\section{CHAPTER VI.}

Excursion from Dorjiling to Great Rungeet-Zones of vegetation-Treeferns-Palms-Leebong, tea plantations-Ging-Boodhist remainsTropical vegetation-Pines-Lepcha clearances-Forest fires-Boodhist monuments-Fig-Cane bridge and raft over Rungeet-India-rubber - Yel Pote-Butterflies and other insects-Snakes-Camp-Junction of Teesta and Rungeet-Return to Dorjiling-Tonglo, excursion to -Bamboo flowering-Oaks-Peepsa-Simonbong, cultivation atEuropean fruits at Dorjiling-Plains of India.

A very favourite and interesting excursion from Dorjiling is to the cane bridge over the Great Rungeet river, 6000 feet below the station. To this an excellent road has been cut, by which the whole descent of six miles, as the crow flies, is easily performed on pony-back; the road distance being only eleven miles. I several times made this trip; on the excursion about to be described, and in which I was accompanied by Mr. Barnes, I followed the Great Rungeet to the Teesta, into which it flows.

In descending from Dorjiling, the zones of regetation are well marked by-1. The oak, chesnut, and Magnolias.-2. Immediately below 6,500 feet, the treefern appears, a widely-distributed plant, common from Nepal eastward to the Malayan peninsula, Java, and Ceylon.-3. Of palms, a species of Rattan-cane, and 
Plectocomia; the latter, though not a very large plant, climbs lofty trees, and extends about 40 yards through the forest. - 4. The fourth striking feature is a wild plantain, which ascends to nearly the same elevation. This is replaced by another, and rather larger species, at lower elevations; both ripen austere and small fruits, which are full of seeds, and quite uneatable: that commonly grown in Sikkim is an introduced stock; it is very large, but poor in flarour, and does not bear seeds. The zones of these conspicuous plants are very clearly defined, and especially if the traveller, standing on one of the innumerable spurs which project from the Dorjiling ridge, cast his eyes up the gorges of green on either hand.

At 1000 feet below Dorjiling a fine wooded spur projects, called Leebong: This beantiful spot is fully ten degrees warmer than Mr. Hodgson's house, and enjoys considerably more sunshine; peaches and English fruit-trees flourish extremely well, but do not ripen fruit. The tea-plant succeeds here armirably, and might be cultivated to great puofit, and be of arlvantage in furthering a trade with Tibet. It has been tried on a large scale by Dr. Campbell at his residence (alt. 7000 feet), but the frosts and snow of that height injure it, as do the hailstorms in spring.

Below Leebong is the village of Ging, surrounder by steeps, cultivated with maize, rice, and millet. It is rendered very picturesque by a long row of tall poles, each bearing a narrow, vertically elongated banner, covered with Boodhist inscriptions, and surmounted by coronet-like ornaments, or spear-heads, 
rudely cut out of wood, or formed of basket-work, and adorned with cotton fringe. Ging is peopled by Bhotan emigrants, and when one dies, if his relations can afford to pay for them, two additional poles and flags are set up by the Lamas in honour of his memory, and that of Sunga, the third member of the Boodhist Trinity.

The heat and hardness of the rocks cause the streams to dry up on these abrupt hills, especially on the eastern slope, and the water is therefore conveyed along the sides of the path, in conduits ingeniously made of bamboo, either split in half, or, what is better, whole, except at the septum, which is removed through a lateral hole.

At about 2000 feet, and ten miles distant from Dorjiling, we arrived at a low, long spur, dipping down to the bed of the Rungeet, at its junction with the Rungmo. This is close to the boundary of the British ground, and there is a guard-louse, and a sepoy or two at it; here we halted. It took the Lepchas about twenty minutes to construct a table and two bedsteads within our tent; each was made of four forked sticks, stuck in the ground, supporting as many side-pieces, across which were laid flat split pieces of bamboo, bound tightly together by strips of the stem of the rattan-palm. 'The beds were afterwards softened by many layers of bamboo leaves, and if not very downy, they were dry, and as firm as if put together with screws and joints.

This spur rises out of a deep ralley, quite surrounded by lofty mountains; it is narrow, and covered with red clay, which the natives chew as a cure for 
goître. North, it looks down into a gully, at the bottom of which the Rungeet's foamy stream winds through a dense forest. In the opposite direction, the Rungmo comes tearing down from the top of Sinchul, 7000 feet above; and though its roar is heard, and its course is visible throughout its length, the stream itself is nowhere seen, so deep does it cut its channel. Except on this, and a few similarly hard rocky hills around, the vegetation is a mass of wood and jungle. At this spot it is rather scanty and dry, with abundance of the long-leaved Pine and Sal. 'The dwarf date-palm also is very abundant.

The descent to the river was exceedingly steep, the banks presenting an impenetrable jungle. The pines on the arid crests of the hills around formed a remarkable feature: they grow like the Scotch fir, their tall, red trunks springing from the steep and dry slopes. But little resin exudes from the stem, which, like that of most pines, is singularly free from lichens and mosses; its wood is excellent, and the charcoal of the burnt leaves is used as a pigment.

The Lepcha never inhabits the same spot for more than three successive years, after which ain increased rent is demanded by the Rajah. He therefore squats in any place which he can render profitable for that period, and then moves to another. His first operation, after selecting a site, is to burn the jungle; then he clears away the trees, and cultivates between the stumps. At this season, firing the jungle is a frequent practice, and the effect by night is exceedingly fine; a forest, so dry and full of bamboo, and extending over 
such steep hills, affording grand blazing spectacles. Heavy clouds canopy the mountains above, and, stretching across the valleys, shut out the firmament; the air is a dead calm, as usual in these deep gorges, and the fires, invisible by day, are seen raging all around, appearing to an inexperienced eye in all but dangerous proximity. The voices of birds and insects being hushed, nothing is audible but the harsh roar of the river's, and occasionally, rising far above it, that of the forest fires. At night we were literally surrounded by them; some smouldering, like shale-heaps at a colliery, other's fitfully bursting forth, whilst others again stalked along with a steadily increasing and enlarging flame, shooting out great tongues of fire, which spared nothing as they advanced with irresistible might. Their triumph is in reaching a great bamboo clump, when the noise of the flames drowns that of the torrents, and as the great stem-joints burst, from the expansion of the confined air, the report is as that of a salvo from a park of artillery. At Dorjiling the blaze is visible, and the deadened reports of the bamboos bursting is heard throughout the night; but in the ralley, and within a mile of the scene of destruction, the effect is the most grand, being heightened by the glare reflected from the masses of mist which hover above.

On the following morning we pursued a path to the bed of the river; passing a rude Boodhist monument, a pile of slate-rocks, with an attempt at the mystical hemisphere at top. A few flags or banners, and slabs of slate, were inscribed with the sacred characters 
"Om Mani Padmi om." Placed on a jutting angle of the spur, backed with the pine-clad hills, and flanked by a torrent on either hand, the spot was wild and picturesque; and I could not but gaze with a feeling of deep interest on these emblems of a religion which perhaps number's more votaries than any other on the face of the globe. Boodhism in some form is the predominating creed, from Siberia and Kamschatka to Ceylon, from the Caspian steppes to Japan, throughout China, Burmah, Ara, and a part of the Malayan Archipelago. Its associations enter into every book of travels over these vast regions, with Boodh, Dhurma, Sunga, Jos, Fo, and praying-wheels. The mind is arrested by the names, the imagination captivated by the symbols; and though I could not worship in the grove, it was impossible to deny to the inscribed stones such a tribute as is commanded by the first glimpse of objects which have long been familiar to our minds, but not previously offered to our senses. My head Lepcha went further: to a due observance of demon-worship he united a deep reverence for the Lamas, and he venerated their symbols rather as theirs than as those of their religion. He walked round the pile of stones three times from left to right repeating his "Om Mani," \&c., then stood before it with his head hung down and his long queue streaming behind, and concluded by a votive offering of three pine-cones. When done, he looker round at me, nodded, smirked, elevated the angles of his little tumedup eyes, and seemed to think we were safe from all perils in the valleys yet to be explored. 
In the valley of the Rungeet the heat was intolerable, though the thermometer did not rise above $95^{\circ}$. The mountains leave but a narrow gorge between them, here

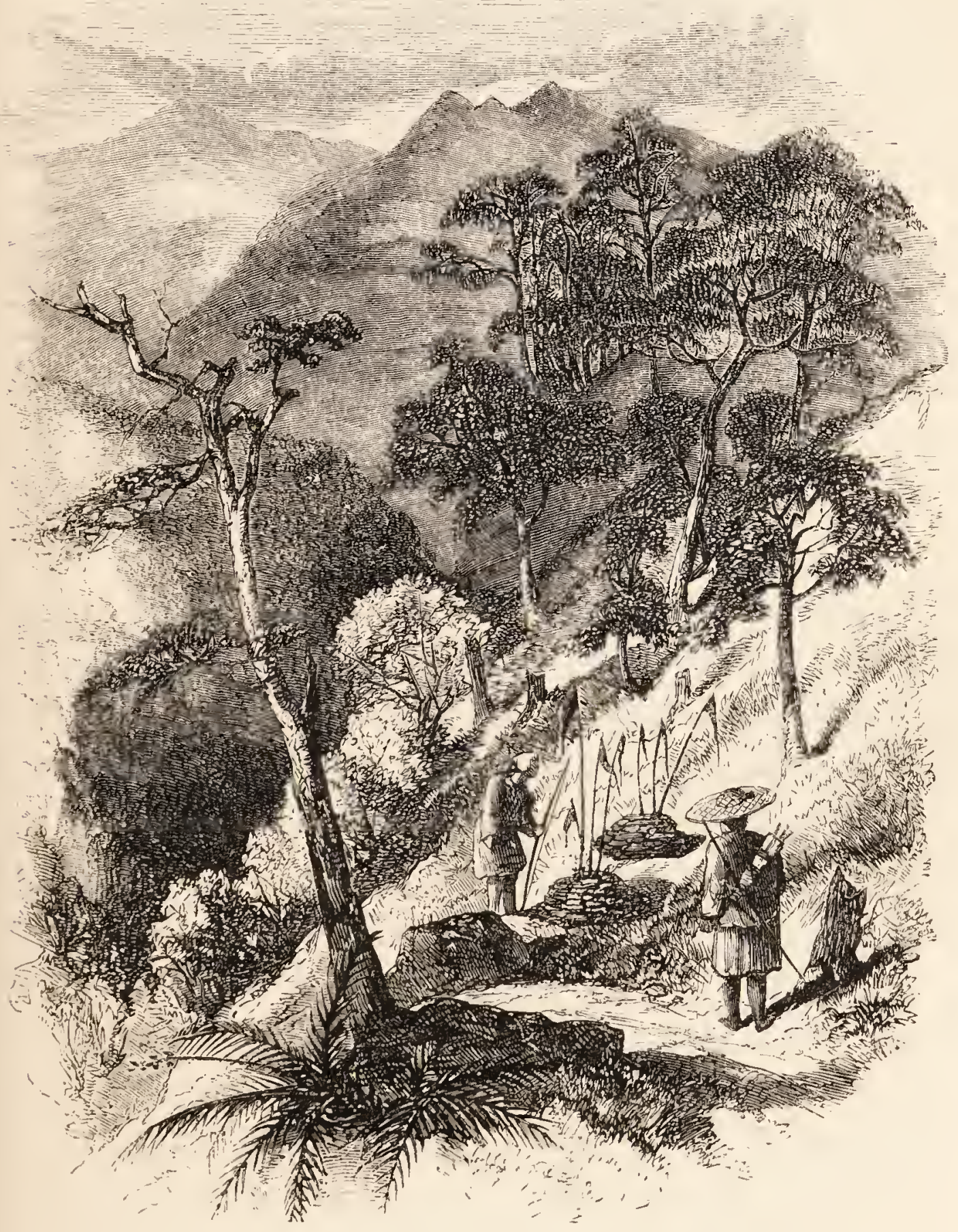

PINES (PINUS LONGIFOLIA), RUNGEET VALLE:。

and there bordered by a belt of rich soil, supporting a towering crop of long cane-like grasses and tall trees. 
The troubled river, about eighty yards wide, rushes along over a gravelly bed. Crossing the Rungmo, where it falls into the Rungeet, we came upon a group of natives drinking fermented Murwa liquor, under a rock; I had a good deal of difficulty in getting my people past, and more in inducing one of the topers to take the place of a Ghorka (Nepalese) of our party who was ill with ferer. Soon afterwards, at a most wild and beautiful spot, I saw, for the first time, one of the most characteristic of Himalayan objects of art, a cane bridge. All the spur's, round the bases of which the river flowed, were steep and rocky, their flanks clothed with the richest tropical forest, their crests tipped with pines. On the river's edge, the Banana, screw-pine, and Bantinia, were frequent, 'and Figs prevailed. One of the latter (of an exceedingly beautiful species) projected over the stream, growing out of a mass of rock, its roots interlaced and grasping at every available support, while its branches, loaded with deep glossy foliage, hung over the water. This tree formed one pier for the canes; that on the opposite bank was constructed of strong piles, propped with large stones; and between them swung the bridge," about eighty yards long, ever rocking over the torrent (forty feet below). The lightness and extreme simplicity of its structure were very remarkable. 'T'wo parallel canes, on the same horizontal plane, were stretched across the stream; from them other's hung in loops, and along the loops were laid one or two bamboo stems for flooring; cross pieces 'below this flooring, hung from the two upper canes, which they thus served

* A sketch of one of these bridges will be found in Vol. ii. 
to keep apart. The traveller grasps one of the canes in either hand, and walks along the loose bamboos laid on the swinging loops: the motion is great, and the rattling of the loose dry bamboos is neither a musical somnd, nor one calculated to inspire confidence; the whole structure seeming as if about to break down. With

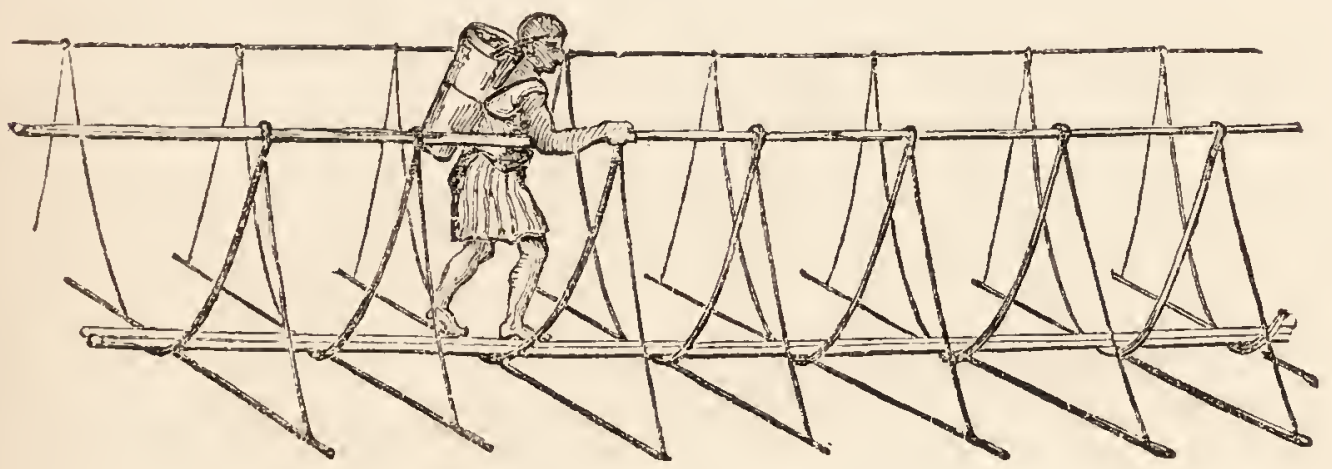

shoes it is not easy to walk; and even with bare feet it is often difficult, there being frequently but one bamboo, which, if the fastening is loose, tilts up, leaving the pedestrian suspended over the torrent by the slender canes. When properly and strongly made, with good fastenings, and a floor of bamboos laid transversely, these bridges are easy to cross. 'The canes are procured from a species of rattan; they are as thick as the finger, and twenty or thirty yards long, knotted together; and the other pieces are fastened to them by strips of the same plant. A Lepcha, carrying one hundred and forty pounds on his back, crosses without hesitation, slowly but steadily, and with perfect confidence.

A deep broad pool below the bridge was made available for a ferry: the boat was a triangular raft of bamboo stems, with a stage on the top, and it was secured on the opposite side of the stream, having a 
cane reaching across to that on which we were. 'The bridge being in a dilapidated condition, a stout Lepcha leapt into the boiling flood, and boldly swam across, holding on by the cane, without which he would have been carried away. He unfastened the raft, and we drew it over by the cane, and, seated on the stage, up to our knees in water, we were pulled across; the raft bobbing up and down over the rippling stream.

We were beyond British ground, on the opposite bank, where any one guiding Europeans is threatened with punishment: we had expected a guide to follow us, but his non-appearance caused us to delay for some hours ; four roads, or rather forest paths, meeting here, all of which were difficult to trace. After a while, part of a wedding-procession came up, headed by the bridegroom, a handsome young Lepcha, leading a cow for the marriage feast; and after talking to him a little, he volunteered to show us the path. Much of the forest had been burnt, and we trarersed large blackened patches, where the heat was intense, and increased by the burning trunks of prostrate trees, which smoulder for months, and leave a heap of white ashes. The larger timber being hollow in the centre, a current of air is produced, which causes the interior to burn rapidly, till the sides fall in, and all is consumed. I was often startled, when walking in the forest, by the hot blast proceeding from such, which I had approached without a suspicion of their being other than cold dead trunks.

Leaving the forest, the path led along the river bank, and orer the great masses of rock which strewed its 
course. The beautiful India-rubber fig was common, as was Bassia butyracea, the "Yel Pote" of the Lepchas, from the seeds of which they express a concrete oil, which is received and hardens in bamboo vessels. On the forest-skirts, parasitical orchids and Ferns abounded; the Chaulmoogra, whose fruit is used to intoxicate fish, was very common; as was an immense mulberry tree, that yields a milky juice and produces a long green sweet fruit. Large fish, chiefly Cyprinoid, were abundant in the beautifully clear water of the river. But by far the most striking feature consisted in the amazing quantity of superb butterflies, large tropical swallow-tails, black, with scarlet or yellow eyes on their wings. They were seen everywhere, sailing majestically through the still hot air, or fluttering from one scorching rock to another, and especially loving to settle on the damp sand of the river-edge; where they sat by thousands, with erect wings, balancing themselves with a rocking motion, as their heavy sails inclined them to one side or the other'; resembling a crowded fleet of yachts on a calm day. Such an entomological display cannot be surpassed. Cicindelce were very numerous, and incredibly active, as were locusts; and the great cicadas were everywhere lighting on the ground, when they uttered a short, sharp, creaking sound, and anon disappeared, as if by magic. Beautiful whip-snakes were gleaming in the sun: they hold on by a few coils of the tail round a twig, the greater part of their body stretched out horizontally, occasionally retracting, and darting an unerring aim at some insect. The narrowness of the gorge, and the excessive steepness of the bounding 
hills, prevented any view, except of the opposite mountain face, which was clothed with a dense forest, in which the wild Banana was conspicuous.

Towards evening we arrived at another cane-bridge, still more dilapidated than the former, but similar in structure. For a few hundred yards before reaching it, we lost the path, and followed the precipitous face of slate-rocks overhanging the stream, which dashed with great riolence below. Though we could not walk comfortably, even with our shoes off, the Lepchas, bearing their enormous loads, proceeded with perfect indifference.

Anxious to avoid sleeping at the bottom of the valley, we crawled, very much fatigued, through burnt dry forest, up a very sharp ridge, so narrow that the tent sat astride on it, the ropes being fastened to the tops of small trees on either slope. The ground swarmed with black ants, which got into our tea, sugar, \&c., while it was so covered with charcoal, that we were soon begrimed. Our Lepchas preferred remaining on the river-bank, whence they had to bring up water to us, in great bamboo "chungis," as they are called. The great dryness of this face is owing to its southern exposure; the opposite mountains, equally high and steep, being clothed in a rich green forest.

Our course down the river was by so rugged a path, that, giddy and footsore with leaping from rock to rock, we at last attempted the jungle, but it proved utterly impervious. On turning a bend of the stream, the mountains of Bhotan suddenly presented themselves, with the Teesta flowing at their base; and we emerged 
at the angle formed by the junction of the Rungeet, which we had followed from the west, of the Teesta, coming from the north, and of their united streams flowing south.

We were not long before enjoying the water, when I was surprised to find that of the Teesta singularly cold, its temperature being $\tau^{\circ}$ below that of the Rungeet.* At the salient angle (a rocky peninsula) of their junction, we could almost place one foot in the cold stream and the other in the warmer. There is a no less marked difference in the colour of the two rivers; the Teesta being sea-green and muddy, the Great Rungeet dark green and very clear; and the waters, like those of the Arve and Rhone at Geneva, preserve their colours for some hundred yards, the line separating the two being most distinctly drawn. The Teesta, or main stream, is much the broadest (about 80 or 100 yards wide at this season), most rapid and deepest. The rocks which skirt its bank were covered with a silt or mud deposit, which I nowhere observed along the Great Rungeet, and which, as well as its colour and coldness, was owing to the vast number of then melting glaciers drained by this river. The Rungeet, on the other hand, though it rises amongst the glaciers of Kinchinjunga and its sister peaks, is chiefly supplied by the rainfall of the outer ranges of Sinchul and Singalelah, and hence its waters are clear, except during the height of the rains.

* This is, no doubt, due partly to the Teesta flowing south, and thus laving less of the sun, and partly to its drainiag snowy mountains throughout a much longer portion of its course. 
From this place we returned to Dorjiling, arriving on the afternoon of the following day.

The most interesting trip to be made from Dorjiling, is that to the summit of 'Tonglo, a mountain on the Singalelah range, 10,0r9 feet high, due west of the station, and twelve miles in a straight line, but fully thirty by the path.

Leaving the station by a native path, the latter plunges at once into a forest, and descends very rapidly, occasionally emerging on cleared spurs, where are fine crops of various millets, with much maize and rice. Of the latter grain as many as eight or ten varieties are cultivated, but seldom irrigated, which, owing to the dampness of the climate, is not necessary: the produce is often eighty-fold, but the grain is large, coarse, reddish, and rather gelatinous when boiled.

At about 4000 feet the great bamboo ("Pao" Lepcha) abounds; it flowers every year, which is not the case with all the species of this genus, most of which flower profusely over large tracts of country, once in a great many years, and then die away; their place being supplied by seedlings, which grow with immense rapidity. This well-known fact is not due, as some suppose, to the life of the species being of such a duration, but to favourable circumstances in the season. The Pao attains a height of 40 to 60 feet, and the culms average in thickness the human thigh; it is used for large water-ressels, and its leaves form admirable thatch, in universal use for European houses at Dorjiling. Besides this, the Lepchas are acquainted with nearly a dozen linds of bamboo; these occur at 
various elevations below 12,000 feet, forming, even in the pine-woods, and above their zone, in the skirts of the Rhododendron scrub, a small and sometimes almost

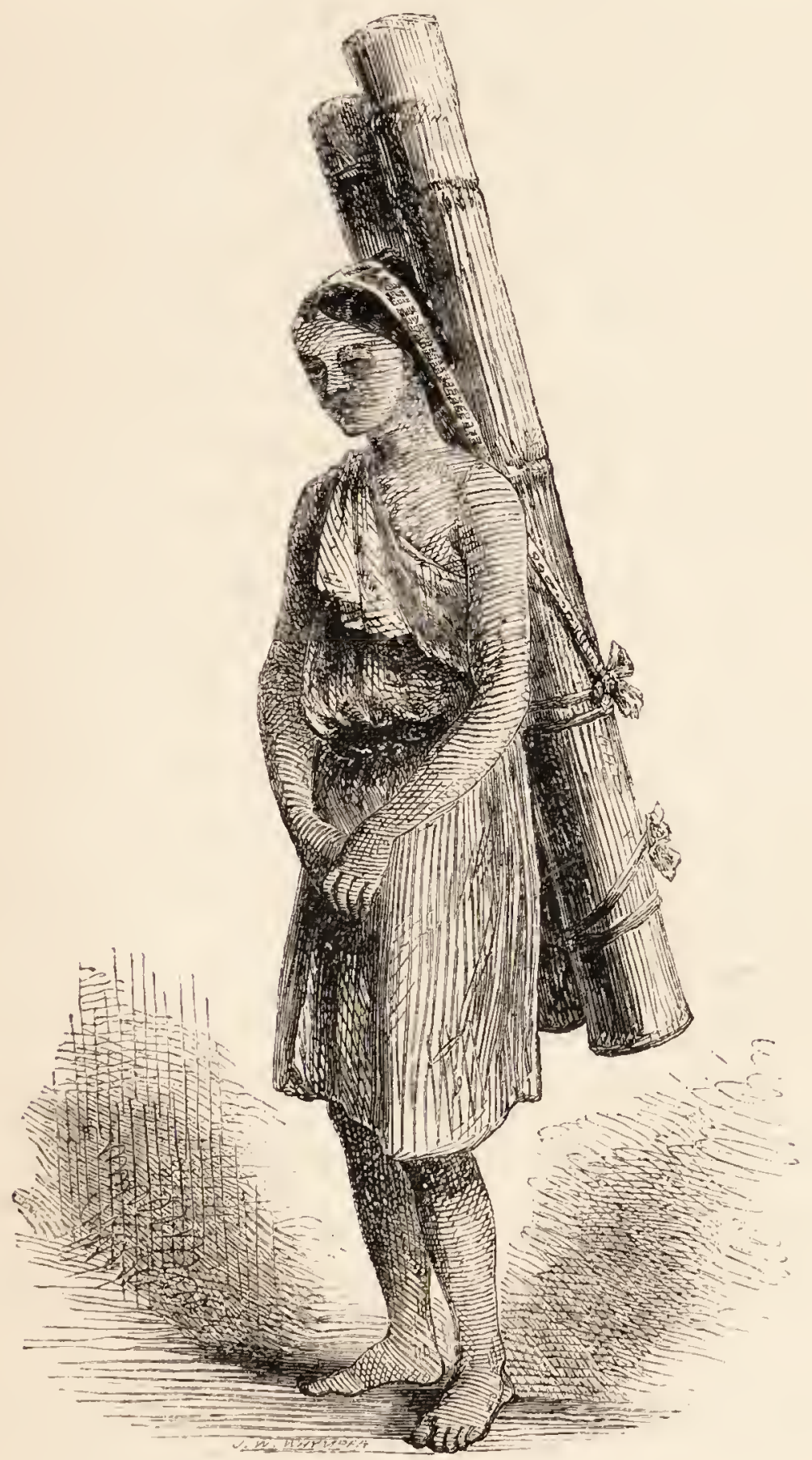

LEPCHA WATER-CARRIER WITH A BAMBOO CHUNGI.

impervious jungle. In an economical point of view they may be classed as those which split readily, and those which do not. The young shoots of several are 
eaten, and the seeds of one are made into a fermented drink, and into bread in times of scarcity; but it would take many pages to describe the numerous purposes to which the various species are put.

Some low steep spurs were well cultivated, though the angle of the field was upwards of $25^{\circ}$; the crops, chiefly maize, were just sprouting. 'The flowers of this plant are occasionally hermaphrodite in Sikkim, where they form a large drooping panicle and ripen small grains; this is, however, a rare occurrence, and the specimens are highly valued by the people.

The general prevalence of figs, and their allies, the nettles,* is a remarkable feature in the botany of the Sikkim Himalaya, up to nearly 10,000 feet. Of the former there were here five species, some bearing eatable and very palatable fruit of enormous size, others with the fruit small, and borne on prostrate, leafless branches, which spring from the root and creep along the ground.

A troublesome, dipterous insect (the "Peepsa," a species of Simulium) swarms on the banks of the streams; it is very small and black, floating like a speck before the eye; its bite leaves a spot of extravasated blood under the cuticle, very irritating if not opened.

Crossing the Little Rungeet river, we camped at the

* Of two of these cloth is made, and of a third, cordage. The tops of two are eaten, as are several species of Procris. To this order belongs the "Poa," from the fibre of which is made that kind of grass-cloth now abundantly imported into Fngland from the Malay Islands, and used extensively for shirting. 
base of Tonglo. The night was calm and clear, with faint cirrus, but no dew; and the following morning was bright, and clear over head, though the clouds over the mountains looked threatening. Dorjiling, perched on a ridge 5000 feet above us, had a singular appearance. We ascended the Simonbong spur of Tonglo, so called from a small village and Lama temple of that name on its summit; where we arrived at noon, and passing some chaits* gained the Lama's residence.

Two species of bamboo, the "Payong" and "Praong" of the Lepchas, here replace the Pao of the lower regions. The former was flowering abundantly, the whole of the culms (which were 20 feet high) being a diffuse panicle of inflorescence. The "Praong" bears a round head of flowers at the ends of the leafy branches. Wild strawberry, violet, geranium, \&c., marked our approach to the temperate zone. Around the temple were potato crops and peach-trees, rice, millet, yam, brinjal (egg-apple), fennel, hemp (for sinoking its narcotic leaves), and cummin, \&c. The potato thrives extremely well as a summer crop, at 7000 feet, in Sikkim, though I think the root (from the Dorjiling stock) cultivated as a winter crop in the plains, is superior both in size and flavour. Peaches never ripen in this part of Sikkim, apparently from the want of sun; the tree grows well at from :3000 to 7000 feet

* The chait of Sikkim, borrowed from Tibet, is a square pedestal, surmounted by a hemisphere, the convex end downwards, and on it is placed a cone, with a crescent on the top. These are erected as monuments to Lamas, and illustrious persons, and are venerated accordingly, the people always passing them from left to right, often repeating the invocation, "Orn Mani Padmi om." 
elevation, and flowers abundantly; the fruit making the nearest approach to maturity (according to the elevation) between July and October. At Dorjiling it follows the English seasons, flowering in March and fruiting in September, when the scarce reddened and still hard fruit falls from the tree.

It is curious that throughout this temperate region, there is hardly an eatable fruit except the native walnut, and some brambles, of which the "yellow" and "ground" raspberries are the best, some insipid figs, and a very austere crab-apple. The European apple will scarcely ripen, and the pear not at all. Currants and gooseberries show no disposition to thrive, and strawberries are the only fruits that really ripen, which they do in the greatest abundance. Vines, figs, pomegranates, plums, apricots, \&c., will not succeed even as trees. European vegetables again grow, and thrive remarkably well throughout the summer of Dorjiling, and the produce is veryfair, sweet and good, but inferior in flavour to the English.

Of tropical fruits cultivated below 4000 feet, oranges and indifferent bananas alone are frequent, with lemons of various kinds. The season for these is, however, very short; oranges abound in winter, and are excellent, but neither so large nor free from white pulp as those of the Khasia hills, the West Indies, or the west coast of Africa. Mangos are brought from the plains, for. though wild in Sikkim, the cultivated kinds do not thrive; I have seen the pine-apple plant, but I never met with good fruit on it.

A singular and almost total absence of the direct 
rays of the sun during the ripening season, is the cause of this dearth of fruit. Both the farmer and orchard gardener in England know full well the value of a bright sky as well as of a warm autumnal atmosphere. Without this corn does not ripen, and fruittrees are blighted. The winter of the plains of India being more analogous in its distribution of moisture and heat to a European summer, such fruits as the peach, vine, and even plum, fig, strawberry, \&c., may be brought to bear well in March, April, and May, if they are only carefully tended through the previous hot and damp season, which is, in respect to the functions of flowering and fruiting, their winter.

Hence it appears that, though some English fruits will turn the winter solstice of Bengal (November to May) into summer, and then flower and fruit, neither these nor others will thrive in the summer of 7000 feet on the Sikkim Himalaya, (though its temperature so nearly approaches that of England,) on account of its rain and fogs. Further, they are often exposed to a winter's cold equal to the average of that of London, the snow lying for a week on the ground, and the thermometer descending to $25^{\circ}$. It is true that in no case is the extreme of cold so great here as in England, but it is sufficient to check vegetation, and to prevent fruit-trees from flowering till they are fruiting at the level of the sea. There is in this respect a great difference between the climate of the central and eastern and western Himalaya, at equal elevations. In the western (Simla, \&c.) the winters are colder than in Sikkim-the summers warmer and less humid. The rainy 
season is shorter, and the sun shines so much more frequently between the heavy showers, that the apple and other fruits are brought to a much better state. The rain-gauge may show as great a fall there, but this is no measure of the humidity of the atmosphere, and still less so of the amount of the sun's direct light and heat intercepted by aqueous vapour, for that instrument takes no account of the quantity of moisture suspended in the air, nor of the depositions from fogs, which are far more fatal to the perfecting of fruits thian the heaviest brief showers.

The Indian climate, where it is marked by one season of excessive humidity and the other of excessive rrought, can never be favourable to the production either of good European or tropical fruits. For this reason not one of the latter is peculiar to the country, and perhaps but one which arrives at full perfection; namely, the mango. The plantains, oranges, and pineapples are less abundant, of inferior kinds, and remain a shorter season in perfection than they do in South America, the West Indies, or Western Africa. 


\section{CHAPTER VII.}

Continue the ascent of Tonglo-Trees-Lepcha construction of hut-Simsibong-Climbing-trees-Frogs-Ticks-Leeches-Summit of TongloRhododendrons-Yew-Rose-Aconite-Bikh poison-English genera of plants-Ascent of tropical orders-Comparison with south temperate zone-Heavy rain-Temperature, \&c. - Descent-Simonbong templeFurniture therein-Praying-cylinder-Thigh-bone trumpet-Morning orisons-Present of Nurwa beer, \&c.

Above Simonbong, the path up Tonglo is little frequented, although it is one of the many routes between Nepal and Sikkim, which cross the Singalelah spur of Kinchinjunga at various elevations between 7000 and 15,000 feet. As usual, the track runs along steep and narrow ridges, wherever these are to be found, through deep humid forests of oaks and Magnolias, many laurels, and a species of cinnamon, ascending to 8,500 feet. Chesnut and walnut here appeared, with some leguminous trees, which however did not ascend to 6000 feet. Scarlet flower's of an epiphytical Vaccinium, were strewed about, and the great blossoms of Rhododendron Dalhousia and of a Magnolia lay together on the ground. The latter forms a tree, with very dense foliage, and shining deep green leaves, a foot to eighteen inches long. Most of its flowers drop unexpanded from the tree, and diffuse a 
very aromatic odour; they are nearly as large as the fist, the outer petals purple, the inner pure white.

Heavy rain came on at 3 p.x., obliging us to seek the nearest camping-ground. For this purpose we ascended to a spring, called Simsibong, at an elevation of 6000 feet; where the Lepchas rapidly constructed a house, and thatched it with bamboo and the broad leaves of the wild plantain. A table was then raised in the middle, of four posts and as many cross pieces of wood, lashed together with strips of bamboo. Across these, pieces of bamboo were laid, ingeniously flattened, by selecting cylinders, crimping them all round, and then slitting each down one side so that it opened into a flat slab. Similar but longer and lower erections, one on each side the table, formed bed or chair; and in one hour, half a dozen men, with only long knives and active hands, had provided us with a tolerably watertight furnished house. A thick flooring of bamboo leares kept the feet dry, and a screen of foliage all round rendered the habitation tolerably warm.

We here found many large scandent trees twisting around the trunks of others, and strangling them: the latter gradually decay, leaving the sheath of climbers as one of the most remarkable regetable phenomena of these mountains. These climbers belong to several order's, and may be roughly classified in two groups.-(1.) 'Those whose stems merely twine, and by constricting certain parts of their support, induce death.-(2.) Those which form a net-work round the trunk, by the coalescence of their branches and aerial roots, \&c.: these wholly envelope and often conceal the 
tree they enclose, whose branches appear rising far above those of its destroyer. To the first of these

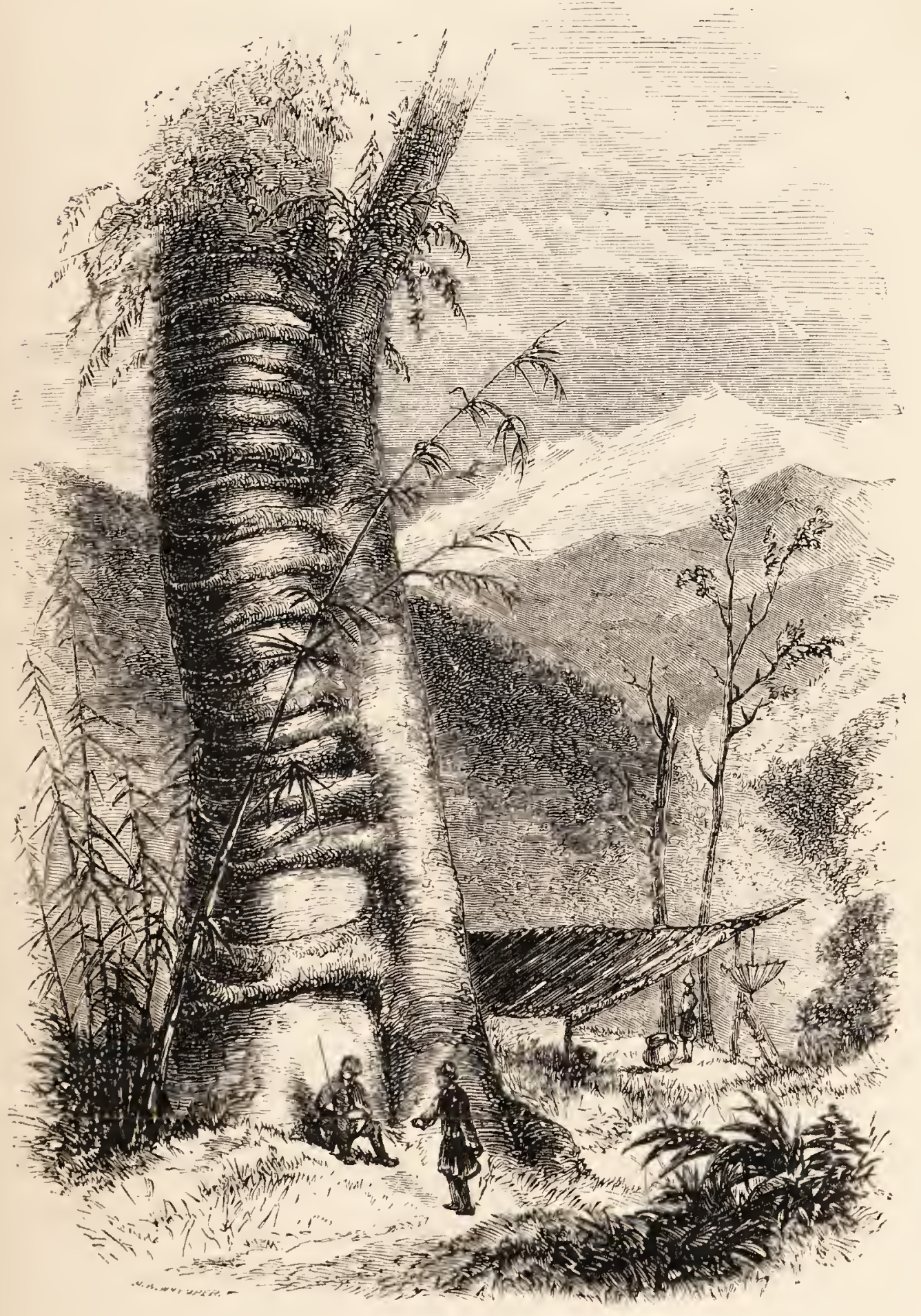

CLASPING ROOTS OF WIGHTIA.

groups belong many natural orders, of which the most prominent are-leguminous and aroid plants, ivies, 
hydrangea, and vines. The inosculating ones are almost all figs and Wightia, a plant allied to Bignonia: the latter is the most remarkable, and I give a cut of its grasping roots, sketched at our encampment.

Except for the occasional hooting of an owl, the night was profoundly still during several hours after dark - the cicadas at this season not ascending so high on the mountain. A dense mist shrouded every thing, and the rain pattered on the leaves of our hut. At midnight a tree-frog broke the silence with his curious metallic clack, and others quickly joined the chorus, keeping up their strange music till morning. Like many Batrachians, this has a voice singularly unlike that of any other organised creature. The cries of beasts, birds, and insects are all explicable to our seuses, and we can recognise most of them as belonging to such or such an order of animal; but the voices of many frogs are like nothing else, and allied species utter totally dissimilar notes. In some, as this, the sound is like the concussion of metals; in others, of the vibration of wires or cords; anything but the natural effects of lungs, larynx, and muscles.*

On the following morning we proceeded upwards, though our prospect was more gloomy than erer. The path, which still led up steep ridges, was very slippery, owing to the rain upon the clayey soil, and was only passable from the hold afforded by the interlacing roots of trees.

A large tick infested the small bamboo, and a more

* A very common Tasmanian species utters a sound that appears to ring in an underground vaulted chamber, beneatl the feet. 
hateful insect I never encountered. The traveller cannot prevent these insects coming on his person (sometimes in great numbers) as he brushes through the forest; they get inside his dress, and insert their proboscis deeply without pain. Buried head and shoulders, and retained by a barbed lancet, the tick is only to be extracted by force, which is very painful. I have devised many tortures, mechanical and chemical, to induce these disgusting intruders to withdraw their proboscis, but in vain. Leeches also swarm below 7000 feet; a small black species above 3000 feet, and a large yellow-brown solitary one below that elevation.

Our ascent to the summit was by the bed of a watercourse, now a roaring torrent, from the heavy and incessant rain. 'The top of the mountain is another flat ridge, with depressions and broad pools. The number of additional species of plants found here was great, and all betokened a rapid approach to the alpine region of the Himalaya. The trees were principally - the scarlet Rhododendron arboreum and barbatum, large bushy luxuriant trees, loaded with beautiful flowers; $R$. Falconeri, in point of foliage the most superb of all the Himalayan species, with trunks thirty feet high, and branches bearing at their ends only leaves eighteen inches long: these are deep green above, and covered beneath with a rich brown down. There were still a few purple Magnolias, very large Pyri, like mountain ash, and the common English yew, eighteen feet in circumference, the red bark of which is used as a dye, and for staining the foreheads of the Brahmins in Nepal. An erect white-flowered rose 
(R. sericea, the only species occurring in Southern Sikkim) was very abundant: its numerous inodorous flowers are pendent, apparently as a protection from the rain; and it is remarkable as being the only species having four petals instead of five. A currant was common, always growing epiphytically on the trunks of large trees. Amongst, the herbs were many of great interest, as a rhubarb, and an aconite, which yields one of the celebrated "Bikh" poisons. Of European genera I found Thalictrum, Anemone, Fumaria, violets, Stellaria, Hypericum, two geraniums, balsams, Epilobium, Potentilla, Paris and Convallarice; one of the latter has verticillate leaves, and its root, also called "bikh," is considered a very virulent poison.

Still, the absence or rarity at this elevation of several very large natural families, which have numerous representatives at and much below the same level in the inner ranges, and on the outer of the Western Himalaya, indicates a decided peculiarity in Sikkim. On the other hand, certain tropical genera are more abundant in the temperate zone of the Sikkim mountains, and ascend much higher there than in the Western Himalaya: of this fact we have conspicuous examples in the palms, plantains, and tree-ferns. The ascent and prevalence of tropical species is due to the humidity and equability of the climate in this temperate zone, and is, perhaps, the direct consequence of these conditions. An application of the same laws accounts for the extension of similar plants far beyond the tropical limit in the Southern Ocean, where rarious natural orders, which do not cross the 30 th and 40 th 
parallels of $\mathrm{N}$. latitude, are extended to the 55th of $\mathrm{S}$. latitude, and are found in Tasmania, New Zealand, the so-called Antarctic Islands south of that group, and at Cape Horn itself.

The rarity of Pines is perhaps the most curious feature in the botany of Tonglo, and on the outer ranges of Sikkim; for, between the level of 2,500 feet (the upper limit of the long-leaved Pine) and 10,000 feet (that of the Yew), there is no coniferous tree whatever on the outer ranges of Southern Sikkim.

We encamped amongst Rhododendrons, on a spongy soil of black vegetable matter, so oozy, that it was difficult to keep the feet dry. The rain poured in torrents all the evening, and with the calm, and the wetness of the wood, prevented our enjoying a fire. Except a transient view into Nepal, a few miles west of us, nothing was to be seen, the whole mountain being wrapped in dense masses of vapour. Gusts of wind, not felt in the forest, whistled through the gnarled and naked tree-tops; and though the temperature was $50^{\circ}$, this wind produced cold to the feelings. Our poor Lepchas were miserably off, but always happy: under four posts and a bamboo-leaf thatch, with no covering but a single thin cotton garment, they crouched on the sodden turf, joking with the Hindoos of our party, who, though supplied with good clothing and shelter, were doleful companions.

I made a shed for my instruments under a tree; Mr. Barnes, ever active and ready, floored the tent with. logs of wood, and I laid a "corduroy road" of the same to my little observatory. 
During the night the rain did not abate; and the tent-roof leaked in such torrents that we had to throw pieces of wax-cloth over our shoulders as we lay in bed; and there was no improvement whatever in the weather on the following morning. Two of the Hindoos crawled into the tent during the night, attacked with fever and ague. The tent being too sodden to be carried, we had to remain where we were, but with abundance of novelty in the botany around, I found no difficulty in getting through the day. Observing the track of sheep, we sent two Lepchas to follow them, who returned at night from some miles west in Nepal, bringing two. The shepherds were Geroongs of Nepal, who were grazing their flocks on a grassy mountain top from which the woods had been cleared, probably by fire. 'The mutton was a great boon to the Lepchas, but the Hindoos would not touch it, and several more sickening during the day, we had the tent most uncomfortably full.

My barometrical observations, taken simultaneously with those of Calcutta, give the height of Tonglo, 10,078.3 feet; Colonel Waugh's, by trigonometry, $10,079^{\circ} 4$ feet, - - remarkable and unusual coincidence.

May 23.-We spent a few hours of alternate fog and sunshine on the top of the mountain, vainly hoping for the most modest view; our inability to obtain it was extremely disappointing, as the summit commands a superb prospect. 'The air, which was always foggy, was alternately cooled and heated, as it blew over the trees, or the open space we occupied; sometimes varying $5^{\circ}$ and $6^{\circ}$ in a quarter of an hour.

Having partially dried the tent in the wind, we com- 
menced the descent, which, owing to the late torrents of rain, was most fatiguing and slippery ; it again commenced to drizzle at noon, nor was it till we had descended to 6000 feet that we emerged from the region of clouds. By dark we arrived at Simonbong, having descended 5000 feet, at the rate of 1000 feet an hour; and were kindly received by the Lama, who gave us his temple for the accommodation of our party. We were surprised at this, both because the Sikkim authorities had represented the Lamas as very averse to Europeans, and because he might well have hesitated before admitting a promiscuous horde of thirty people into a sacred building, where the little valuables on the altar, \&c., were quite at our disposal. A better tribute could not well have been paid to the honesty of my Lepcha followers. Our host only begged us not to disturb his people, nor to allow the Hindoos of our party. to smoke inside.

Simonbong is one of the smallest and poorest Goompas, or temples, in Sikkim; being built of wood only. It consisted of one large room, raised on a stone foundation, with small sliding shutter windows, and roofed with shingles of wood; opposite the door a wooden altar was placed, rudely cliequered with black, white and red; to the right and left were shelves, with a few Tibetan books, wrapped in silk; a model of Symbonath temple in Nepal, a praying-cylinder,* and

* It consisted of a leathern cylinder placed upright in a frame ; a projecting piece of iron struck a little bell at each revolution, the movement being caused by an elbowed axle and string. Within such cylinders are deposited written prayers, and whoever pulls the string properly is 
some implements for common purposes, bags of juniper, English wine-bottles and glasses, with tufts of Abies Webbiana, rhododendron flowers, and peacock's feathers, besides various trifles, clay ornaments and offerings,

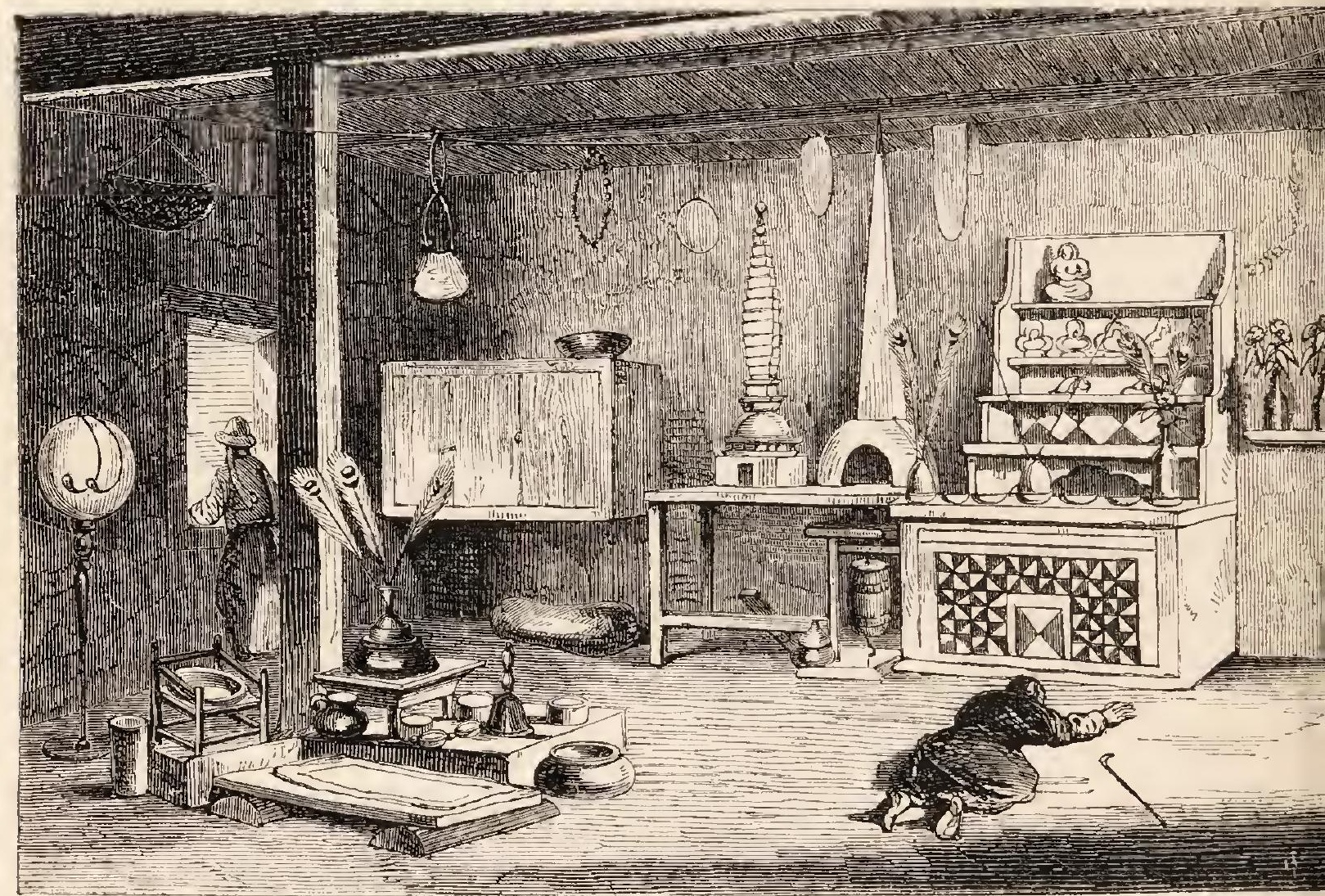

SIMONBONG TEMPLE.

and little Hindoo idols. On the altar were ranged seven little brass cups, full of water; a large conch shell, carved with the sacred lotus; a brass jug from Lhassa, of beautiful design, and a human thigh-bone, hollow, and perforated through both condyles.*

considered to have repeated his prayers as often as the bell rings. Representations of these implements will be found in other parts of these volumes.

* To these are often added a double-headed rattle, or small drum, formed of two crowns of human skulls, cemented back to back; each face is then covered with parchment, and encloses some pebbles. Sometimes this instrument is provided with a handle. 
Facing the altar was a bench and a chair, and on one side a huge tambourine, with two curved iron drumsticks. The bench was covered with bells, handsomely carved with idols, and censers with juniper-ashes; and on it lay the dorge, or double-headed thunderbolt, which the Lama holds in his hand during service. Of all these articles, the human thigh-bone is by much the

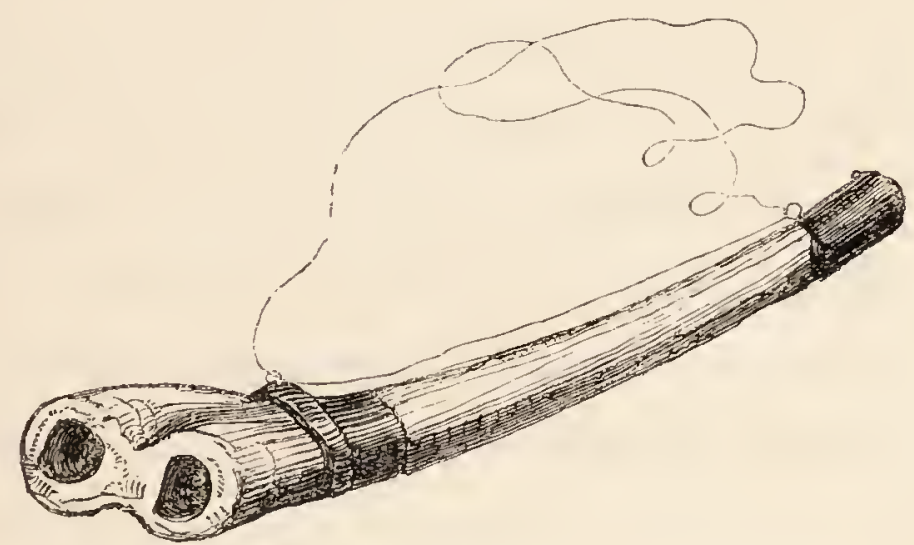

TRUMPET MADE OF A HUMAN THIGH-BONE.

most curious; it is very often that of a Lama, and is valuable in proportion to its length.* As, however, the Sikkim Lamas are burned, these relics are generally procured from Tibet, where the corpses are cut in pieces and thrown to the kites, or into the water.

'Two boys usually reside in the temple, and their beds were given up to us, which being only rough planks laid on the floor, proved clean in one sense, but contrasted badly with the springy couch of bamboo the Lepcha makes, which renders carrying a mattress $\mathrm{Or}^{*}$ aught but blankets superfluous.

* It is reported at Dorjiling, that one of the first Europeans buried at this station, being a tall man, was disinterred by the resurrectionist Bhoteas for his trumpet-bones. 
We were awakened at daylight by the discordant orisons of the Lama; these commenced by the boys beating the great tambourine, then blowing the conchshells, and finally the trumpets and thigh-bone. Shortly afterwards the Lama entered, clad in scarlet, shorn and barefooted, wearing a small red silk mitre, a loose gown girt round the middle, and an under-garment of questionable colour, possibly once purple. He walked along, slowly muttering his prayers, to the end of the apartment, whence he took a brass bell and dorge, and, sitting down cross-legged, commenced matins, counting his beads, ringing the bell, and uttering most dismal prayers. After various disposals of the cups, a larger bell was violently rung for some minutes, himself snapping his fingers and uttering most unearthly sounds. Finally, incense was brought, of charcoal with junipersprigs ; it was swung about, and concluded the morning service; to our great relief, for the noises were quite intolerable. Fervid as the devotions appeared, to judge by their intonation, I fear the Lama felt more curious about us than was proper under the circumstances; and when I tried to sketch him, his excitement knew no bounds; he fairly turned round on the settee, and, continuing his prayers and bell-accompaniment, appeared to be exorcising me, or some spirit within me.

After breakfast the Lama came to visit us, bringing rice, a few vegetables, and a large bamboo-work bowl, thickly varnished with india-rubber, and waterproof, containing half-fermented millet. This mixture, called Murwa, is invariably offered to the traveller, either in the state of fermented grain, or more commonly in a 
bamboo jug, filled up with warm water; when the fluid, sucked through a reed, affords a refreshing drink. He gratefully accepted a few rupees and trifles which we had to spare.

Leaving Simonbong, we descended to the Little Rumgeet, where the heat of the valley was very great; $80^{\circ}$ at noon, and that of the stream $69^{\circ}$; the latter was an agreeable temperature for the coolies, who plunged, teeming with perspiration, into the water, catching fish with their hands. We reached Dorjiling late in the evening, again drenched with rain; our people imprudently remaining for the night in the valley. Owing probably as much to the great exposure they had lately gone through, as to the sudden transition from a mean temperature of $50^{\circ}$ in a bracing wind, to a hot close jungly valley at $75^{\circ}$, no fewer than seven were laid up with fever and ague.

It is always interesting to roam with an aboriginal, and especially a mountain people, through their thinly inhabited valleys, over their grand mountains, and to dwell alone with them in their gloomy and forbidding forests; and no thinking man can do so without learning much, however slender be the means at his command for communion. A more interesting and attractive companion than the Lepcha I never lived with : cheerful, kind, and patient with a master to whom he is attached; rude but not savage, ignorant and yet intelligent; with the simple resource of a plain knife he makes his house and furnishes yours, with a speed, alacrity, and ingenuity that wile away that well-known long hour when the weary pilgrim frets for his couch. 
In all my dealings with these people, they proved scrupulously honest. Except for drunkenness and carelessness, I never had to complain of any of the merry troop; some of whom, bareheaded and barelegged, possessing little or nothing save a cotton garment and a long lnife, followed me for many months, from the scorching plains to the everlasting snows. Ever foremost in the forest or on the bleak mountain, and ever ready to help, to carry, to encamp, collect, or cook, they cheer on the traveller by their unostentatious zeal in his service, and are spurs to his progress.

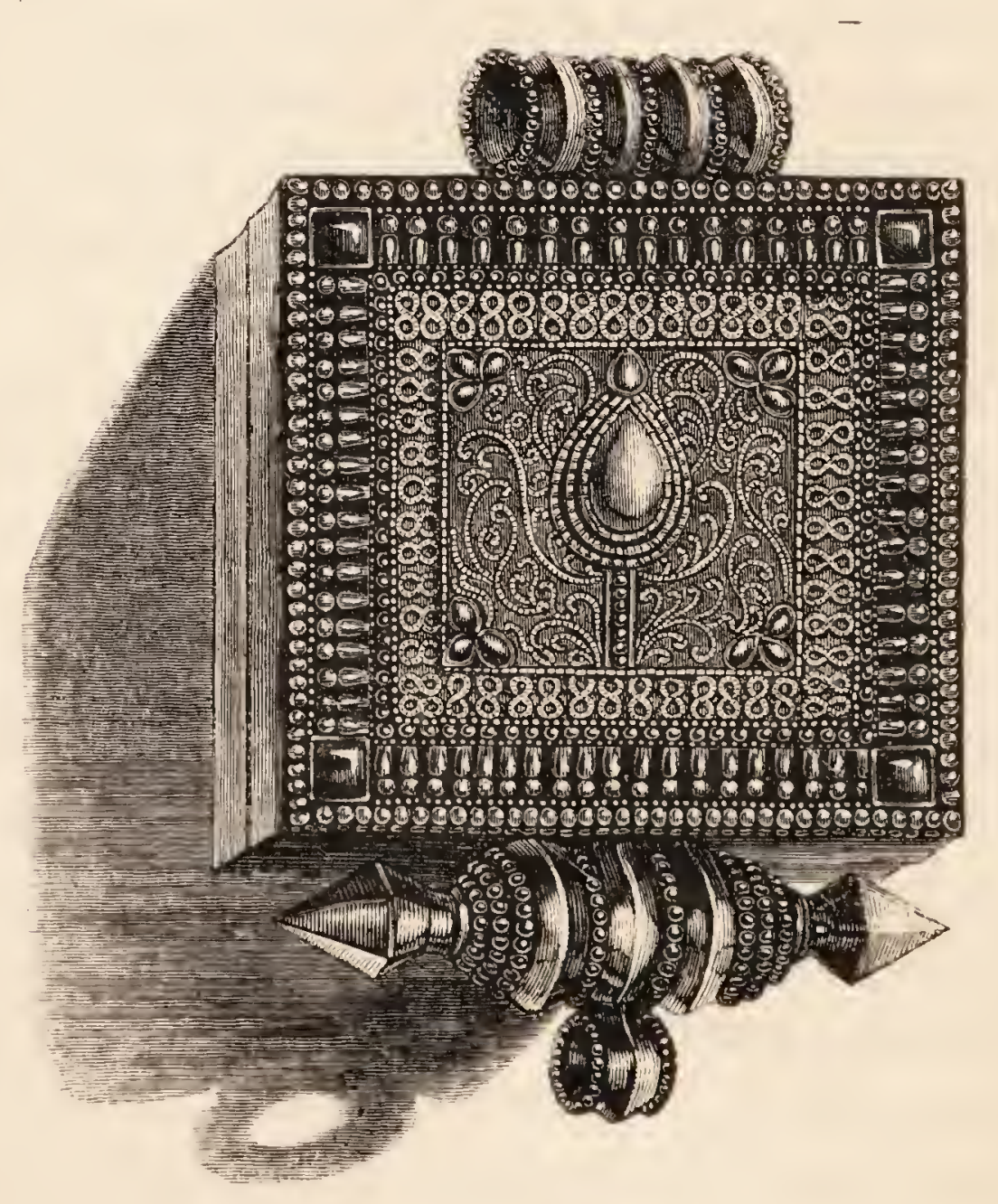

TIEETAN AMLLET. 


\section{CHAPTER VIII.}

Difficulty in procuring leave to enter Sikkim-Obtain permission to travel in East Nepal-Arrangements-Coolies-Stores-Servants-Personal equipment-Mode of travelling - Leave Dorjiling-Goong ridgeBehaviour of Bhotan coolies-Nepal frontier-Myong valley-IlamSikkim massacre-Cultivation-Nettles-Camp at Nanki on Tonglo - Bhotan coolies run away-View of Chumulari-Nepal peaksSakkiazung-Hornbills-Road to Wallanchoon-Searcity of waterSingular view of mountain-valleys-Encampment-My tent and its furniture-Evening occupations-Dunkotah-Cross ridge of Sakkiazung-Yews-Silver-firs-View of Tambur valley-Pemmi riverPebbly terraces-Holy springs-Enormous trees-Luculia gratissima - Khawa river-Arrive at Tambur-Shingle and gravel terracesNatives, indolence of-Canoe ferry-Votive offerings-Bad roadTemperature, \&c.-Chingtam village, view from-Mywn river and Guola-House-Boulders-Chain-bridge-Meepo, arrival of-Fevers.

Owna to the unsatisfactory nature of our relations with the Sikkim authorities, to which I have elsewhere alluded, my endeavours to procure leave to penetrate further beyond the Dorjiling territory than Tonglo, were attended with some trouble and delay.

In the autumn of 1848 , the Governor-General communicated with the Rajah, desiring him to grant me honourable and safe escort through his dominions; but this was at once met by a decided refusal, apparently admitting of no compromise. Pending further negociations, which Dr. Campbell felt sure would terminate 
satisfactorily, though perhaps too late for that season, he applied to the Nepal Rajah for permission for me to visit the Tibetan passes, west of Kinchinjunga; proposing in the meanwhile to arrange for my return through Sikkim. Through the kindness of Colonel Thoresby, the Resident at that Court, and the influence of Jung Bahadur, this request was promptly acceded to, and a guard of six Nepalese soldiers and two officers was sent to Dorjiling to conduct me to any part of the eastern districts of Nepal which I might select. I decided upon following up the Tambur, a branch of the Arun river, and exploring the two easternmost of the Nepalese passes into Tibet (Wallanchoon and Kanglachem), which would bring me as near to the central mass and loftiest part of the eastern flank of Kinchinjunga as possible.

For this expedition (which occupied three months), all the arrangements were undertaken for me by Dr. Campbell, who afforded me every facility which from his position he could command, besides personally superintending the equipment and provisioning of $\mathrm{my}$ party. Taking loaded animals of any kind was not expedient: the whole journey was to be performed on foot, and everything carried on men's backs. As we were to march through wholly unexplored countries, where food was only procurable at uncertain intervals, it was necessary to engage a large body of porters, some of whom should carry bags of rice for the coolies and for themselves too. The difficulty of selecting these carriers, of whom thirty were required, was very great. The Lepchas, the best and most tractable, and orer 
whom Dr. Campbell had the most direct influence, disliked employment out of Sikkim, especially in so warlike a country as Nepal: and they were besides thought unfit for the snowy regions. The Nepalese, of whom there were many residing as British subjects in Dorjiling, were mostly run-aways from their own country, and afraid of being claimed, should they return to it, by the lords of the soil. To employ Limboos, Moormis, Hindoos, or other natives of low elevations, was out of the question; and no course appeared advisable but to engage some of the Bhotan run-aways domiciled in Dorjiling, who are accustomed to travel at all elevations, and fear nothing but a return to the country which they have abandoned as slaves, or as culprits: they are immensely powerful, and though intractable to the last degree, will generally work and behave well for money. The choice, as will hereafter be seen, was unfortunate, though at the time unanimously approved.

My party mustered fifty-six persons, including myself, and one personal servant, a Portuguese halfcaste, who undertook all offices, and spared me the usual train of Hindoo and Mahometan servants. My tent and equipments (for which I was indebted to $\mathrm{Mr}$. Hodgson), instruments, bed, clothes, books and papers, required a man for each. Seven more carried my papers for drying plants, and other scientific stores. The Nepalese guard had two coolies of their own. My interpreter, the coolie Sirdar (or headman), and my chief plant collector (a Lepcha), had a man each. Mr. Hodgson's bird and animal shooter, collector, and VOL. I. 
stuffer, for their ammunition and indispensables, had four more; there were besides, three Lepcha lads to climb trees and change the plant-papers, who had long been in my service in that capacity; and the party was completed by fourteen Bhotan coolies laden with food, consisting chiefly of rice, with ghee, oil, capsicums, salt and flour.

I carried a small barometer, a large knife and digger for plants, note-book, telescope, compass, and other instruments; whilst two or three Lepcha lads accompanied me with a botanising box, thermometers, sextant and artificial horizon, measuring-tape, azimuth compass and stand, geological hammer, bottles and boxes for insects, sketch-book, \&c., arranged in compartments of strong canvas bags. The Nepal officer always kept near me with one of his men, rendering innumerable little services: the other sepoys were distributed amongst the remainder of the party; while one went ahead to prepare the camping-ground, and one brought up the rear.

The course generally pursued by Himalayan travellers is to march early in the morning, and arrive at the camping-ground before or by noon, breakfasting before starting or en route. I never followed this plan, because it sacrificed the mornings, which were profitably spent in collecting; whereas, if I set off early, I was generally too tired with the day's march to employ in any active pursuit the rest of the daylight, which in November only lasted till 6 P.M. The men breakfasted early in the morning, I somewhat later, and all had started by 10 A.M., arriving between 4 and 6 P.м. at the 
next camping-ground. My tent was formed of blankets, spread over cross pieces of wood and a ridge-pole, enclosing an area of 6 to 8 feet by 4 to 6 feet. The bedstead, table, and chair were always made by my Lepchas, in the manner described in the Tonglo excursion. The evenings I employed in writing up my notes and journals, plotting maps, and ticketing the plants collected during the day.

I left Dorjiling on the 27th October, accompanied by Dr. Campbell, who saw me fairly off, the coolies having preceded me. Our direct route would have been over Tonglo, but the threats of the Sikkim authorities rendered it advisable to make for Nepal at once; we therefore kept west along the Goong ridge, a western prolongation of Sinchul.

On overtaking the coolies, I proceeded for six or seven miles along a zig-zag road, at about 7,500 feet elevation, through dense forests, and halted at a little hut within sight of Dorjiling. Rain and mist came on at nightfall, and though several parties of my servants arrived, none of the Bhotan coolies made their appearance, and I spent the night without food or bed, the weather being too foggy and dark to send back to meet them. They joined me late on the following day, complaining unreasonably of their loads, and without their Sirdar, who, after starting his crew, had returned to take leave of his wife and family. On the following day he appeared, and after due admonishment we started, but four miles further on were again obliged to halt for the coolies, who were equally deaf to threats and entreaties. As they did not come up till dusk, we 
were obliged to encamp at the common source of the Balasun, which flows to the plains, and the Little Rungeet, whose course is northwards.

The contrast between the conduct of the Bhotan men and that of the Lepchas and Nepalese was so marked, that I seriously debated the propriety of sending the former back to Dorjiling, but yielded to the remonstrances of their Sirdar and the Nepal guard, who represented the great difficulty I should have in replacing them, and above all, the loss of time, at this season a matter of great importance. I accordingly started again the following morning, and still keeping in a westerly direction, descended into the Myong valley in Nepal, through which flows a river of the same name, a tributary of the Tambur. This valley is remarkably fine: it runs south-west from Tonglo, and its open character and general fertility contrast strongly with the bareness of the lower mountain spurs which flank it, and with the dense, gloomy, steep, and forestclad gorges of Sikkim. At its lower end, about twenty miles from the frontier, is the military fort of Ilam, a celebrated stockaded post of the Ghorkas: its position is marked by a conspicuous conical hill. The inhabitants are chiefly Brahmins, but there are also some Moormis, and a few Lepchas who escaped from Sikkim during the general massacre in 1825. Among these is a man who had formerly much influence in Sikkim; he still retains his title of Kazee, ${ }^{*}$ and has had large lands assigned to him by the Nepalese Government: he sent

* This Mahometan title, by which the officers of state are kuown in Sikkim, is there generally pronounced Kajee. 
me the usual present of a kid, fowls, and eggs, and begged me to express to Dr. Campbell his desire to settle at Dorjiling.

The scenery of this valley is the most beautiful I know of in the lower Himalaya, and the Cheer Pine (P. longifolia) is abundant, cresting the hills, which are loosely clothed with clumps of oaks and other trees, bamboos, and common English bracken. The spurs separate little ravines luxuriantly clothed with tropical vegetation, through which flow pebbly streams of transparent water. The villages, which are merely scattered collections of huts, are surrounded with fields of rice, buckwheat, and Indian corn, which latter the natives were now storing in little granaries, mounted on four posts; men, women, and children being all equally busy. The quantity of gigantic nettles (Urtica heterophylla) on the skirts of the maize fields is quite wonderful : their long white stings look most formidable, but though they sting virulently, the pain only lasts half an hour or so. These, however, with leeches, mosquitos, peepsas, and ticks, sometimes keep the traveller in a constant state of irritation.

However civilised the Hindoo may be in comparison with the Lepcha, he presents a far less attractive picture; he comes to your camping-ground, sits down, and stares, but offers no assistance; if he brings a present he expects a return on the spot, and goes on begging till satisfied. I was amused by the cool way in which my Ghorka guard treated the village lads, when they wanted help, taking them by the shoulder, pulling out their knives for them, placing them in their 
hands, and setting them to cut down a tree, or to chop firewood, which they seldom refused to do, when a little such douce violence was applied.

My object being to reach the Tambur, north of the great east and west mountain ridge of Sakkiazung, without crossing the innumerable feeders of the Myong and their dividing spurs, I ascended the north flank of the valley to a long spur from Tonglo, intending to follow winding ridges of that mountain to the sources of the Pemmi at the Phulloot mountains, and thence descend.

On the 3rd November, I encamped on the flank of Tonglo (called Nanki in Nepal), about 700 feet below the western summit, which is rocky, and connected by a long flat ridge with that which I had visited in the previous May. The Bhotan coolies behaved worse than ever; their conduct being in all respects typical of the turbulent, mulish race to which they belong. They had been plundering my provisions as they came along, and neither their Sirdar nor the Ghorka soldiers had the smallest authority over them. I had hired some Ghorka coolies to assist and eventually to replace them, and had made up my mind to send back the worst from the more populous banks of the Tambur, when I was relieved by their making off of their own accord. The dilemma was however awkward, as it was impossible to procure men on the top of a mountain 10,000 feet high. No course remained but to send to Dorjiling for others, or to return to the Myong valley, and take a more circuitous route over the west end of Sakkiazung, which led through villages from which I 
could procure coolies day by day. I preferred the latter plan, and sent one of the soldiers to the nearest village for assistance to bring the loads down, halting a day for that purpose.

From the summit of Tonglo I enjoyed the view I had so long desired of the Snowy Himalaya; Sikkim being on the right, Nepal on the left, and the plains of India to the southward; and I procured a set of compass bearings, of the greatest use in mapping the country. In the early morning the transparency of the atmosphere rendered this view one of astonishing grandeur. Kinchinjunga bore nearly due north, a dazzling mass of snowy peaks, intersected by blue glaciers, which gleamed in the slanting rays of the rising sun, like aquamarines set in frosted silver. From this the sweep of snowed mountains to the eastward was almost continuous as far as Chola, following a curve of 150 miles, and enclosing the whole of the northern part of Sikkim, which appeared a billowy mass of forest-clad mountains. On the north-east horizon rose Donkia (23,176 feet), and Chumulari (23,929). Though both were much more distant than the snowy ranges, being respectively eighty and ninety miles off, they raised their gigantic heads above them, seeming what they really are, by far the loftiest peaks next to Kinchinjunga; and the perspective of snow is so deceptive, that though from forty to sixty miles beyond, they appeared as though in the same line with the ridges they overtopped. Of these mountains, Chumulari presents many attractions to the geographer, from its long disputed position, its sacred character, and the interest 
attached to it since Turner's mission to Tibet in 1783. It was seen and recognised by Dr. Campbell, and measured by Colonel Waugh, from Sinchul, and also from Tonglo, and was a conspicuous object in my subsequent journey to Tibet. Beyond Junnoo, one of the western peaks of Kinchinjunga, there was no continuous snowy chain; the Himalaya seemed suddenly to decline into black and rugged peaks, till in the far north-west it rose again in a white mountain mass of stupendous elevation at eighty miles distance, called, by my Nepal people, "Tsungau." From the bearings I took of it from several positions, this is probably on the west flank of the Arun valley and river, which latter, in its course from Tibet to the plains of India, receives the waters from the west flank of Kinchinjunga, and from the east flank of the mountain in question. It is perhaps one which has been seen and measured from the Tirhoot district by some of Colonel Waugh's party, and which has been reported as being upwards of 28,000 feet in elevation; and it is the only mountain of the first class in magnitude between Gosainthan (north-east of Katmandoo) and Kinchinjunga.

To the west, the black ridge of Sakkiazung, bristling: with silver-firs, cut off the view of Nepal; but southwest, the Myong valley could be traced to its junction with the Tambur about thirty miles off: beyond which to the south-west low hills rose on the distant horizon, seventy or eighty miles off; and of these the most conspicuous were the Mahavarati, which skirt the Nepal Terai. South and south-east, Sinchul and the Goong range intercepted the view of the plains of 
India, of which I had a distant peep to the southwest only.

A few of the Bhotan coolies having returned, I left Tonglo on the 5th, and proceeded to the Mai, a feeder of the Myong. The descent was as abrupt as that of the east face, but through less dense forest; the Sikkim side being much the dampest. I encamped at dark near a small village (Jummanoo), at 4,360 feet, having descended 5000 feet in five hours. Hence I marched eastward to the village of Sakkiazung, which I reached on the third day.

Though rich and fertile, the country is scantily populated, and I had much difficulty in procuring coolies: I therefore sent back to Dorjiling all but indispensables, and on the 9th of November started up the ridge in a northerly direction, taking the road from Ilam to Wallanchoon. The ascent was gradual, through a fine forest, full of horn-bills (Buceros), a bird resembling the Toucan. Water is very scarce along the ridge; we walked fully eight miles without finding any, and were at length obliged to encamp at 8,350 feet by the only spring that we should be able to reach. With respect to drought, this ridge differs materially from those of Sikkim, where water abounds at all elevations; and the cause is obviously its position to the westward of the great ridge of Singalelah (including Tonglo) by which the S.W. currents are drained of their moisture. Here again, the east flank was much the dampest and most luxuriantly wooded.

While my men were forming their encampment, I ascended a rocky summit, from which I obtained a 
superb view to the westward. Immediately beneath a fearfully sudden descent, ran the Daomy River, bounded on the opposite side by another parallel ridge of Sakkiazung, enclosing, with that on which I stood, a gulf from 6000 to 7000 feet deep, of wooded ridges, which, as it were, radiated outwards in rocky spurs to the fir-clad peaks around. To the south-west, in the extreme distance, were the plains of India, upwards of 100 miles off, with the Cosi meandering through them like a silver thread.

The firmament appeared of a pale steel blue, and a broad low arch spanned the horizon, bounded by a line of little fleecy clouds; below this the sky was of a golden yellow, while in successively deeper strata, many belts or ribbons of vapour appeared to press upon the plains, the lowest of which was of a dark leaden hue, the upper more purple, and vanishing into the pale yellow above. Gradually the golden lines grew dim, and the blues and purples gained depth of colour; till the sun set behind the dark-blue peaked mountains in a flood of crimson and purple, sending broad beams of gray shade and purple light up to the zenith, and all around. As evening advanced, mists rapidly formed below me in little isolated clouds, which coalesced and spread out like a heaving sea, leaving nothing above their surface but the ridges and spurs of the adjacent mountains. These rose like capes, promontories, and islands, of the darkest leaden hue, bristling with pines, and advancing boldly into the snowy ocean, or starting from its bed in the strongest relief. As darkness came on, and the stars arose, a 
light fog gathered round me, and I quitted with reluctance one of the most impressive and magic scenes I had ever beheld.

Returning to my tent, I was interested in observing how well my followers accommodated themselves to their narrow circumstances. Their fires gleamed everywhere amongst the trees, and the people presented an interesting picture of native, savage, and half-civilised life. I wandered amongst them in the darkness, and watched their operations; some were cooking, with their rude bronzed faces lighted up by the ruddy glow, as they peered into the pot, stirring the boiling rice with one hand, while with the other they held back their long tangled hair. Others were bringing water from the spring below, some gathering sprigs of fragrant worm-wood and other shrubs to form couches-some lopping branches of larger trees to screen them from nocturnal radiation; their only protection from the dew being such branches stuck in the ground, and slanting over their recumbent forms. The Bhotanese were rude and boisterous in their pursuits, constantly complaining to the Sirdars, and wrangling over their meals. The Ghorkas were sprightly, combing their raven hair, telling interminably long stories, or singing Hindoo songs through their noses in chorus; and being neater and better dressed, and having a servant to cook their food, they seemed quite the gentlemen of the party. Still the Lepcha was the most attractive, the least restrained, and the most natural in all his actions, the simplest in his wants and appliances, with a bamboo as his water-jug, 
an earthen pot as his kettle, and all manner of herbs collected during the day's march to flavour his food.

My tent was made of a blanket thrown over the limb of a tree; to this others were attached, and the whole was supported on a frame like a house. One half was occupied by my bedstead, beneath which was stowed my box of clothes, while my books and writing materials were placed under the table. The barometer hung in the most out-of-the-way corner, and my other instruments all around. A small candle was burning in a glass shade, to keep the light from draught and insects, and I had the comfort of seeing the knife, fork, and spoon laid on a white napkin, as I entered my snug little house, and flung myself on the elastic couch to ruminate on the proceedings of the day, and speculate on those of the morrow, while waiting for my meal, which usually consisted of stewed meat and rice, with biscuits and tea. My thermometers (wet and dry bulb, and minimum) hung under a temporary canopy made of thickly plaited bamboo leaves close to the tent, and the cooking was performed by my servant under a tree.

After dinner my occupations were to ticket and put away the plants collected during the day, write my journal, plot maps, and take observations till 10 P.M. As soon as I was in bed, one of the Nepal soldiers was accustomed to enter, spread his blanket on the ground, and sleep there as my guard. In the morning the collectors were set to change the plant-papers, while I explored the neighbourhood, and having taken observations and breakfasted, we were ready to start at 10 A.M. 
Following the same ridge, after a few miles of ascent over much broken gneiss rock, the Ghorkas led me aside to the top of a knoll, 9,300 feet high, covered with stunted bushes, and commanding a splendid view to the west, of the broad, low, well cultivated valley of the Tambur, and the extensive town of Dunkotah on its banks, about twenty-five miles off; the capital of this part of Nepal, and famous for its manufactory of paper from the bark of the Daphne. Here too I gained a fine view of the plains of India, including the course of the Cosi river, which, receiving the Arun and Tambur, debouches into the Ganges opposite Colgong.

A little further on I crossed the main ridge of Sakkiazung, a chain stretching for miles to the westward from Phulloot on Singalelah, and forming the most elevated and conspicuous transverse range in this part of Nepal. Silver firs (Abies Webbiana) are found on all the summits; but to my regret none occurred in our path, which led just below their limit (10,000 feet): there were, however, a few yews, exactly like the English. The view that opened on cresting this range was again magnificent, of Kinchinjunga, the western snows of Nepal, and the valley of the Tambur, winding amongst wooded and cultivated hills to a long line of blackpeaked, rugged mountains, sparingly snowed, which intervene between Kinchinjunga and the great Nepal mountain before mentioned. For fully forty miles to the northward there were no lofty forest-clad mountains: villages appeared everywhere, with crops of golden mustard and purple buckwheat in full flower; yellow rice and maize, green hemp, pulse, radishes, 
barley, and brown millet. Here and there deep groves of oranges, the broad-leafed banana, and sugar-cane, skirted the bottoms of the valleys, through which the streams rushed in white foam over their rocky beds. Kinchinjunga was the most prominent object to the north-east, with its sister peaks of Kubra (24,005 feet), and Junnoo (25,312 feet). All these presented bare cliffs for several thousand feet below their summits, composed of white rock with a faint pink tint:-on the other hand the cliffs of the lofty Nepal mountain in the far west were all black. From the summit two routes to the Tambur presented themselves; one, the main road, led west and south along the ridge, and then turned north, descending to the river; the other was shorter, leading down to the Pemmi river, and thence along its banks, west to the Tambur. I chose the latter.

The descent was very abrupt to the bed of the Pemmi, 2000 feet; and the path was infamously bad, generally narrow, winding, and rocky, leading among tangled shrubs and large boulders, brambles, nettles, and thorny bushes, often in the bed of the torrent, or crossing spurs covered with forest. A little cultivation was occasionally met with on the narrow flat pebbly terraces which fringed the stream, usually of rice, and sometimes of the small-leaved variety of hemp grown as a narcotic.

In one little rocky dell the water gushed through a hole in a soft stratum in the gneiss; a trifling circumstance which was not lost upon the crafty Brahmins, who had cut a series of regular holes for the water, ornamented the rocks with red paint, and a row of 
little iron tridents of Siva, and dedicated the whole to Mahadeo.

In some spots the vegetation was exceedingly fine, and several large trees occurred: I measured a Toon (Cedrela) thirty feet in girth at five feet above the ground. The skirts of the forest were adorned with numerous jungle flowers, rice crops, wild cherry-trees covered with scarlet blossoms, and trees of the purple and lilac Banhinia; while Thunbergia, Convolvulus, and other climbers, hung in graceful festoons from the boughs, and on the dry micaceous rocks the Luculia gratissima, one of our choice hot-house ornaments, grew in profusion, its gorgeous heads of blossoms scenting the air.

At the junction of the Pemmi and Khawa rivers, elevated 2250 feet, appeared many trees and plants of the Terai and plains, as pomegranate, peepul, and sal; with extensive fields of cotton, indigo, and irrigated rice.

We followed the north bank of the Khawa, westerly, through a gorge between high cliffs, and reached the east bank of the Tambur, on the 13th of November, at its junction with the Khawa. It formed a grand stream, larger than the Teesta, of a pale, sea-green, muddy colour, and flowed rapidly with a strong ripple, but no foam; it rises six feet in the rains, but ice never descends nearly so low; its breadth was sixty to eighty yards, and that of the foaming Khawa twelve to fifteen yards. I camped at the fork of the rivers, on a fine terrace fifty feet above the water, about serenty yards long, and one hundred broad, quite flat-topped, and composed of shingle, gravel, \&c., with enormous 
water-worn boulders; it was girt by another broken terrace, twelve feet or so above the water, and covered with long grass and bushes.

The main road from Ilam to Wallanchoon, which I quitted on Sakkiazung, descends steeply on the opposite bank of the river: there is considerable traffic along it; and I was visited by numbers of natives, all Hindoos, who coolly squatted before my tent door, and stared with their large black, vacant, lustrous eyes; they appeared singularly indolent, and great beggars.

The land seems highly favoured by nature, and the population, though so scattered, is, in reality, considerable, the varied elevation giving a large surface; but the natives care for no more than will satisfy their immediate wants. The river swarms with fish, but they are too lazy to catch them, and they have seldom anything better to give or sell than sticks of sugarcane, which when peeled form a refreshing morsel in these scorching marches. They have few and poor oranges, citrons, and lemons, very bad plantains, and but little else;--eggs, fowls, and milk are all scarce. Horned cattle are of course never killed by Hindoos, and it was but seldom that I could replenish my larder with a kid. Potatos are unknown, but my Sepoys often brought me large coarse radishes and legumes.

From the junction of the river's the road led up the Tambur to Mywa Guola; about sixteen miles by the river, but fully thirty-five as we wound, ascended, and descended, during three days' marches. We were ferried across the stream in a canoe formed of a hollow trunk of Toon thirty feet long, and much ruder than 
that of the New Zealander. I watched my party crossing by boat-loads of fifteen each; the Bhotan men hung little scraps of rags on the bushes before embarking, - the votive offerings of a Boodhist throughout central Asia; - the Lepcha, less civilised, scooped up a little water in the palm of his hand, and scattered it about, invoking the river god of his simple creed.

We always encamped upon gravelly terraces a few feet above the river; its banks were very steep for 600 feet above the stream, though the mountains which flanked it did not exceed 4000 to 5000 feet: this is a constant phenomenon in the Himalaya, and the paths, when within a few hundred feet of the rivers, are in consequence excessively steep and difficult; it would have been impossible to have talien ponies along that we followed, which was often not a foot broad, running along very steep cliffs, at a dizzy height above the river, and engineered with much ingenuity: often the bank was abandoned altogether, and we ascended several thousand feet to descend again. Owing to the steepness of these banks, and the reflected heat, the valley, even at this season, was excessively hot and close during the day, even when the temperature was below $70^{\circ}$, and tempered by a brisk breeze which rushes upwards from sunrise to sunset. The sun's rays at this season do not, in many places, reach the bottom of these valleys until 10 A.Mr., and are withdrawn by 3 P.Mr. ; and the radiation to a clear sky is so powerful that dew frequently forms in the shade, throughout the day, and it is common at 10 A.xr. to find the thermometer sink from $70^{\circ}$ in a spot dried by the sun, to $40^{\circ}$ in the shade 
close by, where the sun has not yet penetrated. Snow never falls.

In one place the road ascended for 2000 feet above the river, to the village of Chingtam, situated on a lofty spur of the west bank, whence I obtained a grand view of the upper course of the river, flowing in a tremendous chasm, flanked by well-cultivated hills, and emerging fifteen miles to the northward, from black mountains of savage grandeur, whose precipitous faces were streaked with snow, and the tops of the lower ones crowned with the tabular-branched silver-fir, contrasting strongly with the tropical luxuriance around. Chingtam is an extensive village, covering an area of two miles, and surrounded with abundant cultivation; the houses, which are built in clusters, are of wood, or wattle and mud, with grass thatch. The villagers, though an indolent, staring race, are quiet and respectable; the men are handsome, the women, though less so, often good-looking. They have fine cattle, and excellent crops.

Immediately above Chingtam, the Tambur is joined by a large affluent from the west, the Mywa, which is here crossed by an excellent iron bridge, formed of loops hanging from two chains, along which is laid a plank of sal timber. Passing through the village, we camped on a broad terrace, from sixty to seventy feet above the junction of the rivers.

Mywa Guola (or bazaar) is a large village frequented by Nepalese and Tibetans, who bring salt, wool, gold, musk, and blankets, to exchange for rice, coral, and other commodities; and a custom-house officer is 
stationed there, with a few soldiers. The houses are of wood, and well built: the public ones are large, with verandahs, and galleries of carved wood; the workmanship is of Chinese character, and inferior to that of Katmandoo; but in the same style, and unlike anything I liad previously seen.

The river-terrace is similar to that at the junction of the Tambur and Khawa, but very extensive: the stones it contained were of all sizes, from that of a nut to huge boulders upwards of fifteen feet long, of which many strewed the surface, while others were in the bed of the river.

I was here overtaken by a messenger with letters from Dr. Campbell, announcing that the Sikkim Rajah had disavowed the refusal to the Governor-General's letter, and had authorised me to return through any part of Sikkim I thought proper. The bearer was a Lepcha attached to the court: his dress was that of a superior person, being a scarlet jacket over a white cotton dress, the breadth of the blue stripes of which generally denotes wealth; he was accompanied by a sort of attaché, who wore a magnificent pearl and gold ear-ring, and carried his master's bow, as well as a basket on his back; while an attendant coolie bore their utensils and food. Meepo, or Teshoo (in Tibetan, Mr.) Meepo, as he was usually called, soon attached himself to me, and proved an active, useful, and intelligent companion, guide, and often collector, during many months afterwards.

The vegetation round Mywa Guola is thoroughly tropical : the banyan is planted, and thrives tolerably, 
the heat being great during the day. Like the whole of the Tambur valley below 4000 feet, and especially on these flats, the climate is very malarious before and after the rains; and I was repeatedly applied to by natives suffering under attacks of fever.

As it was doubtful if we should be able to procure food further on, I laid in a full stock here, and distributed blankets, \&c., sufficient for temporary use for all the people, dividing them into groups or messes.

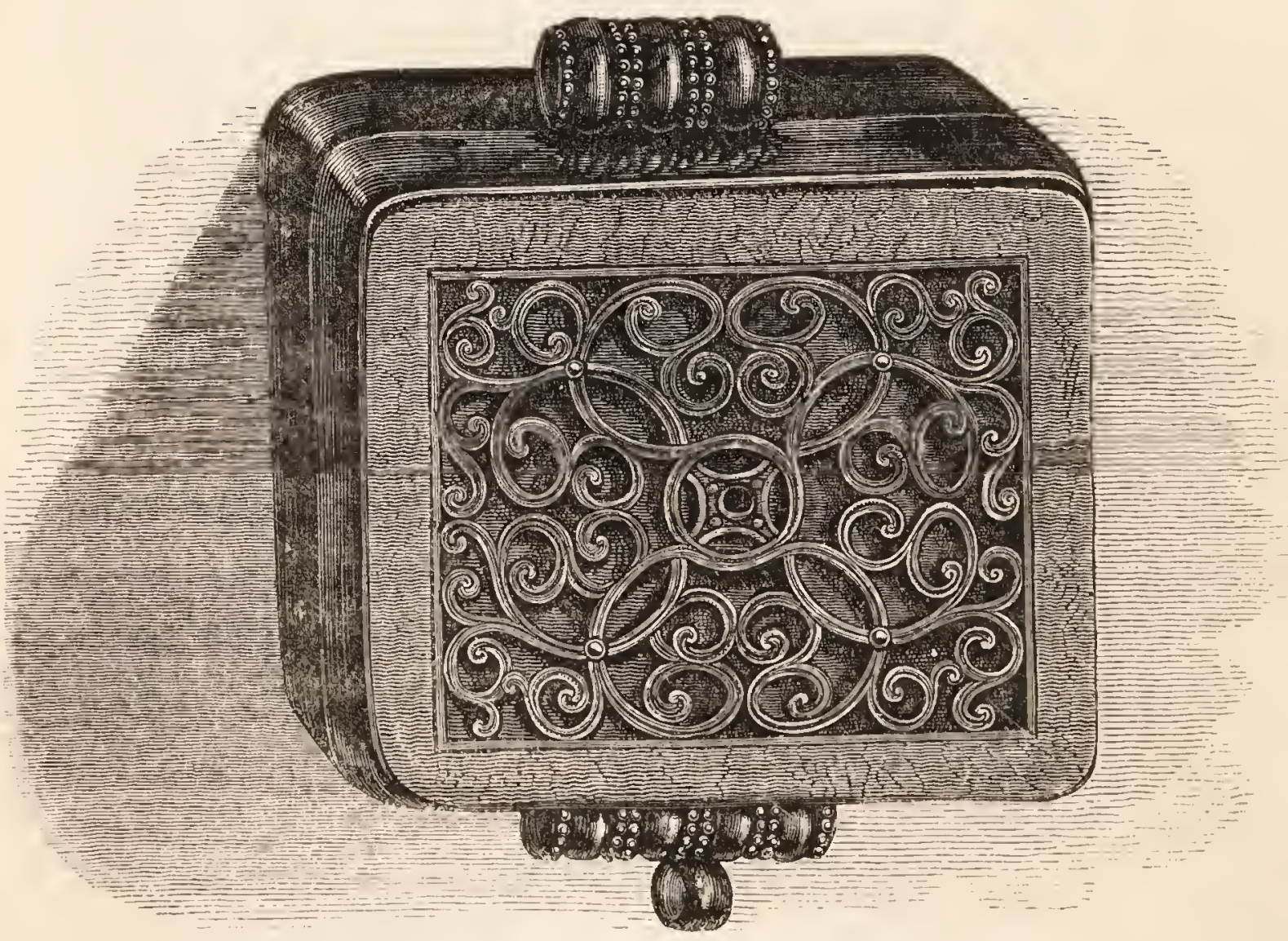

TIBETAN CHARM-BOX. 


\section{CHAPTER IX.}

Leave Mywa - Suspension bridge-Landslips-Vegetation-Bees' nestsGlacial phenomena-Tibetans, clothing, ornaments, amulets, salutation, children, dogs-Last Limboo village, Taptiatok-Beantiful scenery-Tibet village of Lelyp-Edgeworthia-Crab-apple-Chameleon and porcupine-Praying machine-Abies BrunonianaEuropean plants-Grand scenery-Arrive at Wallanchoon-Scenery around-Trees-Tibet houses-Manis and Mendongs-Tibet household-Food-Tea-soup-Hospitality-Yaks and Zobo, uses and habits of-Bhoteas-Yak-hair tents - Guobah of Walloong-Jhatamansi-. Obstacles to proceeding-Climate and weather-Proceed-Rhododendrons, \&c. - Lichens-Poa annua and Shepherd's purse-Tibet camp -Tuquoroma-Scenery of pass-Glaciers and snow-Summit-Plants, woolly, \&c.

On the 18th November, I left Mywa Guola, and continued up the river to the village of Wallanchoon or Walloong, which was reached in six marches. The snowy peak of Junnoo forms a magnificent feature from this point, seen up the narrow gorge of the river, bearing N.N.E. about thirty miles. I crossed the Mewa, an affluent from the north, by another excellent suspension bridge. In these bridges, the principal chains are clamped to rocks on either shore, and the suspended loops occur at intervals of eight to ten feet; the single sal-plank laid on these loops swings terrifically, and the handrails not being four feet high, the sense of insecurity is very great. 
The Wallanchoon path follows the west bank, but the bridge above having been carried away, we crossed by a plank, and proceeded along very steep banks of decomposed schist, affording an insecure footing, especially where great landslips had occurred. The lateral streams (of a muddy opal green) had cut beds 200 feet deep in the soft earth, and were very troublesome to cross, from the crumbling cliffs on either side, and their broad swampy channels.

Five or six miles above Mywa, the valley contracts much, and the Tambur becomes a turbulent river, shooting along its course with immense velocity, torn into foam as it lashes the spurs of rock that flank it, and the enormous boulders with which its bed is strewn. From this elevation to 9000 feet, its sinuous track extends about thirty miles, which gives a fall of 200 feet to the mile, quadruple of what it is for the lower part of its course. So long as its bed is below 5000 feet, a tropical vegetation prevails, but the steep mountain sides above are either bare and grassy, or cliffs with scattered shrubs and trees, their summits bristling with pines: those faces exposed to the south and east are invariably the driest and most grassy; while the opposite are well wooded.

In the contracted parts of the valley, the mountains often dip to the river-bed in precipices, under the ledges of which wild bees build pendulous nests, looking like huge bats suspended by their wings; they are two or three feet long, and as broad at the top, whence they taper downwards: the honey is much sought for, except in spring, when it is said to be poisoned by 
Rhododendron flowers, just as that, eaten by the soldiers in the retreat of the Ten Thousand, was by the flowers of the $R$. ponticum.

Above these gorges are enormous accumulations of rocks, especially at the confluence of lateral valleys, where they rest upon little flats, like the river-terraces of Mywa: some of these boulders were thirty or forty yards across, and split as if they had fallen from a height; the path passing between the fragments; they are probably due to ancient glacial action, especially when laden with such enormous blocks as are probably ice-transported.

A change in the population accompanies that in the natural features of the country, Tibetans replacing the Nepalese who inhabit the lower region. I daily passed parties of ten or a dozen Tibetans, on their way to Mywa Guola, laden with salt; several families of these wild, black, and uncouth-looking people generally travelling together. The men were middlesized or small, very square-built and muscular; they had no beard, moustache, or whiskers, the few hairs on their faces being carefully removed with tweezers. They were dressed in loose blanket robes, girt about the waist with a leather belt, in which they placed their iron or brass pipes, and from which they suspended their long knives, chop-sticks, tobacco-pouch, tweezers, tinder-box, \&c. The robe, boots, and cap were gray, or striped with bright colours, and they wore skull-caps, and the hair plaited into a pig-tail.

The women were dressed in long flannel petticoats and spencer, over which was thrown a sleeveless, short, 
striped cloak, drawn round the waist by a girdle of broad brass or silver links, to which hung their knives, scissors, needle-cases, \&c., and with which they often strapped their children to their backs; the hair was plaited in two tails, and the neck loaded with coral and glass beads, and great lumps of amber, glass, and agate. Both sexes wore silver rings and ear-rings, set with turquoises, and square amulets upon their necks and arms, which were boxes of gold or silver, containing small idols, or the nail-parings, teeth, or other reliques of some sainted Lama, accompanied with musk, written prayers, and charms. All were good-humoured and amiable-looking people, very square and Mongolian in countenance, with broad mouths, high cheek-bones, narrow, upturned eyes, broad, flat noses, and low foreheads. White is their natural colour, and rosy cheeks are common amongst the younger women and children, but all are begrimed with filth and smoke; added to which, they become so weather-worn from exposure to the most rigorous climate in the world, that their natural hues are rarely to be recognised. Their customary mode of saluting one another is to loll out the tongue, grin, nod, and scratch their ear; but this method entails so much ridicule in the low countries, that they do not practise it to Nepalese or strangers; most of them when meeting me, raised their hands to their eyes, threw themselves on the ground, and kotowed most decorously, bumping their foreheads three times on the ground; even the women did this on several occasions. On rising, they begged for a bucksheesh, which I gave in tobacco or snuff, of 
which they are immoderately fond. Both men and women constantly spin wool as they travel.

These groups of Tibetans are singularly picturesque, from the variety in their parti-coloured dresses, and their odd appearance. First comes a middle-aged man or woman, driving a little silky black yak, grunting under his load of $260 \mathrm{lbs}$. of salt, besides pots, pans, and kettles, stools, churn, and bamboo vessels, keeping up a constant rattle; and perhaps, buried amongst all, a rosy-cheeked and lipped baby, sucking a lump of cheese-curd. The main body follow in due order, and you are soon entangled amidst sheep and goats, each with its two little bags of salt: beside these stallss the huge, grave, bull-headed mastiff, loaded like the rest, his glorious bushy tail thrown over his back in a majestic sweep, and a thick collar of scarlet wool round his neck and shoulders, setting off his long sillky coat to the best advantage; he is decidedly the noblest looking of the party, especially if a fine and pure black one, for they are often very ragged, dun-coloured, sorry beasts. He seems rather out of place, neither guarding nor keeping the party together, but he knows that neither yaks, sheep, nor goats, require his attention; all are perfectly tame, so he takes his share of work as salt-carrier by day, and watches by night as well. The children bring up the rear, laughing and chatting together; they, too, have their loads, even to the youngest that can walk alone.

The last village of the Limboos, Taptiatok, is large, and occupies a remarkable amphitheatre, apparently a lake-bed, in the course of the Tambur. After proceeding 
some way through a narrow gorge, along which the river foamed and roared, the sudden opening out of this broad, oral expanse, more than a mile long, was very striking: the mountains rose bare and steep, the west flank terminating in shivered masses of rock, while that on the right was more undulating, dry, and grassy: the surface was a flat gravel-bed, through which meandered the rippling stream, fringed with alder. It was a beautiful spot, the clear, cool, murmuring river, with its rapids and shallows, forcibly reminding me of a tront-stream in the highlands of Scotland.

Beyond 'Taptiatok we again crossed the river, and ascended over dry, grassy, or rocky spurs to Lelyp, the first Bhotea village; it stands on a hill fully 1000 feet above the river, and commands a splendid view up the Yalloong and Kambachen valleys, which open immediately to the east, and appear as stupendous chasms in the mountains leading to the perpetual snows of Kinchin-junga. There were about fifty houses in the village, of wood and thatch, neatly fenced in with wattle, the ground being carefully cultivated with radishes, buckwheat, wheat, and millet. A Lama, the head-man of the place, came out to greet us, with his family and a whole troop of villagers; none had ever before seen an Englishman, and I fear they formed no flattering opinion of the specimen now presented to them, as they seemed infinitely amused at my appearance, and one jolly dame clapped her hands to her sicles, and laughed at my spectacles, till the hills echoed. 
Elcagnus was common here, with Edgeworthia Gardneri,* a beautiful shrub, with globes of waxy, cowslipcoloured, deliciously scented flowers; also a wild apple, which bears a small austere fruit, like the Siberian crab. In the bed of the river rice was still cultivated, and sub-tropical plants continued. I saw, too, a chameleon and a porcupine, indicating much warmth, and seeming quite foreign to the heart of these stupendous mountains. From 6000 to 7000 feet, plants of the temperate regions blend with the tropical; such as rhododendron, oak, ivy, geranium, berberry, and clematis, which all made their appearance at Loongtoong, another Bhotea village. Here, too, I first saw a praying-machine turned by water; it was enclosed in a little wooden house, and consisted of an upright cylinder containing a prayer, and with the words, "Om Mani Padmi om," (Hail to him of the Lotus and Jewel) painted on the circumference: it was placed over a stream, and made to rotate on its axis by a spindle which passed through the floor of the building into the water, where it was terminated by a wheel.

Above this the road followed the west bank of the river; the latter was a furious torrent, fringed with a sombre vegetation, dripping with moisture, and covered with long pendulous lichen, and mosses. The road was very rocky and difficult, sometimes leading along bluff faces of cliffs by wooden steps, and single rotten planks. At 8000 feet I met with Firs, whose trunks I had seen strewing the river for some miles lower down : the first that occurred was Abies Brunoniana,

* A kind of Daphne, from whose bark the Nepal paper is manufactured. 
a beautiful species, which forms a stately pyramid, with branches spreading like the cedar, and drooping gracefully on all sides. It is unknown on the outer ranges of Sikkim, and in the interior occupies a belt about 1000 feet lower than the silver fir. Many subalpine plants occur here, as rose, thistles, alder, birch, ferms, berberry, holly, anemone, strawberry, raspberry, the alpine bamboo, and oaks. The scenery is as grand as any pictured by Salvator Rosa; a river roaring in sheets of foam, sombre woods, crags of gneiss, and tier upon tier of lofty mountains flanked and crested with groves of black firs, terminating in snow-sprinkled rocky peaks.

I now found the temperature getting rapidly cooler, both that of the air, which here at 8,066 feet fell to $32^{\circ}$ in the night, and that of the river, which was always below $40^{\circ}$. It was in these narrow valleys only, that $I$ observed the return cold current rushing down the river-courses during the nights, which were usually brilliant and very cold, with copious dew: so powerful, indeed, was the radiation, that the upper blanket of my bed became coated with moisture, from the rapid abstraction of heat by the frozen tarpaulin of my tent.

I arrived at the village of Walloong, or Wallanchoon, on the 23rd of November. Its situation is fine and open, the Tambur valley there differing from any part lower' down in all its natural features; being broad, with a rapid but not turbulent stream, very grassy, and both the base and sides of the flanking mountains covered with luxuriant dense bushes of rhododendron, rose, berberry, and juniper. There was but little snow on the 


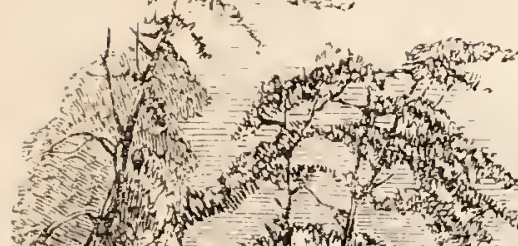

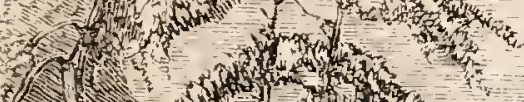

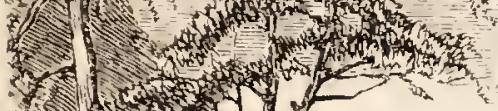

I.

(1)

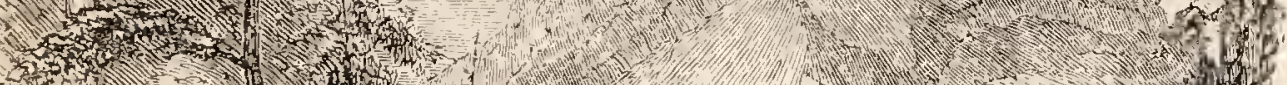
Y.

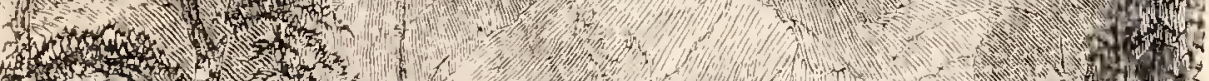
4.

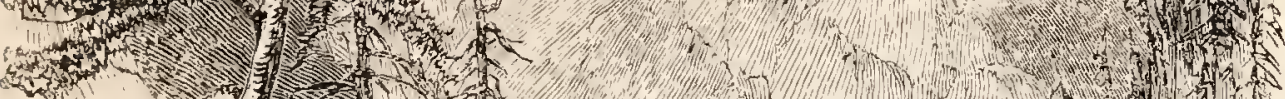

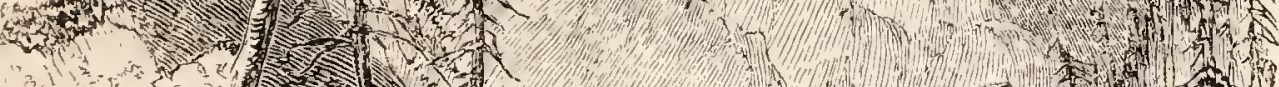
(2) , n

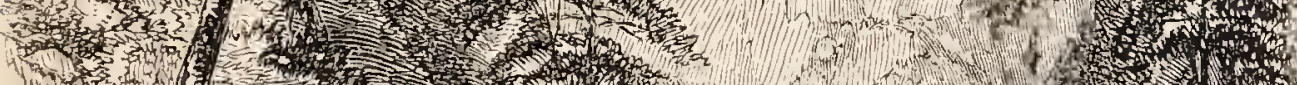
1.

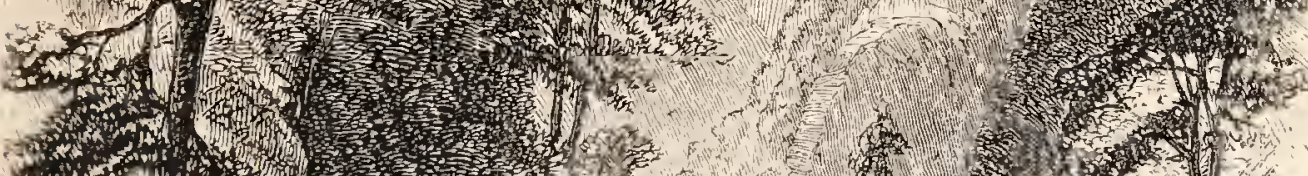

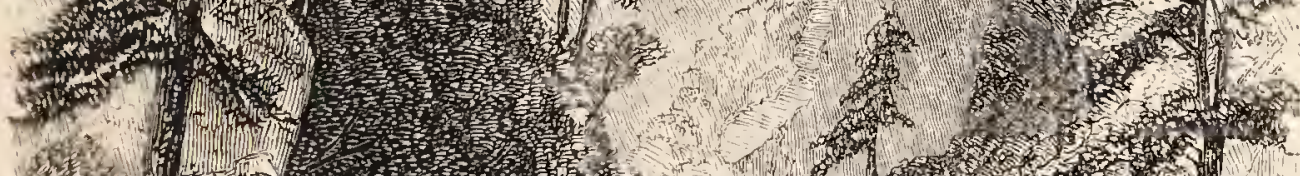

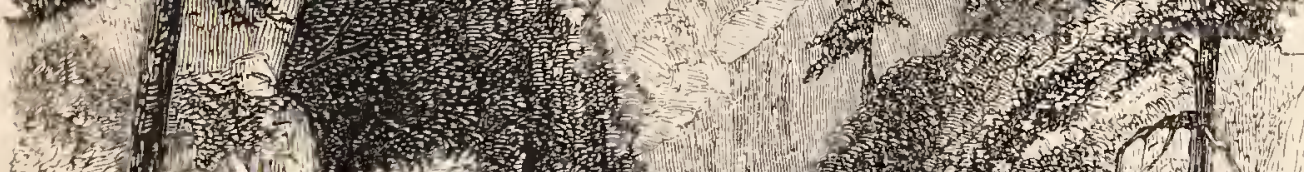

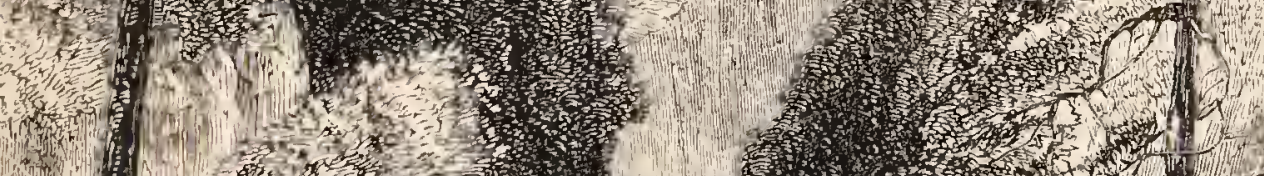

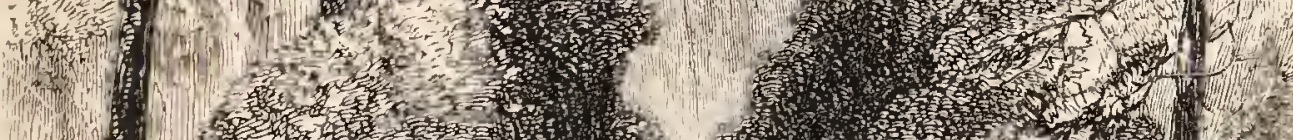

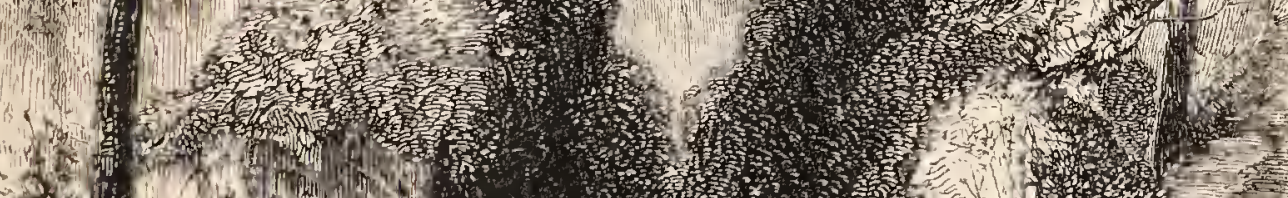

3
3

3
3

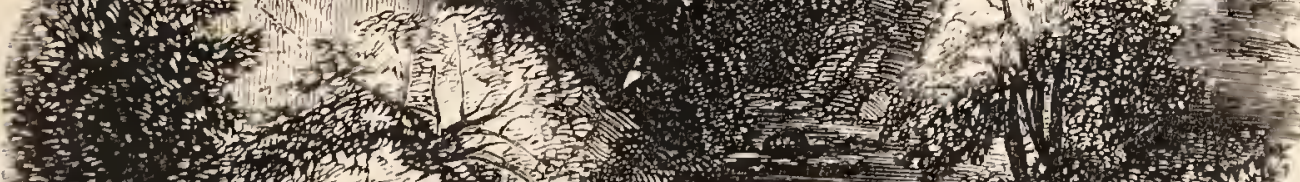

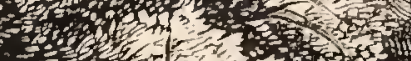

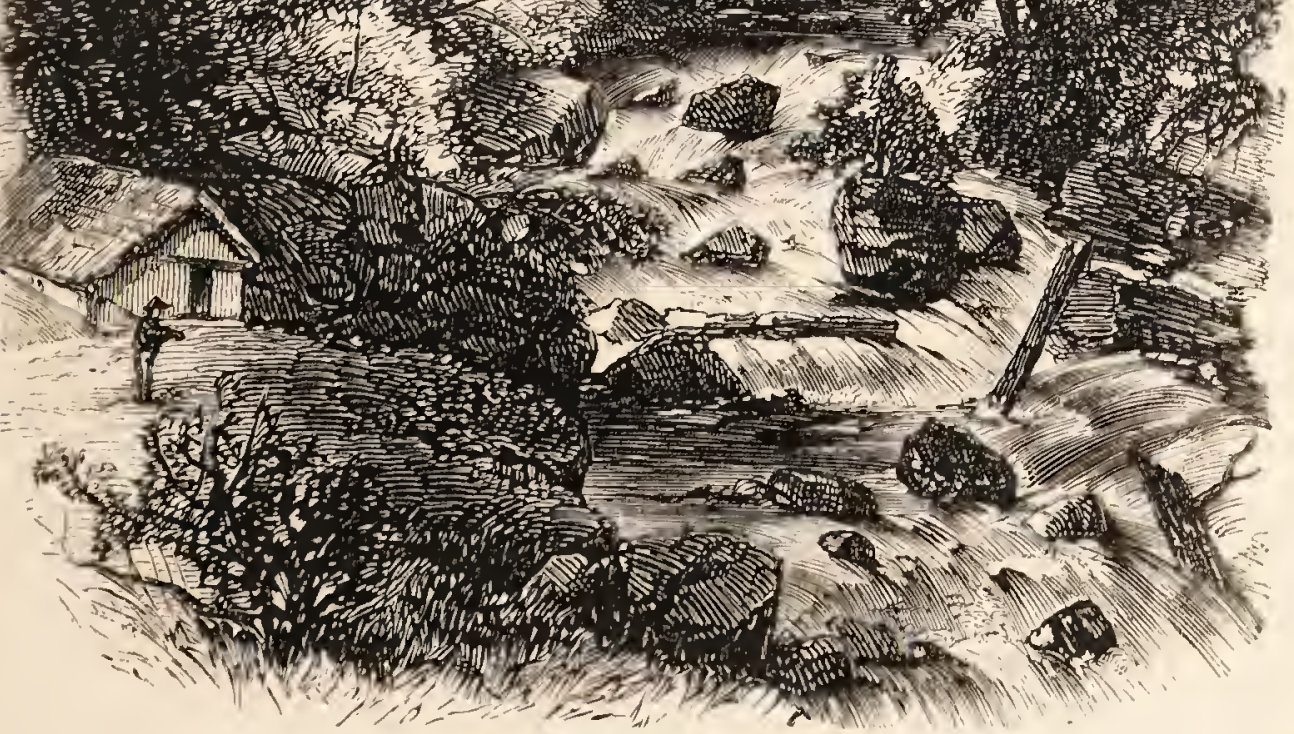

TAHSUL RIVER AT THE LOWER LIMIT OF FIRS. 

mountains around, which are bare and craggy above, but sloping below. Bleak and forbidding as the situation of any Himalayan village at 10,000 feet elevation must be, that of Wallanchoon was rendered more so from the comparatively few trees; for though the silver fir and juniper were both abundant higher up the valley, they had been felled here for building: materials, fuel, and export to Tibet. From the naked limbs and gaunt black trunks of those that remained, stringy masses of bleached lichen (Usnea) many feet long, streamed in the wind: both men and women seemed fond of decorating their hair with wreaths of this lichen, dyed yellow with leaves of Symplocos.

The village was very large, and occupied a flat on the east bank of the river, covered with huge boulder's: the ascent to it was extremely steep, probably over an ancient moraine, though I did not recognise it as such at the time. Cresting this, the valley at once opened, and I was almost startled with the sudden change from a gloomy gorge to an open flat and a populous village of large and good painted wooden houses, ornamented with hundreds of long poles and vertical flags, looking like the fleet of some foreign port; while swarms of good-natured, intolerably dirty Tibetans, were kotowing to me as I advanced.

'The houses crept up the base of the mountain, on the flank of which was a very large, long convent; two-storied, and painted scarlet, with a low black roof, and backed by a grove of dark junipers; and the hillsides around were thickly studded with bushes of deep green rhododendron, scarlet berberry, and withered 
yellow rose. The village contained about one hundred houses, irregularly crowded together, from ten to

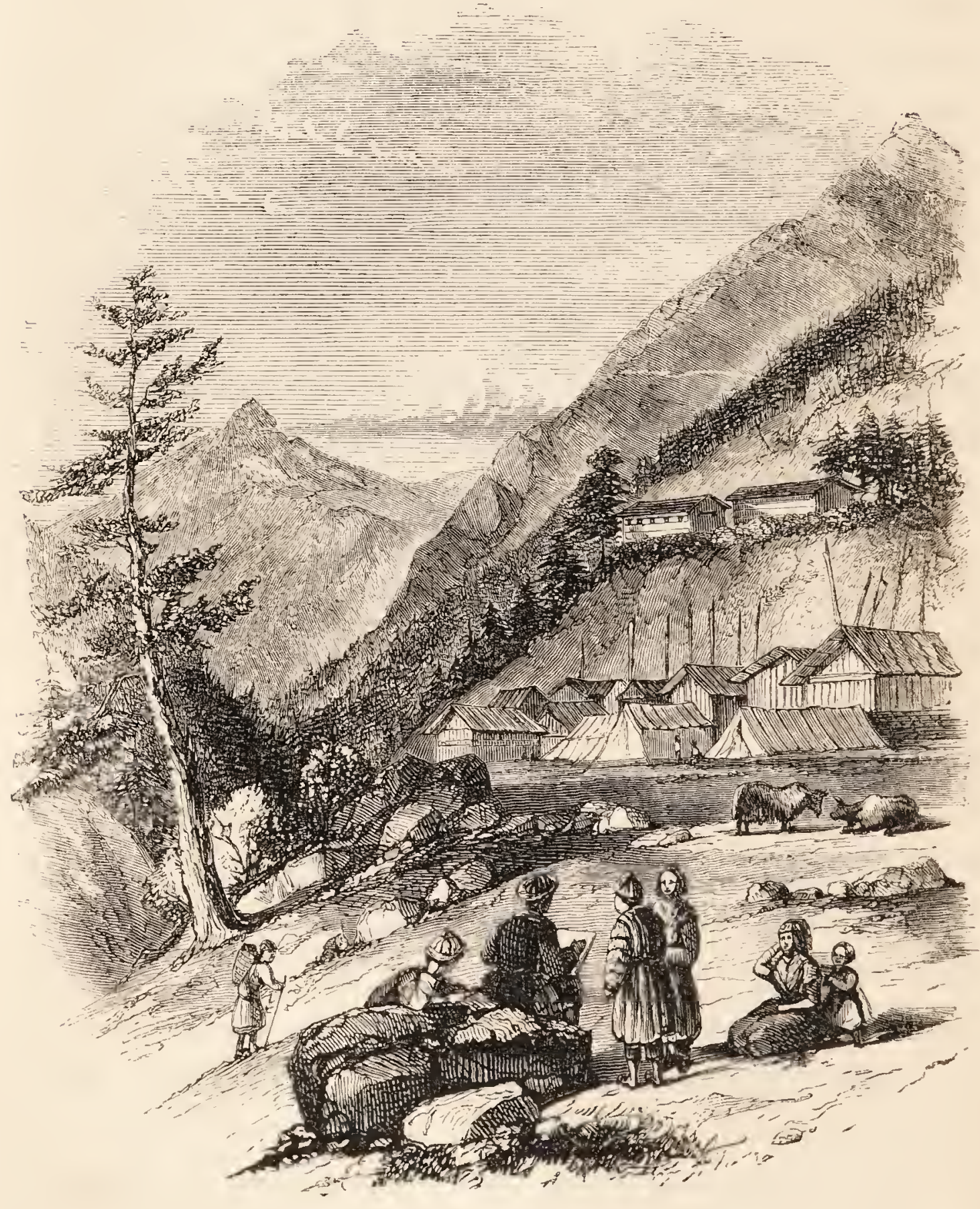

WALLANCHOON VILIAGE.

twenty feet high, and forty to eighty feet long; each accommodating several families. All were built of upright strong pine-planks, the interstices between which 
were filled with yak-dung; and they sometimes rested on a low foundation wall: the door was generally at the gable end; it opened with a latch and string, and turned on a wooden pivot; the only window was a slit closed by a shutter; and the roofs were very low-pitched, covered with shingles kept down by stones. The paths were narrow and filthy; and the only public buildings besides the convents were Manis and Mendongs; of these the former are square-roofed temples, containing rows of praying-cylinders placed close together, from four to six feet high, and gaudily painted; some are turned by hand, and others by water: the latter are walls ormamented with slabs of clay and mica slate, with "Om Mani Padmi om" well carved on them in two characters, and repeated ad infinitum.

A Tibetan household is very slovenly; the family live higgledy-piggledy in two or more apartments, the largest of which has an open fire on the earth, or on a stome if the floor be of wood. The pots and teapots are earthen and copper; and these, with the bamboo churn for the brick tea, some wooden and metal spoons, bowls, and platters, comprise all the kitchen utensils.

Every one carries in the breast of his robe a little wooden cup for daily use; neatly turned from the knotted roots of maple. The Tibetan chiefly consumes barley, wheat, or buckwheat meal-the latter confined to the poorer classes-with milk, butter, curd, and parched wheat; fowls, eggs, pork, and yak flesh when he can afford it, and radishes, a few potatos, legumes, 
and turnips in their short season. His drink is a sort of soup made from brick tea, of which a handful of leaves is churned up with salt, butter, and soda, then boiled and transferred to the tea-pot, whence it is poured scalding hot into each cup, which the good woman of the house keeps incessantly replenishing, and urging you to drain. Sometimes, but more rarely, the Tibetans make a drink by pouring boiling water over malt, as the Lepchas do over millet. A pipe of yellow mild Chinese tobacco generally follows the meal; more often, however, their tobacco is brought from the plains of India, when it is of a very inferior description. The pipe, carried in the girdle, is of brass or iron, often with an agate, amber, or bamiboo mouth-piece.

Many herds of fine yaks were grazing about Wallanchoon: there were a few ponies, sheep, goats, fowls, and pigs, but very little cultivation except turnips, radishes, and potatos. The yak is a very tame, domestic animal, often handsome, and a true bison in appearance; it is invaluable to these mountaineer's from its strength and hardiness, accomplishing, at a slow pace, twenty miles a day, bearing either two bags of salt or rice, or four to six planks of pine-wood slung along both flanks. Their ear's are generally pierced, and ornamented with a tuft of scarlet worsted; they have large and beautiful eyes, spreading horns, long silky hair, and grand bushy tails: black is their prevailing colour, but red, dun, parti-coloured, and white are common. In winter, the flocks graze below 8000 feet, on account of the great quantity of snow above that height; in summer they find pasturage as high as 
17,000 feet, consisting of grass and small tufted sedges, on which they browse with aridity.

The zobo, or cross between the yak and hill cow (much resembling the English cow), is but rarely seen in these mountains, though common in the North West Himalaya. 'The yak is used as a beast of burden; and much of the wealth of the people consists in its rich milk and curd, which are eaten either fresh or dried, or powdered into a kind of meal. The hair is spun into ropes, and woven into a covering for their tents, which is quite pervious to wind and rain; from the same material are made the gauze shades for the eyes used in crossing the snowy passes. The bushy tail forms the wellknown "chowry" or fly-flapper of the plains of India; the bones and dung serve for fuel. The female drops one calf in April; and the young yaks are very full of gambols, tearing up and down the steep grassy and rocky slopes: their flesh is much richer and more juicy than common veal; that of the old yak is sliced and dried in the sum, forming jerked meat, which is eaten raw, the scanty proportion of fat preventing it becoming very rancid, so that I found it palatable food: it is called schat-tchen (dried meat). I never observed the yak to be annoyed by any insects; indeed at the elevation it inhabits, there are no large diptera, bots, or gadflies to infest it. It loves steep places, delighting to scramble among rocks, and to sun its black hide perched on the glacial boulder's which strew the Wallanchoon flat, and on which these beasts

* The latter, however, is of little consequence in the dry climate of Tibet. 
always sleep. Their average value is from two to three pounds, but the price varies with the season. In autumn, when her calf is killed for food, the mother will yield no milk, unless the herdsman gives her the calf's foot to lick, or lays a stuffed skin before her, to fondle, which she does with eagerness, expressing her satisfaction by short grunts, exactly like those of a pig, a sound which replaces the low uttered by ordinary cattle. The yak, though indifferent to ice and snow and to changes of temperature, cannot endure hunger so long as the sheep, nor pick its way so well upon stony ground. Neither can it bear damp heat, for which reason it will not live in summer below 7000 feet, where liver disease carries it off after a very few years.* Lastly, the yak is ridden, especially by the Lamas, who find its shaggy coat warm, and its pace easy; under these circumstances it is always led. The wild yak or bison (D'hong) of central Asia, the superb progenitor of this animal, is the largest native animal of Tibet, in various parts of which country it is found; and the Tibetans say, in reference to its size,

* Nevertheless, the yak seems to have survived the royage to England. I find in Turner's "Tibet" (p. 189), that a bull sent by that traveller to Mr. Hastings, reached England alive, and after suffering from languor, so far recovered its health and vigonr as to become the father of many calves. Turner does not state by what mother these calves were born, an important omission, as he adds that all these died but one cow, which bore a calf by an Indian bull. A painting of the yak (copied into Turner's book) by Stubbs, the animal painter, may be seen in the Museum of the Royal College of Surgeons, London. The artist is probably a little indebted to. description for the appearance of its hair in a native state, for it is represented much too even in length, and reaching to too uniform a depth from the flanks. 
that the liver is a load for a tame yak. The Sikkim Dewan gave Dr. Campbell and myself an animated account of the chase of this animal, which is hunted by large dogs, and shot with a blunderbuss: it is untameable and fierce, falling upon you with horns and chest, and if he rasps you with his tongue, it is so rough as to scrape the flesh from the bones. The horns are used as drinking-cups in marriage feasts, and on other grand occasions. My readers are probably familiar with Messrs. Huc and Gabet's account of a herd of these animals being frozen fast in the headwaters of the Yangtsekiang river.

The inhabitants of these frontier districts belong to two very different tribes, but all are alike called Bhoteas (from Bhote, the proper name of Tibet), and have for many centuries been located in what is-in climate and natural features - a neutral ground between dry Tibet Proper, and the wet Himalayan gorges. They inhabit a climate too cold for either the Lepcha or Nepalese, migrating between 6000 and 15,000 feet with the seasons, accompanied by their herds. In appearance, religion, manners, customs, and language, they are Tibetans and Lama Booddhists, but they pay tax to the Nepal and Sikkim Rajahs, to whom they render immense service by keeping up and facilitating the trade in salt, wool, musk, \&c., which could hardly be conducted without their co-operation. They levy a small tax on all imports, and trade a little on their: own account, but are generally poor and very indolent. In their alpine summer quarters they grow scanty crops of wheat, barley, turnips, and radishes; and at their 
winter quarters, as at Loongtoong, the better classes cultivate fine crops of buckwheat, millet, spinach, \&c.; though seldom enough for their support, as in spring they are obliged to buy rice from the inhabitants of the lower regions. Equally dependent on Nepal and Tibet, they very naturally hold themselves independent of both; and I found that my roving commission from the Nepal Rajah was not respected, and my guard of Ghorkas held very cheap.

On my arrival at Wallanchoon, I was conducted to two tents, each about eight feet long, of yak's hair, striped blue and white, which had been pitched close to the village for my accommodation. Though the best that could be provided, and larger than my own, they were wretched in the extreme, being of so loose a texture that the wind blew through them: each was formed of two cloths with a long slit between them, that ran across the top, giving egress to the smoke, and ingress to the weather: they were supported on two short poles, kept to the ground by large stones, and fastened by yak's hair ropes. A fire was smoking vigorously in the centre of one, and some planks were laid at the end for my bed. A crowd of people soon came to stare and loll out their tongues at me, my party, and travelling equipage; though very civil, and only offensive in smell, they were troublesome, from their eager curiosity to see and handle everything; so that I had to place a circle of stones round the tents, whilst a soldier stood by, on the alert to keep them off. A more idle people are not to be found, except with regard to spinning, which is their constant occupation, 
every man and woman carrying a bundle of wool in the breast of their garments, which is spun by hand with a spindle, and wound off on two cross-pieces at its lower end. Spinning, smoking, and tea-drinking are their chief pursuits; and the women take all the active duties of the dairy and house. They live very happily together, fighting being almost unknown.

Soon after my arrival I was waited on by the Guobah (or head-man), a tall, good-looking person, dressed in a purple woollen robe, with good pearl and coral ear and finger rings, and a broad ivory ring over the left thumb, as a guard when using the bow; he wore a neat thick white felt cap, with the border turned up, and a silk tassel on the top; this he removed with both hands and held before him, bowing three times on entering. He was followed by a crowd, some of whom were his own people, and brought a present of a kid, fowls, rice, and eggs, and some spikenard roots (Nardostachys Jatamansi, a species of valerian smelling strongly of patchouli), which is a very favourite perfume. After paying some compliments, he showed me round the village. During my walk $I$ found that I had a good many objections to overrule before I could proceed to the Wallanchoon pass, nearly two days' journey to the northward. In the first place, the Guobah disputed the Nepal Rajah's authority to pass me through his dominions; and besides the natural jealousy of this people when intruded upon, they have very good reasons for concealing the amount of revenue

* A broad ring of this material, agate, or chalcedony, is a mark of rank here, as amongst the Man-choos, and throughout Central Asia. 
they raise from their position, and for keeping up the delusion that they alone can endure the excessive climate of these regions, or undergo the hardships and toil of the salt trade. My passport said nothing about the passes; my people, and especially the Ghorkas, detested the keen, cold, and cutting wind; at Mywa Guola, I had been persuaded by the Havildar to put off providing snow-boots and blankets, on the assurance. that I should easily get them at Walloong, which I now found all but impossible. My provisions were running short, and I had no present hope of replenishing them. All my party had, I found, reckoned on the certainty that I should have had enough of this elevation and weather by the time I reached Walloong. Some of them fell sick; the Guobah swore that the passes were full of snow, and had been impracticable since October; and the Ghorka Havildar respectfully deposed that he had no orders relative to the pass. Prompt measures were requisite, so I told all my people that I should stop the next day at Walloong, and proceed on the following on a three days' journey to the pass, with or without the Guobah's permission. To the Ghorka soldiers I said that the present they would receive, and the character they would take to their commandant, depended on their carrying out this point, which had been fully explained before starting. I told my servants that their pay and reward depended on their implicit obedience. I took the Guobah aside and showed him troops of yaks (tethered by halters and toggles to a long rope stretched between two rocks), which had that morning arrived laden with salt from 
the north; I told him it was vain to try and deceire me; that my passport was ample, that I should expect a guide, provisions, and snow-boots the next day; and that every impediment and every facility should be reported to the rajah.

During my two days' stay at Walloong, the weather was bitterly cold: as heretofore, the nights and mornings were cloudless, but by noon the whole sky became murky. At this season the prospect was dreary in the extreme; and the quantity of snow upon the mountains, which was continually increasing, held out a dismal promise for my chance of exploring lofty uninhabited regions. All annual and deciduous regetation was long past, and the lofty Himalayas are very poor in mosses and lichens, as compared with arctic regions in general. The temperature fluctuated from $22^{\circ}$ at sumrise, to $50^{\circ}$ at $10 \mathrm{~A} . \mathrm{xr}$; one night it fell to $6 \frac{1}{4}^{\circ}$. Throughout the day, a south wind blew strong and cold up the valley, and at sumset it was replaced by a keen north blast, piercing through tent and blankets. Though the sun's rays were hot for an hour or two in the morning, their genial influence was never felt in the wind. The sky, when cloudless, was generally a cold blue or steel-grey colour, but at night the stars were large, and twinkled gloriously. In my tent the temperature fluctuated with the state of the fire, from $26^{\circ}$ at night to $58^{\circ}$ when the sum beat on it; but the only choice was between cold and suffocating smoke.

After a good many conferences with the Guobah, some bullying, persuasions, and the prescribing of pills, prayers, and charms in the shape of warm water, for" 
the sick of the village, whereby I gained some favour, I was, on the 25th Nov., grudgingly prepared for the trip to Wallanchoon pass, with a guide, and some snowboots for those of my party whom I took with me.

The path lay north-west up the valley, which became thickly wooded with silver-fir and juniper ; we gradually ascended, crossing many streams from lateral gulleys, and huge masses of boulders. Evergreen rhododendrons soon replaced the firs, growing in inconceivable profusion, especially on the slopes facing the southeast, and with no other shrubs or tree-vegetation, but scattered bushes of rose, Spiræa, dwarf juniper, stunted birch, willow, honey-suckle, berberry, and mountainash. At 12,000 feet the valley was wild, open, and broad, with sloping mountains clothed for 1000 feet with dark-green rhododendron bushes; the river ran rapidly, and was broken into falls here and there. Huge angular masses of rock were scattered about, and snowy peaks towered over the surrounding mountains, while among the latter narrow gulleys led up to blue patches of glacial ice, with trickling streams and shoots of stones. Dwarf rhododendrons with strongly-scented leaves ( $R$. anthopogon and setosum), and abundance of a little Andromeda, exactly like ling, with woody stems and tufted branches, gave a heathery appearance to the hill-sides. The prevalence of lichens, common to the Himalaya and to Scotland (especially L. geographicus), which coloured the rocks, added an additional feature to the resemblance to Scotch Highland scenery. Along the narrow path I found the two commonest of all British weeds, a grass (Poa annua), and the 
shepherd's purse! They had evidently been imported by man and yaks, and as they do not occur in India, I could not but regard these little wanderers from the north with the deepest interest.

Such incidents as these give rise to trains of reflection in the mind of the naturalist traveller; and the farther he may be from home, the more wild and desolate the country he is exploring, the greater the difficulties and dangers under which he encounters these subjects of his earliest studies in science; so much keener is the delight with which he recognises them, and the more lasting is the impression which they leave. At this moment these common weeds vividly recal to me that wild scene, and remind me how I went on my way, taxing my memory for all it knew of the geographical distribution of the shepherd's purse, and musing on the probability of the plant having found its way thither over Central Asia, and on the ages that may have been occupied in its march.

On reaching 13,000 feet, the ground was everywhere hard and frozen, and I experienced the first symptoms of lassitude, headache, and giddiness ; which, however, were but slight, and only came on with severe exertion.

We encountered a group of Tibetans, encamped to leeward of an immense boulder of gneiss, against which they had raised a shelter with the salt-bags removed from their herd of yaks, which was grazing close by. They looked miserably cold and haggard, and their eyes, much inflamed and bloodshot, testified to the hardships they had endured in their march from the salt regions : they were crouched round a small fire of 
juniper wood, smoking iron pipes with agate mouthpieces. A resting-house was in sight across the stream -a loose stone hut, to which we repaired. I wondered why these Tibetans had not taken possession of it, not being then aware of the value they attach to a rock, on account of the great warmth which it imbibes from the sun's rays during the day, and retains at night. This invaluable property of otherwise inhospitable granite I had afterwards many opportunities of proving; and when driven to such shelter as rude nature might afford on the bleak mountain, I have had my blankets laid beneath "the shadow of a great rock in a weary land."

The name of Dhamersala is applied, in the mountains as in the plains of Inclia, to a house provided for the accommodation of travellers, whether it be one of the beautiful caravanserais built to gratify the piety, ostentation, or benevolence of a rajah, or such a miserable shieling as that of Tuquoroma, in which we took up our quarters, at 13,000 feet elevation. A cheerful fire soon blazed on the earthen floor, filling the room with the pungent odour of juniper, which made our eyes smart and water. The Ghorkas withdrew to one corner, and my Lepchas to a second, while one end was screened off for my couch; unluckily the wall faced the north-east, and in that direction there was a gulley in the snowy mountains, down which the wind swept with violence, penetrating to my bed. I had calculated upon a good night's rest here, which I much needed, having been worried and unwell at Wallanchoon, owing to the Guobal's obstinacy. I had not 
then learnt how to treat such conduct, and just before retiring to rest had further been informed by the Havildar that the Guobah had declared we should find no food on our return. To remain in these mountains without a supply was impossible, and the delay of sending to Mywa Guola would not have answered; so I long lay awake, occupied in arranging measures. The night was clear and very cold; the thermometer falling to $12^{\circ}$ in the night.

On the following morning (Nov. 26th) I started with a small party to visit the pass, continuing up the broad, grassy valley; much snow lay on the ground, which had fallen the previous month; and several glaciers were seen in lateral ravines. After a couple of miles, we struck northward up a narrow, stony, and steep gorge, crossing an immense ancient moraine at its mouth. This path, which we followed for seven or eight miles, led up to the pass, winding considerably, and keeping along the south-east exposures, which, being the most sunny, are the freest from snow. The morning was splendid, the atmosphere over the dry rocks and earth vibrating from the power of the sun's rays, while vast masses of blue glacier and fields of snow choked every gulley, and were spread over all shady places. Although, owing to the steepness and narrowness of the gorge, no view was obtained, the scenery was wild and very grand. Just below perpetual snow, an ugly carved head of a demon, with blood-stained cheeks and goggle-eyes, was placed in a niche of rock, and protected by a glass.

At 15,000 feet, the snow closed in on the path from 
all sides, whether perpetual, glacial, or only the October fall, I could not tell; the guide declared it to be perpetual, though now deepened by the very heary October fall; the path was cut some three feet through it. Enormous boulders cumbered the gorge, which gradually widened as we approached its summit; and rugged masses of black and red rock pierced the snow, and stood out in dismal relief. For four miles continuously we proceeded over snow; which was much honey-combed on the surface, and treacherous from the icy streams which it covered, and into which we every now and then stumbled: there was scarcely a trace of vegetation, and the cold was excessive.

Towards the summit of the pass we followed the course of a small stream which cut through the snow, which was breast high on each side; we here overtook a small party going to Tibet, with yaks laden with planks. All the party appeared alike overcome by lassitude, difficulty of breathing, a sense of weight on the stomach, giddiness and headache.

Just below the summit was a complete bay of snow, girdled with two sharp peaks of red schists and gneiss, strangely contorted, and permeated with veins of granite. The top itself, or boundary between Nepal and Tibet, was a low saddle between two rugged ridges, with a cairn built on it, adorned with bits of stick and rag covered with 'Tibetan inscriptions. The view into Tibet was not at all distant, and was entirely of snowy mountains, piled ridge over ridge; three spurs must, it is said, be crossed before any descent can be made to the Chomachoo river (as the Arun is called in 
'Tibet), on which is the frontier fort of the Tibetans, and which is reached in two or three days. There is no level ground of any kind before reaching that river, of which the valley is said to be wide and flat.

We started at 10 A.n., but did not reach the top till $3 \frac{1}{2}$ P.ar.; we had halted nowhere, but the last few miles had been most laborious, and the three of us who gained the summit were utterly knocked up. Fortunately I carried my own barometer; it indicated 16.206 inches, giving by comparative observations with Calcutta 16,764 feet, and with Dorjiling, 16,748 feet as the height of the pass. The thermometer stood at $18^{\circ}$, and the sun being now hidden behind rocks, the southeast wind was bitterly cold. Hitherto the sun had appeared as a clearly defined sparkling globe against the dark blue sky; but the depth of the azure was not so striking as I had been led to suppose it would be, by the accounts of previous travellers in very lofty regions. The plants gathered near the top of the pass were species of Compositre, grass, and Arenaria; the most curious was the Sarssurca gossypina, which forms great clubs of the softest white wool, six inches to a foot high, its flowers and leaves seeming clothed with the warmest fur that nature can devise. Generally speaking, the Alpine plants of the Himalaya are quite unprovided with any special protection of this kind; it is the conspicuous nature of the exceptions that misleads, and induces the careless observer to generalise hastily.

We descended to the foot of the pass in about two hours, darkness overtaking us by the way; the 
twilight, however, being prolonged by the glare of the snow. Fearing the distance to Tuquoroma might be too great to permit of our returning thither the same night, I had had a few things brought up during the day, and finding they had arrived, we encamped under the shelter of some enormous boulders (at 13,500 feet); part of an ancient moraine, which extended for some distance along the narrow valley. Except an excruciating headache, I felt no ill effects from my ascent; and after a supper of tea and biscuit, I slept soundly.

On the following morning the temperature was $28^{\circ}$ at sumrise, and rose to $30^{\circ}$ when the sum appeared over the mountains soon after 8 A.Mr. : the sky was brilliantly clear, with a very dry, cold, north wind blowing down the snowy valley of the pass.

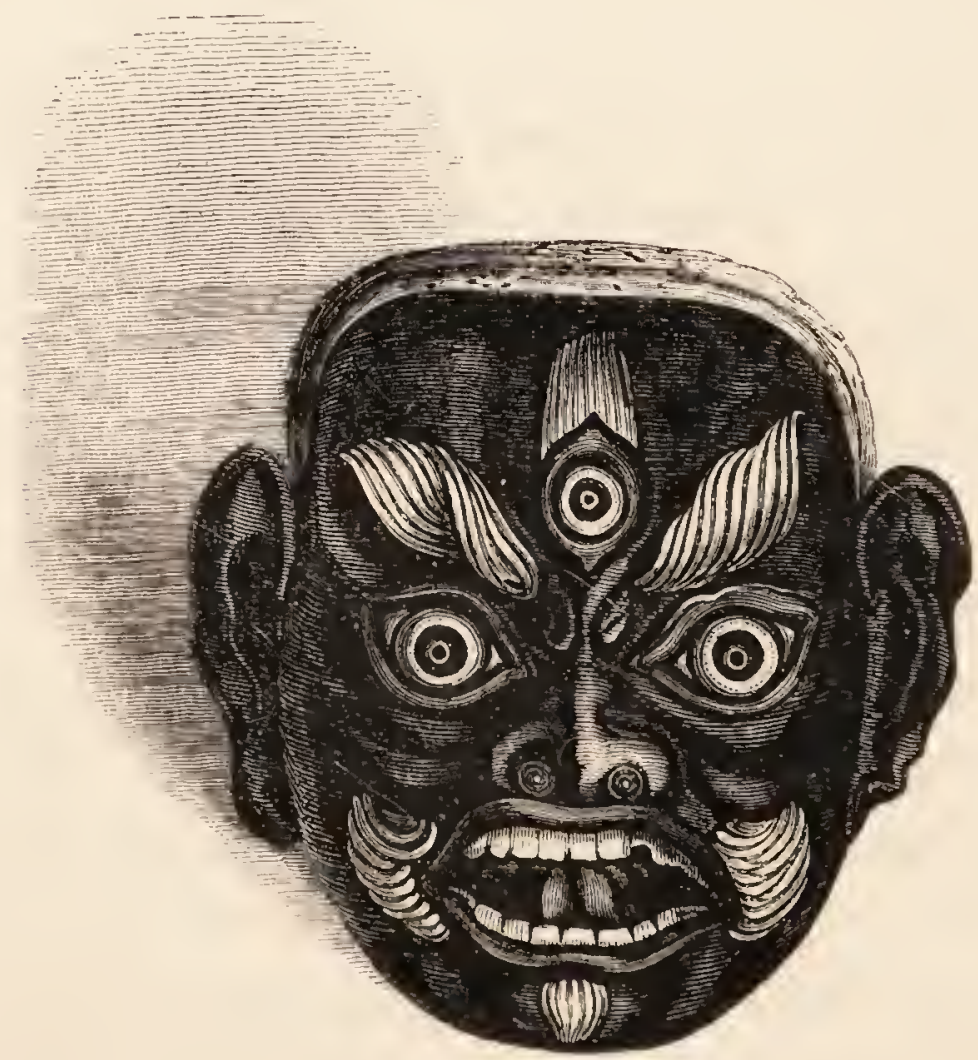

DEMON'S HEAT. 


\section{CHAPTER X.}

Return from Wallanchoon pass-Procure a bazaar at village-Dance of Lamas-Temple and convent-Leave for Kanglachem pass-Send part of party back to Dorjiling-Yangma Guola-Drunken TibetansGuobah of Wallanchoon-Camp at foot of Great Moraine-View from top-Geological speculations-Height of moraines-Cross dry lakebed-Glaciers-More moraines-Terraces-Yangma temples-Jos, books and furniture-Peak of Nango-Arrive at village-Cultivation -Scenery-Potatos-State of my provisions-Pass through villageGigantic boulders-Terraces-Wild sheep-Lake-beds--Sun's power -Piles of gravel and detritus-Glaciers and moraines-Pabuk, elevation of-Moonlight scene-Return to Yangma-Temperature, \&c. -Geological causes of phenomena in valley-Scenery of valley on descent.

I RETURNED to the village of Wallanchoon, after collecting all the plants I could around my camp ; and, on arriving at the village, I refused to receive the Guobah, unless he opened a bazaar on the following morning, where my people might purchase food; and threatened to bring charges against him before his Rajah. At the same time I arranged for sending the main body of my party down the Tambur, and back to Sikkim, whilst I' should, with as few as possible, visit the Kanglachem (Tibetan) pass in the adjacent valley to the eastward, and then, crossing the Nango, Kambachen and Kanglanamo passes, reach. Jongri, in Sikkim, on the south flank of Kinchinjunga.

YOL. I. 
Strolling out in the afternoon I saw a dance of Lamas; they were disfigured with black paint, and covered with rags, feathers, and scarlet cloth, and they carried long poles with bells and banners; thus equipped, they marched through the village, every now and then halting, when they danced and gesticulated to the rude music of cymbals and horns, the bystanders applauding with shouts, crackers, and alms.

I walked up to the convents, which were long ugly buildings, built of wood, and daubed with red and grey paint. The priests were nowhere to be found, and an old withered nun whom I disturbed husking millet in a large wooden mortar, fled at my approach. The adjacent temple had a broad low architrave: its walls sloped inwards, as did the lintels; the doors were black, and almost covered with a gigantic and disproportioned painting of a head, with bloody cheeks and huge teeth; it was surrounded by myriads of goggle eyes, which seemed to follow one about; and though in every respect rude, the effect was somewhat imposing. The similarly proportioned gloomy portals of Egyptian fanes naturally invite comparison; but the Tibetan temples lack the sublimity of those; and the uncomfortable creeping sensation produced by the many sleepless eyes of Boodh's numerous incarnations is very different from the awe with which we contemplate the outspread wings of the Egyptian symbol, and feel as in the presence of him who says, "I am Osiris the Great: no man hath dared to lift my veil."

I had ascended behind the village, but returned down the "via sacra," a steep paved path flanked by 
mendongs or low stone dykes, into which were let rows of stone slabs, inscribed with the sacred "Om Mani Padmi om,"- "Hail to him of the Lotus and Jewel ;" an invocation of Sakkya, who is usually represented holding a lotus flower with a jewel in it.

On the following morning, a scanty supply of very dirty rice was produced, at a very high price. I had, however, so divided my party as not to require a large amount of food, intending to send most of the people back by the Tambur to Dorjiling. I retained nineteen persons in all, selecting the most willing, as it was evident the journey would be one of great hardship; and we took seven days' food, which was as much as they could carry. At noon, I left Wallanchoon, and mustered my party at the junction of the Tambur and Yangma, whence I dismissed those who were to return to Dorjiling, with my collections of plants, minerals, \&c., and proceeded with the chosen ones to ascend the Yangma river. The scenery was wild and very grand, our route lying through a narrow gorge, choked with pine trees, down which the river roared in a furious torrent; while the mountains on each side were crested with castellated masses of rock, and sprinkled with snow. The path was very bad, often up ladders, and along planks lashed to the faces of precipices, and over-hanging the torrent, which it crossed several times by plank bridges. By dark we arrived at Yangma Guola, a collection of empty wooden huts buried in the rocky forest-clad valley, and took possession of a couple. They were well built, raised on posts, with a stage and ladder at the gable end, and each consisted of one good-sized apartment. 
During the night, I was startled from my sleep by a blaze of light, and jumping up, found myself in presence of a party of most sinister-looking, black, ragged Tibetans, bearing huge torches of pine, that filled the room with flame and pitchy smoke. I remembered their arriving just before dark, and their weapons dispelled my fears, for they came armed with bamboo jugs of Murwa beer, and were very drunk and very amiable: they grinned, nodded, kotowed, lolled out their tongues, and scratched their ears in the most seductive manner, then held out their jugs, and besought me by words and gestures to drink and be happy too. I awoke my servant (always a work of difficulty), and with some trouble ejected the visitors, happily without setting the house on fire. I heard them toppling head over heels down the ladder, which I had afterwards drawn up to prevent further intrusion, and in spite of their drunken orgies, was soon lulled to sleep again by the music of the roaring river.

On the 29th November, I continued my course up the Yangma valley, which after five miles opened considerably, the trees disappearing, and the river flowing more tranquilly. The Guobah of Wallanchoon overtook us on the road; on his way, he said, to collect the revenues at Yangma village, but in reality to see what I was about. He owns five considerable villages, and is said to pay a tax of 6000 rupees (600l.) to the Rajah of Nepal : this is no doubt a great exaggeration, but the revenues of such a position, near a pass frequented almost throughout the year, must be considerable. Every yak going and coming is said to pay 
1s., and every horse $4 s$. ; cattle, sheep, ponies, land, and wool are all taxed: he exports also quantities of timber to Tibet, and various articles from the plains of India. He joined my party and halted where I did, had his little Chinese rug spread, and squatted crosslegged on it, whilst his servant prepared his brick tea with salt, butter, and soda, of which he partook, snuffed, smoked, rose up, had his traps repacked, and was off again.

We encamped at a most remarkable place: the valley was broad, with little vegetation but stunted tree-junipers: rocky snow-topped mountains rose on either side, bleak, bare and rugged; and in front, close above my tent, was a gigantic wall of rocks, piled-as if by the Titans-completely across the valley, for about three-quarters of a mile. This striking phenomenon had excited all my curiosity on first obtaining a view of it. The path, I found, led over it, close under its west end, and wound amongst the enormous detached fragments of which it was formed, and which were often eighty feet square : all were of gneiss, schist, and granite. A superb view opened from the top, showing it to be a vast moraine, far below the influence of any existing glaciers, but which at some antecedent period had been thrown across the valley by a glacier descending to 10,000 feet, from a lateral gulley on the east flank. Standing on the top, and looking south, was the Yangma valley (up which I had come), gradually contracting to a defile, girdled by snow-topped mountains, whose rocky flanks mingled with the black pine forest below. Eastward the moraine stretched south of the 
lateral valley, above which towered the snowy peak of Nango, tinged rosy red, and sparkling in the rays of the setting sun: blue glaciers peeped from every gulley on its side, but these were 2000 to 3000 feet above this moraine; they were small too, and their moraines were mere gravel, compared with this. Many smaller consecutive moraines, also, were evident along the bottom of the lateral valley, from this great one up to the existing glaciers. Looking up the Yangma to the north, there appeared a flat grassy plain, hemmed in by mountains, and covered with other stupendous moraines, which rose ridge behind ridge, and cut off the view of all but the mountain tops. The river meandered through the plain (which was about a mile and a half broad at the utmost, and perhaps as long), and cut through the great moraine on its eastern side, just below the junction of the stream from the glacial valley, which, at the lower part of its course, flowed over a broad steep gravel-bed.

I descended to my camp, full of anxious anticipations for the morrow; while the novelty of the scene, and its striking character, the complexity of the phenomena, the lake-bed, the stupendous moraine, and its remoteness from any existing ice, the broad valley and open character of the country, were all so many problems conjured up for my unaided solution, and kept me awake for hours. I had never seen a glacier or moraine before, but being familiar with sea ice and berg transport, during my voyages in the South Polar regions, I was strongly inclined to attribute the formation of this moraine to a period when a glacial 
ocean stood high on the Himalaya, made fiords of the valleys, and floated bergs laden with blocks from the lateral gulleys, which the winds and currents would deposit along certain lines.

On the following morning I carried a barometer to the top of the moraine, which proved to be upwards of 700 feet above the floor of the valley, and 400 above the dry lake-bed which it bounded, and to which we descended on our route up the valley. Isolated moraines occurred along both flanks, and a very long one was thrown nearly across from the upper end of another gulley on the east side, also leading up to the glaciers of Nango. This second moraine commenced a mile and a half above the first, and abutting on the east flank stretched nearly across, and then curving round, ran down it, parallel to and near the west flank, from which it was separated by the Yangma river : it was abruptly terminated by a conical hill of boulders, round whose base the river flowed, entering the dry lake-bed from the west, and crossing it in a south-easterly direction to the western extremity of the great moraine.

The road, on its ascent to the second moraine, passed over an immense accumulation of angular fragments, loosely bound together by felspathic sand. A stream flowed over this débris, dividing into many branches before reaching the lake-bed, where its waters were collected, and whence it meandered southward to fall into the Yangma.

From the top of the second moraine, a very curious scene opened, of another stony and desolate lake-bed, 


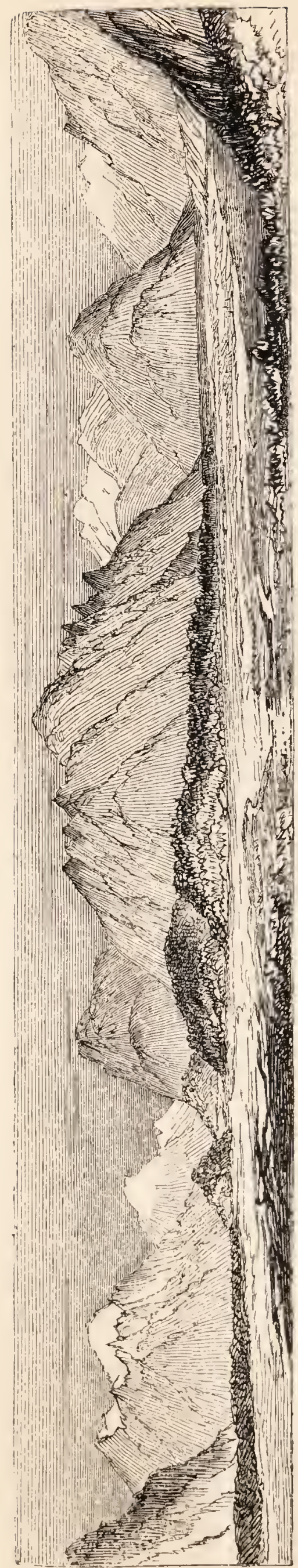

through which the Yangma rushed, cutting a channel about sixty feet deep; the flanks of this second lake-bed were cut most distinctly into two principal terraces, which were again sub-divided into others, so that the general appearance was that of many raised beaches, but each so broken up, that, with one exception, none were continuous for any distance. We crossed the valley and river to a broad flat terrace under the black, precipitous, west flank: this gave me a good opportunity of examining this part of the valley, which was filled with an accumulation, probably 200 feet thick at the deepest part, of angular gravel and enormous boulders, both imbedded in the gravel, and strewed on the flat surfaces of the terraces. The latter were always broadest opposite to the lateral valleys, perfectly horizontal and very barren; there were no traces of fossils, nor could I assure myself of strati- 
fication. The accumulation was wholly glacial; and a lake had probably supervened on the melting of the great glacier and its recedence, which, confined by a frozen moraine, would periodically lose its waters by sudden accessions of heat melting the ice of the glacier. Stratified silt, no doubt, once covered the lake bottom, and the terraces have, in succession, been denuded of it by rain and snow. These causes are now in operation amongst the stupendous glaciers of north-east Sikkim, where valleys, dammed up by moraines, exhibit lakes hemmed in between these, the glaciers, and the flanks of the valleys.

Yangma convents stood at the mouth of a gorge which opened upon the uppermost terrace; they consisted of a wretched collection of stone huts, painted red, and enclosed by loose stone dykes. Two shockingly dirty Lamas conducted me to the temple, which had very thick walls, but was undistinguishable from the other buildings. A small door opened upon an apartment piled full of old battered gongs, drums, scraps of silk hangings, red cloth, broken prayingmachines-relics much resembling those in the lumberroom of a theatre. A ladder led from this dismal hole to the upper story, which was entered by a handsomely carved and gilded door: within all was dark, except from a little lattice-window covered with oiled paper. On one side was the library, a carved case, with a hundred gilded pigeon-holes, each holding a real or sham book, and closed by a little square door, on which hung a bag full of amulets. In the centre of the bookcase was a recess, containing a genuine $J_{O s}$ or $F_{0}$, 
graced with his Chinese attribute of very long pendulous moustaches and beard, and totally wanting that air of contemplative repose which the Tibetan Lamas give to their idols. Banners were suspended around, with paintings of Lhassa, Teshoo-Loombo, and various incarnations of Booddh. The books were of the usual Tibetan form, oblong squares of separate block-printed leaves of paper, made in Nepal or Bhotan from the bark of Daphne, bound together by silk cords, and placed between ornamented wooden boards. On our way up the valley, we had passed some mendongs and chaits, the latter very pretty stone structures, consisting of a cube, pyramid, hemisphere, and cone placed on the top of one another, forming together the tasteful combination which appears on the cover of these volumes.

Beyond the convents the valley again contracted, and on crossing a third, but much lower, moraine, a lake opened to view, surrounded by flat terraces, and a broad gravelly beach, part of the lake being dry. To the west, the cliffs were high, black, and steep: to the east a large lateral valley, filled at about 1500 feet up with blue glaciers, led to the gleaming snows of Nango. Much snow lay on the ground, and the cold was pinching in the shade; still I could not help attempting to sketch this wonderfully grand scene, especially as lakes in the Himalaya are extremely rare: the present one was about a mile long, very shallow, but broad, and as smooth as glass: it reminded me of the tarn in Glencoe. The reflected lofty peak of Nango appeared as if frozen deep down in its glassy bed, 
every snowy crest and ridge being rendered with perfect precision.

Nango is about 18,000 feet high ; it is the next lofty mountain of the Kinchinjunga group to the west of Junnoo, and I doubt if any equally high peak occurs

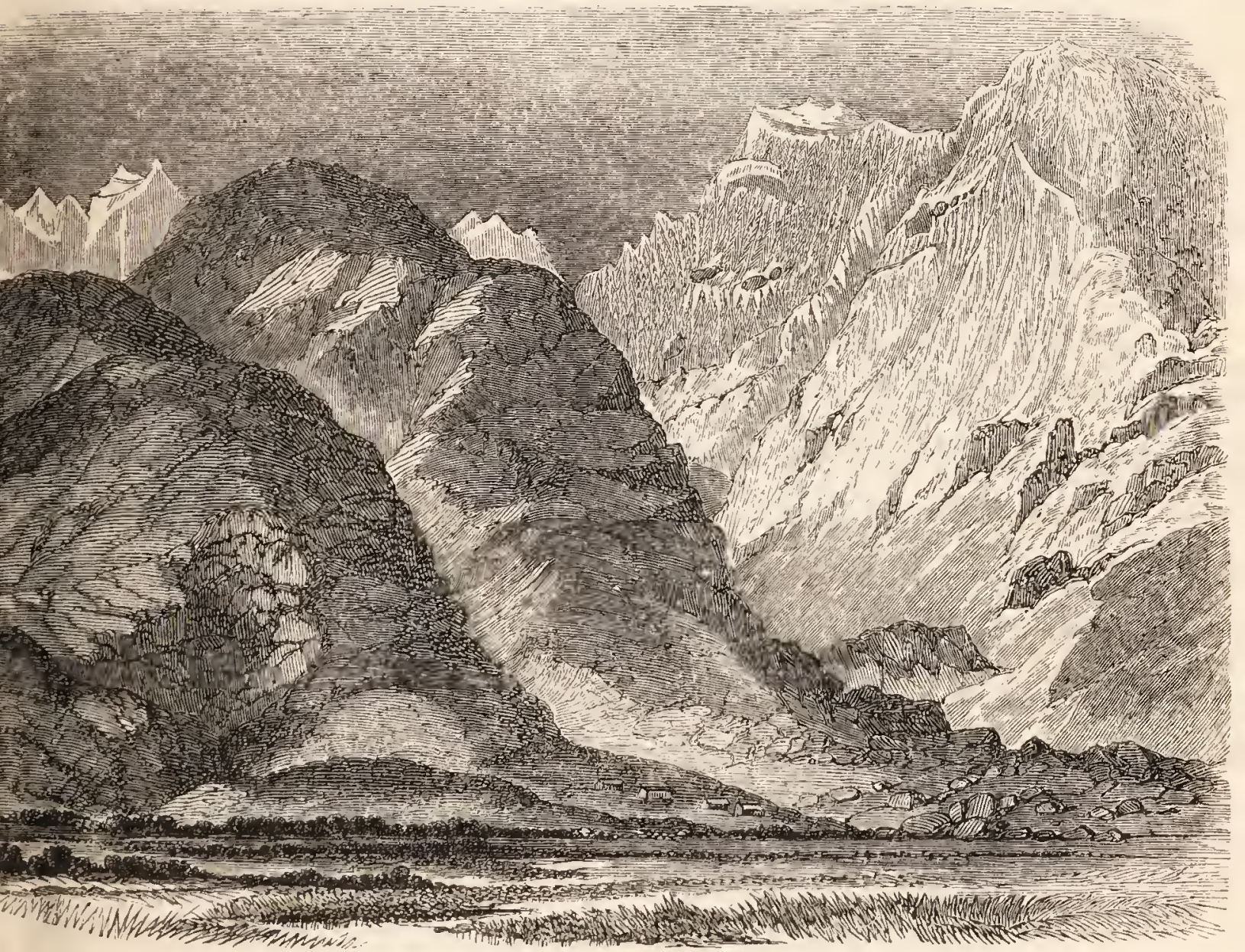

LOOKING ACROSS THE YANGMA VALIEY.

again for some distance further west in Nepal. Facing the Yangma valley, it presents a beautiful range of precipices of black rock, capped with a thick crust of snow: below the cliffs the snow again appears continuously and very steep, for 3000 feet downwards, where it terminates in glaciers that descend to 14,000 feet. The steepest snow-beds appear cut into vertical 
ridges, whence the whole snowy face is-as it werecrimped in perpendicular, closely-set, zig-zag lines, doubtless caused by the melting process, which furrows the surface of the snow into channels by which the water is carried off: the effect is very beautiful, but impossible to represent on paper, from the extreme delicacy of the shadows, and at the same time the perfect definition and precision of the outlines.

In the afternoon I reached the village of Yangma, a miserable collection of 200 to 300 stone huts, nestling under the steep flank of a lofty, flat-topped terrace, laden with gigantic boulders, and projecting southward from a snowy mountain which divides the valley.

Near my camp (of which the elevation was 13,500 feet), radishes, barley, wheat, potatos, and turnips, were cultivated as summer crops, and I even saw some on the terrace, 400 feet above; these were grown in small fields cleared of stones, and protected by dykes.

The scenery, though dismal (no juniper ever attaining this elevation), was full of interest and grandeur, from the number and variety of snowy peaks and glaciers all around the elevated horizon; the ancient lake-beds, now green or brown with scanty regetation; the vast moraines; the ridges of glacial débris; the flat terraces, marking, as it were with parallel roads, the bluff sides of the mountains; the enormous boulders perched upon them, and strewed everywhere around; the little Booddhist monuments of quaint, picturesque shapes, decorated with poles and banners; the manycoloured dresses of the people; the brilliant blue of the 
cloudless heaven by day; the depth of its blackness by night, heightened by the light of the stars, that blaze and twinkle with a lustre unknown in less lofty regions: all these were objects for contemplation, rendered more impressive by the silence that reigned around. The village seemed buried in repose: the inhabitants had already begun to hybernate; their crops were stored, the curd made and dried, the passes closed, the soil frozen, the winter's stock of fuel housed, and the people had retired into the caverns of their half-subterranean houses, to sleep, spin wool, and think of Booddh, if of anything at all, the dead, long winter through. The yaks alone find anything to do; so long as any vegetation remains they roam and eat it, still yielding milk, which the women take morning and evening, when their shrill whistle and cries are heard for a few minutes as they call the grunting animals. No other sounds, save the harsh roar and hollow echo of the falling rock, glacier, or snow-bed, disturbed the perfect silence of the day and night.**

I had taken three days' food to Yangma, and stayed there as long as it lasted: the rest of my provisions I had left below the first moraine, where a lateral valley leads east over the Nango pass to the Kambachen valley, which lay on the route back to Sikkim.

I was premature in complaining of my Wallanchoon tents, those provided for me at Yangma being infinitely wor'se; mere rags, around which I piled sods as a defence from the piercing night-wind that descended

* Snow covers the ground at Yangma from December till April, and the falls are said to be very heavy, at times amounting to 12 feet in depth. 
from the northern glaciers in light but most keen breezes. There was no food to be procured except a little thin milk, and a few small watery potatos. The latter have only recently been introduced amongst the Tibetans, from the English garden at the Nepalese capital, I believe; and their culture has not spread in these regions further east than Kinchinjunga, but they will very soon penetrate into Tibet from Dorjiling, or eastward from Nepal. My private stock of provisions - consisting chiefly of preserved meats from my friend Mr. Hodgson-had fallen very low; and I here found to my dismay that of four remaining two pound cases, provided as meat, three contained prunes, and one "dindon aux truffes!" Never did luxuries come more inopportunely; however the greasy French viand served for many a future meal as sauce to help me to bolt my rice, and according to the theory of chemists, to supply animal heat in these frigid regions. As for my people, they were not accustomed to much animal food; two pounds of rice, with ghee and chilis, forming their common daily diet under cold and fatigue. The poor Tibetans, especially, who undergo great privation and toil, live almost wholly on barley-meal, with tea, and a very little butter and salt: this is not only the case with those amongst whom I mixed so much, but is also mentioned by MM. Huc and Gabet, as having been observed by them in other parts of Tibet.

On the 1 st of December I visited the village and terrace, and proceeded to the head of the Yangma valley, in order to ascend as far towards the Kanglachem pass as practicable. The houses were low, built of 
stone, and clustered in groups against the steep face of the terrace; filthy lanes wound amongst them, so narrow, that by turning my head, I could look into the slits of windows on either hand, and feel the noisome warm air in whiffs against my face. Glacial boulders lie scattered around and beneath the clusters of houses, which it is sometimes difficult to distinguish from the native rock. I entered one house by a narrow low door through walls four feet thick, and found myself in an apartment full of wool, juniper-wood, and dried dung for fuel: no one lived in the lower story, which was quite dark, and as I stood in it my head was in the upper, to which I ascended by a notched pole (like that in the picture of a Kamtschatk house in Cook's voyage), and went into a small low room. The inmates looked half-asleep, they were intolerably indolent and filthy, and were spinning wool and smoking. A door in the wall of the upper apartment led me on to the stone roof of the neighbouring house, from which I passed to the top of a boulder, descending thence by rude steps to the narrow alley. Wishing to see as much as I could, I was led on a winding course through, in and out, and over the tops of the houses of the village, which alternately reminded me of a stone quarry or gravel-pit, and gipsies living in old lime-kilns; and of all sorts of odd places that are turned to account as human habitations.

From the village $I$ ascended the terrace, which is a perfectly level, sandy, triangular plain, pointing down the valley at the fork of the latter, and abutting against the flank of a steep, snow-topped mountain to the 


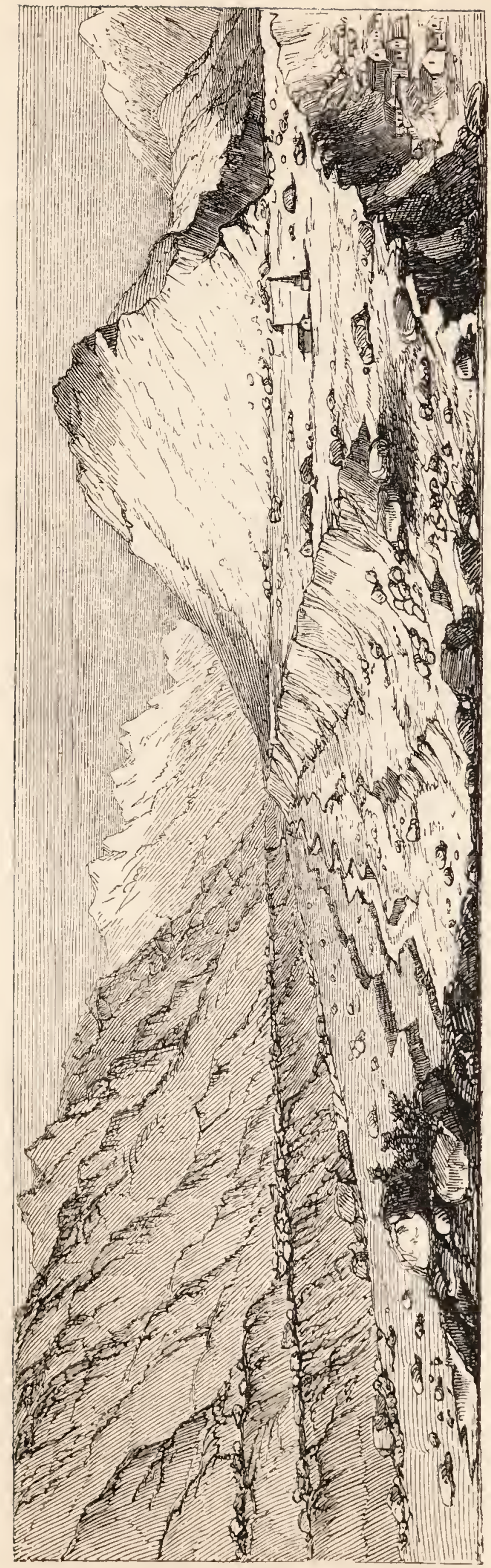

Chap, $X$.

northward. The surface is very uneven, being worn into hollows, and presenting ridges and hillocks of sand and gravel, with small black tufts of rhoclodendron. Enormous granite boulders were scattered over the surface; one of the ordinary size was seventy feet in girth, and fifteen feet above the ground, into which it had partly sunk.

From the southern end I took sketches of the flanks of the valleys east and west. The river was about 400 feet below me, and flowed in a 
little flat lake-bed; other terraces skirted it, cut, as it were, from the side of that I was on. On the opposite flank of the valley were several terraces, of which the highest appeared to tally with the level I occupied, and the lowest was raised very little above the river; none were continuous for any distance, but the upper one, in particular, could be most conspicuously traced up and down the main valley, whilst, on looking across to the eastern valley, a much higher, but less distinctly marked one, appeared on it. The road to the pass lay west-north-west up the north bank of the Yangma on the great terrace; for two miles it was nearly level along the gradually narrowing shelf, at times dipping into the deep gulleys formed by torrents from the mountains; and as the terrace disappeared, or melted, as it were, into the rising floor of the valley, the path descended upon the lower and smaller shelf.

I came suddenly upon a flock of wild sheep, feeding on scanty tufts of sedge and grass; there were twenty-five of these enormous animals, of whose dimensions the term sheep gives no idea: they are very long-legged, stand as high as a calf, and have horns so large that the fox is said to take up his abode in their hollows, when detached and bleaching, on the barren mountains of Tibet. Though very wild, I could easily have killed a couple had I had my gun, but I had found it necessary to reduce my party so uncompromisingly, that I could not afford a man both for my gun and instruments, and had sent the former back to Dorjiling, with Mr. Hodgson's bird-stuffers, who had 
broken one of theirs. Travelling without fire-arms sounds strange in India, but in these regions animal life is very rare, and to come within shot of a flock of wild sheep was a contingency I had never contemplated. Considering how very short we were of any food, and quite out of animal diet, I could not but regret the want of a gun, but consoled myself by reflecting that the instruments were still more urgently required to enable me to survey this extremely interesting valley. As it was, the great beasts trotted off, and turned to tantalise me by grazing within an easy stalking distance. I saw several other flocks of thirty to forty, during the day, but never, either on this or any future occasion, within shot. The Ovis Ammon of Pallas stands from four to five feet high, and measures seven feet from nose to tail; it is quite a Tibetan animal, and is seldom seen below 14,000 feet, except when driven lower by snow; and I have seen it as high as 18,000 feet. The same animal, I believe, is found in Siberia, and is allied to the Big-horn of North America.

Soon after descending to the broad and open floor of the valley, I came on a second dry lake-bed, a mile long, with shelving banks all round, heavily snowed on the shaded side; the river meandered through it, and a fine glacier-bound valley opened into it from the south.

A rather steep ascent through a contracted part of the valley led to another lake-bed, a quarter of a mile long and 100 yards broad, covered with patches of snow, and facing the stupendous masses of snow and ice which filled the upper part of the Yangma valley. This lake-bed (altitude 15,186 feet) was strewed with 


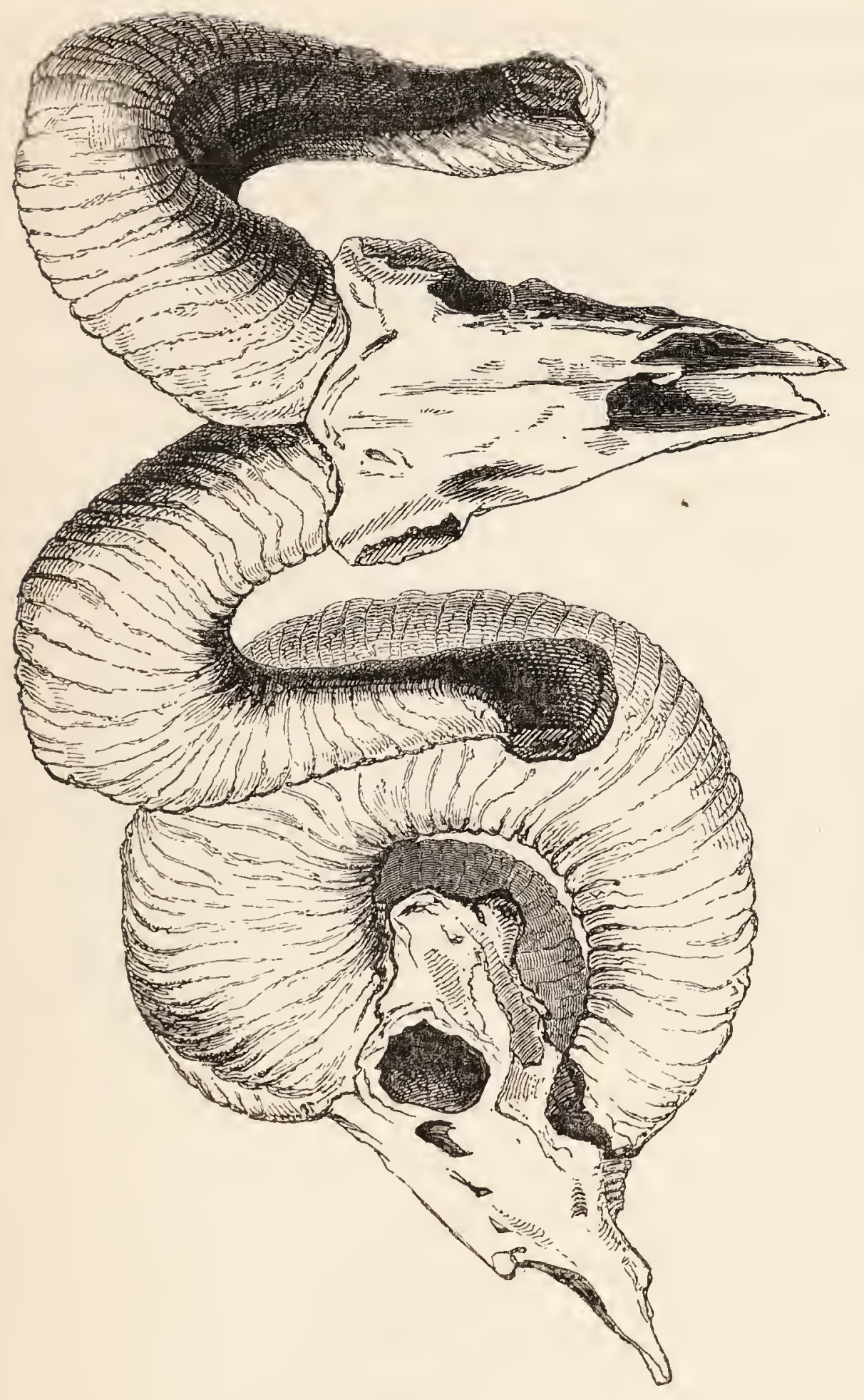

胳 
enormous boulders; a rude stone hut stood near it, where I halted for a few minutes at 1 P.N., when the temperature was $42^{\circ}$.

Following the stream, I soon came to an immense moraine, which blocked up the valley, formed of angular boulders, some of which were fifty feet high. On cresting this a stupendous scene presented itself. A gulf of moraines, and enormous ridges of débris, lay at my feet, girdled by an amphitheatre of snow-clad peaks, rising to 17,000 or 18,000 feet. Black scarped precipices rose on every side; deep snow-beds and blue glaciers rolled down every gulley, converging in the hollow below; and from each transporting its own materials, there ensued a complication of moraines, that presented no order to the eye. In spite of their mutual interference, however, each had raised a ridge of débris or moraine parallel to itself.

We could make no further progress; the pass lay at the distance of several hours' march, up a valley to the north, down which the glacier must have rolled that had deposited this great moraine: it had been closed since October, being very lofty, and the head of this valley was far more snowy than that at Wallanchoon. We halted in the snow from 3 to 4 P.M., during which time I again took angles and observations; the height of this spot, called Pabuk, is 16,038 feet, whence the pass is probably considerably over 17,000 feet, for there was a steep ascent beyond our position. The sun sank at 3 P.M., and the thermometer immediately fell from $35^{\circ}$ to $31^{\circ}$.

After fixing in my note and sketch books the 
as this, it is above all things desirable to seize and book every object worth noticing on the way out: I always carried my note-book and pencil tied to my jacket pocket, and generally walked with them in my hand. It is impossible to observe too soon, or too much: if the excursion is long, little is done on the way home; the bodily powers being mechanically exerted, the mind seeks repose, and being fevered through overexertion, it can endure no train of thought, nor be brought to bear on a subject.

Before leaving the Yangma valley, I measured the elevation of the great village-terrace and that of one on the west flank; the former was about 400 , and the latter 700 feet above the floor of the valley.

Considering this latter as the upper terrace, and concluding that it marks a water level, it is not very difficult to account for its origin. There is every reason to suppose that the flanks of the valley were once covered, to the height of the upper terrace, with an accumulation of débris; though it does not follow that the whole valley was filled to the same depth; the effect of glaciers being to deposit moraines between themselves and the sides of the valley they fill; as also to push forward similar accumulations. Glaciers from each valley, meeting at the fork, where their depth would be 700 feet of ice, would both deposit the necessary accumulation along the flanks of the valley, and also throw a barrier across it. The melting waters of such glaciers would accumulate in lakes, confined by the frozen earth, between the moraines and mountains. Such lakes, on a small scale, are found at the termi- 
nations and sides of existing glaciers, and are surrounded by terraces of gravel and small stones; these terraces being laid bare by the drainage of the lakes during seasons of unusual warmth. To explain the phenomena of the Yangma valley, it may be necessary to demand larger lakes and deeper accumulations of débris than are now familiar to us, but the proofs of glaciers having once descended to from 8000 to 10,000 feet in every Sikkim and East Nepal valley communicating with mountains above 16,000 feet elevation, are incontrovertible, and the glaciers must, in some cases, have been fully forty miles long, and 500 feet in depth. The absence of any moraine, or of blocks of rock in the valley below the fork, is I believe, the only apparent objection to this theory; but the magnitude of the moraines bears no fixed proportion to that of the glacier, and at Pabuk, the steep ridges of débris, which were heaped up 200 feet high, were far more striking than the more usual form of moraine.

On my way up to Yangma I had rudely plotted the valley, and selected prominent positions for improving my plan on my return: these I now made use of, taking bearings with the azimuth compass, and angles by means of a pocket sextant. The result of my running-survey of the whole valley, from 10,000 to 16,000 feet, I have given along with a sketch-map of my routes in India, which accompanies this volume. 


\section{CHAPTER XI.}

Ascend Nango mountain-Moraines-Vegetation-Honey-combed surface of snow-Perpetual snow-Top of pass-View-Elevation-Distance of sound-Plants-Temperature-Scenery-Cliffs of granite and hurled boulders - Camp - Descent - Pheasants - Larch - Distribution of Deodar-Kambachen village-Cultivation-Moraines in valley, distribution of-Picturesque lake-beds, and their vegetation-Tibetan sheep and goats-Cryptogramma crispa-Ascent to Choonjerma pass -View of Junnoo-Rocks of its summit-Misty ocean-Nepal peaks -Top of pass - Temperature, and observations - Gorgeous sunsetDescent to Yalloong valley-Lose path-Night scenes-Musk deer.

WE passed the night a few miles below the great moraine, in a pine-wood (alt. 11,000 feet) opposite the gorge which leads to the Kambachen or Nango pass, over the south shoulder of the mountain of that name: it is situated on a ridge dividing the Yangma river from that of Kambachen, which latter falls into the Tambur opposite Lelyp.

The road crosses the Yangma (which is about fifteen feet wide), and ascends steeply to the south-east, over a moraine, clothed with a dense thicket of rhododendrons, mountain-ash, maples, pine, birch, juniper, \&c. The ground was covered with silvery flakes of birch bark, and that of Rhododendron Hodgsoni, which is as delicate as tissue-paper, and of a pale flesh-colour. I had not before met with this species, and was 
astonished at the beauty of its foliage, which was of a. bright green, with leaves sixteen inches long.

Beyond the region of trees and large shrubs alpine rhododendrons filled the valley, growing with Potentilla, Honeysuckle, Polygonum, and dwarf juniper. The peak of Nango seemed to tower over the gorge, rising behind some black, splintered cliffs, sprinkled with snow; narrow defiles opened up through these cliffs to blue glaciers, and their mouths were invariably closed by beds of moraines, curving outwards from either flank in concentric ridges.

We followed a valley to the south-east, so as to turn the flank of the peak; our road leading over beds of October snow, and over plashy ground, from its melting. Sometimes the path lay close to the black precipices on our right, under which the snow was deep; and we dragged ourselves along, grasping every prominence of the rock with our numbed fingers.

At a little below 15,000 feet, we reached enormous flat beds of snow, which were said to be perpetual, but now deepened by the October fall. They were continuous, and like all the snow I saw at this season, the surface was honeycombed into thin plates, the intervening fissures being about six inches deep. A thick mist here overtook us, and this, with the great difficulty of picking our way, rendered the ascent very fatiguing. Being sanguine about obtaining a good view, I found it almost impossible to keep my temper under the aggravations of pain in the forehead, lassitude, oppression of breathing, a dense drizzling fog, a keen wind, a slippery footing, where I was stumbling at every few VOL. I. 
steps, and icy-cold wet feet, hands, and eyelids; the latter, odd as it sounds, I found a very disagreeable accompaniment of continued raw cold wind.

After an hour and a half's toilsome ascent, I reached the crest, crossing a broad shelf of snow between two rocky eminences: the ridge was unsnowed a little way down the east flank; this was, in a great measure, due to the eastern exposure being the more sunny, to the prevalence of the warm south-east winds that blow up the Kambachen valley, and to the fact that the great snow-beds on the west side are drifted accumulations. The mist cleared off, and I had a partial, though limited, view. To the north the blue peak of Nango was still 2000 feet above me, its snowy mantle falling in great sweeps and curves into glacierbound valleys. The Yangma valley was quite hidden, but to the eastward the view across the stupendous gorge of the Kambachen, 5000 feet below, to the waste of snow, ice, and rock, piled in confusion along the top of the range of Junnoo and Choonjerma, parallel to this but higher, was very grand indeed: this I was to cross in two days, and its appearance was such, that my guide doubted the possibility of our doing it. A third and fourth mountain mass (unseen) lay between me and Sikkim, divided by valleys as deep as those of Yangma and Kambachen.

Having hung up my instruments, I ascended a few hundred feet to some naked rocks, to the northward, when I was struck with the distance to which the voice was carried; I could distinctly hear every word spoken 300 to 400 yards off, and did not raise my voice when 
I asked one of the men, at that distance, to bring me a hammer.

The few plants about were mostly small tufted Arenarias and woolly Compositæ, with a thick-rooted Umbellifer that spread its short, fleshy leaves and branches flat on the ground; the root was very aromatic, but wedged close in the rock. The temperature at 4 P.M. was $23^{\circ}$, and bitterly cold; the elevation was 15,770 feet.

The descent was to a broad, open valley, into which dipped tremendous precipices, which reared their heads in splintered snowy peaks. At their bases were shoots of débris fully 700 feet high, sloping at a steep angle. Enormous masses of rock, detached by the action of the frost and ice, were scattered over the bottom of the valley; they had been precipitated from above, and gaining impetus in their descent, had been hurled to almost inconceivable distances. All were of a very white, fine-grained crystallized granite, with clean, sharpfractured edges, while the weathered surface of each block was black, and covered with moss and lichens. The material of which they were composed was so hard that I found it difficult to detach a specimen.

Darkness had already come on, and the coolies being far behind, we encamped by the light of the moon shining through a thin fog, where we first found dwarf-juniper for fuel, at 13,500 feet.

Having no tent-poles, I had some difficulty in getting my blankets arranged as a shelter, which was done by making them slant from the side of a boulder, on the top of which one end was kept by heavy stones; under 
this roof I laid my bed on a mass of rhododendron and juniper-twigs. The men did the same against other boulders, and lighting a huge fire opposite the mouth of my ground-nest, I sat cross-legged on the bed to eat my supper; my face scorching, and my back freezing. Rice, boiled with a few ounces of greasy dindon aux truffes was now my daily dinner, with chili-vinegar and tea, and I used to relish it keenly: this finished, I smoked a cigar, and wrote up my journal (in short intervals between warming myself) by the light of the fire: took observations by means of a dark-lantern; and when all this was accomplished, I went to roost.

On looking out the following morning, it was with a feeling of arve that I gazed at the stupendous icecrowned precipices that shot up to the summit of Nango, their flanks spotted white at the places whence the gigantic masses with which I was surrounded had fallen; thence my eye wandered down their black faces to the slope of débris at the bottom, thus tracing the course which had probably been taken by that rock under whose shelter I had passed the previous night.

Meepo, the Lepcha sent by the rajah, had snared a couple of beautiful pheasants, one of which I eat for breakfast; it is a small bird, common above 12,000 feet, but very wild; the male has two to five spurs on each of its legs, according to its age; the general colour is greenish, with a broad scarlet patch surrounding the eye. The crop was distended with juniper berries, of which the flesh tasted strongly, and it was the very hardest and toughest bird I ever did eat.

We descended at first through rhododendron and 
juniper, then through black silver-fir (Abies Webbiana), and below that, near the river, we came to the Himalayan larch; a tree quite unknown, except from a notice in the journals of Mr. Griffith, who found it in Bhotan. It is a small tree, twenty to forty feet high, perfectly similar in general characters to a European larch, but with larger cones, which are erect upon the very long, pensile, whip-like branches; its leavesnow red-were falling, and covering the rocky ground on which it grew. It is found as far west as the heads of the Cosi river; but does not inhabit Central nor West Nepal, nor the North-west Himalaya.

This larch is one of the few Conifers confined to the Eastern Himalaya, where several of the western ones, as the Deodar, are absent. I have elsewhere stated that the Deodar is possibly a variety of the Cedar of Lebanon. This is now a prevalent opinion, which is strengthened by the fact that so many more Himalayan plants are now ascertained to be European, than had been supposed before they were compared with European specimens. The cones of the Deodar are identical with those of the Cedar of Lebanon: the Deodar has, generally, longer and more pale bluish leaves and weeping branches,* but these characters seem to be unusually developed in our gardens; for several gentlemen, well acquainted with the Deodar at Simla, when asked to point it out in the Kew Gardens,

* Since writing the above, I have seen, in the magnificent Pinetum at Dropmore, noble cedars, with the length and hue of leaf, and the pensile branches of the Deodar, and far more beautiful than that is, and as unlike the common Lebanon Cedar as possible. 
have indicated the Cedar of Lebanon, and when shown the Deodar, declare that they never saw that plant in the Himalaya!

At the bottom of the valley we crossed the riverwhich was a furious torrent, about twelve yards wide - to the village of Kambachen, on a flat terrace, a few feet above the stream. There were about a dozen houses of wood, plastered with mud, scattered over a grassy plain of a few acres, fenced in, as were also a few fields, with stone dykes. The only cultivation consists of radishes, potatos, and barley: no wheat is grown, the climate being said to be too cold for it, by which is probably meant that it is foggy,- the elevation (11,380 feet) being 2000 feet less than that of Yangma village, and the temperature $6^{\circ}$ to $7^{\circ}$ warmer; but of all the mountain gorges $I$ have ever visited, this is by far the wildest, grandest, and most gloomy; and that man should hybernate here is indeed extraordinary, for there is no route up the valley, and all communication with Lelyp, two marches down the river, is cut off during the winter, when the houses are buried in snow, and drifts fifteen feet deep are said to be common. Standing on the little flat of Kambachen, precipices, with inaccessible patches of fir-trees, appeared towering over head; while across the narrow valley wilder and less wooded crags rose in broken ridges to the glaciers of Nango. Up the valley, the view was cut off by bluff cliffs; whilst down it, the scene was most remarkable: enormous black, roundbacked moraines, rose tier above tier, from a flat lake-bed, apparently hemming in the river between 
the lofty precipices on the east flank of the valley. These had all been deposited at the mouth of a lateral valley, opening just below the village, and descending from Junnoo, a mountain of 25,312 feet elevation, and one of the grandest of the Kinchinjunga group, whose top-though only five miles distant in a straight line-rises 13,932 feet* above the village. Few facts show more decidedly the extraordinary steepness and depth of the Kambachen valley, which, though but 11,400 feet above the sea, lies between two mountains only eight miles apart, the one 25,312 feet high, the other (Nango) 19,000 feet.

The villagers received me very kindly, and furnished me with a guide for the Choonjerma pass, leading to the Yalloong valley, the most easterly in Nepal; but he recommended my not attempting the ascent till the morrow, as it was past 1 P.M., and we should find no camping-ground for half the way up. The villagers gave me the leg of a musk-deer, and some red potatos, about as big as walnuts-all they could spare from their winter stock. With this scanty addition to our stores we started down the valley, for a few miles, till we crossed the stream from the lateral valley, and ascending a little, camped on its bank.

On reaching the top of the great moraine at a place where it overhung the main river, I had a good coupd'cil of the whole scene. The view south-east up the

* This is one of the most sudden slopes in this part of the Himalaya, the angle between the top of Junnoo and Kambachen being 2786 feet per mile, or 1 in 1.8 . The slope from the top of Mont Blanc to the Chamouni valley is 2464 feet per mile, or 1 in $2 \cdot 1$. That from Monte Rosa top to Macugnaga greatly exceeds either. 
glacial valley (represented in the accompanying cut) to the snowy peaks south of Junnoo, was particularly grand, and most interesting from the precision with which one great distant existing glacier was marked by two waving parallel lines of lateral moraines, which formed,

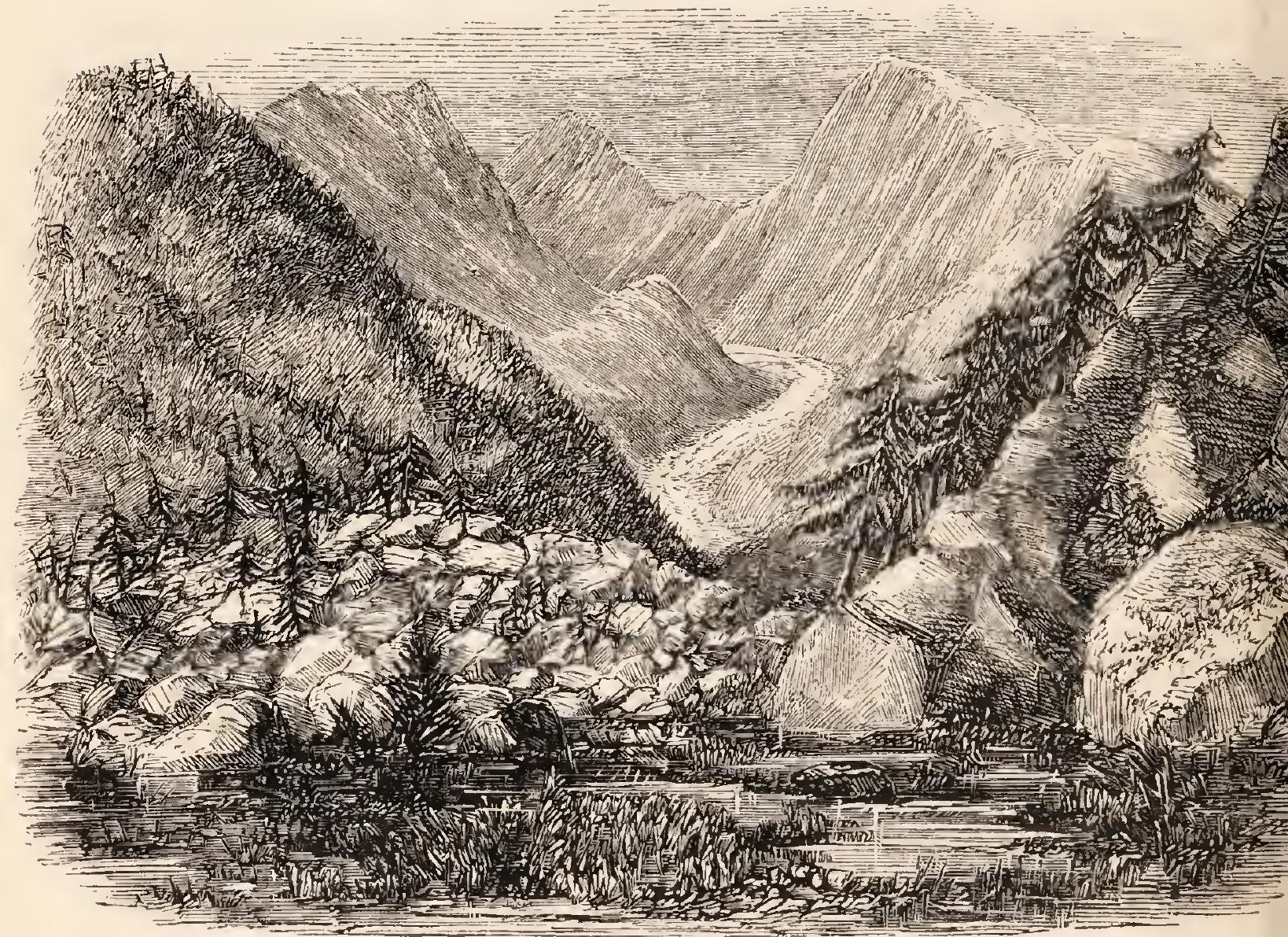

ANCIENT MORAINES IN THE KAMBACHEN VALLEY.

as it were, a vast raised gutter, or channel, ascending from perhaps 16,000 feet elevation, till it was hidden behind a spur. With a telescope I could descry many similar smaller glaciers, with huge accumulations of shingle at their terminations; but this great one was beautifully seen by the naked eye, and formed a very curious feature in the landscape.

Between the moraines, near my tent, the soil was 
perfectly level, and consisted of little lake-beds strewn with gigantic boulders, and covered with hard turf of grass and sedge, and little bushes of dwarf rhododendron and prostrate juniper, as trim as if they had been clipped. Altogether these formed the most picturesque little nooks it was possible to conceive; and they exhibited the withered remains of so many kinds of primrose, gentian, anemone, potentilla, orchis, saxifrage, parnassia, campanula, and pedicularis, that in summer they must be perfect gardens of flowers. Around each plot of a few acres was the grand ice-transported girdle of stupendous rocks, many from 50 to 100 feet long, crested with black tabular-branched silver firs, conical deep green tree-junipers, and feathery larches; whilst amongst the blocks grew a profusion of round masses of evergreen rhododendron bushes. Beyond were stupendous frowning cliffs, beneath which the river roared like thunder; and looking up the glacial valley, the setting sun was bathing the expanse of snow in the most delicate changing tints of pink, amber, and gold.

The boulders forming the moraine were so enormous and angular, that I had great difficulty in ascending it, and where the large rhododendrons grew amongst the rocks I found it impossible to penetrate. The largest of the moraines was piled to upwards of 1000 feet against the south flank of the lateral valley, and stretched far up it beyond my camp, which was in a grove of silver fir's. A large flock of sheep and goats, laden with salt, overtook us here on their route from Wallanchoon to Yalloong. The sheep I observed to feed 
on the Rhododendron Thomsoni and campylocarpum. On the roots of one species a parasitical Broom-rape (Orobanche) grew abundantly; and about the moraines were more mosses, lichens, \&c., than I had elsewhere seen in the loftier Himalaya, encouraged no doubt by the dampness of this grand mountain gorge, which is so hemmed in that the sun never reaches it until four or five hours after it has gilded the overhanging peaks.

December 5.-The morning was bright and clear, and we started early for the Choonjerma pass. I had hoped the route would be up the magnificent glaciergirdled valley in which we had encamped; but it lay up another, considerably south of it, and to which we crossed, ascending the rocky moraine, in the clefts of which grew abundance of a common Scotch fern, Cryptogramma crispa!

Ascending a lofty spur, 1000 feet above the valley, against which the moraine was banked, we saw the pass, bearing north-west, and the valley we had descended on the previous day, topped by Nango mountain, with four glaciers descending from its perpetual snows.

Further on we reached an open grassy valley, and overtook the Tibetans, who had halted here to feed their sheep. A good-looking girl came to ask me for medicine for her husband's eyes, which had suffered from snow-blindness: she brought me a present of snuff, and carried a little child, stark naked, yet warm from the powerful rays of the sun, at nearly 14,000 feet elevation, in December! I prescribed for the man, and gave the mother a bright farthing to hang 
round the child's neck, which delighted the party. My watch was only wondered at; but a little spring measuring-tape that rolled itself up, struck them dumb, and when I threw it on the ground with the tape out, the mother shrieked and ran away, while the little savage howled after her.

The path up the ascent was blocked with snow-beds, and for several miles we alternately scrambled among rocks and over slippery slopes, to the top of a ridge of rocks running east and west from a superb sweep of snowy mountains to the north-west, which presented a chaotic scene of blue glacial ice and white snow, through which splintered rocks and beetling crags thrust their black heads. The view into the Kambachen gorge was magnificent, with the black precipices of its opposite flank rising to the glaciers of Nango, amongst which lay the Kambachen pass. Lower down the valley appeared a broad flat, called Jubla, a halting-place one stage below the village of Kambachen, on the road to Lelyp on the Tambur: it must be a remarkable geological as well as natural feature, for it appeared to jut abruptly and quite horizontally from the black cliffs of the valley.

Looking north, the conical head of Junnoo was just scattering the mists from its snowy shoulders, and standing forth to view, the most magnificent spectacle I ever beheld. It was quite close to me, and is much the steepest of all the peaks of these regions. From whichever side it is viewed, it rises 9000 feet above the general mountain mass of 16,000 feet elevation, towering like a blunt cone, with a short saddle on 
one side, that dips in a steep cliff: it appeared as if uniformly snowed, from its rocks above 20,000 feet being (like those of Kinchinjunga) of white granite, and not contrasting with the snow.*

As evening drew on, another wonderful spectacle presented itself, similar to that which I described at Sakkiazung, but displayed here on an inconceivably grander scale, with all the effects exaggerated. I saw a sea of mist floating 3000 feet beneath me, just below the upper level of the black firs; the magnificent spurs of the snowy range which I had crossed rising out of it in rugged grandeur as promontories and peninsulas, between which the misty ocean seemed to finger up like the fiords of Norway, or the salt water lochs of the west of Scotland; whilst islets tailed off from the promontories, rising here and there out of the deceptive elements. I was so high above this mist, that it had not the billowy appearance I saw before, but was a calm unruffled ocean, boundless to the south and west, where the horizon over-arched it. A little to the north of west I discerned the most lofty group of mountains in Nepal beyond Kinchinjunga, which I believe are on the west flank of the great valley through which the Arun river enters Nepal from Tibet: they were very

* The appearance of Mĩont Cervin, from the Riffelberg, mucl reminded me of that of Junnoo, from the Choonjerma pass, the former bearing the same relation to Monte Rosa that the latter does to Kinchinjunga. Junnoo, though incomparably the more stupendous mass, is not nearly so remarkable in outline, so sharp, or so peaked as is Mont Cervin: it is a very much grander, but far less picturesque object. The whiteness of the sides of Junnoo adds also greatly to its apparent altitude; while the strong relief in which the black cliffs of Mont Cervin protrude through its snowy mantle greatly diminishes both its apparent height and distance. 
distant, and subtended so small an angle, that I could not measure them with the sextant and artificial horizon: their height, judging from the quantity of snow, must be prodigious.

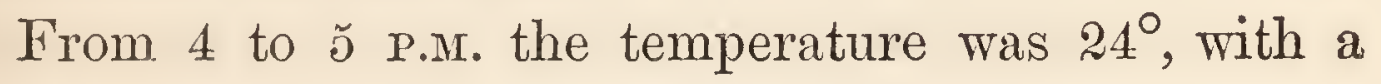
very cold wind; the elevation by the barometer was 15,260 feet.

I waited for an hour, examining the rocks about the pass, till the coolies should come up, but saw nothing worthy of remark, the natural history and geology being identical with those of Kambachen pass. For about four miles we continued at nearly the same level, dipping into the broad head of a snowy valley, and ascending to the second pass, which lay to the south-east.

On the left I passed a very curious isolated pillar of rock amongst the wild crags whose bases we skirted: it resembles the Capuchin on the shoulder of Mont Blanc, as seen from the Jardin. Evening overtook us while still near the last ascent. As the sun declined, the snow at our feet reflected the most delicate peachbloom hue; and looking west from the top of the pass, the scenery was gorgeous beyond description, for the sun was just plunging into a sea of mist, in a blaze of the ruddiest coppery hue. As it sank, the Nepal peaks to the right assumed more definite, darker, and gigantic forms, and floods of light shot across the misty ocean, bathing the landscape in the most wonderful and indescribable changing tints. While the luminary was vanishing, the whole horizon glowed like copper from a smelting furnace, and when it had disappeared, the 
little inequalities of the ragged edges of the mist were lighted up and shone like a row of volcanos in the distance. I have never before or since seen anything, which for sublimity, beauty, and marvellous effects, could compare with what I gazed on that evening from Choonjerma pass. In some of Turner's pictures I have recognized similar effects, caught and fixed by a marvellous effort of genius; such are the fleeting hues over the ice, in his "Whalers," and the ruddy fire in his "Wind, Steam, and Rain," which one almost fears to touch. Dissolving views give some idea of the magic creation and dispersion of the colours, but any combination of science and art can no more recal the scene, than it can the feelings of awe that crept over me, during the hour I spent in solitude amongst these stupendous mountains.

The moon guided us on our descent into the Yalloong valley. I was very uneasy about the coolies, who were far behind, and some of whom had been frost-bitten in crossing the Kambachen pass. Still I thought the best thing was to push on, and light large fires at the first juniper we should reach. The change, on passing from off the snow to the dark earth and rock, was so bewildering, that I had great difficulty in picking my way. Suddenly we came on a small tarn, whose waters gleamed illusively in the pale moonlight: the opposite flanks of the valley were so well reflected on its surface, that we were brought to a stand-still : it looked like a chasm, and whether to jump across it, or go along it, was the question, so deceptive was the spectral landscape. Its true nature was, however, soon 
discovered, and we proceeded round it, descending. Of course we had lost the path, and after some perplexity amongst rocks and ravines, we reached the upper limit of wood, and halted by some bleached junipertrees, which were soon converted into blazing fires.

I wandered away to listen for the voices of the men who had lingered, about whom I was most anxious, from the great difficulty they would encounter if, as we did, they should get off the path. The moon was shining clearly; and its bright light, with the pale glare of the surrounding snow, obscured the milky way, and all the smaller stars; whilst the planets appeared to glow with broader orbs than elsewhere, and the great stars flashed steadily and periodically.

It was a dead calm, and nothing broke the awful silence but the low hoarse murmur of many torrents, whose mingled voices rose and fell as if with the pulsations of the atmosphere; the undulations of which thus appeared to be marked by the ear alone. Some: times it was the faintest possible murmur, and then it rose swelling and filling the air with sound: the effect was that of being raised from the earth's surface, and again lowered to it; or that of waters advancing and retiring. In such scenes and with such accompaniments, the mind wanders from the real to the ideal, the larger and brighter lamps of heaven lead us to imagine that we have risen from the surface of our globe and are floating through the regions of space, and that the ceaseless murmur of the waters is the Music of the Spheres.

Contemplation amid such soothing sounds and 
impressive scenes is very seductive, and withal very dangerous, for the temperature was at freezing-point, my feet and legs were wet through, and it was well that I was soon roused from my reveries by the monosyllabic exclamations of my coolies. They were quite knocked up, and came along grunting, and halting every minute to rest, by supporting their loads, still hanging to their backs, on their stout staves. I had still one bottle of brandy left, which, having been repeatedly begged for in vain, and being no longer expected, was received with unfeigned joy. Fortunately with these people a little spirits goes a long way, and I kept half for future emergencies.

We camped at 13,290 feet, with the air calm and mild to the feeling, though the temperature fell to $22 \frac{3}{4}^{\circ}$. On the following morning we saw two musk-deer, called "Kosturah" by the mountaineers. The musk, which hangs in a pouch near the navel of the male, is the well-known object of traffic with Bengal. This creature ranges between 8000 and 13,000 feet, on the Himalaya, often scenting the air for many hundred yards. It is a pretty grey animal, the size of a roebuck, and something resembling it, with coarse fur, short horns, and two projecting teeth from the upper jaw, said to be used in rooting up the aromatic herbs from which the Bhoteas believe that it derives its odour. This I much doubt, because the animal never frequents those very lofty regions where these herbs are found, nor have I ever seen signs of any having been so rooted up. An Alpine Larkspur (Delphinium glaciale) smells strongly and disagreeably of musk, but it is one of the 
most alpine plants in the world, growing at an elevation of 17,000 feet, far above the limits of the Kosturah. The female and young male are very good eating, much better than any Indian venison I ever tasted, being sweet and tender. Mr. Hodgson once kept a female alive, but it was very wild, and continued so as long as I knew it. Two of my Lepchas gave chase to these animals, and fired many arrows in vain after them: these people are fond of carrying a bow, but are very poor shots.

I descended 3000 feet to the deep valley of the Yalloong river: the path was very bad, over quartz, granite, and gneiss, which cut the shoes and feet severely. The bottom of the valley was filled with an immense accumulation of angular gravel and débris of the above rocks, forming on both sides of the river a terrace 400 feet above the stream, which flowed in a furious torrent. The path led over this deposit for several miles; it varied exceedingly in height, in some places being evidently increased by landslips, and at others apparently by moraines. 


\section{CHAPTER XII.}

Yalloong valley-Find Kanglanamo pass closed-Change route for the southward-Picrorhiza-Cross Yalloong range-Viow - DescentYew-Vegetation-Misty weather-Tonghem village-KhabangTropical vegetation-Sidingbah Mountain-View of KinchinjungaKhabili valley-Ghorkha Havildar's bad conduct-Ascend Singalelah -Plague of ticks-Short commons-Cross Islumbo pass-Boundary of Sikkim-Kulhait valley-Lingcham-Reception by Kajee-Hear of Dr. Campbell's going to meet Rajah-Views in valley-Leave for Teesta river-Tipsy Kajee-Hospitality-Murwa beer-TemplesLong Mendong-Burning of dead-Superstitions-Cross Great Rungeet-Purchase of a dog-Marshes-Lamas-Dismiss GhorkhasBhotea house-Murwa beer.

$\mathrm{ON}_{\mathrm{N}}$ arriving at the bottom we found a party who were travelling with sheep laden with salt; they told us that the Yalloong village, which lay up the valley on the route to the Kanglanamo pass (leading over the south shoulder of Kubra into Sikkim) was deserted, the inhabitants having retired after the October fall of snow to Yankutang, two marches down; also that the Kanglanamo pass was impracticable: I was, therefore, reluctantly obliged to abandon the plan of pursuing that route to Sikkim, and to go south, following the west flank of Singalelah to the first pass I might find open.

These people were very civil, and gave me a handful of the root of one of the many bitter herbs called in 
Bengal "Teeta," and used as a febrifuge: the present one was that of Picrorhiza, a plant allied to Speedwell; which grows at from 12,000 to 15,000 feet elevation, and is a powerful bitter. They had with them above 100 sheep, of a tall, long-legged, Roman-nosed breed. Each carried upwards of forty pounds of salt, done up in two leather bags, slung on either side, and secured by a band going over the chest, and another round the loins, so that they cannot slip off, when going up or down hill. These sheep are very tame, patient creatures, travelling twelve miles a day with great ease, and being indifferent to rocky ground.

December 7.-I ascended the Yalloong ridge to a saddle 11,000 feet elevation, whence the road dips south to the gloomy gorges of the eastern feeders of the Tambur. Here I bade adieu to the grand alpine scenery, and for several days my course lay through Nepal in a southerly direction, parallel to Singalelah, and crossing many spurs and rivers sent off by that mighty range. The latter flow towards the Tambur, and their beds for forty or fifty miles are elevated about 3500 feet. I ascended few of the spurs above 5000 feet, but all of them rise to above 12,000 feet to the westward, where they join the Singalelah range.

Crossing a saddle of the Yalloong range, I clambered to the top of a lofty hummock, through a dense thicket of interwoven Rhododendron bushes, the clayey soil under which was slippery from the quantity of dead leaves. I had hoped for a view of the top of Kinchinjunga, to the north-east, but it was enveloped in clouds, as were all the snows in that direction; to 
the north-west, however, I obtained bearings of the principal peaks, \&c., of the Yangma and Kambachen valleys. To the south and south-east, lofty, rugged and pine-clad mountains rose in confused masses, and white sheets of mist came driving up, clinging to the mountain-tops, and shrouding the landscape with extreme rapidity. The remarkable mountain of Sidingbah bore south-south-east, raising its rounded head above the clouds. I could, however, procure no other good bearing.

The descent from the Yalloong ridge to the Khabili feeders of the Tambur was very steep, and in some places almost precipitous, first through dense woods of silver fir, with Rhododendron Falconeri and Hodgsoni, then through Abies Brunoniana, with yew (now covered with red berries) to the region of Magnolias and Rhododendron barbatum and arboreum. One bush of the latter was in flower, making a gorgeous show. Here also appeared the great oak with lamellated acorns, which I had not seen in the drier valleys to the westward; with many other Dorjiling trees and shrubs. A heavy mist clung to the rank luxuriant foliage, tantalising from its obscuring all the view. After so many days of bright sunshine and dry weather, I found this quiet, damp, foggy atmosphere to have a most depressing effect: there was little to interest in the meteorology, the atmospheric fluctuations being far too small; geographical discovery was at an end, and I groped my way along devious paths in wooded valleys, or ascended spurs and ridges, always clouded before noon, and clothed with heavy forest. 
At the elevation of 5,560 feet I reached a village and spur, called "Tonghem" by the Limboos, and "Yankutang" by the Bhoteas; the winter resort of the inhabitants of the upper Yalloong valley: they received me very kindly, sold me two fowls, and a little rice, and gave me a good deal of information. I found that the Kanglanamo pass had been disused since the Nepal war, that it was very lofty, and always closed in October.

The next day, after crossing the river, a very winding and fatiguing up-and-down march brought me to the village of Khabang, in the magnificent valley of the Tawa, about 800 feet above the river, and 5,500 feet above the sea.

I halted here for a day, to refresh the people, and if possible to obtain some food.

Khabang is a village, of Geroongs, or shepherds, who pasture their flocks on the hills and higher valleys during summer, and bring them down to this elevation in winter: the ground was consequently infested with a tick, equal in size to that common in the bushes, and quite as troublesome, but of a different species.

The temperature here was $72^{\circ}$; and Magnolias and various other tropical trees were common, with the herbaceous vegetation of low elevations. Large sugarcanes, palms, and wild plantains grew near the river, and Rhododendron arboreum was very common on dry slopes, with the gorgeous and sweet-scented Luculia gratissima.

Up the valley of the Tawa the view was very grand of the magnificent rocky mountain called Sidingbah, 
situated on a spur of the Singalelah range which runs westerly, and forms the south flank of the Tawa, and the north of the Khabili valley. This mountain is fully 12,000 feet high, crested with rock and ragged black forest, which, on the north flank, extends to its base: to the eastward, the bare ridges of Singalelah were patched with snow, below which they too were clothed with black firs.

From the opposite side of the Tawa I was most fortunate in obtaining a splendid view of Kinchinjunga with its associates, rising over the dark mass of Singalelah, its flanks showing like tier above tier of green glaciers: its distance was fully twenty-five miles, and as only about 8000 feet from its summit were visible, and Kubra was foreshortened against it, its appearance was not grand; added to which, its top was round and hummocky, not broken into peaks, as when seen from the south and east. Villages and cultivation became more frequent as I proceeded southward to the valley of the Khabili, and my daily marches were up ridges; and down into deep valleys, with feeders from the flanks of Sidingbah to the Tambur. During this part of the journey, though I was day after day marching only seven to ten miles distant from the Tambur river, I did not once see it, so uneven is the country.

The valley of the Khabili is very grand, broad, open, and intersected by many streams and cultivated spurs: the road from Yamroop* to Sikkim, once well frequented, runs up its north flank, and though it had long been closed we determined to follow and clear it.

* A large village and military post to the west of my route. 
Though we passed numerous villages, I found unusual difficulty in obtaining provisions, and received none of the presents so uniformly brought by the villagers to a stranger. I was not long in discovering, to my great mortification, that these were appropriated by the Ghorka Havildar, who seemed to have profited by our many days of short allowance, and diverted the current of hospitality from me to himself. His coolies I saw groaning under heavy burdens, when those of my people were light; and the truth only came out when he had the impudence to attempt to impose a part of his coolies' loads upon mine, to enable the former to carry more food, whilst he was pretending that he used every exertion to procure me a scanty supply of rice with my limited stock of money. I had treated this man and his soldiers with the utmost kindness, nursing them and clothing them from my own stock of flamnels, when sick and shivering amongst the snows. Though a high caste Hindoo, and one who assumed Brahmin rank, he had, I found, no objection to eat forbidden things in secret; and now that we were travelling amongst Hindoos, his caste obtained him everything, while money alone availed me. I took him roundly to task for his treachery, which caused him secretly to throw away a leg of mutton he had concealed; I also threatened to expose the humbug of his pretension to caste, but it was then too late to procure more food. Having hitherto much liked this man, and fully trusted him, I was greatly pained by his conduct.

I proceeded east for three days, up the valley; first through gloomy forests of tropical trees, and then 
ascending to the region of oaks and magnolias. The path was soon obstructed, and we had to tear and cut our way, from 6000 to 10,000 feet, which took two days' very hard work. Ticks swarmed in the bamboo jungle, and my body was covered with these loathsome insects, which got into my bed and hair, and even attached themselves to my eyelids during the night, when the constant annoyance and irritation completely banished sleep. In the daytime they penetrated my trousers, piercing to my body in many places, so that I repeatedly took off as many as twelve at one time. It is indeed marvellous how so large an insect can painlessly insert a stout barbed proboscis, which requires great force to extract it, and causes severe smarting in the operation. What the tick feeds on in these humid forests is a perfect mystery to me, for they literally swarmed, where there was neither path nor animal life. They were, however, more tolerable than a commoner species of parasite, from which I found it impossible to escape, all classes of mountaineers being infested with it.

On the 14th, after an arduous ascent through the pathless jungle, I camped at 9,300 feet on a narrow spur, in a dense forest, amongst immense loose blocks of gneiss. The weather was foggy and rainy, and the wind cold. I ate my last supply of animal food, a miserable starved pullet, with rice and Chili vinegar; my tea, sugar, and all other superfluities having been long before exhausted.

On the following moming I crossed the Islumbo pass over Singalelah into Sikkim, the elevation being 11,000 feet. Above my camp the trees were few and 
stunted, and I quickly emerged from the forest on a rocky and grassy ridge, covered with withered Saxifrages, Umbellifers, Parnassia, Hypericum, \&c. There were no firs on either side of the pass; a very remarkable peculiarity of the damp mountains of Sikkim, which I have elsewhere had occasion to notice: I had left the long-leaved pine (a far from common tree in these valleys) at 3000 feet in the Tawa three days before, and ascended to 11,000 feet without passing a coniferous tree of any kind, except a few yews, covered with red berries.

The top of the pass was broad, grassy, and bushy, with dwarf Bamboo, Rose, and Berberry in great abundance, covered with moss and lichens: it had been raining hard all the morning, and the vegetation was coated with ice; a dense fog obscured everything, and a violent south-east wind blew over the pass in my teeth. I collected some very curious and beautiful mosses, putting these frozen treasures into my box, in the form of exquisitely beautiful glass ornaments, or mosses frosted with silver.

A few stones marked the boundary between Nepal and Sikkim, where I halted for half an hour, and hung up my instruments: the temperature was $32^{\circ}$.

I descended rapidly, proceeding eastward down the broad valley of the Kulhait river, an affluent of the Great Rungeet; and as it had begun to sleet and snow hard, I kept on until I reached 6400 feet before camping.

On the following day I continued down the valley, and reached habitations at 4000 feet: passing many voL. I. 
villages and much cultivation, I crossed the river, and ascended to the village of Lingcham, just below the convent of Changachelling, very tired and hungry. Bad weather had set in, and it was pitch dark and raining hard when I arrived; but the Kajee, or head man, sent out a party with torches to conduct me, and gave me a most hospitable reception, honoured me with a salute of musketry, and brought abundance of milk, eggs, fowls, plantains, and Murwa beer. Plenty of news was awaiting me here, and a messenger with letters was three marches further north, at Yoksun, waiting my expected arrival over the Kanglanamo pass. Dr. Campbell, I was told, had left Dorjiling, and was en route to meet the Rajah at Bhomsong on the Teesta, where no European had ever yet been; and as the Sikkim authorities had for sixteen years steadily rejected every overture for a friendly interview, and had even refused to allow the agent of the GovernorGeneral to enter their dominions, it was evident that grave doings were pending. I knew that Dr. Campbell had long used every exertion to bring the Sikkim Rajah to a friendly conference, but in vain. It will hardly be believed that though this chief's dominions were redeemed by us from the Nepalese, though we had bound ourselves to support him on his throne, and though the terms of the treaty stipulated for free intercourse, mutual protection, and friendship; yet the Sikkim authorities had hitherto been allowed to obstruct all intercourse, and in every way to treat the Governor-General's agent and the East India Company with contempt. An affectation of timidity, 
mistrust, and ignorance was assumed for the purpose of deception, and as a cloak for every insult and resistance to the terms of our treaty, and it was quoted by the Government in answer to every remonstrance on the part of their resident agent at Dorjiling.

On the following morning the Kajee waited on me with a magnificent present of a calf, a kid, fowls, eggs, rice, oranges, plantains, egg-apples, Indian corn, yams, onions, tomatos, parsley, fennel, turmeric, rancid butter, milk, and, lastly, a coolie-load of fermenting milletseeds, wherewith to make the favourite Murwa beer. In the evening two lads arrived from Dorjiling, who had been sent a week beforehand by my kind and thoughtful friend, Mr. Hodgson, with provisions and money.

The valley of the Kulhait is one of the finest in Sikkim, and it is accordingly the site of two of the oldest and richest conventual establishments. Its length is sixteen miles, from the Islumbo pass to the Great Rungeet, for ten of which it is inhabited, the villages being invariably on long meridional spurs that project from either flank; they are about 2000 feet above the river, and about 5000 feet above the sea. Except where these spurs project, the flanks of the valley are very steep, the mountains rising to 8000 feet.

Looking from any spur, up or down the valley, five or six others might be seen on each side of the river, at very nearly the same average level, all presenting great uniformity of contour, namely, a gentle slope towards the centre of the valley, and then an abrupt 
descent to the river. They were about a quarter of a mile broad at the widest, and often narrower, and a mile or so long; some parts of their surfaces and sides were quite flat, and occasionally occupied by marshes or ponds. Cultivation is almost confined to these spurs, and is carried on both on their summits and steep flanks: between every two is a very steep gulley and water-course. The timber has long since been cleared from the tops, but, to a great extent, still clothes their flanks and the intervening gorges. I have been particular in describing these spurs, because it is impossible to survey them without ascribing their comparative uniformity of level to the action of water. Similar ones are characteristic features of the valleys of Sikkim between 2000 and 8000 feet, and are rendered conspicuous by being always chosen as sites for villages and cultivation: the soil is a vegetable mould, over a deep stratum of red clay.

I am far from supposing that any geologically recent action of the sea has levelled these spurs; but as the great chain of the Himalaya has risen from the ocean, and as every part of it has been subjected to sea-action, it is quite conceivable that intervals of rest during the periods of elevation or submergence would effect their levelling. In a mountain mass so tumbled as is that of Sikkim, any level surface, or approach to it, demands study; and when, as in the Kulhait valley, we find several similar spurs with comparatively flat tops, occupying about the same elevation, it is necessary to look for some levelling cause. The action of denudation is still progressing with astonishing rapidity, under an 
annual fall of upwards of 100 inches of rain; but its tendency is to obliterate all such phenomena, and to give sharp, rugged outlines to these spurs, in spite of the conservative effects of vegetation.

A letter from Dr. Campbell reached me three days after my arrival, begging me to cross the country to the Teesta river, and meet him at Bhomsong, on its west bank: I therefore left on the 20th of December, accompanied by my friend the Kajee, who was going to pay his respects to the Rajah. He was followed by a lad, carrying a bamboo of Murwa beer slung round his neck, with which he kept himself always groggy. His dress was thoroughly Lepcha, and highly picturesque, consisting of a very broad-brimmed round-crowned bamboo-platted hat, scarlet jacket, and blue-striped cloth shirt, bare feet, long knife, bow and quiver, rings and earrings, and a long pigtail. He spoke no Hindoostanee, but was very communicative through my interpreters.

Crossing a torrent, we came to the next village, where I was met by a deputation of women, sent by the Lamas of Changachelling, bearing enormous loads of oranges, rice, milk, butter, ghee, and the everflowing Murwa beer.

The villagers had erected a shady bower for me of leaves and branches, and had fitted up a little bamboo stage, on which to squat cross-legged, or to hang my legs from, if I preferred: after conducting me to this, the parties advanced and piled their cumbrous presents on the ground, bowed, and retired; they were succeeded by the beer-carrier, who plunged a clean drinking-tube 
to the bottom of the steaming bamboo jug and held it to my mouth, then placing it by my side, he bowed and withdrew. Nothing can be more fascinating than the simple manners of these kind people, who really love hospitality, and make the stranger feel himself welcome. Just now too, the Durbar had ordered every attention to be paid me; and I hardly passed a village, however small, without receiving a present; or a cottage, where beer was not offered. This I found a most grateful beverage; and of the occasional rests under leafy screens during a hot day's march, and sips at the bamboo jug, I shall ever retain a grateful remem. brance. Happily the liquor is very weak, and except by swilling, as my friend the Kajee did, it would be impossible to get fuddled by it.

At Pemiongchi a superior Lama met me with another overwhelming present: he was a most jolly fat monk, shaven and girdled, and dressed in a scarlet gown : my Lepchas kotowed to him, and he blessed them by the laying on of hands.

Hence we descended suddenly to the Great Rungeet, which we reached at its junction with the Kulhait: the path was very steep and slippery, and led along the side of an enormous Mendong,* which ran down the hill for several hundred yards, and had a large chait at each end, with several smaller ones at intervals. Throughout its length were innumerable inscriptions

* This remarkable structure, called the Kaysing Mendong, is 200 yards long, 10 feet high, and 6 or 8 feet broad; it is built of flat, slaty stones, and both faces are corered with inscribed slates, of which there are upwards of 700. A tall stone, nine feet high, covered also with inscriptions, terminates it at the lower end. 
of "Om Mani Padmi om," with well carved figures of Booddh in his many incarnations, besides Lamas, \&c. At the lower end was a flat area, on which are burnt the bodies of people of consequence; the poorer are

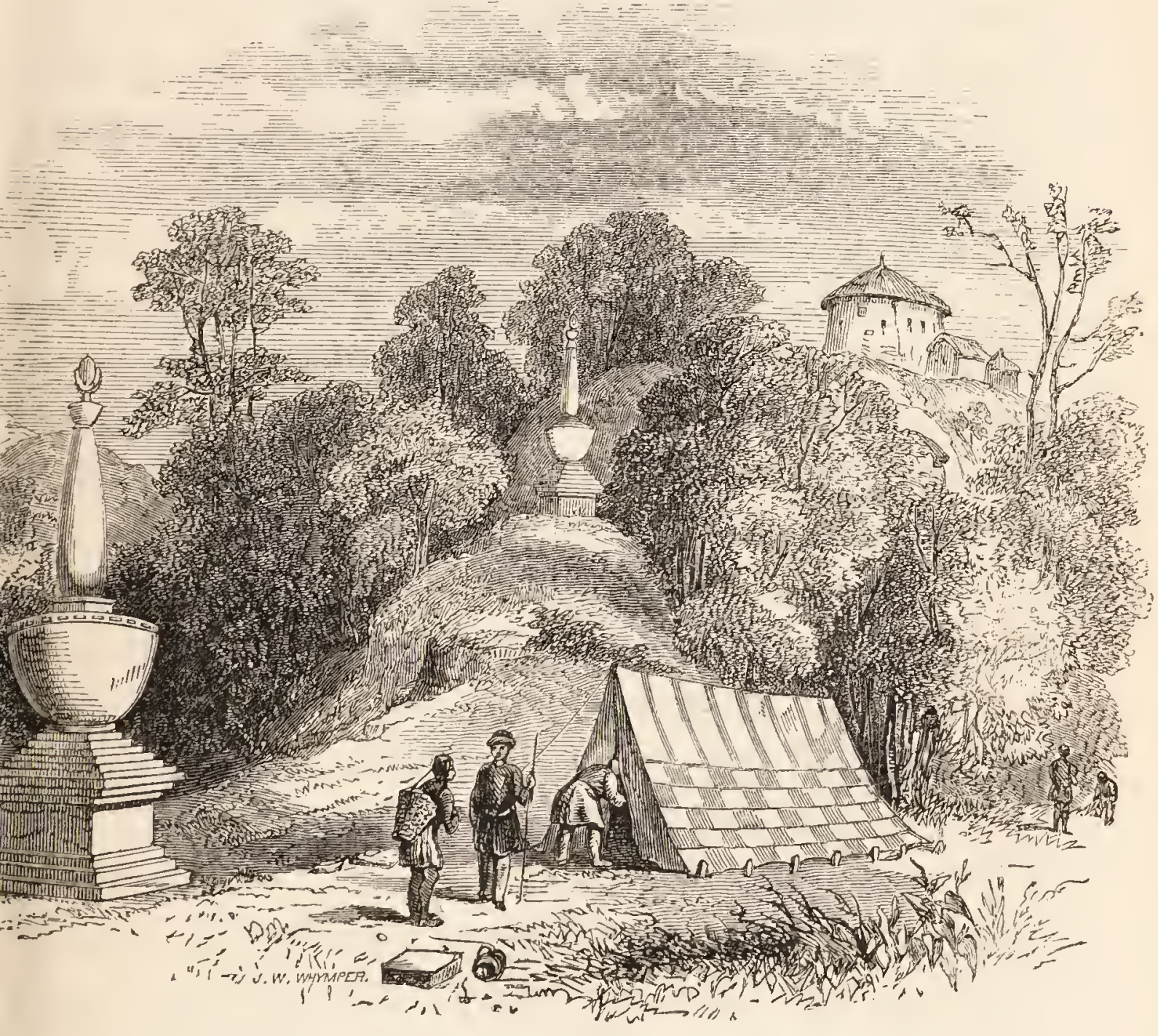

PEMIONGGH GOOMPA AND CHAITS.

buried, the richer burned, and their ashes scattered or interred, but not in graves proper, of which there are none. Nor are there any signs of interment throughout Sikkim; though chaits are erected to the memory of the departed, they have no necessary connection with the remains. Corpses in Sikkim are never cut to 
pieces and thrown into lakes, or exposed on hills for the kites and crows to devour, as is the case in Tibet.

We passed some curious masses of crumpled chlorite slate, presenting deep canals or furrows, along which a demon once drained all the water from the Pemiongchi spur, to the great annoyance of the villagers; the Lamas, however, on choosing this as a site for their temples, easily confounded the machinations of the evil spirit.

I crossed the Great Rungeet at 1840 feet above the sea, where its bed was twenty yards in width; a rude bridge, composed of two culms of bamboo and a handrail, conducted me to the other side, where we camped (on the east bank) in a thick tropical jungle, on a gravel flat, about sixty feet above the river.

I thence proceeded west, following a steep ascent up a very long spur, dividing the Great Rungeet from the Teesta. I ascended by a narrow path, accomplishing 2500 feet in an hour and a quarter, walking slowly but steadily, without resting; this I always found a heavy pull in a hot climate.

At about 4000 feet above the sea, the spur became more open and flat, like those of the Kulhait valley, with alternate slopes and comparative flats: from this elevation the view was very fine; the river flowed below, and a few miles up it was the conical wooded hill of Tassiding, rising abruptly from a fork of the deep gorge, crowned with its curious temples and mendongs, and bristling with chaits ; on it is the oldest monastery in Sikkim, occupying a picturesque and prominent position. North of this spur lay that of Raklang, with 
the temple and monastery of the same name. In front, looking west across the Great Rungeet, were the monasteries of Changachelling and Pemiongchi, perched aloft; and south of these were the flat-topped spurs of the Kulhait valley, with their villages, and the great mendong which I had passed on the previous day, running like a white line down the mountain. To the north, beyond Tassiding, were two other monasteries, Doobdee and Sunnook, both apparently placed on the lower flanks of Kinchinjunga; whilst close by was Dholing, the seventh religious establishment in sight.

We halted at a good wooden house to refresh ourselves with Murwa beer, where I bought a little puppy, of a breed between the famous Tibet mastiff and the common Sikkim hunting-dog, which is a variety of the sorry race called Pariah in the plains. Being only a few weeks old, he looked a mere bundle of black fur; and I carried him off, for he could not walk.

We camped at the village of Lingdam (alt. 5550 feet), occupying a flat, and surrounded by extensive pools of water (for this country) containing Sweet-flag, Potamogeton, and duck-weed. I have often met with such ponds on these terraces, and they are very remarkable, not being dammed in by any conspicuous barrier, but simply occupying depressions in the surface.

This being the high road from Tumloong or Sikkim Durbar (the capital, and Rajah's residence) to the numerous monasteries which I had seen, we passed many Lamas and monks on their way home from Tumloong, where they had gone to be present at the marriage of the Tupgain Lama, the eldest son of the 
Rajah. A dispensation having previously been procured from Lhassa, this marriage had been effected by the Lamas, in order to counteract the efforts of the Dewan, who sought to exercise an undue influence over the Rajah and his family. The Tupgain Lama having only spiritual authority, and being bound to celibacy, the temporal authority had devolved on the second son, who was heir-apparent; he, however, having died, an illegitimate son of the Rajah had been favoured by the Dewan as heir-apparent. The bride was brought from Tibet, and the marriage party was feasted for eighteen days at the Rajah's expense. All the Lamas whom I met were clad in red robes, with girdles, and were shaven, with bare feet and heads, or mitred; they wore rosaries of onyx, turquoise, quartz, lapis-lazuli, coral, glass, amber, or wood: some had staves, and one a trident on a long staff, an emblem of the Hindoo Trinity, called Trisool Mahadeo, which represents Brahma, Siva, and Vishnu, in Hindoo; and Booddh, Dhurma, and Sunga, in Booddhist theology. All were on foot, indeed ponies are seldom used in this country; the Lamas, however, walked with becoming gravity and indifference to all around them.

The Kajee waited upon me in the evening, full of importance, having just received a letter from his Rajah, which he wished to communicate to me in private; so I accompanied him to a house close by, where he was a guest, when the secret came out, that his highness was dreadfully alarmed at my coming with the two Nepalese soldiers, whom I accordingly dismissed. 
The house was of the usual Bhotean form, of wood, built on posts, one-storied, containing a single apartment, hung round with bows, quivers, shields, baskets of rice, and cornucopias of Indian corn. The whole party were deep in a carouse on Murwa beer, and I saw the operation of making it. The millet-seed is moistened, and ferments for two days; sufficient for a day's allowance is then put into a vessel of wickerwork, lined with India-rubber to make it water-tight; and boiling water is poured on with a ladle of gourd, from a huge iron cauldron that stands all day over the fire. The fluid, when quite fresh, tastes like negus of Cape sherry, rather sour.

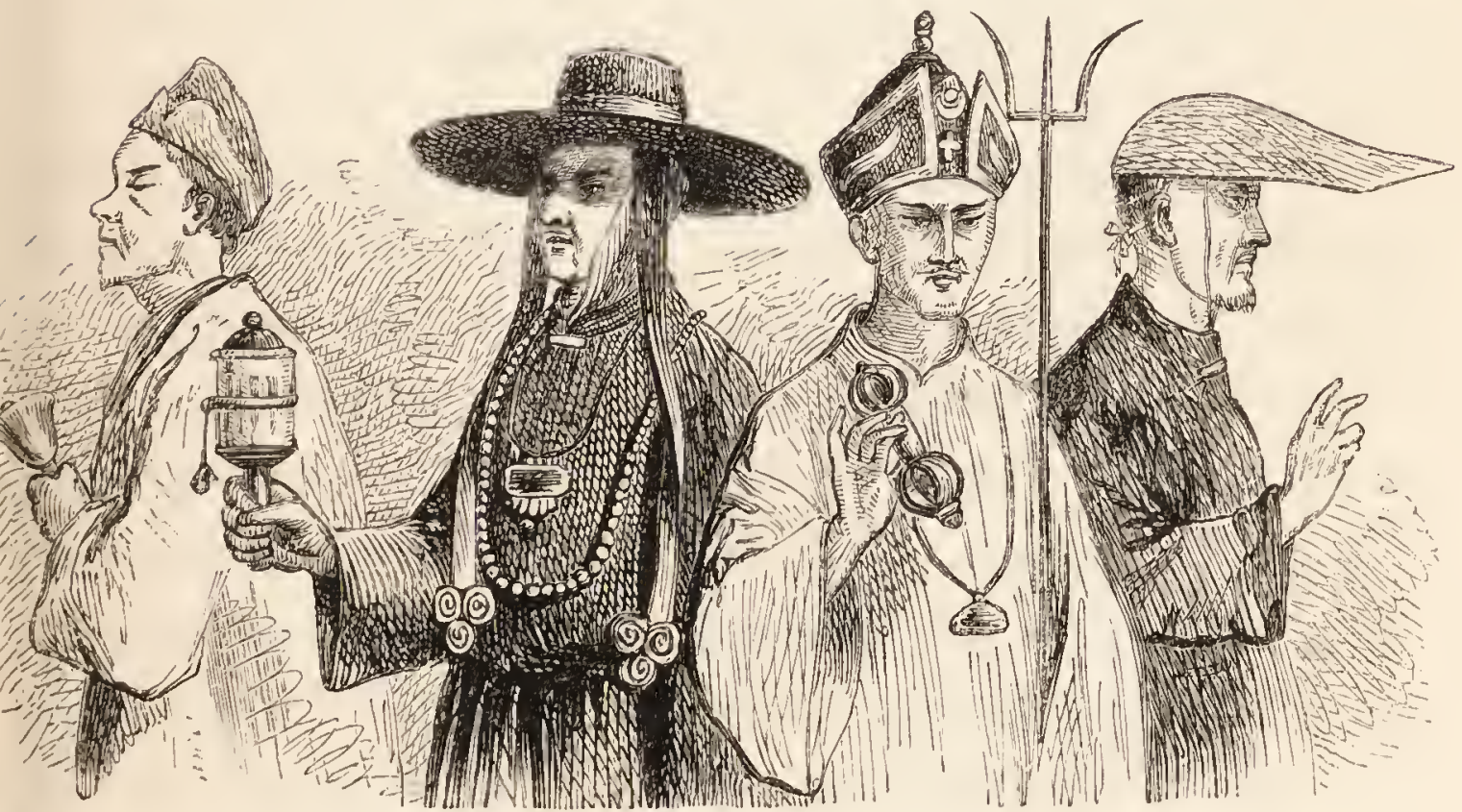

SIKKIM LAMAS WITH PRAYING CYLINDER AND DORJE; THE LATERAL FIGURES ARE MONKS OR GYLONGS. 


\section{CHAPTER XIII.}

Raklang pass-Uses of nettles-Edible plants-Lepcha war-Do-mani stone-Neongong-Teesta valley-Pony, saddle, \&c.-Meet Campbell - Vegetation and scenery-Presents-Visit of Dewan-Characters of Rajah and Dewan-Accounts of Tibet-Lhassa-Siling-Tricks of Dewan-Walk up Teesta-Audience of Rajah-Lamas-KajeesTchebu Lama, his character and position-Effects of interview-Heirapparent-Dewan's house-Guitar-Tibet officers-Gigantic treesNeongong lake-Mainom, ascent of-Vegetation-Camp on snowView from top-Kinchin, \&c.-Vapours-Sunset effect-Temperature, \&c.-Lamas of Neongong-Temples-Religious festival-Bamboo, flowering-Recross pass of Raklang-Numerous temples, villages, \&c. -Domestic animals-Descent to Great Rungeet.

ON the following morning, after receiving the usual presents from the Lamas of Dholing, and from a large posse of women belonging to the village close by, I ascended the Raklang pass, which crosses the range dividing the waters of the Teesta from those of the Great Rungeet. The Kajee still kept beside me, and proved a lively companion: seeing me continually plucking and noting plants, he gave me much local information about them. He told me the uses made of the fibres of the various nettles; some being twisted for bowstrings, others as thread for sewing and weaving; while many are eaten raw and in soups, especially the numerous little succulent species. The great yellow- 
flowered Begonia was abundant, and he cut its juicy stalks to make sauce (as we do apple-sauce) for some pork which he expected to get at Bhomsong; the taste is acid and very pleasant. A large succulent fern, called Botrychium, grew here plentifully; it is boiled and eaten, both here and in New Zealand. Ferns are more commonly used for food than is supposed. In Calcutta the Hindoos boil the young tops of a Polypodium with their shrimp curries; and both in Sikkim and Nepal the watery tubers of an Aspidium are abundantly eaten. So also the pulp of one tree-fern affords food, but only in times of scarcity, as does that of another species in New Zealand: the pith of all is composed of a coarse sago.

A thick forest covers the summit, which is only 6,800 feet above the sea; it is a saddle, connecting the lofty mountain of Mainom (alt. 11,000 feet) to the north, with Tendong (alt. 8,663 feet) to the south. Both these mountains are on a range continuous with Kinchinjunga, projecting from it down into the very heart of Sikkim. A considerable stand was made here by the Lepchas during the Nepal war in 1787; they defended the pass for some hours, and then retired towards the Teesta, making a second stand lower down, where rocks on either side gave them the same advantages. The Nepalese, however, advanced to the Teesta, and then retired with little loss.

Unfortunately a thick mist and heavy rain cut off all view of the Teesta valley, and the mountains of Chola to the eastward; which I much regretted.

Descending by a very steep, slippery path, I came 
to a fine mass of slaty gneiss, thirty feet long and thirteen high, lying on the mountain side: on its sloping face was carved in enormous characters, "Om Mani Padmi om;" of which letters the top-strokes afford an uncertain footing to the enthusiast who is willing to

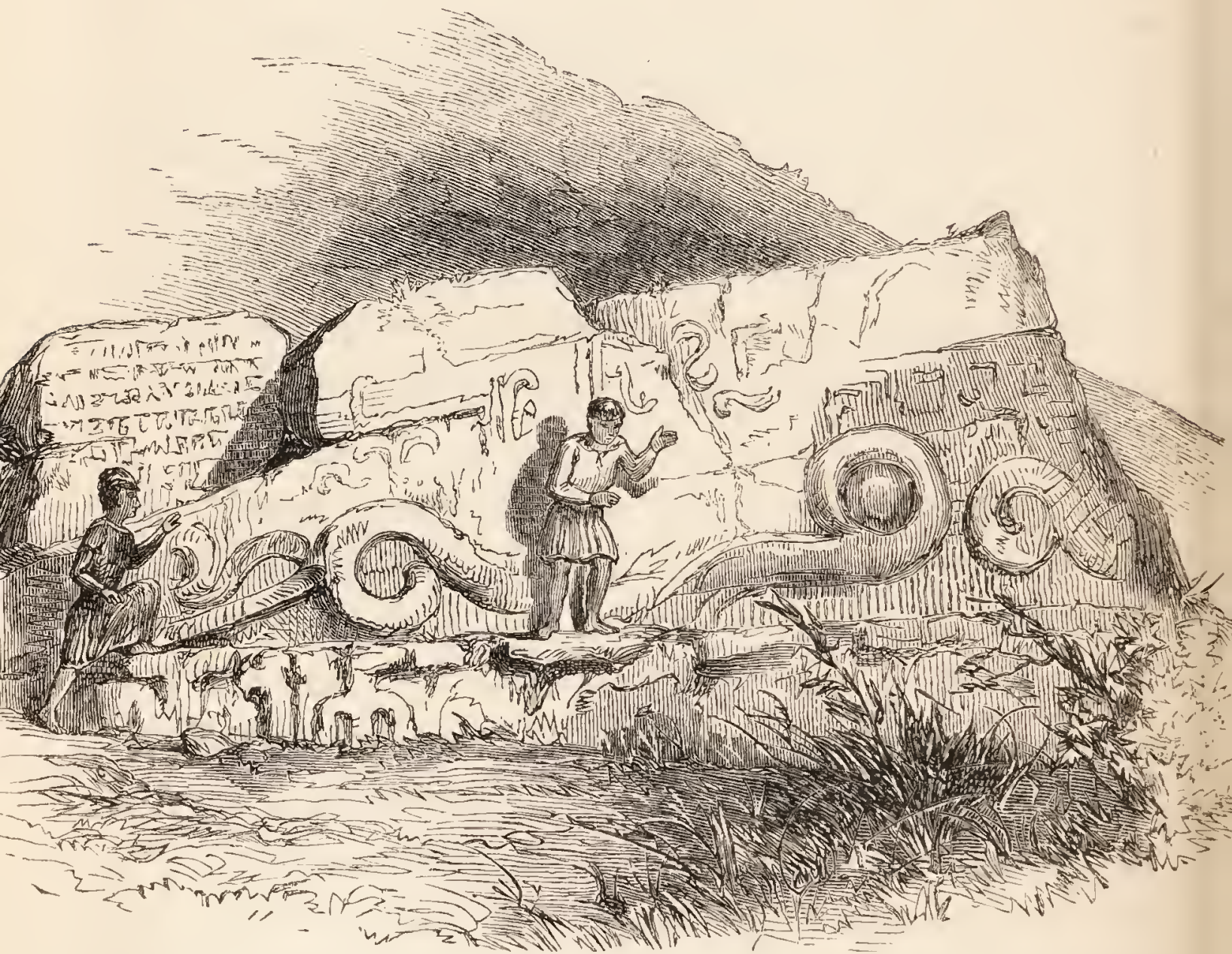

DO-MANI STONE.

purchase a good metempsychosis by walking along the slope, with his heels or toes in their cavities. An inscription in one corner is said to imply that this was the work of a pious monk of Raklang; and the stone is called "Do-mani," literally, "stone of prayer."

The rocks of Mainom are said to overhang the descent with grandeur; but the continued rain hid 
everything but a curious peak, apparently of chlorite schist, which was close by, and reflected a green colour: it was reported to be of turquoise, and inaccessible.

Lower down, I passed the monastery of Neongong, the monks of which were building a new temple; and came to bring me a large present. Below it is a pretty little lake about one hundred yards across, fringed with brushwood. We camped at the village of Nampok, 4,370 feet above the sea; where on the following morning a messenger arrived from Dr. Campbell, who told me he was waiting breakfast; so I left my party, and, accompanied by the Kajee and Meepo, hurried down to the valley of the Rungoon (which flows east to the Teesta), through a fine forest of tropical trees; passing the villages of Broom* and Lingo, to the spur of that name; where I was met by a servant of the Sikkim Dewan, with a pony for my use. I stared at the animal, and felt inclined to ask what he had to do here, where it was difficult even to walk up and down slippery slopes, amongst boulders of rock, heavy forest, and foaming torrents; but I was little aware of what these beasts could accomplish. The Tartar saddle was imported from Tibet, and certainly a curiosity; oncebut a long time ago-it must have been very handsome; it was high-peaked, covered with shagreen and silvered ornaments, wretchedly girthed, and with great stirrups attached to short leathers. The bridle and

* On the ridge above Broom a tall stone is erected, covered with marks, indicating the height of various individuals; there was but one mark above 5 feet $\tau$ inches, and that was six inches higher. It turned out to be Campbell's, who had passed a few days before, and was thus proved to top the natives of Sikkim by a long way. 
head-gear were much too complicated for description; there were good leather, raw hide, hair-rope, and scarlet worsted all brought into use; the bit was the ordinary Asiatic one, jointed and with two rings. I mounted on one side, and at once rolled over, saddle and all, to the other; the pony standing quite still. I preferred walking; but Dr. Campbell had begged of me to use the pony, as the Dewan had procured and sent it at some trouble: I, however, had it led till I was close to Bhomsong, when I was hoisted into the saddle and balanced on it, with my toes in the stirrups and my knees up to my breast; twice, on the steep descent to the river, my saddle and I were thrown on the pony's neck; in these emergencies I was assisted by a man on each side, who supported my weight on my elbows: they seemed well accustomed to easing mounted ponies down bill. Thus I entered Dr. Campbell's camp at Bhomsong, to the pride and delight of my attendants; and received a hearty welcome from my friend, who covered me with congratulations on the successful issue of a journey which, at this season, and under such difficulties, he had hardly thought feasible.

Dr. Campbell's tent was pitched in an orange-grove, on the west bank of the Teesta, close to a small enclosure of pine-apples, with a pomegranate tree in the middle. The valley is very narrow, and the vegetation wholly tropical; the river is a grand feature, broad, deep, swift, and broken by enormous boulders of rock; its waters were of a pale opal green, probably from the materials of the rocks through which 
it flows. A cane bridge crosses it, but had been cut away in feigned distrust of us, and the long canes were streaming from their attachments on either shore down the stream, and a triangular raft of bamboo was plying instead, drawn to and fro by means of a strong cane.

Soon after arriving I received a present from the Rajah, consisting of a brick of Tibet tea, eighty pounds of rancid yak butter, in large squares, done up in yakhair cloth, three loads of rice, and one of Murwa for beer ; rolls of bread, fowls, eggs, dried plums, apricots, jujubes, currants, and Sultana raisins, the latter fruits purchased at Lhassa, but imported thither from westerm Tibet; also some trays of coarse crystallized salt, as dug in Tibet.

In the evening we were visited by the Dewan, the head and front of all our difficulties, whose influence was paramount with the Rajah, owing to the age and infirmities of the latter, and his devotion to religion. The Dewan was a good-looking Tibetan, very robust, fair, and muscular; he had a very broad Tartar face, quite free of hair; a small and beautifully formed mouth and chin, very broad cheekbones, and a low; contracted forehead: his manners were courteous and polite, but evidently affected, in assumption of better breeding than he could in reality lay claim to. The Rajah himself was a Tibetan of just respectable extraction: his Dewan was related to one of his wives,

* These rolls, or rather sticks of bread, are made in Tibet, of fine wheaten flour, and keep for a long time : they are sweet and good, but very dirtily prepared. 
and I believe a Lhassan by birth as well as extraction, having probably also Kashmir blood in him. Though minister, he was neither financier nor politician, but a mere plunderer of Sikkim, introducing his relations, and those whom he called so, into the best estates in the country, and trading in great and small wares, from a Tibet pony to a tobacco pipe, wholesale and retail. Neither he nor the Rajah were considered worthy of notice by the best Tibet families or priests, or by the Chinese commissioners settled in Lhassa and Jigatzi. The latter regard Sikkim as virtually English, and are contented with knowing that its ruler has no army, and with believing that its protectors, the English, could not march an army across the Himalaya, if they would.

The Dewan, trading in wares which we could supply better and cheaper, naturally regarded us with repugnance, and did everything in his power to thwart Dr. Campbell's attempts to open a friendly communication between the Sikkim and English governments. The Rajah owed everything to us, and was, I believe, really grateful; but he was a mere cipher in the hands of his minister. The priests again, while rejoicing in our proximity, were apathetic, and dreaded the Dewan; and the people had long given evidence of their confidence in the English. Under these circumstances it was in the hope of gaining the Rajah's own ear, and representing to him the advantages of promoting an intercourse with us, and the danger of continuing to violate our treaty, that Dr. Campbell had been authorised by government to seek an 
interview with his Highness. At present our relations were singularly infelicitous. There was no agent on the Rajah's part to conduct business at Dorjiling, as the Dewan insisted on sending a creature of his own, who had before been dismissed for insolence. Malefactors who escaped into Sikkim were protected, and our police interrupted in the discharge of their duties; slavery was practised; and government communications were detained for months under false pretences.

In his interviews with us the Dewan appeared to advantage: he was fond of horses and shooting, and prided himself on his hospitality. We gained much information from conversations with him, during which politics were never touched upon. Our queries naturally referred to Tibet, especially its great feature the Yarou Tsampoo river; this he assured us was the Burrampooter of Assam, and that no one doubted it in that country. Lhassa he described as lying in the bottom of a flat-floored valley, surrounded by snowy mountains: neither grapes, tea, silk, nor cotton are produced near it, but in the Tartchi province, one month's journey to the eastward, rice, and a coarse kind of tea are both grown. Two months' journey north-east of Lhassa is Siling, the well-known great commercial entrepott* in west China; and there coarse silk is produced. All Tibet he described as mountainous, and an inconceivably poor country: there are no plains, save flats in the bottoms of the valleys, and the paths lead over lofty mountains. Sometimes,

* The entrepôt is now removed to Tang-Keou-Eul. - See Huc and Gabet. 
when the inhabitants are obliged from famine to change their habitations in winter, the old and feeble are frozen to death, standing and resting their chins on their staves; remaining as pillars of ice, to fall only when the thaw of the ensuing spring commences.

We remained several days at Bhomsong, awaiting an interview with the Rajah, whose movements the Dewan kept shrouded in mystery. On Dr. Campbell's arrival a week before, he found messengers waiting to inform him that the Rajah would meet him here; this being half way between Dorjiling and Tumloong. Thenceforward every subterfuge was resorted to by the Dewan to frustrate the meeting; and even after the arrival of the Rajah on the east bank, the Dewan communicated with Dr. Campbell by shooting across the river arrows to which were attached letters, containing every possible argument to induce him to return to Dorjiling; such as that the Rajaln was sick at Tumloong, that he was gone to Tibet, that he had a religious fast and rites to perform, \&c. \&c.

One day we walked up the Teesta to the Rumphiup river, a torrent from Mainom mountain to the west; the path led amongst thick jungles of palm, prickly rattan canes, and a screw-pine, called "Borr," which has a straight, often forked, palm-like trunk, and an immense crown of grassy, saw-edged leaves, four feet long; it bears clusters of uneatable fruit as large as a man's fist, and their similarity to the pine-apple has suggested the name of "Borr" for the latter fruit also, which has for many years been cultivated in Sikkim, and yields indifferent produce. Beautiful pink balsams 
covered the ground, but at this season few other showy plants were in flower.

Messenger's from the Dewan overtook us at the river to announce that the Rajah was waiting to give us a reception; so we returned, and crossed on the bamboo-raft. As it is the custom on these occasions to exchange presents, I was supplied with some red cloth and beads; these, as well as Dr. Campbell's present, should only have been delivered during or after the audience, but our wily friend the Dewan here played us a very shabby trick; for he managed that our presents should be brought in before our appearance, thus giving to the by-standers the impression of our being tributaries to his Highness!

The audience chamber was a mere roofed shed of neat bamboo wattle, about twenty feet long: two Bhoteas in scarlet jackets, and with bows in their hands, stood on each side of the door, and our own chairs were carried before us for our accommodation. Within was a square wicker throne, six feet high, covered with purple silk, brocaded with dragons in white and gold, and overhung by a canopy of tattered blue silk, with which material part of the walls also was covered. An oblong box (containing papers) with gilded dragons on it, was placed on the stage or throne, and behind this was perched cross-legged, an odd, black, insignificant looking old man, with twinkling upturned eyes: he was swathed in yellow silk, and wore on his head a pink silk hat with a flat broad crown, from all sides of which hung floss silk. This was the Rajah, a genuine Tibetan, about seventy years old. On some steps 
close by, and ranged down the apartment, were his relations, all in brocaded silk robes reaching from the throat to the ground, and girded about the waist; and wearing caps similar to that of the Rajah. Kajees, counsellors, and mitred Lamas were there, to the number of twenty, all planted with their backs to the wall, mute and motionless as statues. A few spectators were huddled together at the lower end of the room, and a monk waved about an incense pot containing burning juniper and other odoriferous plants.

We saluted, but received no return; we then seated ourselves, when the Dewan came in, clad in a superb purple silk robe, worked with circular gold figures, and formally presented us. As the Rajah did not: understand Hindoostanee, our conversation was carried on through the medium of a little bare-headed rosycheeked Lama, named "Tchebu," who acted as inter. preter. The conversation was short and constrained: Tchebu was known as a devoted servant of the Rajah; and in common with all the Lamas hated the Dewan, and desired a friendly intercourse between Sikkim and Dorjiling. He was, further, the only servant of the Rajah capable of conversing both in Hindoo and Tibetan ; and the uneasy distrustful look of the Dewan, who understood the latter language only, was very evident. He was as anxious to hurry over the interview, as Dr. Campbell and Tchebu were to protract it; it was clear, therefore, that nothing satisfactory could be done under such auspices.

As a signal for our departure white silk scarfs were thrown over our shoulders, according to the established 
custom in Tibet, Sikkim, and Bhotan; and presents were made to us of China silks, bricks of tea, woollen cloths, yaks, ponies, and salt, with worked silk purses and fans for Mrs. Campbell; after which we left. The whole scene was novel and very curious. We had had no previous idea of the extreme poverty of the Rajah, of his utter ignorance of the usages of Oriental life, and of his not having any one near to instruct him. The neglect of our salutation, and the conversion of our presents into tribute, did not arise from ill-will; but was owing to the craft of the Dewan in taking advantage of the Rajah's ignorance of his own position, and of good manners. Miserably poor, without any retinue, and taking no interest in what passes in his own kingdom, subsisting on the coarsest food, effectually abstracting his mind from the consideration of earthly things, and wrapt in contemplation, the Sikkim Rajah has arrived at great sanctity, and is all but prepared for that absorption into the essence of Booddh, which is the aim of all good Booddhists. The conduct of his courtiers, who looked like attendants at an inquisition, and the profound attention expressed in every word and gesture of those who did move and speak, recalled a Pekin reception. His attendants treated him as a being of a different nature from themselves; and well might they do so, since they believe that he will never die, but retire from the world only to re-appear under some equally sainted form.

Though productive of no immediate good, our interview had a very favourable effect on the Lamas and 
people, who had long wished it; and the congratulations we received thereon during the remainder of our stay in Sikkim were many and sincere. The Lamas we found universally in high spirits, on account of the marriage of the heir-apparent, who was said to possess much ability and prudence, and hence to be very obnoxious to the Dewan, who vehemently opposed the marriage. As, however, the minister had established his influence over the youngest, and estranged the Rajah from his eldest son, and was moreover in a fair way for ruling Sikkim himself, the Church rose in a body, procured a dispensation from Lhassa for the marriage of a priest, and thus hoped to undermine the influence of the violent and greedy stranger.

In the evening, we paid a farewell visit to the Dewan, whom we found in a bamboo wicker-work hut, neatly hung with bows, arrows, and round Lepcha shields of cane, each with a scarlet tuft of yak-hair in the middle; there were also muskets, Tibetan arms, and much horse-gear; and at one end was a little altar, with cups, bells, pastiles, and images. He was robed in a fawn-coloured silk gown, lined with the softest of wool, that taken from unborn lambs: like most Tibetans, he extracts his beard with tweezers; an operation he civilly recommended to me, accompanying the advice with the present of a neat pair of steel forceps. He aspires to be considered a man of taste, and plays the Tibetan guitar, on which he performed some airs for our amusement; the instrument is roundbodied and long-armed, with six strings placed in pairs, and probably comes from Kashmir: the Tibetan airs 
were simple and quite pretty, with the time well marked.

Dr. Campbell's object being accomplished, he was anxious to make the best use of the few days that remained before his return to Dorjiling, and we therefore arranged to ascend Mainom, and together visit the principal convents; after which he was to return south, whilst I should proceed north to explore the south flank of Kinchinjunga. For the first day our route was that by which I had arrived. We started on Christmas-day, accompanied by two officers, of the ranks of Dingpun and Soupun, answering to those of captain and lieutenant; the titles were, however, nominal, the Rajah having no soldiers, and these men being profoundly ignorant of the mysteries of war or drill. They were splendid specimens of Sikkim Bhoteas (i.e. Tibetans, born in Sikkim, sometimes called Arratts), tall, powerful, and well built, but insolent and bullying: the Dingpun wore the Lepcha knife, ormamented with turquoises, together with Chinese chopsticks. Near Bhomsong, Campbell pointed out a hot bath to me, which he had seen employed; it consisted of a hollowed tree trunk, the water in which was heated by throwing in hot stones with bamboo tongs. The temperature is thus raised to $114^{\circ}$, to which the patient submits at intervals for several days, never leaving till wholly exhausted.

We stopped to measure some splendid trees in the valley, and found the trunk of one to be forty-five feet round the buttresses, and thirty feet above them, a large size for the Himalaya: they were a species of Terminalia. 
We slept at Nampok, and the following morning commenced the ascent: on the way we passed the temple and lake of Neongong. The latter is a mere pool, about 400 yards round, and has no outlet; it contained two English plants, the common duckweed, and Potamogeton natans: some coots were swimming in it, and having flushed a woodcock, I sent for my gun, but the Lamas implored us not to shoot, it being contrary to their creed to take life wantonly.

We left a great part of our baggage at Neongong, as we intended to return there; and took with us bedding, food, \&c., for two days. A path hence up the mountain is frequented once a year by the Lamas, who make a pilgrimage to the top for worship. We met with snow at the level of Dorjiling (7000 feet), indicating a colder climate than at that station, where none had fallen; the vegetation was, however, similar, but not so rich, and at 8000 feet trees common also to the top of Sinchul appeared, with Rhododendron Hodgsoni, and a beautiful little winter-flowering primrose, whose stemless flowers spread like broad purple stars on the deep green foliage. Above, the path runs along the ridge of the precipices facing the south-east, and here we caught a glimpse of the great valley of the Ryott, beyond the Teesta, with Tumloong, the Rajah's residence, on its north flank, and the superb snowy peak of Chola at its head.

One of our coolies, loaded with crockery and various indispensables, had here a severe fall, and was much bruised; he however recovered himself, but not our goods. At 9000 feet the snow became deep and 
troublesome, so we encamped 800 feet below the top, in a wood of Magnolia, Rhododendron, and bamboo; our beds being laid on a thick layer of rhododendron twigs, bamboo, and masses of moss.

On the following morning we reached the summitafter an hour's very laborious ascent, and took up our quarters in a large wooden barn-like temple (goompa) built on a stone-platform. The summit was very broad, but the depth of the snow prevented our exploring much, and the silver firs were so tall, that no view could be obtained, except from the temple. The great peak of Kinchinjunga is in part hidden by those of Pundim and Nursing, but the panorama of snowy mountains is very grand indeed. The effect is quite deceptive; the mountains assuming the appearance of a continuous chain, the distant snowy peaks being seemingly at little further distance than the nearer ones. The whole range appeared to rise uniformly and steeply out of black pine forests, which were succeeded by russet-brown rhododendron, and that again by tremendous precipices and gulleys, into which descended mighty glaciers and perpetual snows. This excessive steepness is however only apparent, being due to foreshortening.

The upper 10,000 feet of Kinchin, and the tops of Pundim, Kubra, and Junnoo, are evidently of granite, and are rounded in outline: the lower peaks, on the contrary, as those of Nursing, \&c., present rugged pinnacles of black and red rocks, in many cases resting on white granite, to which they offer a remarkable contrast. One range presented on every summit a cap of black 
rocks, with precipitous faces; this was clear to the naked eye, the range in question being only fifteen miles distant, running between Pundim and Nursing.

We enjoyed the view of this superb scenery till noon, when the clouds which had obscured Dorjiling since morning were borne towards us by the southerly wind, rapidly closing in the landscape on all sides. At sunset they again broke, retreating from the northward, and rising from Sinchul and Dorjiling last of all, whilst a line of vapour seemed to belt the Singalelah range with a white girdle, darkened to black where it crossed the snowy mountains; and it was difficult to believe that this belt did not really hang upon the ranges from twenty to thirty miles off, against which it was projected; or that its true position was comparatively close to the mountain on which we were standing, and was due to condensation around its cool, broad, flat summit.

As usual from such elevations, sunset produced many beautiful effects. The zenith was a deep blue, darkening opposite the setting sun, and paling over it into a peach colour, and that again near the horizon passing into a glowing orange-red, crossed by coppery streaks of cirrhus. Broad beams of pale light shot from the sun to the meridian, crossing the moon and the planet Venus. Far south, through gaps in the mountains, the position of the plains of India, 10,000 feet below us, was indicated by a deep leaden haze, fading upwards in gradually paler bands (of which I counted fifteen) to the clear yellow of the sunset sky. As darkness came on, the mists collected around the 
top of Mainom, accumulating on the windward side, and thrown off in ragged masses from the opposite.

The second night we passed here was fine, and not very cold (the mean temperature being $27^{\circ}$ ), and we kept ourselves quite warm by pine-wood fires.

Having taken sketches and observations, and collected much information from our guides, we returned on the 28th to our tents at Neongong; descending 7000 feet, a very severe shake along Lepcha paths. In the evening the Lamas visited us, with presents of rice, fowls, eggs, \&c., and begged subscriptions for their temple, which was then being built; reminding Dr. Campbell that he and the Governor-General had an ample share of their prayers, and benefitted in proportion. As for me, they said, I was bound to give alms, as I surely needed praying for, seeing how I exposed myself; besides my having been the first Englishman who had visited the snows of Kinchinjunga, the holiest spot in Sikkim.

On the following morning we visited the unfinished temple. The outer walls were of slabs of stone neatly chiselled, but badly mortared with clay and pounded slate; the partition walls were of clay, shaped in moulds of wood; parallel planks, four feet asunder, being placed in the intended position of the walls, and left open above, the composition was placed in these boxes, a little at a time, and rammed down by the feet of many men, who walked round and round the narrow enclosure, singing, and using rammers of heavy wood. The outer work was of good hard timber, of Magnolia and oak. The common "Ban," or Lepcha knife, 
supplied the place of axe, saw, adze, and plane; and the graving work was executed with small tools, chiefly on Toon, a very soft wood.

This being a festival day, when the natives were bringing offerings to the altar, we also visited the old temple, a small wooden building. Besides more substantial offerings, there were little cones of rice, each with a round wafer of butter at the top, ranged in order on the altar.* Six Lamas were at prayer, psalms, and contemplation, sitting cross-legged on two small benches that ran down the building: one read, with his fore-finger elevated, whilst the others listened; anon they all sang hymns, repeated sacred or silly precepts to the bystanders, or joined in a chorus with boys, who struck brass cymbals, and blew straight copper trumpets six feet long, and conch-shells mounted with broad silver wings, elegantly carved with dragons. There were besides praying-cylinders, drums, gongs, books, and trumpets made of human thigh-bones, both plain and mounted in silver.

Throughout Sikkim, we were roused each morning at daybreak by this wild music, the convents being so numerous that we were always within hearing of it. To me it was deeply impressive, awakening me so

* The worshippers, on entering, walk up to the altar, and before or after having deposited their gifts, they lift both hands to the forehead, fall on their knees, and touch the ground three times with head and hands. They then advance to the head Lama, kotow similarly to him, and he blesses them, laying both hands on their heads and repeating a short formula. Sometimes the dorje is used in blessing, as the cross is in Europe, and when a number of people request a benediction, the Lama pronounces it from the door of the temple with outstretched arms, the people all being prostrate, with their foreheads touching the ground. 
effectually to the strangeness of the wild land in which I was wandering, and of the new and striking objects it contained. After sleep, too, during which the mind has either been at rest, or carried away to more familiar subjects, the feelings of loneliness and sometimes even of despondency, conjured up by this solemn music, were almost oppressive.

Ascending from Neongong, we reached that pass from the Teesta to the Great Rungeet, which I had crossed on the 22nd; and this time we had a splendid view, down both valleys, of the rivers, and the many spurs from the ridge communicating between Tendong and Mainom, often crowned with hamlets, surrounded by patches of cultivation. Near the top I found a plant of "Praong" (a small bamboo) in full seed; this sends up many flowering branches from the root, and but few leaf-bearing ones; and after maturing its seed, and giving off suckers, the parent plant dies. The fruit is a dark, long grain, like rice; it is boiled and made into cakes, or into beer, like Murwa.

Looking west from the summit, no fewer than ten monastic establishments, with their temples, villages, and cultivation, were at once visible, in the valley of the Great Rungeet, and in those of its tributaries; all of considerable size, and perched at elevations varying from 3000 to 7000 feet, and commanding splendid prospects.

We encamped at Lingcham, and the weather being fine, I took bearings of all the convents and mountains around. There was much cultivation here, and many comparatively rich villages. The houses were large, 
and the yards were full of animals familiar to the eye but not to the ear. The cows of Sikkim, though generally resembling the English in stature, form, and colour, have humps, and grunt rather than low; and the cocks wake the morning with a prolonged howling screech, instead of the shrill crow of chanticleer.

Hence we descended north-west to the Great Rungeet, opposite Tassiding; which is one of the oldest monastic establishments in Sikkim, and one we were very anxious to visit. The descent lay through a forest of tropical trees, where small palms, vines, peppers, screw-pine, wild plantain, and Pothos, were interlaced in an impenetrable jungle, and air-plants clothed the trees.

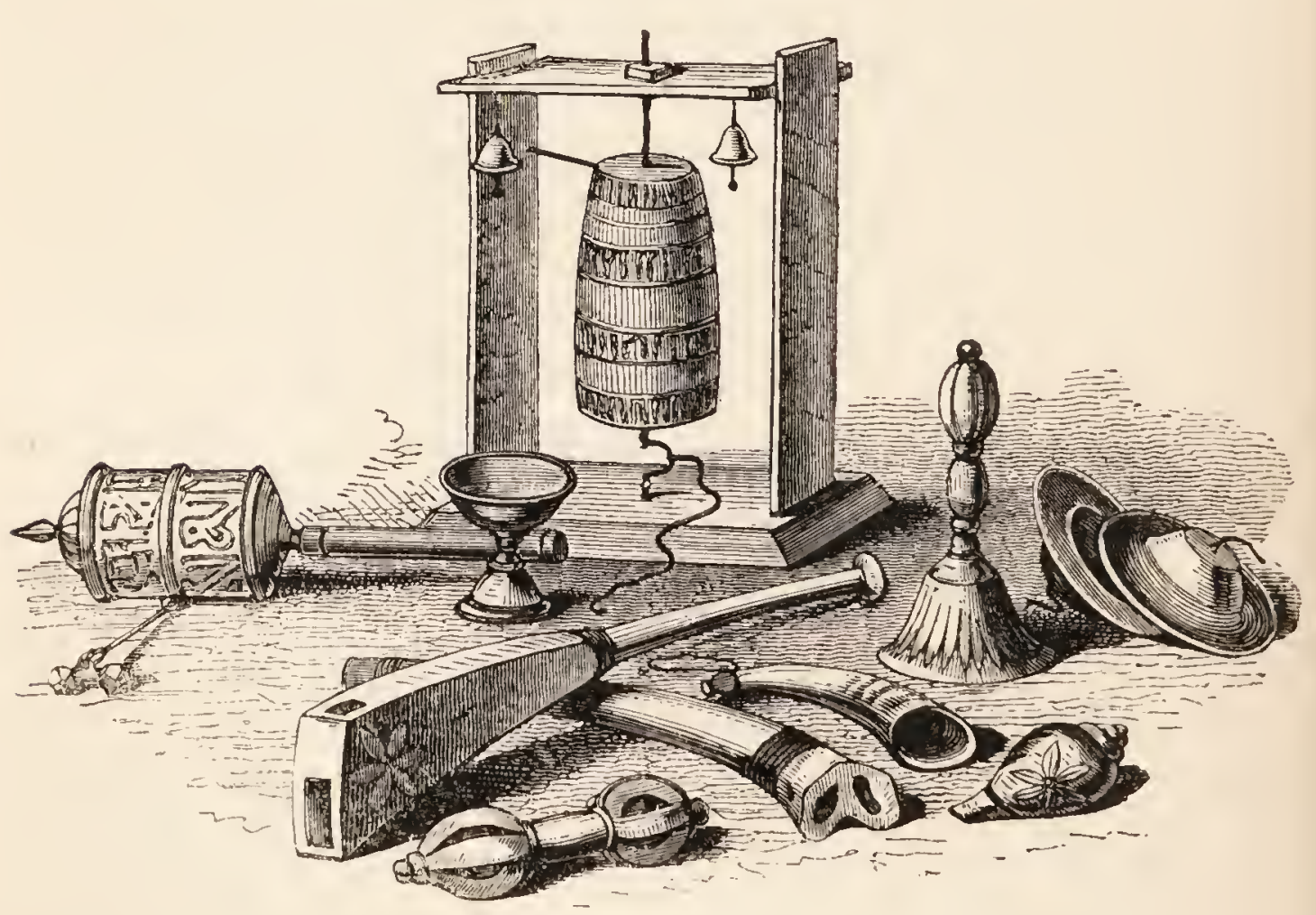

IIPLEMUN' TSED IN DOODHIST TEMPLES.

Praying cylinder in stand; another to be carried in the hand; cymbals; bell; brass cup; three trumpets; conch; dorje. 


\section{CHAPTER XIV.}

Tassiding, view of and from-Funereal cypress-Camp at Sunnook-Hot vapours-Lama's house-Temples, decorations, altars, idols, general effect-Chaits - Date of erection - Plundered by Ghorkas-Cross Ratong-Ascend to Pemiongchi-Pemiongchi, view from-Vegetation-Temple, decorations, \&c.-Former capital of Sikkim-History of Sikkim - Nightingales - Campbell departs - Tchonpong - Edgeworthia-Cross Rungbee and Ratong-Yoksun-Walnuts-ViewFunereal cypresses-Doobdi-Gigantic cypresses-Temples-Snowfall—Sikkim, \&c.-Toys.

Tassiding hill is the steep conical termination of a long spur from a fir-clad shoulder of Kinchinjunga, called Powhungri: it divides the Great Rungeet from its main feeder, the Ratong, which rises from the south face of Kinchin. We crossed the former by a bridge formed of two bamboo stems, slung by canes from two parallel arches of stout branches lashed together.

The ascent was up a very steep, dry, zigzag path, amongst many tropical plants, especially the "Tukla" (Rottlera tinctoria), a plant which yields a brown dye. The top was a flat, covered with temples, chaits, and mendongs of the most picturesque forms and in elegant groups, and fringed with brushwood, wild plantains, small palms, and apple-trees. Here I saw for the first time the funereal cypress, of which some very old trees 
spread their weeping limbs and pensile branchlets over the buildings.* It is not wild in Sikkim, but imported there and into Bhotan from Tibet; it does not thrive

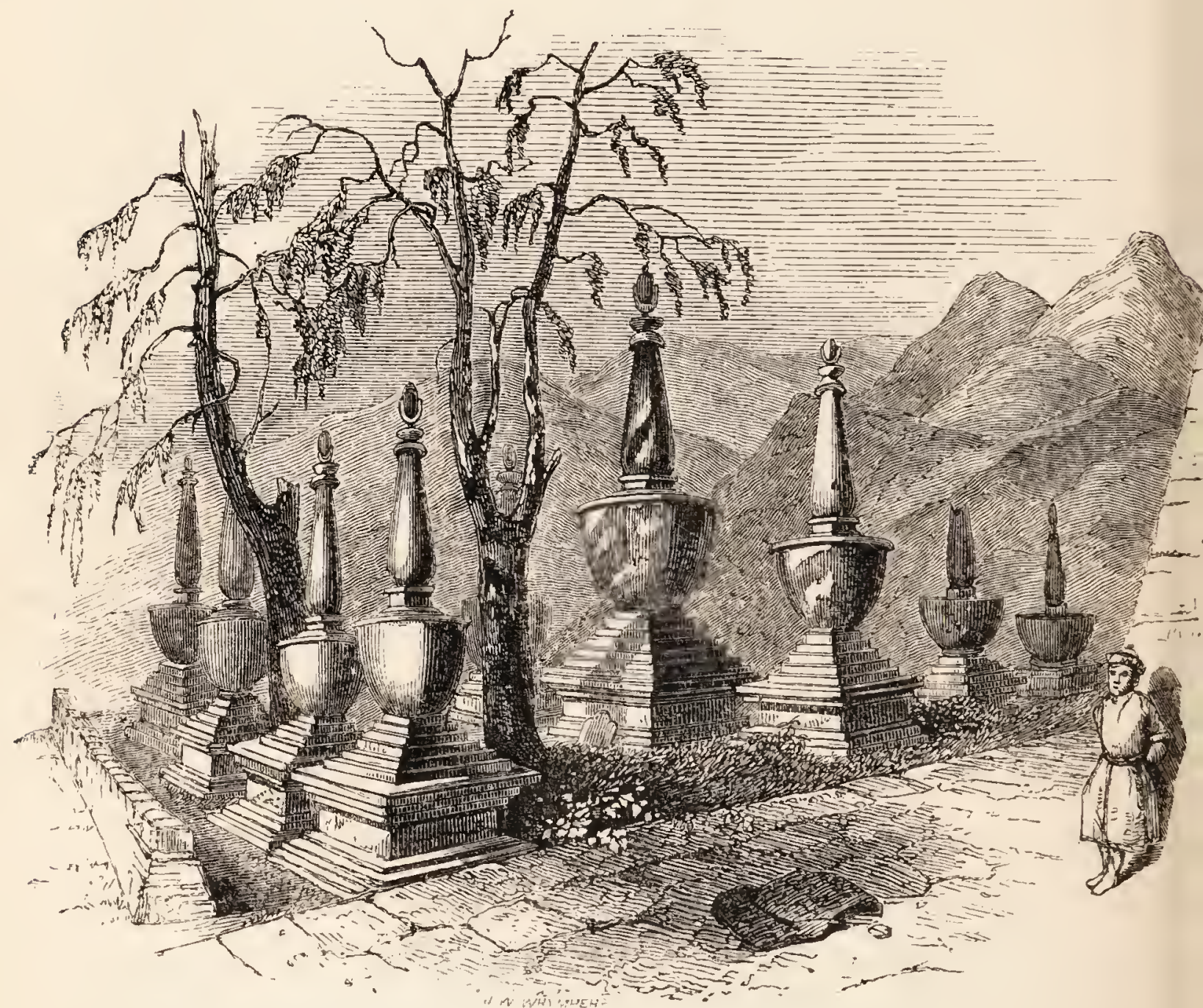

GROUP OF CHAITS AT TASSIDING.

well above 6000 feet elevation. It is called "Tchenden" by the Lepchas, Bhoteas, and Tibetans, and its fragrant red wood is burnt in the temples.

The Lamas met us on the top of the hill, bringing a

* I was not then aware of this tree having been introduced into England by the intrepid Mr. Fortune from China; and as I was unable to procure seeds, which are said not to ripen in Sikkim, it was a great and unexpected pleasure, on my return home, to find it alive and flourishing at Kew. 
noble present of fowls, vegetables and oranges, the latter most acceptable after our long and hot march. The site is admirably chosen, in the very heart of Sikkim, commanding a fine view, and having a considerable river on either side, with the power of retreating to the convents of Sunnook and Powhungri, which are higher up on the same spur, and surrounded by forest enough to conceal an army. Considering the turbulent character of their neighbours, it is not wonderful that the monks should have chosen commanding spots, and good shelter: for the same reason these monasteries secured views of one another.

We camped on a saddle near the village of Sunnook, at 4000 feet above the sea; and on the last day of the year we visited this most interesting monastic establishment; ascending from our camp by a narrow path, cut here and there into steps, and passing many rocks covered with inscriptions, broken walls of mendongs, and other remains of the via sacra between the village and temple. At one spot we found a fissure emitting hot vapour of the temperature of $65 \frac{1}{2}^{\circ}$, that of the air being about $50^{\circ}$. It was simply a hole amongst the rocks; and near the Rungeet a similar one is said to occur, whose temperature fluctuates considerably with the season. It is very remarkable that such an isolated spring should exist on the top of a ridge, 2800 feet above the bottom of this deep valley.

The general arrangement on the summit was, first the Lamas' houses with small gardens, then three large temples raised on rudely paved platforms, and beyond these, a square walled enclosure facing the south, full 
of chaits and mendongs, looking like a crowded cemetery, and planted with funereal cypresses.

The house of the principal Lama was an oblong square, the lower story of stone, and the upper of wood: we ascended a ladder to the upper room, which was 24 feet by 8 , wattled all round, with prettily latticed windows opening upon a bamboo balcony used for drying grain, under the eaves of the broad thatched roof. The ceiling (of neat bamboo work) was hung with glorious bunches of maize, yellow, red, and brown; an altar and closed wicker cage at one end of the room held the Penates, and a few implements of worship. Chinese carpets were laid on the floor for us, and the cans of Murwa brought round.

The Lama, though one of the red sect, was dressed in a yellow flowered silk robe, but his mitre was red: he gave us much information relative to the introduction of Boodhism into Sikkim.

The three temples stand about fifty yards apart, but are not parallel to one another, although their general direction is east and west. Each is oblong, and narrowed upwards, with the door at one end; the middle (and smallest) faces the west, the others the east: the doorways are all broad, low and deep, protected by a projecting carved portico. The walls are immensely thick, of well-masoned slaty stones; the outer surface of each slopes upwards and inwards, the inner is perpendicular. The roofs are low and thickly thatched, and project from eight to ten feet all round, to keep off the rain, being sometimes supported by long poles. There is a very low upper story, inhabited by the 
attendant monks and servants, accessible by a ladder at one end of the building. The main body of the temple

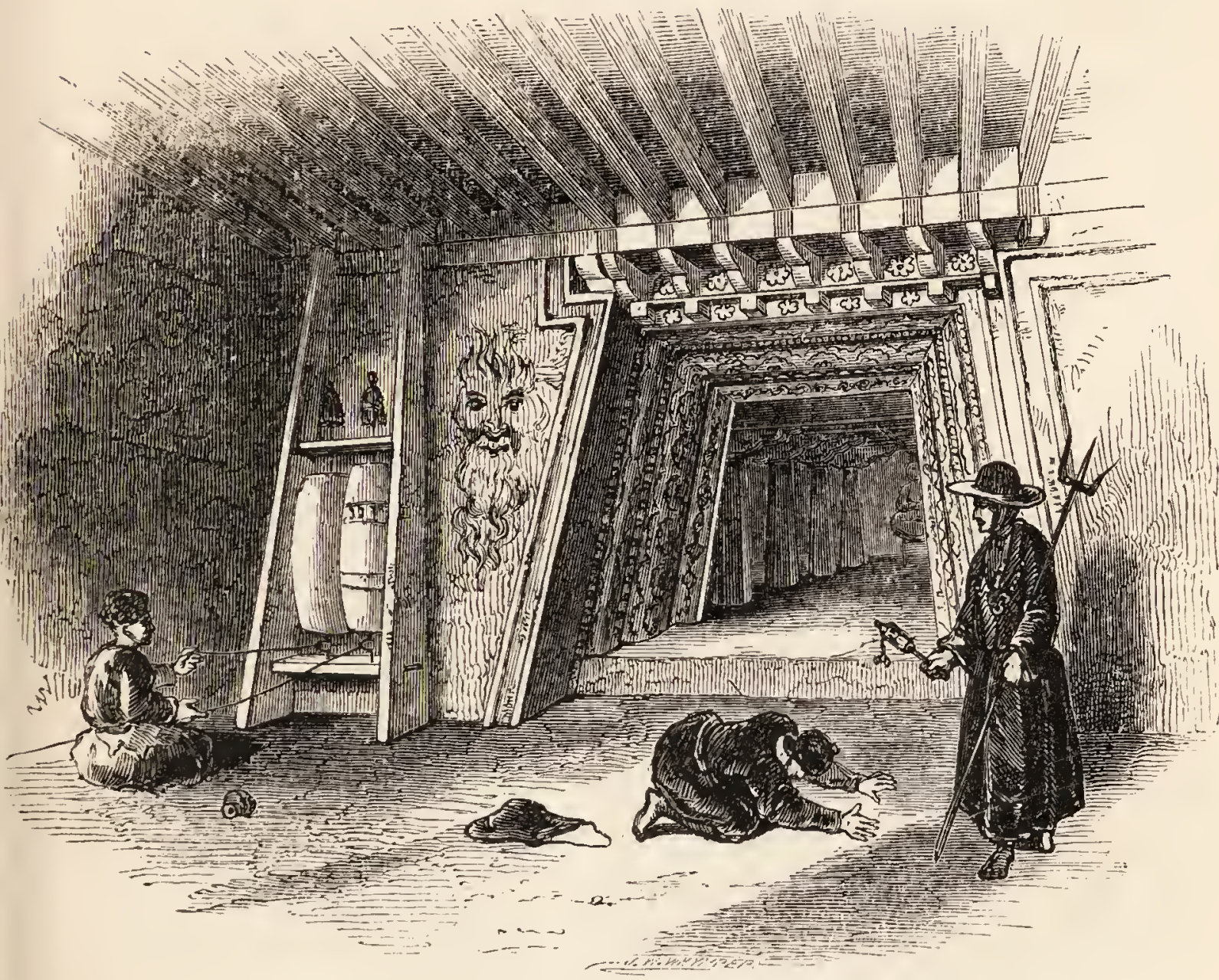

DOORWAY.

is one large apartment, entered through a small transverse vestibule, the breadth of the temple, in which are tall cylindrical praying-machines. The carving round the doors is very beautiful, and they are gaudily painted and gilded. The northern temple is quite plain : the middle one is simply painted red, and encircled with a row of black heads, with goggle eyes and numerous teeth, on a white ground; it is said to have been originally dedicated to the evil spirits of the Lepcha creed. The southern, which contains the library, is 
the largest and best, and is of an irregular square shape. The inside walls and floors are plastered with clay, and painted with allegorical representations of Boodh, \&c. From the vestibule the principal apartment is entered by broad folding-doors, studded with

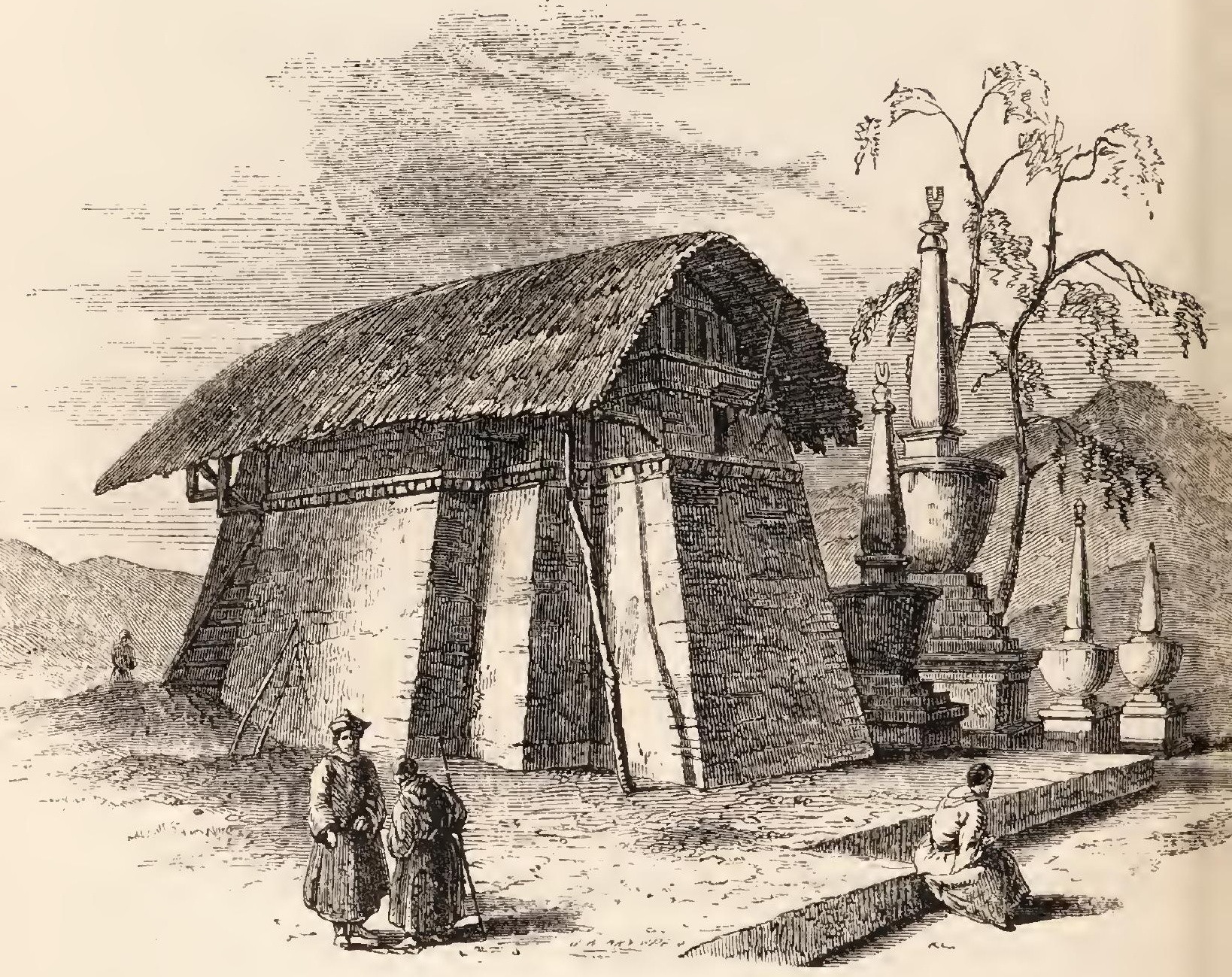

SOUTHERN TEMPLE.

circular copper bosses, and turning on iron hinges. It is lighted by latticed windows, sometimes protected outside by a bamboo screen. Owing to the great thickness of the walls (three or four feet), a very feeble light is admitted. In the principal temple, called "Dugang," six hexagonal wooden columns, narrowed above, with 
peculiar broad transverse capitals, exquisitely gilded and painted, support the cross-beams of the roof, which are likewise beautifully ornamented. Sometimes a curly-maned gilt lion is placed over a column, and it

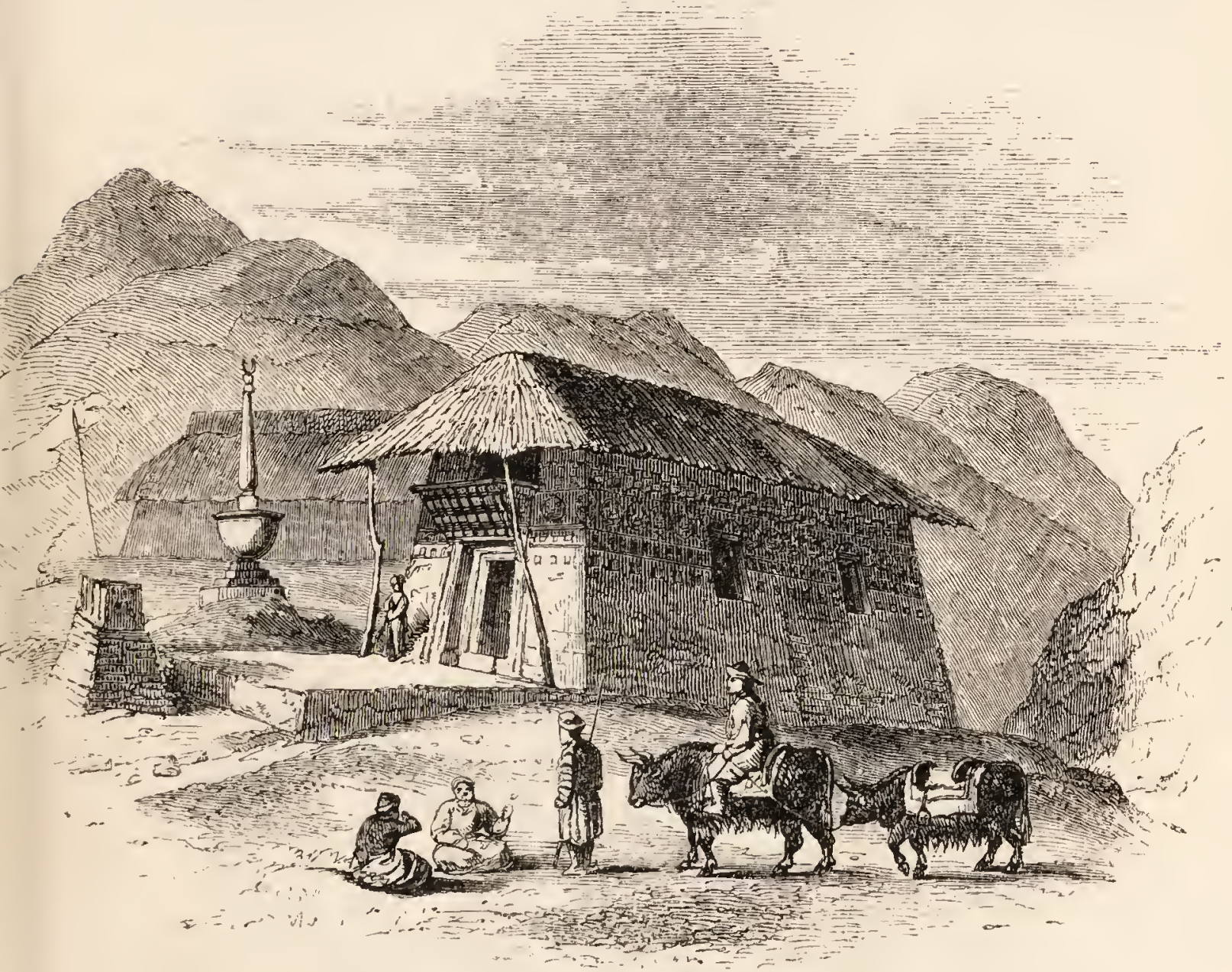

MIDDLE TEMPLE.

is always furnished with a black bushy tail: squares, diamonds, dragons, and groups of flowers, vermilion, green, gold, azure, and white, are dispersed with great artistic taste over all the beams; the heavier masses of colour being separated by fine white lines.

The altars and idols are placed at the opposite end; and two long parallel benches, like cathedral stalls, 
run down the centre of the building; on these the monks sit at prayer and contemplation, the head Lama occupying a stall (often of very tasteful design) near the altar.

The principal Boodh, or image, is placed behind the altar under a canopy, or behind a silk screen: gaily

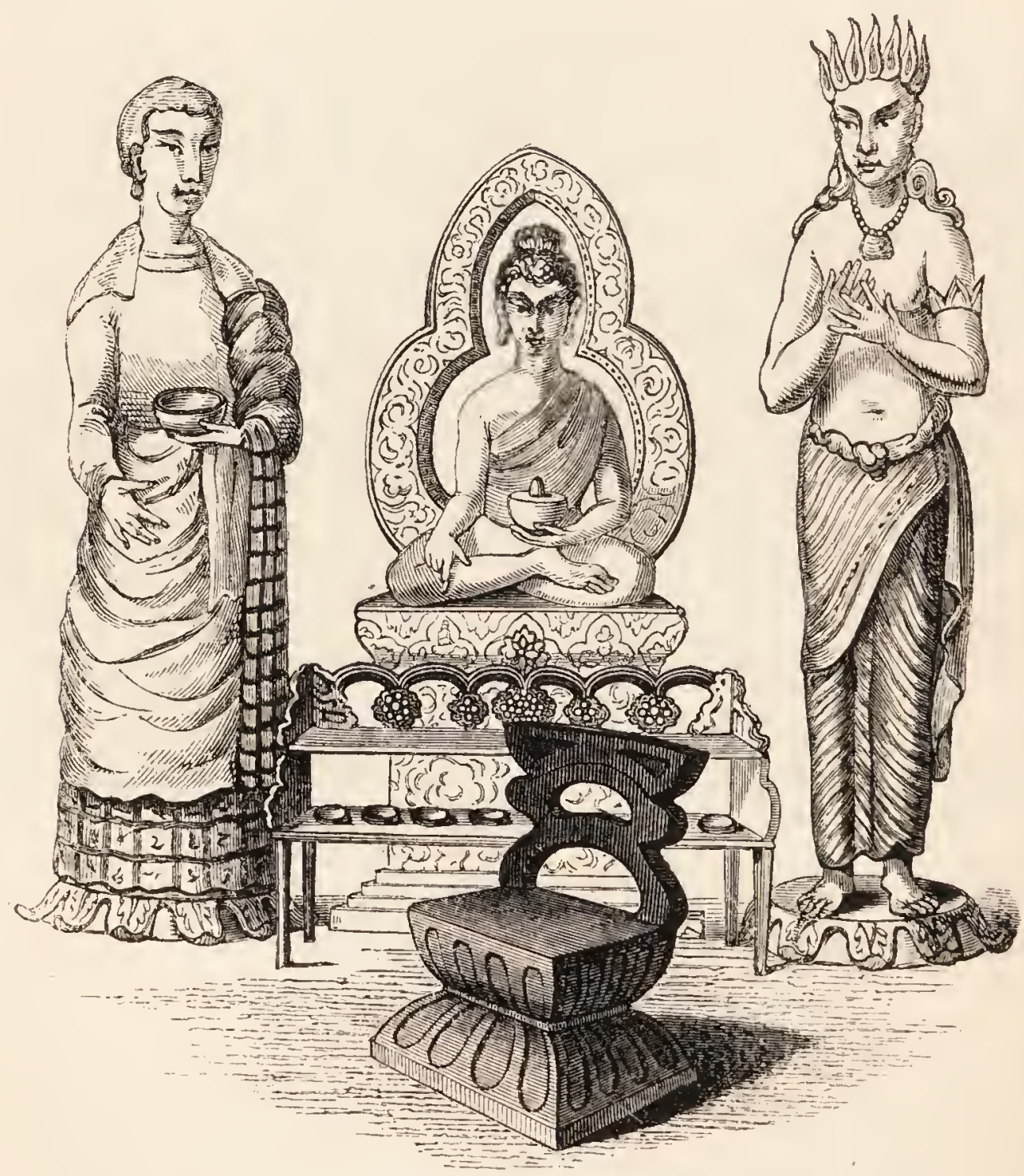

ALTAR AND IMAGES.

Central figure Akshobya, the first of the Paneha Boodha.

dressed and painted effigies of sainted male and female persons are ranged on either side, or placed in niches around the apartment, sometimes with separate altars 
before them; whilst the walls are more or less covered with paintings of monks in prayer or contemplation. The principal Boodh (Sakya Sing) sits cross-legged, with the left heel up : his left hand always rests on his thigh, and holds the padmi or lotus and jewel, which is often a mere cup; the right hand is either raised,

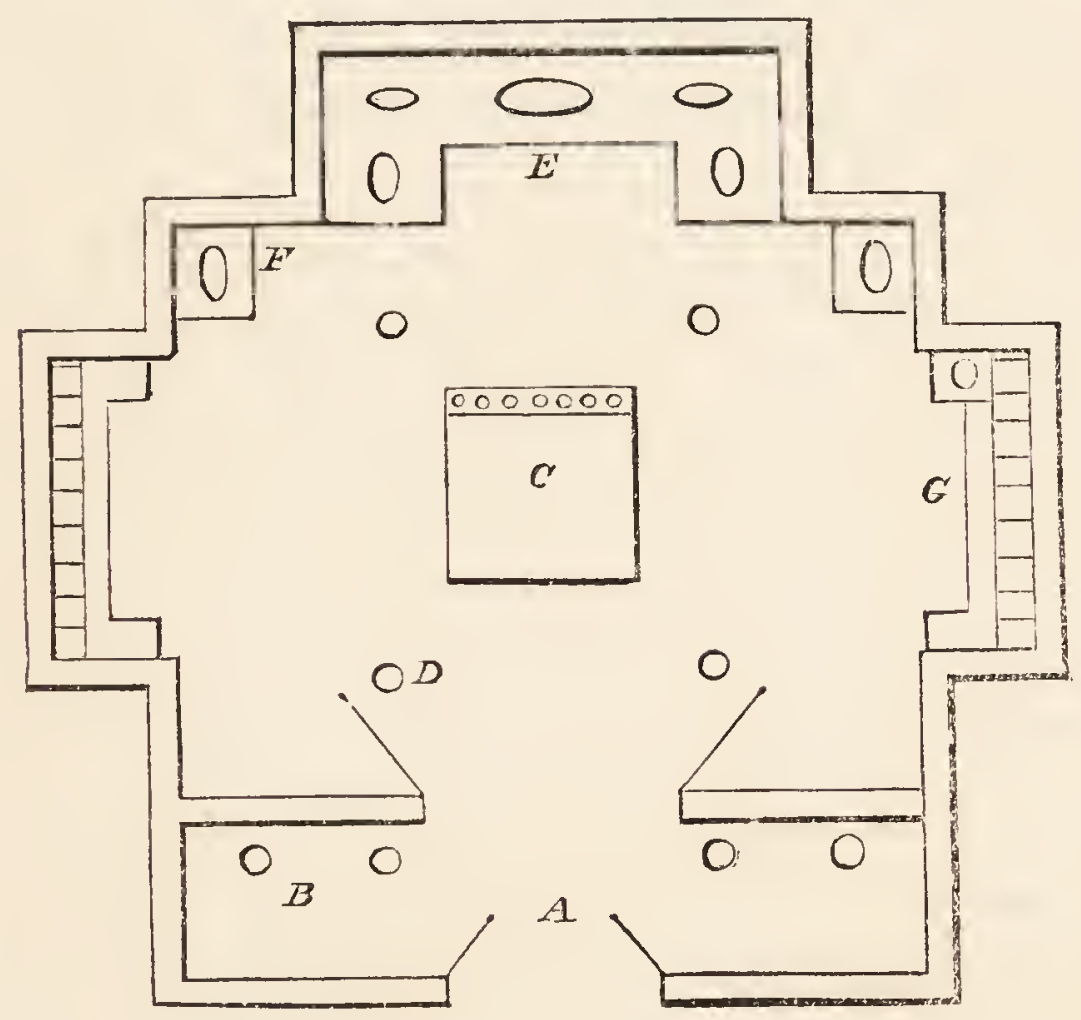

PLAN OF THE SOUTH TEMPLE.

A. entrance; B. four praying cylinders ; c. altar, with seven brass cups of water D. four columus; E. and F. images; G. library.

with the two forefingers up, or holds the dorje, or rests on the calf of the upturned leg. Sakya has generally curled hair, Lamas have mitres, females various headdresses ; most wear immense ear-rings, and some rosaries. All are placed on rude pediments, so painted as to convey the idea of their rising out of the petals of the pink, purple, or white lotus. None are in any way 
disagreeable; on the contrary most have a calm and pleasing expression, suggestive of contemplation.

The great or south temple contained a side altar of very elegant shape, placed before an image encircled by a glory. Flowers, juniper, peacock's feathers, pastiles, and brass cups of water were the chief ornaments of the altars, besides the instruments I have elsewhere enumerated. In this temple was the library, containing several hundred books, in pigeon-holes, placed in recesses.

The effect on entering these cold and gloomy temples is very impressive; the Dugang in particular was exquisitely ornamented with painting, and the vista from the vestibule to the principal idol, of carved and coloured pillars and beams, was very picturesque. Within, the general arrangement of the colours and gilding is felt to be harmonious and pleasing, especially from the introduction of slender white streaks between the contrasting masses of colour, in the same manner as was adopted in the Great Exhibition building of 1851. It is also worthy of remark that the brightest colour's are often used in broad masses, and when so, are always arranged in the sequence of the rainbow's hues, and are hence never displeasing to the eye. The hues, though bright, are subdued by the imperfect light: the countenances of the images are all calm, and their expression solemn. Whichever way you turn, the eye is met by some beautiful specimen of colouring or carving, or some object of veneration. The effect is much heightened by the incense of juniper and sweetsmelling herbs which the priests burn on entering, by 
their grave and decorous conduct, and by the feeling of respect demanded by a religion which inculcates and adores virtue in the abstract, and those only amongst men who practise virtue. To the idol itself the Boodhist attaches no importance; it is an object of reverence, not of worship, and no virtue or attribute belongs to it per se; it is a symbol of the creed, and the adoration is paid to the abstraction which it represents.

Beyond the temples are the chaits and mendongs; scattered without much order; and I counted nearly twenty-five chaits of the same form, between eight and thirty feet high. The largest is consecrated to the memory of the Rajah's eldest son, who, however, is not buried here. A group of these structures is extremely picturesque, and those at Tassiding, from their number, variety, and size, their commanding and romantic position, and their being interspersed with weeping cypresses, are particularly so.

The Tassiding temples and convents were founded upwards of 300 years ago, by the Lamas who accompanied the first Rajah to Sikkim; and they have been continuously served by Lamas of great sanctity, many of whom have been educated at Lhassa. They were formerly very wealthy, but during the Nepal war they were plundered of all therr treasures, their silver gongs and bells, their best idols, dorjes, and manis, and stripped of their ornaments; since which time Pemiongchi has been more popular. In proof of their antiquity, it was pointed out that most of the symbols and decorations were those of pure Lama Boodhism, as practised in Tibet. 
Although the elevation is but 4,840 feet, the weather was cold and raw, with rain at noon, followed by thunder and lightning. These electrical disturbances are frequent about midsummer and midwinter, prevailing over many parts of India.

January 1st, 1849.-The morning of the new year was bright and beautiful, though much snow had fallen on the mountains; and we left Sunnook for Pemiongchi, situated on the summit of a lofty spur on the opposite side of the Ratong.

The ascent to Pemiongchi was very steep, through woods of oaks, chesnuts, and magnolias, but no treefern, palms, Pothos, or plantain, which abound at this elevation on the moister outer ranges of Sikkim. The temple is large, eighty feet long, and in excellent order, built upon the lofty terminal point of the great east and west spur, that divides the Kulhait from the Ratong and Rungbee rivers; and the great Changachelling temple and monastery stand on another eminence of the same ridge, two miles further west.

The view of the snowy range from this temple is one of the finest in Sikkim; the eye surveying at one glance the vegetation of the Tropics and the Poles. Deep in the valleys the river-beds are but 3000 feet above the sea, and are choked with fig-trees, plantains, and palms; to these succeed laurels and magnolias, and still higher up, oaks, chesnuts, birches, \&c.; there is, however, no marked line between the limits of these two last forests, which form the prevailing arboreous vegetation between 4000 and 10,000 feet, and give a lurid hue to the mountains. Fir forests succeed for 
2000 feet higher, when they give place to a skirting of rhododendron and berberry. Among these appear black naked rocks, between which are gulleys, down which the snow now descended to 12,000 feet. The mountain flanks are much more steep and rocky than those at similar heights on the outer ranges, and cataracts are very numerous, and of considerable height, though small in volume.

Pemiongchi temple, ${ }^{*}$ the most ancient in Sikkim, is said to be 400 years old; it stands on a paved platform, and is of the same form and general character as those of Tassiding. Inside, it is most beautifully decorated, especially the beams, columns, capitals and architraves, but the designs are coarser than those of Tassiding. The square end of every beam in the roof is ornamented either with a lotus flower or with a Tibetan character, in endless diversity of colour and form, and the walls are completely covered with allegorical paintings of Lamas and saints with glories round their heads, mitred, and holding the dorje and jewel.

The principal image is a large and hideous figure of Sakya-thoba, in a recess under a blue silk canopy, contrasting with a calm figure of the late Rajah, wearing a cap and coronet.

Pemiongchi was once the capital of Sikkim, and called the Sikkim Durbar: the Rajah's residence was on a curious flat to the south of the temple, and a few hundred feet below it, where are the remains of (for this country) extensive walls and buildings. During the Nepal war, the Rajah was driven east across the

* See Frontispiece to this volume. 
Teesta, whilst the Ghorkas plundered Tassiding, Pemiongchi, Changachelling, and all the other temples and convents to the west of that river. It was then that the famous history of Sikkim,* compiled by the Lamas of Pemiongchi, and kept at this temple, was destroyed, with the exception of a few sheets, with one of which Dr. Campbell and myself were each presented. We were told that the monks of Changachelling and those of this establishment had copied what remained, and were busy compiling the rest from oral information, \&c.: whatever value the original may have possessed, however, is irretrievably lost. A magnificent copy of the Boodhist Scriptures was destroyed at the same time; it consisted of 400 volumes, each containing several hundred sheets of Daphne paper.

The ground about the temple was covered with snow; we therefore descended a few hundred feet, to encamp in a most picturesque grove, among chaits and inscribed stones, with a peep of the temples above. Nightingales warbled deliciously night and morning, which rather surprised us, as the minimum thermometer fell to $28^{\circ}$, and the ground next day was covered with hoar-frost. 'These birds migrate hither' in October and November, lingering in the Himalayan valleys till the cold of early spring drives them further south, to the plains of India, whence they return north in March and April.

* This remarkable and beautiful manuscript was written on thick oblong sheets of Tibet paper, painted black to resist decay, and the letters were yellow and gold. The Nepalese soldiers wantonly employed the sheets to roof the sheds they erected as a protection from the weather. 
On the 2nd of January I parted from my friend, Dr. Campbell, who was obliged to hurry to the great annual fair at Titalya. I regretted much being unable to accompany him to this scene of his disinterested labours, especially as the Nawab of Moorshedabad was to be present, one of the few wealthy native princes of Bengal who still keep a court worth seeing; but I was anxious to continue my explorations northward till the latest moment; I however accompanied him for a short distance on his way towards Dorjiling.

A steep zigzag path, descending amongst long grass and scarlet rhododendrons, led to the Kaysing Mendong. Here I bade adieu to Dr. Campbell, and returned up the hill, feeling very lonely. The zest with which he had entered into all my pursuits, and the aid he had afforded me, together with the charm that always attends companionship with one who enjoys every incident of travel, had so attracted me to him that I found it difficult to recover my spirits. It is impossible for any one who cannot from experience realize the solitary wandering life $I$ had been leading for months, to appreciate the desolate feeling that follows the parting from one who has heightened every enjoyment, and taken far more than his share of every annoyance and discomfort: the few days we had spent together appeared then, and still, as months.

On my return to Pemiongchi I spent the remainder of the day sketching in the great temple, gossipping with the Lamas, and drinking salted and buttered tea-soup, which I had begun to like, when the butter was not rancid. 
My route hence was to be along the south flank of Kinchinjunga, north to Jongri, which lay about four or five marches off, on the road to the long deserted pass of Kanglanamo, by which I had intended entering Sikkim from Nepal, when I found the route up the Yalloong valley impracticable. The village and ruined convents of Yoksun lay near my route, and the temples of Doobdi, Catsuperri and Molli, on the Ratong river.

I descended to the village of Tchonpong, where I was detained a day to obtain rice, of which I required ten days' supply for twenty-five people. On the way I passed groves of the paper-yielding Edgeworthia Gardneri : it bears round heads of fragrant, beautiful, yellow flowers, and would be a valuable acquisition to an English conservatory.

From Tchonpong we descended to the bed of the Rungbee (alt. 3,160 feet), an affluent of the Ratong, flowing in a deep gulley with precipitous sides: it was spanned by a bridge of two loose bamboo culms, about fifteen yards long, laid across without hand-rails; after wet sand had been thrown on it the bare-footed coolies crossed easily enough, but I, having shoes on, required a hand to steady me. From this point we crossed a lofty spur to the Ratong, where we encamped, the coolies being unable to proceed further along such very bad roads.

We encamped on a gravelly flat, fifty feet above the river, strewn with water-worn boulders, and so densely covered with tall Artemisia bushes, gigantic grasses, bamboos, plantains, ferns, and acacias, that we had to clear a space in the jungle, which exhaled a rank heavy smell. 
Hence I ascended to Yoksun, one of the most curious and picturesque spots in Sikkim, and the last inhabited place towards Kinchinjunga. The path was excessively steep and rocky for the first mile or two, and then alternately steep and flat. Mixed with many tropical trees, were walnuts of the common English variety ; a tree, which, though planted here, is wild near Dorjiling, where it bears a small-sized fruit, as hard as a hickory-nut: those I gathered in this place were similar, whereas in Bhotan the cultivated nut is larger, thin-shelled, and the kernel is easily removed. We ascended one slope, which was covered with light black mould, and had been recently cleared by fire; on it we found millet cultivated. From the top the view was very fine: to the north lay Yoksun, appearing from this height to occupy a flat, girdled by steep mountains to the north and east, and dipping very suddenly to the Ratong, the gorge of which opened as a gloomy defile, above which rose partially snowed mountains, which shut out Kinchinjunga. To the right was a lofty hill, crowned with the large temple and convents of Doobdi, shaded by beautiful weeping cypresses, and backed by lofty fir-clad mountains. To the west, massive fir-clad mountains rose steeply; while the little hamlet of Lathiang occupied a remarkable shelf overhanging the river, appearing inaccessible except by ropes from above. South-west, the long spurs of Molli and Catsuperri, each crowned with its convents or temples, descended from Singalelah; and parallel to them on the south, but much longer and more lofty, was the VOL. I. 
great mountain range north of the Kulhait, with the temples and convents of Pemiongchi and Changachelling, towering in the air. The latter range dips suddenly to the Great Rungeet, where Tassiding, with its chaits and cypresses, closed the view. The day was half cloud, half sunshine; and the various effects of light and shade, now bringing out one or other of the villages and temples, now casting the deep valleys into darker gloom, were wonderfully fine.

Yoksun was the earliest civilised corner of Sikkim, and derived its name (which signifies in Lepcha " three chiefs") from having been the residence of three Lamas of great influence, who were the means of introducing the first Tibetan sovereign into the country. At present it boasts of but little cultivation, and a scattered population, inhabiting a few hamlets, 5,500 feet above the sea: beautiful lanes and paths wind everywhere over the gentle slopes, and through the copsewood that has replaced the trees of a former period. Mendongs and chaits are very numerous, some of great size; and there are also the ruins of two very large temples, near which are some magnificent weeping cypresses, eighty feet high. These fine trees are landmarks from all parts of the flat; they form irregular cones of pale bright green, with naked gnarled tops; the branches weep gracefully, but not like the picture in Macartney's Embassy to China, whence originated the familiar "willow-pattern" of our crockery. The ultimate branchlets are very slender and pendulous; my Lepcha boys used to make elegant chaplets of them, binding the withes with scarlet worsted. The 
trunk is quite erect, smooth, cylindrical, and pinelike; it harbours no moss, but air-plants, Orchids, and ferns, nestle on the limbs, and pendulous lichens, like our beard-moss, wave from the branches.

In the evening I ascended to Doobdi. The path

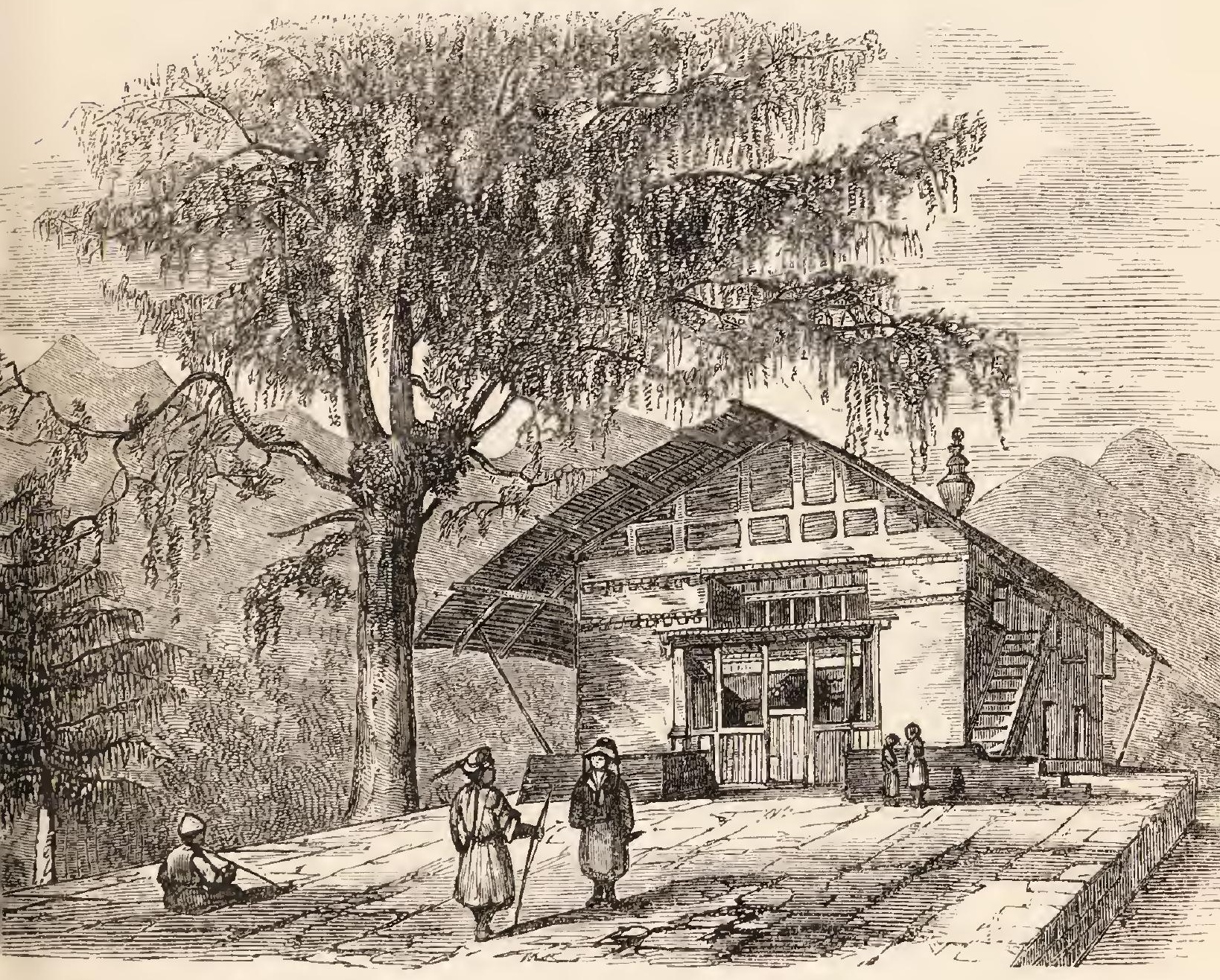

TEMPLE AND WEEPING CYPRESS.

was broad, and skilfully conducted up a very steep slope covered with forest; the top, which is nearly 1000 feet above Yoksun, is a broad partially paved platform, on which stand two temples, surrounded by beautiful weeping cypresses : one of these trees (perhaps the oldest in Sikkim) measured sixteen and a half feet in girth, at five from the ground, and was apparently 
ninety feet high: it was not pyramidal, the top branches being dead and broken, and the lower limbs spreading; they were loaded with masses of whiteflowered Orchids. The younger trees were pyramidal.

I was received by a monk of low degree, who made many apologies for the absence of his superior, who had been ordered an eight years' penance and seclusion from the world, of which only three had passed. On inquiry, I learnt the reason for this; the holy father having found himself surrounded by a family, to which there would have been no objection, had he previously obtained a dispensation. As, however, he had omitted this preliminary, and was able to atone by prayer and payment, he had been condemned to do penance; probably at his own suggestion, as the seclusion will give him sanctity, and eventually lead to his promotion; when his error shall have been forgotten.

Both temples are remarkable for their heavily ornamented, two-storied porticos, which occupy nearly the whole of one end. The interior decorations are in a ruinous condition, and evidently very old; they have no Hindoo emblems.

The head Lama sent me a present of dried peaches, with a bag of walnuts, called "Koal-kun" by the Lepchas, and "Taga-sching" by the Bhoteas; the two terminations alike signifying " tree."

Although the elevation is so low, snow falls abundantly at Doobdi in winter; I was assured that it has been known of the depth of five feet, a statement I consider doubtful ; the quantity is, however, certainly 
greater than at equal heights about Dorjiling, no doubt owing to its proximity to Kinchinjunga.

I was amused here by watching a child playing with a popgun, made of bamboo, similar to that of quill, with which most English children are familiar, which propels pellets by means of a spring-trigger made of the upper part of the quill. It is easy to conclude such resemblances between the familiar toys of different countries to be accidental, but I question their being really so. On the plains of India, men may often be seen for hours together, flying what with us are children's kites; and I procured a jew's harp from Tibet. These are not the toys of savages, but the amusements of people more than half-civilised, and with whom we have had indirect communication from the earliest ages. The Lepchas play at quoits, using slate for the purpose, and at the Highland games of "putting the stone" and "drawing the stone." Chess, dice, draughts, Punch, hockey, and battledore and shuttlecock, are all Indo-Chinese or Tartarian; and no one familiar with the wonderful instances of similarity between the monasteries, ritual ceremonies, attributes, vestments, and other paraphernalia of the Eastern and Western churches, can fail to acknowledge the importance of recording even the most trifling analogies or similarities between the manners and customs of the young as well as of the old. 


\section{CHAPTER XV.}

Leave Yoksun for Kinchinjunga-Ascend Ratong valley-Salt smuggling over Ratong-Plants-Buckeem-Blocks of gneiss-Mon LepchaView-Weather-View from Gubroo-Kinchinjunga, tops of-Pundim cliff-Nursing - Vegetation of Himalaya-Coup d'œil of Jongri--Route to Yalloong-Arduous route of salt-traders from Tibet-Kinchin, ascent of-Lichens-Surfaces sculptured by snow and ice-Weather at Jongri-Snow-Shades for eyes.

I LEFT Yoksun on an expedition to Kinchinjunga on the 7th of January. It was evident that at this season I could not attain any height: but I was most anxious to reach the lower limit of that mass of perpetual snow which descends in one continuous sweep from 28,000 to 15,000 feet, and radiates from the summit of Kinchin, along every spur and shoulder, for ten to fifteen miles, towards each point of the compass.

The route lay for the first mile over the Yoksun flat, and then wound along the almost precipitous east flank of the Ratong, 1000 feet above its bed, leading through thick forest. It was often difficult, crossing torrents by stems of bamboo, and leading up precipices by notched poles and roots of trees. I wondered what could have induced the frequenting of such a route to Nepal, when there were so many better ones over 
Singalelah, till I found from my guide that salt was habitually smuggled over this pass to avoid the oppressive duty exacted by the Dewan on all imports from Tibet by the eastern passes: he further told me that it took five days to reach Yalloong in Nepal from Yoksun, on the third of which the Kanglanamo pass is crossed, which is open from April to November, but is always heavily snowed. Owing to this duty, and the remoteness of the eastern passes, the people in the western districts of Sikkim were compelled to pay an enormous sum for salt; and in consequence the Lamas of Changachelling and Pemiongchi petitioned Dr. Campbell to use his influence with the Nepal Court to have the Kanglanamo pass re-opened, and the power of trading with the Tibetans of East Nepal restored to them: the pass having been closed since the Nepalese war, to prevent the Sikkim people from kidnapping children and slaves, as was alleged to be their custom.**

On the following day, I proceeded north-west up the Ratong river, which I crossed, and then ascended a very steep mountain called "Mon Lepcha." Immense detached pieces of gneiss, full of coarse garnets, lay on

* An accusation in which there was probably some truth; for the Sikkim Dingpun, who guided Dr. Campbell and myself to Mainom, Tassiding, \&c., afterwards kidnapped, or caused to be abducted, a girl of Brahmin parents, from the Mai valley of Nepal, a transaction which cost him some 300 rupees. The Nepal Durbar was naturally furious, the more so as the Dingpun had no caste, and was therefore abhorred by all Brahmins. Restitution was demanded through Dr. Campbell, who caused the incensed Dingpun to give up his paramour and her jewels. He vowed vengeance against Dr. Campbell, and found means to gratify it, as I shall hereafter show. 
the slope, some of which were curiously marked with a series of deep holes, large enough to put one's fist in, and said to be the footprints of the sacred cow. They appeared to me to have been caused by the roots of trees, which spread over the rocks in these humid regions, and wear channels in the hardest material.

I encamped at a place called Buckeem (alt. 8,650 ft.), in a forest of Abies Brunoniana and silver fir, yew, oak, various rhododendrons, and small bamboo. Snow lay in patches, and the night was cold and clear. On the following morning I continued the ascent, alternately up steeps and along perfectly level shelves, on which were occasionally frozen pools, surrounded with dwarf juniper and rhododendrons. Across one I observed the track of a yak in the snow; it presented two ridges, probably from the long hair of this animal, which trails on the ground, sweeping the snow from the centre of its path.

Enormous angular boulders were frequent over the whole of Mon Lepcha. I measured one forty feet high, resting on a steep narrow shoulder in a position to which it was impossible that it could have rolled; though it is almost equally difficult to suppose that glacial ice could have deposited it 4000 feet above the bottom of the gorge, except we conclude the valley to have been filled with ice to that depth.

The toilsome ascent through the soft snow and brushwood delayed the coolies, who scarcely accomplished five miles in the day. Some of them having come up by dark, I prepared to camp on the mountaintop, a broad bare flat, elevated 13,080 feet, and fringed 
by a copse of rose, berberry, and alpine rhododendrons: the Himalayan heather (Andromeda fastigiata) grew abundantly here, affording us good fuel; and thick masses of it, with moss (which latter hung in great tufts from the bushes) laid on the snow, formed my bed: my blankets had not arrived, but there was no prospect of a snow-storm.

The sun was powerful when I reached the summit, and I was so warm that for a few minutes I walked about barefoot on the frozen snow without inconvenience, preferring it to continuing in wet stockings : the temperature at the time was $29 \frac{1}{2}^{\circ}$, with a brisk south-east moist wind.

The night was magnificent, brilliant starlight, with a pale mist over the mountains : the thermometer fell to $15 \frac{1}{2}^{\circ}$, and the snow sparkled with broad flakes of hoar-frost in the full moon, which was so bright, that I recorded my observations by its light. Owing to the extreme cold of radiation, I passed a very uncomfortable night. The minimum thermometer fell to $1^{\circ}$ in shade: the sky was clear; and every rock, leaf, twig, blade of grass, and the snow itself, were covered with broad rhomboidal plates of hoar-frost, nearly one-third of an inch across; while the metal scale of the thermometer instantaneously blistered my tongue. As the sun rose, the light reflected from these myriads of facets had a splendid effect.

Before sunrise the atmosphere was still, and all but cloudless. To the south-east were visible the plains of India, at least 140 miles distant; where, as usual, horizontal layers of leaden purple vapour obscured 
the horizon: behind these the sun rose majestically, instantly dispersing them, while a thin haze spread over all the intervening mountains: this, as the sun mounted higher, became invisible, though still giving that transparency to the atmosphere and brilliant definition of the distances, so characteristic of a damp, yet clear day.

Mon Lepcha commands a most extensive view of Sikkim, southward to Dorjiling. At my feet lay the profound valley of the Ratong, a dark gulf of vegetation. Looking northward, the eye followed that stream along its devious course from the glaciers descending from the summit of Kinchinjunga (distant eighteen miles), which fronts the beholder as Mont Blanc does when seen from the mountains on the opposite side of the valley of Chamouni. To the east are the immense precipices and glaciers of Pundim, and on the west those of Kubra, forming great supporters to the stupendous mountain between them. Mon Lepcha itself is a spur ruming south-east from the Kubra shoulder: it is very open, and covered with rounded hills for several miles further north, terminating in a conspicuous conical black rocky hummock called Gubroo, of 15,000 feet elevation, which presents a black cliff to the sonth.

Kinchinjunga is topped by three small hummocks, rising to nearly equal elevation,* which form a line running north-west. It exposes many white or grey rocks, bare of snow; the colour of all which above

* The eastern and western tops are respectively 27,826 and 28,177 feet above the level of the sea. 
nearly perpendicular; and it presented a superb geological section. This cliff is of black stratified rocks, permeated from top to bottom by veins of white granite, disposed in zigzag lines, which give it a marbled appearance. The summit of Pundim itself is all of white rock, rounded in shape, and forming a cap to the gneiss, which weathers into precipices.

A succession of ridges, 14,000 to 18,000 feet high, presented a line of precipices running south from Pundim for several miles: immense granite veins are exposed on their surfaces, and they are capped by stratified rocks, which, being black, contrast strongly with the white granite beneath them: these ridges, instead of being round-topped, are broken into splintered crags; and behind them rises the beautiful conical peak of Nursing, 19,139 feet above the sea, and eight miles distant.

At the foot of these precipices was a very conspicuous series of lofty moraines, round whose bases the Ratong wound; these appeared to be nearly uniform in height, rising several hundred feet above the valley: they were comparatively level-topped, and had steep shelving rounded sides.

I have been thus particular in describing the upper Ratong valley, because it drains the south face of the loftiest mountain on the globe; and I have been precise in my details, because the ragueness with which terms are usually applied to the apparent altitude and steepness of mountains, is apt to give false impressions. It is essential to attend to such points where scenery of real interest and importance is to be described. It is 
customary to speak of peaks as towering in the air, which yet subtend an angle of very few degrees; of almost precipitous ascents, which, when measured, are found to be slopes of $18^{\circ}$ or $20^{\circ}$; and of cliffs as steep and stupendous, which are inclined at a very moderate angle.

The effect of perspective is as often to deceive in details as to give truth to general impressions; and those accessories are sometimes wanting in nature, which, when supplied by art, give truth to the landscape. Thus, a streak of clouds adds height to a peak which should appear lofty, but which scarcely rises above the true horizon; and a belt of mist will sunder two snowy mountains which, though at very different distances, for want of a play of light and shade on their dazzling surfaces, and from the extreme transparency of the air in lofty regions, appear to be at the same distance from the observer.

The view to the southward from Mon Lepcha is very grand, and neither wanting in variety nor in beauty. From the deep valleys choked with tropical luxuriance to the scanty yak pasturage on the heights above, seems but a step at the first coup-d'ceil, but on a closer inspection resolves itself into five belts: 1, palm and plantain; 2, oak and laurel ; 3, fir; 4, rhododendron and grass; 5, rock and snow. From the bed of the Ratong, in which grow palms with screw-pine and plantain, it is only seven miles in a direct line to the perpetual ice. From the plains of India, or outer Himalaya, one may behold snowy peaks rise in the distance behind a foreground of tropical forest; here, 
on the contrary, all the intermediate phases of vegetation are seen at a glance. Except in the Himalaya this is no common phenomenon, and is there owing to the very remarkable depth of the river-beds. That part of the valley of the Ratong where tropical vegetation ceases, is but 4000 feet above the sea, and though fully fifty miles as the crow flies (and perhaps 200 by the windings of the river) from the plains of India, is only eight in a straight line (and forty by the windings) from the snows which feed that river. In other words, the descent is so rapid, that in eight miles the Ratong waters every variety of vegetation, from the lichen of the poles to the palm of the tropics; whilst throughout the remainder of its mountain course, it falls from 4000 to 300 feet, flowing amongst tropical scenery, through a valley whose flanks rise in mountains 5000 to 12,000 feet above its bed.

From Mon Lepcha we proceeded north-west towards Jongri, a cattle station during summer; the path to which led along a very open rounded bare mountain, covered with enormons boulders. The soil is a thick clay full of angular stones, everywhere scooped out into little depressions which are the dry beds of pools, and are often strewed with a thin layer of pebbles. Black tufts of alpine aromatic rhododendrons of two kinds ( $R$. anthopogon and setosum), with dwarf juniper, composed all the conspicuous vegetation at this season.

After a two hour's' walk, we sighted two stone huts on the bleak face of the spur, undistinguishable at the distance of half a mile from the great blocks around them. To the north Gubroo rose in dismal grandeur, 
backed by the dazzling snows of Kubra, which now seemed quite near, its lofty top (alt. 24,005 feet) being only eight miles distant. Much snow lay on the ground in patches, and there were few remains of herbaceous vegetation; those I recognised were chiefly of poppy, potentilla, gentian, geranium, fritillary, Umbellifers, grass, and sedges.

On our arrival at the huts the weather was still fine, with a strong north-west wind, which, meeting the warm moist current from the Ratong valley, caused much precipitation of vapour. As I hoped to be able to visit the surrounding glaciers from this spot, I made arrangements for a stay of some days; giving up the only habitable hut to my people, I spread my blankets in a slope from its roof to the ground, building a little stone dyke round my dwelling, and a fire-place in front.

Hence the route to Yalloong in Nepal, by the Kanglanamo pass, crosses the Singalelah range at an elevation of about 15,000 feet, south of Kubra, and north of a mountain that forms a conspicuous feature south-west from Jongri, as a crest of black fingered peaks, tipped with snow.

It is difficult to conceive the amount of labour expended upon every pound of salt imported into this part of Sikkim from Tibet, and as an enumeration of the chief features of the route followed, will give some idea of what the circuit of the loftiest mountain in the globe involves, I shall briefly allude to them; premising that the circuit of Mont Blanc may be easily accomplished in four days. The shortest route to 
Yoksun (the first village south of Kinchin) from the nearest Tibetan village north of that mountain, involves a detour of one-third of the circumference of Kinchin. It is evident that the most direct way must be that nearest the mountain-top, and therefore that which reaches the highest accessible elevation on its shoulders, and which, at the same time, dips into the shallowest valleys between those shoulders. The actual distance in a straight line is about fifty miles, from Yoksun to the mart at or near Tashirukpa in Tibet.

The marches between them are as follows:-

1. To Yalloong two days; crossing Kanglanamo pass, 15,000 feet high.

3. To foot of Choonjerma pass, descending to 10,000 feet.

4. Cross Choonjerma pass, 15,260 feet, and proceed to Kambachen, 11,400 feet.

5. Cross Nango pass, 15,770, and camp on Yangma river, 11,000 feet.

6. Ascend to foot of Kanglachem pass, and camp at Pabuk, 15,000 feet.

7. Cross Kanglachem pass, probably 16,000 feet; and

$8-10$. It is said to be three marches hence to the Tibetan custom-house, and that two more snowy passes are crossed.

This allows no day of rest, and gives only five miles - as the crow flies- to be accomplished each day, but I assume fourteen of road distance; the labour expended on which would accomplish fully thirty upon good roads. Four snowed passes at least are crossed, all above 15,000 feet, and after the first day the path does 
not descend below 10,000 feet. By this route about onethird of the circuit of Kinchinjunga is accomplished. Supposing the circuit were to be completed by the shortest practicable route, that is, keeping as near the summit as possible, the average time required for a man with his load would be upwards of a month.

To reach Tashirukpa by the eastern route from Yoksun, being a journey of about twenty-five days, requires a long detour to the southward and eastward, and afterwards the ascent of the Teesta valley, to Kongra Lama, and so north to the Tibetan Arun.

My first operation after encamping and arranging my instruments, was to sink the ground thermometer; but the earth being frozen for sixteen inches, it took four men several hours' work with hammer and chisel, to penetrate so deep. There was much vegetable matter for the first eight or ten inches, and below that a fine red clay. I spent the afternoon, which was fine, in botanising. When the sun shone, the smell of the two alpine rhododendrons was oppressive, especially as a little exertion at this elevation brings on headache. There were few mosses; but crustaceous lichens were numerous, and nearly all of them of Scotch, Alpine, European, and Arctic kinds. The names of these, given by the classical Linnæus and Wahlenberg, tell in some cases of their birth-places, in others of their hardihood, their lurid colours and weather-beaten aspects; such as tristis, gelida, glacialis, arctica, alpina, saxatilis, polaris, frigida, and numerous others equally familiar to the Scotch botanist. I recognised many as natives of the wild mountains of Cape Horn, 
and the rocks of the stormy Antarctic ocean; since visiting which regions I had not gathered them. The lichen called geographicus was most abundant, and is found to indicate a certain degree of cold in every latitude; descending to the level of the sea in latitude $52^{\circ}$ north, and $50^{\circ}$ south, whilst in lower latitudes it is only to be seen on mountains. It flourishes at 10,000 feet on the Himalaya, ascending thence to 18,000 feet. Its name, however, was not intended to indicate its wide range, but the curious maplike patterns which its yellow crust forms on the rocks.

The cutting up of the whole surface of this rounded mountain into little pools, now dry, of all sizes, from ten to one hundred yards in circumference, is a very striking phenomenon. The streams flow in shallow transverse valleys, each passing through a succession of such pools, accompanying a step-like character of the general surface. The beds are stony, becoming more so when they enter the pools, upon several of the larger of which I observed curving ridges of large stones, radiating outwards on to their beds from either margin of the entering stream: more generally large stones were deposited opposite every embouchure.

This superficial sculpturing must have been a very recent operation; and the transport of the heavy stones opposite the entrance of the streams has been effected by ice, and perhaps by snow; just as the aretic ice strews the shores of the Polar ocean with rocks.

The weather had been threatening all day, northern and westerly currents contending aloft with the southeast trade-wind of Sikkim, and meeting in strife over 
the great upper valley of the Ratong. Stately masses of white cumuli wheeled around that gulf of glaciers, partially dissipating in an occasional snow-storm, but on the whole gradually accumulating.

On my arrival the thermometer was $32^{\circ}$, with the sun shining powerfully, and it fell to $28^{\circ}$ at 4 P.M., when the north wind set in. At sunset the moon rose through angry masses of woolly cirrus: its broad full orb first threw a flood of yellow light over the serried tops south of Pundim; thence advancing obliquely towards Nursing, it "stood tip-toe" for a few minutes on that beautiful pyramid of snow, whence it seemed to take flight and mount majestically into mid-air, illuminating Kinchin, Pundim, and Kubra.

I sat at the entrance of my gipsy-like hut, anxiously watching the weather, and absorbed in admiration of the moonrise, from which my thoughts were soon diverted by its fading light as it entered a dense mass of mare's-tail cirrus. It was very cold, and the stillness was oppressive. I had been urged not to attempt such an ascent in January, my provisions were scanty, firewood only to be obtained from some distance, the open undulating surface of Jongri was particularly exposed to heavy snow-drifts, and the path was, at the best, a scarcely perceptible track. I studied every change of the wind, every fluctuation of the barometer and thermometer, and the courses of the clouds aloft. At 7 p.M., the wind suddenly shifted to the west, and the thermometer instantly rose. After 8 P.M., the temperature fell again, and the wind drew round to the north-east, when the fog cleared off. The barometer 
rose no more than it usually does towards 10 P.M., and though it clouded again, with the temperature at $17^{\circ}$, the wind seemed steady, and I went to bed with a relieved mind.

On the following morning I ventured on a walk towards Gubroo, carefully taking bearings of my position. I found a good many plants in a rocky valley close to that mountain, which $I$ in vain attempted to ascend. A strong and damp south-west wind blew, and the cold was so piercing, that two lads who were with me, although walking fast, became benumbed, and could not return without assistance. A thick fog soon obliged us to retrace our steps: it was followed by snow in soft round pellets like sago, that swept across the hard ground. During the afternoon it snowed unceasingly, the wind repeatedly veering round the compass. The flakes were large, soft, and moist with the south wind, and small, hard, and dry with the north. Glimpses of blue sky were constantly seen to the south, under the gloomy canopy above, but they augured no change. As darkness came on, the temperature fell to $11^{\circ}$, and it snowed very hard.

The night was very cold and wintry: I sat for some hours behind a blanket screen (which had to be shifted every few minutes) at my tent-door, keeping up a sulky fire, and peering through the snow for signs of improvement, but in vain. The clouds were not dense, for the moon's light was distinct, shining on the glittering snow-flakes that fell relentlessly: my anxiety was great, and I could not help censuring myself for exposing a party to so great danger at such a season. 
I found comfort in the belief that no idle curiosity had prompted me, and that with a good motive and a strong prestige of success, one can surmount a host of difficulties. Still the snow fell; and my heart sank as the fire declined, and the flakes sputtered on the embers; my little puppy, who had gambolled all day amongst the drifting pellets, now whined, and crouched under my thick woollen cloak; the searching wind drifted the snow into the tent, whose roof so bagged in with the accumulation that I had to support it with sticks, and dreaded being smothered, should it sink upon my bed during my sleep. The increasing cold drove me, however, to my blankets, and taking the precaution of stretching a tripod stand over my head, so as to leave a breathing hole, by supporting the roof if it fell in, I slept soundly, with my dog at my feet.

At sunrise the following morning the sky was clear, with a light north wind; about two feet of snow had fallen, the drifts were deep, and all trace of the path obliterated; while the minimum thermometer had fallen to $3 \frac{3}{4}^{\circ}$.

My light-hearted companions cheerfully prepared to leave the ground; they took their appointed loads without a murmur, and sought protection for their eyes from the glare of the newly fallen snow, some with as much of my crape veil as I could spare, others with shades of brown paper, or of hair from the yaks' tails, whilst a few had spectacles of woven hair; and the Lepchas loosened their pig-tails, and combed their long hair over their eyes and faces. It is from freshfallen snow alone that much inconvenience is felt; 
owing, I suppose, to the light reflected from the myriads of facets which the crystals present. I have never suffered in crossing beds of old snow, or glaciers with weathered surfaces, which absorb a great deal of light, and reflect comparatively little, and that little coloured green or blue.

The descent was very laborious, so that although we started at 10 A.M., it was dark by the time we reached Buckeem, where we found two lame coolies, whom we had left on our way up, and who were keeping up a glorious fire for our reception.

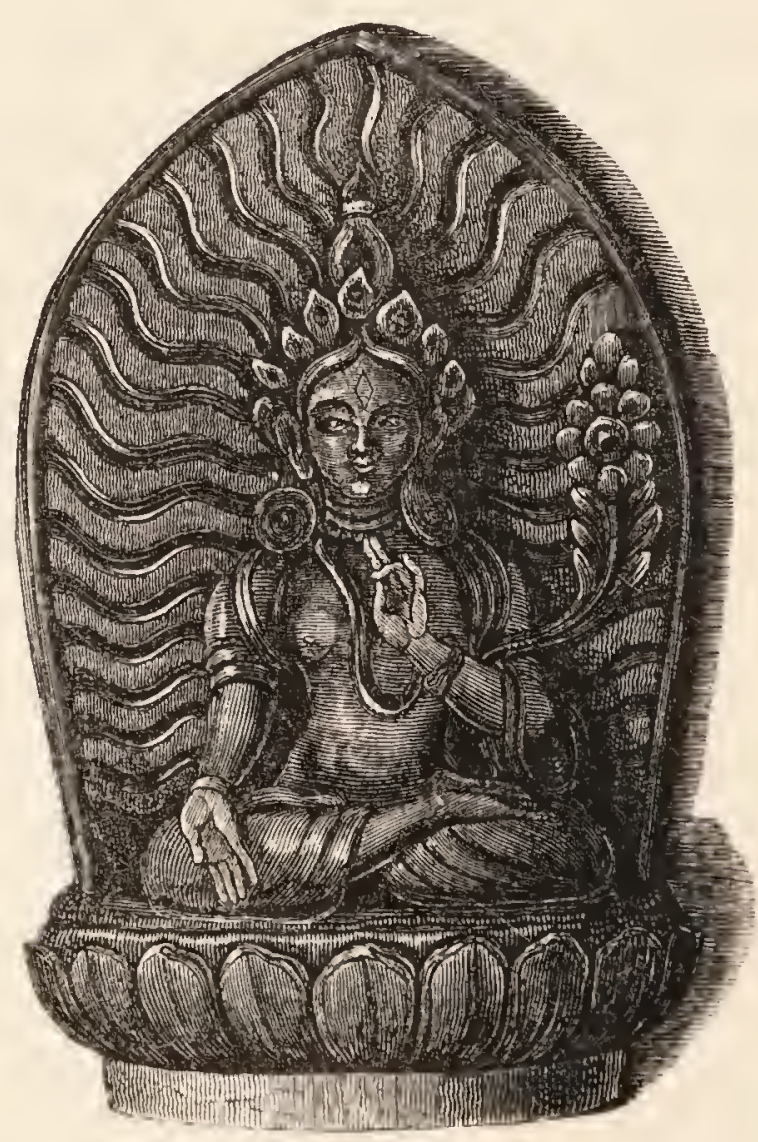




\section{CHAPTER XVI.}

Ratong river below Mon Lepcha-Ferns-Vegetation of Yoksun, tropicalA raliacece, fodder for cattle-Rice-paper plant-Lake-Old temples -Funereal cypresses-Gigantic chait-Altars-Songboom-Catsuperri-Worship at Catsuperri lake--Scenery-Willow_Lamas and ecclesiastical establishments of Sikkim-Tengling-Changachelling temples and monks-Portrait of myself on walls-Lingcham Kajee asks for spectacles-Arrive at Little Rungeet-At Dorjiling-Its deserted and wintry appearance.

ON the following day I marched to Yoksun: the weather was fair, though it was snowing on the mountains. I halted by the Ratong river, at the foot of Mon Lepcha, where I found its elevation to be 7,150 feet; its edges were frozen, and the temperature of the water $36^{\circ}$; it is here a furious torrent flowing between rocks, and is flanked by flat-topped beds of boulders gravel and sand, twelve to fourteen feet thick. Its vegetation resembles that of Dorjiling, but is more alpine, owing no doubt to the proximity of Kinchinjunga. The magnificent Rhododendron argenteum was growing on its banks. On the other hand, I was surprised to see a beautiful fern (a Trichomanes, very like the Irish one) which is not found at Dorjiling. The same day, at about the same elevation, I gathered sixty species of fern, many of very tropical forms: no doubt the range of 
such genera is extended in proportion to the extremely damp and equable climate. Tree-ferns are however absent, and neither plantains, epiphytical orchids, nor palms, are so abundant, or ascend so high as on the outer ranges. About Yoksun itself, which occupies a very warm sheltered flat, many tropical genera occur, such as tall bamboos of two kinds, grasses allied to the sugar-cane, and various Araliacea, amongst which was one species whose pith was of so curious a structure, that I had no hesitation in considering the then unknown Chinese substance called rice-paper, to belong to a closely allied plant.*

The natives collect the leaves of many Aralias as fodder, for which purpose they are of the greatest service in a country where grass for pasture is so scarce; this is the more remarkable, since they belong to the natural family of ivy, which is usually poisonous; the use of this food, however, gives a peculiar taste to the butter. In other parts of Sikkim, fig-leaves are used for the same purpose, and branches of a birdcherry, a plant also of a very poisonous family, abounding in prussic acid.

We were received with great kindness by the villagers of Yoksun, who had awaited our return with some anxiety, and on hearing of our approach had collected large supplies of food; amongst other things

* It is only within the last few months that my supposition has been confirmed, by my father's receiving from China, after many years of correspondence, specimens of the rice-paper plant itself, which very closely resemble, in botanical characters, as well as in outward appearance of size and habit, the Sikkim plant. 
were tares, yams, and bread made by bruising together damp maize and rice into tough thin cakes. The Lamas of Doobdi were especially civil, having a favour to ask, which was that I would intercede with Dr. Campbell to procure the permission of the Nepalese to re-open the Kanglanamo pass, and thus give some occupation to their herds of yaks, which were now wandering idly about.

The Yoksun flat abounds in depressions that must formerly have been lake-beds, and are now marshes in the rainy season; but there is only one existing pool, and this has no permanent affluent or outlet, its drainage being either subterranean, or more probably by evaporation. It is eighty to a hundred yards across, and nearly circular; its depth three or four feet, increased to fifteen or sixteen in the rains; like all similar pools in Sikkim, it contains little or no animal life at this season, and I searched in vain for shells, insects, or frogs. Around it lay many great blocks, some fully twelve feet square.

The situation of this lake is very romantic, buried in a tall forest of oaks and laurels, and fringed by wild camellia shrubs; the latter are not the leafy, largeblossomed plants of our greenhouses, but twiggy bushes with small scattered leaves, and little yellowish flowers, like those of the tea-plant. The massive walls of a ruined temple rise close to the water, which looks like the still moat of a castle: beside the ruins are some grand old funereal cypresses, with ragged scattered branches below, where they struggle for light in the dense forest, but raising their heads aloft as bright green pyramids. 
After some difficulty I found the remains of a broad path that divided into two; one led to a second ruined temple, fully a mile off, and the other I followed to a grove, in which was a gigantic chait; it was a beautiful lane throughout, bordered with bamboo, brambles, gay-flowered Melastomas like hedge-roses, and scarlet Erythrina: there were many old mendongs and chaits on the way, which I was always careful to leave on the right hand in passing, such being the rule among Boodhists, the same which ordains that the prayingcylinder or "Mani" be made to revolve in a direction against the sun's motion.

This great chait is the largest in Sikkim, and appears to be fully forty feet high; facing it is a stone altar about fifteen feet long and four broad, and behind this again is a very curious erection called "Song-boom," used for burning juniper as incense; it resembles a small smelting furnace, and consists of an elongated conical stone building eight feet high, raised on a single block; it is hollow, and divided into three stories or chambers, in the lower of which is a door, by which fuel is placed inside, and the smoke ascending through holes in the upper slabs, escapes by lateral openings from the top compartment. These structures are said to be common in Tibet, but I saw no other in Sikkim.

On the 14th January I left Yoksun for the lake and temples of Catsuperri, the former of which is by much the largest in Sikkim. After a steep descent we reached the Ratong, here a turbulent stream, twelve yards across, bordered as usual with gravel terraces strewed 
soon on the shores of what is, for Sikkim, a grand sheet of water, (6,040 feet above the sea), without any apparent outlet: it may be from three to five hundred yards across in the rainy season, but at the time I saw it was much less, and was bordered by a broad marsh of bog-moss (Sphagnum), in which was abundance of Azolla, colouring the waters red, and sedges. Along the banks were bushes of Rhododendrons and a new kind of berberry, , but the mass of the vegetation was similar to that of Dorjiling.

We crossed the marsh to the edge of the lake by a rude paved way of decaying logs, through which we often plunged up to our knees. The Lama was provided with a piece of bark, shaped like a boat, some juniper incense and a match-box, with which he made a fire, and put it in the boat, which he then launched on the lake as a votive offering to the presiding deity. It was a dead calm, but the impetus he gave to the bark shot it far across the water, whose surface was soon covered with a thick cloud of white smoke. Taking a rupee from me, the priest then waved his arm aloft, and pretended to throw the money into the water, singing snatches of prayers in Tibetan, and at times shrieking at the top of his voice to the Spirit, who claims these woods and waters as his own. There was neither bird, beast, nor insect to be seen, and the scenery was as impressive to me, as the effect of the simple service was upon my people, who prayed

* Berberis insignis. This magnificent species has not yet been introduced into England; it forms a large bush, with deep-green leaves seven inches long, and bunches of yellow flowers. 
with redoubled fervour, and hung more rags on the bushes.

I need hardly say that this invocation of the gods of the woods and waters forms no part of Lama worship; but the Lepchas are but half Boodhists ; in their hearts they dread the demons of the grove, the lake, the snowy mountain and the torrent, and the crafty Lama takes advantage of this, modifies his practices to suit their requirements, and is content with their formal recognition of the spiritual supremacy of his church. This is most remarkably shown in their acknowledgment of the day on which offerings had been made from time immemorial by the pagan Lepchas to the genius of Kinchinjunga, by holding it as a festival of the church throughout Siklkim.

The two Catsuperri temples occupy a spur above the lake; they are poor, and only remarkable for a miserable weeping-willow tree planted near them, said to have been brought from Lhassa. The monks were very civil to me, and offered amongst other things a present of excellent honey. One was an intelligent man, and gave me much information: he told me that there were upwards of twenty religious establishments in Sikkim, containing more than 1000 priests. These have various claims upon the devout: thus, Tassiding, Doobdi, Changachelling, and Pemiongchi, are celebrated for their antiquity, and the latter also for being the residence of the head Lama; Catsuperri for its lake; Raklang for its size, \&c. All are under one spiritual head, who is the Tupgain Lama, or eldest son of the Rajah, and who resides at the Phadong convent, 
near Tumloong; the Lama of Pemiongchi is, however, the most highly respected, on account of his age, position, and sanctity. Advancement in the hierarchy is dependent chiefly on interest, but indirectly on works also ; pilgrimages to Lhassa and Teshoo Loombo are the highest of these, and it is clearly the interest of the supreme pontiffs of those ecclesiastical capitals to encourage such, and to intimate to the Sikkim authorities the claims those who perform them have for preferment. Dispensations for petty offences are granted to Lamas of low degree and monks, by those of higher station, but crimes against the church are invariably referred to Tibet, and decided there.

The election to the Sikkim Lamaseries is generally conducted on the principle of self-government, but Pemiongchi and some others are often served by Lamas appointed from Tibet. I never heard of any Sikkim Lama arriving at such sanctity as to be considered immortal, and to reappear after death in another individual, nor is there any election of infants. All are of the Ningma, Dookpa, or Shammar sect, and are distinguished by their red mitres; they were once dominant throughout Tibet, but after many wars with the yellowcaps, they were driven from that country, and took refuge principally in the Himalaya. The Bhotan or Dhurma Rajah became the spiritual head of this sect; and I am indebted to Dr. Campbell for a fac-simile and translation of his great seal, containing the attributes of his spirituality, a copy of which I have appended to the end of this chapter.

The internal organisation of the different monastic 
establishments is very simple. The head or Teshoo Lama rules supreme; then come the monks and various orders of priests, and then those who are candidates for orders, and dependants, both lay-brothers and slaves: there are a few nunneries in Sikkim, and the nuns are all relatives or connections of the Rajah. During the greater part of the year, all lead a more or less idle life; the dependants being the most occupied in carrying wood and water, cultivating the land, \&c.

The lay-brothers are often skilful workmen, and are sometimes lent or hired out as labourers, especially as house-builders and decorators. No tax of any kind is levied on the church, which is frequently very rich in land, flocks, and herds, and in contributions from the people; land is sometimes granted by the Rajah, but is oftener purchased by the priests, or willed, or given by the proprietor. The services are very irregularly performed; in most temples only on festival days, which correspond to the Tibetan ones so admirably described in MM. Huc and Gabet's narrative; in a few, however, service is performed daily, especially in such as stand near frequented roads, and hence reap the richest harvest.

Like all the natives of Tibet and Sikkim, the priests are intolerably filthy; in some cases so far carrying out their doctrines as not even to kill the vermin with which they swarm. All are nominally bound to chastity, but exemptions in favour of Lamas of wealth, rank, or power, are granted by the supreme pontiffs, both in Tibet and Sikkim. I constantly found swarms 
of children about the Lamaseries, who were invariably called nephews and nieces.

Descending from the Catsuperri temples, I encamped at the village of Tengling, where I was waited upon by a bevy of forty women, Lepchas and Sikkim Bhoteas, accompanied by their children, and bringing presents of fowls, rice and vegetables, and apologising for the absence of their male relatives, who were gone to carry tribute to the Rajah.

I did not visit the Molli temples, but crossed the spur of that name, and ascended to the Changachelling temples. The ridge on which both Pemiongchi and Changachelling are built, is excessively narrow at top; it is traversed by a "via sacra," connecting these two establishments; this is a pretty wooded walk, passing mendongs and chaits hoary with lichens and mosses; to the north the snows of Kinchinjunga are seen glimmering between the trunks of oaks, laurels, and rhododendrons, while to the south the Sinchul and Dorjiling ranges shut out the view of the plains of India.

Changachelling temples and chaits crown a beautiful rocky eminence, the ascent to which is by broad flights of steps cut in the rocks, up which shaven and girdled monks, with rosaries and long red gowns, were dragging loads of bamboo stems, that produced a curious rattling noise. The monks were repairing the principal temple, which consisted of a large chamber and vestibule: the outside walls were daubed red, with a pigment of burnt clay, which is dug hard by. Some were painting the vestibule with colours brought from Lhassa, where 
they had been trained to the art. Amongst other figures was one playing on a guitar, a very common symbol in Sikkim temples: I also saw an angel playing on a flute, and a snake-king offering fruit to a figure in the water, who was grasping a serpent. Amongst the figures I was struck by that of an Englishman, whom, to my amusement, and the 'limner's great delight, I recognised as myself. I was depicted in a flowered silk coat instead of a tartan shooting jacket, my shoes were turned up at the toes, and I had on spectacles and a tartar cap, and was writing notes in a book. On one side a snake-king was politely handing me fruit, and on the other a horrible demon was writhing.

A crowd had collected to see whether I should recognise myself, and when I did so, the merriment was extreme. They begged me to send them a supply of vermilion, gold-leaf, and brushes; our so-called camel's-hair pencils being much superior to theirs, which are made of marmot's hair.

I was then conducted to a house, where I found salted and buttered tea and Murwa beer smoking in hospitable preparation. As usual, the house was of wood, and the inhabited apartments above the low basement story were approached by an outside ladder, like a Swiss cottage: within were two rooms floored with earth; the innermost of which was small, and opened on a verandah that faced Kinchinjunga, whence the keen wind whistled through the apartment.

The head Lama, my jolly fat friend of the 20th of December, came to breakfast with me, followed by 
several children, nephews and nieces he said; but they were uncommonly like him for such a distant relationship, and he seemed extremely fond of them, and much pleased when I stuffed them with sugar.

The view of the Kinchin range from this spot being one of the finest in Sikkim, and the place itself being visible from Dorjiling, I took a very careful series of bearings, which, with those obtained at Pemiongchi, were of the utmost use in improving my map, which was gradually progressing. To my disappointment I found that neither priest nor people knew the name of a single snowy mountain.

Hence I descended to the Kulhait river, on my route back to Dorjiling, visiting my very hospitable tippling friend, the Kajee of Lingcham, on the way down: he earnestly begged me to give him a pair of spectacles, for no other object than to look wise, as he had the eyes of a hawk; he told me that mine procured me universal respect in Sikkim, and that I had been drawn with them on, in the temple at Changachelling; and that a pair would not only wonderfully become him, but afford him the most pleasing recollections of myself. Happily I had the means of gratifying him, and have since been told that he wears them on state occasions.

On the next day I crossed Hee hill, and camped in a dense forest. The next march was southward to the Little Rungeet guard-house, below Dorjiling spur, which I reached after a fatiguing walk through torrents of rain. On the 19th of January, I ascended the Tukvor spur to Dorjiling, and received a most 



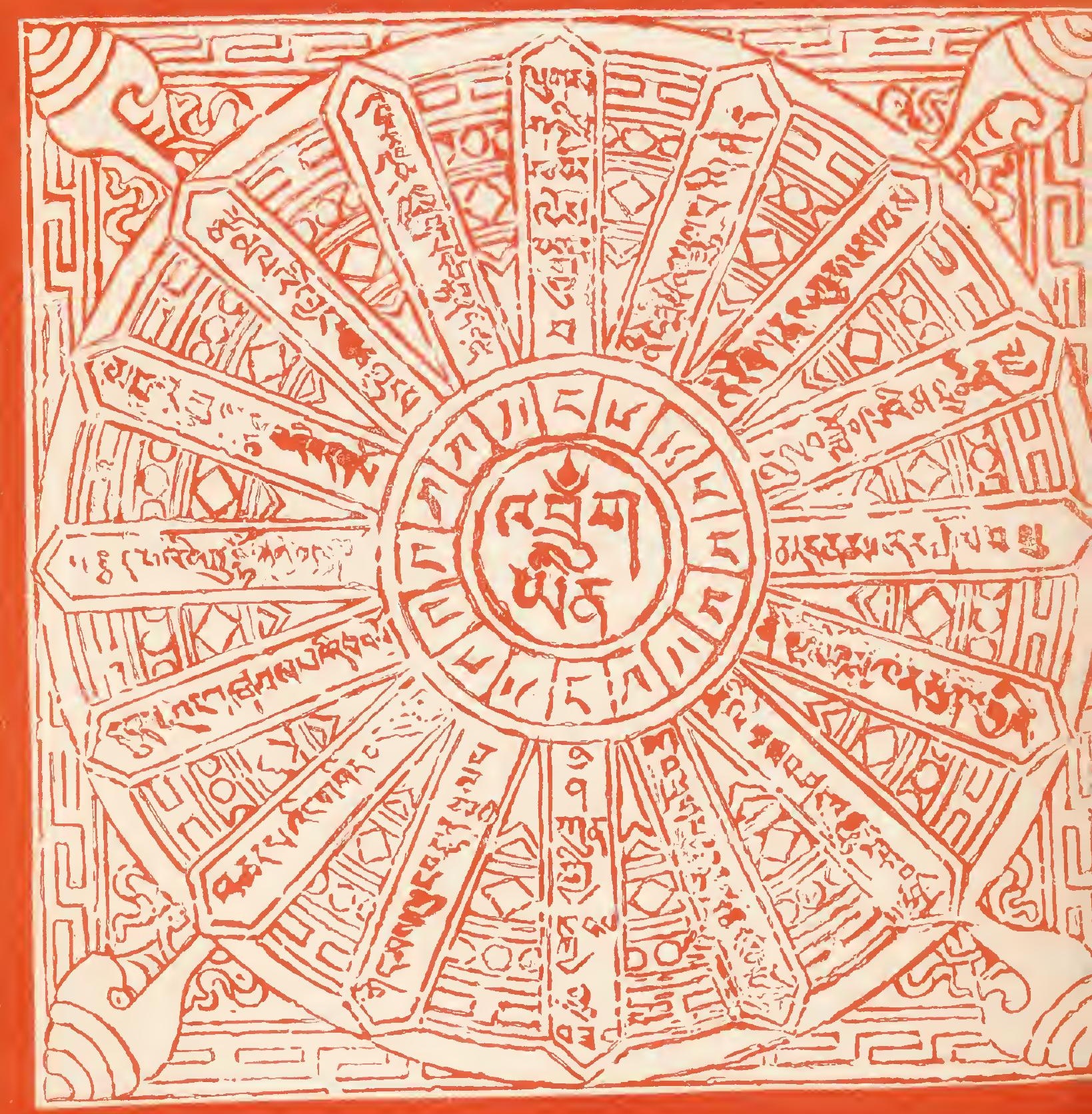


hospitable welcome from my friend Mr. Muller, now almost the only European inhabitant of the place; Mr. Hodgson having gone on a shooting excursion in the Terai, and Dr. Campbell being on duty on the Bhotan frontier, the place looked what it really was -wholly deserted. The rain I had experienced in the valley had here been snow, and the appearance of the broad snowed patches clear of trees, the many houses without smoke or inhabitants, and the tall scattered trees with black bark and all but naked branches, was dismal in the extreme. The effect was heightened by an occasional Hindoo, who flitted here and there along the road, crouching and shivering, with white cotton garments and bare legs.

The delight of my Lepcha attendants at finding themselves safely at home again, knew no bounds; and their parents waited on me with presents, and other tokens of their goodwill and gratitude. I had no lack of volunteers for a similar excursion in the following season, though with their usual fickleness, more than half failed me, long before the time arrived for putting their zeal to the proof.

I am indebted to Dr. Campbell for the accompanying impression and description of the seal of the Dhurma Rajah, or sovereign pontiff of Bhotan, and spiritual head of the whole sect of the Dookpa, or red-mitred Lama Boodhists. The translations were made by Aden Tchebu Lama, who accompanied us into Sikkim in 1849, and I believe they are quite correct. The Tibetan characters run from left to right.

The seal of the Dhurma Rajah is divided into a centre portion and sixteen rays. In the centre is the word Dookyin, which means "The Dookpa Creed;" around the "Dookyin" are sixteen similar letters, 
meaning "I," or "I am." The sixteen radial compartments contain his titles and attributes, thus, commencing from the centre erect one, and passing round from left to right :-

1. I am the Spiritual and Temporal Chief of the Realm.

2. The Defender of the Faith.

3. Equal to Saruswati in learning.

4. Chief of all the Boodhs.

5. Head expounder of the Shasters.

6. Caster out of devils.

7. The most learned in the Holy Laws.

S. An Avatar of God (or, by God's will.)

9. Absolver of sins.
10. I am above all the Lamas of the Dookpa Creed.

11. I am of the best of all Religionsthe Dookpa.

12. The punisher of unbelievers.

13. Unequalled in expounding the Shasters.

14. Unequalled in holiness and wisdom.

15. The head (or fountain) of all Religious Knowledge.

16. The Enemy of all false Avatars.

END OF TOL. I. 



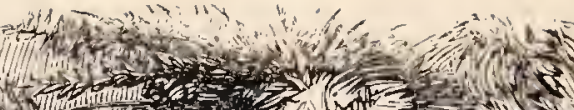

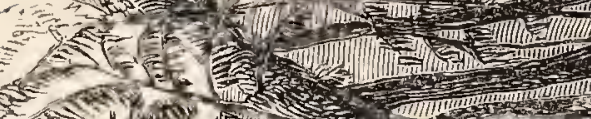

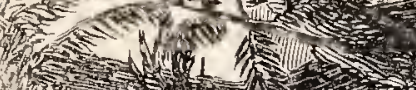

th

t.

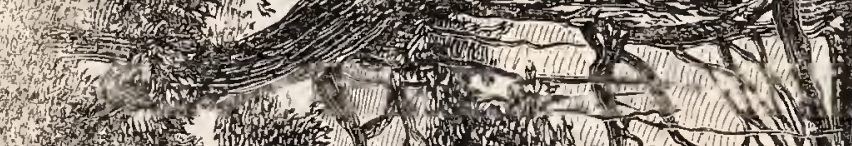

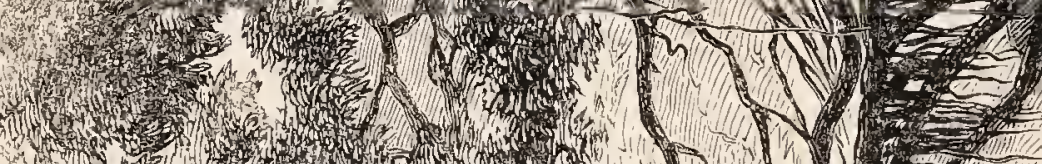

17.6.

6

m.

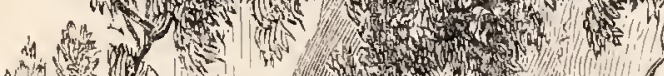

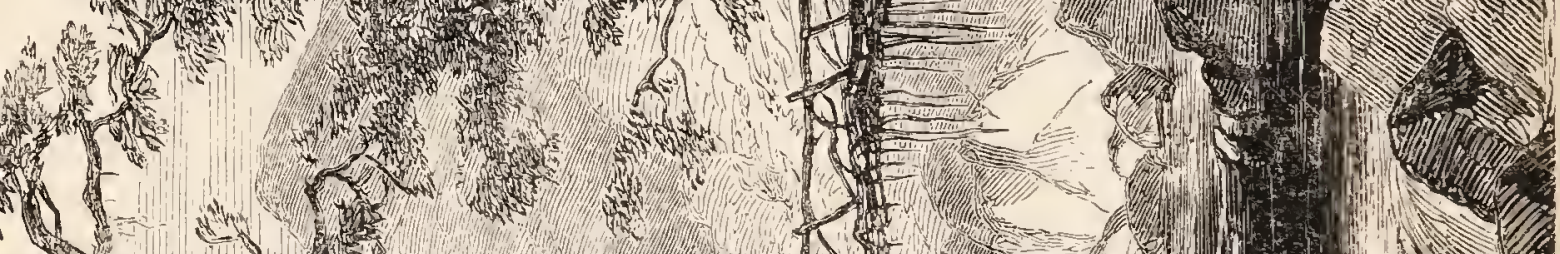

的

2 (

mon

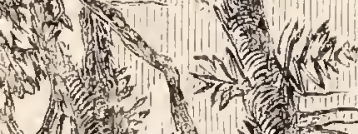

(1)

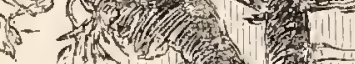

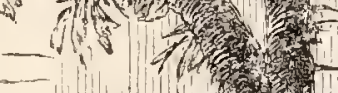

(3)

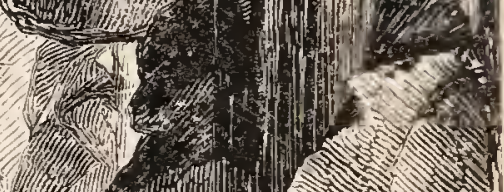

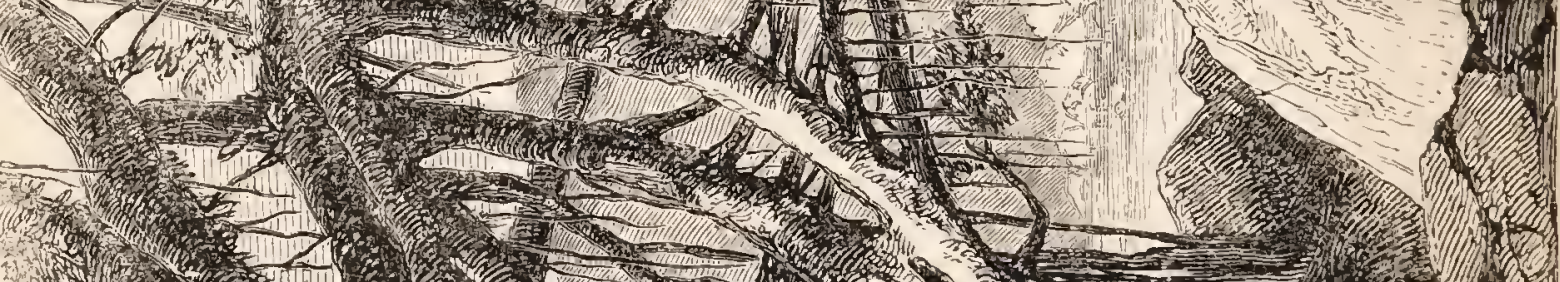
3. $5 \Rightarrow+1$ mat?

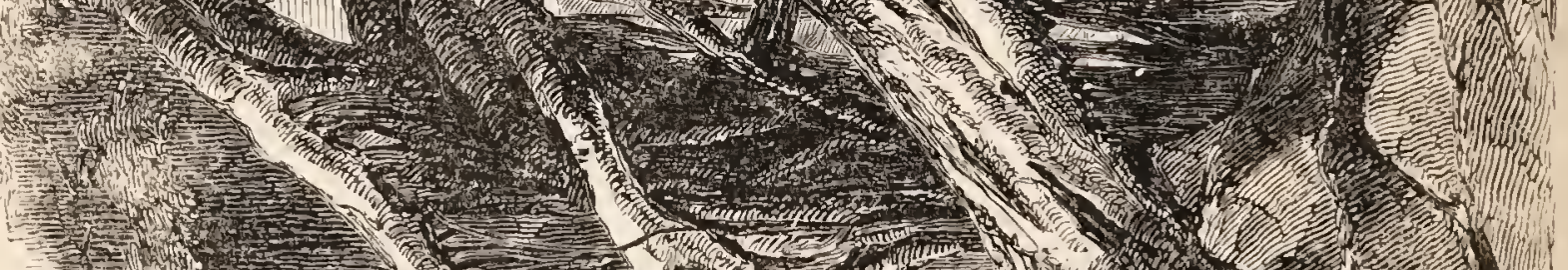

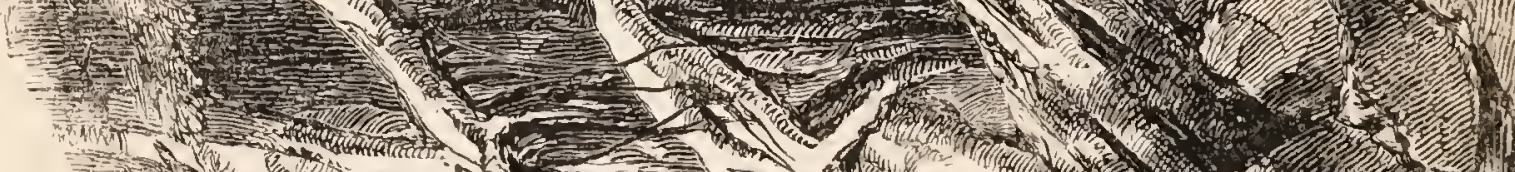
(1) 


\title{
HIMALAYAN JOURNALS.
}

\author{
NOTES OF A NATURALIST
}

IN BENGAL, THE SIKKIM AND NEPAL HIMALAYAS, THE KHASIA MOUNTAINS, \&c.

BY JOSEPH DALTON HOOKER, M.D. R.N. F.R.S.

A NEW EDITION, CAREFULLY REVISED AND CONDENSED.

IN TWO VOLUMES.-VOL. II.

WITH WOODCUTS.

LONDON :

JOHN MURRAY, ALBEMARLE STREET. 1855. 


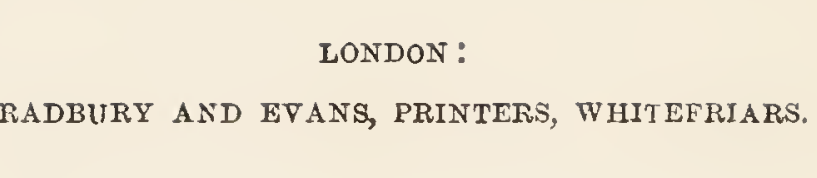




\section{LIST OF ILLUSTRATIONS.}

"LIVING BRIDGE" FORMED OF THE A ̈̈RIAL ROOTS OF THE

india-rUbBer aNd other kinds of FIGS - Frontispiece. Page

A MECH, NATIVE OF THE SIKKIM TERAI . . . . . 25

POCKET-COMB USED BY THE MECH TRIBES . . . . . 27

BORR, PANDANUS . . . . . . . . . . . . . 34

CANE-BRIDGE AND TUKOHAM MOUNTAIN . . . . . . 46

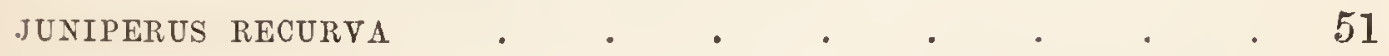

LAMTENG VILLAge . . . . . . . . 57

BLAOK JUNIPER AND YOUNG LARCH . . . . . . 74

TUNGU VILlaGe • . . . . . . . . . . 91

LEPCHA GIRLS AND TIBETAN WOMEN . . . . . . 104

TIBET MARMOT . . . . . . . . . . 109

LACHOONG VALLEY AND VILLAge, LOOKING SOUTH . . . 116

LOFTY ANCIENT MORAINES IN THE LACHOONG VALLEY, LOUKING

SOUTH-EAST • . . . . . . . . 117

HEAD AND FEET OF TIBET MARMOT . . . . . . . 119

GNEISS-BLOCK WITH GRANITE BANDS, ON THE KINCHINJHOW

GLACIER . . . . . . . . . 141

SUMMIT OF FOREED DONKIA, AND "GOA" ANTELOPES • . 144

IIEW FROM AN ELEVATION OF 18,000 FEET OF THE EAST TOP OF

KINCHINJHOW, AND OF TIBET, OVER THE RIDGE THAT CONNECTS IT WITH DONKIA. WILD SHEEP (OVIS AMMON) IN THE FOREGROUND . . . . . . 147 ANTELOPE'S HEAD . . . . . 165 


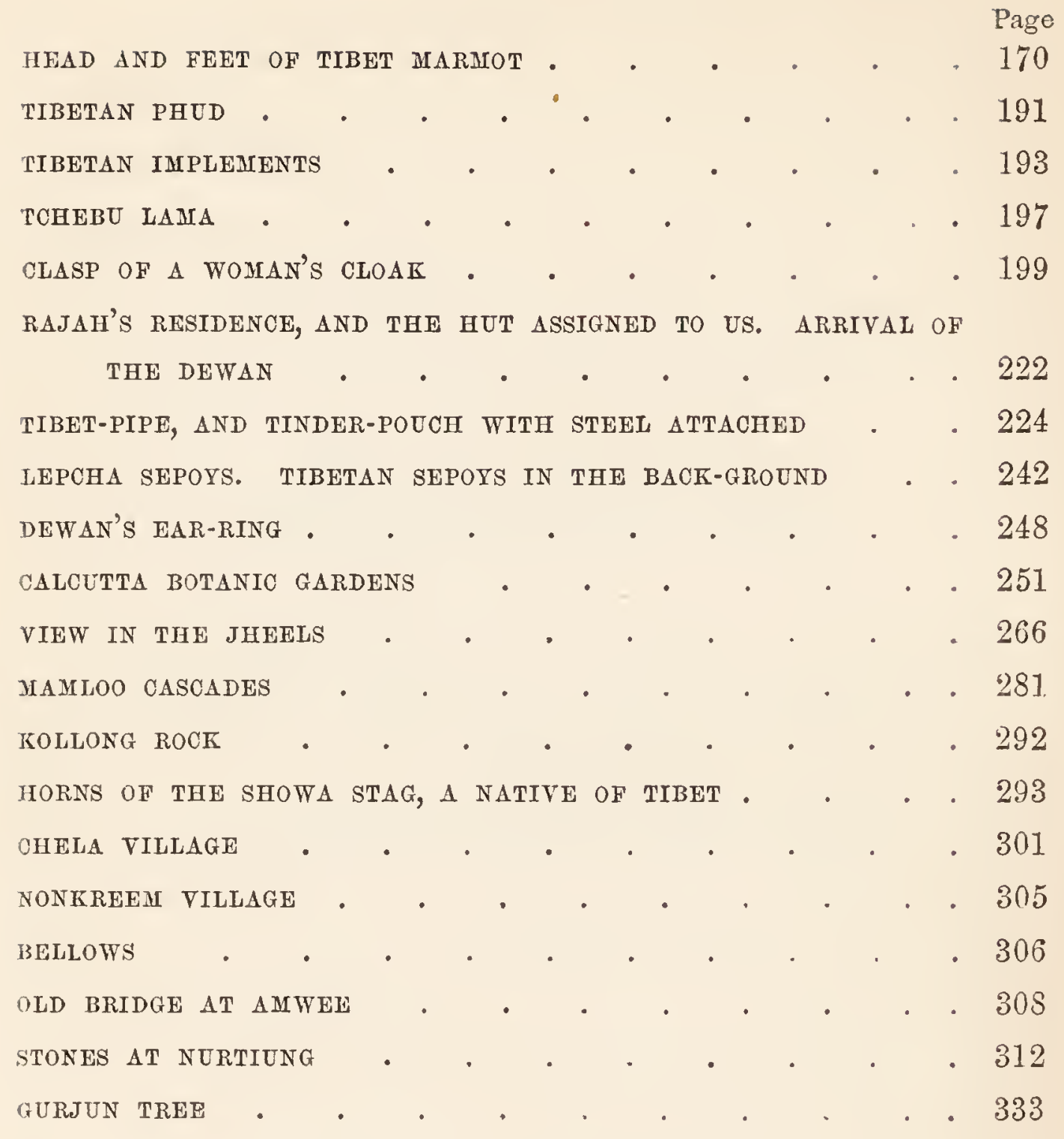




\section{CONTENTS.}

\section{CHAPTER XVII.}

EXodrston to TeraI. - Dispatch collections-Acorns-Heat-Punkabaree-Bees-Titalya-Earthquake-Proceed to Nepal frontierTerai, geology of-Physical features of Himalayan valleys-Elephants, purchase of, \&c.-Mechi river-Return to Titalya-Leave for Teesta-Jeelpigoree-Cooches-Alteration in the appearance of country by fires, \&c.-Grasses-Cottages-Rajah of Cooch Behar-Condition of people-Hooli festival-Ascend TeestaCanoes - Cranes - Forest - Baikant-pore - Rummai - Exit of Teesta-Canoe voyage down to Rangamally-Birds-Beautiful scenery-Botanising on elephants-Willow-Iron-Lohar-ghur -Coal and sandstone beds-Mechi fisherman-HailstormAscent to Dorjiling

\section{CHAPTER XVIII.}

Arrangements for second journey into Sikkim-Opposition of Dewan - Lassoo Kajee-Tendoug-Legend of flood-Lama of Silok-foke - Namtchi-Tchebu Lama-Top of Tendong-Gigantic oakPlants-Teesta valley - Commencement of rains - BhomsongAscent to Lathiang-View-Gorh-Opposition of Lama-Arrival of Meepo-Cross Teesta-Difficulties of travelling-Lepchas swimming-Moxa for sprains-Singtam-Singtam Soubah-Bees'nests and honey-seekers-Land-slips-Leeches, \&c.-Chakoong -Vegetation-Gravel terraces-Unpleasant effects of wormwood -Choongtam, scenery and vegetation of-Inhabitants-Tibetan. salute-Lamas-Difficulty of procuring food-Venomous snakes - Hornets and other insects-Choongtam temple-Pictures of Lhassa-Scenery 


\section{CHAPTER XIX.}

Routes from Choongtam to Tibet frontier-Choice of that by the Lachen river-Arrival of supplies-Departure-Features of the valley - Eatable Polygonum - Cross Taktoong river - Pines, larches, and other trees-Chateng pool-Water-plants and insects - Tukcham mountain - Lamteng village - Inhabitants Alpine monkey-Botany of temperate Himalaya-European and American fauna-Japanese and Malayan genera-Superstitious objections to shooting-Customs of people-Rain-Run short of provisions-Altered position of Tibet frontier-Zemu SamdongImposition-Vegetation-Uses of pines-Ascent to Thlonok river - Balanophora wood for making cups-Snow-beds-Eatable mushrooms and Smilacina-View of Kinchinjunga-Arum-roots, preparation of for food-Liklo mountain-Behaviour of my party -Bridge constructed over Zemu-Cross river-Alarm of my party-Camp on Zemu river . . . . . . .

\section{CHAPTER XX.}

Camp on Zemu river-Scenery-Falling rocks-Tukcham mountain - Height of glaciers-Botany-Gigantic rhubarb-Storm-Temperature of rivers-Behaviour of Lachen Phipun-Hostile conduct of Bhoteas-View from mountains above camp-Descend to Zemu Samdong-Vegetation-Letters from Dorjiling-Arrival of Singtam Soubah-Presents from Rajah-Parties collecting Arum-roots -Insects-Ascend Lachen river-Tallum Samdong villageCottages-Mountains-Plants-Entomology-Weather-Conduct of Singtam Soubah-His character and illness-Agrees to take me to Kongra Lama-Tungu-Appearance of country-Houses -Poisoning by Arum-roots-Yaks and calves-Tibet poniesJourney to Kongra Lama-Tibetan tents-Butter, curds, and churns-Hospitality-Kinchinjhow and Chomiomo-Magnificent scenery-Reach Kongra Lama Pass . . . . .

\section{CHAPTER XXI.}

Top of Kongra Lama-Tibet frontier-Elevation-View-Vegetation-Descent to Tungu-Tungu-choo-Ponies-Kinchinjhow and Changokhang mountains - Palung plains - Tibetans - Dogs Dingcham province of Tibet-Inhabitants - Dresses - Women's ornaments - Blackening faces - Coral - Tents - Elevation of 
Palung-Lama-Shawl-wool goats-Shearing-Siberian plants - Height of glaciers, and perpetual snow-Plants, and wild animals - Marmots - Insects - Birds - Choongtam Lama - Religious exercises - Tibetan hospitality - Delphinium-Perpetual snow-Return to Tallum Samdong-To Lamteng-HousesCicadas - Landslips-Arrival at Choongtam-Cobra-RageuVelocity and volume of rivers measured-Leave for Lachoong valley-Keadom-General features of valley-Lachoong village -Tunkra mountain-Moraines-Cultivation-Lachoong Phipun -Lama ceremonies beside a sick-bed . . . . .

\section{. CHAPTER XXII.}

Leave Lachoong for Tunkra pass-Moraines and their vegetationPines of great dimensions-Wild currants-Glaciers-Summit of pass - Elevation - Views - Plants - Winds - Lacheepia rockExtreme cold-Kinchinjunga-Himalayan grouse-Return to Lachoong-Ascent to Yeumtong - Flats and débâcles-Buried pine-trunks-Hot-springs-Behaviour of Singtam Soubah-Leave for Momay Samdong-Upper limit of trees-Glacial terraces, \&c. -Forked Donkia-Ascent to Donkia pass-Scenery-LakesTibet-Bhomtso - Arun river - Kianglah mountains - YaruTsampu river-Appearance of Tibet-Kinchinjhow, and Kinchinjunga-Chola range-Deceptive appearance of distant landscape - Perpetual snow-Pulses-Plants-Tripe de roche-Return to Momay-Dogs and yaks-Birds-Insects-Quadrupeds-Hotsprings-Marmots-Kinchinjhow glacier . . . .

\section{CHAPTER XXIII.}

Donkia glaciers-Moraines-Dome of ice-Honey-combed surfaceAccident to instruments-Sebolah pass-Bees and May-fliesView-Lamas and travellers at Momay-Weather and climateSensations arising from elevation-Dr. Campbell leaves Dorjiling for Sikkim-Leave Momay-Yeumtong-Lachoong-Retardation of vegetation at low elevations - Choongtam - Landslips and débâcle-Meet Dr. Campbell-Motives for his journey-Second visit to Lachen valley-Autumnal tints-Red currants-Lachen Phipun - Tungu-Scenery-Animals-Poisonous rhododendrons -Fire-wood - Palung - Elevations - Sitong - Kongra LamaTibetans-Enter Tibet-Desolate scenery-Plants-AnimalsGeology-Cholamoo lakes-Antelopes-Return to Yeumtso-Dr. 
Campbell lost-Extreme cold-Headaches-Tibetan Dingpun and guard-Arms and accoutrements-Temperature of YeumtsoMigratory birds-Visit of Dingpun-Yeumtso lakes . . .

\section{CHAPTER XXIV.}

Ascent of Bhomtso-View of snowy mountains-Chumulari-Arun river-Jigatzi-Lhassa-Dingcham province of Tibet-Misapplication of term "Plain of Tibet"-Sheep, flocks of-CropsProbable elevation of Jigatzi-Yaru-Tsampu river-Tame elephants-Wild horses-Cholamoo lakes-Effects of great elevation -Ascent of Donkia-Moving piles of debris-Cross Donkia pass - Second visit to Momay Samdong-Descent to Ý Lachoong-Retardation of vegetation-Jerked meat-Fish-Lose a thermometer-Lepcha lad sleeps in hot-spring-Keadom Bucklandia-Arrive at Choongtam-Mendicant-MeepaLachen-Lachoong river-Wild grape-Virulent nettle . . .

\section{CHAPTER XXV.}

Journey to the Rajah's residence at Tumloong-Ryott valley-Rajah's house-Tupgain Lama-Lagong nunnery - Phadong GoompaPhenzong ditto-Lepcha Sepoys-Proceedings at TumloongRefused admittance to Rajah-Women's dresses-Meepo's and Tchebu Lama's families-Chapel-Leave for Chola pass-Ryott river-Rungpo, view from-Deputation of Kajees, \&c.-Conference - Laghep - Cathcartia - Phieung-goong - Rutto riverBarfonchen-Curling of rhododendron leaf-Woodcock-Chola pass-Tibet guard and Sepoys-Dingpun-Arrival of Sikkim sepoys-Their conduct-Meet Singtam Soubah-ChumanakoWe are seized by the Soubah's party—Soubah's conduct-Dingpun Tinli-Treatment of Dr. Campbell-Bound and guardedSeparated from Campbell-Marched to Tumloong-Motives for such conduct-Arrive at Rungpo-At Phadong-Presents from Rajah-Visits of Lama-Of Singtam Soubah-I am crossquestioned by Amlah-Confined with Campbell-Seizure of my coolies-Threats of attacking Dorjiling . . . .

\section{CHAPTER XXVI.}

Dr. Campbell is ordered to appear at Durbar-Lamas called to council-Threats-Scarcity of food-Arrival of Dewan-Our 
jailor, Thoba-sing-Temperature, \&c., at Tumloong-Services of Goompas-Lepcha girl - Jews'-harp—Terror of servants - Ilamsing's family-Interview with Dewan-Remonstrances-Dewan feigns sickness-Lord Dalhousie's letter to Rajah-Treatment of Indo-Chinese-Concourse of Lamas-Visit of Tchebu Lama-Close confinement-Dr. Canpbell's illness-Conference with AmlahRelaxation of confinement-Pemiongchi Lama's intercessionEscape of Nimbo-Presents from Rajah, Ranee and peopleProtestations of friendship-Mr. Lushington sent to Dorjiling - Leave Tumloong-Cordial farewell-Dewan's merchandiseGangtok Kajee - Dewan's pomp - Governor-General's letter Dikkeeling-Suspicion of poison-Dinner and pills-TobaccoBhotanese colony - Katong-ghat on Teesta - Wild lemonsSepoy's insolence-Dewan alarmed-View of Dorjiling-Threats of a rescue-Fears of our escape-Tibet flutes-Negociate our release-Arrival at Dorjiling-Dr. Thomson joins me-Movement of troops at Dorjiling-Seizure of Rajah's Terai property .

\section{CHAPTER XXVII.}

Leave Dorjiling for Calcutta-Jung Bahadoor-Dr. Falconer-Improvements in Botanic Gardens-Palmetum-Victoria-Amherstia-Orchids spread by seed-Banyan-Importation of American plants in ice-Return to Dorjiling-Leave with Dr. Thomson for the Khasia mountains-Mahanuddee river-Vegetation of banks - Maldah - Alligators - Rampore-Beauleah - Climate of Ganges-Pubna-J ummul river-Altered course of Burrampooter and Megna-Dacca-Conchshells-Saws-Cotton muslins-Fruit - Vegetation-Rose of Bengal-Burrampooter-Delta of Soormah river - Jheels - Soil - Vegetation - Navigation - MosquitosEffects of geological changes-Imbedding of plants-Teelas or islets-Chattuc-Salubrious climate-Rains-Canoes-PunduaTerrya Ghat-Ascent to Churra-Scenery and vegetation at foot of mountains-Cascades. . . . . . . .

\section{CHAPTER XXVIII.}

Churra, English station of-Khasia people-Garrow people-Houses - Habits - Dress - Arms - Dialects - Marriages - Food Funerals - Superstitions - Flat of Churra - Scenery - Lime and coal-Mamloo-Cliffs-Caseades-Flora of, Churra-OrchidsRhododendrons - Pine - Climate - Extraordinary rain-fall - Its 
effects - Gardens of Lieuts. Raban and Cave-Leave Churra to cross the mountain range-Kalapanee river-Lailangkot-Bogapanee river-View of Himalaya-Age of Pine-cones-Moflong plants-Coix-Chillong mountain-Extensive view-Road to Syong-Broad valleys-Myrung-Kollong rock-Pine-woodsFeatures of country-Orchids-Iron forges . . . .

\section{CHAPTER XXIX.}

View of Himalaya from the Khasia-Great masses of snow-Chumulari - Donkia - Grasses - Nunklow - Burrampooter - Tropical forest-Borpanee-Rhododendrons-Wild elephants-Blocks of Syenite-Return to Churra-August temperature-Leave for Chela-Birds-Habits of leaf-insects-Curious village-Houses -Canoes-Boga-panee river-Jheels-Chattuc-Churra-Leave for Jyntea hills-Trading parties-Dried fish-Cherries-Cinnamon - Fraud - Nonkreem - Granite boulders-Iron washingForges-Tanks-Siberian Nymphoea-Pomrang-Patchouli plant -Mooshye-Pitcher-plant-Joowye cultivation and vegetationSulky hostess - Nurtiung-Sacred grove and gigantic stone structures-Altars-Pyramids, \&c.-Origin of names-CollectionsNovember vegetation . . . . . .

\section{CHAPTER XXX.}

Boat voyage to Silhet-River-Palms-Fish weirs-Forests of Cachar -Sandal-wood, \&c. - Porpoises - Alligators - Silchar - Tigers -Rice-crops - Cookies-Munniporees-Hockey-Dance-Nagas -Excursion to Munniporee frontier-Elephant bogged-Climate, \&c. of Cachar-Mosquitos-Fall of bank-Silhet-Tree-fernsChattuc-Megna - Noacolly - Salt-smuggling-Delta of Ganges and Megna-Westward progress of Megna-Tide-Wares-Dangerous navigation-Moonlight scenes-Mud island-ChittagongViews-Trees-Coffee-Pepper-Excursions from ChittagongGurjun trees-Earthquake - Birds-Papaw-Poppy and sun fields-Seetakoond bungalow and hill-Perpetual flame-Climate -Leave for Calcutta - Hattiah island_Plants - SunderbundsSteamer-Tides-Nipa fruticans-Crocodiles-Phonix paludosa-Fishing-Otters-Departure from India 


\section{HIMALAYAN JOURNALS.}

\section{CHAPTER XVII.}

EXCORSTON TO TERAI.

Dispatch collections - Acorns - Heat - Punkabaree - Bees - 'litalyaEarthquake-Proceed to Nepal frontier-Terai, geology of-Physical features of Himalayan valleys-Elephants, purchase of, \&c.-Mechi river-Return to Titalya-Leave for Teesta-Jeelpigoree-CoochesAlteration in the appearance of country by fires, \&c.-GrassesCottages-Rajah of Cooch Behar-Condition of people-Hooli festivalAscend Teesta-Canoes-Cranes-Forest-Baikant-pore-RummaiExit of Teesta-Canoe voyage down to Rangamally-Birds-Beautiful scenery - Botanising on elephants - Willow - Iron - Lohar-ghurCoal and sandstone beds-Mechi fisherman-Hailstorm-Ascent to Dorjiling.

HAVING arranged the collections (amounting to eighty loads) made during 1848 , they were conveyed by coolies to the foot of the hills, where carts were provided to carry them five days' journey to the Mahanuddee river, which flows into the Ganges, whence they were transported by water to Calcutta.

On the 27th of February, I left Dorjiling to join Mr. Hodgson, at Titalya on the plains. The weather was raw, cold, and threatening; snow lay here and voL. II. 
there, and all vegetation was very backward, and wore a wintry garb. The laurels, maples, and deciduousleaved oaks, hydrangea and cherry, were leafless, but the abundance of chesnuts and evergreen oaks, rhododendrons, Aucuba, and other shrubs, kept the forest well clothed. The oaks had borne a very unusual number of acorns during the last season, which were now falling, and strewing the road in some places so abundantly, that it was hardly safe to ride down hill.

The plains of Bengal were all but obscured by a dense haze, partly owing to a peculiar state of the atmosphere that prevails in the dry months, and partly to the fires raging in the Terai forest, from which white wreaths of smoke ascended, stretching obliquely for miles to the eastward, and filling the air with black particles of grass-stems, carried 4000 feet aloft by the heated ascending currents that impinge against the flanks of the mountains.

The evening was sultry and close, the heated surface of the earth seemed to load the atmosphere with warm vapours, and the sensation, as compared with the cool pure air of Dorjiling, was that of entering a confined tropical harbour after a long sea-voyage; and the forest, which had looked so gigantic on $\mathrm{my}$ arrival the previous year, now appeared small after the far more lofty and bulky oaks and pines of the upper regions.

I slept in the little bungalow of Punkabaree, and was awakened next morning by sounds to which I had long been a stranger, the voices of innumerable birds, 
and the humming of great bees that bore large holes for their dwellings in the beams and rafters of houses: never before had I been so forcibly struck with the absence of animal life in the regions of the upper Himalaya.

Breakfasting early, I pursued my way in the socalled cool of the morning, but this was neither bright nor fresh; the earth was dusty and parched; while the sun rose through a murky yellowish atmosphere with ill-defined orb. Thick clouds of smoke pressed upon the plains, and the faint easterly wind wafted large flakes of grass charcoal sluggishly along. Coarse, ill-favoured vultures wheeled through the air, languid Bengalees replaced the active mountaineers, jackal-like curs teemed at every village, and ran howling away from the onslaught of my Alpine dog; and the tropics, with all their beauty of flower and genial warmth, looked as forbidding and unwholesome as they felt oppressive to a frame that had so long breathed the fresh mountain air.

Mounted on a stout pony, I enjoyed my scamper of sixteen miles over the wooded plains and undulating gravelly slopes of the Terai, intervening between the foot of the mountains and Siligoree bungalow. In the afternoon I rode on leisurely to Titalya, sixteen miles further, along the banks of the Mahanuddee. The atmosphere was so hazy, that objects a few miles off were invisible, and the sun quite concealed, though its light was so powerful that no part of the sky could be steadily gazed upon. During the afternoon the wind blew with violence, but being hot and dry, brought no 
relief to my unacclimated frame. My pony alone enjoyed the freedom of the plains, and the gallop or trot being fatiguing in the heat, I tried in vain to keep him at a walk; his spirits did not last long, however; for he flagged after a few days' of tropical heat. My little dog had run thirty miles the day before, exclusive of all the detours he had made for his own enjoyment, and he became so tired after twenty more this day, that I had to take him on my saddle-bow, where, after licking his hot swollen feet, he fell fast asleep.

At Titalya bungalow, I received a hearty welcome from Mr. Hodgson, and congratulations on the success of my Nepal journey, which afforded a theme for many conversations.

In the evening we had three sharp jerking shocks of an earthquake in quick succession, at 9.8 P.M., appearing to come up from the southward: they were accompanied by a hollow rumbling sound like that of a waggon passing over a wooden bridge. They were felt strongly at Dorjiling, and registered by Mr. Muller at 9.10 P.M.: we had accurately adjusted our watches (chronometers) the previous morning, and the motion may therefore fairly be assumed to have been transmitted northwards through the intervening distance of forty miles, in two minutes. Both Mr. Muller and Mr. Hodgson had noted a much more severe shock at 6.10 p.x. the previous evening, which I, who was walking down the mountain, did not experience; this caused a good deal of damage at Dorjiling, in cracking well-built walls. Earthquakes are frequent all along the Himalaya, and are felt far in 
Tibet; they are, however, most common towards the eastern and western extremities of India; owing in the former case to the proximity of the volcanic forces in the bay of Bengal. Cutch and Scinde, as is well known, have suffered severely on many occasions, and in several of them the motion has been propagated through Affghanistan and Little Tibet, to the heart of Central Asia.

On the morning of the 1st of March, Dr. Campbell arrived from his tour of inspection along the frontier of Bhotan; and we accompanied him as far as the Mechi river, which bounds Nepal on the east.

Terai is a name applied to a tract of country at the very foot of the Himalaya: the word is Persian, and signifies damp. Politically, the Terai generally belongs to the hill-states beyond it; geographically, it should appertain to the plains of India; and geologically, it is a sort of neutral country, being composed neither of the alluvium of the plains, nor of the rocks of the hills, but for the most part of alternating beds of sand, gravel, and boulders brought from the mountains; the soil being 'generally light, dry, and gravelly. Botanically it is readily defined as the region of forest-trees; amongst which the Sal, the most valuable of Indian timber, is conspicuous in most parts, though not in Sikkim, where it has been destroyed. The Terai varies in breadth, from ten miles on the Sikkim frontier, to thirty and more on the Nepalese. In the latter country it is called the Morung, and supplies Sal and Sissoo timber for the Calcutta market, the logs being floated down the Konki and Cosi rivers 
to the Ganges. The gravel-beds extend upon the plains for fully twenty miles south of the Sikkim mountains, the gravel becoming smaller as the distance increases, and large blocks of stone not being found beyond a few miles from the Himalaya itself, even in the beds of rivers, however large and rapid. Throughout its breadth this formation is conspicuously cut into flat-topped terraces, flanking the spurs of the mountains, at elevations varying from 250 to nearly 1000 feet above the sea. This deposit contains no fossils; and its general appearance and mineral constituents are the only evidence of its origin, which is no doubt due to a retiring ocean that once washed the base of the Sikkim Himalaya, received the contents of its rivers, and, wearing away its bluff spurs, spread a talus upwards of 1000 feet thick along its shores.

The alluvium of the Gangetic valley was no doubt deposited in deep water, whilst the coarser matter was accumulating at the foot of the mountains.

This view has occurred, I believe, to almost every observer, at whatever part of the base of the Himalaya he may have studied this deposit. Its position indicates its recent formation; but it still remains a subject of the utmost importance to discover the extent and nature of the ocean to whose agency it is referred. The alluvium of the Gangetic valley may to a great degree be the measure of the denudation which the Himalaya has suffered along its Indian watershed. It was, no doubt, during the gradual rise of that chain from the ocean, that the gravel and alluvium were deposited; and in the terracing and alternation of 
these deposits, there is evidence that there have been many subsidences and elevations of the coast-line, during which the gravel has suffered greatly from lenudation.

I never looked at the Sikkim Himalaya from the pains without comparing its bold spurs enclosing sinuous river gorges, to the weather-beaten front of a mountainous coast; and in following any of its great rivers, the scenery of its deep valleys no less strikingly resembles that of such narrow arms of the sea (or fiords) as characterise every mountainous coast, of whatever geological formation: such as the west coasts of Scotland and Norway, of South Chili and Fuegia, of New Zealand and Tasmania. There are too in these Himalayan valleys terraced pebble-beds, rising in some cases eighty feet above the rivers, which I believe could only have been deposited by them when they debouched into deep water; and both these, and the beds of the rivers, are strewed with masses of rock. Such accumulations and transported blocks are seen on the raised beaches of our narrow Scottish salt water lochs, exposed by the rising of the land, and they are yet forming of immense thickness on many coasts by the joint action of tides and streams.

In every Himalayan valley which 'I ascended, I met with ancient moraines at or about 7000 or 8000 feet elevation, proving, that at one period, the glaciers descended fully so much below the position they now occupy: this can only be explained by a change of climate, or by a depression of the mountain mass equal to 8000 feet, since the formation of these moraines. 
The country about Titalya looks desert, from that want of trees and cultivation, so characteristic of the upper level throughout this part of the plains, which is covered with short, poor, pasture-grass.

Shortly after Dr. Campbell's arrival, the meadows about the bungalow presented a singular appearance, being dotted over with elephants, brought for purchase by Government. It was curious to watch the arrival of these enormous animals, which were visible nesrly. two miles across the flat plains; nor less interesing was it to observe the wonderful docility of these giants of the animal kingdom, often only guided by naked boys, perched on their necks, scolding, swearing, and enforcing their orders with an iron goad. There appeared as many tricks in elephant-dealers as in horse-jockeys, and of many animals brought, but few were purchased. Government limits the price to about $75 l$., and the height to the shoulder must not be under seven feet, which, incredible as it appears, may be estimated within a fraction as being three times the circumference of the forefoot. The pedigree is closely inquired into, the feet are examined for cracks, the teeth for age, and many other points attended to.

The Sikkim frontier, from the Mahanuddee westward to the Mechi, is marked by a row of tall posts. The country is undulating; and though fully 400 miles from the ocean, and not sixty from the top of the loftiest mountain on the globe, its average level is not 300 feet above that of the sea. The upper levels are gravelly, and loosely covered with scattered thorny 
jujube bushes, occasionally tenanted by the Florican, which scours these downs like a bustard. Sometimes a solitary fig, or a thorny acacia, breaks the horizon, and there are a few gnarled trees of the scarlet Butea frondosa.

At this season few insects but grasshoppers are to be seen, even mosquitos being rare. Birds, however, abound, and we noticed the common sparrow, hoopoe, water-wagtail, skylark, osprey, and several egrets.

We arrived on the third day at the Mechi river, to the west of which the Nepal Morung begins, whose belt of Sal forest loomed on the horizon, so raised by refraction as to be visible as a dark line, from the distance of many miles. It is, however, very poor, all the large trees having been removed. We rode for several miles into it, and found the soil dry and hard, but supporting a prodigious undergrowth of gigantic harsh grasses that reached to our heads, though we were mounted on elephants. Tigers, wild elephants, and the rhinoceros, are said to be found here; but we saw none.

The old and new Mechi rivers are several miles apart, but flow in the same depression, a low swamp many miles broad, which is grazed at this season, and cultivated during the rains. The grass is very rich, partly owing to the moisture of the climate, and partly to the retiring waters of the rivers; both circumstances being the effects of proximity to the Himalaya. Hence cattle (buffalos and the common humped cow of India) are driven from the banks of the Ganges 300 miles to these feeding grounds, for the use of which a 
trifling tax is levied on each animal. The cattle are very carelessly herded, and many are carried off by tigers.

Having returned to Titalya, Mr. Hodgson and I set off in an eastern direction for the Teesta river, whose embouchure from the mountains to the plains I was anxious to visit. Though the weather is hot, and oppressively so in the middle of the day, there are few climates more delicious than that of these grassy savannahs from December to March. We always started soon after daybreak on ponies, and enjoyed a twelve to sixteen miles' gallop in the cool of the morning before breakfast, which we found prepared on our arrival at a tent sent on ahead the night before. The route led across an open country, or followed paths through interminable rice-fields, now dry and dusty. On poor soil a white-flowered Leucas monopolised the space, like our charlock and poppy: it was apparently a pest to the agriculturist, covering the surface in some places like a sprinkling of snow.

On the second day we arrived at Jeelpigoree, a large straggling village near the banks of the Teesta, a good way south of the forest: here we were detained for several days, waiting for elephants with which to proceed northwards. The natives are Cooches, a Mogul (Mongolian) race, who inhabit the open country of this district, replacing the Mechis of the Terai forest. They are a fine athletic people, not very dark, and formed the once powerful house of Cooch Behar. Latterly the upper classes have adopted the religion of the Brahmins, and have had caste conferred upon them; 
while the lower orders have turned Mahometans: these, chiefly agriculturists, are a timid, oppressed class, who everywhere fled before us, and were with difficulty prevailed upon even to direct us along our road. A rude police is established by the British Government all over the country, and to it the traveller applies for guides and assistance; but the Cooches were so shy and difficult to deal with, that we were generally obliged to depend on our own resources. Turf is the prevailing feature of the country, there being few shrubs, and still fewer trees. Goats and the common Indian cow are plentiful, but it is not swampy enough for the buffalo, and sheep are scarce, on account of the heat of the climate. This uniformity of feature over so immense an area is, however, due to the agency of man, and is of recent introduction; as all concur in affirming, that within the last hundred years the face of the country was covered with the same tall junglegrasses which abound in the Terai forest; and the troops cantoned at Titalya (a central position) from 1816 to 1828 , confirm this statement as far as that immediate neighbourhood is concerned.

These gigantic grasses seem to be destroyed by fire with remarkable facility at one season of the year ; and it is well that this is the case ; for, whether as a retainer of miasma, a shelter for wild beasts, both carnivorous and herbivorous, alike dangerous to man, or from their liability to ignite, and spread destruction far and wide, the grass-jungles are most serious obstacles to civilisation. Next to the rapidity with which it can be cleared, the adaptability of a great part of the soil to irrigation 
during the rains, has greatly aided the bringing of it under cultivation.

At Jeelpigoree we were waited upon by the Dewan, who governs the district for the Rajah, a boy about ten years old, whose estates are locked up during the trial of an interminable suit for the succession, that has been instituted against him by a natural son of the late Rajah: we found the Dewan to be a man of. intelligence, who promised us elephants as soon as the great Hooli festival, now commenced, should be over.

The large village, at the time of our visit, was gay with holiday dresses. It was surrounded by trees, chiefly of banyan, jack, mango, peepul, and tamarind: endless rice-fields extended on all sides, but except bananas, slender betel-nut palms, and sometimes pawn, or betel-pepper, there was little other cultivation. The rose-apple, orange, and pine-apple were rare, as were cocoa-nuts; there were few date or fan-palms, and only occasionally poor crops of castor-oil and sugar-cane. In the gardens I noticed many of the very commonest Indian ornamental plants; while for food were cultivated Chenopodium, yams, sweet potatos, and more rarely peas, beans, and gourds. Bamboos were planted round the little properties and smaller clusters of houses in oblong squares, the ridge on which the plants grew being usually bounded by a shallow ditch. The species selected was not the most graceful, the stems being densely crowded, erect, as thick at the base as the arm, copiously branching, and very feathery throughout their whole length of sixty feet. 
The cottages were remarkable, presenting nothing but a low white-washed platform of clay, and an enormous high, narrow, black, neatly-thatched roof, so arched along the ridge, that its eaves nearly touched the ground at each gable; looking at a distance like a gigantic reund-backed elephant. The walls were of neatly-platted bamboo: each window (of which there were two) was crossed by slips of bamboo, and wanted only glass to make it look European; they had besides, shutters of wattle, that opened upwards, projecting during the day like the port-hatches of a ship, and let down at night. Within, the rooms were airy and clean; one end contained the machans (bedsteads), the other some raised clay benches, the fire, frequently an enormous Hookah, round wattled stools, and various implements. The inhabitants appeared more than ordinarily well-dressed; the men in loose flowing robes of fine cotton or muslin, the women in the usual garb of a simple thick cotton cloth, drawn tight immediately above the breast, and thence falling perpendicularly to the knee; the colour of this was a bright blue in stripes, bordered above and below with red.

I anticipated some novelty from a visit to a Durbar (court) so distant from European influence as that of the Rajah of Jeelpigoree. All Eastern courts, subject to the Company, are, however, now shorn of much of their glory; and the condition of the upper classes is greatly changed.

One evening we visited the young Rajah at his residence, which had rather a good appearance at a distance, its white walls gleaming through a dark tope 
of mango, betel, and cocoa-nut. A short rude avenue led to the entrance, under the trees of which a large bazaar was being held; stocked with clothes, simple utensils, ornaments, sweetmeats, fish from the Teesta, and betel-nuts.

We entered through a guard-house, where were some of the Rajah's Sepoys in European costume, and a few of the Company's troops, lent to the Rajah as a security against some of the turbulent pretenders to his title. Within was a large court-yard flanked by a range of buildings, some of good stone-work, some of wattle, in all stages of disrepair. A great crowd of people occupied one end of the court, and at the other we were received by the Dewan, and seated on chairs under a canopy supported by slender silvered columns. Some slovenly Natch-girls were dancing before us, kicking up clouds of dust, and singing or rather bawling through their noses, the usual indelicate hymns in honour of the Hooli festival; there were also fiddlers, cutting uncouth capers in rhythm with the dancers. Anything more deplorable than the music, dancing, and accompaniments, cannot well be imagined; yet the people seemed vastly pleased, and extolled the performers.

The arrival of the Rajah and his brothers was announced by a crash of tom-toms and trumpets, while over their heads were carried gilt canopies. With them came a troop of relations, of all ages; and amongst them a poor little black girl, dressed in honour of us in an old-fashioned English chintz frock and muslin cap, in which she cut the drollest figure imaginable; 
she was carried about for our admiration, like a huge Dutch doll, crying lustily all the time.

The festivities of the evening commenced by handing round trays full of pith-balls, the size of a nutmeg, filled with a mixture of flour, sand, and red lac-powder; with these each pelted his neighbour, the thin covering bursting as it struck any object, and powdering it copiously with red dust. A more childish and disagreeable sport cannot well be conceived; and when the balls were expended, the dust itself was resorted to, not only fresh, but that which had already been used was gathered up, with whatever dirt it might have become mixed. One rude fellow, with his, hand full, sought to entrap his victims into talking, when he would stuff the nasty mixture into their mouths.

At the end attar of roses was brought, into which little pieces of cotton, fixed on slips of bamboo, were dipped, and given to each person. The heat, dust, stench of the unwashed multitude, noise, and increasing familiarity of the lower orders, warned us to retire, and we effected our retreat with precipitancy.

The Rajah and his brother were very fine boys, lively, frank, unaffected, and well disposed: they have evidently a good guide in the old Dewan; but it is melancholy to think how surely, should they grow up in possession of their present rank, they will lapse into slothful habits, and take their place amongst the imbeciles who now represent the once powerful Rajahs of Bengal.

We rode back to our tents by a bright moonlight, very dusty and tired, and heartily glad to breathe 
the cool fresh air, after the stifling ordeal we had undergone.

On the following evening the elephants were again in waiting to conduct us to the Rajah. $\mathrm{He}$ and his relations were assembled outside the gates, mounted upon elephants, amid a vast concourse of people. The children and Dewan were seated in a sort of cradle; the rest were some in howdahs, and some astride on elephants' backs, six or eight together. All the idols were paraded before them, and powdered with red dust; the people howling, shouting, and quarrelling. When the mob had sufficiently pelted one another with balls and dirty red powder, a torchlight procession was formed, headed by the idols, to a very large tank, bounded by a high rampart, within which was a broad esplanade round the water.

The effect of the whole scene was very striking, the glittering cars and barbaric gaud of the idols showing best by torchlight; while the white robes and turbans of the undulating sea of people, and the great black elephants picking their way with matchless care and consideration, contrasted strongly with the quiet moonbeams sleeping on the still broad waters of the tank.

Thence the procession moved to a field, where the idols were placed on the ground, and all dismounted: the Dewan then took the children by the hand, and each worshipped his tutelary deity in a short prayer dictated by the attendant Brahmin, and threw a handful of red dust in its face. After another ordeal of powder, singing, dancing, and suffocation, our share in the Hooli ended; and having been promised 
elephants for the following morning; we bade a cordial farewell to our engaging little hosts and their staid old governor.

On the 10th of March we left for Rangamally, a village eight miles distant in a northerly direction, our course lying along the west bank of the Teesta.

The river is here navigated by canoes, thirty to forty feet long, some being rudely cut out of a solid log of Sal, while others are built, the planks, of which there are but few, being sewed together, or clamped with iron, and the seams caulked with the fibres of the root of Dhak (Butea frondosa), and afterwards smeared with the gluten of Diospyros embryopteris.

The whole country improved in fertility as we advanced towards the mountains; the grass became greener, and more trees, shrubs, herbs, and birds appeared. Flocks of cranes were abundant over-head, flying in wedges, or breaking up into "open order," preparing for their migration northwards, which takes place in April, their return occurring in October; a small quail was also common on the ground. Tamarisk grew in the sandy bed of the river; its flexible young branches are used in various parts of India for wattling and basket-making.

In the evening we walked to the skirts of the Sal forest. The great trunks of the trees were often scored by tigers' claws, this animal indulging in the cat-like propensity of rising and stretching itself against such objects.

At Rangamally, the height of the sandy banks of the Teesta varies from fifteen to twenty feet. The bed is a 
mile across and all sand, but the stream does not occupy one-third of this space; the current is much divided, and opaque green, from the glacial origin of most of its head-streams. The west bank was covered with a small Sal forest, mixed with Acacia Catechu, and brushwood, growing in a poor vegetable loam, over very dry sand.

The opposite (or Bhotan) bank is much lower, and always flooded during the rains, which is not the case on the western side, where the water rises to ten feet below the top of the bank, or from seven to ten feet above its height in the dry season, and when it fills its whole bed. This information we had from a police Jemandar, who has resided many years on this unhealthy spot, and annually suffers from fever. The Sal forest has been encroached upon from the south, for many miles, within the memory of man, by clearing in patches, and by indiscriminate felling.

About ten miles north of Rangamally, we came to an extensive flat, occupying a recess in the high west bank, the site of the old capital (Bai-kant-pore) of the Jeelpigoree Rajah. Hemmed in as it is on three sides by a dense forest, and on all by many miles of malarious Terai, it appears sufficiently secure from ordinary enemies, during a great part of the year.

About eight miles on, we left the river-bed, and struck westerly through a dense forest, to a swampy. clearance occupied by the village of Rummai, which appeared thoroughly malarious; and we pitched our tent on a narrow low ridge, above the level of the plain. 
In the evening we rode into the forest (which was dry and very unproductive), and thence along the riverbanks, through Acacia Catechu, belted by Sissoo, which often fringes the stream, always occupying the lowest flats. The foliage at this season is brilliantly green; and as the evening advanced, \& yellow convolvulus burst into flower like magic, adorning the bushes over which it climbed.

On the following morning we left for the exit of the Teesta, proceeding northwards, sometimes through a dense forest of Sal timber, sometimes dipping into marshy depressions, or riding through grassy savannahs, breast-high. The coolness of the atmosphere was delicious, and the beauty of the jungle seemed to increase the further we penetrated into these primeval forests.

Eight miles from Rummai we came on a small river from the mountains, with a Cooch village close by, inhabited during the dry season by timber-cutters from Jeelpigoree.

We here mounted the elephants, and proceeded several miles through the prairie, till we again struck upon the high Sal forest-bank: it formed one of many terraces which stretch along the foot of the hills, from Punkabaree to the Teesta, but of which none are said to occur for eight miles eastwards along the Bhotan Dooars: if true, this is probably due in part to the alteration of the course of the Teesta, which is gradually working to the westward, and cutting away these lofty banks.

The Sal bank formed a very fine object: it was quite 
perpendicular, and beautifully stratified with various coloured sands and gravel: it tailed off abruptly at the junction of the rivers, and then trended away southwest, forming the west bank of the Teesta. The latter river is at its outlet a broad and rapid, but hardly impetuous stream, now fifty yards across, gushing from between two low forest-clad spurs: it appeared about five feet deep, and was beautifully fringed on both sides with green Sissoo.

Some canoes were here waiting for us, formed of hollowed trunks of trees, thirty feet long: two were lashed together with bamboos, and the boatmen sat one at the head and one at the stern of each: we lay along the bottom of the vessels, and in a second we were darting down the river, at the rate of at least ten or fifteen miles an hour, the bright waters leaping up on all sides, and bounding in jets-d'eau between prows and sterns of the coupled vessels. Sometimes we glided along without perceptible motion, and at others jolted down bubbling rapids, the steersmen straining every nerve to keep their bark's head to the current, as she impatiently swerved from side to side in the eddies. On our jaded and parched frames, after the hot forenoon's ride on the elephants, the effect was delicious: the fresh breeze blew on our heated foreheads and down our open throats; we dipped our hands into the clear, cool stream, and there was "music in the waters" to our ears. Fresh verdure on the banks, clear pebbles, soft sand, long English river-reaches, forest glades, and deep jungles, followed in rapid succession; and as often as we rounded a bend or 
shot a rapid, the scene changed from bright to brighter still; so continuing until dusk, when we were slowly paddling along the then torpid current opposite Rangamally.

The absence of large stones or boulders of rock in the bed of the Teesta is very remarkable, considering the great volume and rapidity of the current, and that it shoots directly from the rocky hills to the gravelly plains. At the embouchure there are boulders as big: as the head, and in the stream, four miles below the exit, the boatmen pointed out a stone as large as the body as quite a marvel.

They assured us that the average rise at the mouth of the river, in the rains, was not more than five feet: the mean breadth of the stream is from seventy to ninety yards. From the point where it leaves the mountains, to its junction with the Megna, is at this season thirteen days' voyage, the return occupying from twenty to twenty-five days, with the boats unladen. The name "Teesta" signifies "quiet," this river being so in comparison with other Himalayan torrents further west, the Cosi, Konki, \&c., which are devastators of all that bounds their course.

We passed but two crossing-places: at one the river is divided by an island, covered with the rude chaits and flags of the Boodhists. We also saw some Cooch fishermen, who throw the net much as we do: a fine "Mahaser" (a very large carp) was the best fish they had. Of cultivation there was very little, and the only habitations were a few grass-huts of the boatmen or buffalo herdsmen, a rare Cooch village of Catechu and 
Sal cutters, or the shelter of timber-floaters, who seem to pass the night in nests of long dry grass.

On the 14th of March we proceeded west to Siligoree, along the skirts of the ragged Sal forest. Birds are certainly the most conspicuous branch of the natural history of this country, and we saw many species, interesting either from their habits, beauty, or extensive distribution. We noticed no less than sixteen kinds of swimming birds, several of which are migratory and English. The Shoveller, white-eyed and common wild ducks : Merganser, Brahminee, and Indian goose, common and Gargany teal; two kinds of gull; one of Shearwater; three of tern, and one of cormorant. Besides these there were three egrets, the large crane, stork, green heron, and the demoiselle; the English sand-martin, king-fisher, peregrine-falcon, sparrowhawk, kestrel, and the European vulture; the wild peacock, and jungle-fowl. There were at least 100 peculiarly Indian birds in addition, of which the more remarkable were several kinds of mina, starling, vulture, kingfisher, magpie, quail, and lapwing.

The country gradually became quite beautiful, much undulated and varied by bright green meadows, sloping lawns, and wooded streams, which led from the Sal forest and meandered through this varied landscape. More beautiful sites for fine mansions could not well be, and it is difficult to suppose so lovely a country should be so malarious as it is before and after the rains, excessive heat probably diffusing widely the miasma from small stagnant surfaces. We noticed a wild hog, absolutely the first wild beast of any size I 
saw on the plains, except the spiny hare, and the barking deer. The hare we found to be the best game of this part of India, except the teal. The pheasants of Dorjiling are poor, the deer all but uneatable, and the florican, however dressed, I considered a far from excellent bird.

A good many plants grow along the streams, the sandy beds of which are everywhere covered with the marks of tigers' feet. The only safe way of botanising is by pushing through the jungle on elephants; an uncomfortable method, from the quantity of ants and insects which drop from the foliage above, and from the risk of disturbing pendulous bees' and ants' nests. A peculiar species of willow is common here ; which is a singular fact, as the genus is characteristic of cold and arctic latitudes, and no species is found below 8000 feet elevation on the Sikkim mountains, where it grows on the inner Himalaya only, some kinds ascending to 16,000 feet.

The latter part of the journey I performed on elephants during the heat of the day, and a more uncomfortable mode of conveyance surely never was adopted; the camel's pace is more fatiguing, but that of the elephant is extremely trying after a few miles, and is so injurious to the human frame that the Mahouts (drivers) never reach an advanced age, and often succumb young to spine-diseases, brought on by the incessant motion of the vertebral column. The broiling heat of its black back, and the odour of its oily driver, are disagreeable accompaniments, as are its habit of snorting water from its trunk over its parched 
skin, and the consequences of the great bulk of green food which it consumes.

The Duabanga is the pride of these forests. Its trunk, from eight to fifteen feet in girth, is generally forked from the base, and the long pendulous branches which clothe the trunk for 100 feet, are thickly leafy, and terminated by racemes of immense white flowers, which, especially when in bud, smell most disagreeably of assafoetida.

The report of a bed of iron-stone eight or ten miles west of Punkabaree determined us on visiting the spot; and the locality being in a dense jungle, the elephants were sent on a-head.

Lohar-ghur, or "iron hill," lies in a thick dry forest. Its plain-ward flanks are very steep, and covered with scattered weather-worn masses of ochreous and black iron-stone, many of which are several yards long: it fractures with faint metallic lustre, and is very earthy in parts; it does not affect the compass. There are no pebbles of iron-stone, nor water-worn rocks of any kind found with it.

Below Punkabaree the Baisarbatti stream cuts through banks of gravel overlying the tertiary sandstone. The latter is gritty and micaceous, intercalated with beds of indurated shale and clay; in which I found the shaft (apparently) of a bone. In the bed of the stream were carbonaceous shales, with obscure impressions of fossil fern leaves, characteristic of the Burdwan coal-fields, but too imperfect to justify any conclusion as to the relation between these formations. 
Ascending the stream, these shales are seen in situ, overlain by the metamorphic clay-slate of the mountains. This is at the foot of the Punkabaree spur, and close

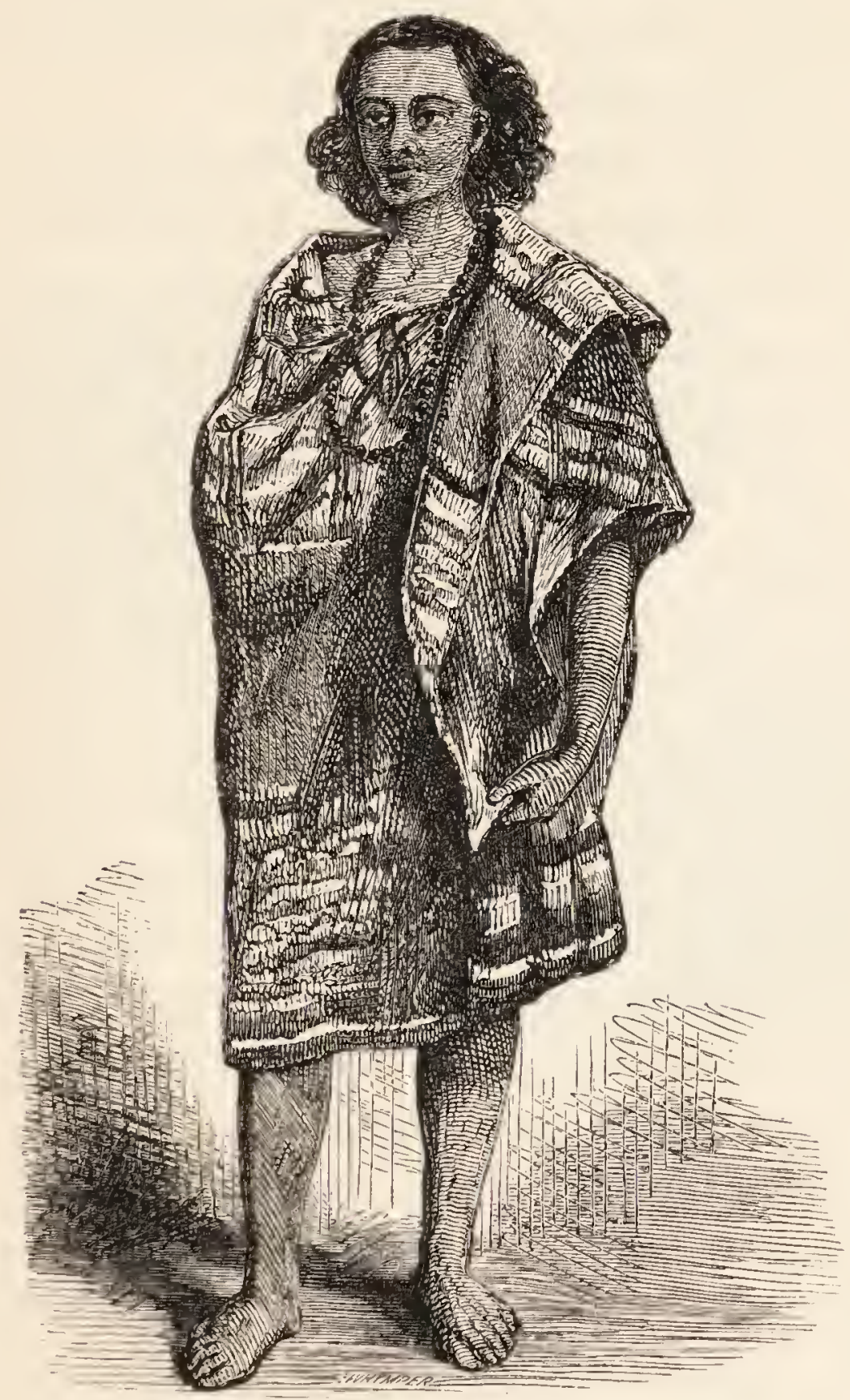

A MECH, NATIVE OF THE SIKKIM TERAI.

to the bungalow, where a stream and land-slip expose good sections. The coal-seams are few in number, six to twelve inches thick, very confused, and full of FOL. II. 
nodules of quartzy slate, covered with concentric scaly layers of coal. These scanty notices being collected in a country clothed with the densest tropical forest, where a geologist pursues his investigations under disadvantages that can hardly be realised in England, will I fear long remain unconfirmed.

A poor Mech was fishing in the stream, with a basket curiously formed of a cylinder of bamboo, cleft all round in innumerable strips, held together by the joints above and below, and stretched out as a balloon in the middle, and kept apart by a hoop: a small hole is cut in the cage, and a mousetrap entrance formed; the cage is placed in the current with the open end upwards, where the fish get in, and though little bigger than minnows, cannot find their way out.

On the 20th we had a change in the weather: a violent storm from the south-west occurred at noon, with hail of a strange form, the stones being sections of hollow spheres, half an inch across and upwards, formed of cones with truncated apices and convex bases; these cones were aggregated together with their bases outwards. The large masses were followed by a shower of separate conical pieces, and that by heavy rain. On the mountains this storm was most severe; the stones lay at Dorjiling for seven days, congealed into masses of ice several feet long and a foot thick in sheltered places: at Purnea, fifty miles south, stones one and two inches across fell, probably as whole spheres. When we reached Dorjiling on the 24th of March, we found that the hail which had 
fallen on the 20th was still lying in great masses of crumbling ice in sheltered spots. The fall had done great damage to the gardens, and Dr. Campbell's teaplants were cut to pieces.

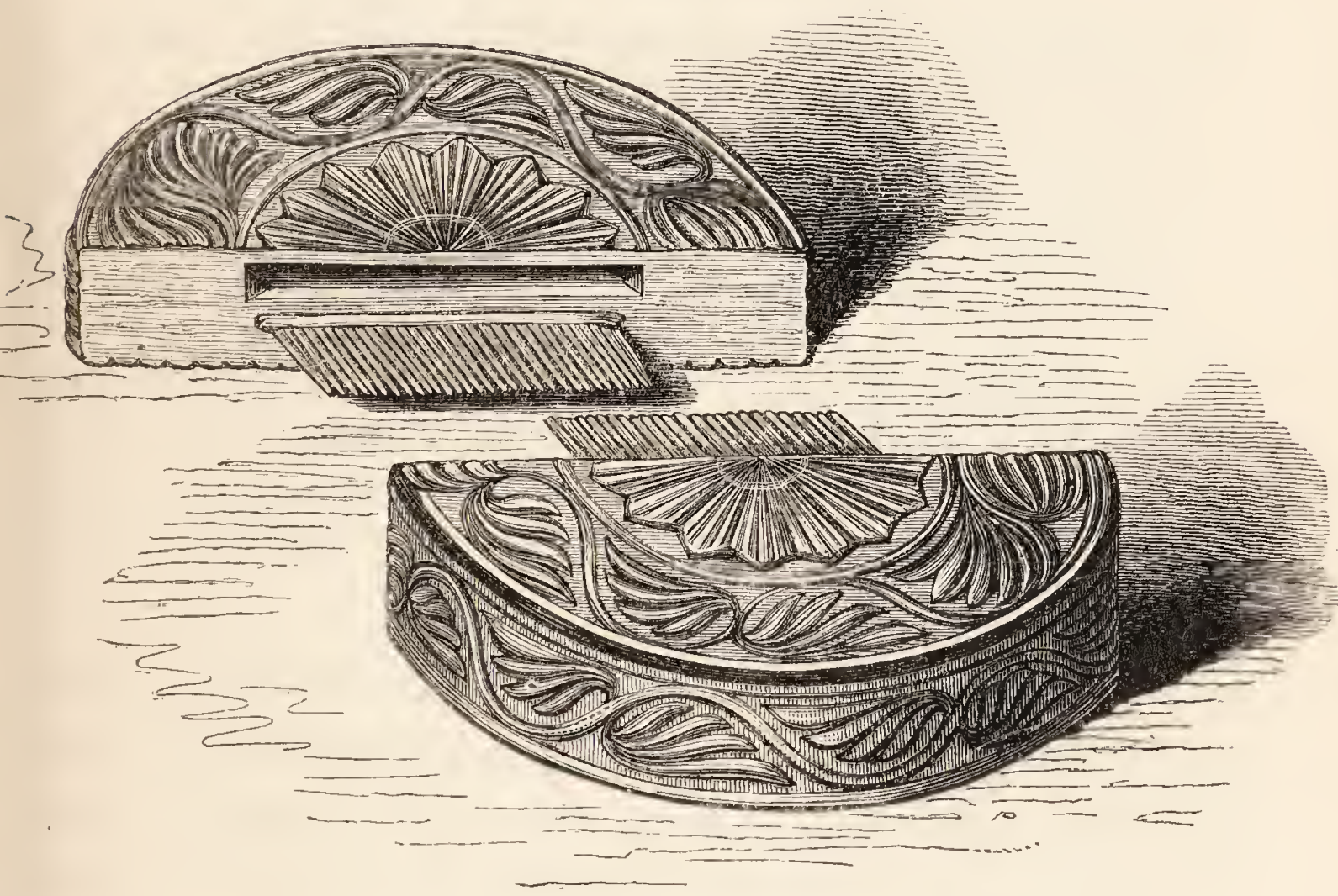

POCKET-COMB USED BY THE MECH TRIBES. 


\section{CHAPTER XVIII.}

Arrangements for second journey into Sikkim-Opposition of DewanLassoo Kajee-Tendong-Legend of flood-Lama of Silok-fokeNamtchi-Tchebu Lama-Top of Tendong-Gigantic oak-PlantsTeesta valley-Commencement of rains-Bhomsong-Ascent to Lathiang -View-Gorh-Opposition of Lama-Arrival of MeepoCross Teesta-Difficulties of travelling-Lepchas swimming-Moxa for sprains - Singtam-Singtam Soubah-Bees'-nests and honey-seekersLand-slips-Leeches, \&c.-Chakoong-Vegetation-Gravel terracesUnpleasant effects of wormwood-Choongtam, scenery and vegetation of-Inhabitants-Tibetan salute-Lamas-Difficulty of procuring food -Venomous snakes-Hornets and other insects-Choongtam temple - Pictures of Lhassa-Scenery.

After my return to Dorjiling; I was occupied during the month of April in preparations for an expedition to the loftier parts of Sikkim. The arrangements were the same as for my former journey, except with regard to food, which it was necessary should be sent out to me at intervals; for I had had ample proof that the resources of the country were not equal to provisioning a party of from forty to fifty men, even had the Dewan been favourable to my travelling, which was clearly not the case.

Dr. Campbell communicated to the Rajah my intention of starting early in May for the upper Teesta valley, and, in the Governor-General's name, requested 
that he would facilitate my visiting the frontier of Sikkim, north-east of Kinchinjunga. The desired permission was, after a little delay, received; which appeared to rouse the Dewan to institute a series of obstructions to my progress, which led to so many delays that my exploration of the country was not concluded till October, and I was prevented returning to Dorjiling before the following Christmas.

Since Dr. Campbell's and my visit to the Rajah in December, no Vakeel (agent) had been sent by the Durbar to Dorjiling, and consequently we could only communicate indirectly with his Highness, while we found it impossible to ascertain the truth of various reports promulgated by the Dewan, and meant to deter me from entering the country. In April, the Lassoo Kajee was sent as Vakeel, but, having on a previous occasion been dismissed for insolence and incapacity, and again rejected when proposed by the Dewan at Bhomsong, he was refused an audience; and he retired exasperated, pretending that he had orders to delay my starting, and that he was prepared to use strong measures should I cross the frontier.

No notice was taken of these threats; the Rajah was again informed of my intended departure, unless his orders to the contrary were received through a proper accredited agent, and I left Dorjiling on the 3rd of May, accompanied by Dr. Campbell, who saw me fairly over the frontier.

Arrangements were made for supplies of rice following me by instalments; our daily consumption being 80 lbs., a man's load. After crossing into Sikkim, I 
mustered my party at the Great Rungeet river. I had forty-two in all, of whom the majority were young Lepchas, all were active and cheerful-looking fellows; only one was goitred, and he had been a salt-trader. I was accompanied by a guard of five Sepoys, and had a Lepcha and Tibetan interpreter. I took but one personal servant, a Portuguese half-caste who cooked for me; he was a native of Calcutta, and though hardy, patient, long-suffering, and far better tempered, was, in other respects, very inferior to my servant of the previous year, who, having been bred to the sea, was as handy as he was clever; but who, like all other natives of the plains, grew intolerably weary of the hills, and left me.

The first part of my route lay over Tendong, a conspicuous feature from Dorjiling, where it is known as Mount Ararat. The Lepchas have a curious legend of a man and woman having saved themselves on its summit, during a flood that once deluged Sikkim. The coincidence of this story with the English name of Ararat suggests the probability of the legend being fabulous; but I am positively assured that it is not so, and that it was current amongst the Lepchas before its English name was heard of, the latter having been suggested from the form of its summit resembling that given in children's books as the resting-place of the ark.

On the route I was met by the Lama of Silolifoke Goompa. Though a resident on the Lassoo Kajee's estates, he politely brought me a present, at the same time apologising for not waiting till I had encamped, owing to his excessive fat, which prevented his 
climbing. I accepted his excuses, though well aware that the real reason was that he wished to pay his respects, and show his good feeling, in private. Besides his ordinary canonicals, he carried a tall crozier-headed staff, and had a curious horn slung round his neck, full of amulets; it was short, of a transparent red colour, and beautifully carved, and was that of the small cow of Lhassa.

Namtchi was once a place of considerable importance; and still possesses a mendong, with six rows of inscribed slabs, a temple, and a Lama attached thereto; the latter waited on me soon after I had encamped; but he brought no present, and I was not long kept in suspense as to his motives. These people are poor dissemblers; if they intend to obstruct, they do it clumsily and hesitatingly: in this instance the Lama first made up to my people, and, being coolly received, kept gradually edging up to my tent-door, where, after an awkward salute, he delivered himself with a very bad grace of his mission, which was from the Lassoo Kajee to stop my progress. I told him I knew nothing of the Lassoo Kajee or his order's, and should proceed on the following morning: he then urged the bad state of the roads, and requested me to wait till he should receive orders from the Rajah; upon which I dismissed him.

Soon afterwards I saw twenty or thirty men rapidly descending the rocky path; they were Lepchas, with blue and white striped garments, bows and quivers, and long knives gleaming in the sun: they seemed to be following a Lama with a scarlet handkerchief wound 
round his head, its ends streaming out behind him. Though expecting this apparition to prove the renowned Kajee and his myrmidons, coming to put a termination to my progress, I could not help admiring the picturesqueness of the scenery and party. My fears were soon dissipated by my men joyfully shouting, "The Tchebu Lama! the Tchebu Lama!" and I soon recognised the rosy face and twinkling eyes of my friend of Bhomsong, the only man of intelligence about the Rajah's court, and the one whose services as Vakeel were particularly wanted at Dorjiling.

He told me that the Lassoo Kajee had orders (from whom, he would not say) to stop my progress, but that I should proceed nevertheless, and that there was no objection to my doing so; and he despatched a messenger to the Rajah, announcing my progress and requesting him to send me a guide, and to grant me every facility, asserting that he had all along fully intended doing this.

On the following morning $I$ continued the ascent of Tendong, by a narrow winding path, covered with oaks, rhododendrons, and various shrubs, not found at equal elevation on the wetter Dorjiling ranges. The last ascent is up a steep rounded cone with a broad flat top, covered with dwarf bamboo, a few oaks, laurels, magnolias, and white-flowered rhododendron trees, which obstructed the view. I hung the barometers near one of the many chaits on the summit, where there is also a rude temple, in which worship is performed once a year; and found the elevation to be 8,671 feet. 
The descent on the north side was steep, through a rank vegetation, very different from that of the south face. The oaks are very grand, and I measured one (whose trunk was decayed and split into three, however), which I found to be 49 feet in girth at 5 feet from the ground.

From Temi the road descends to the Teesta, the course of which it afterwards follows. The valley was fearfully hot, and infested with mosquitos and peepsas. Many fine plants grew in it: I especially noticed an Aristolochia, which climbs the loftiest trees, bearing its curious pitcher-shaped flowers near the ground only; its leaves are said to be good food for cattle. Houttuynia, a curious herb allied to pepper, grew on the banks, which, from the profusion of its white flowers, resembled strawberry-beds; the leaves are eaten by the Lepchas. But the most magnificent plant of these jungles is Hodgsonia, (a genus I have dedicated to my friend Mr. Hodgson,) a gigantic climber allied to the gourd, bearing immense yellowish-white pendulous blossoms, whose petals have a fringe of buff-coloured curling threads several inches long. The fruit is of a rich brown, like a small melon in form, and contains six large nuts whose kernels are eaten. The stem, when cut, discharges water profusely from whichever end is held downwards. The "Took" (Hydnocarpus) is a beautiful evergreen tree, with tufts of yellow blossoms on the trunk; its fruit is as large as an orange, and is used to poison fish, while from the seeds an oil is expressed. Tropical oaks and Terminalias are the giants of these low forests; the latter especially, having 
buttressed trunks, appear truly gigantic; one measured 47 feet in girth, at 5 feet, and 21 at 15 feet from the

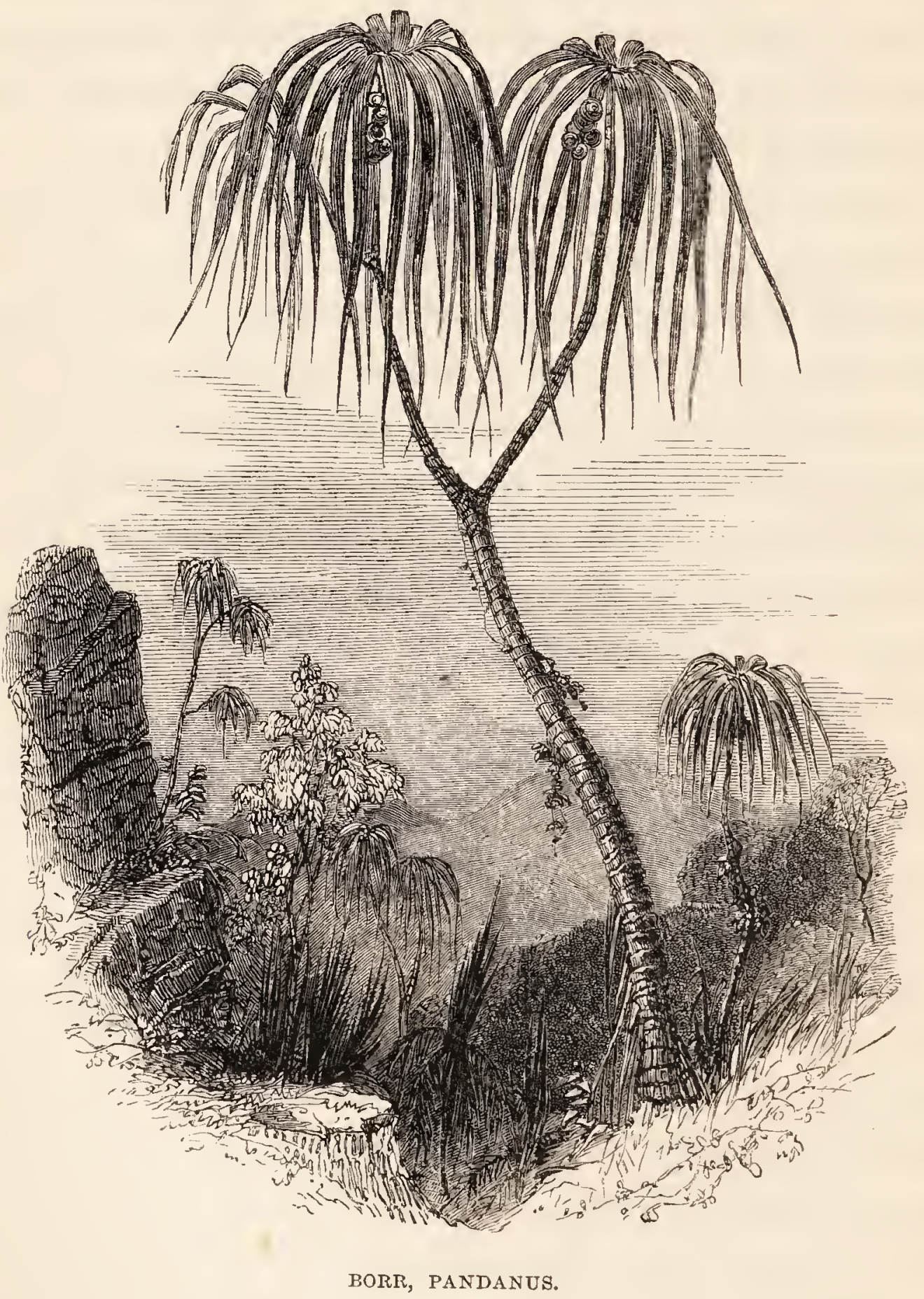

ground; and was fully 200 feet high. I could only procure the leaves by firing a ball into the crown.

The rains commenced on the 10th of May, moderating the heat by drenching thunder-storms, but greatly 
increasing the discomforts of travelling, and so soaking the men's loads, that I was obliged to halt a day in the Teesta valley to have waterproof covers made of platted bamboo-work, enclosing Phrynium leaves. I was delighted to find that my little tent was impervious to water, though its thickness was but of one layer of blanket: it was a single ridge with two poles, 7 feet high, 8 feet long, and 8 feet broad at the base, forming nearly an equilateral triangle in front.

Bhomsong was looking more beautiful than ever in its rich summer clothing of tropical foliage. I halted during an hour of heavy rain on the spot where I had spent the previous Christmas, and could not help feeling doubly lonely in a place where every rock and tree reminded me of that pleasant time. The isolation of my position, the hostility of the Dewan, and consequent uncertainty of the success of a journey that absorbed all my thoughts, the prevalence of fevers in the valleys I was traversing, and the many difficulties that beset my path, all crowded on the imagination when fevered by exertion and depressed by gloomy weather, and my spirits involuntarily sank as I counted the many miles and months intervening between $\mathrm{me}$ and my home.

The little flat on which I formerly encamped was now covered with a bright green crop of young rice. The house then occupied by the Dewan was now empty and unroofed; but the suspension bridge had been repaired, and its light framework of canes, spanning the boiling flood of the Teesta, formed a graceful object in this beautiful landscape. I had rather expected to 
meet either with a guide, or with some further obstruction here, but as none appeared, I proceeded onwards as soon as the weather moderated.

Higher up, the banks are so steep as to allow of no road, and the path ascends from the river, for nearly 4000 feet, to Lathiang village, up a wild, rocky torrent that descends from Mainom.

From the village the view was superb, embracing the tropical gulley, with the fiat of Bhomsong deep in the gorge, its bright rice-fields gleaming like an emerald amid the dark vegetation that surrounded it; the Teesta winding to the southward; the pine-clad rocky top of Mainom to the south-west; the cone of Tendong far to the south; to the north, black mountains tipped with snow; and to the east the magnificent snowy range of Chola, crowning the valley of the Ryott with a diadem of frosted silver.

Descending to Gorh (4,100 feet), I was met by the Lama of that district, a tall, disagreeable-looking fellow, who informed me that the road ahead was impassable. The day being spent, I was obliged to camp at any rate; after which he visited me in full canonicals, bringing me a handsome present, but assuring me that he had no authority to let me advance. I treated him with civility, and regretted my objects being so imperative, and my orders so clear, that I was obliged to proceed on the following morning; on which he abruptly decamped, as I suspected, in order to damage the road and bridges. He came again at daylight, and expostulated further; but finding it of no use, he volunteered to accompany me, officiously offering me 
the choice of two roads. I asked for the coolest, knowing that it was useless to try and outwit him in such matters. At the first stream the bridge was destroyed, but seeing the planks peeping through the bushes in which they had been concealed, I desired the Lama to repair it, which he dia without hesitation. So it was at every point: the path was cumbered with limbs of trees, crossing-stones were removed from the streams, and all natural difficulties were increased. I kept constantly telling the Lama that as he had volunteered to show me the road, I felt sure he intended to remove all obstacles, and accordingly I put him to all the trouble I possibly could, which he took with a very indifferent grace. When $I$ arrived at the swinging bridge across the Teesta, I found the canes were loosened, and slips of bamboo, so small as nearly to escape observation, were ingeniously placed low down over the single bamboo that formed the footing, intended to trip up the unwary passenger, and overturn him into the river, which was deep, and with a violent current. Whilst the Lama was cutting these, one of my party found a charcoal writing on a tree, announcing the speedy arrival from the Rajah of my old guide, Meepo; and he shortly afterwards appeared, with instructions to proceed with me, though not to the Tibetan frontier. The lateness of the season, the violence of the rains, and the fears, on the Rajah's part, of my coming to mischief through fever or accident, were all urged to induce me to return, or at least only to follow the west branch of the Teesta to Kinchinjunga. These reasons failing, I was threatened 
with Chinese interference on the frontier. All these objections I overruled, by refusing to recognise any instructions that were not officially communicated to the Superintendent of Dorjiling.

The Gorh Lama here took leave of me; he was a friend of the Dewan, and was rather surprised to find that the Rajah had sent me a guide, and now attempted to pass himself off as my friend, pompously charging Meepo with the care of me, and bidding me a very polite farewell. I could not help telling him civilly, but plainly, what I thought of him; and so we parted.

Meepo was very glad to join my party again; he was a thorough Lepcha in heart, a great friend of his Rajah and of Tchebu Lama, and one who both feared and hated the Dewan. He assured me of the Rajah's good wishes and intentions, but spoke with great doubt as to the probability of a successful issue to my journey: he was himself ignorant of the road, but had brought a guide, whose appearance, however, was against him, and who turned out to be sent as a spy on us both.

Instead of crossing the Teesta here, we kept on for two days up its west bank, to a cane bridge at Lingo, where the bed of the river is still only 2000 feet above the sea, though 45 miles distant from the plains, and flowing in a valley bounded by mountains 12,000 to 16,000 feet high. The heat was oppressive, from the closeness of the atmosphere, the great power of the sun, now high at noon day, and the reflection from the rocks. Leeches and stinging flies of various 
kinds began to swarm as the damp increased. My clothes were drenched with perspiration during five hours of every day, and the crystallising salt irritated the skin. On sitting down to rest, I was overcome with languor and sleep, and, but for the copious supply of fresh water everywhere, travelling would have been intolerable. The coolies were all but naked, and were constantly plunging into the pools of the rivers; they are powerful swimmers, and will stem a very strong current, striking out with each arm alternately. It is an animated sight when twenty or thirty of these swarthy children of nature are disporting their muscular figures in the water, diving after large fish, and sometimes catching them by tickling them under the stones.

My servant having severely sprained his wrist by a fall, the Lepchas wanted to apply a moxa, which they do by lighting a piece of puff-ball, or of Nepal paper (that burns like tinder), laying it on the skin, and blowing it till a large open sore is produced: they shook their heads at my treatment, which consisted in transferring some of the leeches from our persons to the inflamed part.

After crossing the Teesta our route lay over a ridge 5,500 feet high; hence a rapid descent leads to the village of Singtam, 3000 feet above the river, which is here no longer called the Teesta, but the LachenLachoong, from its double origin in the rivers of these names, which unite at Choongtam, twenty miles higher up. Of these, the source of the Lachen is in the Cholamoo lakes in Tibet; while the Lachoong rises on 
the south flank of Donkia mountain, both many marches north of my present position.

At Singtam I was waited on by the Soubah of the district, a tall portly Bhotea, who was destined to prove the most active enemy to my pursuits. He governs the country between Gorh and the Tibet frontier, for the Maha-Ranee (wife of the Rajah), whose dowry it is; and she being the Dewan's relative, I had little assistance to expect from her agent. His conduct was very polite, and he brought me a handsome offering for myself; but after delaying me a day on the pretext of collecting food for my people, I was obliged to move on with no addition to my store, and trust to obtaining some at the next village, or from Dorjiling. Owing, however, to the increasing distance, and the destruction of the roads by the rains, my supplies from that place were becoming irregular: I therefore thought it prudent to reduce my party, by sending back my guard of Sepoys, who could be of no further use.

From this point the course of the Teesta is materially different from what it is lower down; it becomes a boisterous torrent, as suddenly as the Tambur does, above Mywa Guola. Its bed is narrower, large masses of rock impede its course, nor is it practicable for rafts at any season; the only means of passing it being by cane bridges that are thrown across, high above the stream.

The slope on either side of the valley is very steep; that on the north, in particular, appearing too precipitous for any road, and being only frequented by honey-seekers, who scale the rocks by cane ladders, 
and thus reach the pendulous bees'-nests, which are so large as in some instances to be conspicuous features at the distance of a mile. This pursuit appeared extremely perilous, the long thread-like canes in many places affording the only footing over many yards of cliff: the procuring of this honey, however, is the only means by which many of the idle poor raise the rent which they must pay to the Rajah.

The most prominent effect of the steepness of the valleys is the prevalence of land-slips, which sometimes descend for 3000 feet, carrying devastation along their course; they are caused either by the melting of the snow-beds on the mountains, or by the action of the rains on the rocks; and are much increased in effect and violence by the heavy timber-trees which, swaying forwards, loosen the earth at their roots, and give impetus to the mass. This phenomenon is as frequent and destructive as in Switzerland, where, however, more lives are lost, from the country being more populous, and from the people recklessly building in places particularly exposed to such accidents. A most destructive one had occurred here the previous year, by which a village was destroyed, together with twelve of its inhabitants, and all the cattle. I crossed its debris on the first march beyond Singtam; the whole face of the mountain appeared more or less torn up for fully a mile, presenting a confused mass of white clay, full of angular masses of rock. The path was very difficult and dangerous, being carried along the steep slope, at an angle, in some places, of $35^{\circ}$; and it was constantly shifting, from the continued downward 
sliding, and from the action of streams, some of which are large, and cut deep channels. In one I had the misfortune to lose my only sheep, which was carried away by the torrent. These streams were crossed by means of sticks and ricketty bamboos, and the steep sides (sometimes twenty or thirty feet high) were ascended by notched poles.

Leeches swarmed in incredible profusion in the streams and damp grass, and among the bushes: they got into my hair, hung on my eyelids, and crawled up my back. I repeatedly took upwards of a hundred from my legs, where the small ones used to collect in clusters on the instep: the sores which they produced were not healed for five months afterwards, and I retain the scars to the present day. Snuff and tobacco leaves are the best antidote, but when marching in the rain, it is impossible to apply this simple remedy. The best plan I found to be rolling the leaves over the feet, inside the stockings, and powdering the legs with snuff.

Another pest is a small midge, or sand-fly, which causes intolerable irritation, and is in this respect the most insufferable torment in Sikkim; the minutest rent in one's clothes is detected by this insatiable bloodsucker, which is itself so small as to be barely visible without a microscope. We daily arrived at our camping ground, streaming with blood, and mottled with the bites of peepsas, gnats, midges, and mosquitos, besides being infested with ticks.

As the rains advanced, insects seemed to be called into existence in countless swarms; moths, cock- 
chafers, glow-worms, and cockroaches, made my tent a Noah's ark by night, when the candle was burning; together with winged ants, May-flies, flying earwigs, and many beetles, while a very large species of daddylong-legs swept across my face as I wrote my journal, or plotted off my map. After putting out the light, they gradually departed, except a few which could not find the way out, and remained to disturb my slumbers.

Chakoong is a remarkable spot in the bottom of the valley, at an angle of the Lachen-Lachoong, which here receives an affluent from a mountain 17,557 feet high, on the Chola range to the east. There is no village, but some grass huts used by travellers, which are built close to the river on a very broad flat, fringed with alder, hornbeam, and birch: the elevation is 4,400 feet, and many European genera not found about Dorjiling, and belonging to the temperate Himalaya, grow intermixed with tropical plants that are found no further north. The birch, willow, alder, and walnut grow side by side with wild plantain, and gigantic bamboos: figs, balsams, peppers, and gigantic climbing vines, grow mixed with brambles, speedwell, forget-menot, and nettles that sting like poisoned arrows. The wild English strawberry is common, but bears a tasteless fruit: its inferiority is however counterbalanced by the abundance of a grateful yellow raspberry. Parasitical Orchids cover the trunks of oaks, while Thalictrum and Geranium grow under their shade. Monotropa and Balanophora, both parasites on the roots of trees (the one a native of north Europe and the other of tropical latitudes), push their leafless 
stems and heads of flowers through the soil together: and lastly, tree-ferns grow associated with the brake and Lycopodium of our British moors; and amongst mosses, the superb Himalayan Lyellia crispa, with the English Funaria hygrometrica.

The dense jungles of Chakoong completely cover the beautiful flat terraces of sand and gravel, which rise in three shelves to 150 feet above the river, and whose edges appear as sharply cut as if the latter had but lately retired from them. Everywhere immense boulders are scattered about, some of which are sixty feet long: their surfaces are water-worn into hollows, proving the river to have cut through nearly 300 feet of deposit, which once floored its valley. Lower down the valley, and fully 2000 feet above the river, I had passed numerous angular blocks resting on gentle slopes where no land-slips could possibly have deposited them, and which I therefore refer to ancient glacial action; one of these was nearly square, eighty feet long, and ten high.

It is a remarkable fact, that this hot, damp gorge is never malarious; this is attributable to the coolness of the river, and to the water on the flats not stagnating; for at Choongtam, 1500 feet higher, fevers and ague prevail in summer on similar flats, but which have been cleared of jungle, and are therefore exposed to the sun.

I had had constant headache for several mornings on waking, which I did not fail to attribute to coming fever, or to the unhealthiness of the climate; till I accidentally found it to arise from the wormwood (the common English Artemisia vulgaris), upon a thick couch 
of the cut branches of which I was accustomed to sleep, and which in dry weather produced no such effects.

From Chakoong to Choongtam the route lay northwards, following the course of the river, or crossing steep spurs that dip into the valley, and leave no space between their perpendicular sides and the furious torrent. Immense land-slips seamed the steep mountain flanks; and we crossed with precipitation one that extended fully 4000 feet (and perhaps much more) up a mountain 12,000 feet high; it moves every year, and the mud and rocks shot down by it were strewn with the green leaves and twigs of shrubs, some of the flowers on which were yet fresh and bright, while others were crushed: these were mixed with gigantic trunks of pines, with ragged bark and scored timbers. The talus which had lately been poured into the valley formed a gently sloping bank, twenty feet high, over which the Lachen-Lachoong rolled from a pool above, caused by the damming up of its waters. On either side of the pool were cultivated terraces, fifty feet high, whose alder-fringed banks, joined by an elegant canebridge, were reflected in the placid water; forming a little spot of singular quiet and beauty, that contrasted with the savage grandeur of the surrounding mountains, and the headstrong course of the foaming torrent below, amid whose deafening roar it was impossible to speak and be heard.

The mountain behind Choongtam is about 10,000 feet high; it divides the Lachen from the Lachoong river, and terminates a range that runs for twenty. two miles south from the lofty mountain of Kinchinjhow. 
Its south exposed face is bare of trees, except clumps of pines towards the top, and is very steep, grassy, and rocky, without water. The scenery much resembles that of Switzerland, and of the north-west Himalaya, especially in the great contrast between the southern

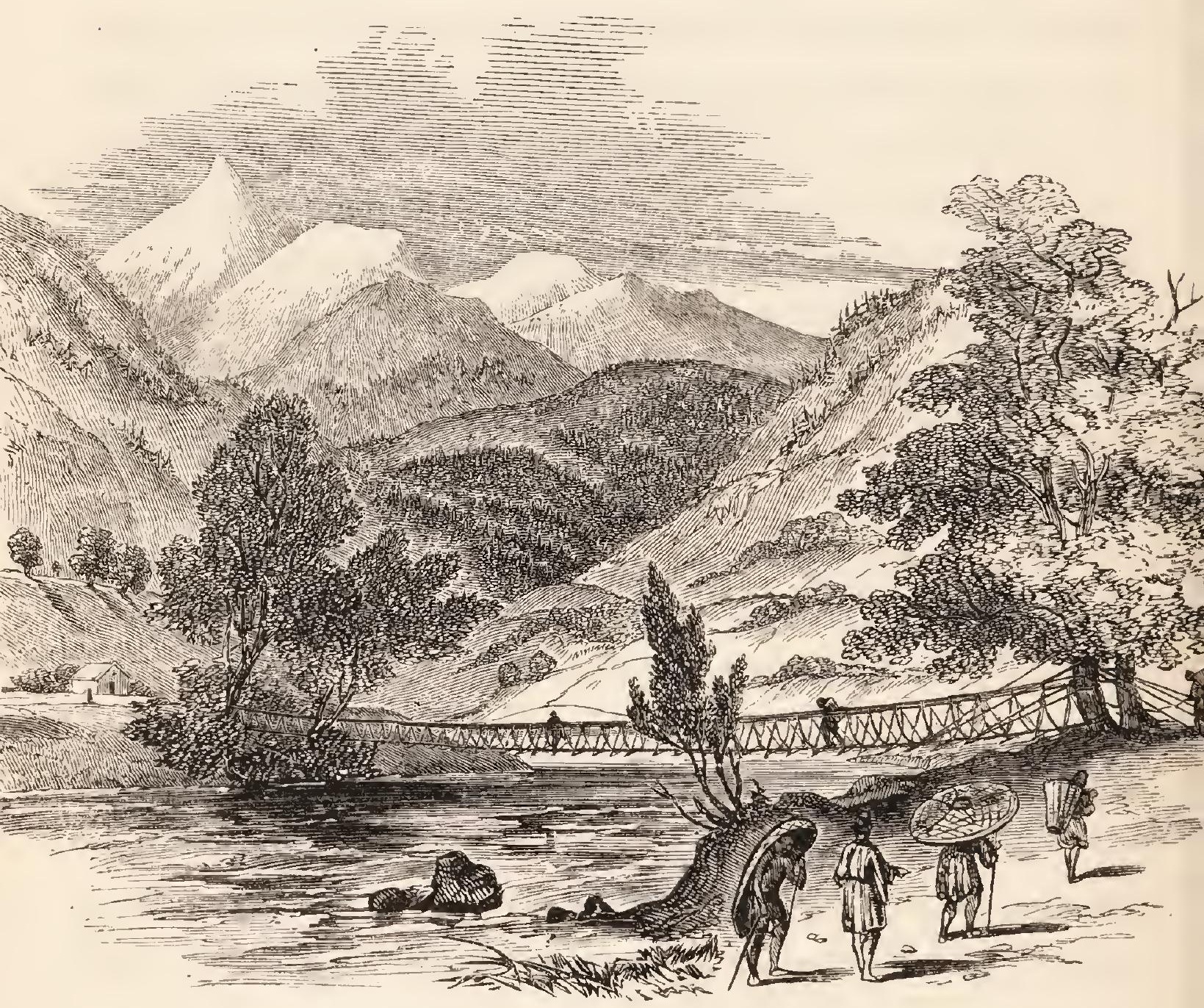

CANE-BRIDGE AND TUKCHAM MOUNTAIN.

and northern exposures, the latter being always clothed with a dense vegetation. At the foot of this very steep mountain is a broad triangular flat, 300 feet above the river, to which it descends by three level cultivated shelves. The village, consisting of a temple and twenty houses, is placed on the slope of the hill. I camped 
on the flat in May, before it became very swampy: it was covered with tufts of sedge and fringed with scarlet rhododendron, walnut, Andromeda, and small trees of a Photinia, a plant allied to hawthorn, of the leaves of which the natives make tea. Rice cultivated in pools surrounded by low banks, was just peeping above ground; and scanty crops of millet, maize, and buckwheat flourished on the slopes around.

The inhabitants of Choongtam are of Tibetan origin; few of them had seen an Englishman before, and they flocked out, displaying the most eager curiosity: the Lama and Phipun (or superior officer) of the Lachoong valley came to pay their respects with a troop of followers, and there was lolling out of tongues, and scratching of ears, at every sentence spoken, and every object of admiration. This extraordinary Tibetan salute at first puzzled me excessively, nor was it until reading MM. Huc and Gabet's travels on my return to England, that I knew of its being the ton at Lhassa, and in all civilised parts of Tibet.

As the valley was under the Singtam Soubah's authority, I experienced a good deal of opposition; and the Lama urged the wrath of the gods against my proceeding. This argument, I said, had been disposed of the previous year, and I was fortunate in recognising one of my Changachelling friends, who set forth my kindly offices to the Lamas of that convent, and the friendship borne me by its monks, and by those of Pemiongchi. Many other modes of dissuading me were attempted, but with Meepo's assistance I succeeded in gaining my point. The 
difficulty and delays in the remittance of food, caused by the land-slips having destroyed the road, had reduced our provisions to a very low ebb; and it became not only impossible to proceed, but necessary to replenish my stores on the spot. At first provisions enough were brought to myself, for the Rajah had issued orders for my being cared for, and having some practice among the villagers in treating rheumatism and goîtres, I had the power of supplying my own larder; but I found it impossible to buy food for my people. At last, the real state of the case came out; that the Rajah having gone to Choombi, his usual summer-quarters in Tibet, the Dewan had issued orders that no food should be sold or given to my people, and that no roads were to be repaired during my stay in the country; thus cutting off my supplies from Dorjiling, and, in short, attempting to starve me out. At this juncture, Meepo received a letter from the Durbar, purporting to be from the Rajah, commanding my immediate return, on the grounds that I had been long enough in the country for my objects: it was not addressed to me, and I refused to receive it as an official communication; following up my refusal by telling Meepo that if he thought his orders required it, he had better leave me and return to the Rajah, as I should not stir without directions from Dr. Campbell, except forwards. He remained, however, and said he had written to the Rajah, urging him to issue stringent orders for my party being provisioned.

We were reduced to a very short allowance before 
the long-expected supplies came, by which time our necessities had almost conquered my resolution not to take by force of the abundance I might see around, however well I might afterwards pay. It is but fair to state that the improvident villagers throughout Sikkim are extremely poor in vegetable food at this season, when the winter store is consumed, and the crops are still green. They are consequently obliged to purchase rice from the lower valleys, which, owing to the difficulties of transport, is very dear; and to obtain it they barter wool, blankets, musk, and Tibetan produce of all kinds. Still they had cattle, which they would willingly have sold to me, but for the Dewan's orders.

I have seldom had occasion to allude to snakes, which are rare and shy in most parts of the Himalaya; I, however, found an extremely venomous one at Choongtam; a small black viper, a variety of the cobra di capello, which it replaces in the drier grassy parts of the interior of Sikkim, the large cobra not inhabiting the mountain regions. Altogether I only collected about twelve species in Sikkim, seven of which are venomous, and all are dreaded by the Lepchas. An enormous hornet nearly two inches long, was here brought to me alive in a cleft-stick, lolling out its great thorn-like sting, from which drops of a milky poison distilled: its sting is said to produce fatal fevers in men and cattle, which may very well be the case, judging from that of a smaller kind, which left great pain in my hand for two days, while a feeling of numbness remained in the arm for several weeks. 
It is called Vok by the Lepchas, a common name for any bee: its larvæ are said to be greedily eaten, as are those of various allied insects.

Choongtam boasts a profusion of beautiful insects, amongst which the British swallow-tail butterfly disports itself in company with magnificent black, gold, and scarlet-winged butterflies, so typical of the Indian tropics. At night my tent was filled with small waterbeetles that quickly put out the candle; and with lovely moths came huge cockchafers and enormous and foetid flying-bugs, which bear great horns on the thorax. The irritation of mosquito and midge bites, and the disgusting insects that clung with spiny legs to the blankets of my tent and bed, were often as effectual in banishing sleep, as were my anxious thoughts regarding the future.

The temple at Choongtam is a poor wooden building, but contains some interesting drawings of Lhassa, with its extensive Lamaseries and temples; they convey the idea of a town, gleaming, like Moscow, with gilded and copper roofs; but on a nearer aspect it is found to consist of a mass of stone houses, and large religious edifices many stories high, the walls of which are regularly pierced with small square ornamented windows.

The weather in May was cloudy and showery, but the rain which fell was far less in amount than that at Dorjiling: during the day the sun's power was great; but though it rose between five and six A.M., it never appeared above the lofty peaked mountains that girdle the valley till eight A.m. Dark firs crest the heights 
around, and landslips score their flanks with white seams below; while streaks of snow remain throughout the month at 9000 feet above; and everywhere silvery torrents leap down to the Lachen and Lachoong.

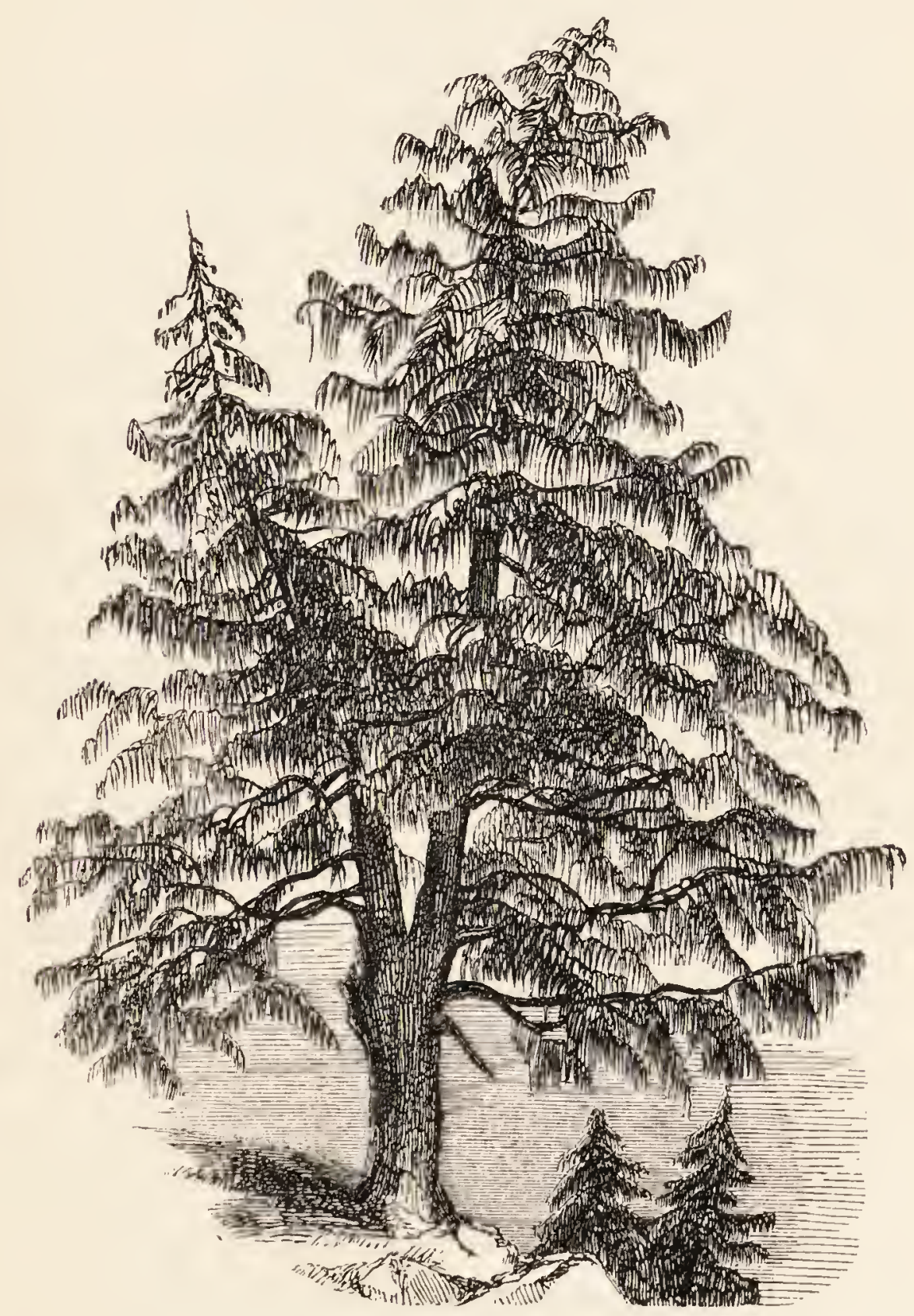

JUNIPERUS RECURYA (height 30 feet). 


\section{CHAPTER XIX.}

Routes from Choongtam to Tibet frontier-Choice of that by the Lachen river-Arrival of supplies-Departure-Features of the valleyEatable Polygonum-Cross Taktoong river-Pines, larches, and other trees-Chateng pool-Water-plants and insects-Tukcham mountain - Lamteng village-Inhabitants-Alpine monkey-Botany of temperate Himalaya--European and American fauna-Japanese and Malayan genera-Superstitious objections to shooting-Customs of peopleRain-Run short of provisions-Altered position of Tibet frontierZemu Samdong-Imposition-Vegetation-Uses of pines-Ascent to Thlonok river-Balanophora wood for making cups-Snow-bedsEatable mushrooms and Smilacina-View of Kinchinjunga-Arumroots, preparation of for food-Liklo mountain-Behaviour of my party-Bridge constructed over Zemu-Cross river-Alarm of my party-Camp on Zemu river.

From this place there were two routes to Tibet, each of about six days' journey. One lay to the north-west up the Lachen valley to the Kongra Lama pass, the other to the east up the Lachoong to the Donkia pass. To both Donkia and Kongra Lama I had every right to go, and was determined, if possible, to reach them, in spite of Meepo's ignorance, our guide's endeavours to frighten my party and mislead myself, and the country people's dread of incurring the Dewan's displeasure.

The Lachen valley being pronounced impracticable in the height of the rains, a month later, it behoved me to attempt it first, and it possessed the attraction of 
leading to a frontier described as far to the northward of the snowy Himalaya, on a lofty plateau, whose plants and animals were different from anything I had previously seen.

After a week the coolies arrived with supplies: they had been delayed by the state of the paths, and had consequently consumed a part of my stock, reducing it to eight days' allowance. I therefore divided my party, leaving the greater number at Choongtam, with a small tent, and instructions to forward all food to me as it arrived. I started with about fifteen attendants, on the 25th of May, for Lamteng, three marches up the Lachen.

Descending the step-formed terraces, I crossed the Lachen by a good cane bridge. The river is a headstrong torrent, and turbid from the vast amount of earthy matter which it bears along; and this character of extreme impetuosity, unbroken by any still bend, or even swirling pool, it maintains uninterruptedly at this season from 4000 to 10,000 feet. It is crossed three times by cane bridges, and I cannot conceive any valley of a similar nature to be more impracticable at such a season. On both sides the mountains rose, densely forest-clad, to 10,000 and 15,000 feet. Its extreme narrowness, and the grandeur of its scenery, were alike recalled to my mind, on visiting the Sachs valley in the Valais of Switzerland; from which, however, it differs in its luxuriant forest, and in the slopes being more uniform and less broken up into those imposing precipices so frequent in Switzerland. At times we scrambled over rocks or descended into 
gorges, through whose tributary torrents we waded; or crossed swampy terraced flats of debris above the stream; whilst it was sometimes necessary to round rocky promontories in the river, stemming the foaming torrent, as, one by one, we were dragged along by powerful Lepchas. Our halting-places were on flats close to the river, covered with large trees, and carpeted with a most luxuriant herbage, amongst which a wild buckwheat (Polygonum) was abundant, which formed an excellent spinach: it is called "Pullop-bi;" a name I shall hereafter have occasion to mention with gratitude.

A few miles above Choongtam, we passed some cottages, but between this and Lamteng, the country is uninhabited, nor is it frequented during the rains. We consequently found that the paths had suffered, the little bridges and aids to climb precipices and cross landslips had been carried away, and at one place we were all but turned back. This was at the Taktoong river, a tributary on the east bank, which rushes down in a sheet of silvery foam, eighteen yards broad. It does not flow in a deep gulley, having apparently raised its bed by an accumulation of enormous boulders; and a plank bridge was thrown across it, against whose slippery and narrow foot-boards the water dashed, loosening the supports on either bank, and rushing between their foundation-stones.

My unwilling guide had gone ahead with some of the coolies: I had suspected him all along (perhaps unjustly) of avoiding the most practicable routes; but when I found him waiting for me at this bridge, to which he sarcastically pointed with his bow, I felt that 
had he known of it, to have made difficulties before would have been a work of supererogation. He seemed to think I should certainly turn back, and assured me there was no other crossing (a statement I afterwards found to be untrue); so, comforting myself with the hope that if the danger were imminent, Meepo would forcibly stop me, I took off my shoes, and walked steadily over: the tremor of the planks was like that felt when standing on the paddle-box of a steamer, and I was jerked up and down, as my weight pressed them into the boiling flood, which shrouded me with spray. I looked neither to the right nor to the left, lest the motion of the swift waters should turn my head, but kept my eye on the white jets d'eau springing up between the woodwork, and felt thankful when fairly on the opposite bank: my loaded coolies followed, crossing one by one without fear or hesitation. The bridge was swept into the Lachen very shortly afterwards.

Towards Lamteng, the path left the river, and passed through a wood of Abies Smithiana. Larch appeared at 9000 feet, with Abies Brunoniana. An austere crabapple, walnut, and the willow of Babylon (the two latter perhaps cultivated), yellow jessamine and ash, all scarce trees in Sikkim, were more or less abundant in the valley, at about 7000 feet; as was an ivy, very like the English, but with fewer and smaller yellow or reddish berries; and many other plants, not found at equal elevations on the outer ranges of the Himalaya.

Chateng, a spur from the lofty peak of Tukcham, rises 1000 feet above the west bank of the river; and where I crossed it commanded one of the finest alpine views 
in Sikkim. It was grassy, strewn with huge boulders, and adorned with clumps of firs: on the summit was a small pool, beautifully fringed with bushy trees of white rose, a white-blossomed apple, a Pyrus like mountainash, scarlet rhododendrons, holly, and maples; there were also Daphnes, purple magnolia and a pink sweet-blossomed Sphærostema. Many English waterplants grew in the pond, but I found no shells; tadpoles, however swarmed, which later in the season become large frogs. The "painted-lady" butterfly and a pretty "blue" were flitting over the flower's, together with some great tropical kinds, that wander so far up these valleys, accompanying Marlea, the only sub-tropical tree that ascends to 8,500 feet in the interior of Sikkim.

Lamteng village, where I arrived on the 27th of May, is quite concealed by a moraine to the south, which, with a parallel ridge on the north, forms a beautiful bay in the mountains, 8,900 feet above the sea. The village stands on a grassy and bushy flat, around which the fir-clad mountains rise steeply to the black cliffs and snowy peaks which tower above. It contains above forty houses, forming the winterquarters of the inhabitants of the valley, who, in summer, move with their flocks and herds to the alpine pastures of the Tibet frontier. The dwellings are like those described at Wallanchoon, but the elevation being lower, and the situation better sheltered, they are more scattered; whilst on account of the dampness of the climate, they are raised higher from the ground, and the shingles with which they are tiled decay in two or three years. Many are painted lilac, with the gables 


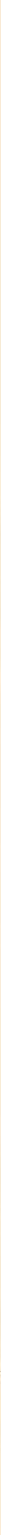



in diamonds of red, black, and white : the roofs are either of wood or bark, held down by large stones: within they are airy and comfortable. They are surrounded by a little cultivation of buck-wheat, radishes, turnips, and mustard. The inhabitants, though paying rent to the Sikkim Rajah, consider themselves as Tibetans, and are so in language, dress, features, and origin : they seldom descend to Choongtam, but yearly travel to the Tibetan towns of Jigatzi, Kambajong, Giantchi, and even to Lhassa, having commercial and pastoral transactions with the Tibetans, whose flocks are pastured on the Sikkim mountains during summer, and who trade with the plains of India through the medium of these villagers.

The snow having disappeared from elevations below 11,000 feet, the yaks, sheep, and ponies had just been driven 2000 feet up the valley, and the inhabitants were preparing to follow, with their tents and goats, to summer quarters at Tallum and Tungu. Many had goîtres and rheumatism, for the cure of which they flocked to my tent; dry-rubbing for the latter, and tincture of iodine for the former, gained me some credit as a doctor: I could, however, procure no food beyond trifling presents of eggs, meal, and more rarely, fowls.

On arriving I saw a troop of large monkeys gambolling in a wood of Abies Brunoniana; this surprised me, as I was not prepared to find so tropical an animal associated with a vegetation typical of a boreal climate. The only other quadrupeds seen here were some small earless rats, and musk-deer; the young female of which latter sometimes afforded me a dish of excellent venison; 
being, though dark-coloured and lean, tender, sweet, and short-fibred. Birds were scarce, with the exception of alpine pigeons, red-legged crows, and the horned pheasant. The vegetation in the neighbourhood of Lamteng is European and North American; that is to say, it unites the boreal and temperate floras of the east and west hemispheres; presenting also a few features peculiar to Asia. This is a subject of very great importance in physical geography; as a country combining the botanical characters of several others, affords materials for tracing the direction in which genera and species have migrated, the causes that favour their migrations, and the laws that determine the types or forms of one region, which represent those of another. Sikkim is, geographically, peculiarly well situated for investigations of this kind, being centrically placed, whether as regards south-eastern Asia or the Himalayan chain. Again, the Lachen valley at this spot is nearly equi-distant from the tropical forests of the Terai and the sterile mountains of Tibet, for which reason representatives both of the dry Asiatic and Siberian, and of the humid Malayan floras meet there.

The mean temperature of Lamteng (about $50^{\circ}$ ) is that of the isothermal which passes through Britain in lat. $52^{\circ}$, cutting the parallel of $45^{\circ}$ in Siberia (due north of Lamteng itself), descending to lat. $42^{\circ}$ on the east coast of Asia, ascending to lat. $48^{\circ}$ on the west of America, and descending to that of New York in the United States. I shall take for comparison the flora of 7000 to 10,000 feet; of the mean temperature, namely, between $53^{\circ}$ and $43^{\circ}$, the isothermal lines 
corresponding to which embrace, at the level of the sea, a space varying from three to twelve degrees of latitude.* At first it appears incredible that so limited an area should present nearly all the types of the flora of the north temperate zone; not only, however, is this the case, but space is also found for the intercalation of types of a Malayan flora, otherwise wholly foreign to the north temperate region.

A few examples will show this. Amongst trees the Conifers are conspicuous at Lamteng, and all are of genera typical both of Europe and North America; namely, silver fir, spruce, larch, juniper, and yew: there are also species of birch, alder, ash, apple, oak, willow, cherry, bird-cherry, mountain-ash, thorn, walnut, hazel, maple, poplar, ivy, holly, andromeda, rhamnus. Of bushes; rose, berberry, bramble, rhododendron, elder, cornel, willow, honeysuckle, currant, \&c. Herbaceous plants are far too numerous to be enumerated, as a list would include most of the common genera of European and North American plants.

Of North American genera, not found in Europe, were Buddleia, Magnolia, Sassafras, Hydrangea, Aralia, Panax, Trillium. The absence of heaths is also equally a feature in the flora of North America. The Japanese and Chinese floras are represented in Sikkim by Camellia, Deutzia, Aucuba, Hydrangea, Skimmia, and Enkianthus. The Malayan by Magnolias, vacciniums, rhododendrons, and many genera of orchids.

* On the west coast of Europe, where the distance between these isothermal lines is greatest, this belt extends almost from Stockholm and the Shetlands to Paris. 
Shortly after my arrival at Lamteng, the villagers sent to request that I would not shoot, as they said it brought on excessive rain, and consequent damage to the crops. My necessities did not admit of my complying with their wish unless I could procure food by other means; and I at first paid no attention to their request. The people, however, became urgent, and the Choongtam Lama giving his high authority to the superstition, it appeared impolitic to resist their earnest supplication; though I was well aware that the story was trumped up by the Lama for the purpose of forcing me to return. I yielded on the promise of provisions being supplied from the village, which was done to a limited extent; and I was enabled to hold out till more arrived from Dorjiling, now, owing to the state of the roads, at the distance of twenty days' march. The people were always civil and kind: there was no concealing the fact that the orders were stringent, which prohibited my party being supplied with food, but many of the villagers sought opportunities by night of replenishing my stores. Superstitious and timorous, they regard a doctor with great veneration; and when to that is added his power of writing, drawing, and painting, their admiration knows no bounds: they flocked round my tent all day, scratching their ears, lolling out their tongues, making a clucking noise, smiling, and timidly peeping over my shoulder, but flying in alarm when my little dog resented their familiarity by snapping at their legs. The men spend the whole day in loitering about, smoking, and spinning wool, while the women take the active duties; a few 
were engaged in drying the leaves of a shrub (Symplocos) for the Tibet market, which are used as a yellow dye; whilst, occasionally, a man might be seen cutting a spoon or a yak-saddle out of rhododendron wood.

During my stay at Lamteng, the weather was all but uniformly cloudy and misty, with drizzling rain, and a southerly, or up-valley wind, during the day, which changed to an easterly one at night: occasionally distant thunder was heard. My tent was constantly wet, nor did $I^{*}$ once sleep in a dry bed till the 1st of June, which ushered in the month with a brilliant sunny day. At night it generally rained in torrents, and the roar of landslips and avalanches was then all but uninterrupted: sometimes it was a rumble, at others a harsh grating sound, and often accompanied with the crashing of immense timber-trees.

It was sometimes clear at sunrise, and I made many ascents of Tukcham, hoping for a view of the mountains towards the passes; but I was only successful on one occasion, when I saw the table top of Kinchinjhow, the most remarkable and one of the most distant peaks of dazzling snow which is seen from Dorjiling. I kept up a constant intercourse with Choongtam, sending my plants thither to be dried, and gradually reducing my party as our necessities urged my so doing; lastly, I sent back the shooters, who had procured very little, and whose occupation was now gone.

On the 2nd of June, I received the bad news that a large party of coolies had been sent from Dorjiling with rice, but that being unable or afraid to pass the landslips, they had returned: we had now no food 
except a kid, a few handfuls of flour, and some potatos, which had been sent from Choongtam. All my endeavours to gain information respecting the distance and position of the frontier were unavailing; the villagers calling all the lofty pastures a few marches beyond Lamteng "Bhote" or "Cheen" (Tibet). Dr. Campbell had procured for me information by which I might recognise the frontier were $I$ once on it; but no description could enable me to find my way in a country so rugged and forest-clad, through tortuous and perpetually forking valleys, along often obliterated paths, and under cloud and rain. To these difficulties must be added the deception of the rulers, and the fact (of which I was not then aware), that the Tibet frontier was formerly at Choongtam; but from the Lepchas constantly harassing the Tibetans, the latter, after the establishment of the Chinese rule over their country, retreated first to Zemu Samdong, a few hours' walk above Lamteng, then to Tallum Samdong, 2000 feet higher; and, lastly, to Kongra Lama, 16,000 feet up the west flank of Kinchinjhow.

On the $3 \mathrm{rd}$ of June I took a small party, with my tent, and such provisions as I had, to explore up the river. On hearing of my intention, the Phipun volunteered to take me to the frontier, which he said was only two hours distant, at Zemu Samdong, where the Lachen receives the Zemu river from the westward: this I knew must be false, but I accepted his services, and we started, accompanied by a large body of villagers, who eagerly gathered plants for me along the road. 
The scenery was very pretty; the path crossed extensive and dangerous landslips, or ran through fine woods of spruce and Abies Brunoniana, and afterwards along the river-banks, which were fringed with willow (called "Lama") and Hippophae. A great red rose, one of the most beautiful Himalayan plants, whose single flowers are as large as the palm of the hand, was blossoming, while golden Potentillas and purple primroses bordered the stream.

Just above the fork of the valley, a wooden bridge (Samdong) crosses the Zemu, which was pointed out to me as the frontier, and I was entreated to respect two sticks and a piece of worsted stretched across it; this I thought ridiculous, so as my followers halted on one side, I went on the bridge, threw the sticks into the stream, crossed, and asked the Phipun to follow; the people laughed, and came over: he then told me that he had authority to permit of my botanising there, but that I was in Cheen, and that he would show me the guard-house to prove the truth of his statement. He accordingly led me up a steep bank to an extensive flat, several hundred feet above the river, amid the jungle of which were several ruined stone houses, with thick walls pierced with loopholes: these had no doubt been occupied by Tibetans at the time when this was the frontier.

The elevation which I had attained (that of the river being 8,970 feet) being excellent for botanising, I camped; and the villagers, contented with the supposed success of their strategy, returned to Lamteng.

My guide from the Durbar had stayed behind at 
Lamteng, and though Meepo and all my men well knew that this was not the frontier, they were ignorant as to its true position, nor could we even ascertain which of the rivers was the Lachen.* The only routes I possessed indicated two paths northwards from Lamteng, neither crossing a river; and I therefore thought it best to remain at Zemu Samdong till provisions should arrive. I accordingly halted for three days, collecting many new and beautiful plants, and exploring the roads, of which five (paths or yak-tracks) diverged from this point, one on either bank of each river, and one leading up the fork.

On one occasion I ascended the steep hill at the fork; it was dry and rocky, and crowned with stunted firs. Stacks of different sorts of fir-wood were stored on the flat at its base, for export to Tibet, all thatched with bark. Of these the larch splits well, and is the most durable of any; but the planks are small, soft, and white.t The silver fir also splits well ; it is white, soft, and highly prized for durability. The wood of Abies Brunoniana is like the others in appearance, but is not durable; its bark is however very useful. The spruce (Abies Smithiana) has also white wood, which is employed for posts and beams.t These are the only firs whose woods are considered very useful; and it is a curious circumstance that none produce any quantity of resin, turpentine, or pitch;

* The eastern afterwards proved to be the Lachen.

+ I never saw this wood to be red, close-grained, and hard, like that of the old Swiss larch; nor does it ever reach so great a size.

‡ These woods are all soft and loose in grain, compared with their European allies. 
which may perhaps be accounted for by the humidity of the climate.

On the flat were flowering a beautiful magnolia with globular sweet-scented flowers like snow-balls, several balsams, honeysuckle, \&c. On the hill-side were creeping brambles, lovely yellow, purple, pink, and white primroses, anemone, berberry, white rose, fritillary, \&c.

Our guide had remained at Lamteng, on the plea of a sore on his leg from leech-bites: his real object, however, was to stop a party on their way to Tibet with madder and canes, who, had they continued their journey, would inevitably have pointed out the road to me. The villagers themselves now wanted to proceed to the pasturing-grounds on the frontier; so the Phipun sent me word that I might proceed as far as I liked up the east bank of the Zemu. I had explored the path, and finding it practicable, and likely to intersect a less frequented route to the frontier, I determined to follow it. A supply of food arrived from Dorjiling on the 5th of June, reduced, however, to one bag of rice, but with encouraging letters, and the assurance that more would follow at once. My men, of whom I had eight, behaved admirably, although our diet had for five days chiefly consisted of Polygonum, wild leeks, nettles, and Procris (an allied, and more succulent herb), eked out by eight pounds of Tibet meal which I had bought for ten shillings by stealth from the villagers.

From Zemu Samdong the valley turns north-west to the junction of the Zemu with the Thlonok, which rises 
on the north-east flank of Kinchinjunga: at this place I halted for several days, while building a bridge over the Thlonok. The path runs first through a small forest of birch, alder, and maple, on the latter of which I found Balanophora growing abundantly: this species produces the great knots on the maple roots, from which the Tibetans form the cups mentioned by MM. Huc and Gabet. I was so fortunate as to find a small store of these knots, cleaned, and cut ready for the turner, and hidden behind a stone by some poor Tibetan: they had evidently been there a very long time.

In the ravines there were enormous accumulations of ice, the result of avalanches; one of them crossed the river, forming a bridge thirty feet thick, at an elevation of only 9,800 feet above the sea. In the fir-woods a large mushroom was abundant, which also forms a favourite article of food. Another potherb (to which I was afterwards more indebted than any) was a beautiful Smilacina, which grows from two to five feet high, and has plaited leaves and crowded panicles of white bell-shaped flowers, like those of its ally the lily of the valley, which it also resembles in its mucilaginous properties. It is called "Chokli-bi," and its young flower-heads, sheathed in tender green leaves, form an excellent vegetable. Nor must I forget to include amongst the eatable plants of this hungry country, young shoots of the mountain bamboo, which are good either raw or boiled, and may be obtained up to 12,000 feet in this valley. At 10,000 feet silver-fir commenced, with a close undergrowth of a small twiggy 
holly. This, and the dense thicket of rhododendron* on the banks of the river and edges of the wood, rendered the march very fatiguing, and swarms of midges kept up a tormenting irritation.

The Zemu continued an impetuous muddy torrent, whose hoarse voice, mingled with the deep grumbling noise of the boulders rolling along its bed, was my lullaby for many nights. At its junction with the Thlonok, it comes down a steep gulley from the north, foreshortened into a cataract 1000 feet high, and appearing the smaller stream of the two; whilst the Thlonok winds down from the snowy face of Kinchinjunga, whose summit is seen up the valley, about twenty miles distant. All around are lofty and rocky mountains, sparingly wooded with pines and larch, chiefly on their south flanks, which receive the warm, moist, up-valley winds; the faces exposed to the north being colder and more barren: exactly the reverse of what is the case at Choongtam, where the rocky and sunny south-exposed flanks are the driest.

My tent was pitched on a broad terrace, opposite the junction of the Zemu and Thlonok; it was sheltered by some enormous transported blocks fifteen feet high, and surrounded by a luxuriant vegetation of most beautiful rhododendrons in full flower, willow, white rose, white-flowered cherry, thorn, maple and birch. Some great tukerous-rooted arums were very abundant; and the ground was covered with small pits, in which were large wooden pestles: these are used in the preparation of food from the arums, to which the miser-

* Of which I had already gathered thirteen kinds in this valley. 
able inhabitants of the valley have recourse in spring, when their yaks are calving. The roots are bruised with the pestles, and thrown into these holes with water. Acetous fermentation commences in seven or eight days, which is a sign that the acrid poisonous principle is dissipated: the pulpy, sour, and fibrous mass is then boiled and eaten; its nutriment being the starch, which exists in small quantities, and which they have not the skill to separate by grating and washing. This preparation only keeps a few days, and produces bowel complaints, and loss of the skin and hair, especially when insufficiently fermented. Besides this, the "chokli-bi," and many other esculents, abounded here; and we had great need of them before leaving this wild uninhabited region.

I repeatedly ascended the north flank of Tukcham along a watercourse, by the side of which were immense slips of rocks and snow-beds; the mountain-side being excessively steep. My object was chiefly to obtain views and compass-bearings, in which $I$ was generally disappointed: once only I had a magnificent prospect of Kinchinjunga, sweeping down in one unbroken mass of glacier and ice, fully 14,000 feet high, to the head of the Thlonok river, whose upper valley appeared a broad bay of ice; being doubtless one of the largest glaciers in the Himalaya. The south side of the Thlonok valley is formed by a range from Kinchinjunga, running east to Tukcham, where it terminates: from it rises the beautiful mountain Liklo, 22,582 feet high, which, from Dorjiling, appears as a sharp peak, but is here seen to be a jagged crest running north and south. 
I made two futile attempts to ascend the Thlonok river to the great glaciers at the foot of Kinchinjunga, following the south bank, and hoping to find a crossingplace, and so to proceed north to Tibet. The fall of the river is not great at this part of its course, nor up to 12,000 feet, which was the greatest height I could attain, and about eight miles beyond my tents; above that point, at the base of Liklo, the bed of the valley widens, and the rhododendron shrubbery was quite impervious, while the sides of the mountain were inaccessible. We crossed extensive snow-beds, by cutting holes in their steep faces, and rounded rocks in the bed of the torrent, dragging one another through the violent current, whose temperature was below $40^{\circ}$.

On these occasions, the energy of the Lepchas was quite remarkable, and they were as keenly anxious to reach the holy country of Tibet as I could possibly be. It was sometimes dark before we got back to our tents, tired, with torn clothes and cut feet and hands, returning to a miserable dinner of boiled herbs; but never did any of them complain, or express a wish to leave me. In the evenings and mornings they were always busy, changing my plants, and drying the papers over a sulky fire at my tent-door; and at night they slept, each wrapt in his own blanket, huddled together under a rock, with another blanket thrown over them all. Provisions reached us so seldom, and so reduced in quantity, that I could never allow more than one pound of rice to each man in a day, and frequently during this trying month they had not even that; and I eked out our meagre supply with a few 
ounces of preserved meats, occasionally "splicing the main brace" with weak rum-and-water.

At the highest point of the valley which I reached, water boiled at $191^{\circ} 3$, indicating an elevation of 11,903 feet: here the temperature at 1 P.M. was nearly $70^{\circ}$. After boiling my thermometer on these occasions, I generally made a little tea for the party; a refreshment to which they looked forward with child-like eagerness. The fairness with which these good-hearted people used to divide the scanty allowance, and afterwards the leaves, which are greatly relished, was an engaging trait in their simple character: I have still vividly before me their sleek swarthy faces and twinkling Tartar eyes, as they lay stretched on the ground in the sun, or crouched in the sleet and snow beneath some sheltering rock; each with his little polished wooden cup of tea, watching my notes and instruments with curious wonder, asking, "How high are we?" "How cold is it?" and comparing the results with those of other stations, with much interest and intelligence.

On the 11th June, my active people completed a most ingenious bridge of branches of trees, bound by withes of willow; by which I crossed to the north bank, where I camped on an immense flat terrace at the junction of the rivers, and about fifty feet above their bed.

Our first discovery, after crossing, was of a good bridge across the Zemu, above its junction, and of a path leading down to Zemu Samdong; this was, however, scarcely traceable up either stream. My men were better housed here in sheds; and I made several more ineffectual attempts to ascend the valley to the 
glaciers. The path, gradually vanishing, ran alternately through fir-woods, and over open grassy spots, covered with vegetation, amongst which the gigantic arum was plentiful, whose roots seemed to be the only attraction in this wet and miserable valley.

On my return one day, I found my people in great alarm, the Phipun having sent word that we were on the Tibet side of the rivers, and that Tibetan troops were coming to plunder my goods, and carry my men into slavery. I assured them he only wanted to frighten them; that the Cheen soldiers were civil orderly people; and that as long as Meepo was with us, there was no cause for fear. Fortunately a young musk-deer soon afterwards broke cover close to the tent, and its flesh wonderfully restored their courage : still I was constantly harassed by threats; some of my people were suffering from cold and bowel complaints, and I from rheumatism; while one fine lad, who came from Dorjiling, was delirious with a violent fever, contracted in the lower valleys, which sadly dispirited my party.

Having been successful in finding a path, I took my tent and a few active lads up the Zemu, camping on a high rock above the forest region, hoping thence to penetrate northwards. I left my collections in the interim at the junction of the rivers, where the sheds and an abundance of firewood were great advantages for preserving the specimens. I repeatedly followed the river for several miles, but though its valley widened, the rhododendron thicke's below, and the cliffs above, defeated all endeavours to reach the drier climate beyond, of which I had abundant evidence in 
the arch of brilliant blue that spanned the heavens to the north, beyond a black canopy of clouds that hid everything around, and poured down rain without one day's intermission, during the eight which I spent here.

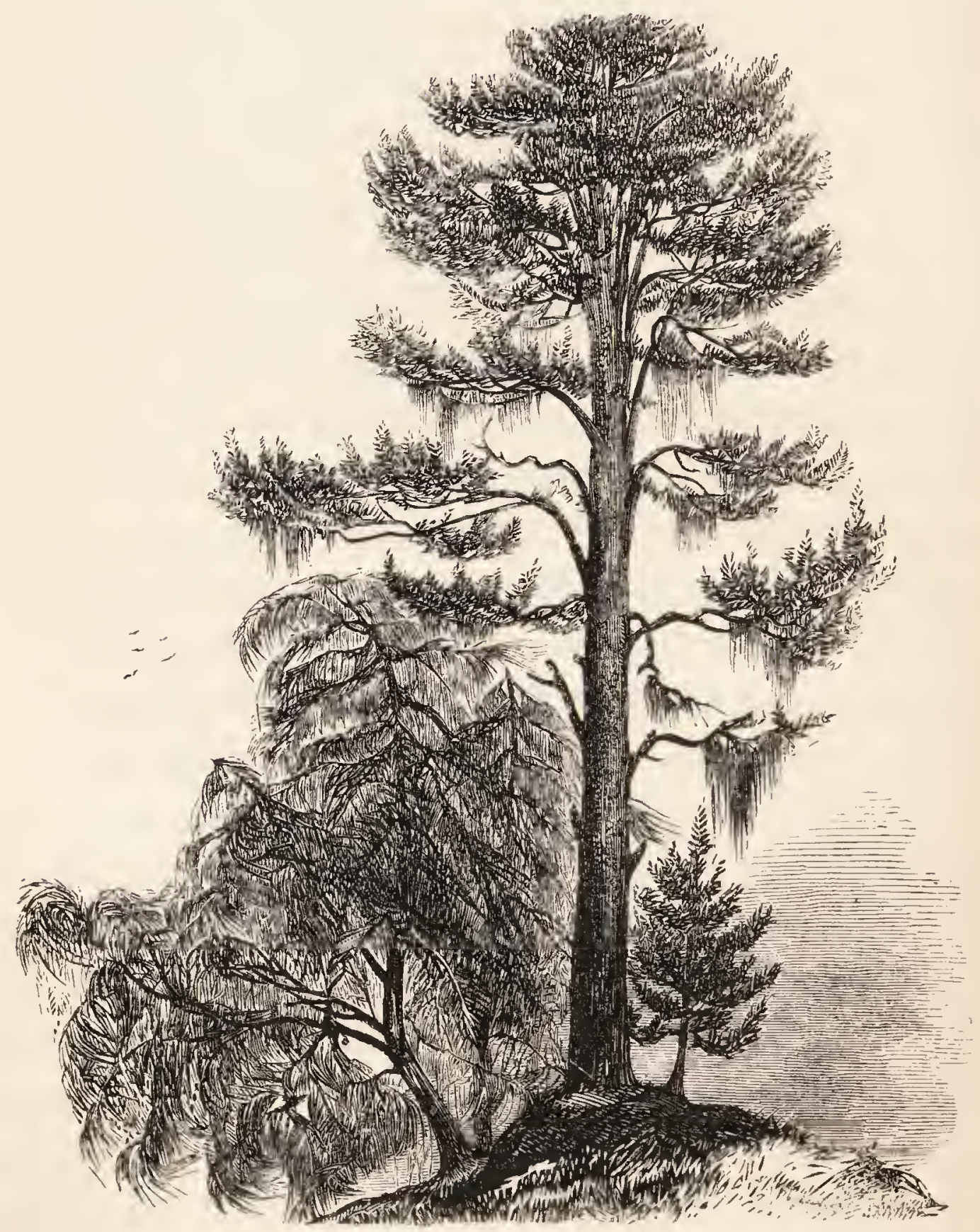

BLACK JUNIPER (height sixty feet) AND YOUNG LARCH. 


\section{CHAP'TER XX.}

Camp on Zemu river-Scenery-Falling rocks-Tukcham mountain-Height of glaciers-Botany-Gigantic rhubarb-Storm-Temperature of rivers-Behaviour of Lachen Phipun-Hostile conduct of Bhoteas - View from mountains above camp-Descend to Zemu SamdongVegetation-Letters from Dorjiling-Arrival of Singtam SoubahPresents from Rajah-Parties collecting Arum-roots-Insects-Ascend Lachen river-Tallum Samdong village-Cottages-MountainsPlants-Entomology-Weather-Conduct of Singtam Soubah-His character and illness-Agrees to take me to Kongra Lama-TunguAppearance of country-Houses-Poisoning by Arum-roots-Yaks and calves-Tibet ponies-Journey to Kongra Lama-Tibetan tentsButter, curds, and churns-Hospitality-Kinchinjhow and Chomiomo -Magnificent scenery-Reach Kongra Lama Pass.

Mr little tent was pitched in a commanding situation, on a rock fifty feet above the Zemu, overlooking the course of that river to its junction with the Thlonok. The descent of the Zemu in one thousand feet is more precipitous than that of any other river of its size with which I am acquainted in Sikkim, yet immediately above my camp it was more tranquil than at any part of its course onwards to the plains of India, whether as the Zemu, Lachen, or Teesta. On the west bank a fine mountain rose in steep ridges and shrubby banks to 15,000 feet; on the east a rugged cliff towered above the stream, and from this (owing to the melting of the snow, and consequent disintegration of the blocks) huge masses 
were ever and anon precipitated into the torrent, with a roar that repeatedly spread consternation amongst us. During rains especially, and at night, when the chilled atmospheric currents of air descended, and the sound was not dissipated as in the day-time, the noise of these falls was sufficiently alarming. My tent was pitched near the base of the cliff, and so high above the river, that I had thought it beyond the reach of danger; but one morning I found that a large fragment of granite had been hurled during the night to my very door, my dog having had a most narrow escape. I have seen few finer sights than the fall of these stupendous blocks into the furious torrent, along which they were carried amid feathery foam for many yards before settling.

Across the Thlonok to the southwards, rose the magnificent mountain of Tukcham, but I only once caught a glimpse of its summit, which even then clouded over before I could get my instruments adjusted for ascertaining its height. Its top is a sharp cone, surrounded by rocky shoulders, that rise from a mass of snow.

Glaciers in the north-west Himalaya descend to 11,000 feet; but I could not discover any in these valleys even so low as 14,000 feet, though at this season extensive snow-beds remain unmelted at but little above 10,000 feet. The foot of the stupendous glacier filling the broad head of the Thlonok is certainly not below 14,000 feet; though being continuous with the perpetual snow (or névé) of the summit of Kinchinjunga, it must have 14,000 feet of ice, in perpendicular height, to urge it forwards. 
All my attempts to advance up the Zemu were fruitless, and a snow bridge by which $I$ had hoped to cross to the opposite bank was carried away by the daily swelling river, while the continued bad weather prevented any excursions for days together. Botany was my only resource, and as vegetation was advancing rapidly under the influence of the southerly winds, I made a rich harvest: for though some of the finest Himalayan plants flower later, June is still the most glorious month for show.

Rhododendrons occupied the most prominent place, clothing the mountain slopes with a deep green mantle glowing with bells of brilliant colours; of the eight or ten species growing here, every bush was loaded with as great a profusion of blossoms as are their northern congeners in our English gardens. Primroses were next, both in beauty and abundance; and they were accompanied by yellow cowslips, three feet high, purple polyanthus, and pink large-flowered dwarf kinds nestling in the rocks, and an exquisitely beautiful blue miniature species, whose blossoms sparkled like sapphires on the turf. Gentians began to unfold their deep azure bells, aconites to rear their tall blue spikes, and fritillaries to burst into flower. On the black rocks the gigantic rhubarb formed pale pyramidal towers a yard high, of inflated reflexed bracts, that conceal the flower's, and over-lapping one another like tiles, protect them from the wind and rain; a whorl of broad green leaves edged with red spreads on the ground at the base of the plant, contrasting in colour with the transparent bracts, which are yellow, margined with 
pink. This is the handsomest herbaceous plant in Sikkim : it is called "Tchuka," and the acid stems are eaten both raw and boiled; they are hollow and full of pure water: the root resembles that of the medicinal rhubarb, but it is spongy and inert; it attains a length of four feet, and grows as thick as the arm. The dried leaves afford a substitute for tobacco; a smaller kind of rhubarb is, however, more commonly used in Tibet for this purpose.

The last days of June (as is often the case) were marked by violent storms, and for two days my tent proved no protection; similar weather prevailed all over India, the barometer falling very low. Snow fell abundantly as low as 13,000 feet, and the rivers were much swollen, the size and number of the stones they rolled along producing a deafening turmoil. The wind was southerly, very raw and cold, and drizzling rain constantly fell.

The temperature of these river's varies extremely at different parts of their course, depending on that of their affluents. The Teesta is always cool in summer (where its bed is below 2000 feet), its temperature being $20^{\circ}$ below that of the air ; whereas in mid-winter, when there is less cloud, and the snows are not melting, it is only a few degrees colder than the air. At this season, in descending from 12,000 to 1000 feet, its temperature does not rise $10^{\circ}$, though that of the air rises $30^{\circ}$ or $40^{\circ}$. It is a curious fact, that the temperature of the northern feeders of the Teesta, in some parts of their course, rises with the increasing elevation! Of this the Zemu afforded a conspicuous 
example: during my stay at its junction with the Thlonok it was $40^{\circ}$, or $6^{\circ}$ warmer than that river; at 1,100 feet higher it was $48^{\circ}$, and at 1,100 feet higher still it was $49^{\circ}$ ! These observations were repeated in different weeks, and several times on the same day, both in ascending and descending, and always with the same result: they told, as certainly as if I had followed the river to its source, that it rose in a drier and comparatively sunny climate, and flowed amongst little snowed mountains.

Meanwhile, the Lachen Phipun continued to threaten us, and I had to send back some of the more timorous of my party. On the 28th of June fifty men arrived at the Thlonok, and turned my people out of the shed at the junction of the rivers, together with the plants they were preserving, my paste-boards, papers, and utensils. The Lepchas came to me breathless, saying that there were Tibetan soldiers amongst them, who declared that I was in Cheen, and that they were coming on the following morning to drive me back to Dorjiling. I had little fear for myself, but was anxious with respect to my collections; it was getting late in the day, and raining, and I had no mind to go down and expose myself to the first brunt of their insolence, which I felt sure a night of such weather would materially wash away. Meepo was too frightened, but Nimbo, my Bhotan coolie Sirdar, volunteered to go, with two stout fellows; and he accordingly brought away my plants and papers, having held a parley with the enemy, who, as I suspected, were not Tibetans. The best news he brought was, that they were half-clad and 
without food; the worst, that they swaggered and bullied: he added, with some pride, that he gave them as good as he got, which I could readily believe, Nimbo being really a resolute fellow, and moreover accom. plished in Tibet slang.

On the following morning it rained harder than ever, and the wind was piercingly cold. My timid Lepchas huddled behind my tent, which, from its position, was only to be stormed in front. I dismantled my little observatory, and packed up the instruments, tied my dog, Kinchin, to one of the tentpegs, placed a line of stones opposite the door, and seated myself on my bed on the ground, with my gun beside me.

The dog gave tongue as twenty or thirty people defiled up the glen, and gathered in front of my tent; they were ragged Bhoteas, with bare heads and legs, in scanty woollen garments sodden with rain, which streamed off their shaggy hair, and furrowed their sooty faces; their whole appearance recalled to my mind Dugald Dalgetty's friends, the children of the mist.

They appeared nonplussed at seeing no one with me, and at my paying no attention to them, whilst the valiant Kinchin effectually scared them from the tentdoor. When they requested a parley, I sent the interpreter to say that I would receive three men, and that only provided all the rest were sent away immediately; this, as I anticipated, was acceded to at once, and there remained only the Lachen Phipun and his brother. Without waiting to let him speak, I rated him soundly, saying, that I was ready to leave the 
spot when he could produce any proof of my being in Bhote (or Tibet), which he knew well I was not; that, since my arrival at Lachen, he had told me nothing but lies, and had contravened every order, both of the Rajah and of Tchebu Lama. I added, that I had given him and his people kindness and merlicine, their return was bad, and he must go about his business at once, having, as I knew, no food, and I having none for him. He behaved very humbly, and finally took himself off much discomfited, and two days afterwards sent men to assist me in moving my things.

The 1st of July was such a day as I had long waited for to obtain a view, and I ascended the mountain west of my camp, to an elevation of 14,914 feet.

Drizzling mist, which had shrouded Tukcham all the morning, prevented any prospect from the highest point reached; but on the ascent I had an excellent view up the Zemu, which opened into a broad grassy valley, where I saw with the glass some wooden sheds, but no cattle or people. To reach these, however, involved crossing the river, which was now impossible; and I reluctantly made up my mind to return on the morrow to Zemu Samdong, and thence try the other river.

On my descent to the Thlonok, I found that the herbaceous plants on the terraces had grown fully two feet during the fortnight, and now presented almost a tropical luxuriance and beauty. At Zemu Samdong I found the vegetation even more gay and beautiful: the gigantic lily was in full flower, and scenting the air, with a lovely red rose. Neillia also was blossoming 
profusely at my old camping-ground, to which I now returned after a month's absence.

Soon after my arrival I received letters from Dr. Campbell, who had strongly and repeatedly represented to the Rajah his opinion of the treatment I was receiving; and this finally brought an explicit answer, to the effect that his highness' orders had been full and peremptory that I should be supplied with provisions, and safely conducted to the frontier. With these came letters on the Rajah's part from Tchebu Lama to the Lachen Phipun, ordering him to take me to the pass, but not specifying its position; fortunately, however, Dr. Campbell sent me a route, which stated the pass to be at Kongra Lama, several marches beyond this, and in the barren country of Tibet.

On the 5th of July the Singtam Soubah arrived: he was charged to take me to the frontier, and brought letters from the Rajah and a handsome present, consisting of Tibet cloth, and a dress of China silk brocaded with gold; the Ranee also sent me a basket of Lhassa sweetmeats, consisting of Sultana raisins from Bokhara, sliced and dried apricots from Lhassa, and Diospyros fruit from China. The Soubah wanted to hurry me to the frontier and back at once, being no doubt instigated to do so by the Dewan, and by his having no desire to spend much time in the dreary regions I wanted to explore. I positively refused, however, to start until more supplies arrived, unless he used his influence to provide me with food; and as he insisted that the frontier was at Tallum Samdong, only one march up the Lachen, I foresaw that this 
move was to be but one step forward, though in the right direction. He went forward to Tallum at once, leaving me to follow.

The Lamteng people had all migrated beyond that point to Tungu, where they were pasturing their cattle: I sent thither for food, and procured a little meal at a very high price, a few fowls and eggs; the messenger brought back word that Tungu was in Tibet, and that the villagers ignored Kongra Lama. A large piece of yak-flesh being brought for sale, I purchased it; but it proved the toughest meat I ever ate, being no doubt that of an animal that had succumbed to the arduous duties of a salt-carrier over the passes: at this season, however, when the calves are not a month old, it was in vain to expect better.

Large parties of women and children were daily passing my tent, on their way from Tungu, to collect arum-roots at the Thlonok, all with baskets at their backs, down to rosy urchins of six years old; they returned after several days, their baskets neatly lined with rhododendron leaves, and full of a nauseous-looking yellow acid pulp, which told forcibly of their extreme poverty. The children were very fair; indeed the young Tibetan is as fair as an English brunette, before his perennial coat of smoke and dirt has stained his face, and it has become bronzed and wrinkled by the scorching sun and rigorous climate of these inhospitable countries. Children and women were alike decked with roses, and all were good-humoured and pleasant, behaving with great kindness to one another, and unaffected politeness to me. 
During my ten days' stay at Zemu Samdong, I formed a large collection of insects, which was in great part destroyed by damp: many were new, beautiful, and particularly interesting, from belonging to types whose geographical distribution is analogous to that of the vegetation. The caterpillar of the swallow-tail butterfly was common, feeding on umbelliferous plants, as in England; and that of a Sphynx was devouring the euphorbias; the English "painted-lady" was common, as were "sulphurs," "marbles," "whites," "blues," and Thecla, of British aspect but foreign species. Amongst these, tropical forms were rare, except one fine black swallow-tail. Beetles were most rare, and (what is remarkable) the wood-borers particularly so. A large Telephora was very common, and had the usual propensity of its congeners for blood; lamellicorn beetles were also abundant.

On the 11th of July five coolies arrived with rice: they had been twenty days on the road, and had been obliged to make great detours, the valley being in many places impassable. They brought me a parcel of English letters; and I started up the Lachen on the following day, with renewed hopes and high spirits. The road first crossed the Zemu and the spur beyond, and then ascended the west bank of the Lachen, a furious torrent for five or six miles, during which it descends 1000 feet, in a chasm from which rise lofty black pine-clad crags, topped by snowy mountains, 15,000 feet high.

Above 11,000 feet the valley expands remarkably, the mountains recede, become less wooded, and more 
grassy, while the stream is suddenly less rapid, meandering in a broader bed, and bordered by marshes, covered with sedges, dwarf Tamarisk, and many kinds of yellow and red Pedicularis. There are far fewer rhododendrons here than in the damper Zemu valley at equal elevations, and more Siberian, or dry country types of vegetation.* The Singtam Soubah and Lachen Phipun received me at the bridge at Tallum, and led me across the river (into Tibet they affirmed) to a pretty green sward, near some gigantic boulders, where I camped.

The village of Tallum consisted of a few wretched stone huts, placed in a broad part of the valley, which is swampy, and crossed by several ancient moraines, which descend from the gullies on the east flank. The cottages were from four to six feet high, without windows, and consisted of a single apartment, in which the inmates were huddled together amid smoke, filth, and darkness: it contained neither table, chair, nor stool ; their beds were merely a plank, and their only utensils a bamboo churn, copper, bamboo and earthenware vessels for milk, butter, \&c.

Grassy or stony mountains slope upwards from

* The following common English wild and garden plants grow here. Umbelliferce, with sage, Ranunculus, Anemone, Aconites, Gentians, Panax, Euphrasia, speedwell, Prunella vulgaris, thistles, bistort, Parnassia, purple orchis, Prenanthes, and Lactuca. The woody plants of this region are willows, bircl,, Cotoneaster, maple, three species of Viburnum, three of Spircea, Vaccinium, Aralia, Deutzia, Philadelphus, rhododendrons, two junipers, silver fir, larch, three honeysuckles, Neillia, and a Pieris, whose white blossoms are so full of honey as to be sweet and palatable. 
these flats to 15,000 feet, but no snow is visible, except on Kinchinjhow and Chomiomo, about fifteen miles up the valley. Both these are flat-topped, and dazzlingly white, rising into peaks, and precipitous on all sides; they are grand, bold, isolated masses, quite unlike the ordinary snowy mountains in form, and far more imposing even than Kinchinjunga, though not above 22,000 feet in elevation.

Herbaceous plants are much more numerous here than in any other part of Sikkim; and sitting at my tent-door, I could gather forty-three species,* of which all but two belonged to English genera. In the rich soil about the cottages were crops of dock, shepherd's. purse, balsams, nettle, mustard, radish, turnip, \&c. On the neighbouring hills I found many fine plants, partaking more or less of the Siberian type. Altogether I gathered upwards of 200 species, nearly all belonging to North European genera. Twenty-five were woody shrubs, and six were ferns; sedges were in great profusion, amongst them three of British kinds; seven or eight were orchids, including a beautiful lady'sslipper.

The entomology of Tallum, like its botany, was Siberian, Arctic types occurring at lower elevations than in the wetter parts of Sikkim. Of beetles the honey-feeding ones prevailed, with European forms of

* In England thirty is, on the average, the number of plants, which in favourable localities I have gathered in an equal space. In both cases many are seedlings of short-lived annuals, and in neither is the number a test of the luxuriance of the vegetation; it but shows the power which the different species exert in their struggle to obtain a place. 
others that inhabit yak-droppings. Bees were common, but there were no wasps, and but few ants. Grasshoppers were rare; Tipula was common, with a small sand-fly; but there were neither leeches, mosquitos, ticks, nor midges. Pigeons, red-legged crows, and hawks were the common birds; with a few waders in the marshes.

Being now fairly behind most of the great raincollecting mountains, I experienced a considerable change in the climate; very little rain fell, and that chiefly drizzle; but this was so constant that the weather felt chilly and comfortless, and I never returned dry from botanising. The early mornings were bright, with views northwards of blue sky and Kinchinjhow, while to the south the lofty peak of Tukcham, though much nearer, was seldom seen, and black clouds rolled up the steep valley of the Lachen to be dissipated in mist over Tallum.

These streams are not marked by the diurnal rise and fall, so characteristic of the Swiss rivers and those of the western Himalaya, where a powerful sun melts the glaciers by day, and their head-streams are frozen by night. Here the clouds prevent alike solar and nocturnal radiation, the temperature is more uniform, and the corroding power of the damp southerly wind that blows strongly throughout the day is the great melting agent.

The Singtam Soubah visited me daily, and we held long friendly conversations: he still insisted that the Yangchoo (the name he gave to the Lachen at this place) was the boundary, and that I must not go any 
further. His first question was always "How long do you intend to remain here? have you not got all the plants and stones you want? you can see the sun much better with those brasses and glasses (alluding to the sextant, \&c.) lower down; it is very cold here, and there is no food: "- to all which I had but one reply, that I should not return till I had visited Kongra Lama. He was, I think, at heart good-natured; I had no difficulty in drawing him on to talk about Tibet, and the holy city of Teshoo Loombo, with its gilt temples, and convents, its holiest of all the holy grand Lamas of Tibet, and all the wide Boodhist world besides. Had it even been politic, I felt that it would be unfair to be angry with a man who was evidently in a false position between myself and his two rulers, the Rajah and Dewan; who had a wife and family on the smiling flanks of Singtam, and who longed to be soaking in the warm rain of Sikkim, drinking Murwa beer (a luxury unknown among these Tibetans) and gathering in his crops of rice, millet, and buckwheat. Though I may owe him a grudge for his subsequent violence, I still recal with pleasure the hours we spent together on the banks of the Lachen. In all matters respecting the frontier, his lies were circumstantial; and he further took the trouble of bringing country people to swear that this was Cheen, and that there was no such place as Kongra Lama. I had written to ask Dr. Campbell for a definite letter from T'chebu Lama on this point, but unfortunately my despatches were lost; the messenger who conveyed them missed his footing in crossing the Lachen, and narrowly 
escaped with life, while the turban in which the letters were placed was carried down the current.

Finally the Soubah tried to persuade my people that one so incorrigibly obstinate must be mad, and that they had better leave me. One day, after we had had a long discussion about the geography of the frontier, he inflamed my curiosity by telling me that Kinchinjhow .was a very holy mountain; more so than its sisterpeaks of Chumulari and Kinchinjunga; and that both the Sikkim and Tibetan Lamas, and Chinese soldiers, were ready to oppose my approach to it. This led to my asking him for a sketch of the mountains; he called for a sheet of paper, and some charcoal, and wanted to form his mountains of sand; I however ordered rice to be brought, and though we had but little, scattered it about wastefully. This had its effect; he stared at my wealth, for he had calculated on starving me out, and retired, looking perplexed and crestfallen. Nothing puzzled him so much as my being always occupied with such, to him, unintelligible pursuits; a Tibetan "cui bono?" was always in his mouth: "What good will it do you?" "Why should you spend weeks on the coldest, hungriest, windiest, loftiest place on the earth, without even inhabitants?" Drugs and idle curiosity he believed were my motives, and possibly a reverence for the religion of Boodh, Sakya, and 'T'songkaba. Latterly he had made up his mind to starve me out, and was dismayed when he found I could hold out better than himself, and when I assured him that I should not retrace my steps until his statements should be verified by a letter 
from Tchebu; that I had written to him, and that it would be at least thirty days before I could receive an answer.

On the 19th of July he proposed to take me to Tungu, at the foot of Kinchinjhow, and back, upon ponies, provided I would leave my people and tent, which I refused to do. After this I saw little of him for several days, and began to fear he was offended, when one morning his attendant came to me for medicine with a dismal countenance, and in great alarm; he twisted his fingers together over his stomach to symbolise the nature of the malady which produced a commotion in his master's bowels, and which was simply the colic. I was aware that he had been reduced to feed upon "Tong" (the arum-root) and herbs, and had always given him half the pigeons I shot, which was almost the only animal food I had myself. Now I sent him a powerful dose of medicine; adding a few spoonfuls of China tea and sugar for friendship.

On the 22nd, being convalescent, he visited me, looking wofully yellow. After a long pause, he offered to take me to Tungu with my tent and people, and thence to Kongra Lama, if I would promise to stay but two nights. I asked whether Tungu was in Cheen or Sikkim; he replied that after great enquiry he had heard that it was really in Sikkim; "Then," said I, "we will go to-morrow morning to Tungu, and I will stay there as long as I please:" he laughed, and gave in with apparent good grace.

After leaving Tallum, the valley contracts, passing 


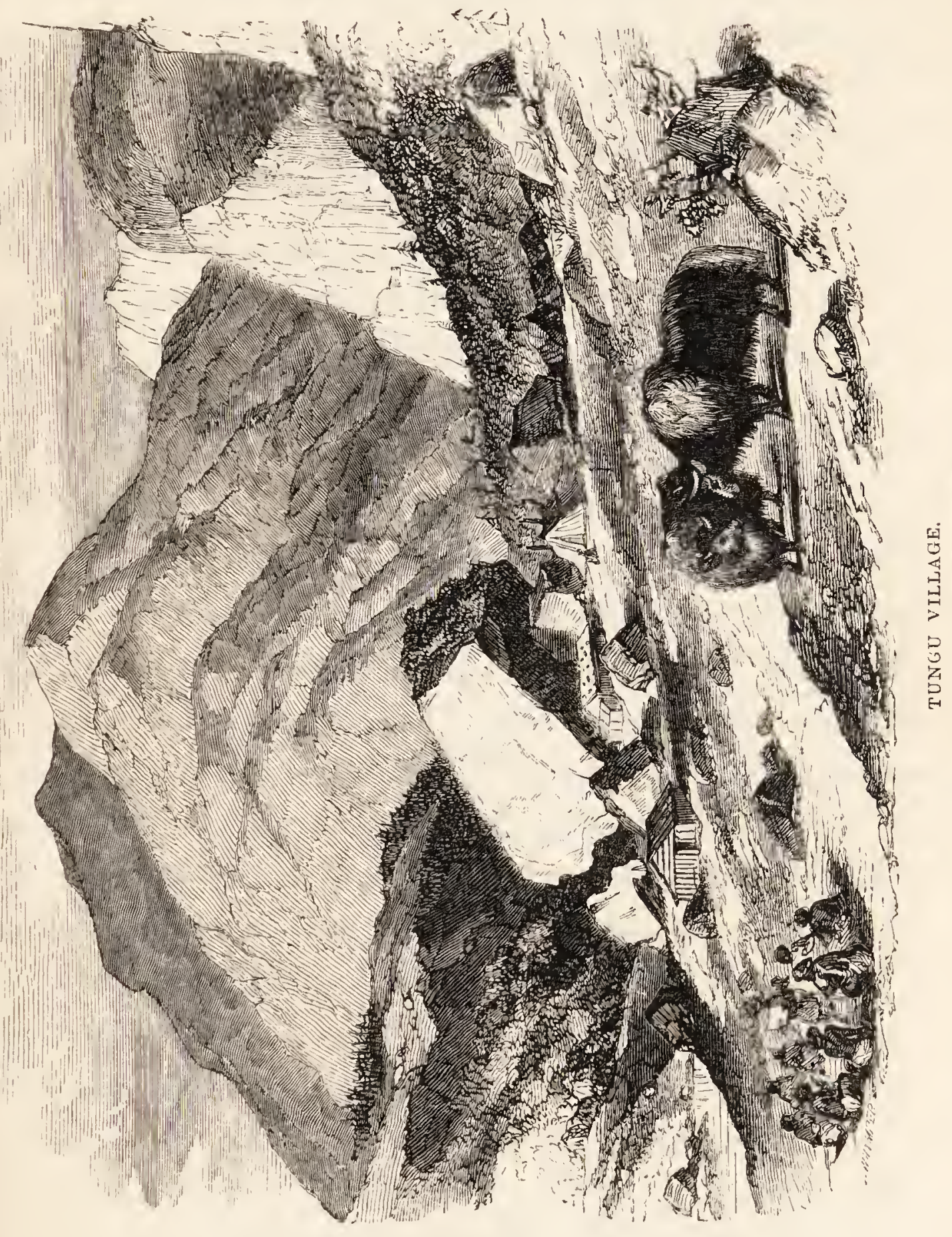


over great ancient moraines, and again expanding wider than before into broad grassy flats. The vegetation rapidly diminishes in stature and abundance, and though the ascent to Tungu is trifling, the change in species is very great.

Tungu occupies a very broad grassy valley, from which the hills slope gently upwards to 16,000 feet; no snow is anywhere to be seen.* A stupendous rock, about fifty feet high, lay in the middle of the valley, broken in two: it may have been detached from a cliff, or have been transported thither as part of an ancient moraine which extends from the mouth of the Tungu-choo valley across that of the Lachen. The appearance and position of this great block, and of the smaller piece lying beside it, rather suggest the idea of the whole mass having fallen pexpendicularly from a great height through a crevasse in a glacier than of its having been hurled from so considerable a distance as from the cliffs on the flanks of the valley: it is faithfully represented in the accompanying woodcut. A few wooden houses were collected near this rock, and several black tents were scattered about. I encamped at an elevation of 12,750 feet, and was waited on by the Lachen Phipun with presents of milk, butter, yak-flesh, and curds; and we were not long before we drowned old enmity in buttered and salted tea.

On my arrival I found the villagers in a meadow, all squatted cross-legged in a circle, smoling their brass

* In the woodcut the summit of Chomiomo is introduced, as it appears from a few hundred feet above the point of view. 
and iron pipes, drinking tea, and listening to a letter from the Rajah, concerning their treatment of me. Whilst my men were pitching my tent, I gathered forty plants new to me, all of Tartarian types. Wheat or barley I was assured had been cultivated at Tungu when it was possessed by Tibetans, and inhabited by a frontier guard; but I saw no appearance of any cultivation. The fact is an important one, as barley requires a mean summer temperature of $48^{\circ}$ to come to maturity. According to my observations, the mean temperature of Tungu in July is upwards of $50^{\circ}$, and, by calculation, that of the three summer months, June, July, and August, should be about $46 \frac{1}{2}^{\circ}$. As, however, I do not know whether these cerealia were grown as productive crops, much stress cannot be laid upon the fact of their having been cultivated, for in many parts of Tibet the barley is cut green for fodder.

In the evening the sick came to me; their complaints, as usual, being rheumatism, ophthalmia, goîtres, cuts, bruises, and poisoning by Tong, fungi, and other deleterious vegetables. At Tallum I attended an old woman who dressed her ulcers with plantain leaves, a very common Scotch remedy; the ribs being drawn out from the leaf, which is applied fresh: it is rather a strong application.

On the following morning I was awakened by the shrill cries of the Tibetan maidens, calling the yaks to be milked, "Toosh-toosh-toooosh," in a gradually higher key; to which Toosh seemed supremely indifferent, till quickened in her movements by a stone or stick, levelled with unerring aim at her ribs; these 
animals were changing their long winter's wool for sleek hair, and the former hung about them in ragged masses, like tow. Their calves gambolled by their sides, the drollest of animals, kicking up their short hind-legs, whisking their bushy tails in the air, rushing up and down the grassy slopes, and climbing like cats to the top of the rocks.

The Soubah and Phipun came early to take me to Kongra Lama, bringing ponies, genuine Tartars in bone and breed. Remembering the Dewan's impracticable saddle at Bhomsong, I stipulated for a horsecloth or pad, upon which I had no sooner jumped than the beast threw back his ears, seated himself on his haunches, and, to my consternation, slid backwards down a turfy slope, pawing the earth as he went, and leaving me on the ground, amid shrieks of laughter from my Lepchas. My steed being caught, I again mounted, when he took to shaking himself like a dog till the pad slipped under his belly, and I was again unhorsed. Other ponies displayed equal prejudices against my mode of riding, or having my weight anywhere but well on their shoulders, being all powerful in their fore-quarters; so I was compelled to adopt the high demi-pique saddle with short stirrups, which forced me to sit with my knees up to my nose, and to grip with the calves of my legs and heels. All the gear was of yak or horse hair, and the bit was a curb and ring, or a powerful twisted snaffle.

About six miles above Tungu, the Lachen meanders along a broad stony bed, and the path rises over a great ancient moraine, whose level top is covered with pools, 
but both that and its south face are bare, from exposure to the south wind, which blows with fury through this contracted part of the valley to the rarified atmosphere of the lofty, open, and dry country beyond. Its north slope, on the contrary, is covered with small trees and brushwood, of rhododendron, birch, honeysuckle, and mountain-ash. These are the most northern shrubs in Sikkim, and I regarded them with deep interest, as being possibly the last of their kind to be met with in this meridian, for many degrees further north: perhaps even no similar shrubs occur between this and the Siberian Altai, a distance of 1,500 miles.

At the foot of the moraine was a Tibetan camp of black yak-hair tents, looking at a distance-(to borrow M. Huc's graphic simile)-like fat-bodied, longlegged spiders! Their general shape was hexagonal; they were about twelve feet in diameter, and were stretched over six short posts, and encircled with a low stone wall, except in front. In one of them $I$ found a buxom girl, the image of good humour, making butter and curd from yak-milk. The churns were of two kinds; one being an oblong box of birch-bark, or close bamboo wicker-work, full of branched rhododendron twigs, in which the cream was shaken: she goodnaturedly showed me the inside, which was frosted with snow-white butter, and alive with maggots. The other churn was a goat-skin, which was rolled about, and shaken by the four legs. The butter is made into great squares, and packed in yak-hair cloths; the curd is eaten either fresh, or dried and pulverised. 
Except bamboo and copper milk-vessels, wooden ladles, tea-churn, and pots, these tents contained no furniture but goat-skins and blankets, to spread on the ground as a bed. The fire was made of sheep and goats'-droppings, lighted with juniper-wood; above it hung tufts of yaks'-hair, one for every animal lost during the season, by which means a reckoning is kept. Although this girl had never before seen a European, she seemed in no way discomposed at my visit, and gave me a large slice of fresh curd.

Five miles further on we arrived at the tents of the Phipun, whose wife was prepared to entertain us with Tartar hospitality: magnificent tawny Tibet mastiffs were baying at the tent-door, and some yaks and ponies were grazing close by. We mustered twelve, and sat cross-legged in a circle inside the tent, the Soubah and myself being placed on a Chinese rug. Salted and buttered tea was prepared in a tea-pot for us on the mat, and in a great cauldron for the rest of the party; parched rice and wheat-flour, curd, and roasted maize* were offered us, and we each produced our wooden cup, which was kept constantly full of scalding tea-soup, which, being made with fresh butter, was very good. The flour was the favourite food, of which each person dexterously formed little dough-balls in his cup, an operation I could not manage, and only succeeded in making a nauseous paste, that stuck to my jaws and in my throat.

* Prepared by roasting the maize in an iron vessel, when it splits and turns partly inside out, exposing a snow-white spongy mass of farina. It looks very handsome, and would make a beautiful dish for dessert. 
We were suddenly startled from our repast by a noise like loud thunder, crash following crash, and echoing through the valley. The Phipun got up, and coolly said, "The rocks are falling, it is time we were off, it will rain soon." The moist vapours had by this time so accumulated, as to be condensed in rain on the cliffs of Chomiomo and Kinchinjhow; which, being loosened, precipitated avalanches of rocks and snow. We proceeded amidst dense fog, soon succeeded by rain; the roar of falling rocks on either hand increasing as these invisible giants spoke to one another in voices of thunder through the clouds. The effect was indescribably grand; and as the weather cleared, and I obtained transient peeps of precipices of blue ice and black rock towering 5000 feet above me on either hand, the feeling of awe produced was almost overpowering. Heavy banks of vapour still veiled the mountains, but the rising mist exposed a broad stony track, along which the Lachen wandered, split into innumerable channels, and enclosing little oases of green vegetation, lighted up by occasional gleams of sunshine. Though all around was enveloped in gloom, there was in front a high blue arc of cloudless sky, between the beetling cliffs that formed the stern portals of the Kongra Lama pass. 


\section{CHAPTER XXI.}

Top of Kongra Lama-Tibet frontier-Elevation-View-Vegetation-De. scent to Tungu-Tungu-choo-Ponies-Kinchinjhow and Changokhang mountains - Palung plains - Tibetans - Dogs - Dingcham province of Tibet-Inhabitants - Dresses - Women's ornaments-Blackening faces-Coral-Tents-Elevation of Palung-Lama-Shawl-wool goats -Shearing-Siberian plants-Height of glaciers, and perpetual snow -Plants, and wild animals-Marmots-Insects-Birds-Choongtam Lama-Religious exercises-Tibetan hospitality - DelphiniuinPerpetual snow-Return to Tallum Samdong-To Lamteng-Houses -Cicadas - Landslips - Arrival at Choongtam - Cobra-RageuVelocity and volume of rivers measured-Leave for Lachoong valleyKeadom-General features of valley-Lachoong village-Tunkra mountain-Moraines-Cultivation-Lachoong Phipun-Lama ceremonies beside a sick-bed.

$W_{E}$ reached the boundary between Sikkim and Tibet early in the afternoon; it is drawn along Kongra Lama, which is a low flat spur running east from Kinchinjhow towards Chomiomo, at a point where these mountains are a few miles apart, thus crossing the Lachen river: it is marked by cairns of stone, some rudely fashioned into chaits, covered with votive rags on wands of bamboo. I made the altitude by barometer 15,745 feet above the sea, and by boiling water, 15,694 feet: the temperature of the air varied from $41 \frac{1}{2}^{\circ}$ to $42 \frac{1}{2}^{\circ}$; that of the Lachen river was $47^{\circ}$, which was remarkably high. We were bitterly cold; as the previous rain had 
wetted us through, and a keen wind was blowing. The mist and fog intercepted all view, except of the flanks of the mountains on either hand, of the rugged snowy ones to the south, and of those bounding the Lachen to the north. The latter were unsnowed, and appeared lower than Kongra Lama, but when I ascended them, three months afterwards, I found they were 3000 feet higher! a proof how utterly fallacious are estimates of height, when formed by the eye alone.

Isolated patches of vegetation appeared on the top of the pass, where I gathered forty kinds of plants, most of them being of a tufted habit characteristic of an extreme climate; some forming hemispherical balls on the naked soil, others growing in matted tufts level with the ground. The greater portion had no woolly covering, nor did I find any of the cottony species of Saussurea, which are so common at equal elevations on the moister mountains to the southward. Some most delicate-flowered plants even defy the biting winds of these exposed regions; such as a prickly Meconopsis with slender flower-stalks and four large blue poppylike petals, a Cyananthus with a bell-shaped corolla, and a fritillary. Other curious plants were a little yellow saxifrage with long runners, and the strongscented spikenard.

We made a fire at the top with sheep's droppings (of which the Phipun had brought up a bagful), with the aid of a pair of goat-skin bellows, which worked by a slit that was opened by the hand in the act of raising; when inflated the hole was closed, and the skin pressed 
down, thus forcing the air through the bamboo nozzle: this is the common form of bellows throughout Tibet and the Himalaya.

After two hours I was very stiff and cold, and suffering from headache and giddiness, owing to the elevation; and having walked about thirteen miles botanizing, I was glad to ride back. We reached the Phipun's tents about 6 P.M., and had more tea before proceeding to Tungu. The night was fortunately fine and calm, with a few stars and a bright young moon, which, with the glare from the snows, lighted up the valley, and revealed magnificent glimpses of the majestic mountains. As the moon sank, and we descended the narrowing valley, darkness came on, and with a boy to lead my sure-footed pony, I was at liberty to reflect on the events of a day on which I had attained the object of so many years' ambition. Now that all obstacles were surmounted, and I was returning laden with materials for extending the knowledge of a science which had formed the pursuit of my life, will it be wondered at that I felt proud, not less for my own sake, than for that of the many friends who were interested in my success?

We arrived at Tungu at 9 P.M., my pony not having stumbled once, though the path was rugged, and crossed by many rapid streams. The Soubah's little shaggy steed had carried his portly frame (fully fifteen stone weight) the whole way out and back, and when he dismounted, it shook itself, snorted, and seemed quite ready for supper.

On the 26th of July the Phipun, who waited on 
me every morning with milk and butter, and whose attentions were now unremitting, proposed that I should accompany him to an encampment of Tibetans, at the foot of Kinchinjhow. We mounted ponies, and ascended the Tunguchoo eastwards: it was a rapid river for the first thousand feet, flowing in a narrow gorge, between sloping, grassy, and rocky hills, on which large herds of yaks were feeding, tended by women and children, whose black tents were scattered about. The yak-calves left their mothers to run beside our ponies, which became unmanageable, being almost callous to the bit; and the whole party was sometimes careering over the slopes, chased by the grunting herds: in other places, where the path was narrow and dangerous, the sagacious animals proceeded with the utmost gravity and caution. Rounding one rocky spur, my pony stumbled, and pitched me forwards; fortunately I alighted on the path.

A sudden bend in the valley opened a superb view of Kinchinjhow, its perpendicular sides extending for four or five miles east and west, and studded with immense icicles, which are said to have obtained for it the name of "jhow," - the "bearded" Kinchin. Eastward a jagged spur stretched south, rising into another splendid mountain called Chango-khang (the Eagle's crag), from whose flanks descend great glaciers, the sources of the 'Tunguchoo.

We followed the course of an affluent, called the Chachoo, along whose bed ancient moraines rose in successive ridges: over one of these the path ascends to the plains of Palung, an elevated grassy expanse, 
two miles long and four broad, extending northward to the base of Kinchinjhow. Its surface, though very level for so mountainous a country, is yet varied with open valleys and sloping hills, upwards of 500 feet high : it is bounded on the west by low rounded spurs from Kinchinjhow, that form the flank of the Lachen valley; while on the east it is separated from Changokhang by the Chachoo, which cuts a deep east and west trench immediately under the cliffs of Kinchinjhow, and then turns south to the Tunguchoo. The lower course of the Chachoo is most curious; it meanders in sickle-shaped curves along the marshy bottom of an old lake-bed, with steep shelving sides, 500 feet deep, and covered with juniper bushes. It is fed by the glaciers of Kinchinjhow, and some little lakes to the east.

The mean height of Palung plains is 16,000 feet: they are covered with transported blocks, and I have no doubt their surface has been much modified by glacial action. I was forcibly reminded of them by the slopes of the Wengern Alp, but those of Palung are far more level. The ice-clad cliffs of Kinchinjhow rise before the spectator, just as those of the Jungfrau, Mönch, and Eigher Alp do from that magnificent point of view.

On ascending a low hill, we came in sight of the Tibet camp at the distance of a mile, when the great mastiffs that guarded it immediately bayed; and our ponies starting off at full gallop, we soon reached an enclosure of stone dykes, within which the black tents were pitched. The dogs were of immense size, and ragged, like the yaks, from their winter coat hanging 
to their flanks in great masses ; each was chained near a large stone, on and off which he leapt as he gave tongue; they are very savage, but great cowards, and not remarkable for intelligence.

The people were natives of the adjacent province of Dingcham, which is the loftiest, coldest, most windy and arid in Eastern Tibet; they repair yearly to Palung, with their flocks, herds, and tents, paying tribute to the Sikkim Rajah for the privilege: they arrive in June and leave in September. Both men and women were indescribably filthy; as they never wash, their faces were perfectly black with smoke and exposure, and the women's with a pigment of grease as a protection from the wind. The men were dressed as usual in the blanket-cloak, with brass pipes, long knives, flint, steel, and amulets; the women wore similar, but shorter cloaks, with silver and copper girdles, trowsers, and flannel boots. Their headdresses were very remarkable. A circular band of plaited yak's hair was attached to the back hair, and encircled the head like a saint's glory, at some distance round it. A band crossed the forehead, from which coins, corals, and turquoises, hung down to the eyebrows, while lappets of these ornaments fell over the ears. Their hair was plaited in two tails, brought over the shoulders, and fastened together in front; and a little yellow felt cap, traversely elongated, so as not to interfere with the shape of the glory, was perched on the head. Their countenances were pleasing, and their manners timid.

The children crawled half-naked about the tent, or 
burrowed like moles in an immense heap of goats' and sheep's droppings, piled up for fuel, upon which the family lounged. An infant in arms was playing with a "coral," ornamented much like ours, and was covered

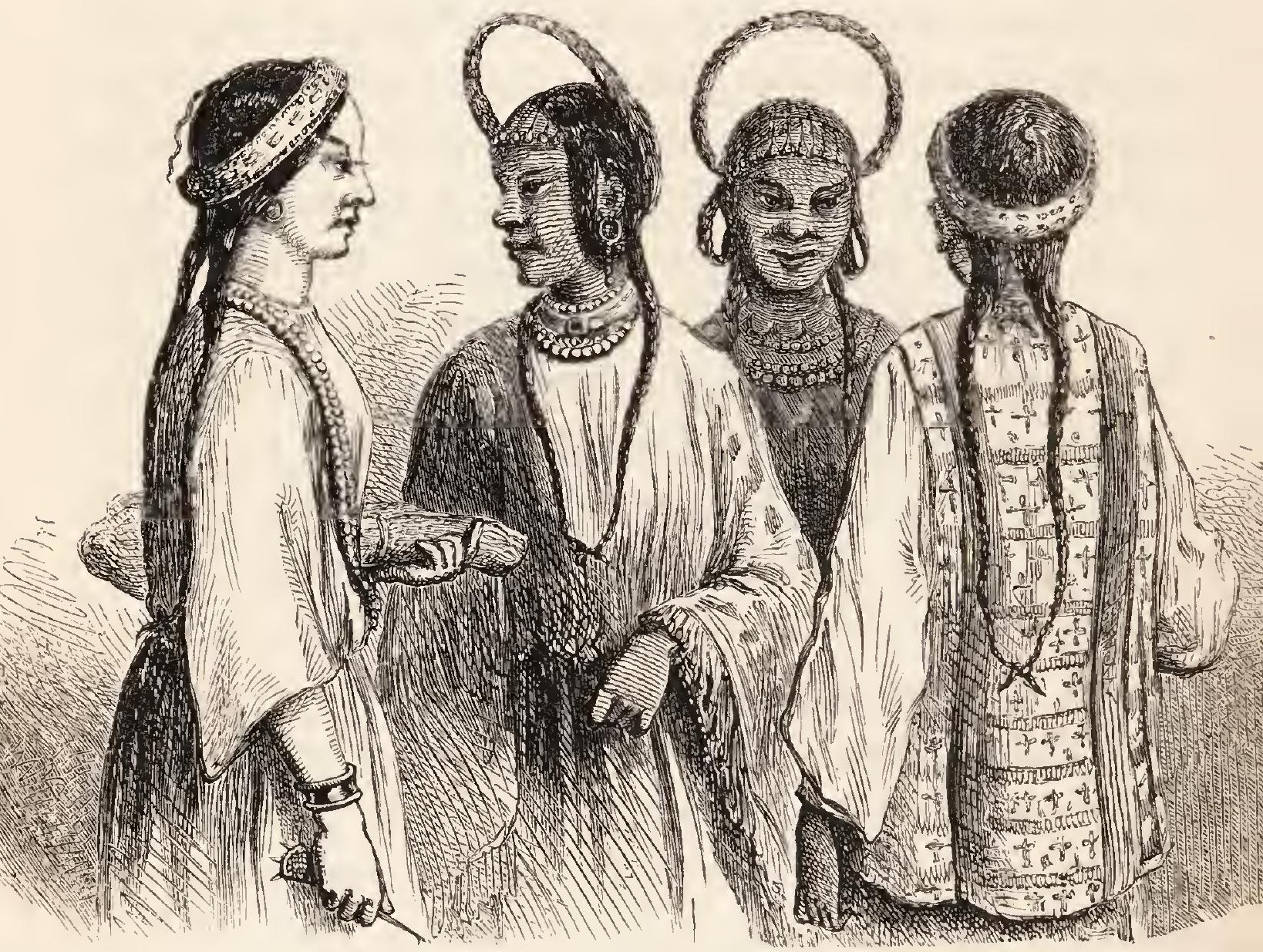

LEPCHA GIRLS (THE OUTER FIGURES), AND TIBETAN WOMEN.

with jewels and coins. This custom of decorating children is very common amongst half-civilised people; and the coral is, perhaps, one of the last relics of a barbarous age that is retained amongst ourselves. One mother was nursing her baby, and churning at the same time, by rolling the goat-skin of yak-milk about on the ground. Extreme poverty induces the practice of nursing the children for years; and in one tent I 
saw a lad upwards of four years of age unconcernedly taking food from his aunt, and immediately afterwards chewing hard dry grains of maize.

The tents were pitched in holes about two feet and a half deep; and within the tent a wall of similar height was built all round: in the middle was a long clay arched fire-place, with holes above, over which the cauldrons were placed, the fire being underneath. Saddles, horse-cloths, and the usual accoutrements and implements of a nomade people, all of the rudest description, hung about: there was no bed nor stool, but Chinese rugs for sleeping on. I boiled water on the fire-place, and obtained an elevation of 15,867 feet.

A Lama accompanied this colony of Tibetans, a festival in honour of Kinchinjhow being annually held at a large chait hard by, which is painted red, ornamented with banners, and surmounted by an enormous yak's skull, that faces the mountain. The Lama invited me into his tent, where I found a wife and family. An extempore altar was at one end, covered with wafers and other pretty ornaments, made of butter, stamped or moulded with the fingers.* The tents being insupportably noisome, I preferred partaking of the buttered brick-tea in the open air; after which, I went to see the shawl-wool goats sheared in a pen close by. There are two varieties: one is a large animal, with great horns, called "Rappoo;" the other smaller, and with slender horns, is called "Tsilloo."

* The extensive use of these ornaments throughout Tibet, on the occasion of religious festivals, is alluded to by MMI. Huc and Gabet. 
The latter yields the finest wool, but they are mixed for ordinary purposes. I was assured that the sheep (of which large flocks were grazing near) afford the finest wool of any. The animals were caught by the tail, their legs tied, the long winter's hair pulled out, and the remainder cut away with a broad flat knife, which was sharpened with a scythe-stone. The operation was clumsily performed, and the skin much cut.

Turnips are grown at Palung during the short stay of the people, and this is the most alpine cultivation in Sikkim; the seed is sown early in July, and the tubers are fit to be eaten in October, if the season is favourable. They did not come to maturity this year, as I found on again visiting this spot in October; but their tops had afforded the poor Tibetans some good vegetables. The mean temperature of the three summer months at Palung is probably about $40^{\circ}$, an element of comparatively little importance in regulating the growth and ripening of vegetables at great elevations in Tibetan climates; where a warm exposure, the amount of sunshine, and of radiated heat, have a much greater influence.

On the top of the surrounding hills, which, for barrenness, reminded me of the descriptions given of the Siberian Steppes, I found, at 17,000 feet elevation, several minute arctic plants, with Rhododendron nivale, the most alpine of woody plants. On their sterile slopes grew a curious plant allied to the Cherleria of the Scotch Alps, forming great hemispherical balls on the ground, eight to ten inches across, altogether 
resembling in habit the curious Balsam-bog (Bolax glebaria) of the Falkland Islands, which grows in very similar scenes.

A few days afterwards, I again visited Palung, with the view of ascertaining the height of perpetual snow on the south face of Kinchinjhow; unfortunately, bad weather came on before I reached the Tibetans, from whom I obtained a guide in consequence. From this place a ride of about four miles brought me to the source of the Chachoo, in a deep ravine, containing the terminations of several short, abrupt glaciers, and into which were precipitated avalanches of snow and ice. I found it impossible to distinguish the glacial ice from the perpetual snow; the larger beds of snow, where presenting a flat surface, being generally drifts collected in hollows, or accumulations that had fallen from above: when these rest on slopes they become converted into ice, and, obeying the laws of fluidity, flow downwards as glaciers. It was snowing heavily at this time, and we crouched under a gigantic boulder, benumbed with cold. I had fortunately brought a small phial of brandy, which, with hot water from the apparatus for taking elevations, refreshed us wonderfully.

The plants found close to the snow were minute primroses, Parnassia, Draba, tufted wormwoods, saxifrages, gentian, small Compositæ, grasses, and sedges. Our ponies unconcernedly scraped away the snow with their hoofs, and nibbled the scanty herbage. When I mounted mine, he took the bit between his teeth, and scampered back to Palung, over rocks and 
hills, through bogs and streams; and though the snow was so blinding that no object could be distinguished, he brought me to the tents with unerring instinct, as straight as an arrow.

Wild animals are few in kind and rare in individuals, at Tungu and elsewhere on this frontier; though there is no lack of cover and herbage. This must be owing to the moist cold atmosphere; and it reminds me that a similar want of animal life is characteristic of those climates at the level of the sea, which I have adduced as bearing a great analogy to the Himalaya, in the want of certain natural orders of plants. Thus, New Zealand and Fuegia possess, the former no land animal but a rat, and the latter very few indeed, and none of any size. Such is also the case in Scotland and Norway. Again, on the damp west coast of Tasmania, quadrupeds are rare; whilst the dry eastern half of the island once swarmed with opossums and kangaroos. A few miles north of Tungu, the sterile and more lofty provinces of Tibet abound in wild horses, antelopes, hares, foxes, marmots, and numerous other quadrupeds; although their altitude, climate, and scanty vegetation are apparently even more unsuited to support such numbers of animals of so large a size than the karroos of South Africa, and the steppes of Siberia and Arctic America, which similarly abound in animal life. The laws which govern the distribution of large quadrupeds seem to be intimately connected with those of climate; and we should have regard to these considerations in our geological speculations, and not draw hasty conclusions from the 
the other some yards off, put him down on his hands and knees, threw a cloth over his back, and mounted; then kicking, spurring, and cuffing his steed, he was galloped back to the Lama and kicked off; when the catechising recommenced.

I spent a week at Tungu most pleasantly, ascending the neighbouring mountains, and mixing with the people, whom I found uniformly kind, frank, and extremely hospitable; sending their children after me to invite me to stop at their tents, smoke, and drink tea; often refusing any remuneration, and giving my attendants curds and yak-flesh. If on foot, I was entreated to take a pony; and when tired I never scrupled to catch one, twist a yak-hair rope over its jaw as a bridle, and throwing a goat-hair cloth upon its back (if no saddle were at hand), ride away whither I would. Next morning a boy would be sent for the steed, perhaps bringing an invitation to come and take it again. So I became fond of bricktea boiled with butter, salt, and soda; and expert in the Tartar saddle; riding about perched on the shoulders of a rough pony, with my feet nearly on a level with my pockets, and my knees almost meeting in front.

On the 28th of July much snow fell on the hills around, and rain at Tungu; the former soon melted, and I made an excursion to Chomiomo on the following day, hoping to reach the line of perpetual snow. Ascending the valley, I struck north up a steep slope, that ended in a spur of vast masses of quartz and felspar, piled like slabs in a stone quarry. 
Large silky cushions of a forget-me-not grew amongst the rocks, spangled with beautiful blue flowers, and looking like turquoises set in silver: the Delphinium glaciale was also abundant, exhaling a rank smell of musk. It indicates a very great elevation in Sikkim, and on my ascent far above it, therefore, I was not surprised to find an altitude of 16,754 feet.

A dense fog, with sleet, shut out all view; and I did not know in what direction to proceed higher, beyond the top of the sharp, stony ridge I had attained. Here there was no perpetual snow, which is to be accounted for by the nature of the surface facilitating its removal, the edges of the rocks which project through the snow, becoming heated, and draining off the water as it melts.

I left Tungu on the 30th of July, and spent that night at Tallum, where a large party of men had just arrived, with loads of madder, rice, canes, bamboos, planks, \&c., to be conveyed to Tibet on yaks and ponies.* On the following day I descended to Lamteng, gathering a profusion of fine plants by the way.

The flat on which I had encamped at this place in May and June being now a marsh, I took up my abode for two days in one of the houses, and paid the usual penalty of communication with these filthy people; for which my only effectual remedy was boiling all my

* About 300 loads of timber, each of six planks, are said to be taken across the Kongra Lama pass annually; and about 250 of rice, besides canes, madder, bamboos, cottons, cloths, and Symplocos leaves for dyeing. This is, no doubt, a considerably exaggerated statement, and may perhaps refer to both the Kongra Lama and Donkia passes. 
garments and bedding. Yet the house was high, airy, and light; the walls composed of bamboo, lath, and plaster.

Tropical Cicadas ascend to the pine-woods above Lamteng in this month, and chirp shrilly in the heat of the day; and glow-worms fly about at night. The common Bengal and Java toad abounded in the marshes, a remarkable instance of wide geographical distribution, for a Batrachian which is common at the level of the sea under the tropics.

On the 3rd of August I descended to Choongtam, which I reached on the 5th.

Terrific landslips had taken place along the valley, carrying down acres of rock, soil, and pine-forests, into the stream; and I saw one which swept over 100 yards in breadth of forest. The bridge at the Tuktoong being carried away, we had to ascend for 1000 feet to a place where the river could be crossed. In many places we had great difficulty in proceeding, the track being obliterated by the rains and landslips. Along the flats, now covered with a dense vegetation, we waded often knee-deep in mud, swarming with leeches; and instead of descending into the valley of the now swollen Lachen, we made long detours, rounding spurs by canes and bamboos suspended from trees.

The venomous black cobra was common, and we left the path with great caution, as it is a lazy reptile, and lies basking in the sun; many beautiful and harmless green snakes, four feet long, glided amongst the bushes. My dogs caught a "Rageu," a very 
remarkable animal, half goat and half deer; the flesh was good and tender, dark-coloured, and lean.

I remained here till the 15th of August, arranging my Lachen valley collections previous to starting for the Lachoong, whence I hoped to reach Tibet by a different route, crossing the Donkia pass, and thence exploring the sources of the Teesta at the Cholamoo lakes.

Whilst here I ascertained the volume and velocity of the Lachen and Lachoong rivers. Both were rapid torrents, the rains being at their height, and the melting of the snows at its maximum. I first measured several hundred yards along the banks of each river above the bridges, and then I timed floating masses thrown in at the upper point. I was surprised to find the velocity of the Lachen only nine miles an hour, for its waters seemed to shoot past with the speed of an arrow. The breadth of the river averaged sixty-eight feet, and the discharge was 4,420 cubic feet of water in a second.

The mean velocity of the Lachoong was eight miles an hour, the breadth ninety-five feet, the depth about the same as that of the Lachen, and the discharge 5,700 cubic feet of water in a second.**

On the 15th of August, having received supplies from Dorjiling, I started up the north bank of the

* Hence it appears that the Lachoong, being so much the more copious, should in one sense be regarded as the main stream of the Teesta, rather than the Lachen, which, however, has by far the most distant source. Their united streams discharge upwards of 10,000 cubic feet of water per second in the height of the rains! which, is, however, a mere fraction of the discharge of the Teesta where that river leaves the Himalaya. The Ganges, where it leaves the Himalaya at Hurdwar, discharges 8000 feet per second during the dry season. 
Lachoong, with the Singtam Soubah, who accompanied me officially, and with a very bad grace; poor fellow, he expected me to have gone back to Dorjiling, and many a sore struggle we had on this point. At Choongtam he had been laid up with ulcerated legs from the bites of leeches and sand-flies, which required my treatment.

We crossed to the south bank by a fine cane-bridge forty yards long, the river being twenty-eight across: and here I have to record the loss of my dog Kinchin; the companion of all my late journeyings, and to whom I had become really attached. He had a bad habit, of which I had vainly tried to cure him, of running for a few yards on the round bamboos by which the canebridges are crossed, and on which it was impossible for a dog to retain his footing: in this situation he used to get thoroughly frightened, and lie down with his legs hanging over the water, and having no hold whatever. I had several times rescued him from this perilous position, which was always rendered more imminent from the shaking of the bridge as I approached him. On the present occasion, I had stopped below the bridge, botanizing, and Kinchin having scrambled up the rocks, ran on to the bridge. I could not see him, and was not thinking about him, when suddenly his shrill, short barks of terror rang above the roaring torrent. I hastened to the bridge, but before I could get to it, he had lost his footing, and had disappeared. Holding on by the canes, I strained my eyes till the bridge seemed to be swimming up the valley, and the swift waters to be standing still, but to 
no purpose; he had been carried under at once, and swept away miles below. For many days I missed him by my side on the mountain, and by my feet in my tent. He had become a very handsome dog, with glossy black hair, pendent triangular ears, short muzzle, high forehead, jet-black eyes, straight limbs, arched neck, and a most glorious tail curling over his back.

A very bad road led to the village of Keadom, situated on a flat terrace several hundred feet above the river, where I spent the night. Here are cultivated plantains and maize, although the elevation is equal to parts of Dorjiling, where these plants do not ripen.

In the afternoon we reached Lachoong, which is by far the most picturesque village in the temperate region of Sikkim. Grassy flats of different levels, sprinkled" with brushwood and scattered clumps of pine and maple, occupy the valley; whose west flanks rise in steep, rocky, and scantily wooded grassy slopes. About five miles to the north the valley forks; two conspicuous domes of snow rising from the intermediate mountains. On the east, Tunkra mountain rises in a superb unbroken sweep of dark fir-wood and cliffs, surmounted by black rocks and white fingering peaks of snow. South of this, the valley of the Tunkrachoo opens, backed by sharp snowed pinnacles, which form the continuation of the Chola range; over which a pass leads to the Phari district of Tibet, which intervenes between Sikkim and Bhotan. Southwards the view is bounded by snowy mountains, and the valley seems blocked up by a remarkable morainelike spur. 


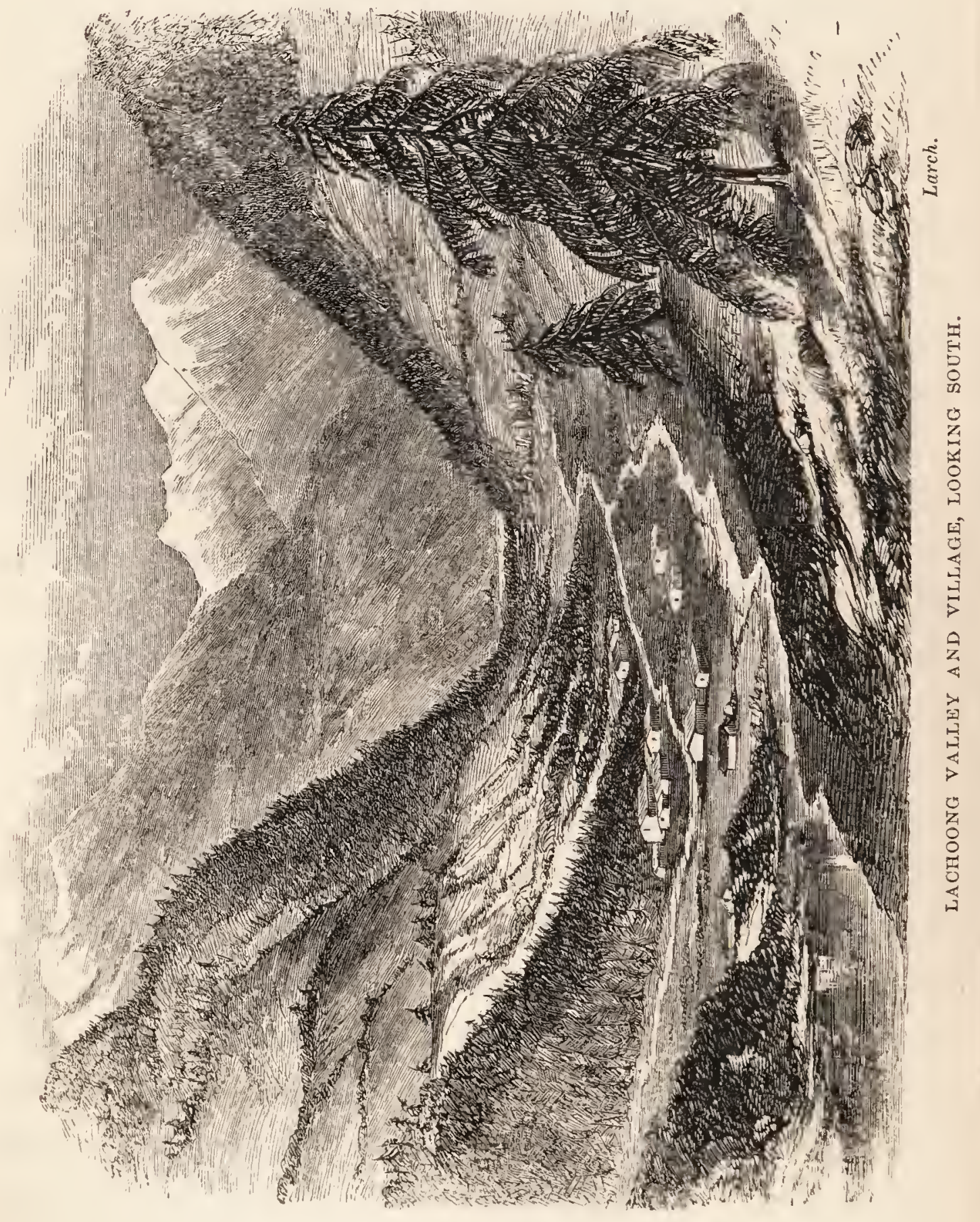




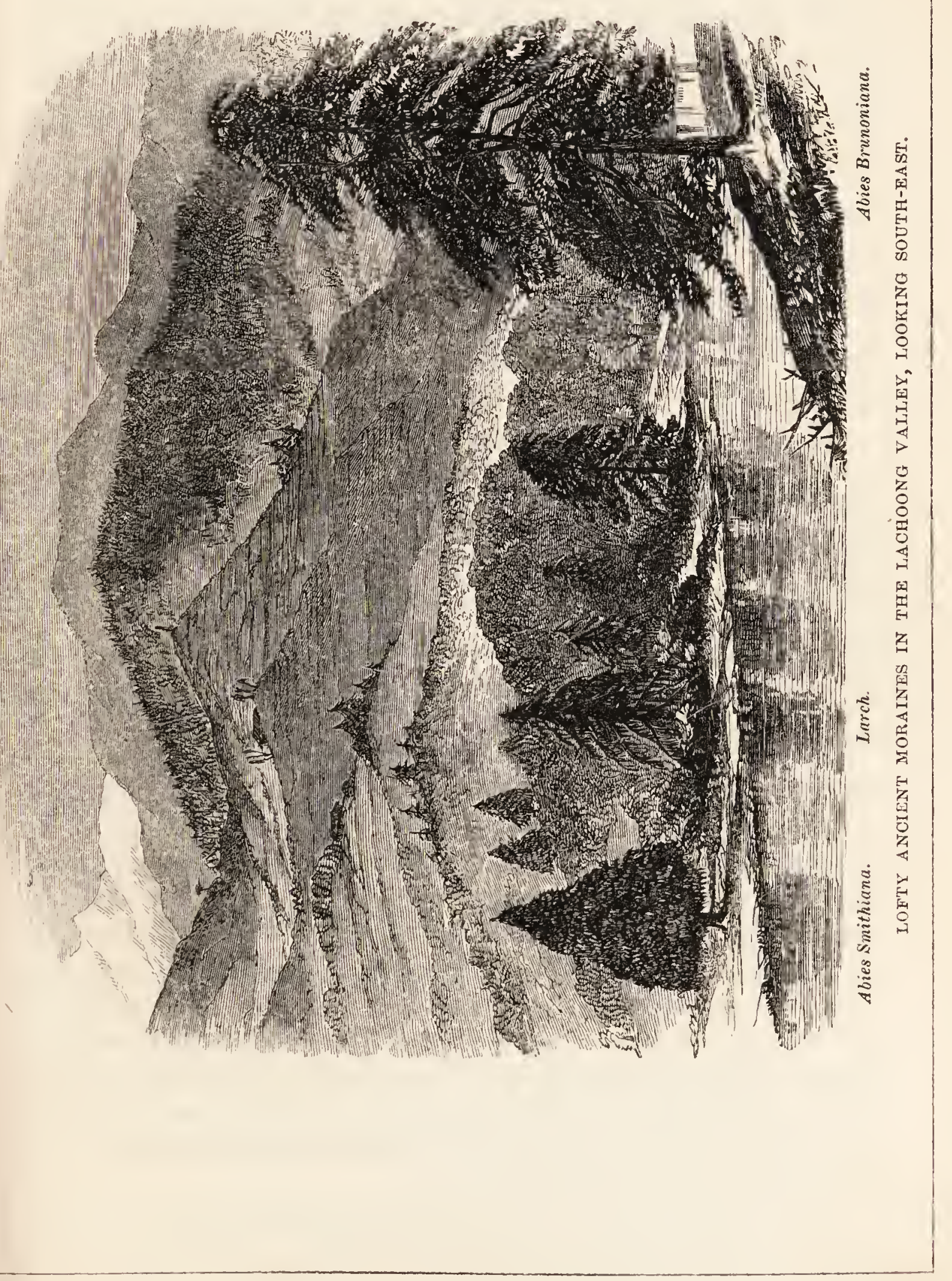


Stupendous moraines rise 1,500 feet above the Lachoong in several concentric series, curving downwards and outwards, so as to form a bell-shaped mouth to the valley of the Tunkrachoo. Those on the upper flank are much the largest; and the loftiest of them terminates in a conical hill crowned with Boodhist flags, and its steep sides are cut into horizontal roads or terraces, one of which is so broad and flat as to suggest the idea of its having been cleared by art. On the south side of the Tunkrachoo river the moraines are also more or less terraced, as is the floor of the Lachoong valley, and its east slopes, 1000 feet up.*

The river is fourteen yards broad, and neither deep nor rapid: the village is on the east bank, and contains fully 100 good wooden houses, raised on posts, and clustered together without order. It was muddy and intolerably filthy, and intersected by some small streams, whose beds formed the roads, and at the same time the common sewers of the natives. There was some wretched cultivation in fields, $\uparrow$ of wheat,

* I have since been greatly struck with the similarity between the features of this valley, and those of Chamouni, (though the latter is on a smaller scale) above the Lavanchi moraine. The spectator standing in the expanded part below the village of Argentière, and looking upwards, sees the valley closed above by the ancient moraine of the Argentière glacier, and below by that of Lavanchi; and on all sides the slopes are cut into terraces, strewed with boulders. The average slope of these pine-clad Sikkim valleys much approximates to that of Chamouni, and never approaches the precipitous character of the Bernese Alps'valleys, Kandersteg, Lauterbrunnen, and Grindenwald.

+ Full of such English weeds as shepherd's purse, nettles, and dock; besides many Himalayan ones, as balsams, thistles, a beautiful geranium, mallow, and Cucurbitaceous plants. 
barley, peas, radishes, and turnips. Rice was once cultivated at this elevation ( 8000 feet), but the crop was uncertain; some very tropical grasses grow wild here. In gardens the hollyhock is seen; said to have been introduced through Tibet from China; also Pinus excelsa from Bhotan, peaches, wainuts, and weeping willows. A tall poplar was pointed out to me as a great wonder; it had two species of Pyrus growing on its boughs, evidently from seed; one was a mountain ash, the other like Pyrus Aria.

Soon after camping, the Lachoong Phipun, a very tall, intelligent, and agreeable-looking man, waited on me with the usual presents, and a request that I would visit his sick father. His house was lofty and airy: in the inner room the sick man was stretched on a board, covered with a blanket, and dying of pressure on the brain; he was surrounded by a deputation of Lamas from Teshoo Loombo, sent for in this emergency. The principal one was a fat fellow, who sat cross-legged before a block-printed Tibetan book, plates of raw meat, rice, and other offerings, and the bells, dorje, \&c. of his profession. Others sat around, reading or chanting services, and filling the room with incense. At one end of the apartment was a good library in a beautifully carved book-case. 


\section{CHAPTER XXII.}

Leave Lachoong for Tunkra pass-_-Moraines and their vegetation-Pines of great dimensions-Wild currants-Glaciers-Summit of passElevation-Views-Plants-Winds-Lacheepia rock-Extreme cold -Kinchinjunga-Himalayan grouse-Return to Lachoong-Ascent to Yeumtong-Flats and debâcles-Buried pine-trunks-Hot-springsBehaviour of Singtam Soubah-Leave for Momay Samdong-Upper limit of trees-Glacial terraces, \&c.-Forked Donkia-Ascent to Donkia pass - Scenery - Lakes - Tibet-Bhomtso-Arun riverKiang-lah mountains-Yaru-Tsampu river-Appearance of TibetKinchinjhow, and Kinchinjunga_Chola range-Deceptive appearance of distant landscape-Perpetual snow-Pulses-Plants-Tripe de roche-Return to Momay-Dogs and yaks-Birds-Insects-Quadrupeds-Hot springs-Marmots-Kinchinjhow glacier.

The Singtam Soubah being again laid up here from the consequences of leech-bites, I took the opportunity of visiting the Tunkra-lah pass, represented as the most snowy in Sikkim; which I found to be the case. The route lay over the moraines on the north flank of the Tunkrachoo, which are divided by narrow dry gullies, and composed of enormous blocks disintegrating into a deep layer of clay. All are clothed with luxuriant herbage and flowering shrubs, besides small larches and firs, rhododendrons, and maples; with Pyrus, cherry, Pieris, laurel, and Goughia. The musk-deer inhabits these woods, and at this season I 
have never seen it higher. Large monkeys are also found on the skirts of the pine-forests, and a curious long-tailed animal, Ailurus ochraceus, peculiar to the Himalaya, something between a diminutive bear and a squirrel. In the dense and gigantic forest of Abies Brunoniana and silver fir, I measured one of the former trees, and found it twenty-eight feet in girth, and above 120 in height. The silver fir attains thirtyfive feet in girth, with a trunk unbranched for forty feet.

The path was narrow and difficult in the wood, and especially along the bed of the stream, where grew ugly trees of larch, eighty feet high, and abundance of a new species of alpine strawberry with oblong fruit. Currant-bushes also were plentiful, generally growing on the pine-trunks, in strange association with a small species of Begonia, a hothouse tribe of plants in England. Emerging from the forest, vast old moraines are crossed, in a shallow mountain valley, several miles long and broad, 12,000 feet above the sea, choked with rhododendron shrubs, and nearly encircled by snowy mountains. Heavy rain fell in the afternoon, and we halted under some rocks: as I had brought no tent, my bed was placed beneath the shelter of one, near which my followers burrowed.

On the next morning we proceeded up the valley, towards a very steep rocky barrier, through which the river cut a narrow gorge, and beyond which rose lofty snowy mountains; the peak of Tunkra being to our left hand (north). Saxifrages grew here in profuse tufts of golden blossoms, with rushes, VOL. II. 
mountain-sorrel and the bladder-headed Saussurea, whose flowers are enclosed in inflated membranous bracts, and smell like putrid meat; there. were also splendid primroses, the spikenard, valerian, and golden Potentillas.

The ascent was steep and difficult, up a stony valley bounded by precipices; in this the river flowed in a north-west direction, and we were obliged to wade along it, though its waters were bitterly cold. At 15,000 feet we passed from great snow-beds to the surface of a glacier, partly an accumulation of snow, increased by lateral glaciers: its slope was very gentle for several miles; the surface was eroded by rain, and very rough, whilst those of the lateral glaciers were ribboned, crevassed, and often conspicuously marked with dirtbands.

A gently sloping saddle, bare of snow, which succeeds the glacier, forms the top of the Tunkra pass; it unites two snowy mountains, and opens on the great valley of the Machoo, which flows in a part of Tibet between Sikkim and Bhotan; its height is 16,083 feet above the sea. Nothing can be more different than the two slopes of this pass; that by which I had come presented a gentle snowy acclivity, bounded by precipitous mountains; while that which opened before me was a steep, rocky, broad, grassy valley, where not a particle of snow was to be seen, and yaks were feeding near a small lake not 1000 feet down. Nor were snowy mountains visible anywhere in this direction, except far to the south-east, in Bhotan. This remarkable difference of climate is due to the southerly wind 
which ascends the Tibetan or Machoo valley being drained by intervening mountains before reaching this pass, whilst the Sikkim current brings abundant vapours up the Teesta and Lachoong valleys.

Very few plants grew amongst the stones at the top of the Tunkra pass, and those few were mostly different from those of Palung and Kongra Lama. A pink-flowered Arenaria, two kinds of Corydalis, the cottony Saussurea, and diminutive primroses, were the most conspicuous. The wind was variable, blowing alternately up both valleys, bringing much snow when it blew from the Teesta, though deflected to a northwest breeze; when, on the contrary, it blew from Tibet, it was, though southerly, dry. Clouds obscured all distant view. The temperature was $39 \frac{1}{2}^{\circ}$, the air being extremely damp and consequently very cold.

Returning to the foot of the glacier, I took up my quarters for two days under an enormous rock overlooking the broad valley in which I had spent the previous night, and directly fronting Tunkra mountain, which bore north about five miles distant. This rock was sixty to eighty feet high, and placed on the top of a bleak ridge, facing the north; no shrub or bush being near it. The gentle slope outwards of the rock afforded the only shelter, and a more utterly desolate place than Lacheepia, as it is called, I never laid my unhoused head in. It commanded an incomparable view across the Lachoong and Lachen valleys, of the whole group of Kinchinjunga snows, from Tibet southwards, and was therefore a most valuable position for geographical purposes. 
The night was misty, and though the temperature was $35^{\circ}$, I was miserably cold; for my blankets being laid on the bare ground, the chill seemed to strike from the rock to the very marrow of my bones. At sunrise the mist rose majestically from all the mountaintops; but the view obtained was transient, for in less than an hour the dense fog which choked the valleys ascended to the warmed atmosphere above, and slowly threw a veil over the landscape. I waited till the last streak of snow was shut out from my view, when I descended, to breakfast on Himalayan grouse (Tetraoperdix nivicola), a small gregarious bird which inhabits the loftiest mountains, and utters a short cry of "Quiok, quiok; " in character and appearance it is intermediate between grouse and partridge, and is good eating, though tough.

Hoping to obtain another view, which might enable me to correct the bearings taken that morning, I was tempted to spend a second night at Lacheepia, passing the day in botanizing and taking observations. Little rain fell during the day, but it was heavy at night, though there was fortunately no wind; and I made a more comfortable bed with tufts of juniper brought up from below. My fire was principally of wet rhododendron wood, with masses of the aromatic dwarf species, which, being full of resinous glands, blazed with fury. Next day, after a very transient glimpse of the snows, I descended to Lachoong, where I remained for some days botanizing.

During my stay at Lachoong I was several times awakened by all the noises and accompaniments of a 
night-attack or alarm ; screaming voices, groans, shouts, and ejaculations, the beating of drums and firing of guns, and flambeaux of pine-wood gleaming amongst the trees, and flitting from house to house. The cause, I was informed, was the presence of a demon, who required exorcisement, and who generally managed to make the villagers remember his visit, by their missing various articles after the turmoil made to drive him away.

On the 29th of August I left Lachoong and proceeded up the valley, along a terrace covered with long grass, and bounded by lofty banks of gravel and sand. The old moraines were very difficult to cross, and on one I found a barricade, which had been erected to deceive me regarding the frontier, had I chosen this route instead of the Lachen one, in May.

Broad flats clothed with rhododendron, alternated with others covered with mud, boulders, and débris, which had flowed down from the gorges on the west, and which still contained trees, inclined in all directions, and buried up to their branches; some of these débâcles were 400 yards across, and sloped at an angle of $2^{\circ}$ to $3^{\circ}$, bearing on their surfaces blocks fifteen feet in diameter.* They seem to subside materially, as I perceived they had left marks many feet higher on the tree-trunks. Such débâcles must often bury standing forests in a very favourable material, climate, and position for becoming fossilized.

I arrived at Yeumtong, a small summer cattle-station,

* None were to be compared in size and extent with that at Bex, at the mouth of the Rhone valley. 
the general features of which closely resemble those of the narrow Swiss valleys. The west flank was lofty and precipitous, with narrow gulleys still retaining the winter's snow; the east gradually sloped up to the two snowy domes seen from Lachoong; the bed of the valley was alternately a flat lake-bed, in which the river meandered at the rate of three and a half miles an hour, and a sudden descent, cumbered with old moraines, over which it rushed in sheets of foam. Up the valley Chango-Khang was visible, with a superb glacier descending to about 14,000 feet on its south flank. Enormous masses of rock were continually precipitated from the west side, close to the shed in which I had taken up my quarters, keeping my people in constant alarm, and causing a great commotion among the yaks, dogs, and ponies. On the opposite side of the river was a deep gorge ; in which an immense glacier descended lower than any I have seen in Sikkim. I made several attempts to reach it by the gulley of its discharging stream, but was always foiled by the rocks, and the dense jungle of pines, rhododendron, and dwarf holly.

Some hot-springs burst from the bank of the Lachen a mile below the village: they are used as baths, the patient remaining three days at a time in them, only retiring to eat in a little shed close by. The discharge amounts to a few gallons per minute; the temperature at the source is $112 \frac{1}{2}^{\circ}$, and in the bath $106^{\circ}$. The water has a slightly saline taste; it is colourless, but emits bubbles of sulphuretted hydrogen gas, blackening silver. A cold spring (temperature $42^{\circ}$ ) emerged close by, and the Lachoong, not ten yards off, was $47^{\circ}$. 
The Singtam Soubah had been very sulky since leaving Choongtam, and I could scarcely get a drop of milk or a slice of curd here. I had to take him to task severely for sanctioning the flogging of one of my men; a huntsman, who had offered me his services at Choongtam, and who was a civil, industrious fellow, though he had procured me little besides a huge monkey, which had nearly bitten off the head of his best dog. I had made a point of consulting the Soubah before hiring him, for fear of accidents; but this did not screen him from the jealousy of the Choongtam Lama, who twice flogged him in the Goompa with rattans (with the Soubah's consent), alleging that he had quitted his service for mine. My people knew of this, but were afraid to tell me, which the poor fellow did himself.

The Lachoong Phipun visited me on the 7th of September: he had officiously been into Tibet to hear what the Tibetan people would say to my going to Donkia, and finding them supremely indifferent, returned to be my guide. A month's provision for ten men having arrived from Dorjiling, I left Yeumtong the following day for Momay Samdong, the loftiest yak-grazing station in Sikkim, and within a few hours' journey of the Donkia pass.

The valley was almost level for several miles, the road continuing along the east bank of the Lachen. Shoots of stones had descended from the ravines, all of a white fine-grained granite, stained red with a minute conferva, which has been taken by Himalayan travellers for red snow; a phenomenon I never saw in Siklkim : 
nor do I know any authentic record of its having been seen in the Himalaya.

At a fork of the valley several miles above Yeumtong, and below the great glacier of Chango-Khang, the ancient moraines are prodigious, much exceeding any I have elsewhere seen, both in extent, in the size of the boulders, and in the height to which the latter are piled on one another. Many boulders I measured were twenty yards across, and some even forty; and the chaotic scene they presented baffles all description: they were scantily clothed with stunted silver firs.

Beyond this, the path crossed the river, and ascended rapidly over a mile of steeply sloping landslip, composed of angular fragments of granite, which were constantly falling from above, and were extremely dangerous. At 14,000 feet, trees and shrubs ceased, willow and honeysuckle being the last; and thence onward the valley was bleak, open, and stony, with lofty rocky mountains on either side. The south wind brought a cold drizzling rain, which numbed us, and two of the lads who had last come up from Dorjiling were seized with a remittent fever, originally contracted in the hot valleys: luckily we found some cattle-sheds, in which I left them, with two men to attend on them.

Momay Samdong is situated in a broad part of the Lachoong valley, where three streams meet; it is on the west of Chango-Khang, and is six miles south-east of Kinchinjhow, and seven south-west of Donkia: it is in the same latitude as Palung, but scarcely so lofty; 
being nearly the elevation of Lacheepia (near the Tunkra pass), from which, however, its scenery and vegetation entirely differ.

I pitched my tent close to a little shed at the base of a mountain that divided the Lachoong river from a western tributary. It was a wild and most exposed spot: stony mountains, grassy on the base near the river; distant snowy peaks, stupendous precipices, moraines, glaciers, transported boulders, and rocks rounded by glacial action, formed the landscape which everywhere met the view. There was not a bush six inches high, and the only approach to woody plants were minute creeping willows and dwarf rhododendrons, with a very few prostrate junipers and Ephedra.

The base of the spur was cut into broad flat terraces, composed of sand, pebbles, and boulders; the remains, doubtless, of an enormously thick glacial deposit. Another tributary falls into the Lachoong at Momay, which leads eastwards up to an enormous glacier that descends from Donkia. Snowy mountains rise nearly all around it: those on its south and east divide Sikkim from the Phari province in Tibet; those on the north terminate in a forked or cleft peak, which is a remarkable and conspicuous feature from Momay. This, which I have called Forked Donkia, is elevated about 21,870 feet, and is the termination of a magnificent amphitheatre of stupendous snow-clad precipices, continuously upwards of 20,000 feet high, that forms the east flank of the upper Lachoong valley. From Donkia top again, the mountains sweep round to the westward, rising into fingered peaks of extraordinary magnificence; 
and thence-still running west-dip to 18,500 feet, forming the Donkia pass, beyond which they rise again as the great mural mass of Kinchinjhow. This girdle of mountains encloses the head waters of the Lachoong, which rises in countless streams from its perpetual snows, glaciers, and small lakes: its northern drainage is to the Cholamoo lakes in Tibet; in which is the source of the Lachen, which flows round the north base of Kinchinjhow to Kongra Lama.

The Lachoong is here twelve or fifteen yards wide, and runs over a pebbly bed, cutting a shallow channel down to the subjacent rock, which is in some cases scooped out six or eight feet deep by its waters.

On our arrival, we found that a party of buxom, goodnatured looking girls who were tending yaks, were occupying the hut, which, however, they cheerfully gave up to my people, spreading a black tent close by for themselves; and next morning they set off with all their effects packed upon the yaks. The spot appearing highly favourable for observations, I determined to remain here during the equinoctial month, and put my people on "two-thirds allowance," i.e., four pounds of rice daily for three men, allowing them to send down the valley for what more they could get. The Singtam Soubah was intensely disgusted with my determination: he accompanied me next day to the pass, and having exhausted his persuasions, threats, and warnings, about snow, wind, robber's, starvation, and Tibetan sepoys, departed on the 12th for Yeumtong, leaving me truly happy for the first time since quitting Dorjiling. I had now a 
prospect of uninterruptedly following up my pursuits at an elevation little below that of Mont Blanc, surrounded by the loftiest mountains, and perhaps the vastest glaciers on the globe; my instruments were in perfect order, and I saw around me a curious and varied flora.

The morning of the 9th of September promised fair, though billowy clouds were rapidly ascending the valley. To the eastward my attention was attracted by a double rainbow; the upper was an arch of the usual form, and the lower was the curved illuminated edge of a bank of cumulus, with the orange hues below. I took the path to the Donkia pass, fording the river, and ascending in a north-east direction, along the foot of stony hills that rise at a gradual slope to broad unsnowed ridges, 18,000 to 19,000 feet high. Shallow valleys, glacier-bound at their upper extremities, descend from the still loftier rearward mountains; and in these occur lakes. About five miles up, a broad opening on the west leads to Tomo Chamo, as the eastern summit of Kinchinjhow is called. Above this the valley expands very much, and is stony and desert: stupendous mountains rear themselves on all sides, and the desolation and grandeur of the scene are unequalled in my experience.

I passed several shallow lakes at 17,500 feet; their banks were green and marshy, and supported thirty or forty kinds of plants. I collected in the dry bed of a stream a curious white substance like thick felt, formed of felspathic silt (no doubt the product of glacial streams) and the siliceous cells of infusorix 
(Diatomaceæ). It much resembles the fossil or meteoric paper of Germany, which is also formed of the lowest tribes of fresh-water plants, though considered by Ehrenberg as of animal origin. At the head of the valley a steep crest rises between two precipitous snowy peaks, and a very fatiguing ascent (at this elevation) leads to the sharp rocky summit of the Donkia pass, 18,466 feet above the sea. The view on this occasion was obscured by clouds and fogs, except towards Tibet, in which direction it was magnificent; but as I afterwards twice ascended this pass, and also crossed it, I shall here bring together all the particulars I noted.

The Tibetan view, from its novelty, extent, and singularity, demands the first notice: the Cholamoo lake lay 1,500 feet below me, at the bottom of a rapid descent; it was a blue sheet of water, three or four miles from north to south, and one and a half broad, hemmed in by rounded spurs from Kinchinjhow on the one side, and from Donkia on the other: the Lachen flowed from its northern extremity, and turning westward, entered a broad barren valley, bounded on the north by red stony mountains, called Bhomtso, which I saw from Kongra Lama, and ascended with Dr. Campbell in the October following: though 18,000 to 19,000 feet high, these mountains were wholly unsnowed. Beyond this range lay the broad valley of the Arun, and in the extreme north-west distance, to the north of Nepal, were some immense snowy mountains, reduced to mere specks on the horizon. The valley of the Arun was bounded on the north by very 
precipitous black rocky mountains, sprinkled with snow; beyond these again, snow-topped range rose over range in the clear purple distance. The nearer of these was the Kiang-lah, which forms the axis or water-shed of this meridian; its south drainage being to the Arun river, and its north to the Yaru-tsampu : it appeared forty to fifty miles off, and of great mean elevation: the vast snowy mountains that rose beyond it were, I was assured, beyond the Yaru, in the saltlake country.* A spur from Chomiomo cut off the view to the southward of north-west, and one from Donkia concealed all to the east of north.

The most remarkable features of this landscape were its enormous elevation, and its colours and contrast to the black, rugged, and snowy Himalaya of Sikkim. All the mountains between Donkia pass and the Arun were of a yellowish red colour, rising and falling in long undulations like dunes, and perfectly bare of perpetual snow or glaciers. Rocks everywhere broke out on their flanks, and often along their tops, but the general contour of the whole immense area was very open and undulating, like the great ranges of central Asia described by MM. Huc and Gabet. Still further, the mountains were rugged, often rising into peaks, which from the angles I took here, and subsequently at Bhomtso, cannot be below 24,000 feet, and are probably higher. The most lofty mountains were on the range

* This salt country was described to me as enormously lofty, perfectly sterile, and fourteen days' march for loaded men and sheep from Jigatzi: there is no pasture for yaks, whose feet are cut by the rocks. The salt is dug (so they express it) from the margin of lakes; as is the carbonate of soda. 
north of Nepal, not less than 120 miles distant, and, though heavily snowed, were below the horizon of Donkia pass.

Cholamoo lake lay in a broad, scantily grassed, sandy and stony valley; snow-beds, rocks, and glaciers dipped abruptly towards its head, and on its west bank a lofty brick-red spur sloped upwards from it, conspicuously cut into terraces for several hundred feet above its waters.

Donkia rises to the eastward of the pass, but its top is not visible. I ascended over loose rocks to between 19,000 and 20,000 feet, and reached vast masses of blue ribboned ice, capping the ridges, but obtained no further prospect. To the west, the beetling summit of Kinchinjhow rises at two miles' distance, 3000 to 4000 feet above the pass. A little south of it, and north of Chango-Khang, the view extends through a gap in the Sebolah range, across the valley of the Lachen, to Kinchinjunga, distant forty-two miles. The monarch of mountains looked quite small and low from this point, and it was difficult to believe it was 10,000 feet more lofty than my position. I repeatedly looked from it to the high Tibetan mountains in the extreme north-west distance, and was more than ever struck with the apparently immense distance, and consequent altitude of the latter ; I put, however, no reliance on such estimates.

To the south the eye wandered down the valley of the Lachoong to the mountains of the Chola range, which appear so lofty from Dorjiling, but from here are sunk far below the horizon: on comparing these 
with the northern landscape, the wonderful difference between their respective snow-levels, amounting to fully 5000 feet, was very apparent. South-east the stupendous snowy amphitheatre formed by the precipitous flank of Donkia was a magnificent spectacle.

This wonderful view forcibly impressed me with the fact, that all eye-estimates in mountainous countries are utterly fallacious, if not corrected by study and experience. I had been given to understand that from Donkia pass the whole country of Tibet sloped away in descending steppes to the Yaru river, and was more or less of a plain; and could I have trusted my eyes only, I should have confirmed this assertion so far as the slope was concerned. When, however, the levelled theodolite was directed to the distance, the reverse was found to be the case. Unsnowed and apparently low mountains touched the horizon line of the telescope; which proves that, if only 37 miles off, they must, from the dip of the horizon, be at least 1000 feet higher than the observer's position. The same infallible guide cuts off mountain-tops and deeply snowed ridges, which to the unaided eye appear far lower than the point from which they are viewed; but which, from the quantity of snow on them, must be several thousand feet higher, and, from the angle they subtend in the instrument, must be at an immense distance. The want of refraction to lift the horizon, the astonishing precision of the outlines, and the brilliancy of the images of mountains reduced by distance to mere specks, are all circumstances tending to depress them to appearance. The absence of trees, houses, and 
familiar objects to assist the eye in the appreciation of distance, throws back the whole landscape; which, seen through the rarified atmosphere of 18,500 feet, looks as if diminished by being surveyed through the wrong end of a telescope.

A few rude cairns were erected on the crest of the pass, covered with wands, red banners, and votive offerings of rags. I found a fine slab of slate, inscribed with the Tibetan characters, "Om Mani Padmi om," which Meepo allowed me to take away as the reward of my exertions. The ridge is wholly formed of angular blocks of white gneissy granite, split by frost. There was no snow on the pass itself, but deep drifts and glaciers descended in hollows on the north side to 17,000 feet. The rounded northern red shoulder of Kinchinjhow by Cholamoo lake, apparently 19,000 feet high, was quite bare, and, as I have said, I ascended Donkia to upwards of 19,000 feet before I found the rocks crusted with ice, and the ground frozen. I assume, therefore, that 19,000 feet at this spot is not below the mean level at which all the snow melts that falls on a fair exposure to the south : this probably coincides with a mean temperature of $20^{\circ}$. Forty miles further north (in Tibet) the same line is probably at 20,000 feet; for there much less snow falls, and much more melts in proportion. From the elevation of about 19,300 feet, which I attained on Donkia, I saw a fine illustration of that atmospheric phenomenon called the "spectre of the Brocken," my own shadow being projected on a bank of thin mist that rose above the tremendous precipices on whose 
crest I stood. My head was surrounded with a brilliant circular glory or rainbow.

The temperature of the Donkia pass is much higher than might be anticipated from its great elevation, and from the fact of its being always bitterly cold to the feelings. This is no doubt due to the warmth of the ascending currents, and to the heat evolved during the condensation of their vapours.

I left a minimum thermometer on the summit on the 9th of September, and removed it on the 27 th, but it had been lifted and turned over by the action of the frost and snow on the loose rocks amongst which I had placed it; the latter appearing to have been completely shifted. Fortunately, the instrument escaped unhurt; the index standing at $28^{\circ}$.

A violent southerly wind, with a scud of mist, and sometimes snow, blew over the pass; but we found shelter on the north face, where I twice kindled a fire, and boiled my thermometers. On one occasion I felt the pulses of my party several times during two hours' repose (without eating); the mean of eight persons was $105^{\circ}$, the extremes being $92^{\circ}$ and $120^{\circ}$, and my own $108^{\circ}$.

I found one flowering plant on the summit; the tufted alsinaceous one before mentioned. The Fescue grass, a little fern, and a Saussurea ascended nearly to the summit, and several Lichens grew on the top; also some barren mosses. At 18,300 feet, I found on one stone only a fine lichen, the "tripe de roche" of Arctic voyagers, and the food of the Canadian hunters; it is also abundant on the Scotch alps. 
Before leaving, I took one more long look at the boundless prospect; and, now that its important details were secured, I had leisure to reflect on the impression it produced. There is no loftier country on the globe than that embraced by this view, and no more howling wilderness; well might the Singtam Soubah describe it as the loftiest, coldest, windiest, and most barren country in the world. Were it buried in everlasting snows, or burnt by a tropical sun, it might still be as utterly sterile; but with such sterility I had long been familiar. Here the colourings are those of the fiery desert or volcanic island, while the climate is that of the poles. Never, in the course of all my wanderings, had my eye rested on a scene so dreary and inhospitable. The "cities of the plain" lie sunk in no more death-like sea than Cholamoo lake, nor are the tombs of Petra hewn in more desolate cliffs than those which flank the valley of the Tibetan Arun.

On our return it drizzled and sleeted all the way, and was dark before we arrived at the tent.

At night the Tibetan dogs are let loose, when they howl dismally: on one occasion they robbed me of all my meat, a fine piece of yak's flesh. The yaks are also troublesome, and bad sleepers; they used to try to effect an entrance into my tent, pushing their muzzles under the flaps at the bottom, and awakening me with a snort and moist hot blast. Before the second night I built a turf wall round the tent, and in future slept with a heavy tripod by my side, to poke at intruders.

Birds flock to the grass about Momay; larks, 
finches, warblers, abundance of sparrows, feeding on the yak-droppings, with occasionally the hoopoe; waders, cormorants, and wild ducks were sometimes seen in the streams, but most of them were migrating south. The yaks are driven out to pasture at sunrise, and home at sunset, till the middle of the montl, when they return to Yeumtong. All their droppings are removed from near the tents, and piled in heaps; as these animals, unlike their masters, will not sleep amid such dirt. These heaps swarm with the maggots of two large flies, a yellow and black, affording abundant food to red-legged crows, ravens, and swallows. The wild quadrupeds are huge sheep, in flocks of fifty, the Ovis Ammon, called "Gnow." I never shot one, not having time to pursue them, for they were very seldon seen, and always at great elevations. The larger marmot is common, and I found the horns of the "Tchiru" antelope. Neither the wild horse, fox, hare, nor tailless rat, cross the Donkia pass. White clover, shepherd's purse, dock, plantain, and chickweed, are imported here by yaks; but the common Prunella of Europe is wild, and so are a groundsel and Ranunculus. I also collected about 200 other plants near my tent; amongst which grasses were numerous; chiefly belonging to European genera.

I repeatedly attempted to ascend both Kinchinjhow and Donkia from Momay, and generally reached from 18,000 to 19,000 feet, but never much higher.* The observations taken on these excursions are sufficiently

* An elevation of 20,000, and perhaps 22,000 feet might, I should think, easily be attained by practice, in Tibet, north of Sikkim. 
illustrated by those of Donkia pass: they served chiefly to perfect my map, measure the surrounding peaks, and determine the elevation reached by plants; all of which were slow operations, the weather during this month being so bad that I rarely returned dry to my tent; fog and drizzle, if not sleet and snow, coming on every day, without exception.

I made frequent excursions to the great glacier of Kinchinjhow. Its valley is about four miles long, broad and flat; Chango-Khang rears its blue and white cliffs 4,500 feet above its west flank, and throws down avalanches of stones and snow into the valley. Hotsprings burst from the ground near some granite rocks on its floor, about 16,000 feet above the sea, and only a mile below the glacier, and the water collects in pools: its temperature is $110^{\circ}$, and in places $116^{\circ}$, or $4^{\circ}$ hotter than that of the Yeumtong hot-springs, though 4000 feet higher, and of precisely the same character. A few plants make the neighbourhood of the hot-springs a little oasis, and the large marmot is common, uttering its sharp, chirping squeak.

The terminal moraine is about 500 feet high, quite barren, and thrown obliquely across the valley, from north-east to south-west, completely hiding the glacier. From its top successive smaller parallel ridges (indicating the periodic retirements of the glacier) lead down to the ice, which must have sunk several hundred feet. This glacier descends from Kinchinjhow, the huge cliff of whose eastern extremity dips into it. The surface, less than half a mile wide, is exceedingly undulated, and covered with large pools of water, 
ninety feet deep, and beds of snow, and is deeply corroded; gigantic blocks are perched on pinnacles of ice on its surface, and the gravel cones are often twenty feet high. Between the moraine and the west flank of the valley is a large lake, with terraced banks, whose bottom is several hundred feet above that of the valley; it is half a mile long, and a quarter broad, and fed partly by glaciers from Chango-Khang and Sebolah, and partly by filtration through the lateral moraine.

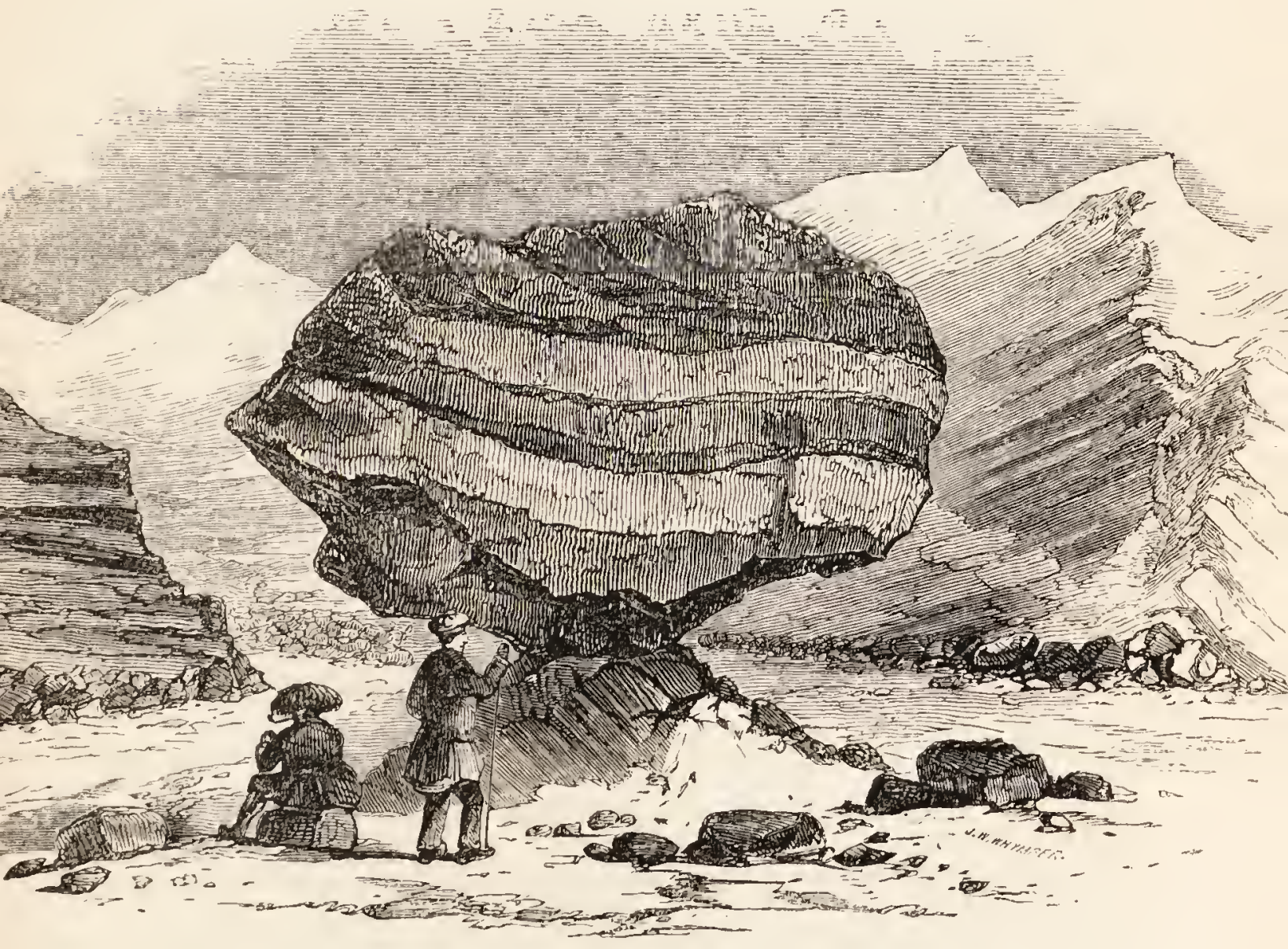




\section{CHAPTER XXIII.}

Donkia glaciers-Moraines-Dome of ice-Honey-combed surface-Accident to instruments-Sebolah pass-Bees and May-flies-ViewLamas and travellers at Momay-Weather and climate-Sensations arising from elevation-Dr. Campbell leaves Dorjiling for SikkimLeave Momay-Yeumtong-Lachoong-Retardation of vegetation at low elevations-Choongtam-Landslips and débâcle-Meet Dr. Campbell-Motives for his journey-Second visit to Lachen valleyAutumnal tints-Red currants-Lachen Phipun-Tungu-SceneryAnimals-Poisonous rhododendrons-Fire-wood-Palung-Elevations - Sitong-Kongra Lama-Tibetans-Enter Tibet-Desolate scenery -Plants-Animals - Geology-Cholamoo lakes-Antelopes-Return to Yeumtso-Dr. Campbell lost-Extreme cold-Headaches-Tibetan Dingpun and guard-Arms and accoutrements-Temperature of Yeumtso-Migratory birds-Visit of Dingpun-Yeumtso lakes.

On the 20th of September I ascended to the great Donkia glaciers, east of Momay; the valley is much longer than that leading to the Kinchinjhow glacier, and at 16,000 or 17,000 feet elevation contains four marshes or lakes, alternating with as many transverse moraines that seem to have been deposited where rocks in the bed of the valley obstructed the downward progress of the ancient glacier; hence, when this latter finally retired, it rested at these obstructions, and accumulated there great deposits, which do not cross the valley, but project from each side obliquely into it. The rocks on the floor of the valley are all polished on 
the top, sides, and face looking up the valley, but are rugged on that looking down it: gigantic blocks are poised on some.

Under the red cliff of Forked Donkia the valley becomes very broad, bare, and gravelly, with a confusion of moraines, and turns more northwards. At the angle, the present terminal moraine rises about 800 feet high, and from the summit a most striking scene opened. The ice filling an immense basin, several miles broad and long, formed a low dome, with Forked Donkia on the west, and a serried range of rusty-red scarped mountains, 20,000 feet high, on the north and east, separating large tributary glaciers. Other and loftier tops of Donkia appeared behind these, but I could not recognise the true summit $(23,176$ feet). The surface was very rugged, and so deeply honey-combed that the foot often sank from six to eight inches in crisp wet ice. I proceeded a mile on it, with much more difficulty than on any Swiss glacier; this was owing to the elevation, and the corrosion of the surface into pits and pools of water; the crevasses being but few and distant. I attained an elevation of 18,307 feet; the weather was then very cold, the thermometer fell to $34^{\circ}$, and it snowed heavily after 3 P.s.

On another occasion $I$ ascended, to the north of this, a second spur from Donkia, to 19,000 feet, which abutted on the scarped precipices of that mountain; I had been attracted to the spot by its bright orange-red colour, which I found to be caused by peroxide of iron.

At these great heights the weather was never fine for more than an hour at a time, and thick snow drove 


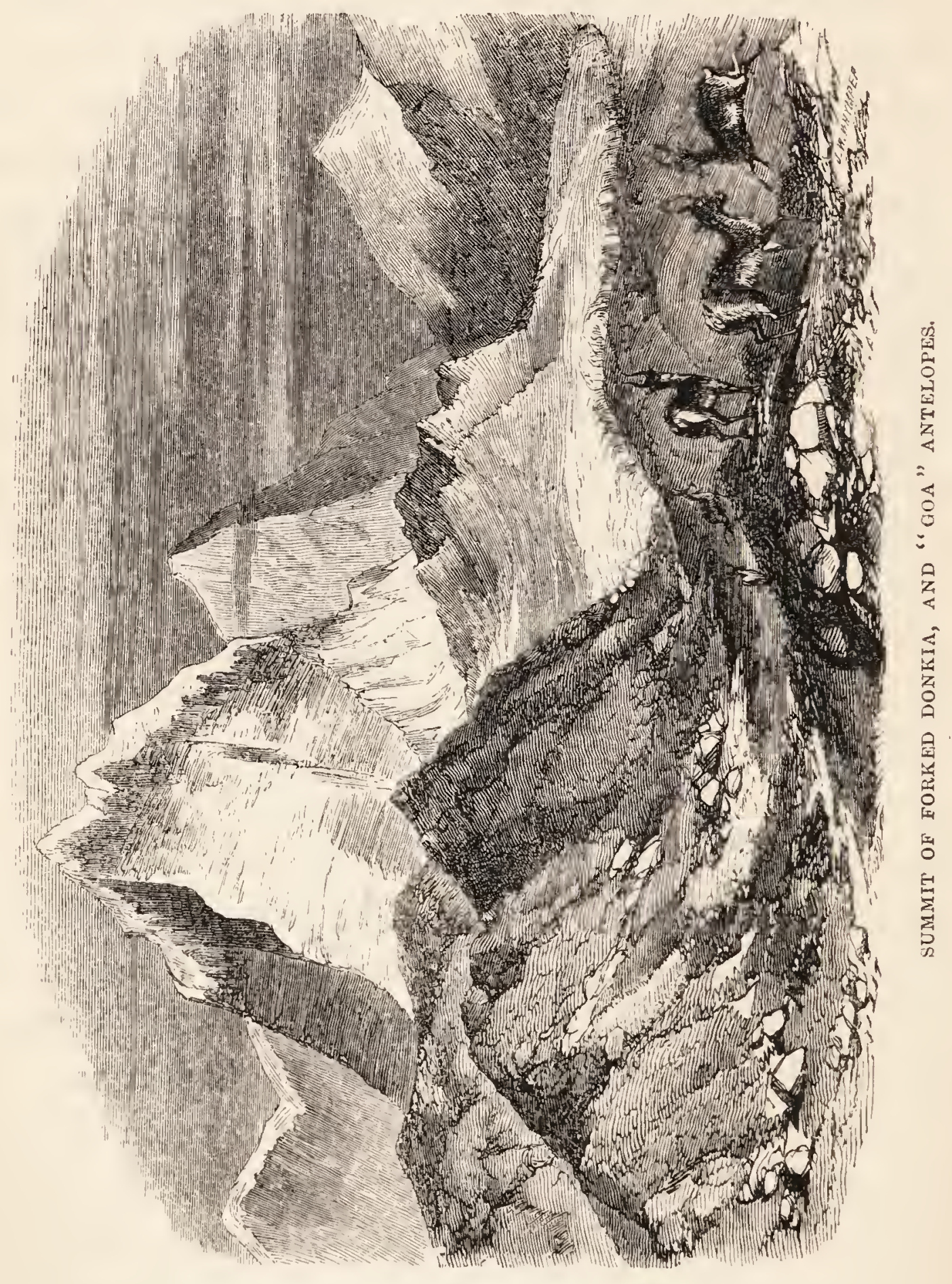


me down on both these occasions. Another time I ascended a third spur from this great mountain, and was overtaken by a heavy gale and thunder-storm, the latter of which is a rare phenomenon; it blew down my tripod and instruments which I had thought securely propped with stones, and the thermometers were broken, but fortunately not the barometer. On picking up the latter, which lay with its top down the hill, a large bubble of air appeared, which I passed up and down the tube, and then allowed to escape; when I heard a rattling of broken glass in the cistern. Having another barometer at my tent, I hastened to ascertain by comparison whether the instrument which had travelled with me from England, and with which I had taken so many thousand observations, were seriously injured: to my delight, however, I found the damage to be very trifling.

The Kinchinjhow spurs are not accessible to so great an elevation as those of Donkia, but they afford finer views over Tibet, across the ridge connecting Kinchinjhow with Donkia.

Broad summits here, as on the opposite side of the valley, are quite bare of snow at 18,000 feet, though where they project as sloping hog-backed spurs from the parent mountain, the snows of the latter roll down on them and form glacial caps, the reverse of glaciers in valleys, but which overflow, as it were, on all sides of the slopes.

On the 18th of September I ascended the range which divides the Lachen from the Lachoong valley, to the Sebolah pass, a very sharp ridge which runs south 
from Kinchinjhow to Chango-Khang; following a yaktrack, which led across the Kinchinjhow glacier, along the bank of the lake, and thence westward up a very steep spur, on which was much ice and snow. At nearly 17,000 feet I passed two small lakes, on the banks of one of which I found bees, a May-fly and gnat; the two latter bred on stones in the water.

The view from the summit commands the whole castellated front of Kinchinjhow, the sweep of the Donkia cliffs to the east, and Chango-Khang's blunt cone of ribbed snow over head, while to the west, across the grassy Palung slopes, rise Chomiomo, the Thlonok mountains, and Kinchinjunga in the distance. The Palung plains, now yellow with withered grass, were the most curious part of the landscape: hemmed in by this range which rises 2000 feet above them, and by the Lachen hills on the east, they appeared a dead level, from which Kinchinjhow reared its head, like an island from the ocean. The black tents of the Tibetans were still there, but the flocks were gone. The broad fosselike valley of the Chachoo was at my feet, with the river winding along its bottom, and its flanks dotted with black juniper bushes.

Throughout September various parties passed my tent at Momay, generally Lamas or traders: the former, wrapped in blankets, wearing scarlet and gilt mitres, usually rode grunting yalks, which were sometimes led by a slave-boy or a mahogany-faced nun, with a broad yellow sheep-skin cap with flaps over her ears, short petticoats, and striped boots. The domestic utensils, pots, pans, and bamboos of butter, tea-churn, 


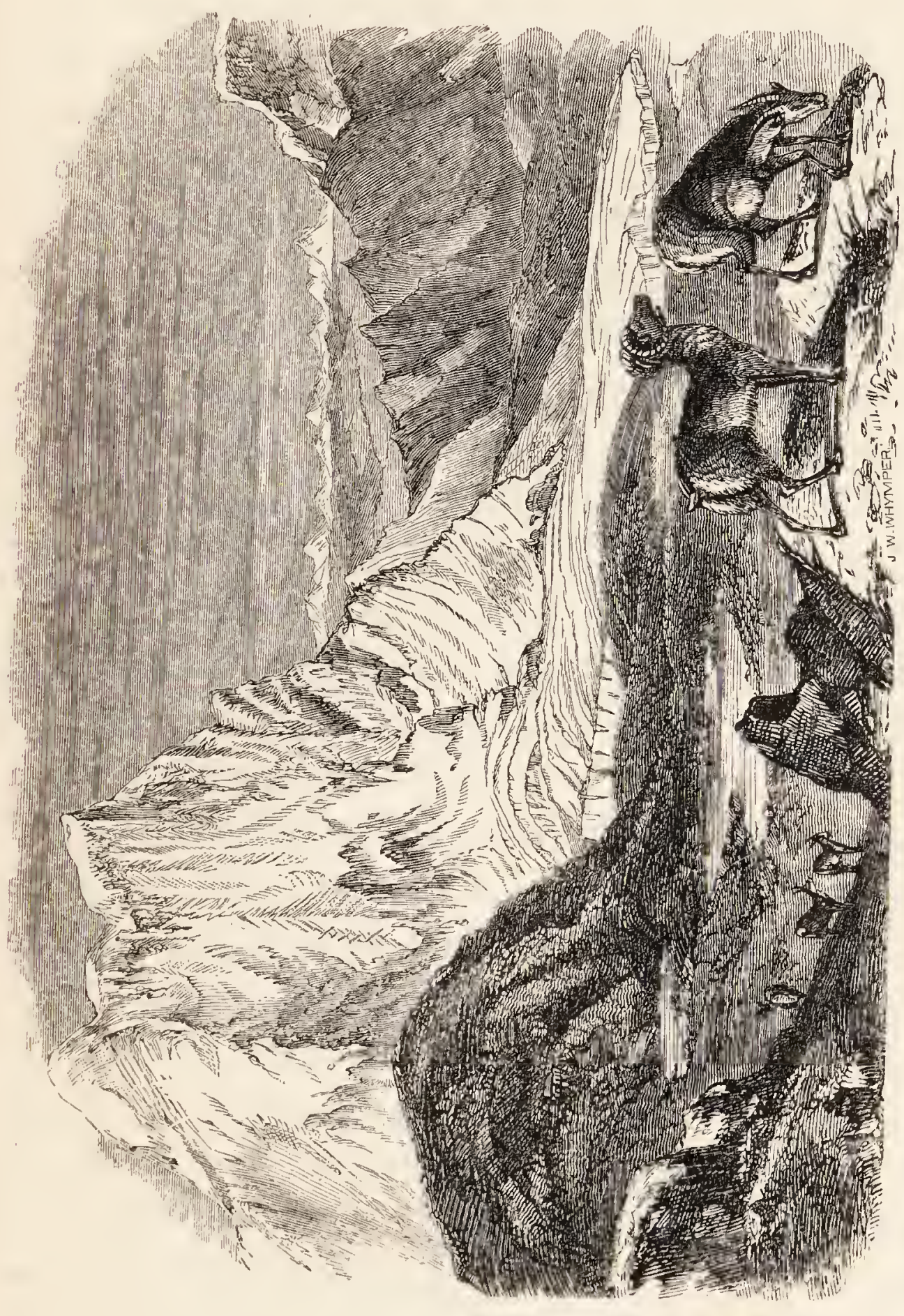

是

본

O

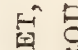

⿶凵

\&

동 웅

点昆

\&

恣

0

艼

点

5 \&

要 of

.

5

员

量

불

I

s

留

둥

됙

8

8

我

5 in

$\circ 5$

哭实

E

48

5

昜先

곡

द

突量

5 
bellows, stools, books, and sacred implements, usually hung rattling on all sides of his holiness, and a sumpter yak carried the tents and mats for sleeping. On several occasions large parties of traders, with thirty or forty yaks laden with planks, passed, and occasionally a shepherd with Tibet sheep, goats, and ponies. I questioned many of these travellers about the courses of the Tibetan rivers; they all agreed in stating the Kambajong or Chomachoo river, north of the Lachen, to be the Arun of Nepal, and that it rose near the Ramchoo lake (of Turner's route). The lake itself discharges either into the Arun, or into the Painomchoo (flowing to the Yaru); but this point I could never satisfactorily ascertain.

The weather at Momay, during September, was generally bad after 11 A.Mr.; little snow or rain fell, but thin mists and drizzle prevailed. The mornings were sometimes fine, cold, and sunny, with a north wind which had blown down the valley all night, and till 9 A.M., when the south-east wind, with fog, came on. Throughout the day a north current blew above the southern; and when the mist was thin, the air sparkled with spiculæ of snow, caused by the cold dry upper current condensing the vapours of the lower. This southern current passes over the tops of the loftiest mountains, ascending to 24,000 feet, and discharging frequent showers in Tibet, as far north as Jigatzi, where, however, violent dry easterly gales are said to be the most prevalent.

The equinoctial gales set in on the 21st, with a falling barometer, and sleet at night; on the $23 \mathrm{rd}$ and 
24th it snowed heavily, and being unable to light a fire at the entrance of my tent, I spent two wretched days, taking observations; on the 25th it cleared, and the snow soon melted.

On first arriving at Momay I experienced the usual sensations accompanying great elevations, but these gradually wore off, and I was more than ever impressed. with the fact that of all the phenomena of climate, the weight of the atmosphere is the most remarkable for its elusion of direct observation, when unaided by instruments. At the level of the sea, a man of ordinary bulk and stature is pressed upon by a superincumbent weight of 30,000 pounds, or $13 \frac{1}{2}$ tons. An inch rise or fall of the barometer shows that this load is lightened or increased, sometimes in a few hours, by nearly 1000 pounds; yet no notice is taken of it, except by the meteorologist, or by the speculative physician, seeking the subtle causes of epidemic and endemic complaints. At Dorjiling ( 7,400 feet elevation), the load is reduced to less than 22,500 pounds, with no appreciable result whatever on the frame, however suddenly it be transported to that elevation. And an observation of my own habits convinced me that I tools the same amount of food, drink, sleep, exercise and work, not only without inconvenience, but without the slightest perception of my altered circumstances. On ascending to 14,000 feet, owing to the greatly diminished supply of oxygen, exercise brings on vertigo and headache; ascending higher still, lassitude and tension across the forehead ensue, with retching, and a sense of weight dragging down the stomach, probably 
due to the dilatation of the air contained in that organ. Such are the all but invariable effects of high elevations; varying with most persons according to the suddenness and steepness of the ascent, the amount and duration of exertion, and the length of time previously passed at great heights. After having lived for some weeks at Momay where I was relieved of upwards of six tons of pressure(!), I have thence ascended several times to 18,500 , and once above 19,000 feet, without any sensations but lassitude and quickness of pulse; but in these instances it required great caution to avoid painful symptoms. Residing at Momay, however, my functions were wholly undisturbed; nor could I detect any quickness of pulse or of respiration when the body was at rest, below 17,000 feet.

Not only is the frame of a transient visitor unaffected (when at rest) by the pressure on his body being reduced from 30,000 to 13,000 pounds, but the Tibetan, born and constantly residing at upwards of 14,000 feet, differs in no respect that can be attributed to diminished pressure, from the native of the level of the sea. The average duration of life, and the amount of food and exercise is the same; eighty year's are rarely reached by either. The Tibetan, too, however inured to cold and great elevations, still suffers when he crosses passes 18,000 or 19,000 feet high, and apparently neither more nor less than I did.

Liebig remarks (in his "Animal Chemistry") that in an equal number of respirations, we consume a larger amount of oxygen at the level of the sea than on a mountain; and it can be shown that under ordinary 
circumstances at Dorjiling, 20.14 per cent less is inhaled than on the plains of India. Yet the chest cannot expand so as to inspire more at once, nor is the respiration appreciably quickened; by either of which means nature would be enabled to make up the deficincy. It is true that it is difficult to count one's own respirations, but the average is considered in a healthy man to be eighteen in a minute; in my own case it is sxteen, an acceleration of which by three or four could not have been overlooked, in the repeated trials I made at Dorjiling; and still less the eight additional inhalstions required at 15,000 feet to make up for the deficiency of oxygen in the air of that elevation.

It his long been surmised that an alpine vegetation may ore some of its peculiarities to the diminished atmospleric pressure; and that the latter being a condition which the gardener cannot supply, he for this reason seldom successfully cultivates such plants. I klow of no foundation for this hypothesis; many plarts, natives of the level of the sea in other parts of the world, and some even of the hot plains of Benal, ascend to 12,000 and even 15,000 feet on the Himlaya, unaffected by the diminished pressure. A grat number of species from low countries may be cultirted, and some have been for ages, at 10,000 to 14,00 feet without change. It is the same with the lower animals; innumerable instances may with ease be adciced of pressure alone inducing no appreciable changt whilst there is absence of proof to the contrary. The phenomena that accompany diminished pressue are the real obstacles to the cultivation of 
alpine plants; of which cold and the excessive climate are perhaps the most formidable. Plants that grow in localities marked by sudden extremes of heat an? cold, are always very variable in stature, habit, and foliage. In a state of nature we say the plants "accommodate themselves to these changes," and so they do within certain limits; but for one that survires of all the seeds that germinate in these inhospitajle localities, thousands die. In our gardens we can neither imitate the conditions of an alpine climate nor offer others suited to the plants of such climates.

On the 28th of the month the Singtam Soubah came up from Yeumtong, to request leave to depart br his home, on account of his wife's illness; and to inform me that Dr. Campbell had left Dorjiling, accompanied (by the Rajah's orders) by the Tchebu Lama. I therefore left Momay on the 30th, to meet him at Choongtam, arriving at Yeumtong the same n'ght, amid heavy rain and sleet.

Autumnal tints reigned at Yeumtong, and the florers had disappeared from its heath-like flat; a snall eatable cherry with a wrinkled stone was ripe, and acceptable in a country so destitute of fruit.* Tlence I descended to Lachoong, on the 1st of October, igain through heavy rain, the snow lying on Tunkra nountain at 14,000 feet. The larch was shedding its leaves, which turn red before they fall, but the anual

* The absence of Vaccinia (whortleberries and cranberries) an catable $R u b i$ (brambles) in the alpine regions of the Himalaya is very rentrable, and they are not replaced by any substitute. With regard to Vocinium, this is the more anomalous, as several species grow in the tmperate regions of Sikkim. 
vegetation was much behind that at 14,000 feet, and so many late flowers had come into blossom, that the place still looked gay and green; the blue climbing gentian (Crawfurdia) now adorned the bushes; this plant would be a great acquisition in English gardens. A Polygonum still in flower here, was in ripe fruit near Momay, 6000 feet higher up the valley.

On the following day I made a long and very fatiguing march to Choongtam, but the coolies were not all able to accomplish it. The backwardness of the flora in descending was even more conspicuous than on the previous day: the jungles, at 7000 feet, being gay with a handsome Cucurbitaceous plant. Crossing the Lachoong cane-bridge, I paid the tribute of a sigh to the memory of my poor dog, and reached my old camping-ground at Choongtam by 10 P. M., having been marching rapidly for twelve hours. My bed and tent came up two hours later, and not before the leeches and mosquitos had taxed me severely. On the 4th of October I heard the nightingale for the first time in the season.

As I expected Dr. Campbell on the following morning, I proceeded down the river to meet him : the whole valley was buried under a torrent or débacle of mud and boulders, and half a mile of its course was dammed up into a deep lake. Amongst the granite boulders brought down by this débacle, I collected some actinolites: but all minerals are extremely rare in the Sikkim Himalaya, and I never heard of a gem or crystal of any size or beauty, or of an ore of any consequence, being found in this country. 
I met my friend on the other side of the mud torrent, and I was truly rejoiced to see him, though he was looking much the worse for his trying journey through the hot valleys at this season; in fact, I know no greater trial of the constitution than the exposure and hard exercise that is necessary in traversing these valleys, below 5000 feet, in the rainy season: delay is dangerous, and the heat, anxiety, and bodily suffering from fatigue, insects and bruises, banish sleep, and urge the restless traveller onward to higher and more healthy regions. . Dr. Campbell had, I found, in addition to the ordinary dangers of such a journey, met with an accident which might have proved serious; his pony having been dashed to pieces by falling over a precipice, a fate he barely escaped himself, by adroitly slipping from the saddle when he felt the animal's foot giving way.

On our way back to Choongtam, he detailed to me the motives that had led to his obtaining the authority of the Deputy-Governor of Bengal (Lord Dalhousie being absent) to his visiting Sikkim. Foremost, was his earnest desire to cultivate a better understanding with the Rajah and his officers. He had always taken the Rajah's part, from a conviction that his Highness was not to blame for the misunderstandings that the Sikkim officers pretended existed between their country and Dorjiling; he had, whilst urgently remonstrating with the Rajah, insisted on forbearance on my part, and had long exercised it himself. In detailing the treatment to which I was subjected, I had not hesitated to express my opinion that the Rajah was more 
compromised by it than his Dewan : Dr. Campbell, on the contrary, knew that the Dewan was the head and front of the whole system of annoyance. In one point of view it mattered little who was in the right; the transaction was a violation of good faith on the part of the Sikkim government towards the British, for which the Rajah, however helpless, was yet responsible. To act upon my representations would have been unjust, and no course remained but for Dr. Campbell to inquire personally into the matter. The authority to do this gave him further the opportunity of becoming acquainted with the country which we were bound to protect, as well by our interest as by treaty, but from which we were so jealously excluded, that should any contingency occur, we were ignorant of what steps to take for defence, and, indeed, of what we were pledged to defend.

On the 6th of October we left Choongtam for my second visit to the Kongra Lama pass, hoping to get round by the Cholamoo lakes and the Donkia pass. As the country beyond the frontier was uninhabited, the Tchebu Lama saw no difficulty in this, provided the Lachen Phipun and the Tibetans did not object. Our great obstacle was the Singtam Soubah, who (by the Rajah's order) accompanied us to clear the r'oad, and give us every facility, but who was very sulky, and undisguisedly rude to Campbell; he was in fact extremely jealous of the Lama, who held higher authority than he did, and who alone had the Rajah's confidence.

Our first day's march up the Lachen valley was of 
about ten miles to one of the river-flats, which was covered with wild apple-trees, whose fruit, when stewed with sugar, we found palatable. The river, though still swollen, was comparatively clear; the rains usually ceasing, or at least moderating, in October.

During the second day's march we were stopped at the Taktoong river by the want of a bridge, which the Singtam Soubah refused to exert himself to have repaired; its waters were, however, so fallen, that our now large party soon bridged it with admirable skill. We encamped the second night at Chateng, and the following day made a long march, crossing the Zemu, and ascending half-way to Tallum Samdong. The alpine foliage was rapidly changing colour; and that of the berberry turning scarlet, gave a warm glow to the mountains above the forest. Lamteng village was deserted; turnips were maturing near the houses, and buckwheat on the slope behind; the latter is a wintercrop at lower elevations, and harvested in April. At Zemu Samdong the willow-leaves were becoming sear and yellow, and the rose-bushes bore enormous scarlet hips, two inches long, and covered with bristles; they were sweet, and rather good eating. Near Tungu (where we arrived on the 9th) the great Sikkim currant was in fruit; the berries are much larger than the English, and of the same beautiful red colour, but bitter and very acid; they are, however, eaten by the Tibetans.

Near the village I found Dr. Campbell remonstrating with the Lachen Phipun on the score of the delays and rude treatment I had received in June and July: 
the man, of course, answered every question with falsehoods; such being the custom of these people; and he produced the Rajah's orders for my being treated with every civility, as a proof that he must have behaved as he ought! The Singtam Soubah, as was natural, hung back, for it was owing to him alone that the orders had been contravened, and the Phipun appealed to the bystanders for the truth of this.

The Phipun (accompanied by his Larpun or subordinate officer) had prepared for us a sumptuous refreshment of tea-soup, which was brewing by the road-side, and in which all animosities were soon washed away. We took up our abode at Tungu in a wooden hut under the great rock, where we were detained for several days by bad weather: I was assured that during all August and September the weather had been uniformly gloomy, as at Momay, though little rain had fallen.

We had much to do in purchasing blankets * for some of the people, and arranging for our journey, to which the Lachen Phipun was favourable, promising us ponies. The vegetation around was wholly changed since my July visit: the rhododendron scrub was verdigris-green from the young leaves which burst in autumn; the jungle was spotted yellow with the withered birch, maple and mountain-ash, and scarlet with berberry bushes; while above, the pastures were yellow-brown with the dead grass, and streaked with snow.

* These were made of goat's wool, teazed into a satiny surface by little teazle-like brushes of bamboo. 
Amongst other luxuries, we procured the flesh of yak calves, which is excellent veal; the Tibetan mutton we generally found dry and stringy.

In these regions many of my goats and kids had died foaming at the mouth and grinding their teeth; and I here discovered the cause to arise from their having eaten the leaves of Rhododendron cinnabarinum, which species alone is said to be poisonous; when used as fuel, it causes the face to swell and the eyes to inflame; of which I observed several instances. As the subject of fire-wood is of every-day interest to the traveller in these regions, I may here mention that the rhododendron woods give poor fires; juniper burns the brightest, and with least smoke. The silver fir, though emitting much smoke, gives a cheerful fire, far superior to larch, spruce, or Abies Brunoniana. At Dorjiling, oak is the common fuel: alder is also good. Chesnut is invariably used for blacksmith's charcoal. Magnolia has a disagreeable odour, and laurel burns very badly. The phenomenon of phosphorescence is very conspicuous on stacks of fire-wood. At Dorjiling during the damp, warm, summer months (May to October), at elevations of 5 to 8000 feet, it may be witnessed every night by walking a few yards in the forest-at least it was so in 1848 and 1849 ; and during my stay there billets of decayed wood were repeatedly sent me by residents, with inquiries as to the cause of their luminosity. It is no exaggeration to say that one does not need to remove from the fireside to see this phenomenon, for if there is a partially decayed log amongst the fire-wood, it is almost sure to glow with 
a pale phosphoric light. A stack of fire-wood, collected near my host's (Mr. Hodgson's) cottage, presented a beautiful spectacle for two months (in July and August), and on passing it at night, my pony was always alarmed by it. The phenomenon invariably accompanies decay, and is common on oak, laurel, birch, and probably other timbers; it equally appears on cut wood and on stumps, but is most frequent on branches lying close to the ground in the wet forests. . I have reason to believe that it spreads with great rapidity from old surfaces to fresh-cut ones. That it is a vital phenomenon, and due to the mycelium of a fungus, I do not in the least doubt, for I have observed it occasionally circumscribed by those black lines which are often seen to bound mycelia on dead wood, and to precede a more rapid decay. I have often tried, but always in vain, to coax it into developing some fungus, by placing it in damp rooms, \&c. When camping in the mountains, I have caused the natives to bring phosphorescent wood into my tent, for the pleasure of watching its soft undulating light, which appears to pale and glow with every motion of the atmosphere: but except in this difference of intensity, it presents no change in appearance night after night. Alcohol, heat, and dryness soon dissipate it; electricity I never tried. It has no odour, and my dog, who had a fine sense of smell, paid no heed when it was laid under his nose.

The weather continuing bad, and snow falling, the country people began to leave for their winter quarters at Lamteng. In the evenings we enjoyed the company 
of the Phipun and Tchebu Lama, who relished a cup of sugarless tea more than any other refreshment we could offer. From them we collected much Tibetan information:- the former was an inveterate smoker, using a pale, mild tobacco, mixed largely with leaves of the small wild Tibetan Rhubarb. Snuff is little used, and is principally procured from the plains of India.

We visited Palung twice, chiefly in hopes that Dr. Campbell might see the magnificent prospect of Kinchinjhow from its plains: the first time we gained little beyond a ducking, but on the second the view was superb; and I caught a glimpse of Kinchinjunga from the neighbouring heights, bearing south-west, and distant forty miles. I also measured barometrically the elevation at the great chait at Palung, and found it 15,620 feet.

The mean temperature at Tungu had fallen from $50^{\circ}$ in July to $41^{\circ}$ : the weather during October, was, however, uniformly cold and misty. Much more rain fell in October at Tungu than at Dorjiling, which is the opposite to what occurs during the rainy season.

October 15th. Having sent the coolies forward with instructions to halt and camp on this side the Kongra Lama pass, we followed them, taking the route by Palung, and thence over the hills to the Lachen, to the east of which we descended, and further up its valley joined the advanced party in a rocky glen, called Sitong, an advantageous camping ground; being sheltered by rocks which ward off the keen blasts: its elevation is 15,370 feet above the sea, and the 
magnificent west cliff of Kinchinjhow towers over it not a mile distant. The afternoon was misty, but at sunset the south-east wind fell, and was immediately succeeded by the biting north return current, which dispelled the fog: hoar-frost sparkled on the ground, and the moon shone full on the snowy head of Kinchinjhow, over which the milky-way and the broad flashing orbs of the stars formed a jewelled diadem.

On the 16th we were up early. I felt very anxious about the prospect of our getting round by Donkia pass and Cholamoo, which would enable me to complete the few remaining miles of my survey of the Teesta river, and which promised immense results in the views I should obtain of the country, and of the geology and botany of these lofty snowless regions. Campbell, though extremely solicitous to obtain permission from the Tibetan guard, (who were waiting for us on the frontier,) was nevertheless bound by his official position to yield at once to their wishes, should they refuse us a passage.

The sun rose on our camp at $7 \cdot 30$ A.M., when the north wind fell; and within an hour afterwards the temperature had risen to $45^{\circ}$. We started on ponies, accompanied by the Lama only, to hold a parley with the 'Tibetans; ordering the rest of the party to follow more leisurely. We had not proceeded far when we were joined by two Tibetan Sepoys, who, on our reaching the pass, bellowed lustily for their companions; when Campbell and the Lama drew up at the chait on Kongra Lama, and announced their wish to confer with their commandant. 
My anxiety was now wound up to a pitch; I saw men with matchlocks emerging from amongst the rocks under Chomiomo, and despairing of permission being obtained, I goaded my pony with heels and stick, and dashed on up the Lachen valley, resolved to make the best of a splendid day, and not turn back till I had followed the river to the Cholamoo lakes. The Sepoys followed me a few paces, but ruming being difficult at 16,000 feet, they soon gave up the chase.

A few miles ride in a north-east direction over an open, undulating country, brought me to the Lachen, flowing westward in a broad, open, stony valley, bounded by Kinchinjhow on the south (its face being as precipitous as that on the opposite side), and on the north by a low range of rocky, sloping mountains, of which the summits were 18,000 to 19,000 feet above the sea. Fnormous erratic blocks strewed the ground, which was sandy or gravelly, and cut into terraces along the shallow, winding river, the green and sparkling waters of which rippled over pebbles, or expanded into lagoons. The already scanty vegetation diminished rapidly, and consisted chiefly of scattered bushes of a dwarf scrubby honeysuckle and tufts of nettle, both so brittle as to be trodden into powder, and the short leafless twiggy Ephedra, a few inches higher. The most alpine rhododendron ( $R$. nivale) spread its small rigid branches close to the ground; the hemispherical Arenaria, another type of sterility, rose here and there, and tufts of forget-me-not, Artemisia, Astragali, and Androsace, formed flat cushions level with the soil. Grass was very scarce, 
but a running wiry sedge bound the sand like that of our English coasts.

A more dismally barren country cannot well be conceived, nor one more strongly contrasting with the pastures of Palung at an equal elevation. The long lofty wall of Kinchinjhow and Donkia presents an effectual barrier to the transmission of moisture to the head of the Lachen valley, which hence becomes a type of such elevations in Tibet. As I proceeded, the soil became still more sandy, chirping under the pony's feet; and where harder it was burrowed by innumerable marmots, foxes, and the "Goomchen," or tailless rat, sounding hollow to the tread, and being so dangerous that I was obliged to dismount and walk.

The upper part of Kinchinjhow is composed of bold ice-capped cliffs of gneiss, and long spurs stretch northwards from it, forming the rounded terraced hills I had seen from Donkia pass. Between these spurs were narrow valleys, at whose mouths stupendous blocks of gneiss rest on rocks of a much later geological formation.

Opposite the most prominent of these spurs the river runs west, forming marshes, which were full of Zannichellia palustris and Ranunculus aquatilis, both English and Siberian plants: the waters were full of a species of shell, and the soil near the edge, which was covered with tufts of short grass, was whitened with effloresced carbonate of soda. Here were some square stone enclosures two feet high, used as pens, and for pitching tents in; within them I gathered some unripe barley. 
Beyond this I recognised a hill of which I had taken bearings from Donkia pass, and a few miles further, on rounding a great spur of Kinchinjhow, I arrived in sight of Cholamoo lakes, with the Donkia mountain rearing its stupendous precipices of rock and ice on the east. My pony was knocked up, and I felt very giddy from the exertion and elevation; I had broken his bridle, and so led him on by my plaid for the last few miles to the banks of the lake; and there, with the pleasant sound of the waters rippling at my feet, I yielded for a few moments to those emotions of gratified ambition which, being unalloyed by selfish considerations for the future, become springs of happiness during the remainder of one's life.

The landscape about Cholamoo lakes is simple in its elements, stern and solemn, and though my solitary situation rendered it doubly impressive to me, still I doubt whether the world contains any scene with more sublime associations than this calm sheet of water, 17,000 feet above the sea, with the shadows of mountains 22,000 to 24,000 feet high, sleeping on its bosom.

There was much short grass about the lake, on which large antelopes and deer were feeding. There were also many slate-coloured hares with white rumps, with marmots and tailless rats. The abundance of animal life was wonderful, compared with the want of it on the south side of Donkia pass, not five miles distant in a straight line! this is partly due to the profusion of carbonate of soda, of which all ruminants are fond, and partly to the dryness of the climate, which is favourable to burrowing quadrupeds. A flock of 
common English teal were swimming in the lake, the temperature of which was $55^{\circ}$.

I had come about fifteen miles from the pass, and arrived at 1 P.N., remaining half an hour. I could not

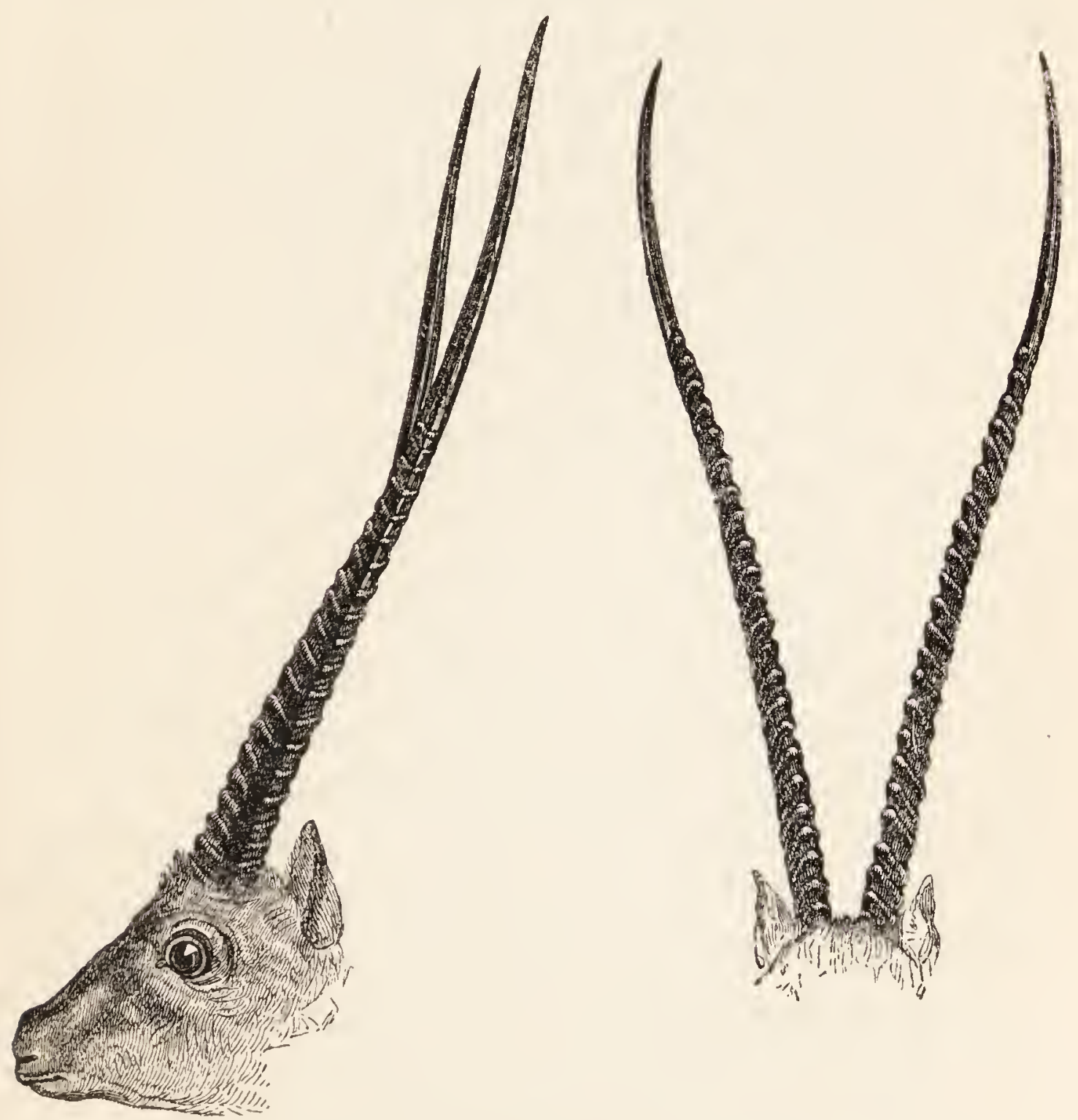

ANTELOPE'S HEAD.

form an idea as to whether Campbell had followed or not, and began to speculate on the probability of having to pass the night in the open air, by the warm side of my steed. Though the sun shone brightly, the wind was bitterly cold, and I arrived at the stone dykes of 
Yeumtso at 3 P.x., quite exhausted with fatigue and headache: I there found, to my great relief, the Tchebu Lama and Lachen Phipun in some alarm at my absence; they thought I was not aware of the extreme severity of the temperature on the north side of the snows, or of the risk of losing my way: they told me that after a long discourse with the Dingpun (or commander) of the Tibetan Sepoys, the latter had allowed all the party to pass; that they themselves had brought on the coolies, who were close behind, but that they had seen nothing of Campbell; of whom the Lama then went in search.

The sun set behind Chomiomo at 5 p.nr., and the wind at once dropped; so local are these violent atmospheric currents, which are caused by the heating of the upper extremities of lofty valleys, and consequent rarefaction of the air. Intense terrestrial radiation immediately follows the withdrawal of the sun's rays, and the temperature sinks rapidly.

Soon after sunset the Lama returned, bringing Campbell; who, having mistaken some glacier-fed lakes at the back of Kinchinjhow for those of Cholamoo, was looking for me. He too had speculated on having to pass the night under a rock, with one plaid for himself and servant; in which case I am sure they would both have been frozen to death, having no pony to lie down beside. He told me that after I had quitted Kongra Lama, leaving him with the Tchebu Lama and Phipun, the Tibetan Dingpun and twenty men came up, and very civilly but formally forbad his crossing the frontier; but that upon explaining his motives, and 
representing that it would save him ten days' journey, the Dingpun had relented, and promised to conduct the whole party to the Donkia pass.

We pitched our little tent in the corner of the cattle pen, and our coolies soon afterwards came up; mine were in capital health, though suffering from headaches, but Campbell's were in a distressing state of illness and fatigue, with swollen faces and rapid pulses, and some were insensible from symptoms like pressure on the brain; these were chiefly Nepalese. The Tibetan Dingpun and his soldiers arrived last of all; he was a droll little object, short, fat, deeply marked with small-pox, swarthy, and greasy; he was robed in a green woollen mantle, and was perched on the back of a yak, which also carried his bedding, and cooking utensils, the latter rattling about its flanks, horns, neck, and every point of support: two other yaks bore the tents of the party. His followers were tall savagelooking fellows, with broad swarthy faces, and their hair in short pig-tails. They wore long-sleeved cloaks, short trousers and boots, all of thick woollen, and felt caps on their heads. Each was armed with a long matchlock slung over his back, with a moveable rest having two prongs like a fork, and a hinge, so as to fold up along the barrel, when the prongs project behind the shoulders like antelope horns, giving the uncouth warrior a droll appearance. A dozen cartridges, each in an iron case, were slung round the waist, and they also carried a long knife, flint, steel, and iron tobacco pipe, pouch, and purse, suspended from a leather girdle. 
The night was fine but intensely cold, and the vault of heaven was very dark, and blazing with stars; the air was electrical, and flash lightning illumined the sky; this was the reflection of a storm that was not felt at Dorjiling, but which raged on the plains of India, beyond the Terai, fully 120 miles, and perhaps 150 , south of our position. No thunder was heard. The thermometer fell to $5^{\circ}$; at sunrise it rose to $10^{\circ}$, and soon after 8 A.Mr. to $33^{\circ}$; till this hour the humidity was great, and a thin mist hung over the frozen surface of the rocky ground; when this dispersed, the air became very dry. The light of the sun, though sometimes intercepted by vapours aloft, was very brilliant.

This being the migrating season, swallows flitted through the air; finches, larches, and sparrows were hopping over the sterile soil, seeking food, though it was difficult to say what. The geese ${ }^{*}$ which had roosted by the river, cackled; the wild ducks quacked and plumed themselves; ouzels and waders screamed or chirped; and all rejoiced as they prepared themselves for the last flight of the year, to the valleys of the southern Himalaya, to the Teesta, and other rivers of the Terai and plains of India.

* An enormous quantity of water-fowl breed in Tibet, including many Indian species that migrate no further north. The natives collect their eggs for the markets at Jigatzi, Giantchi, and Lhassa, along the banks of the Yaru river, Ramchoo, and Yarbru and Dochen lakes. Amongst other birds the Sara, or great crane of India (see "Turner's Tibet," p. 212), repairs to these enormous elevations to breed. The fact of birds characteristic of the tropics dwelling for months in such climates is a very instructive one, and should be borne in mind in our speculations upon the climate supposed to be indicated by the imbedded bones of birds. 
The Dingpun paid his respects to us in the morning, wearing, besides his green cloak, a white cap with a green glass button, denoting his rank; he informed us that he had written to his superior officer at Kambajong, explaining his motives for conducting us across the frontier, and he drew from his breast a long letter, written on Daphne paper, the ends of which were tied with floss silk, with a large red seal; this he pompously delivered, with whispered orders, to an attendant, and sent him off. He admired our clothes extremely, and then my percussion gun, the first he had seen; but above all he admired rum and water, which he drank with intense relish, leaving a mere sip for his comrades at the bottom of his little wooden cup, which they emptied, and afterwards licked clean, and replaced in his breast for him. We prepared a large basin full of very weak grog for his party, who were all friendly and polite; and having made us the unexpected offer of allowing us to rest ourselves for the day at Yeumtso, he left us, and practised his men at firing at a mark, but they were very indifferent shots.

I ascended with Campbell to the lake he had visited on the previous day, about 600 or 800 feet above Yeumtso : it is a mile and a half long, and occupies a large depression between two rounded spurs, being fed by glacier's from Kinchinjhow.

The ice on the cliffs and summit of Kinchinjhow

* All Tibetans admire and value English broad-cloth beyond any of our products. Woollen articles are very familiar to them, and warm clothing is one of the first requisites of life.

VOL. II. 
was much greener and clearer than that on the south face (opposite Palung); and rows of immense icicles hung from the cliffs. A conferva grew in the waters of the lake, and short, hard tufts of sedge on the banks, but no other plants were to be seen. Brahminee geese, teal, and widgeon, were swimming in the waters, and a beetle was coursing over the wet banks; finches and other small birds were numerous, eating the sedgeseeds, and picking up the insects. No view could be obtained to the north, owing to the height of the mountains on the north flank of the Lachen.
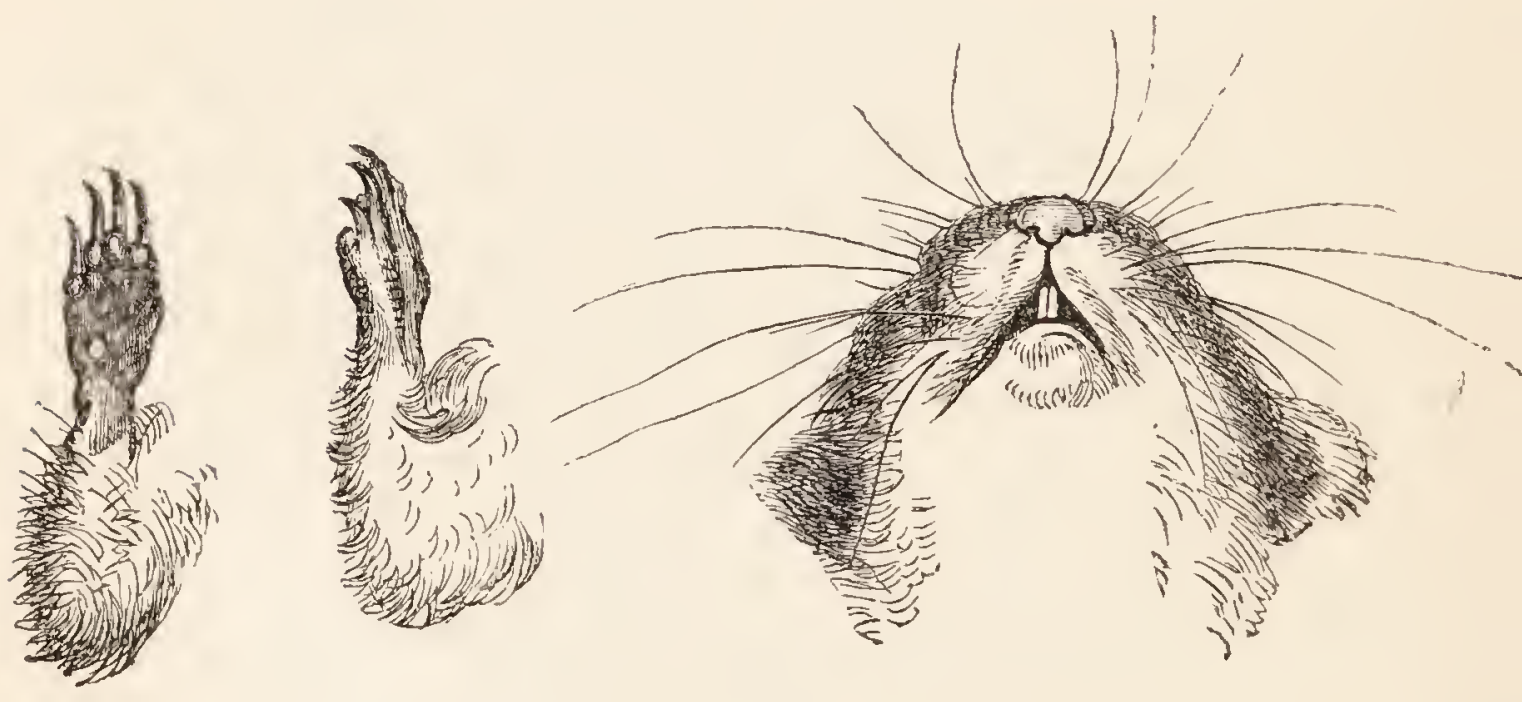

HEAD AND FEEF OF TIBLT MARMOT. 


\section{CHAPTER XXIV.}

Ascent of Bhomtso-View of snowy mountains-Chumulari-Arun river -Jigatzi-Lhassa-Dingcham province of Tibet-Misapplication of term "Plain of Tibet"-Sheep, flocks of-Crops-Probable elevation of Jigatzi-Yaru-Tsampu river-Tame elephants-Wild horsesCholamoo lakes-Effects of great elevation-Ascent of DonkiaMoving piles of debris-Cross Donkia pass-Second visit to Momay Samdong-Descent to Yeumtong-Lachoong-Retardation of regetation-Jerked meat-Fish-Lose a thermometer-Lepcha lad sleeps in hot spring - Keadom - Bucklandia - Arrive at Choongtam Mendicant-Meepo-Lachen-Lachoong river-Wild grape-Virulent nettle.

Is the afternoon we crossed the valley, and, after fording the river, ascended Bhomtso. Some stupendous boulder's from Kinchinjhow are deposited in a broad sandy track on the north bank, by ancient glaciers, which once crossed this valley from Kinchinjhow.

The ascent was alternately over steep rocky slopes, and broad shelf-like flats; many more plants grew here than I had expected, in inconspicuous scattered tufts.

Bhomtso is 18,590 feet above the sea : it presented an infinitely more extensive prospect than I had ventured to anticipate, commanding all the most important Sikkim, North Bhotan, and Tibetan mountains, including Kinchinjunga and Chumulari. Due south, across the sandy valley of the Lachen, Kinchin- 
jhow reared its long and rugged precipices, and under its cliffs lay the lake to which we had walked in the morning: beyond Kongra Lama were the Thlonok mountains, where I had spent the month of June; with Kinchinjunga in the distance. Westward Chomiomo rose abruptly to 22,000 feet elevation. To the east of Kinchinjhow were the Cholamoo lakes, with the rugged mass of Donkia stretching continuously southwards to Forked Donkia, which overhung Momay Samdong.

A long sloping spur sweeps from the north of Donkia to Bhomtso, rising to a height of more than 20,000 feet without snow. Over this spur the celebrated Chumulari peeps, from its isolated position and sharpness looking low and small; it appeared quite near, though thirty-nine miles distant.

North-east of Chumulari, and far beyond it, are several ranges of very much loftier mountains, which terminated the view of the snowy Himalaya; the distance embraced being fully 150 miles, and perlaps much more. Of one of these eastern masses I afterwards took bearings and angular heights from the Khasia momtains, in Bengal, upwards of 200 miles south-east of its position.

Turning to the northward, a singular contrast was presented: the broad sandy valley of the Arun lay a few miles off, and perhaps 1,500 feet below me; low brown and red ridges, 18,000 to 19,000 feet high, of stony sloping mountains with rocky tops, divided its feeder's, which appeared to be dry, and to occupy flat sandy valleys. For thirty miles north not a particle of snow was to be seen; beyond that, rugged purple- 
flanked and snowy-topped mountains girdled the horizon, appearing no nearer than they did from the Donkia pass, and their angular heights and bearings being almost the same as from that point of view. The nearer of these are said to form the Kiang-lah chain, the furthest I was told by various authorities are in the salt districts north of Jigatzi.

To the north-east was the lofty region traversed by Turner on his route by the Ramchoo lakes to Teshoo Loombo; its elevation may be 17,000 feet above the sea. Beyond it a gorge led through rugged mountains, by which the Painom river flows north-west to the Yaru; and at an immense distance to the north-east were the Khamba mountains, a long blue range, which divides the Lhassan or " $U$ " from the "T'sang" or Jigatzi province of Tibet; it appeared fully 100 miles off, and was probably much more; and though so lofty as to be heavily snowed throughout, was much below the horizon-line of Bhomtso ; it is crossed on the route from Sikkim to Lhassa, and is considered very lofty, from affecting the breathing.

But the mountains which appeared both the highest and the most distant on the northern landscape, were those I described when at Donkia, as being north of Nepal, and beyond the Arun river. Both Dr. Campbell and I made repeated estimates of their height and distance by the eye; comparing their size and snow-level with those of the mountains near us, and assuming 4000 to 5000 feet as the minimum height of their snowy cap, this would give them an elevation of 23,000 to 25,000 feet. An excellent telescope brought out no 
features on their flanks not visible to the naked eye, and by the most careful levellings with the theodolite, they were depressed below the horizon of Bhomtso, whence the distance must be above 100 miles.

The transparency of the pale blue atmosphere of these lofty regions can hardly be described, nor the clearness and precision with which the most distant objects are projected against the sky. From having afterwards measured peaks 210 miles distant from the Khasia mountains, I feel sure that I underrated the estimates made at Bhomtso, and I have no hesitation in saying, that the mean elevation of the sparinglysnowed * watershed between the Yaru and Arun will be found to be greater than that of the snowy Himalaya south of it, and to follow the chain rumning from Donkia, north of the Arun, along the Kiang-lah mountains, towards the Nepal frontier, at Tingri Maidan. No part of that watershed perhaps rises so high as 24,000 feet,but its lowest elevation is probably nowhere under 18,000 feet.

This broad belt of lofty country, north of the snowy Himalaya, is the Dingcham province of Tibet, and

* Were the snow-level in this part of Tibet country as low as it is in Sikkim, the whole from Donkia almost to the Yaru-Tsampu river would be everywhere intersected by glaciers and other impassable barriers of snow and ice, for a breadth of fifty miles, and the country would have no parallel for amount of snow beyond the Polar circles. It is impossible to conjecture what would have been the effects on the climate of northern India and central Asia under these conditions. When, however, we reflect upon the evidences of glacial phenomena that abound in all the Himalayan valleys at and above 9000 feet elevation, it is difficult to avoid the conclusion that such a state of things once existed, and that at a seologically very recent period. 
skirts the frontier of Sikkim, Bhotan, and Nepal. It gives rise to all the Himalayan rivers, and its mean elevation is probably 15,000 feet: its general appearance, as seen from greater heights, is that of a much less mountainous country than the snowy and wet Himalayan regions; this is because its mean elevation is so enormous, that ranges of 20,000 to 22,000 feet appear low and insignificant upon it. The absence of forest and other obstructions to the view, the breadth and flatness of the valleys, and the undulating character of the lower ranges that traverse its surface, give it a comparatively level appearance, and suggest the term "plains" to the Tibetan, when comparing his country with the complicated ridges of the deep Sikkim valleys. Here one may travel for many miles without rising or falling 3000 feet, yet never descending below 14,000 feet, partly because the flat winding valleys are followed in preference to exhausting ascents, and partly because the passes are seldom more than that elevation above the valleys; whereas, in Sikkim, rises and descents of 6000, and even 9000 feet, are met with in passing from valley to valley, sometimes in one day's march.

'The swarthy races of Dingcham are an honest, hospitable, and very hardy people, differing from the northern Tibetans chiefly in colour, and in invariably wearing the pigtail, which MM. Huc and Gabet assure us is not usual in Lhassa.* They are a pastoral race,

* Amongst Lhassan customs alluded to by these travellers, is that of the women smearing their faces with a black pigment, the object of which they affirm to be that they may render themselves odious to the male sex, and thus aroid temptation. The custom is common enough, but the 
and Campbell saw a flock of 400 hornless sheep, grazing on short sedges and fescue-grass, in the middle of October, at 18,000 feet above the sea. An enormous ram attended the flock, whose long hair hung down to the ground; its back was painted red.

There is neither tree nor shrub in this country; and, with the exception of a very little wheat (which seldom ripens), and occasionally peas, barley, turnips, and radishes are, I believe, the only crops. Other legumes, cabbages, \&c., are cultivated in the sheltered valleys of the Yaru feeders, where great heat is reflected from the rocks; and there also stunted trees grow, as willows, walnuts, poplars, and perhaps ashes; all of which, however, are said to be planted, and scarce. Even at Teshoo Loombo and Jigatzi buckwheat is a rare crop, and only a prostrate very hardy kind is grown. Clay teapots and pipkins are the most valuable exports to Sikkim from the latter city, next to salt and soda. Jewels and woollen cloaks are also exported, the latter especially from Giantchi, which is famous for its woollen fabrics and mart of ponies.

Digarchi, Jigatzi (or Shigatzi-jong, the fort of Shigatzi), is the capital of the "Tsang" province, and Teshoo Loombo is the neighbouring city of temples and monasteries, the ecclesiastical capital of Tibet,

real object is to preserve the skin, which the dry cold wind peels from the face. The pigment is mutton-fat, blackened, according to Tchebu Lama, with catechu and other ingredients; but I believe more frequently by the dirt of the face itself. I fear I do not slander the Tibetan damsels in saying, that personal cleanliness and chastity are both lightly esteemed amongst them; and as the Lama naively remarked, when questioned on the subject, "the Tibetan women are not so different from those of other countries as to wish to conceal what charms they possess." 
and the abode of the grand (Teshoo) Lama, or everliving Boodh. Whether we estimate this man by the number of his devotees, or the perfect sincerity of their worship, he is without exception the most honoured being living in the world.

Of the Iaru liver at Jigatzi, which all affirm becomes the Burrampooter in Assam, I have little information to add to Turner's description : it is sixty miles north of Bhomtso, and I assume its elevation there to be 1314,000 feet; it approaches the Nepal frontier west of Tingri, and sweeping to the northward turns south to Jigatzi, whence it makes another and greater bend to the north, and again turning south flows west of Lhassa, receiving the Kechoo river from that holy city. From Jigatzi it is said to be navigable to near Lhassa by skin and plank-built boats. Thence it flows southeast to the Assam frontier, and while still in Tibet, is said to enter a warm climate, where tea, silk, cotton and rice are grown. Of its course after entering the Assam Himalaya little is known, and in answer to my enquiries why it had not been followed, I was always told that the country through which it flowed was inhabiter by tribes of savages, who live on snakes and vermin, and are fierce and warlike. These are no doubt the Singpho, Bor and Bor-abor tribes who inhabit the mountains of Upper Assam. A travelling mendicant was once sent to follow up the Dihong to the Burrampooter, under the joint auspices of $\mathrm{Mr}$. Hodgson and Major Jenkins, the commissioner of Assam; but the poor fellow was speared on the frontier by these savages. The concurrent testimony of the 
Assamese, that the Dihong is the Yaru, on its southern course to become the Burrampooter, renders this point as conclusively settled as any resting on mere oral evidence is likely to be.

Lhassa, as all agree, is at a much lower elevation than Jigatzi; and apricots (whose ripe stones Dr. Campbell procured for me) and walnuts are said to ripen there, and the Dama or Himalayan furze (Caragana), is said to grow there. The Bactrian camel also thrives and breeds at Lhassa, together with a small variety of cow (not the yak), both signs of a much more temperate climate than Jigatzi enjoys. It is, however, a remarkable fact, that there are two tame elephants near the latter city, kept by the Teshoo Lama. They were taken thither through Bhotan; and I have been informed that they have become clothed with long hair, owing to the cold of the climate; but Tchebu Lama contradicted this, adding, that his countrymen were so credulous, that they would believe blankets grew on the elephants' backs, if the Lamas told them so.

A kind of wild ass, the Equus Hemionus of Pallas, the untameable Kiang of Tibet, abounds in Dingcham, and we saw several. It resembles the ass more than the horse, from its size, heavy head, small limbs, thin tail, and the stripe over the shoulder. The flesh is eaten and much liked. The Kiang-lah mountains are so named from their being a great resort of this creature. It differs widely from the wild ass of Persia, Sind, and Beloochistan, but is undoubtedly the same as the Siberian animal.

No village or house is seen throughout the extensive 
area over which the eye roams from Bhomtso, and the general character of the desolate landscape was similar to that which I have described as seen from Donkia pass. The wild ass grazing with its foal on the sloping downs, the hare bounding over the stony soil, the antelope scouring the sandy flats, and the fox stealing along to his burrow, are all desert and Tartarian types of the animal creation. The shrill whistle of the marmot alone breaks the silence of the scene, recalling the snows of Lapland to the mind; while the kite and raven wheel through the air, with as steady a pinion as if that atmosphere possessed the same power of resistance that it does at the level of the sea. Still higher in the heavens, long black V-shaped trains of wild geese cleave the air, shooting over the glaciercrowned top of Kinchinjhow, and winging their flight in one day, perhaps, from the Yaru to the Ganges, over 500 miles of space, and through 22,000 feet of elevation. One plant alone, a yellow lichen (Borrera), is found at this height, and that only as a visitor; for, Tartar-like, it migrates over these lofty slopes and ridges, blown about by the violent winds. I found a small beetle on the very top, probably blown up also, for it was a flower-feeder, and seemed benumbed with cold.

Every night that we spent in Tibet, we enjoyed a magnificent display of sumbeams converging to the east, and making a false sun-set. As the sun set, broad purple beams rose from a dark, low, leaden bank on the eastern horizon, and spreading up to the zenith, covered the intervening space: they remained from 
fifteen to twenty minutes, fading gradually into the blackness of night. I looked in vain for the beautiful lancet beam of the zodiacal light; its position was obscured by Chomiomo.

On the 18th of October we had another brilliant morning, after a cold night, the temperature having fallen to $4^{\circ}$. I took the altitude of Yeumtso by carefully boiling two thermometers, and the result was 16,279 feet, the barometrical observations giving 16,808 feet. Before leaving I removed a thermometer sunk three feet in the gravelly soil, which showed a temperature of $43^{\circ}$, which is $12 \frac{3}{4}^{\circ}$ above the mean temperature of the two days we camped here.

This accumulated heat in the upper strata of soil must have a very powerful effect upon vegetation, preventing the delicate rootlets of shrubs from becoming frozen, and preserving vitality in the more fleshy roots, such as those of the large rhubarbs and small orchids, whose spongy cellular tissues would, no doubt, be ruptured by severe frosts. To the burrowing rodents, the hares, marmots, and rats, which abound at 15,000 to 17,000 feet in Tibet, this phenomenon is even more conspicuously important; for were the soil in winter to acquire the mean temperature of the air, it would take very long to heat after the melting of the snow, and indeed the latter phenomenon would be greatly retarded. The rapid development of vegetation after the disappearance of the snow, is no doubt also proximately due to the heat of the soil, quite as much as to the increased strength of the sun's direct rays in lofty regions. 
This result, which at first sight appears anomalous, is in accordance with what I have observed elsewhere, namely that the mean temperature of the soil in India, at two or three feet depth, is almost throughout the year above that of the surrounding atmosphere.

Our fires were made of dry yak droppings, which soon burn out with a fierce flame, and much black smoke; they give a disagreeable taste to whatever is cooked with them.

Having sent the coolies forward to Cholamoo lake, we re-ascended Bhomsto, to verify my observations. As on the previous occasion, a violent dry north-west wind blew, peeling the skin from our faces, loading the air with grains of sand, and rendering theodolite observations very uncertain; besides injuring all my instruments, and exposing them to great risk of breakage.

The Tibetan Sepoys did not at all understand our ascending Bhomtso a second time; they ran after Campbell, who was ahead on a stout pony, girding up their long garments, bracing their matchlocks tight over their shoulders, and gasping for breath at every step, the long horns of their muskets bobbing up and down as they toiled amongst the rocks. When I reached the top I found Campbell seated behind a little stone wall which he had raised to keep off the violent wind, and the uncouth warriors in a circle round him, puzzled beyond measure at his admiration of the view. My instruments perplexed them extremely, and in crowding round me, they broke my azimuth compass. They left us to ourselves when the 
fire I made to boil the thermometers went out, the wind being intensely cold. I had given my barometer to one of Campbell's men to carry, who not coming up, the latter went to search for him, and found him on the ground quite knocked up and stupified by the cold, and there, if left alone, he would have lain till overtaken by death.

We descended in the afternoon, and it became dark before we reached the Cholamoo lake, where we lost our way amongst glaciers, moraines, and marshes. We expected to have seen the lights of the camp, but were disappointed, and as it was freezing hard, we began to be anxious, and shouted till the echos of our voices against the opposite bank were heard by Tchebu Lama, who met us in great alarm for our safety. Our camp was pitched some way from the shore, on a broad plain, 16,900 feet above the sea. A cold wind descended from Donkia; yet, though more elevated than Yeumtso, the climate of Cholamoo, from being damper and misty, was milder.

The coolies of Dr. Campbell's party were completely knocked up by the rarified air; they had taken a whole day to march here from Yeumtso, scarcely six miles, and could eat no food at night. A Lama of our party offered up prayers to Kinchinjhow for the recovery of a stout Lepcha lad who showed no signs of animation, and had all the symptoms of serous apoplexy. The Lama perched a saddle on a stone, and burning incense before it, scattered rice to the winds, involing Kinchin, Donkia, and all the neighbouring peaks. A strong dose of 
calomel and jalap, which we poured down the sick lad's throat, contributed materially to the success of these incantations.

All diseases are attributed by the Tibetans to the four elements, who are propitiated accordingly in cases of severe illness. The winds are invoked in cases of affections of the breathing; fire in fevers and inflammations; water in dropsy, and diseases whereby the fluids are affected; and the God of earth when solid organs are diseased, as in liver complaints, rheumatism, \&c. Propitiatory offerings are made to the deities of these elements, but never sacrifices.

The Tibetan Sepoys were getting tired of our delays, which so much favoured my operations; but though showing signs of impatience and sulkiness, they behaved well to the last; taking the sick man to the top of the pass on their yaks, and assisting all the party: nothing, however, would induce them to cross into Sikkim, which they considered as "Company's territory."

Before proceeding to the pass, I reascended Donkia to upwards of 19,000 feet, vainly hoping to get a more distant view, and other bearings of the Tibetan mountains. The ascent was over enormous piles of loose rocks split by the frost, and was extremely fatiguing. I reached a peak overhanging a steep precipice, at whose base were small lakes and glaciers, from which flowed several sources of the Lachen, afterwards swelled by the great affuent from Cholamoo lake. A few rocks projected at the very summit, with frozen snow amongst them, beyond which the ice and 
precipices rendered it impossible to proceed: but though exposed to the north, there was no perpetual snow in the ordinary acceptation of the term, and an arctic European lichen (Lecidea oreina) grew on the top, so faintly discolouring the rocks as hardly to be detected without a magnifying-glass.

I descended obliquely, down a very steep slope, over upwards of a thousand feet of débris, the blocks on which were so loosely poised on one another, that it was necessary to proceed with the utmost circumspection, for I was alone, and a false step would almost certainly have been followed by breaking a leg. The alternate freezing and thawing of rain amongst these masses, must produce a constant downward motion in the whole pile of débris (which was upwards of 2000 feet high), and may account for the otherwise unexplained phenomenon of continuous shoots of angular rocks reposing on very gentle slopes in other places.

The north ascent to the Donkia pass is by a path well selected amongst immense angular masses of rock, and over vast piles of débris. I arrived at the top at 3 P.x., thoroughly fatigued, and found two of my faithful Lepcha lads nestling under a rock with my theodolite and barometers, having been awaiting my arrival in the biting wind for three hours. My pony stood there too, the picture of patience, and laden with minerals. After repeating my observations, I proceeded to Momay Samdong, where I arrived after dusk. I left a small bottle of brandy and some biscuits with the lads, and it was well I did so, for the pony knocked up before reaching Momay, and rather than leave 
my bags of stones, they passed the night by the warm flank of the beast, under a rock at 18,000 feet elevation, without other food, fire, or shelter.

I found my companion encamped at Momay, on the spot I had occupied in September; he had had the utmost difficulty in getting his coolies on, as they threw down their light loads in despair, and lying with their faces to the ground, had to be roused from a lethargy that would soon have been followed by death.

We rested for a day at Momay, and on the 20th, attempted to ascend to the Donkia glacier, but were driven back by a heavy snow-storm. The scenery presented a wide difference to that we had left; snow lying at 16,500 feet, whereas immediately to the north of the same mountain there was none at 19,000 feet.

We descended to Yeumtong in a cold drizizle, arriving by sunset and remained through the following day, hoping to explore the lower glacier, on the opposite side of the valley; which, however, the weather entirely prevented. I have before mentioned that in descending in autumn from the drier and more sunny rearward Sikkim valleys, the regetation is found to be most backward in the lowest and dampest regions. On this occasion, I found asters, grasses, polygonums, and other plants that were withered, brown, and seeding at Momay (14,000 to 15,000 feet), at Yeumtong (12,000 feet) green and unripe; and 2000 feet lower still, at Lachoong, the contrast was even more marked. 'Thus the short backward spring and summer of the Arctic zone are overtaken by an 
early and forward seed-time: so far as regards the effects of mean temperature, the warmer station is in autumn more backward than the colder. This is everywhere recognisable in all natural orders, some of which I have on the same day gathered in ripe fruit at 13,000 feet; and found still in flower at 9000 feet. The brighter skies and more powerful and frequent solar radiation at the greater elevations, account for this apparent inversion of the order of nature.

I was disappointed at finding the rhododendron seeds still immature at Yeumtong, for I was doubtful whether the same kinds might be met with at the Chola pass, which I had yet to visit; besides which, their tardy maturation threatened to delay me for an indefinite period in the country. Viburnum and Lonicera, however, were ripe and abundant; the fruits of both are considered poisonous in Europe, but here the black berries of a species of the former are eatable and agreeable; as are those of a Gualtheria, which are pale blue. Except these, and the cherry, there are no other autumnal fruits above 10,000 feet: brambles, strange as it may appear, do not ascend beyond that elevation in the Sikkim Himalaya, though so abundant below it, both in species and individuals, and though so typical of northern Europe.

At Lachoong we found all the yaks that had been grazing till the end of September at the higher elevations; and the Phipun presented our men with one of a gigantic size, and proportionally old and tough. The Lepchas slaughtered it with arrows, and feasted on the flesh and entrails, singed and fried the skin, 
and made soup of the bones, leaving nothing but the horns and hoofs. Having a fine day, they prepared some as jerked meat, cutting it into thin strips, which they dried on the rocks. This is a very common and favourite food in Tibet, and I found it palatable, but on the other hand, the dried saddles of mutton, of which they boast so much, taste so strongly of tallow, that I found it impossible to swallow a morsel of them.

Raw, dried, and split fish are abundantly cured (without salt) in Tibet: they are caught in the Yaru and great lakes of Ramchoo, Dobtah, and Yarbru, and are chiefly carp, and allied fish, which attain a large size. It is one of the most remarkable facts in the zoology of Asia, that no trout or salmon inhabit any of the rivers that débouche into the Indian Ocean (the so-called Himalayan trout is a species of carp). This widely distributed natural order of fish (Salmonide) is however, found in the Oxus, and in all the rivers of central Asia that flow north and west. The central Himalayan rivers often rise in Tibet from lakes full of fish, but have none (at least during the rains) in that rapid part of their course from 10,000 to 14,000 feet elevation; below that fish abound, but I believe invariably of different species from those found at the sources of the same rivers. The nature of the tropical ocean into which all the Himalayan rivers débouche, is no doubt the proximate cause of the absence of Salmonida.

We stayed two days at Lachoong, two of my lads being again laid up with fever; one of them had been similarly attacked at the same place nearly two months 
before; the other had been repeatedly ill since June, and at all elevations. Both cases were returns of a fever caught in the low unhealthy valleys some months previously, and excited by exposure and hardship.

I here found that I had lost a thermometer for high temperatures, owing to a hole in the bag in which my attendant carried those of my instruments which were in constant use. It had been last used at the hot springs of the Kinchinjhow glacier; and the poor lad was so concerned at his mishap, that he came to me soon afterwards, with his blanket on his back and a few handfuls of rice in a bag, to make his salaam before setting out to search for it. There was not a single inhabitant between Lachoong and that dreary spot, and strongly against my wish he started, without a companion. Three days afterwards he overtook us at Keadom, radiant with joy at having found the instrument: he had gone up to the hot springs, and rainly sought around them that evening; then rather than lose the chance of a day-light search on his way back, he had spent the cold October night in the hot water, without fire or shelter, at 16,000 feet above the sea. Next morning his search was again fruitless; and he was returning disconsolate, when he descried the brass case glistening between two planks of the bridge, crossing the river at Momay, over which torrent the instrument was suspended. The Lepchas are generally considered timorous of evil spirits, and especially averse to travelling at night, even in company. However little this gallant lad may have been given to superstition, he was nevertheless a 
Lepcha, born in a warm region, and had never faced the cold till he became my servant; and it required a stout heart and an honest one, to spend a night in so awful a solitude as that which reigns around the foot of the Kinchinjhow glacier.

The villagers at Keadom, where we slept on the 26th, were busy cutting the crops of millet, maize, and Amaranthus. A girl who, on my way down the previous month, had observed my curiosity about a singular variety of the maize, had preserved the heads on their ripening, and now brought them to me. The peaches were all gathered, and though only half ripe, were better than Dorjiling produce. A magnificent tree of Bucklandia, one of the most beautiful evergreens in Sikkim, grew near this village; it had a trunk twenty-one feet seven inches in girth, at five feet from the ground, and was unbranched for forty feet.* Ferns and the beautiful air-plant Cologyne Wallichii grew on its branches with other orchids, while Clematis and Stauntonia climbed the trunk. Such great names (Buckland, Staunton; and Wallich) thus brought before the traveller's notice, never fail to excite lively and pleasing emotions; it is the ignorant and unfeeling alone who can ridicule the association of the names of travellers and naturalists with those of animals and plants.

We arrived at Choongtam (for the fourth time) at

* This superb tree is a great desideratum in our gardens; I believe it would thrive in the warm west of England. Its wood is brown, and not valuable as timber, but the thick, bright, glossy, evergreen foliage is particularly handsome, and so is the form of the crown. 
noon, and took up our quarters in a good house near the temple. The autumn and winter flowering plants now prevailed here, such as Labiatæ, which are generally late at this elevation; and grasses, which, though rare in the damp forest regions, are so common on these slopes that I here gathered twenty-six kinds. I spent a day here in order to collect seeds of the superb rhododendrons which I had discovered in May, growing on the hills behind. The ascent was now difficult, from the length of the wiry grass, which rendered the slopes so slippery that it was impossible to ascend without holding on by the tussocks.

A ragged Tibetan mendicant (Phud) was amusing the people: he put on a black mask with cowrie shells for eyes, and danced uncouth figures with a kind of heel and toe shuffle, in excellent time, to rude Tibetan songs of his own; for this he received ample alms, which a little boy collected in a wallet. These vagrants live well upon charity; they bless, curse, and transact little affairs of all kinds up and down the valleys of Sikkim and Tibet; this one dealt in red clay teapots, sheep and puppies.

We found Meepo at Choongtam: I had given him leave (when here last) to go back to the Rajah, and to visit his wife; and he had returned with instructions to conduct me to the Chola and Yakla passes in Eastern Sikkim. These passes, like that of Tunkra, lead over the Chola range to that part of Tibet which is interposed betwen Siklim and Bhotan. My road lay past the Rajah's residence, which we considered very fortunate, as apparently affording Campbell an oppor- 
tunity of a conference with his highness, for which both he and the Tchebu Lama were most anxious.

On our way down the Lachen-Lachoong, we found

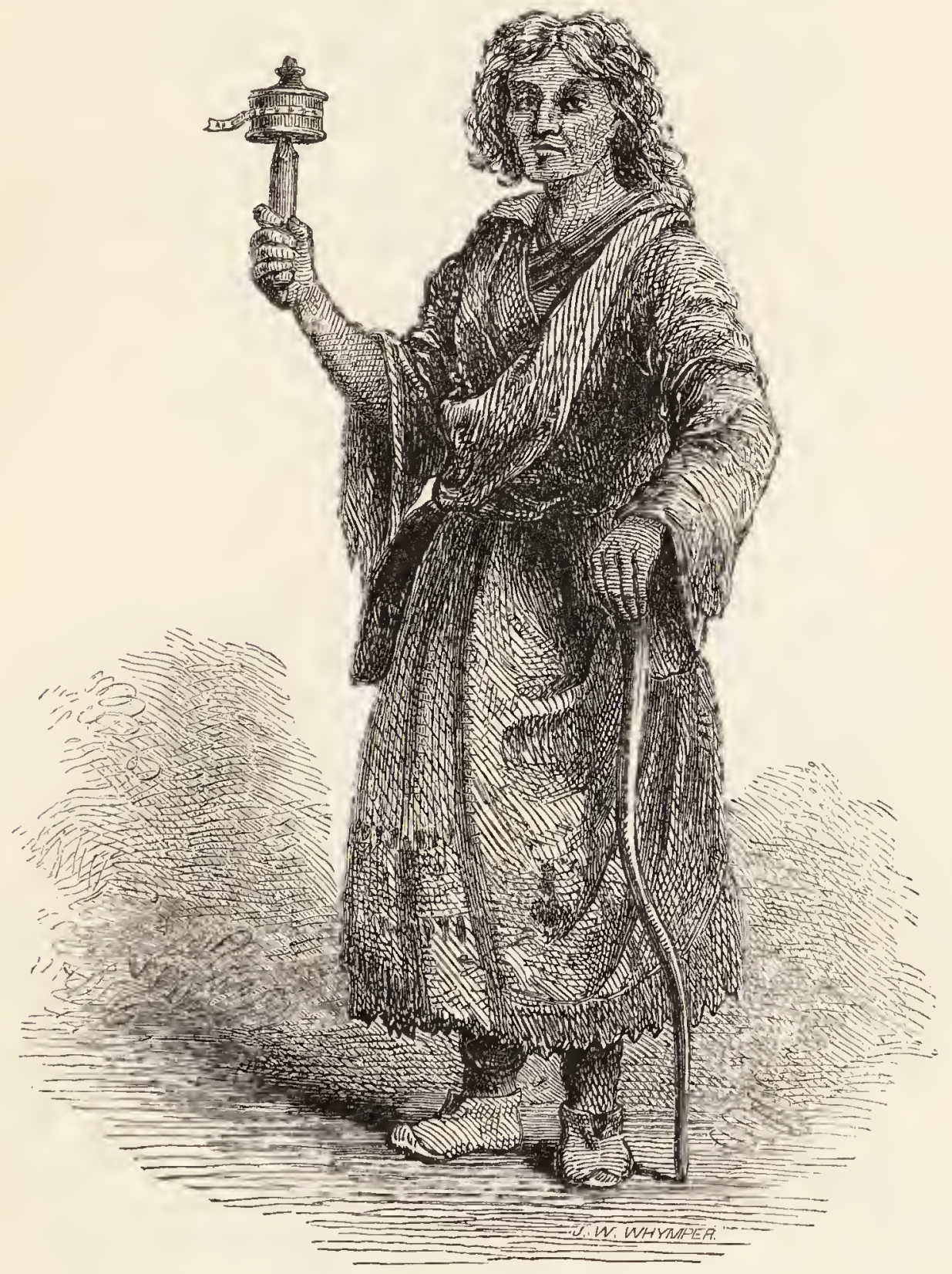

TIBETAN PHUD.

the valley still flooded, and the alders standing with their trunks twelve feet under water; but the shingle dam was now dry and hard: it would probably soften, and be carried away by the first rains of the following year. I left here the temperate flora of northern 
Sikkim, tropical forms beginning to appear; of these the nettle tribe were most numerous in the woods. A large grape, with beautiful clusters of round purple berries, was very fair eating; it is not the common vine of Europe, which nevertheless is probably an Himalayan plant, the Vitis Indica.

We did not halt at Chakoong, but proceeded to Namgah, a very long and fatiguing march. Thence a short march took us to Singtam, which we reached on the 30 th of October. The road by which I had come up was for half the distance obliterated in most parts by landslips, but they were hard and dry, and the leeches were gone.

Bad weather, and Campbell's correspondence with the Sikkim officials, who prevented all communication with the Rajah, detained us here two days, after which we crossed to the Teesta valley, and continued along its east bank.

The great shrubby nettle (Urtica crenulata) is common here: this plant, called "Mealum-ma," has broad glossy leaves, and though apparently without stings, is held in so great dread,* that I had difficulty in getting help to cut it down. I gathered many specimens without allowing any part to touch my skin; still the

* The stinging hairs are microscopic, and confined to the young shoots, leaf, and flower-stalks. Leschenault de la Tour describes being stung by this nettle on three fingers of his hand only at the Calcutta Botanical Gardens, and the subsequent sneezing and running at the nose, followed by tetanic symptoms and two days' suffering, nor did the effects disappear for nine days. It is a remarkable fact, that the plant stings violently only at this season. I frequently gathered it with impunity on subsequent occasions, and suspected some inaccuracy in my observations; but in Silhet both Dr. Thomson and I experienced the same effects in autumn. 


\section{CHAPTER XXV.}

Journey to the Rajah's residence at Tumloong-Ryott valley-Rajah's house - Tupgain Lama-Lagong nunnery-Phadong Goompa-Phenzong ditto-Lepcha Sepoys-Proceedings at Tumloong-Refused admittance to Rajah-Women's dresses-Meepo's and Tchebu Lama's families_Chapel-Leave for Chola pass-Ryott river-Rungpo, view from-Deputation of Kajees, \&c.-Conference-Laghep-Cathcartia -Phieung-goong - Rutto river-Barfonchen-Curling of rhododendron leaf-Woodcock-Chola pass-Tibet guard and Sepoys-DingpunArrival of Sikkim sepoys-Their conduct-Meet Singtam SoubahChumanako-We are seized by the Soubah's party-Soubah's cona ${ }^{*}$ uct -Dingpun Tinli-Treatment of Dr. Campbell-Bound and guarded - Separated from Campbell-Marched to Tumloong-Motives for such conduct-Arrive at Rungpo-At Phadong-Presents from RajahVisits of Lama-Of Singtam Soubah-I am cross-questioned by Amlah-Confined with Campbell-Seizure of my coolies-Threats of attacking Dorjiling.

We started on the 3rd of November for Tumloong (or Sikkim Durbar), Dr. Campbell sending Tchebu Lama forward with letters to announce his approach. A steep ascent through large Rhododendron trees led over a sharp spur, beyond which the whole bay-like valley of the Ryott opened before us, presenting one of the most lovely and fertile landscapes in Sikkim. It is ten miles long, and three or four broad, flanked by lofty mountains, and its head girt by the beautiful snowy range of Chola, from which silvery rills descend 
through black Fir-woods, dividing innumerable converging cultivated spurs, and uniting about 2000 feet below us, in a profound gorge. Houses were scattered everywhere amidst purple crops of buck-wheat, green fields of young wheat, yellow millet, broad green plantains, and orange groves.

We crossed spur after spur, often under or over precipices about fifteen hundred feet above the river, proceeding eastwards till we caught sight of the Rajah's house. It was an irregular low stone building of Tibetan architecture, with slanting walls and small windows high up under the broad thatched roof, above which, in the middle, was a Chinese-looking square copper-gilt canopy, with projecting eaves and bells at the corners, surmounted by a ball and square spire. On either gable of the roof was a round-topped cylinder of gilded copper, something like a closed umbrella: this is a very frequent and characteristic Boodhist ornament, and is represented in 'Turner's plate of the mausoleum of Teshoo Lama; indeed the Rajah's canopy at Tumloong is probably a copy of the upper part of the building there represented, having been built by architects from Teshoo Loombo. It was surrounded by chaits, mendongs, poles with banners, and other religious erections; and though beautifully situated on a flat terrace overlooking the valley, we were much disappointed with its size and appearance.

On the brow of the hill behind was the large red Goompa of the Tupgain Lama, the late heir apparent to the temporal and spiritual authority in Sikkim; and near it a nunnery called Lagong, the lady abbess of 
which is a daughter of the Rajah, who, with the assistance of sisters, keeps an enormous Mani, or praying-cylinder, revolving perpetually to the prayer of "Om Mani Padmi om." On this side was a similar spur, on which the gilded pinnacles and copper canopy of the Phadong* goompa gleamed through the trees. At a considerable distance across the head of the valley was still a third goompa, that of Phenzong.

We were met by a large party of armed Lepchas, dressed in blue and white striped kirtles, broad loose scarlet jackets, and little bamboo wattle hats lined with talc, and surmounted by a peacock's feather; they escorted us to the village, and then retired.

We encamped a few hundred feet below the Rajah's house, and close by those of Meepo and the Tchebu Lama's family, who are among the oldest and most respectable of Tibetan origin in Sikkim. Crowds came to see us, and many brought presents, with which we were overwhelmed; but we could not help remarking that our cordial greetings were wholly from the older families attached to the Rajah, and from the Lamas; none proceeded from the Dewan's relatives or friends, nor therefore any in the name of the Rajah himself, or of the Sikkim government.

Tchebu Lama vainly used every endeavour to procure for us an audience with his highness; who was surrounded by his councillors, or Amlah, all of whom were adherents of the Dewan, who was in Tibet. Meepo, and the Tchebu Lama, who were ordered to

* Phadong means Royal, and this temple answers to a chapel royal for the Rajah. 
continue in official attendance upon us, shrugged their shoulders, but could suggest no remedy. On the following morning Campbell was visited by many parties, amongst whom were the Lama's family, and

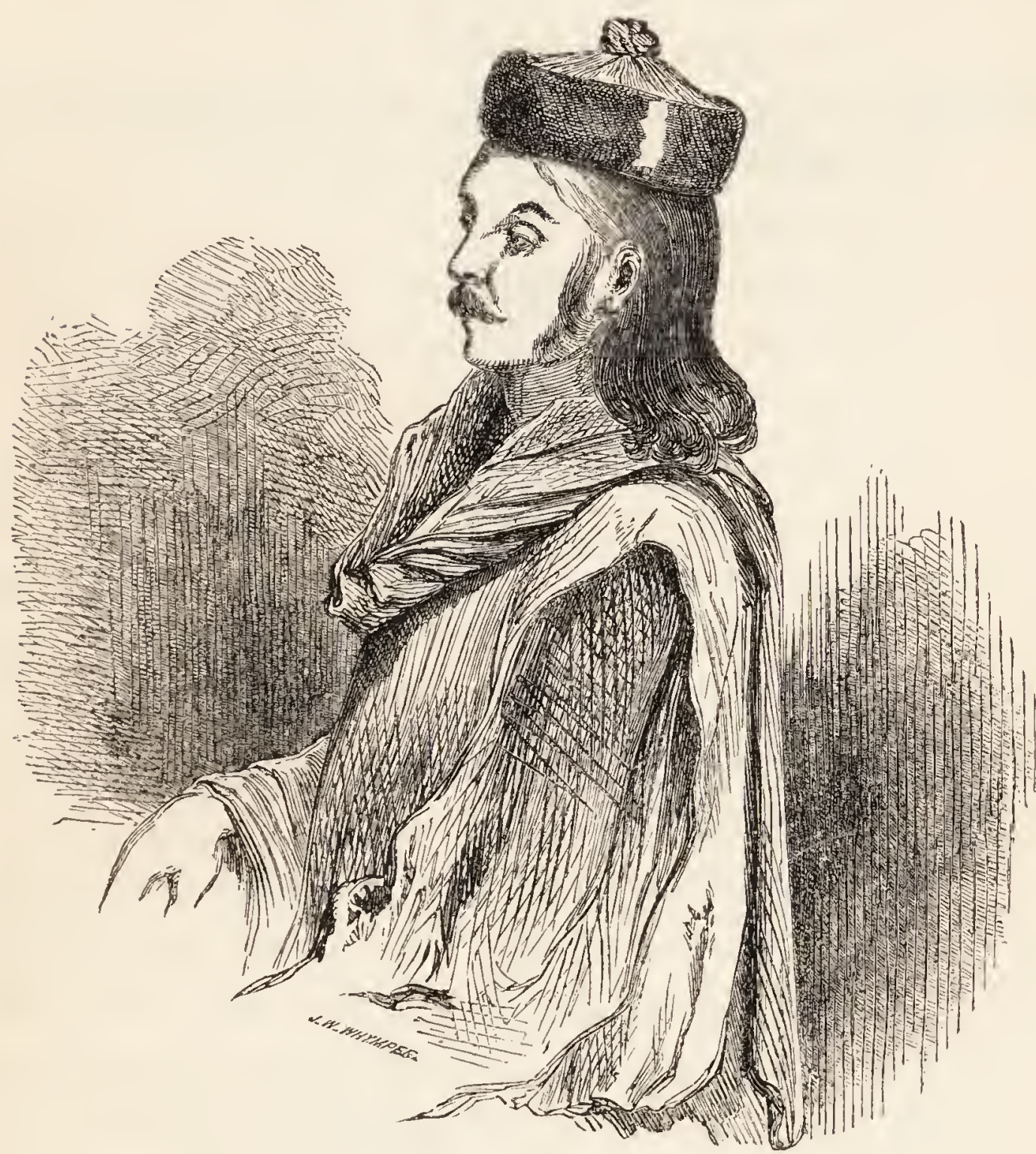

TCHEBU LAMA.

that of the late Dewan (Ilam Sing), who implored us to send again to announce our presence, and not to dismiss at once the moonshie and his office, ${ }^{*}$ who

* It is usual in India for Government officers when about to transact business, to travel with a staff (called office) of native interpreters, clerks, $\& c$. of whom the chief is commonly called moonshie. 
had accompanied us for the purpose of a conference with the Rajah. Their wishes were complied with, and we waited till noon before proceeding.

A gay and animated scene was produced by the concourse of women dressed in their pretty striped and crossed cloaks, who brought tokens of good-will. Amongst them Meepo's wife appeared conspicuous from the large necklaces* and amulets, corals, and silver filagree work, with which her neck and shoulders were loaded: she wore on her head a red tiara bedizened with seed pearls and large turquoises, and a gold fillet of filagree bosses united by a web of slender chains; her long tails were elaborately plaited, and woven with beads, and her cloak hooked in front by a chain of broad silver links studded with turquoises. White silk scarfs, the emblem of peace and friendship, were thrown over our hands by each party; and rice, eggs, fowls, kids, goats, and Murwa beer, poured in apace, to the great delight of our servants.

We returned two visits of ceremony, one to Meepo's house, a poor cottage, to which we carried presents of chintz dresses for his two little girls; who were busy teasing their hair with cylindrical combs, formed of a single slender joint of bamboo slit all round half-way up into innumerable teeth. Our other visit was paid to the Lama's family, who inhabited a large house not far from the Rajah's. The lower story was an area enclosed by stone walls, into which the cattle, \&c., were driven. An outside stone stair led to the upper

* The lumps of amber forming these were larger than the fist; they are procured in East Tibet, probably from Birmah. 
was a good library of books. More presents were brought here, and tea served.

The route to Chola pass, which crosses the range of that name south of the Chola peak, at the head of this valley, is across the Ryott, and then eastwards along a lofty ridge. Campbell started at noon, and I waited behind with Meepo, who wished me. to see the Rajah's dwelling, to which we therefore ascended; but, to my guide's chagrin, we were turned back. We were followed by a messenger, apologising and begging me to return; but I had already descended 1000 feet, and felt no inclination to reascend the hill, especially as there did not appear to be anything worth seeing. Soon after I had overtaken Campbell, he was accosted by an excessively dirty fellow, who desired him to return for a conference with the officials; this was of course declined, but, at the same time, Campbell expressed his readiness to receive them at our halting place.

The Ryott flows in a very tropical gorge 2000 feet above the sea; whence the ascent is very steep to Tumloong, where we took up our quarters at a resthouse called Rungpo (alt. 6008 feet). This road is well kept, and hence onwards is traversed yearly by the Rajah on his way to his summer residence of Choombi, two marches beyond the Chola pass; whither he is taken to avoid the Sikkim rains, which are peculiarly disagreeable to Tibetans. Rungpo commands a most beautiful view northwards, across the valley, of the royal residence, temples, goompas, hamlets, and cultivation, scattered over spurs, which are 
studded below with tree-ferns and plantains, and backed by black fir-woods and snowy mountains. In the evening the officers of the court arrived to confer with Campbell; at first there was a proposal of turning us out of the house, in which there was plenty of room, but as we declined to move, except by the Rajah's order, they put up in houses close by.

On the following morning they met us as we were departing for the Chola pass, bringing large presents in the name of the Rajah, and excuses on their and his part for having paid us no respect at Tumloong, saying, that it was not the custom to receive strangers till after they had rested a day, that they were busy preparing a suitable reception, \&c.; this was all false, and contrary to etiquette, but there was no use in telling them so. Campbell spoke firmly and kindly to them, and pointed out their incivility and the unfriendly tone of their whole conduct. They then desired Campbell to wait and discuss business affairs with them; this was out of the question, and he assured them that he was ever ready to do so with the Rajah, that he was now (as he had informed his Highness) on his way with me to the Chola and Yakla passes, and that we had, for want of coolies, left some loads behind us, which, if they were really friendly, they would forward. This they did, and so we parted; they (contrary to expectation) making no objection to Campbell's proceeding with me.

A long march up a very steep, narrow ridge took us by a good road to Laghep, a stone resting-house on a very narrow flat. I had abundance of occupation in 
gathering rhododendron-seeds, of which I procured twenty-four kinds on this and the following day.

A very remarkable plant, which $I$ had seen in flower in the Lachen valley, grew on the ridge at 7000 feet; it bears a yellow fruit like short cucumbers, full of a soft, sweet, milky pulp, and large black seeds; it belongs to a new genus, allied to Stauntonia, of which two Himalayan kinds produce similar, but less agreeable edible fruits. At Laghep, iris was abundant, and a small bushy berberry with oval eatable berries. The north wall of the house (which was in a very exposed spot) was quite bare, while the south was completely clothed with moss and weeds.

A beautiful yellow poppy-like plant grew in clefts at 10,000 feet; it has flowered in England, from seeds which I sent home, and bears the name of Cathcartia.*

We continued, on the following morning, in an easterly direction, up the same narrow steep ridge, to a lofty eminence called Phieung-goong, from being covered with the Phieung, or small bamboo. Hence we followed an oblique descent to the bed of the Rutto river, through thick woods of silver-fir and rhododendron, and halted at Barfonchen, a stone hut in the forest. Some yaks were grazing in the vicinity, and from their herdsman we learnt that the

* The name was given in honour of the memory of my friend, the late J. F. Cathcart, Esq., of the Bengal Civil Service. This gentleman was devoted to the pursuit of botany, and caused a magnificent series of drawings of Dorjiling plants to be made by native artists during his residence there. Mr. Cathcart, after the expiration of his Indian service, returned to Europe, and died at Lausanne on his way to England. 
Dewan was at Choombi, on the road to Yakla: he had kept wholly out of the way during the summer, directing every unfriendly action to be pursued towards myself and the government by the Sikkim officers, consisting of his brothers and relatives, whom he left at Tumloong.

The night was brilliant and starlight; the minimum thermometer fell to $27^{\circ}$, a strong north-east wind blew down the valley, and there was a thick hoar-frost, with which the black yaks were drolly powdered. The broad leaves of the rhododendrons were curled, from the expansion of the frozen fluids in the layer of cells on the upper surface of the leaf, which is exposed to the greatest cold of radiation. The sun restores them a little, but as winter advances they become irrecoverably curled, and droop at the ends of the branches.

We left Barfonchen on the 7th November, and ascended the river, near which we put up a woodcock. Emerging from the woods the mountains became bleak, bare, and stony. At 13,000 feet the ground was covered with ice, and all the streams were frozen. Crossing several rocky ledges, behind which were small lakes, a gradual ascent led to the summit of the Chola pass, a broad low depression, 14,925 feet above the sea, wholly bare of snow.

Campbell had preceded me, and I found him conversing with some 'Tibetans, who told him that there was no road hence to Yakla, and that we should not be permitted to go to Choombi. As a Chinese guard was posted in the neighbourhood, he accom- 
panied one of the Tibetans to see the commandant, whilst I remained taking observations.

In about an hour Meepo and some of my people came up and asked for Campbell, for whom the Tchebu Lama was waiting below: the Lama had remained at Rungpo, endeavouring to put matters on a better footing with the Sikkim officers. Wishing to see the Tibet guard, I accompanied the two remaining Tibetans down a steep valley with cliffs on either hand, for several hundred feet, when I was overtaken by some Sikkim sepoys in red jackets, who wanted to turn me back forcibly: I was at a loss to understand their conduct, and appealed to the Tibetan sepoys, who caused them to desist. About 1000 feet down I found Campbell, with a body of about ninety Tibetans, a few of whom were armed with matchlocks, and the rest with bows and arrows. They were commanded by a Dingpun, a short swarthy man, with a flat-crowned cap with floss-silk hanging all round, and a green glass button in front; he wore a loose scarlet jacket, broadly edged with black velvet, and having great brass buttons of the Indian naval uniform; his subaltern was similarly dressed, but his buttons were those of the 44th Bengal Infantry. The commandant having heard of our wish to go round by Choombi, told Campbell that he had come purposely to inform him that there was no road that way to Yakla; he was very polite, ordering his party to rise and salute me when I arrived, and doing the same when we both left.

On our return we were accompanied by the Dingpun of the Tibetans and a few of his people, and were soon 
met by more Sikkim sepoys, who said they were sent from the Durbar, to bring Campbell back to transact business; they behaved very rudely, and when still half a mile from the Sikkim frontier, jostled him and feigned to draw their knives, and one of them pointed a spear-headed bow to his breast. Campbell defended himself with a stick, and remonstrated with them on their rudeness; and I, who had nothing but a barometer in my hand, called up the Tibetans. The Dingpun came instantly, and driving the Sikkim people forward, escorted us to the frontier, where he took an inscribed board from the chait, and showed us the great vermilion seal of the Emperor of China (or more probably of the Lhassan authorities) on one side, and two small brown ones of the Sikkim Rajah on the other; and giving us to understand that here his jurisdiction ceased, he again saluted and left us.

On descending, I was surprised to meet the Singtam Soubah, whom I had not seen since leaving Tungu; he was seated on a rock, and I remarked that he looked ashy pale and haggard, and that he salaamed to me only, and not to Campbell; and that Tchebu Lama, who was with him, seemed very uncomfortable. 'The Soubah wanted Campbell to stop for a conference, which at such a time, and in such a wind, was impossible; so he followed us to Chumanako, where we proposed to pass the night.

A great party of Sikkim Bhoteas had assembled here, all strangers to me : I certainly thought the concourse unusually large, and the previous conduct to Campbell strange, rude, and quite unintelligible, 
especially before the Tibetans. But the Bhoteas were always a queer, and often insolent people, whom I was long ago tired of trying to understand, and they might have wanted to show off before their neighbours; and such was the confidence with which my long travels amongst them had inspired me, that the possibility of danger or violence never entered my head.

We went into the hut, and were resting ourselves on a log at one end of it, when, the evening being very cold, the people crowded in; on which Campbell went out, saying, that we had better leave the hut to them, and that he would see the tents pitched. $\mathrm{He}$ had scarcely left, when I heard him calling loudly to me, "Hooker! Hooker! the savages are murdering me!" I rushed to the door, and caught sight of him striking out with his fists, and struggling violently; being tall and powerful, he had already prostrated a few, but a host of men bore him down, and appeared to be trampling on him; at the same moment I was myself seized by eight men, who forced me back into the hut, and down on the log, where they held me in a sitting posture, pressing me against the wall; here I spent a few moments of agony, as I heard my friend's stifled cries grow fainter and fainter. I struggled but little, and that only at first, for at least fire-and-twenty men crowded round and laid their hands upon me, rendering any effort to move useless; they were, however, neither angry nor violent, and signed to me to keep quiet. I retained my presence of mind, and felt comfort in remembering that I saw no knives used by the party who fell on Campbell, and that if their 
intentions had been murderous, an arrow would have been the more sure and less troublesome weapon. It was evident that the whole animus was directed against Campbell, and though at first alarmed on my own account also, all the inferences which, with the rapidity of lightning my mind involuntarily drew, were favourable.

After a few minutes, three persons came into the hut, and seated themselves opposite to me: I only recognised two of them; namely, the Singtam Soubah, pale, trembling like a leaf, and with great drops of sweat trickling from his greasy brow; and the Tchebu Lama, stolid, but evidently under restraint, and frightened. The former ordered the men to leave hold of me, and to stand guard on either side, and, in a violently agitated manner, he endeavoured to explain that Campbell was a prisoner by the orders of the Rajah, who was dissatisfied with his conduct as a government officer, during the past twelve years; and that he was to be taken to the Durbar and confined till the supreme government at Calcutta should confirm such articles as he should be compelled to subscribe to; he also wanted to know from me how Campbell would be likely to behave. I refused to answer any questions till I should be informed why I was myself made prisoner; on which he went away, leaving me still guarded. My own Sirdar then explained that Campbell had been knocked down, tied hand and foot, and taken to his tent, and that all his coolies were also bound, our captors claiming them as Sikkimites, and subjects of the Rajah.

Shortly afterwards the three returned, the Soubah 
looking more spectral than ever, and still more violently agitated; and I thought I perceived that whatever were his plans, he had failed in them. He asked me what view the Governor-General would take of this proceeding? and receiving no answer, he went off with the Tchebu Lama, and left me with the third individual. The latter looked steadily at me for some time, and then asked if I did not know him. I said I did not, when he gave his name as Dingpun Tinli, and I recognised in him one of the men whom the Dewan had sent to conduct us to the top of Mainom the previous year. This opened my eyes a good deal, for he was known to be a right-hand man of the Dewan's, and had a short time before been convicted of kidnapping a Brahmin girl from Nepal,* and had vowed vengeance against Campbell for the duty he liad performed in bringing him to punishment.

I was soon asked to go to my tent, which I found pitched close by; they refused me permission to see my fellow-prisoner, or to be near him, but allowed me to hang up my instruments, and arrange my collections. My guards were frequently changed during the night, Lepchas often taking a turn; they repeatedly assured me that there was no complaint or ill-feeling against me, that the better classes in Silkim would be greatly ashamed of the whole affair, that Tchebu Lama was equally a prisoner, and that the grievances

* This act, as I have mentioned, was not only a violation of the British treaty, but an outrage on the religion of Nepal. Jung Bahadoor demanded instant restitution, which Campbell effected; thus incurring the Dingpun's wrath, who lost, besides his prize, a good deal of money which the escapade cost him. 
against Campbell were of a political nature, but what they were they did not know.

The night was very cold (thermometer $26^{\circ}$ ), and two inches of snow fell. I took as many of my party as I could into my tent, they having no shelter fit for such an elevation (12,590 feet) at this season. Through the connivance of some of the people, I managed to correspond with Campbell, who afterwards gave me the following account of the treatment he had received. He stated that on leaving the hut, he had been met by Meepo, who told him the Soubah had ordered his being turned out. A crowd of sepoys then fell on him and brought him to the ground, knocked him on the head, trampled on him, and pressed his neck down to his chest as he lay, as if endeavouring to break it. His feet were tied, and his arms pinioned behind, the wrist of the right hand being bound to the left arm above the elbow; the cords were then doubled, and he was violently shaken. The Singtam Soubah directed all this, which was performed chiefly by the Dingpun Tinli and Jongpun Sangabadoo.* After this the Soubah came to me, as I have related; and returning, had Campbell brought bound before him, and asked him, through Tchebu Lama, if he would write from dictation. The Soubah was violent, excited, and nervous; Tchebu Lama scared. Campbell answered, that if they continued torturing him (which was done by twisting the cords round his wrists by a bamboowrench), he might say or do anything, but that his

* This was the other man sent with us to Mainom, by the Dewan, in the previous December. 
government would not confirm any acts thus extorted. The Soubah became still more violent, shook his bow in Campbell's face, and drawing his hand significantly across his throat, repeated his questions, adding others, enquiring why he had refused to receive the Lassoo Kajee as Vakeel, \&c. The Soubah's people, meanwhile, gradually slunk away, seeing which he left Campbell, who was taken to his tent.

Early next morning Meepo was sent by the Soubah, to ask whether I would go to Yakla pass, or return to Dorjiling, and to say that the Rajah's orders had been very strict that I was not to be molested, and that I might proceed to whatever passes I wished to visit, whilst Campbell was to be taken back to the Durbar, to transact business. I was obliged to call upon the Soubah and Dingpun to explain their conduct of the previous day, which they declared arose from no illfeeling, but simply from their fear of my interfering in Campbell's behalf; they could not see what reason I had to complain, so long as I was neither hurt nor bound. I tried in vain to explain to them that they could not so play fast and loose with a British subject, and insisted that if they really considered me free, they should place me with Campbell, under whose protection I considered myself, he being still the Governor-General's agent.

Much discussion followed this: Meepo urged me to go on to Yakla, and leave these bad people; and the Soubah and Dingpun, who had exceeded their orders in laying hands on me, both wished me away. My course was, however, clear as to the propriety of 
keeping as close to Campbell as I was allowed, so they reluctantly agreed to take me with him to the Durbar.

Tchebu Lama came to me soon afterwards, looking as stolid as ever, but with a gulping in his throat; he alone was glad I was going with them, and implored me to counsel Campbell not to irritate the officials by a refusal to accede to their dictates, in which case his life might be the forfeit. As to himself, the opposite faction had now got the mastery, there was nothing for it but to succumb, and his throat would surely be cut. I endeavoured to comfort him with the assurance that they dared not hurt Campbell, and that this conduct of a party of ruffians, influenced by the Dewan and their own private pique, did not represent his Rajah's feelings and wishes, as he himself knew; but the poor fellow was utterly unnerved, and shaking hands warmly with his eyes full of tears, he took his leave.

We were summoned by the Dingpun to march at 10 A.M. : I demanded an interview with Campbell first, which was refused; but I felt myself pretty safe, and insisting upon it, he was brought to me. He was sadly bruised about the head, arms, and wrists, walked very lame, and had a black eye to boot, but was looking stout and confident.

I may here mention that seizing the representative of a neighbouring power, and confining him till he shall have become amenable to terms, is a common practice along the Tibet, Sikkim, and Bhotan frontiers. It had been resorted to in 1837 , by the Bhotanese, under the instructions of the Paro Pilo, who waylaid the Sikkim 
Rajah when still in Tibet, on his return from Jigatzi, and beleagured him for two months, endeavouring to bring him to their terms about some border dispute; on this occasion the Rajah applied to the British government for assistance, which was refused; and he was ultimately rescued by a Tibetan force.

In the present case the Dewan had issued orders that Campbell was to be confined at Tumloong till he himself should arrive there; and the Rajah was kept in ignorance of the affair. The Sepoys who met us on our approach to Tumloong on the 3rd of November, were, I suspect, originally sent for the purpose; and I think that the officials who followed us to Rungpo had the same object. Their own extreme timidity, and the general good-feeling in the country towards Campbell prevented its execution before, and, as a last resource, they selected the Singtam Soubah and Dingpun Tinli for the office, as being personally hostile to him. Meanwhile, the Dewan being in Tibet, and knowing that we were about to visit the frontier, for which I had full permission and an escort, sent up the Tibetan guard, hoping to embroil them in the affair; in this he failed, and it drew upon him the anger of the Lhassan authorities.* The Soubah, in

* In the following summer (1850), when the Rajah, Dewan, and Soubah repaired to Choombi, the Lhassan authorities sent a Commissioner to inquire into the affair, understanding that the Dewan had attempted to embroil the Tibetans in it. The commissioner asked the Rajah why he had committed such an outrage on the representative of the British government, under whose protection he was; thus losing his territory, and bringing English troops so near the Tibet frontier. The Rajah answered that he never did anything of the kind; that he was old and infirm, and 
endeavouring to extort a new treaty by force, and the Dingpun, who had his own revenge to gratify, exceeded their instructions in using violence towards Campbell, whom the Dewan ordered should be simply taken and confined; they were consequently disgraced, long before we were released, and the failure of the stratagem thrown upon their shoulders.

During the march down to Laghep, Campbell was treated by the Dingpun's men with great rudeness : I kept as near as I was allowed, quietly gathering rhododendron-seeds by the way. At the campingground we were again separated, at which I remonstrated with the Dingpun, also complaining of his people's insolent behaviour towards their prisoner, which he promised should be discontinued.

The next day we reached Rungpo, where we halted for further instructions: our tents were placed apart, but we managed to correspond by stealth. On the 10 th of November, we were conducted to Tumloong: a pony was brought for me, but I refused it, on seeing that Campbell was treated with great indignity, and obliged

unable to transact all his affairs; that the mischief had arisen out of the acts and ignorance of others; and finally he begged the Commissioner to investigate the whole affair, and satisfy himself about it. During the inquiry that followed, the Dewan threw all the blame on the Tibetans, who, he said, were alone implicated: this assertion was easily disproved, and on the conclusion of the inquiry the Commissioner railed vehemently at the Dewan, saying:- "You tried to put this business on the people of my country; it is an abominable lie. You did it yourselves, and no one else. The Company is a great monarchy; you insulted it, and it has taken its revenge. If you, or any other Tibetan, ever again cause a rupture with the English, you shall be taken with a rope round your neck to Pekin, there to undergo the just punishment of your offence under the sentence of the mighty Emperor." 
to follow at the tail of the mule ridden by the Dingpun, who thus marched him in triumph up to the village.

I was taken to a house at Phadong, and my fellow prisoner was confined in another at some distance to the eastward, a stone's throw below the Rajah's; and thrust into a little cage-like room. I was soon visited by an old Lama, who assured me that we were both perfectly safe, but that there were many grievances against Campbell. The Soubah arrived shortly after, bringing me compliments, nominally in the Rajah's name, and a substantial present, consisting of a large cow, sheep, fowls, a brick of tea, bags of rice, flour, butter, eggs, and a profusion of vegetables. I refused to take them on the friendly terms on which they were brought, and only accepted them as provisions during my detention. I remonstrated again about our separation, and warned the Soubah of the inevitable consequence of this outrage upon the representative of a friendly power, travelling under the authority of his own government, unarmed and without escort: he was greatly perplexed, and assured me that Campbell's detention was only temporary, because he had not given satisfaction to the Rajah, and as the latter could not get answers to his demands from Calcutta in less than a month, it was determined to keep him till then; but to send me to Dorjiling. He returned in the evening to tell me that Campbell's men (with the exception only of those who were natives of Nepal*)

* These people stood in far greater fear of the Nepalese than of the English, and the reason is obvious: the former allow no infraction of their treaties to pass unnoticed, whereas we had permitted every article of our treaty to be contravened. 
had been seized because they were runaway slaves from Sikkim; but that I need not alarm myself, for mine should be untouched.

The hut being small, and intolerably dirty, I pitched my tent close by, and lived in it for seven days: I was not guarded, but so closely watched, that I could not go out for the most trifling purpose, except under surveillance. They were evidently afraid of my escaping; I was however treated with civility, but forbidden to communicate either with Campbell or with Dorjiling.

The Soubah frequently visited me, always protesting I was no prisoner, that Campbell's seizure was a very trifling affair, and the violence employed all a mistake.

He always brought presents, and tried to sound me about the government at Calcutta. On the 12th he paid his last visit, looking wofully dejected, being out of favour at court, and dismissed to his home: he referred me to Meepo for all future communications to the Rajah, and bade me a most cordial farewell, which I regretted being unable to return with any show of kind feeling. Poor fellow! he had staked his last, and lost it, when he undertook to seize the agent of the most powerful government in the east, and to reduce him to the condition of a tool of the Dewan. Despite the many obstructions he had placed in my way, we had not fallen out since July; we had been constant companions, and though at issue, never at enmity. I had impeached him, and my grievances had been forwarded to the Rajah with a demand for his punishment, but he never seemed to owe me a 
grudge for that, knowing the Rajah's impotence as compared with the power of the Dewan whom he served; and, in common with all his party, presuming on the unwillingness of the British government to punish.

On the 13th of November I was hurriedly summoned by Meepo to the Phadong temple, where I was interrogated by the Amlah, as the Rajah's councillors (in this instance the Dewan's adherents) are called. I found four Chinese mats placed on a stone bench, on one of which I was requested to seat myself, the others being occupied by the Dewan's elder brother, a younger brother of the Gangtok Kajee (a man of some wealth), and an old Lama: the conference took place in the open air, amongst an immense crowd of Lamas, men, women, and children.

I took the initiative (as I made a point of doing on all such occasions) and demanded proper interpreters, which were refused; and the Amlah began a rambling interrogatory in Tibetan, through my Lepcha attendant, who spoke very little Tibetan or Hindostanee, and my half-caste servant, who spoke as little English. The Dewan's brother was very nervously counting his beads, and never raised his eyes while I kept mine steadily upon him.

He suggested most of the queries, every one of which took several minutes, as he was constantly interrupted by the Kajee, who was very fat and stupid: the Lama scarcely spoke, and the bystanders never. My connection with the Indian government was first enquired into; next they came to political matters, 
upon which I declined entering; but I gathered that their object was to oblige Campbell to accept the Lassoo Kajee as Vakeel, to alter the slavery laws, to draw a new boundary line with Nepal, to institute direct communication between themselves and the GovernorGeneral,* and to engage that there should be no trade or communication between Sikkim and India, except through the Dewan: all of these subjects related to the terms of the original treaty between the Rajah and the Indian government. They told me they had sent these proposals to the government through Dorjiling, $\uparrow$ but had received no acknowledgment from the latter place, and they wanted to know the probable result at Calcutta. As the only answer I could give might irritate them, I again declined giving any. Lastly, they assured me that no blame was imputed to myself, that on the contrary I had been travelling under the Rajah's protection, who rejoiced in my success, that I might have visited Yakla pass as I had intended doing, but that preferring to accompany my friend, they had allowed me to do so, and that I might now either join

* They were prompted to demand this by an unfortunate oversight that had occurred at Calcutta some years before. Representatives of the Sikkim court repaired to that capital, and though unaccredited by the GovernorGeneral's agent at Dorjiling, were (in the absence of the Governor-General) received by the president of the council in open court. The effect was of course to reduce the Governor-General's agent at Dorjiling to a cipher.

* These letters had arrived at Dorjiling; but being written in Tibetan, and containing matters into which no one but Campbell could enter, they were laid on one side till his return. The interpreter did not read the last line, which stated that Dr. Campbell was detained at Tumloong till answers were received, and the facts of our capture and imprisonment consequently remained unknown for several weeks. 
him, or continue to live in my tent : of course I joyfully accepted the former proposal. After being refused permission to send a letter to Dorjiling, except I would write in a character which they could read, I asked if they had anything more to say, and being answered in the negative, I was taken by Meepo to Campbell, heartily glad to end a conference which had lasted for an hour and a half.

I found my friend in good health and spirits, strictly guarded in a small thatched hut, of bamboo, wattle and clay: the situation was pretty, and commanded a view of the Ryott valley and the snowy mountains; there were some picturesque chaits hard by, and a blacksmith's forge. Our walks were confined to a few steps in front of the hut, and included a puddle and a spring of water. We had one dark room with a small window, and a fire in the middle on a stone; we slept in a narrow apartment behind it, which was the cage in which Campbell had been at first confined, and which exactly admitted us both, lying on the floor. Two or three Sepoys occupied an adjoining room, and had a peep-hole through the partition-wall.

My gratification at our being placed together was damped by the seizure of all my faithful attendants except my own servant, and one who was a Nepalese: the rest were bound, and placed in the stocks and close confinement, charged with being Sikkim people who had no authority to take service in Dorjiling. On the contrary they were all registered as British subjects, and had during my travels been recognised as such by the Rajah and all the authorities. Three times the 
Soubah and others had voluntarily assured me that my person and people were inviolate; nor was there any cause for this outrage but the fear of their escaping with news to Dorjiling, and possibly a feeling of irritation amongst the authorities at the failure of their schemes. Meanwhile we were not allowed to write, and we heard that the bag of letters which we had sent before our capture had been seized and burnt. Campbell greatly feared that they would threaten Dorjiling with a night attack,* as we heard that the Lassoo Kajee was stationed at Namtchi with a party for that purpose, and all communication cut off, except through him.

* Threats of sacking Dorjiling had on several previous occasions been made by the Dewan, to the too great alarm of the inhabitants, who were ignorant of the timid and pacific disposition of the Lepchas, and of the fact that there are not fifty muskets in the country, nor twenty men able to use them. On this occasion the threats were coupled with the report that we were murdered, and that the Rajah had asked for 50,000 Tibetan soldiers, who were being marched twenty-five days' journey over passes 15,000 feet high, and deep in snow, and were coming to drive the English out of Sikkim! I need hardly observe that the Tibetans (who have repeatedly refused to interfere on this side the snows) had no hand in the matter, or that, supposing they could collect that number of men in all Tibet, it would be impossible to feed them for a week, there or in Sikkim. Such reports unfortunately spread a panic in Dorjiling: the guards were called in from all the outposts, and the ladies huddled into one house, whilst the men stood on the defensive; to the great amusement of the officials at Tumloong, whose insolence to us increased proportionally. 


\section{CHAPTER XXVI.}

Dr. Campbell is ordered to appear at Durbar-Lamas called to councilThreats-Scarcity of food-Arrival of Dewan-Our jailor, Thoba-sing -Temperature, \&c., at Tumloong-Services of Goompas-Lepcha girl - Jews'-harp-Terror of servants-Ilam-sing's family-Interview with Dewan-Remonstrances-Dewan feigns sickness-Lord Dalhousie's letter to Rajah-Treatment of Indo-Chinese-Concourse of Lamas - Visit of T'chebu Lama-Close confinement-Dr. Campbell's illness -Conference with Amlah-Relaxation of confinement-Pemiongchi Lama's intercession-Escape of Nimbo-Presents from Rajah, Ranee and people-Protestations of friendship-Mr. Lushington sent to Dorjiling-Leave Tumloong-Cordial farewell-Dewan's merchandise - Gangtok Kajee-Dewan's pomp-Governor-General's letterDikkeeling-Suspicion of poison-Dinner and pills-Tobacco-Bhotanese colony-Katong-ghat on Teesta-Wild lemons-Sepoy's insolence-Dewan alarmed-View of Dorjiling-Threats of a rescue-Fears of our escape-Tibet flutes-Negociate our release-Arrival at Dorjiling-Dr. Thomson joins me-Movement of troops at DorjilingSeizure of Rajah's Terai property.

Since his confinement, Dr. Campbell had been desired to attend the Durbar for the purpose of transacting business, but had refused to go, except by compulsion, considering that in the excited state of the authorities, amongst whom there was not one person of responsibility or judgment, his presence would not only be useless, but he might be exposed to further insult, or possibly violence.

On the 15th of November we were informed that the 
Dewan was on his way from Tibet: of this we were glad, for knave as he was, we had hitherto considered him to possess sense and understanding. His agents were beginning to find out their mistake, and summoned to council the principal Lamas and Kajees of the country, who, to a man, repudiated the proceedings, and refused to attend. Our captors were extremely anxious to induce us to write letters to Dorjiling, and sent spies of all kinds to offer us facilities for secret correspondence. The simplicity and clumsiness with which these artifices were attempted would have been ludicrous under other circumstances; while the threat of murdering Campbell only alarmed us inasmuch as it came from people too stupid to be trusted. We made out that all Sikkim people were excluded from Dorjiling, and the officials consequently could not conceal their anxiety to know what had befallen their letters to government.

Meanwhile we were but scantily fed, and our imprisoned coolies got nothing at all. Our guards were supplied with a handful of rice or meal as the day's allowance; they were consequently grumbling,* and were daily reduced in number. The supplies of rice

* The Rajah has no standing army; not even a body-guard, and these men were summoned to Tumloong before our arrival; they had no arms and received no pay, but were fed when called out on duty. There is no store for grain, no bazaar or market, in any part of the country, each. family growing barely enough for its own wants; consequently Sikkim. could not stand on the defensive for a week. The Rajalı receives his supply of grain in annual contributions from the peasantry, who thus pay a rent in kind, which varies from little to nothing, according to the year, \&c. He had also property of his own in the Terai, but the slender proceeds only enabled him to trade with Tibet for tea, \&c. 
from the Terai, beyond Dorjiling, were cut off by the interruption of communication, and the authorities evidently could not hold us long at this rate: we sent up complaints, but of course received no answer.

The Dewan arrived one afternoon in great state,

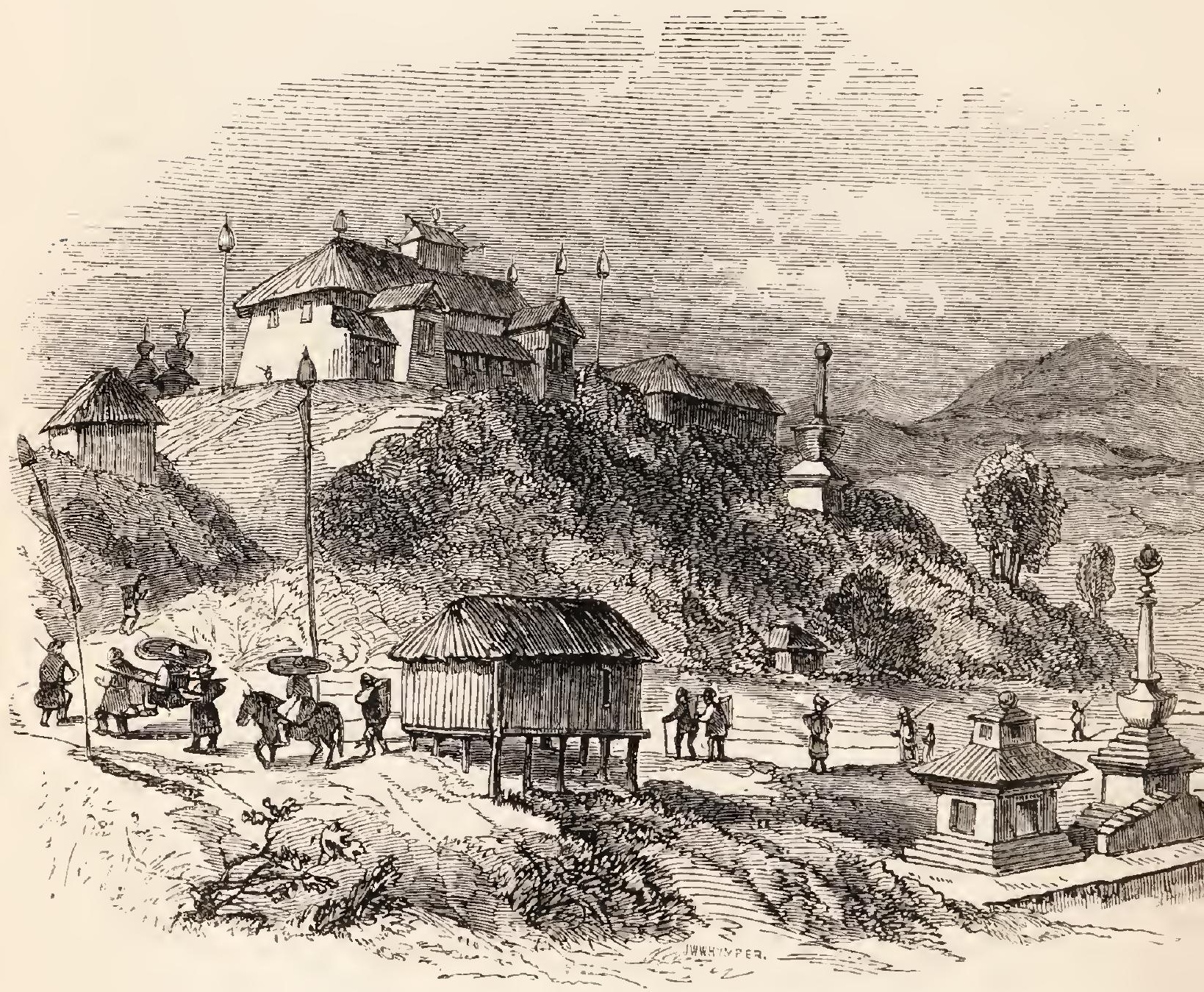

RAJAH'S RESIDENCE, AND THE HUT ASSIGNED TO US. ARRIVAL OF THE DEWAY.

carried in an English chair, given him by Campbell some years before, habited in a blue silk cloak lined with lambskin, and wearing an enormous straw hat with a red tassel, and black velvet butterflies on the flapping brim. He was accompanied by a household of women, who were laden with ornaments, and wore 
boots, and sat astride on ponies; many Lamas were also with him, one of whom wore a broad Chinese hat covered with polished copper foil. Half a dozen Sepoys with matchlocks preceded him, and on approaching Tumloong bawled out his titles, dignities, \&c., as was formerly the custom in England.

At Dorjiling our seizure was still unknown: our letters were brought to us, but we were not allowed to answer them. Now that the Dewan had arrived, we hoped to come to a speedy explanation with him, but he shammed sickness, and sent no answer to our messages, if indeed he received them. Our guards were reduced to one sepoy with a knife, who was friendly; and a dirty, cross-eyed fellow named Thobasing, who, with the exception of Tchebu Lama, was the only Bhotea about the Durbar who could speak Hindostanee, and who did it very imperfectly: he was our attendant and spy, the most bare-faced liar I ever met with, even in the east; and as cringing and obsequious when alone with us, as he was to his masters on other occasions, when he never failed to show off his authority over us in an offensive manner. Though he was the most disagreeable fellow we were ever thrown in contact with, I do not think he was selected for that reason, but solely from his possessing a few words of Hindostanee, and his presumed capability of therefore playing the spy.

The weather was generally drizzling or rainy, and we were getting very tired of our captivity; but I beguiled the time by carefully keeping my meteorological register, and by reducing many of my previous 
observations. Each morning we were awakened at daybreak by the prolonged echos of the conchs, trumpets, and cymbals, beaten by the priests before the many temples in the valley: wild and pleasing sounds, often followed by their choral chants. After dark we sat over the fire, generally in company with a little Lepcha girl, who was appointed to keep us in fire-wood, and who sat watching our movements with childish curiosity. Dolly, as we christened her, was a quick child and a kind one, intolerably dirty, but very entertaining from her powers of mimicry. She was fond of hearing me whistle airs, and procured me a Tibetan Jews'-harp,* with which, and coarse tobacco,

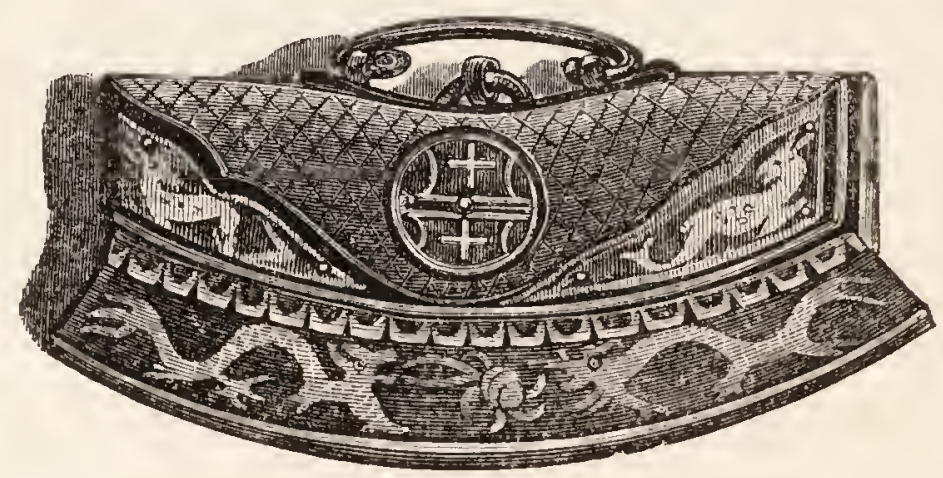

TIBEI-PIPE, AND TINDER•POUCH WITH STEEL ATTACHED.

which I smoked out of a Tibetan brass pipe, I wiled away the long evenings, whilst my cheerful companion

* This instrument (which is common in Tibet) is identical with the European, except that the tongue is produced behind the bow, in a strong steel spike, by which the instrument is held firmer to the mouth. 
amused himself with an old harmonicon, to the enchantment of Dolly and our guards and neighbours.

The messengers from Dorjiling were kept in utter ignorance of our confinement till their arrival at Tumloong, when they were cross-questioned, and finally sent to us. They gradually became too numerous, there being only one apartment for ourselves, and such of our servants as were not imprisoned elsewhere. Some of them were frightened out of their senses, and the state of abject fear and trembling in which one Limboo arrived, and continued for nearly a week, was quite distressing* to every one except Dolly, who mimicked him in a manner that was irresistibly ludicrous. Whether he had been beaten or threatened we could not make out, nor whether he had heard of some dark fate impending over ourselves - a suspicion which would force itself upon our minds; especially as Thoba-sing had coolly suggested to the Amlah the despatching of Campbell, as the shortest way of getting out of the scrape! We were also ignorant whether any steps were being taken at Dorjiling for our release, which we felt satisfied must follow any active measures against these bullying cowards, though they themselves frequently warned us that we should be thrown into the Teesta if any such were pursued.

* It amounted to a complete prostration of bodily and mental powers: the man trembled and started when spoken to, or at any noise, a cold sweat constantly bedewed his forehead, and he continued in this state for eight days. No kindness on Campbell's part could rouse him to give any intelligible account of his fears or their cause. His companions said he had lost his goroo, i.e., his charm, which the priest gives him while yet a child, and which he renews or gets re-sanctified as occasion requires. To us the circumstance was extremely painful. 
So long as our money lasted, we bought food, for the Durbar had none to give; and latterly my ever charitable companion fed our guards, including Dolly and Thoba-sing, in pity to their pinched condition: Several families sent us small presents by night, especially that of the late estimable Dewan, Ilam-sing, whose widow and daughters lived close by, and never failed to express in secret their sympathy and good feeling. Tchebu Lama's and Meepo's families were equally forward in their desire to serve us; but they were marked men, and could only communicate by stealth.

Our coolies were released on the 18th, more than half starved, but the Sirdars were still kept in chains or the stocks: some were sent back to Dorjiling, and the British subjects billetted off amongst the villagers, and variously employed by the Dewan: one lad was set to collect the long leaves of a plant which yield a sweet juice, and were chopped up and mixed with tobacco for the Dewan's hookah.

November 20th.-The Dewan, we heard this day, ignored all the late proceedings, professing to be enraged with his brother and the officials, and refusing to meddle in the matter. This was no doubt a pretence: we had sent repeatedly for an explanation with himself or the Rajah, from which he excused himself on the plea of ill health, till this day, when he apprized us that he would meet Campbell, and a cotton tent was pitched for the purpose.

We went about noon, and were received with great politeness and shaking of hands by the Dewan, the young Gangtok Kajee, and the old monk who had 
been present at my previous examination. Tchebu Lama's brother was also there, as a member of the court, lately taken into favour; while Tchebu himself acted as interpreter, the Dewan speaking only Tibetan. They all sat cross-legged on a bamboo bench on one side, and we on chairs opposite them: walnuts and sweetmeats were brought us, and a small present in the Rajah's name, consisting of rice, flour, and butter.

The Dewan opened the conversation both in this and another conference, which took place on the 22nd, by requesting Campbell to state his reasons for having desired these interviews. Neither he nor the Sikkim officers seemed to have the smallest idea of the nature and consequences of the acts they had committed, and they therefore anxiously sought information as to the view that would be taken of them by the British Government. They could not see why Campbell should not transact business with them in his present condition, and wanted him to be the medium of communication between themselves and Calcutta. He, however, confined himself to pointing out his own views of the following subjects:-1. The seizing and imprisoning of the agent of a friendly power, travelling unarmed and without escort, under the formal protection of the Rajah, and with the authority of his own government. 2. The aggravation of this act of the Amlah, by our present detention under the Dewan's authority. 3. The chance of collision, and the disastrous consequences of a war, for which they had no preparation. of any kind. 4. The impossibility of the supreme 
government paying any attention to their letters so long as we were illegally detained.

All this sank deep into the Dewan's heart: he answered "You have spoken truth, and I will submit it all to the Rajah;" but at the same time he urged that there was nothing dishonourable in the imprisonment, and that the original violence being all a mistake, it should be overlooked by both parties. We parted on good terms, and heard shortly after the second conference that our release was promised and arranged: when a communication * from Dorjiling changed their plans, the Dewan conveniently fell sick on the spot, and we were thrown back again.

In the meantime, however, we were allowed to write to our friends, and to receive money and food, of which we stood in great need. I transmitted a private account of the whole affair to the Governor-General, who was unfortunately at Bombay, but to whose prompt and vigorous measures we were finally indebted for our release. His lordship expedited a despatch to the Rajah, such as the latter was accustomed to receive from Nepal, Bhotan, or Lhassa, and such as alone commands attention from these half-civilized IndoChinese, who measure power by the firmness of tone adopted towards them; and who, whether in Sikkim,

* I need scarcely say that every step was taken at Dorjiling for our release that the most anxious solicitude for our safety could suggest; but the first communication to the Rajah, though it pointed out the heinous nature of his offence, was, through a natural fear of exasperating our captors, couched in very moderate language. The particulars of our seizure, and the reasons for it, and for our further detention, were unknown at Dorjiling, or a very different line of policy would have been pursued. 
Birmah, Siam, Bhotan, or China, have too long been accustomed to see every article of our treaties contravened, with no worse consequences than a protest or threat, which is never carried into execution till some fatal step calls forth the dormant power of the British Government.*

The end of the month arrived without bringing any prospect of our release, whilst we were harassed by false reports of all kinds. The Dewan went on the 25th to a hot bath, a few hundred feet down the hill; he was led past our hut, his burly frame tottering as if in great weakness, but a more transparent fraud could not have been practised: he was, in fact, lying on his oars, pending further negociations. The Amlah proposed that Campbell should sign a bond, granting immunity for all past offences on their part, whilst they were to withdraw the letter of grievances against him. The Lamas cast horoscopes for the future, little presents continually arrived for us, and the Ranee sent me some tobacco, and to Campbell brown sugar and Murwa beer. The blacksmiths, who had been ostentatiously making long knives at the forge hard by, were dismissed; troops were said to be arriving at

* We forget that all our concessions to these people are interpreted into weakness; that they who cannot live on an amicable equality with one another, cannot be expected to do so with us; that all our talk of power and resources are mere boasts to habitual bullies, so long as we do not exert ourselves in the correction of premeditated insults. No Government can be more tolerant, more sincerely desirous of peace, and more anxious to confine its sway within its own limits than that of India, but it can only continue at peace by demanding respect, and the punctilious enforcement of even the most trifling terms in the treaties it makes with IndoChinese. 
Dorjiling, and a letter sternly demanding our release was received.

The Lamas of Pemiongchi, Changachelling, Tassiding, \&c., and the Dewan's enemies, and Tchebu Lama's friends, began to flock from all quarters to Tumloong, demanding audience of the Rajah, and our instant liberation. The Dewan's game was evidently up; but the timidity of his opponents, his own craft, and the habitual dilatoriness of all, contributed to cause endless delays. The young Gangtok Kajee tried to curry favour with us, sending word that he was urging our release, and adding that he had some capital ponies for us to see on our way to Dorjiling! Many similar trifles showed that these people had not a conception of the nature of their position, nor of that of an officer of the British Government.

The Tchebu Lama visited us only once, and then under surveillance; he renewed his professions of good faith, and we had every reason to know that he had suffered severely for his adherence to us, and consistent repudiation of the Amlah's conduct: he was in great favour with his brother Lamas, but was not allowed to see the Rajah, who was said to trust to him alone of all his counsellors. He told us that peremptory orders had arrived from Calcutta for our release, but that the Amlah had replied that they would not acknowledge the despatch, from its not bearing the Governor-General's great seal! The country-people refusing to be saddled with the keep of our coolies, they were sent to Dorjiling in small parties, charged to say that we were free, and following them. 
The weather continued rainy and bad, with occasionally a few hours of sunshine, which, however, always rendered the ditch before our door offensive: we were still prevented leaving the hut, but as a great annual festival was going on, we were less disagreeably watched. Campbell was very unwell, and we had no medicine; and as the Dewan, accustomed to such duplicity himself, naturally took this for a ruse, and refused to allow us to send to Dorjiling for any, we were more than ever convinced that his own sickness was simulated.

On the 2nd and 3rd December we had further conferences with the Dewan, who said that we were to be taken to Dorjiling in six days, with two Vakeels from the Rajah. The Pemiongchi Lama, as the oldest and most venerated in Sikkim, attended, and addressed Campbell in a speech of great feeling and truth. Having heard, he said, of these unfortunate circum. stances a few days ago, he had come on feeble limbs, and though upwards of seventy winters old, as the representative of his holy brotherhood, to tender advice to his Rajah, which he hoped would be followed. Since Sikkim had been connected with the British rule, they had experienced continued peace and protection; whereas before they were in constant dread of their lives and properties, which, as well as their most sacred temples, were violated by the Nepalese and Bhotanese. He then dwelt upon Campbell's invariable kindness and good feeling, and his exertions for the benefit of their country, and for the cementing of friendship, and hoped he would not let these untoward events induce 
an opposite course in future; but that he would continue to exert his influence with the GovernorGeneral in their favour.

The Dewan listened attentively; he was anxious and perplexed, and evidently losing his presence of mind: he talked to us of Lhassa and its gaieties, dromedaries, Lamas, and everything Tibetan; offered to sell us ponies cheap, and altogether behaved in a most undignified manner; ever and anon calling attention to his pretended sick leg, which he nursed on his knee. He gave us the acceptable news that the government at Calcutta had sent up an officer to carry on Campbell's duties, which had alarmed him exceedingly. The Rajah, we were told, was very angry at our seizure and detention; he had no fault to find with the GovernorGeneral's agent, and hoped he would be continued as such. In fact, all the blame was thrown on the brothers of the Dewan, and of the Gangtok Kajee, and more irresponsible stupid boors could not have been found on whom to lay it, or who would have felt less inclined to commit such folly if it had not been put on them by the Dewan. On leaving, white silk scarfs (emblems of peace and friendship) were thrown over our shoulders, and we went away, still doubtful, after so many disappointments, whether we should really be set at liberty at the stated period.

Although there was so much talk about our leaving, our confinement continued as rigorous as ever. The Dewan curried favour in every other way, sending us Tibetan wares for purchase, with absurd prices attached, he being an arrant pedlar. All the principal families 
waited on us, desiring peace and friendship. The coolies who had not been dismissed were allowed to run away, except my Bhotan Sirdar, Nimbo, against whom the Dewan was inveterate: * he, however, managed soon afterwards to break a great chain with which his legs were shackled, and marching at night, eluded a hot pursuit, and proceeded to the Teesta, swam the river, and reached Dorjiling in eight days; arriving with a large iron ring on each leg, and a link of several pounds weight attached to one.

Parting presents arrived from the Rajah on the 7th, consisting of ponies, cloths, silks, woollens, immense squares of butter, tea, and the usual et ceteras, to the utter impoverishment of his stores: these he offered to the two Sahibs, "in token of his amity with the British government, his desire for peace, and deprecation of angry discussions." The Ranee sent silk purses, fans, and similar Tibetan paraphernalia, with an equally amicable message, that "she was most anxious to avert the consequences of whatever complaints had gone forth against Dr. Campbell, who might depend on her strenuous exertions to persuade the Rajah to do whatever he wished!" These friendly messages were probably evoked by the information that an English regiment, with three guns, was on its way to Dorjiling, and that 300 Sepoys had already arrived there. The government of Bengal sending another agent was also a contingency they had not anti-

* The Sikkim people are always at issue with the Bhotanese. Nimbo was a runaway slave of the latter country, who had been received into Sikkim, and retained there until he took up his quarters at Dorjiling. 
cipated, having fully expected to get rid of any such obstacle to direct communication with the GovernorGeneral.

A present from the whole population followed that of the Ranee, coupled with earnest entreaties that Campbell would resume his position at Dorjiling; and on the following day forty coolies mustered to arrange the baggage. Before we left, the Ranee sent three rupees to buy a yard of chalé and some gloves, accompanying them with a present of white silk, \&c., for Mrs. Campbell, to whom the commission was intrusted: a singular instance of the insouciant simplicity of these odd people.

The 9th of December was a splendid and hot day, one of the very few we had had during our captivity. We left at noon, descending the hill through an enormous crowd of people, who brought farewell presents, all wishing us well. We were still under escort as prisoners of the Dewan, who was coolly marching a troop of forty unloaded mules and ponies, and double that number of men's loads of merchandise, purchased during the summer in Tibet, to trade with at Dorjiling and the Titalya fair! His impudence or stupidity was thus quite inexplicable; treating us as prisoners, ignoring every demand of the authorities at Dorjiling, of the Supreme Council of Calcutta, and of the GovernorGeneral himself; and at the same time acting as if he were to enter the British territories on the most friendly and advantageous footing for himself and his property, and incurring so great an expense in all this as to prove that he was in earnest in thinking so.

Tchebu Lama accompanied us, but we were not 
allowed to converse with him. We halted at the bottom of the valley, where the Dewan invited us to partake of tea; from this place onwards he gave us mules or ponies to ride. On the following day we crossed a high ridge from the Ryott valley to that of the Rungmi; where we camped at Tikbotang, and on the 11th at Gangtok Sampoo, a few miles lower down the same valley.

We were now in the Soubahship of the Gangtok Kajee, a member of the oldest and most wealthy family in Sikkim; he had from the first repudiated the late acts of the Amlah, in which his brother had taken part, and had always been hostile to the Dewan. The latter conducted himself with disagreeable familiarity towards us, and hauteur towards the people; he was preceded by immense kettle-drums, carried on men's backs, and great hand-bells, which were beaten and rung on approaching villages; on which occasions he changed his dress of sky-blue, for yellow silk robes worked with Chinese dragons, to the indignation of 'T'chebu Lama, an amber robe in polite 'Tibetan society being sacred to royalty and the Lamas. We everywhere perceived unequivocal symptoms of the dislike with which he was regarded. Cattle were driven away, villages deserted, and no one came to pay respects, or bring presents, except the Kajees, who were ordered to attend, and his elder brother, for whom he had usurped an estate near Gangtok.

On the 13th, he marched us a few miles, and then halted for a day at Serriomsa, at the bottom of a hot valley full of irrigated rice-crops and plantain and orange-groves. Here the Gangtok Kajee waited on us 
with a handsome present, and informed us privately of his cordial hatred of the "upstart Dewan," and hopes for his overthrow; a demonstration of which we took no notice. The Dewan's brother (one of the Amlah) also sent a large present, but was ashamed to appear. Another letter reached the Dewan here, directed to the Rajah; it was from the Governor-General at Bombay, and had been sent across the country by special messengers: it demanded our instant release, or his Raj would be forfeited; and declared that if a hair of our heads were touched, his life should be the penalty.

The Rajah was incessantly urging the Dewan to hasten us onwards as free men to Dorjiling, but the latter took all remonstrances with assumed coolness, exercised his ponies, played at bow and arrow, intruded on us at meal-times to be invited to partake, and loitered on the road, changing garments and hats, which he pestered us to buy. Nevertheless, he was evidently becoming daily more nervous and agitated.

From the Rungmi valley we crossed on the 14th southward to that of Rumniok, and descended to Dikkeeling, a large village of Bhotanese, which is much the most populous, industrious, and at the same time turbulent in Sikkim. This district once belonged to Bhotan, and was ceded to the Siklkim Rajah by the Paro Pilo, ${ }^{*}$ in consideration of some military services, rendered by the former in driving off the Tibetans, who had usurped it for the authorities of Lhassa. Since then the Sikkim and Bhotan people have

* The temporal sovereign, in contra-distinction to the Dhurma Rajah, or spiritual sovereign of Bhotan. 
repeatedly fallen out, and Dikkeeling has become a refuge for runaway Bhotanese, and kidnapping is constantly practised on this frontier.

The Bhotanese are more industrious than the Lepchas, and better husbandmen; besides having superior crops of all ordinary grains, they grow cotton, hemp, and flax. The cotton is cleansed here as elsewhere, with a simple gin. The Lepchas use no spinning wheel, but a spindle and distaff; their loom, which is Tibetan, is a very complicated one framed of bamboo; it is worked by hand, without beam, treddle, or shuttle.

The Dewan halted us here for three days, for no assigned cause. On the 16th, letters arrived, including a most kind and encouraging one from Mr. Lushington, who had taken charge of Campbell's office at Dorjiling. Immediately after arriving, the messenger was seized with violent vomitings and gripings: we could not help suspecting poison, especially as we were now amongst adherents of the Dewan, and the Bhotanese are notorious for this crime. Only one means suggested itself for proving this, and with Campbell's permission I sent my compliments to the Dewan with a request for one of his hunting dogs to eat the vomit. It was sent at once, and performed its duty without any ill effects. I must confess to have felt a malicious pleasure in the opportunity thus afforded of showing our jailor how little we trusted him; feeling indignant at the idea that he should suppose he was making any way in our good opinion by his familiarities, which we were not in circumstances to resist. The crafty fellow, however, outwitted me by inviting us to dine 
with him the same day, and putting our stomachs and noses to a severe test. Our dinner was served in Chinese fashion, but most of the luxuries, such as bêche-de-mer, were very old and bad. We ate, sometimes with chop-sticks, and at others with Tibetan spoons, knives, and two-pronged forks. After the usual amount of messes served in oil and salt water, sweets were brought, and a strong spirit. Thoba-sing, our filthy, cross-eyed spy, was waiter, and brought in every little dish with both hands, and raised it to his greasy forehead, making a sort of half bow previous to depositing it before us. Sometimes he undertook to praise its contents, always adding, that in Tibet none but very great men indeed partook of such sumptuous fare. Thus he tried to please both us and the Dewan, who conducted himself with pompous hospitality, showing off what he considered his elegant manners and graces. Our blood boiled within us at being so patronised by the squinting ruffian, whose insolence and ill-will had sorely aggravated the discomforts of our imprisonment.

Not content with giving us what he considered a magnificent dinner (and it had cost him some trouble), the Dewan produced a little bag from a double-locked escritoire, and took out three dinner-pills, which he had received as a great favour from the Rimbochay Lama, and which were a sovereign remedy for indigestion and all other ailments; he handed one to each of us, reserving the third for himself. Campbell refused his; but there appeared no help for me, after my groundless suspicion of poison, and so I swallowed the pill with 
the best grace I could. But in truth, it was not poison I dreaded in its contents, so much as being compounded of some very questionable materials, such as the Rimbochay Lama blesses and dispenses far and wide. To swallow such is a sanctifying work, according to Boodhist superstition, and I believe there was nothing in the world, save his ponies, to which the Dewan attached a greater value.

To wind up the feast, we had pipes of excellent mild yellow Chinese tobacco, made from Nicotiana rustica, which is cultivated in East Tibet, and in West China. It resembles in flavour the finest Syrian tobacco, and is most agreeable when the smoke is passed through the nose. The common tobacco of India is much imported into Tibet, where it is called "Tamma," (probably a corruption of the Persian "Toombac,") and is said to fetch the enormous price of $30 \mathrm{~s}$. per $1 \mathrm{~b}$. at Lhassa, which is sixty times its value in India. Rice at Lhassa, when cheap, sells at $2 s$. for $5 \mathrm{lbs}$.; it is all bought up for rations for the Chinese soldiery.

On the 18th we were marched three miles only, and on the following day five miles farther, to Katong Ghat on the Teesta river, which we crossed with rafts, and camped on the opposite bank, a few miles above its junction with the Great Rungeet. The water, which is sea-green in colour, had a temperature of $53 \frac{1}{2}^{\circ}$; its current was very powerful. The climate was hot, and the vegetation on the banks tropical; on the hills around, lemon-bushes were abundant, apparently growing wild.

The Dewan was now getting into a very nervous and 
depressed state: he was determined to keep up appearances before his followers, but was almost servile to us; he caused his men to make a parade of their arms, as if to intimidate us, and in descending narrow gulleys we had several times the disagreeable surprise of finding some of his men at a sudden turn, with drawn bows and arrows pointed towards us. Others gesticulated with their long knives, and made fell swoops at soft plantain-stems; but these artifices were all as shallow as they were contemptible, and a smile at such demonstrations was generally answered with another from the actors.

From Katong we ascended the steep east flank of Tendong or Mount Ararat, through forests of Sal and long-leaved pine, to Namten, where we halted two days. The Dingpun Tinli lived near, and waited on us with a present, which, with all others that had been brought, Campbell received officially, and transferred to the authorities at Dorjiling.

The Dewan was thoroughly alarmed at the news here brought in, that the Rajah's present of yaks, ponies, \&c., which had been sent forward, had been refused at Dorjiling; and equally so at the clamorous messages which reached him from all quarters, demanding our liberation; and at the desertion of some of his followers, on hearing that large bodies of troops were assembling at Dorjiling. Repudiated by his Rajah and countrymen, and paralysed between his dignity and his ponies, (which he now perceived would not be welcomed at the station, and which were daily losing flesh, looks, and value in these hot valleys, 
where there is no grass pasture,) he knew not what olive-branch to hold out to our government, except ourselves, whom he therefore clung to as hostages.

On the 22nd of December he marched us eight miles further, to Cheadam, on a bold spur, overlooking the Great Rungeet, and facing Dorjiling, from which it is only twenty miles distant. The white bungalows of our friends gladdened our eyes, while the new barracks erecting for the daily arriving troops struck terror into the Dewan's heart. The six Sepoys* who had marched valiantly beside us for twenty days, carrying the muskets given to the Rajah the year before by the Governor-General, now lowered their arms, and vowed that if a red coat crossed the Great Rungeet, they would throw down their guns and run away. News arrived that the Bhotan inhabitants of Dorjiling, headed by my bold Sirdar Nimbo, had arranged a night attack for our release; an enterprise to which they were quite equal, and in which they have had plenty of practice in their own misgoverned country. Watch-fires gleamed amongst the bushes, we were thrust into a doubly-guarded house, and bows and arrows were ostentatiously levelled so as to rake the doorway, should we attempt to escape. Some of the ponies were sent back, though the Dewan still clung to his merchandise and the feeble hope of traffic. The confusion increased daily, but

* These Sepoys, besides the loose red jacket and striped Lepcha kirtle, wore a very curious national black hat of felt, with broad flaps turned up all round: this is represented in the right-hand figure, in the illustration on the next page. A somewhat similar hat is worn by some classes of Nepal soldiery. 
though Tchebu Lama looked brisk and confident, we were extremely anxious; scouts were hourly arriving from the road to the Great Rungeet, and if our troops

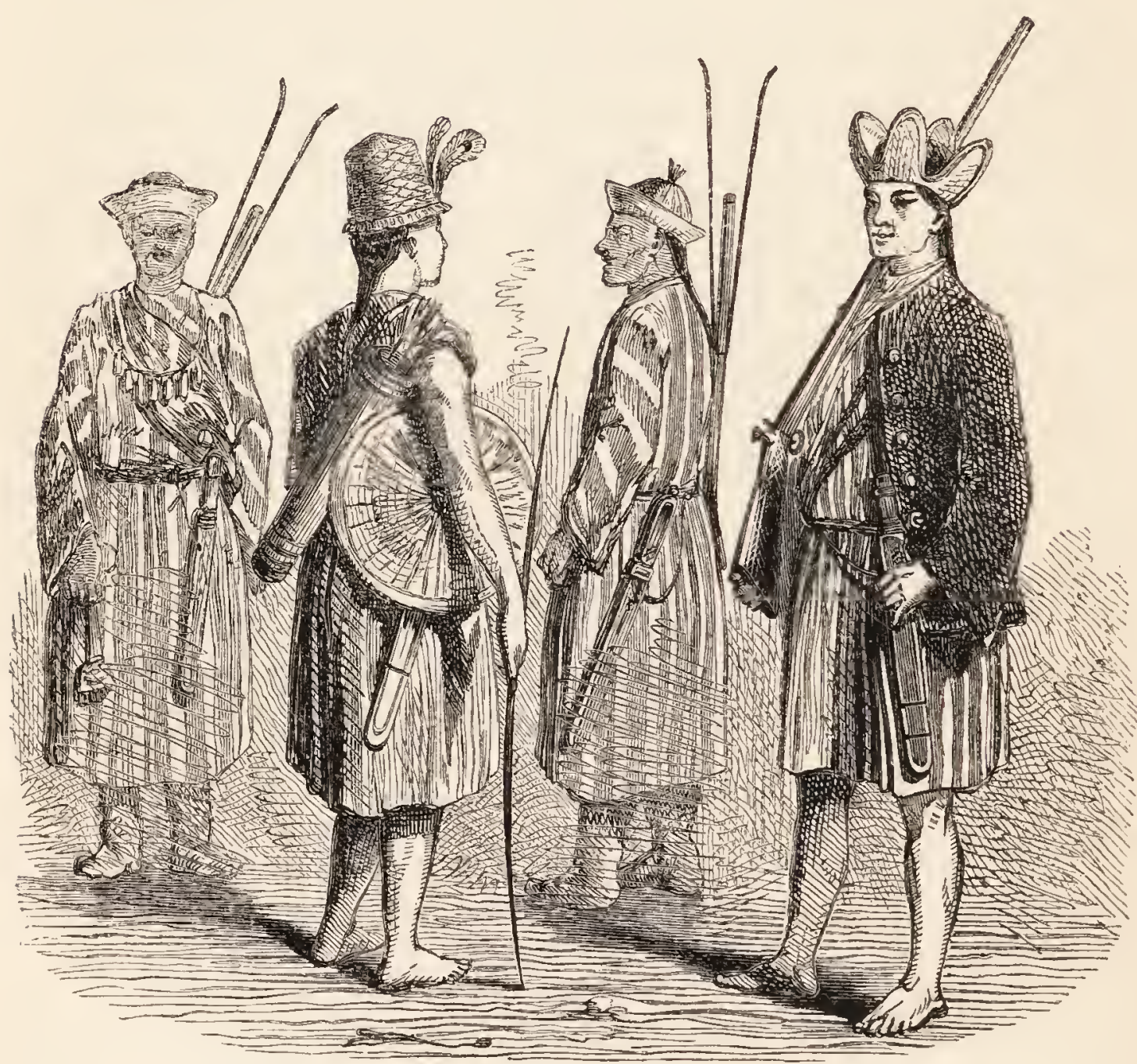

LEPCHA SEPOYS. TIBETAN SEPOYS IN THE BACE-GROUND.

had advanced, the Dewan might have made away with us from pure fear.

One morning he paid us a long visit, and brought some flutes, of which he gave me two very common ones of apricot wood, from Lhassa, producing at the same time a beautiful one, which I believe he intended for Campbell, but his avarice got the better, and he commuted his gift into the offer of a tune, and 
pitching it in a high key, he went through a Tibetan air that almost deafened us by its screech. He tried bravely to maintain his equanimity, but as we preserved a frigid civility, and only spoke when addressed, the tears would start from his eyes in the pauses of conversation. In the evening he came again; he was excessively agitated and covered with perspiration, and thrust himself unceremoniously between us on the bench we occupied. As his familiarity increased, he put his arm round my neck, and since he was armed with a small dagger, I felt rather uneasy about his intentions, but he ended by forcing on my acceptance a coin, value threepence, for he was in fact beside himself with terror.

Next morning Campbell received a hint that this was a good opportunity for a vigorous remonstrance. The Dewan came with Tchebu Lama, his own younger brother (who was his pony-driver), and the Lassoo Kajee; who had for two months placed himself in an attitude of hostility opposite Dorjiling, with a ragged company of followers, but now sought peace and friendship as much as the Dewan. The latter told us he was waiting for a reply to a letter addressed to $\mathrm{Mr}$. Lushington, after which he would set us free. Campbell said: "As you appear to have made up your mind, why not dismiss us at once?" He answered that we should go the next day at all events. Here I came in, and on hearing from Campbell what had passed, I added, that he had better for his own sake let us go at once; that the next day was our great and only annual Poojah (religious festival) of Christmas, when we all 
met; whereas he and his countrymen had dozens in the year. As for me, he knew I had no wife, nor children, nor any relation, within thousands of miles, and it mattered little where $I$ was, he was only bringing ruin on himself by his conduct to me as the GovernorGeneral's friend; but, as regarded Campbell, the case was different; his home was at Dorjiling, which was swarming with English soldiers, all in a state of exasperation, and if he did not let us depart before Christmas, he would find Dorjiling too hot to hold him, let him offer what reparation he might for the injuries he had done us. I added: "We are all ready to godismiss us." The Dewan again turned to Campbell, who said, "I am quite ready; order us ponies at once, and send our luggage after us." He then ordered the ponies, and three men, including Meepo, to attend us; whereupon we walked out, mounted, and made off with all speed.

We arrived at the cane bridge over the Great Rungeet at 4 P.M., and to our chagrin found it in the possession of a posse of ragged Bhoteas, though there were thirty armed Sepoys of our own at the guard-house on the opposite bank. At Meepo's order they cut the network of fine canes by which they had rendered the bridge impassable, and we crossed. The Sepoys at the guard-house turned out with their clashing arms and bright accoutrements, and saluted to the sound of bugles; scaring our three companions, who ran back as fast as they could go. We rode up at once to Dorjiling, and I arrived at 8 P.n. at Hodgson's house, where I was taken for a ghost, and received with shouts of welcome 
by my kind friend and his guest Dr. Thomson, who had been awaiting my arrival for upwards of a month.

Thus terminated our Sikkim captivity, and my last Himalayan exploring journey, which in a botanical and geographical point of view had answered my purposes beyond my most sanguine expectations, though my collections had been in a great measure destroyed by so many untoward events. It enabled me to survey the whole country, and to execute a map of it, and Campbell had further gained that knowledge of its resources which the British Government should all along have possessed, as the protector of the Rajah and his territories.

It remains to say a few words of the events that succeeded our release, in so far as they relate to my connection with them. The Dewan moved from Cheadam to Namtchi, immediately opposite Dorjiling, where he remained throughout the winter. The supreme government of Bengal demanded of the Rajah that he should deliver up the most notorious offenders, and come himself to Dorjiling, on pain of an army marching to Tumloong to enforce the demand; a step which would have been easy, as there were neither troops, arms, ammunition, nor other means of resistance, even had there been the inclination to stop us, which was not the case. The Rajah would in all probability have delivered himself up at Tumloong, throwing himself on our mercy, and the army would have sought the culprits in vain, both the spirit and the power to capture them being wanting on the part of the people and their ruler. 
The Rajah expressed his willingness, but pleaded his inability to fulfil the demand, whereupon the threat was repeated, and additional reinforcements were moved to Dorjiling. The general officer in command at Dinapore was ordered to Dorjiling to conduct operations: his skill and bravery had been proved during the progress of the Nepal war so long ago as 1815. From the appearance of the country about Dorjiling, he was led to consider Sikkim to be impracticable for a British army. This was partly owing to the forestclad mountains, and partly to the fear of Tibetan troops coming to the Rajah's aid, and the Nepalese* taking the opportunity to attack us. With the latter we were in profound peace, and we had a resident at their court; and I have elsewhere shown the impossibility of a Tibet invasion, even if the Chinese or Lhassan authorities were inclined to interfere in the affairs of Sikkim, which they long ago formally declined doing in the case of aggressions of the Nepalese and Bhotanese; the Sikkim Rajah being under British protection.

There were not wanting offers of leading a company of soldiers to Tumloong, rather than that the threat should have twice been made, and then withdrawn; but they were not accepted. A large body of troops was however marched from Dorjiling, and encamped on

* Jung Bahadoor was at this time planning his visit to England, and to his honour I must say, that on hearing of our imprisonment he offered to the government at Calcutta to release us with a handful of men. This he would no doubt have easily effected, but his offer was wisely declined, for the Nepalese want Sikkim and Bhotan too, and we had undertaken the protection of the former country, mainly to keep the Nepalese out of it. 
the north bank of the Great Rungeet for some weeks; but after that period they were recalled without any further demonstration; the Dewan remaining encamped the while on the Namtchi hill, not three hours' march above them. The simple Lepchas daily brought our soldiers milk, fowls, and eggs, and would have continued to do so had they proceeded to Tumloong, for I believe both Rajah and people would have rejoiced at our occupation of the country.

After the withdrawal of the troops, the threat was modified into a seizure of the Terai lands, which the Rajah had originally received as a free gift from the British, and which were the only lucrative or fertile estates he possessed. This was effected by four policemen taking possession of the treasury (which contained exactly twelve shillings, I believe), and announcing to the villagers the confiscation of the territory to the British government, in which they gladly acquiesced. At the same time there was annexed to it the whole southern part of Sikkim, between the Great Rungeet and the plains of India, and from Nepal on the west to the Bhotan frontier, and the Teesta river on the east; thus confining the Rajah to his annual grant of $£ 300$ a year which he formerly received. He has forbidden the culprits his court, but can do no more. The Dewan, disgraced and turned out of office, is reduced to poverty, and is deterred from entering Tibet by the threat of being dragged to Lhassa with a rope round his neck. Considering, however, his energy, a rare quality in these countries, I should not be surprised at his yet cutting a figure in 
Bhotan, if not in Sikkim itself : especially if, at the Rajah's death, the British government should refuse to take the country under their protection. The Singtam Soubah and the other culprits live disgraced at their homes. Tchebu Lama has received a handsome reward, and a grant of land at Dorjiling, where he resides, and whence he sends me his salaams by every opportunity.

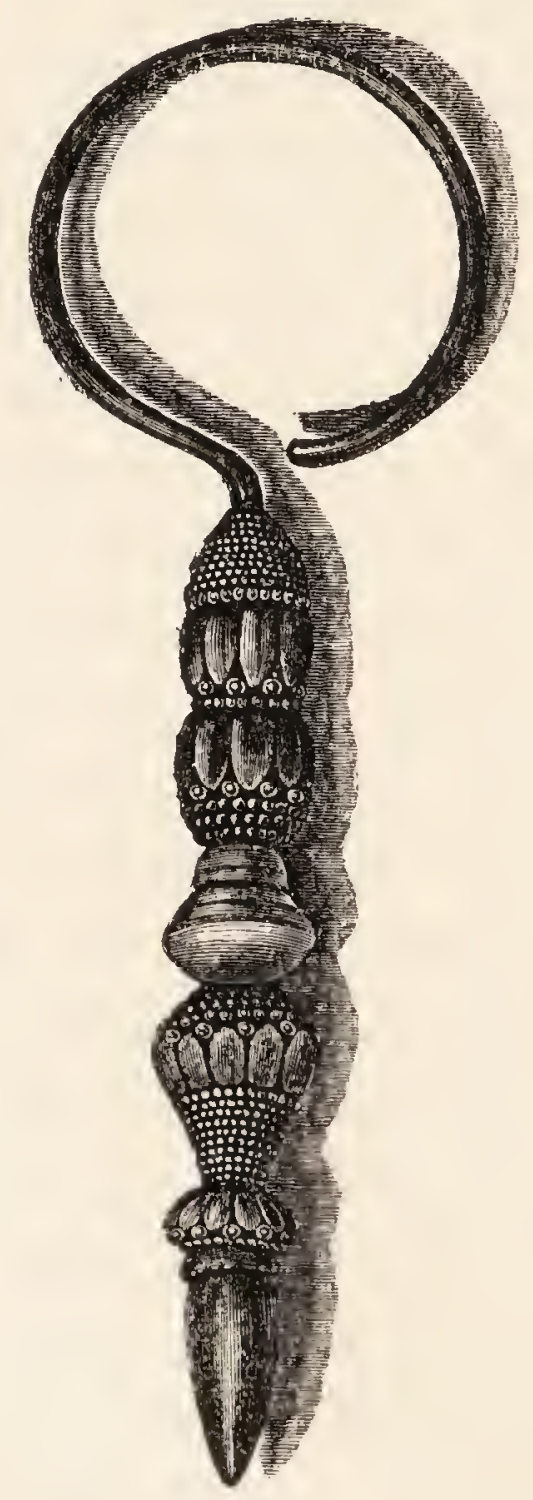

DEWAN'S EAR-RING. 


\section{CHAPTER XXVII.}

Leave Dorjiling for Calcutta-Jung Bahadoor-Dr. Falconer-Improvements in Botanic Gardens - Palmetum - Victoria - AmherstiaOrchids spread by seed-Banyan-Importation of American plants in ice-Return to Dorjiling-Leave with Dr. Thomson for the Khasia mountains-Mahanuddee river-Vegetation of banks-MaldahAlligators-Rampore-Beauleah_Climate of Ganges-Pubna_Jummul river-Altered course of Burrampooter and Megna-Dacca-Conchshells-Saws-Cotton muslins-Fruit-Vegetation-Rose of BengalBurrampooter-Delta of Soormah river-Jheels-Soil-VegetationNavigation-Mosquitos-Effects of geological changes-Imbedding of plants-Teelas or islets - Chattuc-Salubrious climate-Rains Canoes-Pundua-Terrya Ghat-Ascent to Churra-Scenery and vegetation at foot of mountains-Cascades.

I was chiefly occupied during January and February of 1850, in arranging and transmitting my collections to Calcutta, and in completing my manuscripts, maps, and surveys. My friend Dr. Thomson having joined me here, for the purpose of our spending a year in travelling and botanising together, it became necessary to decide on the best field for our pursuits. Bhotan offered the most novelty, but it was inaccessible to Europeans; and we therefore turned our thoughts to Nepal, and, failing that, to the Khasia mountains.

The better to expedite our arrangements I made a 
trip to Calcutta in March, where I expected to meet both Lord Dalhousie, on his return from the Straits of Malacca, and Jung Bahadoor (the Nepalese minister), who was then en route as envoy to England. I stayed at Government House, where every assistance was afforded me towards obtaining the Nepal Rajah's permission to proceed through the Himalaya from Dorjiling to Katmandu. Jung Bahadoor received me with much courtesy, and expressed his great desire to serve me; but begged me to wait until his return from England, as he could not be answerable for my personal safety when travelling during his absence; and he referred to the permission he had formerly given me (and such was never before accorded to any European) in earnest of his disposition, which was unaltered. I therefore made up my mind to spend the season of 1850 in the Khasia mountains in eastern Bengal, at the head of the great delta of the Ganges and Burrampooter.

I devoted a few days to the Calcutta Botanic Gardens, where I found my kind friend Dr. Falconer established and very busy. The destruction of most of the palms, and of all the noble tropical features of the gardens, during Dr. Griffith's incumbency, had necessitated the replanting of the greater part of the grounds, the obliteration of old walks, and the construction of new ; it was also necessary to fill up tanks whose waters, by injudicious cuttings, were destroying some of the most valuable parts of the land, to drain many acres, and to raise embankments to prevent the encroachments of the Hoogly: the latter being a work 


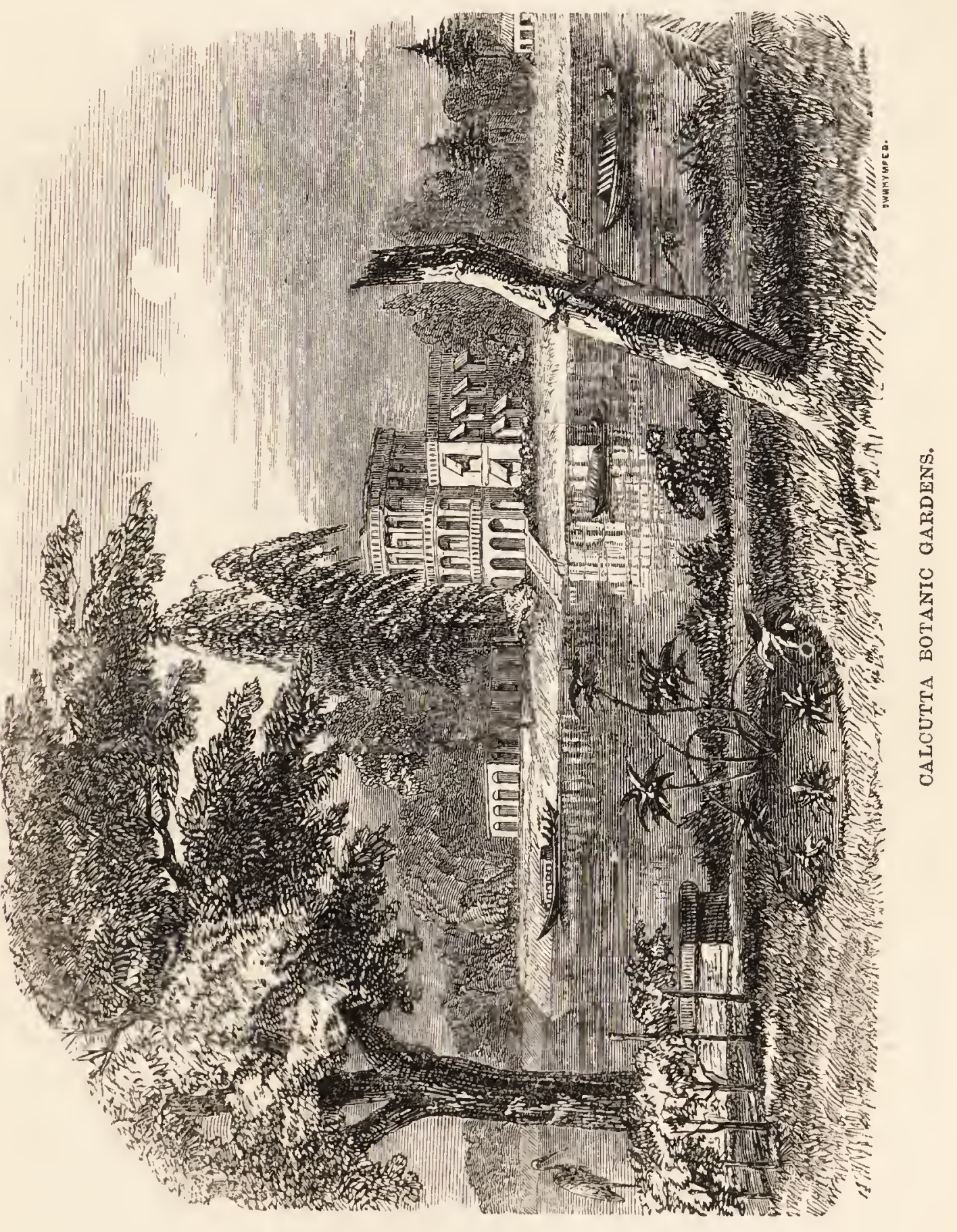


attended with great expense, crippled the resources of the garden library, and other valuable adjuncts; for the trees which were planted for the purpose having been felled and sold, it became necessary to buy timber at an exorbitant price.

The avenue of Sago-palms, once the admiration of all visitors, and which for beauty and singularity was unmatched in any tropical garden, had been swept away by the same unsparing hand which had destroyed the teak, mahogany, clove, nutmeg, and cinnamon groves. In 1847, when I first visited the establishment, nothing was to be seen of its former beauty and grandeur, but a few noble trees or graceful palms rearing their heads over a low ragged jungle, or spreading their broad leaves or naked limbs over the forlorn hope of a botanical garden, that consisted of open clay beds, disposed in concentric circles, and baking into brick under the fervid heat of a Bengal sun. The rapidity of growth is so great in this climate, however, that within eight months from the commencement of the improvements, a great change had already taken place. The grounds bore a park-like appearance, broad shady wallis had replaced the narrow winding paths that ran in distorted lines over the ground, and a large Palmetum, or collection of tall and graceful palms of various kinds, occupied several acres at one side of the garden; whilst a still larger portion of ground was being appropriated to a picturesque assemblage of certain closely allied families of plants, whose association promised to form a novel and attractive object of 
study to the botanist, painter, and landscape-gardener. This consists of groups of all kinds of bamboos, tufted growing palms, rattan-canes, plantains, screwpines, and similar genera of tropical monocotyledonous plants. All are evergreens of the most vivid hue, some of which, having slender trailing stems, form magnificent masses; others twine round one another, and present impenetrable hillocks of green foliage; whilst still others shoot out broad long wavy leaves from tufted roots; and a fourth class is supported by aerial roots, diverging on all sides and from all heights on their stems, every branch of which is crowned with an enormous plume of grasslike leaves.**

The great Amherstia tree had been nearly killed by injudicious treatment, and the baking of the soil above its roots. This defect was remedied by sinking bamboo pipes four feet and a half in the earth, and watering through them. Some fine Orchids were in flower in the gardens, but few of them fruit; some appear to be spread by birds amongst the trees; but the different species of Vanda are increasing so fast, that there seems no doubt that this tribe of air-plants grows freely from seed in a wild state, though we generally fail to rear them thus in England.

The great Banyan tree is still the pricle and orna-

* Since I left India, these improvements have been still further carried out, and I have since heard of five splendid Victoria plants flowering at once, with Euryale ferox, white, blue, and red water lilies, and white, yellow, and scarlet lotus, rendering the tanks gorgeous, sunk as their waters are in frames of green grass, ornamented with clumps of Nipa fruticans and Phonix paludosa. 
ment of the garden.* Dr. Falconer has ascertained satisfactorily that it is only seventy-five years old: annual rings, size, \&c., afford no evidence in such a case, but people were alive a few years ago, who remembered well its site being occupied (in 1782) by a wild Date-palm, out of whose crown the Banyan sprouted, and beneath which a Fakir sat. It is a remarkable fact that the banyan seed rarely vegetates on the ground; but its figs are eaten by birds, and the seeds deposited in the crowns of palms, where they grow, sending down roots that embrace and eventually kill the palm, which decays away. This tree is now eighty feet high, and throws an area 300 feet in diameter into a dark, cool shade. The gigantic limbs spread out about ten feet above the ground, and on Dr. Falconer's arrival there were no more than eighty-nine descending roots or props; there are now several hundreds, and the growth of this grand mass of vegetation is proportionably stimulated and increased. The props are induced to sprout by wet clay and moss tied to the branches, beneath which a little pot of water is hung, and after they have made some progress, they are inclosed in bamboo tubes, and so coaxed down to the ground. They are mere slender whip-cords before reaching the earth, where they root, remaining very

* Had this tree been growing in 1849 over the great palm-stove at Kew, only thirty feet of each end of that vast structure would have been uncovered : its increase was proceeding so rapidly, that by this time it could probably cover the whole. Large banyans are common in Bengal; but few are so symmetrical as this in shape and height. As the tree gets old, it breaks up into separate masses, the original trunk decaying, and the props becoming separate trunks of the different portions. 
lax for several months; but gradually, as they grow and swell to the size of cables, they tighten, and eventually become very tense. This is a curious phenomenon, and so rapid, that it appears to be due to the rooting part mechanically dragging down. the aerial. The branch meanwhile continues to grow outwards, and being supplied by its new support, thickens beyond it, whence the props always slant outwards from the ground towards the circumference of the tree.

During my stay at the gardens, Dr. Falconer received a box of living plants packed in moss, and transported in a frozen state by one of the ice ships from North America: * they left in November, and arriving in March, I was present at the opening of the boxes, and saw 391 plants (the whole contents) taken out in the most perfect state. They were chiefly fruittrees, apples, pears, peaches, currants, and gooseberries, with beautiful plants of the Venus' fly-trap. More perfect success never attended an experiment: the plants were in vigorous bud, and the day after being released from their icy bonds, the leaves sprouted and unfolded, and they were packed in Ward's cases for immediate transport to the Himalaya mountains.

I returned to Dorjiling on the 17th of April, and Dr. Thomson and I commenced our arrangements for proceeding to the Khasia mountains. We started on

* The ice from these ships is sold in the Calcutta market for a penny a pound, to great profit; it has always proved an invaluable remedy in cases of inflammation and fever, and has diminished mortality to a very appreciable extent. 
the Ist of May, and I bade adieu to Dorjiling with no light heart; for I was leaving the kindest and most disinterested friends I had ever made in a foreign land, and a country whose mountains, forests, productions, and people, had all become endeared to me by many ties and associations. The prospects of Dorjiling itself are neither doubtful nor insignificant. Whether or not Sikkim will fall again under the protection of Britain, the station must prosper, and that very speedily. I saw both its native population and its European houses doubled in two years; and its salubrious climate, its scenery, and accessibility, insure it so rapid a further increase that it will become the most populous hill-station in India. Strong prejudices against a damp climate, and the complaints of loungers and idlers who seek pleasure only, together with a groundless fear of the natives, have hitherto retarded its progress; but its natural advantages will outweigh these and all other obstacles.

From Sikkim to the Khasia mountains our course was by boat down the Mahanuddee to the upper Gangetic delta, whose many branches we followed eastwards to the Megna; whence we ascended the Soormah to the Silhet district. We arrived at Kishengunj, on the Màhanuddee, on the 3rd of May, and were delayed two days for our boat, which should have been waiting here to take us to Berhampore on the Ganges.

The approach of the rains was indicated by violent easterly storms of thunder, lightning, and rain; the thermometer ranging from $70^{\circ}$ to, $85^{\circ}$. The country 
around Kishengunj is flat and very barren; it is composed of a deep sandy soil, covered with a short turf, now swarming with cockchafers. Water is found ten or twelve feet below the surface, and may be supplied by underground streams from the Himalaya, distant forty-five miles. The river, which at this season is low, may be navigated up to Titalya during the rains: its bed averages 60 yards in width, and is extremely tortuous; the current is slight, and though shallow, the water is opaque. We slowly descended to Maldah, where we arrived on the 11th: the temperature both of the water and of the air increased rapidly; and the atmosphere became drier as we receded from the mountains.

The boatmen always brought up by the shore at night; and our progress was so slow, that we could keep up with the boat when walking along the bank. So long as the soil and river-bed continued sandy, few bushes or herbs were to be found, and it was difficult to collect a hundred kinds of plants in a day; gradually, however, clumps of trees appeared, with jujube bushes, Acacia, a few fan-palms, bamboos, and Jack-trees. I only saw one shell in the river, which harboured few water-plants or birds, and neither alligators nor porpoises ascend so high.

About eighty miles in a straight line from the foot of the Himalaya the stream contracted, and the features of its banks were materially improved by a jungle of tamarisk, wormwood, and white rose-bushes; whilst mango trees became common, with tamarinds, banyan, and figs. Date and Caryota palms, and rattan-canes, 
grew in the woods, and parasitic Orchids on the trees, which were covered with a climbing fern, so that we easily doubled our flora of the river banks before arriving at Maldah.

This once populous town is, like Berhampore, now quite decayed, since the decline of its silk and indigo trades: the staple product, called "Maldy," a mixture of silk and cotton, very durable, and which washes well, now forms its only trade, and is exported through Sikkim to the north-west provinces and Tibet. It is still famous for the size and excellence of its mangos, which ripen late in May; but this year the crop had been destroyed by the damp heats of spring, the usual north-west dry winds not having prevailed.

The ruins of the once famous city of Gour, a few miles distant, are now covered with jungle, and the buildings are fast disappearing, owing to the bricks being carried away to be used elsewhere.

Below Maldah the river gets broader, and willow becomes common. We found specimens of a Planorbis in the mud of the stream, and saw apparently a boring shell in the alluvium, but could not land to examine it. Chalky masses of alligators' dropping, like coprolites, were very common, buried in the banks, which become twenty feet high at the junction with the Ganges, where we arrived on the 14th. The waters of this great river were nearly two degrees cooler than those of the Mahanuddee.

Rampore-Bauleah is a large station on the north bank of the Ganges, whose stream is at this season fully a mile wide, with a very slow current; its banks 
are thirty feet above the water. We were most kindly received by Mr. Bell, the collector of the district, to whom we were greatly indebted for furthering us on our voyage: boats being very difficult to procure, we were detained here from the 16th to the 19th. The elevation of the station is 130 feet above the sea, that of Kishengunj 131: so that the Gangetic valley is nearly a dead level for fully a hundred miles north, beyond which it rises. As Rampore is at the head of the Gangetic delta, which points from the Sunderbunds obliquely to the north-west, it is much damper than any locality further west, as is evidenced by the abundance of two kinds of palm, which do not ascend the Ganges beyond Monghyr.

From Rampore we made very slow progress southeastwards, with a gentle current, but against constant easterly winds, and often violent gales and thunderstorms, which obliged us to bring up under shelter of banks and islands of sand. Sometimes we sailed along the broad river, whose opposite shores were rarely both visible at once, and at others tracked the boat through narrow creeks that unite the many Himalayan streams, causing them to form a network soon after leaving their mountain valleys.

A few miles beyond Pubna we passed from a narrow canal at once into the main stream of the Burrampooter at Jaffergunj: our maps had led us to expect that this river flowed fully seventy miles to the eastward in this latitude; and we were surprised to hear that within the last twenty years the main body had shifted its course thus far to the westward. This 
alteration was not effected by the gradual working westwards of the main stream, but by the old eastern channel so rapidly silting up as to be now unnavigable; while the Jummul, which receives the Teesta, and which is laterally connected by branches with the Burrampooter, became consequently wider and deeper, and eventually the principal stream.

Nothing can be more dreary and uninteresting than the scenery of this part of the delta. The water is clay-coloured and turbid, always cooler than the air, which again was $4^{\circ}$ or $5^{\circ}$ below that of Calcutta, with a damper atmosphere.

Ascending the Jummul, we turned off into a narrower channel, sixty miles long, which passes by Dacca, where we arrived on the 28th, and where we were again detained for boats. We botanised in the neighbourhood of the town, which was once very extensive, and is still large, though not flourishing. The population is mostly Mahometan; the site, though beautiful and varied, being unhealthy for Europeans. Ruins of great Moorish brick buildings still remain, and a Greek style of ornamenting the houses prevails to a remarkable degree.

The manufacture of rings for the arms and ancles, from conch-shells imported from the Malayan Archipelago, is still almost confined to Dacca: the shells are sawn across for this purpose by semicircular saws, the hands and toes being both actively employed in the operation. The introduction of circular saws has been attempted by some European gentlemen, but steadily resisted by the natives, despite their obvious advan- 
tages. The Dacca muslin manufacture, which once employed thousands of hands, is quite at an end, so that it was with great difficulty that the specimens of these fabrics sent to the Great Exhibition of 1851, were procured. The kind of cotton employed (which is very short in the staple), is now hardly grown, and scarcely a loom exists which is fit for the finest fabrics. The jewellers still excel in gold and silver filagree.

Pine-apples, plantains, mangos, and oranges, abound in the Dacca market, betokening a better climate for tropical fruits than that of Western Bengal; and we also saw the fruit of Euryale ferox, which is round, soft, pulpy, and the size of a small orange; it contains from eight to fifteen round black seeds as large as peas, which are full of flour, and are eaten roasted in India and China, in which latter country the plant is said to have been in cultivation for upwards of 3000 years.

The native vegetation is very similar to that of the Hoogly, except that the white rose is irequent here. The fact of a plant of this genus being as common on the plains of Bengal as a dog-rose is in England, and associated with cocoa-nuts, palms, mangos, plantains, and banyans, has never yet attracted the attention of botanists, though the species was described by Roxburgh. As a geographical fact it is of great importance, for the rose is usually considered a northern genus, and no kind but this inhabits a damp

* An Indian water-lily with a small red flower, covered everywhere with prickles, and closely allied to Victoria regia. 
hot tropical climate. Even in mountainous countries situated near the equator, as in the Himalaya and Andes, wild roses are very rare, and only found at great elevations, whilst they are unknown in the southern hemisphere. It is curious that this rose, which is also a native of Birma and the Indian Peninsula, does not in this latitude grow west of the meridian of $87^{\circ}$; it is confined to the upper Gangetic delta, and inhabits a climate in which a wild rose would least of all be looked for.

We pursued our voyage on the 30th of May, to the old bed of the Burrampooter, an immense shallow sheet of water, of which the eastern bank is for eighty miles occupied by the delta of the Soormah. This river rises on the Munnipore frontier, and flows through Cachar, Silhet, and the Jheels of east Bengal, receiving the waters of the Cachar, Jyntea, Khasia, and Garrow mountains. The immense area thus drained by the Soormah is hardly raised above the level of the sea, and covers 10,000 square miles. The anastomosing rivers that traverse it, flow very gently, and do not materially alter their course; hence their banks gradually rise above the mean level of the surrounding country, and on them the small villages are built, surrounded by extensive rice-fields that need no artificial irrigation. At this season the general surface of the Jheels is marshy; but during the rains, which are excessive on the neighbouring mountains, they resemble an inland sea, the water rising gradually to within a few inches of the floor of the huts; as, however, it subsides as slowly in autumn, it commits no devastation. The 
communication is at all seasons by boats, in the management of which the natives (chiefly Mahometans) are expert.

The want of trees and shrubs is the most remarkable feature of the Jheels; in which respect they differ from the Sunderbunds, though the other physical features of each are similar, the level being exactly the same: for this difference there is no apparent cause, beyond the influence of the tide and sea atmosphere. Long grasses of tropical genera, ten feet high, form the bulk of the vegetation, with occasionally low bushes along the firmer banks of the natural canals that everywhere intersect the country; amongst these the rattan-cane, rose, a laurel, and fig, are the most common; while beautiful convolvuli throw their flowering shoots across the water.

The soil, which is sandy along the Burrampooter, is more muddy and clayey in the centre of the Jheels, with immense spongy accumulations of vegetable matter in the marshes, through which we poked the boat-staves without finding bottom: they were for the most part formed of decomposed grass roots, with occasionally leaves, but no quantity of moss or woody plants. Along the courses of the larger streams drift timber and various organic fragments are no doubt imbedded, but as there is no current over the greater part of the flooded surface, there can be little or no accumulation, except perhaps of old canoes, or of such vegetables as grow on the spot. The waters are darkcoloured, but clear and lucid, even at their height.

We proceeded up the Burrampooter, crossing it 
obliquely; its banks were on the average five miles apart, and formed of sand, without clay, and with very little silt or mud: the water was clear and brown, like that of the Jheels, and very different from that of the Jummul. We thence turned eastwards into the delta of the Soormah, which we traversed in a north-easterly direction to the stream itself. We often passed through very narrow channels, where the grasses towered over the boats: the boatmen steered in and out of them as they pleased, and we were utterly at a loss to know how they guided themselves, as they had neither compass nor map, and there were few villages or landmarks; and on climbing the mast we saw multitudes of other masts and sails peering over the grassy marshes, doing just the same as we did. All that go up have the southwest wind in their favour, and this helps them to their course, but beyond this they have no other guide but that instinct which habit begets. Often we had to retreat from channels that promised to prove short cuts, but which turned out to be blind alleys. Sometimes we sailed up broader streams of chesnut-brown water, accompanied by fleets of boats repairing to the populous districts at the foot of the Khasia, for rice, timber, lime, coal, bamboos, and long reeds for thatching, all of which employ an inland navy throughout the year in their transport to Calcutta.

Leeches and mosquitos were very troublesome, the latter appearing in clouds at night; during the day they were rarer, but the species was the same. A large cray-fish was common, but there were few birds and no animals to be seen. 
To the geologist the Jheels and Sunderbunds are a most instructive region, as whatever may be the mean elevation of their waters, a permanent depression of ten to fifteen feet would submerge an immense tract, which the Ganges, Burrampooter, and Soormah would soon cover with beds of silt and sand. There would be extremely few shells in the beds thus formed, the southern and northern divisions of which would present two very different floras and faunas, and would in all probability be referred by future geologists to widely different epochs. To the north, beds of peat would be formed by grasses; and in other parts, temperate and tropical forms of plants and animals would be preserved in such equally balanced proportions as to confound the palæontologist; with the bones of the long-snouted alligator, Gangetic porpoise, Indian cow, buffalo, rhinoceros, elephant, tiger, deer, boar, and a host of other animals, he would meet with acorns of several species of oak, pine-cones and magnolia fruits, rose seeds, and Cycas nuts, with palm nuts, screw-pines, and other tropical productions. On the other hand, the Sunderbunds portion, though containing the bones of the tiger, deer, and buffalo, would have none of the Indian cow, rhinoceros, or elephant; there would be different species of porpoise, alligator, and deer, and none of the above-mentioned plants, which would be replaced by numerous others, all distinct from those of the Jheels, and many of them indicative of the influence of salt water, whose proximity (from the rarity of sea-shells) might not otherwise be suspected.

On the 1st of June we entered the Soormah, a full YOL. II. 


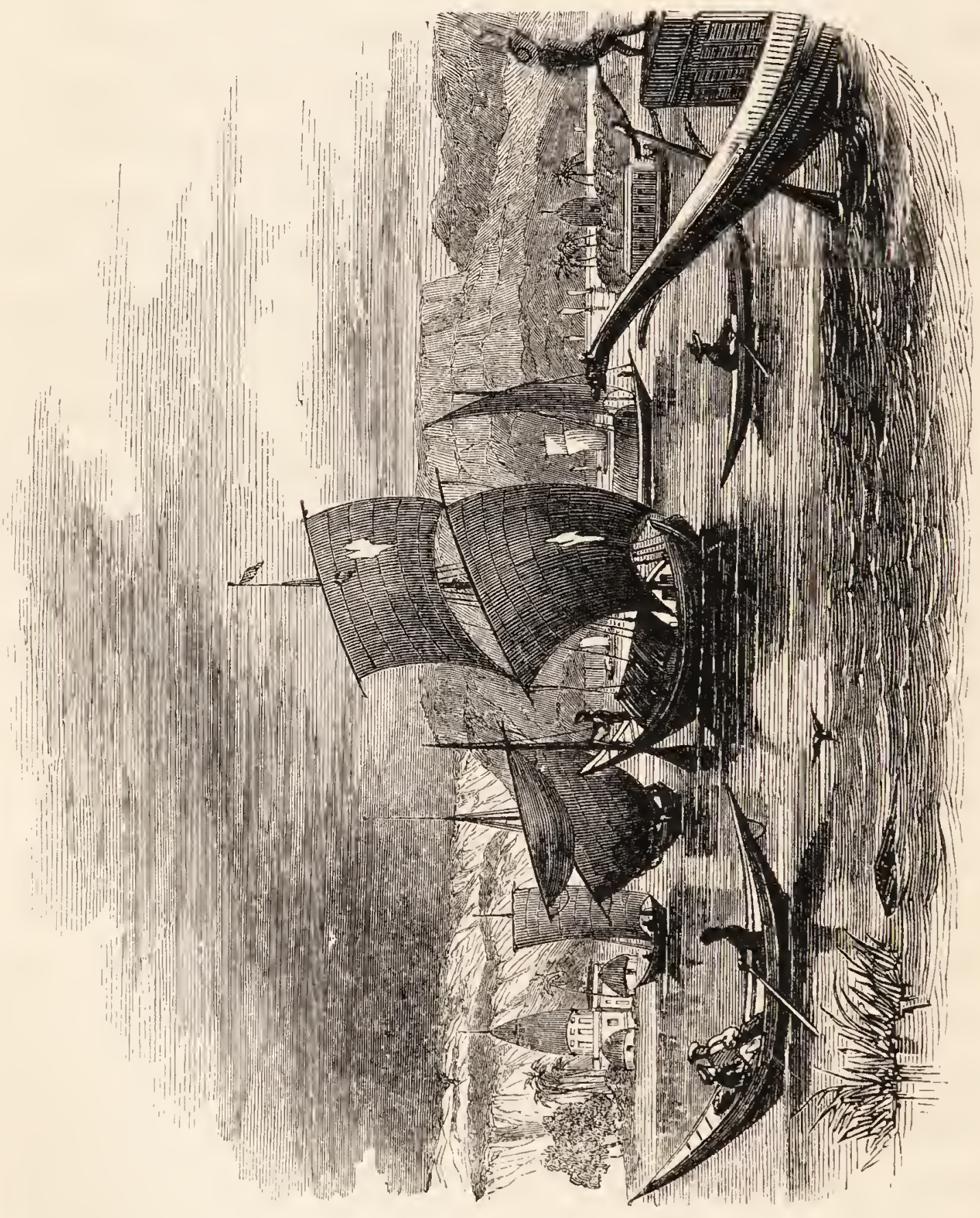

空 
and muddy stream flowing west, a quarter of a mile broad, with banks of mud and clay twelve or fifteen feet high, separating it from marshes, and covered with betel-nut and cocoa-nut palms, figs, and banyans. Many small villages were scattered along the banks, each with a swarm of boats, and rude kilns for burning the lime brought from the Khasia mountains, which is done with grass and bushes. We ascended to Chattuc, against a gentle current, arriving on the 9 th.

From this place the Khasia mountains are seen as a long table-topped range running east and west, about 4000 to 5000 feet high, with steep faces towards the Jheels, out of which they appear to rise abruptly. Though twelve miles distant, large waterfalls are very clearly seen precipitating themselves over the cliffs into a bright green mass of foliage, that seems to creep half way up their flanks. Large valleys enter the hills, and are divided by hog-backed spurs, and it is far within these valleys that the waterfalls and precipices occur; but the nearer and further cliffs being thrown by perspective into one range, they seem to rise out of the Jheels so abruptly as to remind one of some precipitous island in the ocean.

Chattuc is mainly indebted for its existence to the late Mr. Inglis, who resided there for upwards of sixty years, and opened a most important trade between the Khasia and Calcutta in oranges, potatos, coal, lime, and timber. We were kindly received by his son, whose bungalow occupies a knoll, of which there are several, which attracted our attention as being the only elevations fifty feet high which we had met with 
since leaving the foot of the Sikkim Himalaya. They rise 'as islets (commonly called Teela, Beng.) out of the Jheels, within twelve to twenty miles of the Khasia; they are chiefly formed of stratified gravel and sand, and are always occupied by villages and large trees. They seldom exceed sixty feet in height, and increase in number and size as the hills are approached; they are probably the remains of a deposit that was once spread uniformly along the foot of the mountains, and they in all respects resemble those $I$ have described as rising abruptly from the plains near Titalya.

The climate of Chattuc is excessively damp and hot throughout the year, but though sunk amid interminable swamps, the place is perfectly healthy! Such indeed is the character of the climate throughout the Jheels, where fevers and agues are rare; and though no situations can appear more malarious to the common observer than Silhet and Cachar, they are in fact eminently salubrious. These facts admit of no explanation in the present state of our knowledge of endemic diseases. Much may be attributed to the great amount and purity of the water, the equability of the climate, the absence of forests and of sudden changes from wet to dry; but such facts afford no satisfactory explanation.

The rains generally commence in May: they were unusually late this year, though the almost daily gales and thunderstorms we experienced, foretold their speedy arrival. From May till October they are unremitting, and the country is then under water, the Soormah rising about fifty feet. 
China roses and tropical plants rendered Mr. Inglis' bungalow gay, but little else will grow in the gardens. Pine apples are the best fruit, and oranges from the foot of the Khasia; plantains ripen imperfectly, and the mango. is always acid, attacked by grubs, and having a flavour of turpentine. The violent hailstorms of the vernal equinox cut both spring and cold season flowers and vegetables, and the rains destroy all summer products. The soil is a wet clay, in which some European vegetables thrive well if planted in October or November. We were shown marrowfat peas that had been grown for thirty years without degenerating in size, but their flavour was poor.

Small long canoes, paddled rapidly by two men, were procured here, whereby to ascend the narrow rivers that lead up to the foot of the mountains: they each carry one passenger, who lies along the bottom, protected by a bamboo platted arched roof. We started at night, and early the next morning arrived at Pundua, where there is a dilapidated bungalow: the inhabitants are employed in the debarkation of lime, coal, and potatos. Large fleets of boats crowded the narrow creeks, some of the vessels being of several tons' burden.

Elephants were kindly sent here for us by $\mathrm{Mr}$. H. Inglis, to take us to the foot of the mountains, about three miles distant, and relays of mules and ponies to ascend to Churra, where we were received with the greatest hospitality by that gentleman, who entertained us till the end of June, and procured us servants and collectors. 
We spent two days at Pundua, waiting for our great boats (which drew several feet of water), and botanizing in the vicinity. The old bungalow, without windows and with the roof falling in, was a most miserable shelter; and whichever way we turned from the door, a river or a swamp lay before us. Birds, mosquitos, leeches, and large wasps swarmed, also rats and sandflies. A more pestilential hole cannot be conceived; and yet people traverse this district, and sleep here at all seasons of the year with impunity. We did so ourselves in the month of June, when the Sikkim and all other Terais are deadly; we returned in September, traversing the Jheels and nullahs at the very foot of the hills during a short break of fine weather in the middle of the rains; and we again slept here in November,* always exposed in the heat of the day to wet and fatigue, and never having even a soupçon of fever, ague, or rheumatism. This immunity does not, however, extend to the very foot of the hills, as it is considered imprudent to sleep at this season in the bungalow of Terrya, only three miles off, at the very foot of the first rise of the mountains.

The sub-tropical scenery of the lower and outer Sikkim Himalaya, though on a much more gigantic

* At the north foot of the Khasia, in the heavily-timbered dry Terai stretching for sixty miles to the Burrampooter, it is almost inevitable death for a European to sleep, any time between the end of April and of November. Many have crossed that tract, but not one without taking fever : Mr. H. Inglis was the only survivor of a party of five, and he was ill from the effects for upwards of two years, after having been brought to death's door by the first attack, which came on within three weeks of his arrival at Churra, and by several relapses. 
seale, is not comparable in beauty and luxuriance with the really tropical vegetation induced by the hot, damp, and insular climate of these perennially humid mountains. At the Himalaya forests of gigantic trees, many of them deciduous, appear from a distance as masses of dark grey foliage, clothing mountains 10,000 feet high : here the individual trees are smaller, more varied in kind, of a brilliant green, and contrast with grey limestone and red sandstone rocks and silvery cataracts. Palms are more numerous here, upwards of twenty kinds being indigenous; the cultivated betelnut especially, raises its graceful stem and feathery crown, "like an arrow shot down from heaven," in luxuriance and beauty above the verdant slopes. This difference is at once expressed to the Indian botanist by defining the Khasia flora as of Malayan character; by which is meant the prevalence of brilliant glossyleaved evergreen tribes of trees. Figs abound in the hot gulleys, where the property of their roots, which inosculate and form natural grafts, is taken advantage. of in bridging streams, and in constructing what are called living bridges, of the most picturesque forms.* Oaks, oranges, gamboge, Diospyros, figs, Jacks, plantains, and screw-pines are more frequent here, together with vines and peppers, and above all, palms, both climbing ones with pinnated shining leaves, and erect ones with similar foliage (as cultivated cocoa-nut, and Areca), the broader-leaved wild betel-nut, and beautiful Caryota or wine-palm, whose immense leaves are twelve feet long. Laurels and wild nutmegs are frequent in

* See Frontispiece. 
the forest, with the usual prevalence of parasites, mistleto, epiphytical Orchids, ferns, mosses, and Lycopodiums; and on the ground grow ferns, beautiful balsams, and herbaceous and shrubby nettles. Bamboos of many kinds are very abundant, and these hills further differ remarkably from those of Sikkim in the great number of species of grasses.

The ascent was at first gradual, along the sides of a sandstone spur, but at 2000 feet it suddenily became steep and rocky, and at 3000 feet above the sea treevegetation disappeared, and we commanded a magnificent prospect of the upper scarped flank of the valley of Moosmai, with four or five beautiful cascades rolling over the table-top of the hills, broken into silvery foam as they leapt from ledge to ledge of the horizontally stratified precipice, and throwing a veil of silver gauze over the gulf of emerald-green vegetation, 2000 feet below. The views of the many cataracts thus precipitated over the bare table-land on. which Churra stands, into the valleys on either side, surpass anything of the kind that I have elsewhere seen, though in many respects vividly recalling the scenery around Rio de Janeiro: nor do I know any spot in the world more calculated to fascinate the naturalist who, while appreciating the elements of which a landscape is composed, is also keenly alive to the beauty and grandeur of tropical scenery. 


\section{CHAPTER XXVIII.}

Churra, English station of-Khasia people-Garrow people-HousesHabits - Dress - Arms - Dialects - Marriages - Food - FuneralsSuperstitions-Flat of Churra-Scenery-Lime and coal-MamlooCliffs-Cascades-Flora of Churra-Orchids-Rhododendrons-Pine -Climate-Extraordinary rain-fall-Its effects-Gardens of Lieuts. Raban and Cave--Leave Churra to cross the mountain range-Kalapanee river-Lailangkot-Boga-panee river-View of Himalaya-Age of Pine-cones-Moflong plants-Coix-Chillong mountain-Extensive view-Road to Syong-Broad valleys-Myrung-Kollong rock-Pinewoods-Features of country-Orchids-Iron forges.

Churra PoonjI is said to be so called from the number of streams in the neighbourhood, and poonji, "a village" (Khas.) : it was selected for a European station, partly from the elevation and consequent healthiness of the spot, and partly from its being on the high road from Silhet to Gowahatty, on the Burrampooter, the capital of Assam, which is otherwise only accessible by ascending that river, against both its current and the perennial east wind. A rapid postal communication is hereby secured: but the extreme unhealthiness of the northern foot of the mountains effectually precludes all other intercourse for nine months in the year.

On the first opening up of the country, the Europeans 
were brought into sanguinary collision with the Khasias, who fought bravely with bows and arrows, displaying a most blood-thirsty and cruel disposition. This is indeed natural to them; and murders continued very frequent as preludes to the most trifling robberies, until the extreme penalty of our law was put in force. Even now, some of the tributary Rajahs are far from quiet under our rule, and various parts of the country are not safe to travel in. The Garrows, who occupy the western extremity of this range, at the bend of the Burrampooter, are still in a savage state. Human sacrifices and polyandry are said to be frequent amongst them, and their orgies are detestable. Happily we are hardly ever brought into collision with them, except by their occasional depredations on the Assam and Khasia frontier: their country is very unhealthy, but is said to contain abundance of coal, iron, and lime.

We seldom employed fewer than twelve or fourteen of the natives as collectors; and when travelling, from thirty to forty as coolies, \&c. They are averse to rising early, and are intolerably filthy in their persons, though not so in their cottages, which are very poor, with broad grass roofs reaching nearly to the ground, and usually encircled by bamboo fences; the latter custom is not common in savage communities, and perhaps indicates a dread of treachery. The beams are of hewn wood (they do not use saws,) often neatly carved, and the doors turn on good wooden pivots. They have no windows, and the fire is made on the floor: the utensils, \&c. are placed on hanging shelves and in baskets. 
The Khasia people are of the Indo-Chinese race; they are short, very stout, and muscular, with enormous calves and knees, rather narrow eyes and little beard, broad, high cheekbones, flat noses, and open nostrils. I believe that a few are tattooed. The hair is gathered into a top knot, and sometimes shaved off the forehead and temples. A loose cotton shirt, often striped blue and red, without sleeves, and bordered with long thread fringes, is their principal garment; people of rank wear it gathered into a girdle of silver chains. A cotton robe is sometimes added, with a large cotton turban or small skull cap. The women wear a long cloth tied in a knot across the breast. During festivals both men and women load themselves with silk robes, fans, peacocks' feathers, and gold and silver ornaments of great value, procured from Assam, many of which are said to be extremely curious, but I never saw any of them. On these occasions spirits are drunk, and dancing kept up all night: the dance is described as a slow ungraceful motion, the women being tightly swathed in cloths.

All their materials are brought from Assam; the only articles in constant use, of their own manufacture, being a rude sword or knife with a wooden handle and a long, narrow, straight blade of iron; and the baskets with headstraps, like those used by the Lepchas, but much neater; also a netted bag of pineapple fibre (said to come from Silhet) which holds a clasp-knife, comb, flint, steel, and betel-nut box. They are much addicted to chewing pawn (betel nut, pepper leaves, and lime) all day long, and their red saliva 
looks like blood on the paths. Besides the sword I have described, they carry bows and arrows, and rarely a lance, and a bamboo wicker-work shield.

We found the Khasias to be sulky intractable fellows, contrasting unpleasantly with the Lepchas; wanting in quickness, frankness, and desire to please, and obtrusively independent in manner; nevertheless we had a head man who was very much the reverse of this, and whom we had never any cause to blame. Their language is, I believe, Indo-Chinese and monosyllabic: it is disagreeably nasal and guttural, and there are several dialects and accents in contiguous villages. All inflections are made by prefixing syllables, and when using the Hindoo language, the future is invariably substituted for the past tense. They count up to a hundred, and estimate distances by the number of mouthfuls of pawn they eat on the road.

Education has been attempted by missionaries with partial success, and the natives are said to have shown themselves apt scholars. Marriage is a very loose tie amongst them, and hardly any ceremony attends it. We were informed that the husband does not take his wife home, but enters her father's household, and is entertained there. Divorce and an exchange of wives is common, and attended with no disgrace: thus the son therefore often forgets his father's name and person before he grows up, but becomes strongly attached to his mother. The sister's son inherits both property and rank, and the proprietors' or Rajahs' offspring are consequently often reared in porerty and neglect. The 
usual toy of the children is the bow and arrow, with which they are seldom expert; they are said also to spin pegtops like the English, climb a greased pole, and run round with a beam turning horizontally on an upright, to which it is attached by a pivot.

The Khasias eat fowls, and all meat, especially pork, potatos and vegetables, dried and half-putrid fish in abundance, but they have an aversion to milk, which is very remarkable, as a great proportion of their country is admirably adapted for pasturage. In this respect, however, they assimilate to the Chinese, and many Indo-Chinese nations who are indifferent to milk; as are the Sikkim people: the Bengalees, Hindoos, and Tibetans, on the other hand, consume immense quantities of milk. They have no sheep, and few goats or cattle, the latter of which are kept for slaughter ; they have, however, plenty of pigs and fowls. Eggs are most abundant, but used for omens only, and it is a common, but disgusting occurrence, to see large groups employed for hours in breaking them upon stones, shouting and quarrelling, surrounded by the mixture of yellow yokes and their red pawn saliva.

The funeral ceremonies are the only ones of any importance, and are often conducted with barbaric pomp and expense; and rude stones of gigantic proportions ar eerected as monuments, singly or in rows, circles, or supporting one another, like those of Stonehenge, which they rival in dimensions and appearance. The corpse is burned, though seldom during the rains, from the difficulty of obtaining a fire; it is therefore preserved in honey (which is abundant and good) till 
the dry season : a practice said to prevail among some tribes in the Malay peninsula. Spirits are drunk on these occasions; but the hill Khasias are not addicted to drunkenness, though some of the natives of the low valleys are very much so. These ascend the rocky faces of the mountains by ladders, to the Churra markets, and return loaded at night, apparently all but too drunk to stand; yet they never miss their footing in places which are most dangerous to persons unaccustomed to such situations.

The Khasias are superstitious, but have no religion ; like the Lepchas, they believe in a supreme being, and in deities of the grove, cave, and stream. Altercations are often decided by holding the disputants' heads under water, when the longest winded carries his point. Fining is a common punishment, and death for grave offences. The changes of the moon are accounted for by the theory that this orb, who is a man, monthly falls in love with his wife's mother, who throws ashes in his face. The sun is female; and the Pleiades are called "the Hen-man" (as in Italy "the chickens"): they have names for the twelve months; they do not divide their time by weeks, but hold a market every fourth day. These people are industrious, and good cultivators of rice, millet, and legumes of many kinds. Potatos were introduced amongst them about twenty years ago by Mr. Inglis, and they have increased so rapidly that the Calcutta market is now supplied by their produce. They keep bees in rude hives of logs of wood.

The flat table-land on which Churra Poonji is placed, 
is three miles long and two broad, dipping abruptly in front and on both sides, and rising behind towards the main range, of which it is a spur. The surface of this area is everywhere intersected by shallow, rocky watercourses, which are the natural drains for the deluge that annually inundates it. The western part is undulated and hilly, the southern rises in rocky ridges of limestone and coal, and the eastern is very flat and stony, broken only by low isolated conical mounds.

The scenery varies extremely at different parts of the surface. Towards the flat portion, where the English reside, the aspect is as bleak and inhospitable as can be imagined; and there is not a tree, and scarcely a shrub to be seen, except occasional clumps of screw-pine. The low white bungalows are few in number, and very scattered, some of them being a mile asunder, enclosed with stone walls and shrubs; and a small white church, disused on account of the damp, stands lonely in the centre of all.

The views from the margins of this plateau are magnificent : 4000 feet below are bay-like valleys, carpeted as with green velvet, from which rise tall palms, tree-ferms with spreading crowns, and rattans shooting their pointed heads, surrounded with feathery foliage, as with ostrich plumes, far above the great trees. Beyond are the Jheels, looking like a broad shallow sea with the tide half out, bounded in the blue distance by the low hills of Tippera. To the right and left are the scarped red rocks and roaring waterfalls, shooting far over the cliffs, and then arching their necks as they expand in feathery foam, over which 
rainbows float, forming and dissolving as the wind sways the curtains of spray from side to side.

To the south of Churra the lime and coal measures rise abruptly in flat-topped craggy hills, covered with brushwood and small trees. Similar hills are seen far westward across the intervening valleys in the Garrow country, rising in a series of steep isolated ranges, 300 to 400 feet above the general level of the country, and always skirting the south face of the mountains. Considerable caverns penetrate the limestone, the broken surface of which presents many picturesque and beautiful spots, like the same rock in England.

Westward the plateau becomes very hilly, bare, and grassy, with the streams broad and full, but superficial and rocky, precipitating themselves in low cascades over tabular masses of sandstone. At Mamloo their beds are deeper, and full of brushwood, and a splendid valley and amphitheatre of red cliffs and cascades, rivalling those of Moosmai, burst suddenly into view. Mamloo is a large village, on the top of a spur to the westward: it is buried in a small forest, particularly rich in plants, and is defended by a stone wall behind; the only road is tunnelled through the sandstone rock, under the wall; and the spur on either side dips precipitously, so that the place is almost impregnable if properly defended. A sanguinary conflict took place here between the British and the Khasias, which terminated in the latter being driven over the precipices, beneath which many of them were shot. The fanpalm grows on the cliffs near Mamloo: it may be seen on looking over the edge of the plateau, its long curved 


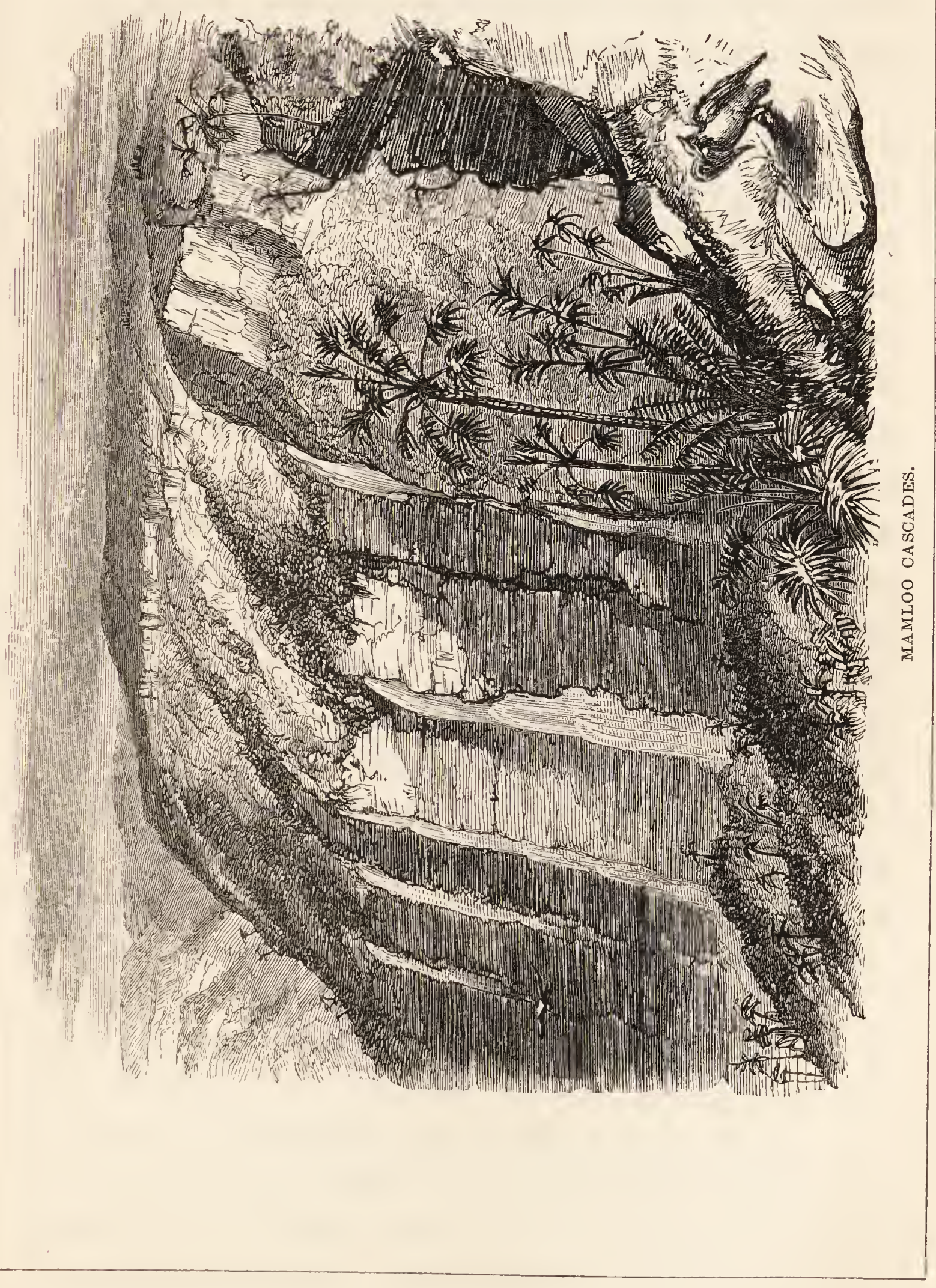


trunk rising out of the naked rocks, but its site is generally inaccessible; while near it grows the Saxifraga ciliaris of our English gardens, a common plant in the north-west Himalaya, but extremely scarce in Sikkim and the Khasia mountains.

It is extremely difficult to give within the limits of this narrative any idea of the Khasia flora, which is, in extent and number of fine plants, the richest in India, and probably in all Asia. We collected upwards of 2000 flowering plants within ten miles of the station of Churra, besides 150 ferns, and a profusion of mosses, lichens, and fungi. This extraordinary exuberance of species is not so much attributable to the elevation, for the whole Sikkim Himalaya (three times more elevated) does not contain 500 more flowering plants, and far fewer ferns, \&e.; but to the variety of exposures; namely, 1. the Jheels, 2. the tropical jungles, both in deep, hot, and wet valleys, and on drier slopes; 3. the rocks; 4 . the bleak table-lands and stony soils; 5. the moorlike uplands, naked and exposed, where many species and genera appear at 5000 to 6000 feet, which are not found on the outer ranges of Sikkim under 10,000. In fact, strange as it may appear, owing to this last cause, the temperate flora descends fully 4000 feet lower in the latitude of Khasia than in that of Sikkim, though the former is two degrees nearer the equator.

Orchideæ are, perhaps, the largest natural order in the Khasia, where fully 250 kinds grow, chiefly on trees and rocks, but many are terrestrial, inhabiting damp woods and grassy slopes. I doubt whether in 
any other part of the globe the species of orchids outnumber those of any other natural order, or form so large a proportion of the flora. Balsams are next in relative abundance (about twenty-five), both tropical and temperate kinds, of great beauty and variety in colour, form, and size of blossom. Palms amount to twenty, of which the Chamerops and Arenga are the only genera not found in Sikkim. Of bamboos there are fifteen, and of other grasses 150, which is an immense proportion, considering that the Indian flora (including those of Ceylon, Kashmir, and all the Himalaya), hardly contains 400 .

No rhododendron grows at Churra, but several species occur a little further north: there is but one pine besides the yew, and that is only found in the drier interior regions. Singular to say, it is a Chinese species not a native of the Himalaya, but very nearly allied to the long-leaved pine, though more closely resembling the Scotch fir than that tree does.

The climate of Khasia is remarkable for the excessive rain-fall. Attention was first drawn to this by Mr. Yule, who stated, that in the month of August, 1841, 264 inches fell, or twenty-two feet; and that during five successive days, thirty inches fell in every twenty. four hours! Dr. Thomson and I also recorded thirty inches in one day and night, and during the seven months of our stay, upwards of 500 inches fell, so that the total annual fall perhaps greatly exceeded 600 inches, or fifty feet, which has been registered in succeeding year's! From April, 1849, to April, 1850, 502 inches (forty-two feet) fell. This unparalleled amount is 
attributable to the abruptness of the mountains which face the Bay of Bengal, from which they are separated by 200 miles of Jheels and Sunderbunds.

This fall is very local: at Silhet, not thirty miles further south, it is under 100 inches; at Gowahatty, north of the Khasia in Assam, it is about 80; and even on the hills, twenty miles inland from Churra itself, the fall is reduced to 200. At the Churra station, the distribution of the rain is very local; my gauges, though registering the same amount when placed beside a good one in the station, when removed half a mile, received a widely different quantity, though the different gauges gave nearly the same mean amount at the end of each month.

The direct effect of this deluge is to raise the little streams about Churra fourteen feet in as many hours, and to inundate the whole flat; from which, however, the natural drainage is so complete, as to render a tract, which in such a climate and latitude should be clothed with exuberant forest, so sterile, that no tree finds support, and there is no soil for cultivation of any kind whatsoever, not even of rice. Owing, however, to the hardness of the sandstone, the streams do not cut deep channels, nor have the cataracts worked far back into the cliffs. The limestone alone seems to suffer, and the turbid streams from it prove how rapidly it is becoming worn away.

The mean temperature of Churra (alt. 4000 feet) is about $66^{\circ}$, or $16^{\circ}$ below that of Calcutta. In summer the thermometer often rises to $90^{\circ}$; and in the winter, owing to the intense radiation, hoar-frost is frequent. 
Such a climate is no less inimical to the cultivation of plants, than is the wretched soil: of this we saw marked instances in the gardens of two of the resident officers, Lieutenants Raban and Cave, to whom we were indebted for the greatest kindness and hospitality. These gentlemen were indefatigable horticulturists, and took a zealous interest in our pursuits, accompanying us in our excursions, enriching our collections in many ways, and keeping an eye to them and to our plant-driers during our absence from the station. In their gardens the soil had to be brought from a considerable distance, and dressed copiously with vegetable matter. Bamboo clumps were planted for shelter within walls, and native shrubs, rhododendrons, \&c., introduced. Many orchids grew well on the branches of the stunted trees which they had planted, and some superb kinds of Hedychium in the ground; but very few English garden plants throve in the flower-beds. Even in pots and frames, geraniums, \&c., would rot, from the rarity of sunshine, which is as prejudicial as the damp and exposure. Still many wild shrubs of great interest and beauty flourished, and some European ones succeeded with skill and management; as geraniums, Salvia, Petunia, nasturtium, chrysanthemum, Kennedya, Maurandya, and Fuchsia. The daisy seed sent from England as double, came up very poor and single. Dahlias do not thrive, nor double balsams. Now they have erected small but airy greenhouses, and sunlight is the only desideratum.

At the end of June, we started for the northern or 
Assam face of the mountains. The road runs between the extensive and populous native village, or poonji, on the left, and a deep valley on the right, and commands a beautiful view of more waterfalls.

We passed Lailang-kot, a village full of iron forges, from a height near which a splendid view is obtained over the Churra fiat. A few old and very stunted shrubs of laurel and Symplocos grow on its bleak surface, and these are often sunk from one to three feet in hollows in the horizontally stratified sandstone. I could only account for these by supposing them to be caused by the drip from the trees, and if so, it is a wonderful instance of the wearing effects of water, and of the great age which small bushes sometimes attain.

At about 5000 feet the country is very open and bare, the ridges being so uniform and flat-topped, that the broad valleys they divide are hidden till their precipitous edges are reached; and the eye wanders far to the east and west over a desolate level grassy country, unbroken, save by the curious flat-topped hills I have before described. These features continue for eight miles, when a sudden descent of 600 or 700 feet, leads into the valley of the Kala-panee (Black water) river, where there is a very dark and damp bungalow, which proved a great accommodation to us.

Beyond the Kala-panee, a high ridge is gained above the valley of the Boga-panee, the largest river in the Khasia; and from this the Bhotan Himalaya may be seen in clear weather, at the astonishing distance of from 160 to 200 miles! The vegetation here suddenly assumes a different aspect, from the quantity of stunted 
fir-trees clothing the north side of the valley, which rises very steeply 1000 feet above the river: quite unaccountably, however, not one grows on the south face. A new oak also appears abundantly; it has leaves like the English, whose gnarled habit it also assumes.

After descending a very steep slope, the road follows a clear affluent of the Boga-panee, and winds along the margin of that river, which is a rapid turbulent stream, very muddy, and hence contrasting remarkably with the Kala-panee. It derives its mud from the decomposition of granite, which is washed by the natives for iron, and in which rock it rises to the eastward. An elegant iron suspension-bridge is thrown across the stream, from a rock matted with tufts of little parasitic orchids. Crossing it, we came on many pine-trees; these had five-years' old cones on them, as well as those of all succeeding years; they bear male flowers in autumn, which impregnate the cones formed the previous year. Thus, the cones formed in the spring of 1850 are fertilised in the following autumn, and do not ripen their seeds till the second following autumn, that of 1852.

A very steep ascent leads to the bungalow of Moflong, on a broad, bleak hill-top, near the axis of the range (alt. 6,062 feet). Hiere there is a village, and some cultivation, surrounded by hedges of Erythrina, Pieris, Viburnum, and Pyrus, amongst which grew an autumn-flowering larkspur, with most fœtid flowers.

We passed the end of June here, and experienced 
the same violent weather, thunder, lightning, gales, and rain, which prevailed during every midsummer I spent in India. A great deal of Coix (Job's tears) is cultivated about Moflong: it is of a dull greenish purple, and though planted in drills, and carefully hoed and weeded, is a very ragged crop. The shell of the cultivated sort is soft, and the kernel is sweet; whereas the wild Coix is so hard that it cannot be broken by the teeth. The produce is small, not above thirty or forty-fold.

From a hill behind Moflong bungalow, on which are some stone altars, a most superb view is obtained to the northward of the Bhotan Himalaya, their snowy peaks stretching in a broken series from north-east to north-west; all are below the horizon of the spectator, though from 17,000 to 20,000 feet above his level. The finest view in the Khasia mountains, and perhaps a more extensive one than has ever before been described, is that from Chillong hill, the culminant point of the range, about six miles north-east from Moflong bungalow. This hill, 6,660 feet above the sea, rises from an undulating grassy country, covered with scattered trees and occasional clumps of wood; the whole scenery being parklike, and as little like that of India at so low an elevation as it is possible to be.

I visited Chillong in October with Lieutenant Cave; starting from Churra, and reaching the bungalow, two miles from its top, the same night, with relays of ponies, which he had kindly provided. We were unfortunate in not obtaining a brilliant view of the 
snowy mountains, their tops being partially clouded; but the coup d'ail was superb. Northward, beyond the rolling Khasia hills, lay the Assam valley, seventy miles broad, with the Burrampooter winding through it, fifty miles distant, reduced to a thread. Beyond this, banks of vapour obscured all but the dark range of the Lower Himalaya, crested by peaks of frosted silver, at the immense distance of from 100 to 220 miles from Chillong. All are below the horizon of the observer; yet so false is perspective, that they seem high in the air. The mountains occupy sixty degrees of the horizon, and stretch over upwards of 250 miles, comprising the greatest extent of snow visible from any point with which $\mathrm{I}$ am acquainted.

Westward from Chillong the most distant Garrow hills visible are about forty miles off; and eastward those of Cachar, which are loftier, are about seventy miles. To the south the view is limited by the Tippera hills, which, where nearest, are 100 miles distant; while to the south-west lies the sea-like Gangetic delta, whose horizon, lifted by refraction, must be fully 120. The extent of this view is therefore upwards of 340 miles in one direction, and the visible horizon of the observer encircles an area of fully thirty thousand square miles, which is greater than that of Ireland!

Continuing northward from Moflong, after five miles, a sudden descent of 400 feet leads to a broad flat grassy valley, called Syong, beyond which the road passes over low rocky hills, wooded on their north or sheltered flanks only, dividing flat-floored valleys.

VOL. II. 
Extensive moors succeed, covered with stunted pines, brake, and tufts of harsh grasses.

We descended to the valley of Myrung, one of the most beautiful spots in the Khasia, and a favourite resort, having a superb view of the Himalaya: it is two miles broad, and full of rice cultivation. There is a guard here of light infantry, and a little garden, boasting a gardener and some tea-plants, so that we had vegetables during our four visits to the place, on two of which occasions we stayed some days.

From Kala-panee to Myrung, a distance of thirtytwo miles, the road does not vary 500 feet above or below the mean level of 5,700 feet, and the features are the same throughout, of broad flat-floored, steepsided valleys, divided by bleak, grassy, tolerably leveltopped hills.

We twice visited a very remarkable hill, called Kollong, which rises as a dome of granite, 5,400 feet high, ten or twelve miles north-west of Myrung, and conspicuous from all directions. The path to it strikes westerly along the shallow valley of Monai, in which is a village, and much cultivation. Near this there is a large square stockade, formed of tall bamboos placed close together, very like a New Zealand "Pa;" indeed, the whole country much recals the grassy clay hills, marshy valleys, and bushy ridges of the Bay of Islands.

The hills on either side are sometimes dotted with pine-woods, sometimes conical and bare, with small clumps of pines on the summit only; while in other places are broad tracts containing nothing but young 
trees, resembling plantations, but which, I was assured, are not planted; on the other hand, however, it is stated that the natives do plant fir-trees, especially near the iron forges, which give employment to all the people of Monai.

All the streams rise in flat marshy depressions amongst the hills with which the whole country is covered; rock is hardly anywhere seen, except in the immediate vicinity of Kollong, where are many scattered boulders of gneiss, of which are made the broad stone slabs, placed as seats, and the other erections of this singular people. We repeatedly remarked cones of earth, clay, and pebbles, about twelve feet high, upon the hills, which appeared to be artificial, but of which the natives could give no explanation. Wild apple and birch are common trees, but there is little jungle, except in the hollows, and on the north slopes of the higher hills. Coarse long grass, with bushes of Labiate and Composite plants, are the prevalent features.

Kollong rock is a steep dome of red granite, accessible from the north and east, but almost perpendicular to the southward. The elevation is 400 feet above the mean level of the surrounding ridges, and 700 above the bottom of the valleys. The south or steepest side is encumbered with enormous detached blocks, while the north is clothed with a dense forest, containing scarlet tree-rhododendrons and oaks; on its skirts grew a white bushy rhododendron, which we found nowhere else. The top was covered with matted mosses, lichens, Lycopodiums, and ferns, 
amongst which were many curious and beautiful airplants.*

The view from the top is very extensive to the northward, commanding the Assam valley and the

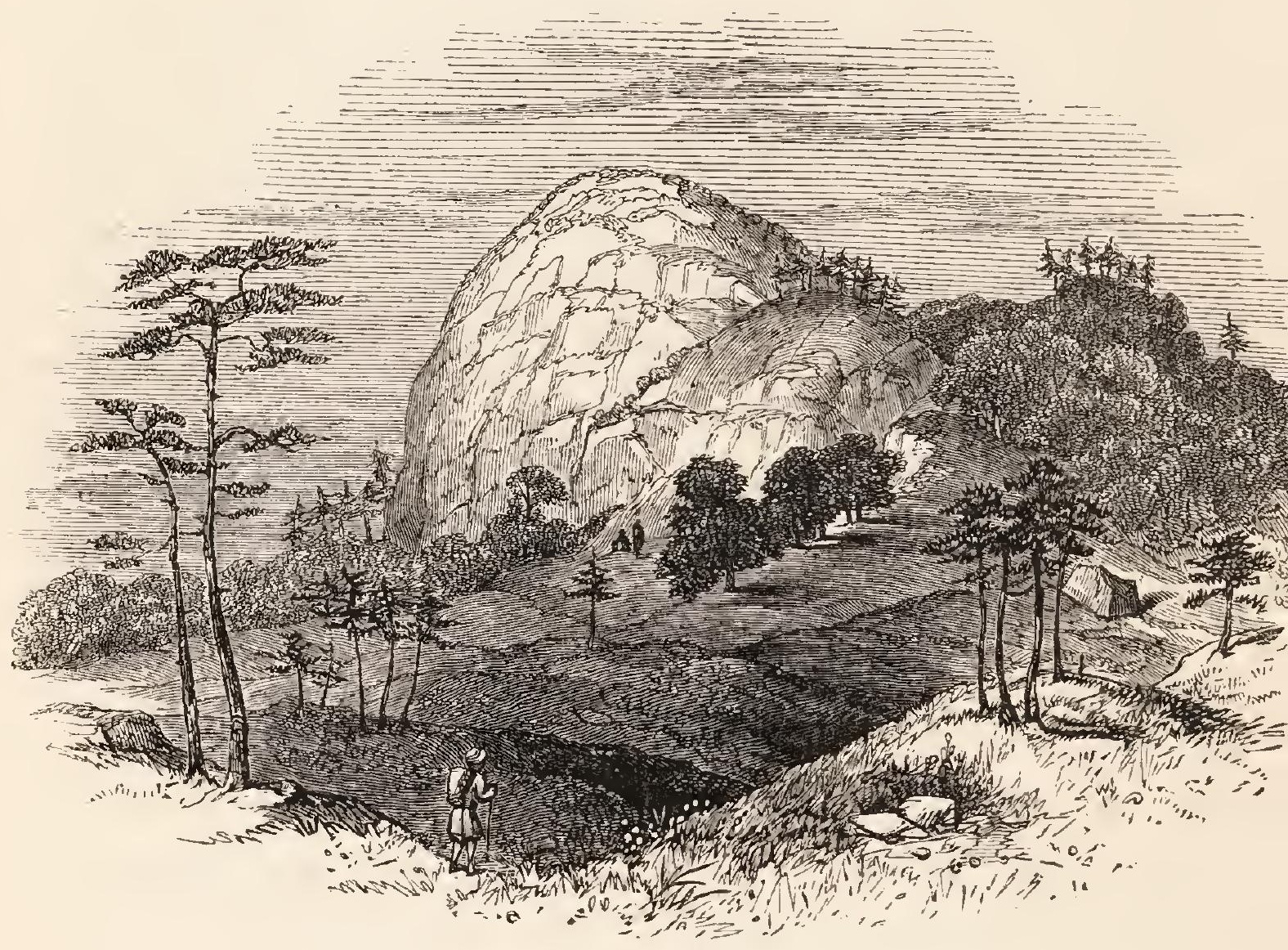

KOLLONG ROCK,

Himalaya, and the billowy range of undulating grassy Khasia mountains. Few houses were visible, but the curling smoke from the valleys betrayed their lurkingplaces, whilst the tinkling sound of the hammers from the distant forges on all sides was singularly musical

* Eria, Calogyne, Cymbidium, Dendrobium, and Sunipia, some of them flowering profusely; and though freely exposed to the sun and wind, dews and frosts, rain and droughts, they were all fresh, bright, green and strong, under very different treatment from that to which they are exposed in the damp, unhealthy, steamy orchid-houses of our English gardens. 
and pleasing; they fell on the ear like "bells upon the wind," each ring being exquisitely melodious, and chiming harmoniously with the others. The solitude and beauty of the scenery, and the emotions excited by the music of chimes, tended to tranquillise our minds, wearied by the fatigues of travel, and the excitement of pursuits that required unremitting attention; and we rested for some time, our imaginations wandering to far-distant scenes, brought vividly to our minds by these familiar sounds.

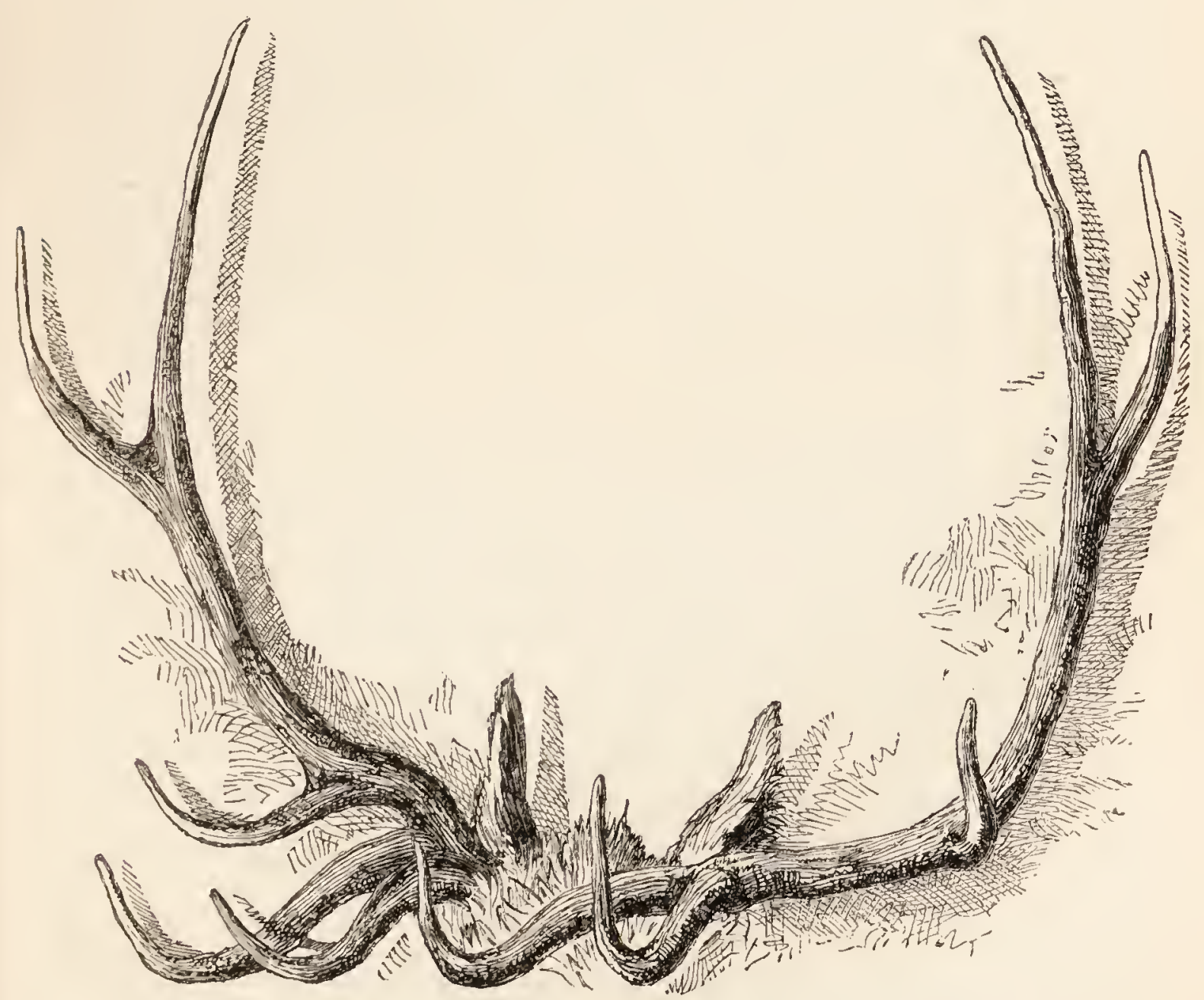

horns of the showa stag (Cerver Wallichii), a Native of Choombi IN TIBET.

Length of antler, 4 feet 6 inches. 


\section{CHAPTER XXIX.}

View of Himalaya from the Khasia-Great masses of snow-ChumulariDonkia-Grasses-Nunklow-Burrampooter-Tropical forest-Borpanee-Rhododendrons-Wild elephants-Blocks of Syenite-Return to Churla-August temperature-Leave for Chela-Birds-Habits of leaf-insects-Curious village-Houses-Canoes-Boga-panee river -Jheels-Chattuc-Churra_-Leave for Jyntea hills-Trading parties -Dried fish-Cherries - Cinnamon - Fraud - Nonkreem - Granite boulders-Iron washing-Forges-Tanks-Siberian Nymphwa-Pomrang-Patchouli plant-Mooshye-Pitcher-plant_Joowye cultivation and vegetation-Sulky hostess-Nurtiung-Sacred grove and gigantic stone structures-Altars-Pyramids, \&c.-Origin of names-Collections-November vegetation.

The snowy Himalaya was not visible during our first stay at Myrung, from the 5th to the 10th of July; but on three subsequent occasions, viz., 27th and 28th of July, 13th to 17th October, and 22nd to 25th October, we saw these magnificent mountains, and repeatedly took angular heights and bearings of the principal peaks. The range, as seen from the Khasia, does not form a continuous line of snowy mountains, but the loftiest eminences are conspicuously grouped into masses, whose position is probably between the great rivers which rise far beyond them and flow through Bhotan.

The most conspicuous group of snows seen from the 
Khasia bears N.N.E. from Myrung, and consists of three beautiful mountains with wide-spreading snowy shoulders. These are distant (reckoning from west to east) respectively 164, 170, and 172 miles from Myrung.

It is singular, that to the eastward of this group, no snowy mountains are seen, and the lower Himalaya also dip suddenly. This depression is no doubt partly due to perspective; but as there is no such sudden disappearance of the chain to the westward, it is far more probable that the valley of the Soobansiri river, which rises in Tibet far behind these peaks, is broad and open; as is that of the Dihong, still farther east, which we have every reason to believe is the Tibetan Yaru or Burrampooter.

Far to the westward again, and distant 200 miles from Myrung, is a very lofty peaked mountain bearing N.N.W., apparently either Chumulari, or that great peak which I saw due east from Bhomtso top, and which $I$ then estimated at ninety miles off and 23,500 feet high. Donkia, if seen, would be distant 230 miles from the same spot in the Khasia, and Kinchinjunga 260 ; possibly they are visible (by refraction) from Chillong, though even further from it.

The distance from Myrung to Nunklow is ten miles, along an excellent road. The descent is at first sudden, beyond which the country is undulating, interspersed with jungle (of low trees, chiefly oaks) and marshes, with much rice cultivation. Grasses are exceedingly numerous; we gathered fifty kinds, besides twenty sedges: four were cultivated, namely sugar- 
cane, rice, Coix, and maize. Most of the others were not so well suited to pasturage as those of higher localities. Dwarf Date palm occurs by the roadside at 5000 feet elevation.

Nunklow is placed at the northern extremity of a broad spur that overhangs the valley of the Burrampooter river, thirty miles distant. The elevation of the bungalow is 4,688 feet, and the climate being hot, it swarms with mosquitos, fleas, and rats. It commands a superb view to the north, of the Himalayan snows, of the Burrampooter, and the intervening malarious Terai; and to the south, of the undulating Khasia, with Kollong rock bearing south-west.

A thousand feet below the bungalow, a tropical forest begins, containing figs, birches, horse-chesnuts, oaks, and nutmegs, in the gulleys, and tall pines on the dry slopes. The pines grow down to the very bottom of the valley in which flows the Bor-panee; many of them are eighty feet high, and three or four in diameter, but none form gigantic trees. The quantity of balsams in the wet ravines is very great, and treeferns of several kinds are common.

The Bor-panee is a broad and rapid river that descends from Chillong, and winds round the base of the Nunklow spur; it is about forty yards wide, and is spanned by an elegant iron suspension-bridge, clamped to the rocks on either bank; beneath the bridge is a series of cascades, none high, but all of great beauty from the broken masses of rocks and picturesque scenery on either side. We frequently botanised along the river with great success: many curious plants grow 
on its rocky banks, and amongst them Rhododendron formosum at the low elevation of 2000 feet. A most splendid fern, Dipteris Wallichii, is abundant, with the dwarf Date palm and Cycas pectinata.

Wild animals are very abundant here, though extremely rare on the higher part of the Khasia range; tigers, however, and bears, ascend to Nunklow. We saw troops of wild dogs, deer, and immense quantities of the droppings of the wild elephant; an animal considered in Assam dangerous to meet, whereas in other parts of India it is not dreaded till provoked. There is, however, no quadruped that varies more in its native state than this; and an experienced judge will tell at once whether the newly caught elephant is from Assam, Silhet, Cuttack, Nepal, or Chittagong. Some of the differences in size, roundness of shoulders and back, quantity of hair, length of limb, and shape of head, are very marked; and their dispositions are equally various.

The Nunklow spur is covered with enormous rounded blocks of syenite, reposing on clay or on one another. These do not descend the hill, and are the remains of an extensive formation which we could only find in situ at one spot on the road to Myrung, but which must have been of immense thickness. One block within ten yards of the bungalow door was fifteen feet long, six high, and eight broad; it appeared half buried, and was rapidly decomposing from the action of the rain. Close by, to the westward, in walking amongst the masses we were reminded of a moraine of most gigantic sized blocks; one which I 
measured was forty feet long and eleven above the ground; its edges were rounded, and its surface flaked off in pieces a foot broad and a quarter of an inch thick. Trees and brushwood often conceal the spaces between these fragments, and afford dens for bears and leopards, into which man cannot follow them.

Sitting in the cool evenings on one of these great blocks, and watching the Himalayan glaciers glowing with the rays of sunset, appearing to change in form and dimensions with the falling shadows, it was impossible to refrain from speculating on the possibility of these great boulders heaped on the Himalayan-ward face of the Khasia range, having been transported thither by ice at some former period; especially as the Mont Blanc granite, in crossing the lake of Geneva to the Jura, must have performed a hardly less wonderful ice journey: but this hypothesis is clearly untenable; and unparalleled in our experience as the results appear, if attributed to denudation and weathering alone, we are yet compelled to refer them to these causes. The further we travel, and the longer we study, the more positive becomes our conviction that the part played by these great agents in sculpturing the surface of our planet, is as yet but half recognised.

We returned on the 7th of August to Churra, where we employed ourselves during the rest of the month in collecting and studying the plants of the neighbourhood. We hired a large and good bungalow, in which three immense coal fires were kept up for drying plants and papers, and fifteen men were always employed, 
some in changing, and some in collecting, from morning till night. The coal was procured within a mile of our door, and cost about six shillings a month; it was of the finest quality, and gave great heat and few ashes. Torrents of rain descended almost daily, twelve inches in as many hours being frequently registered.

Though the temperature in August rose to $75^{\circ}$, we never felt a fire oppressive, owing to the constant damp, and absence of sun. The latter, when it broke through the clouds, shone powerfully, raising the thermometer $30^{\circ}$ in as many minutes. On such occasions, hot blasts of damp wind ascend the valleys, and impinge suddenly against different houses on the flat, giving rise to extraordinary differences between the mean daily temperatures of places not half a mile apart.

On the 4th of September we started for the village of Chela, which lies west from Churra, at the embouchure of the Boga-panee on the Jheels. The path runs through very tropical vegetation, with pepper, ginger, maize, and Betel palm, cultivated around small cottages, which are only distinguishable in the forest by their yellow thatch of dry Rattan leaves.

Hot gusts of wind blow up the valleys, alternating with clouds and mists, and it was curious to watch the effects of the latter in stilling the voices of insects and birds. Common crows and vultures haunt the villages, but these, and all other large birds, are very rare in the Khasia. A very few hawks are occasionally seen, also sparrows and kingfishers, and $\mathrm{I}$ once heard a cuckoo; pheasants are sometimes shot, but we never 
saw any. Kites become numerous after the rains, and are regarded as a sign of their cessation. More remarkable than the rarity of birds is the absence of all animals except domestic rats, as a more suitable country for hares and rabbits could not be found. Reptiles, and especially snakes, are very common in the Khasia mountains, and I procured sixteen species and many specimens. The natives repeatedly assured us that these were all harmless, and Dr. Gray, who has kindly examined all my snakes, informs me of the remarkable fact that whereas none of these are poisonous, four out of the eleven species which I found in Sikkim are so. One of the Khasia blind-worms belongs to a truly American genus, a fact as important as is that of the Sikkim skink and Agama being also American forms.

The curious leaf-insect (Mantis) was very abundant on the orange trees, on the leaves of which the natives believe it to feed; nor indeed could we persuade some of our friends that its thin sharp jaws are unsuited for masticating leaves, and that these and its prehensile feet indicate its predacious nature: added to which, its singular resemblance to a leaf is no less a provision against its being discovered by its enemies, than an aid in deceiving its prey.

We descended rapidly for many miles through beautiful woods, with villages nestling amongst groves of banana and trellised climbers; and from the brow of a hill looked down upon a slope covered with vegetation and huts, which formed the mart of Chela, and below which the Boga-panee flowed in a deep 


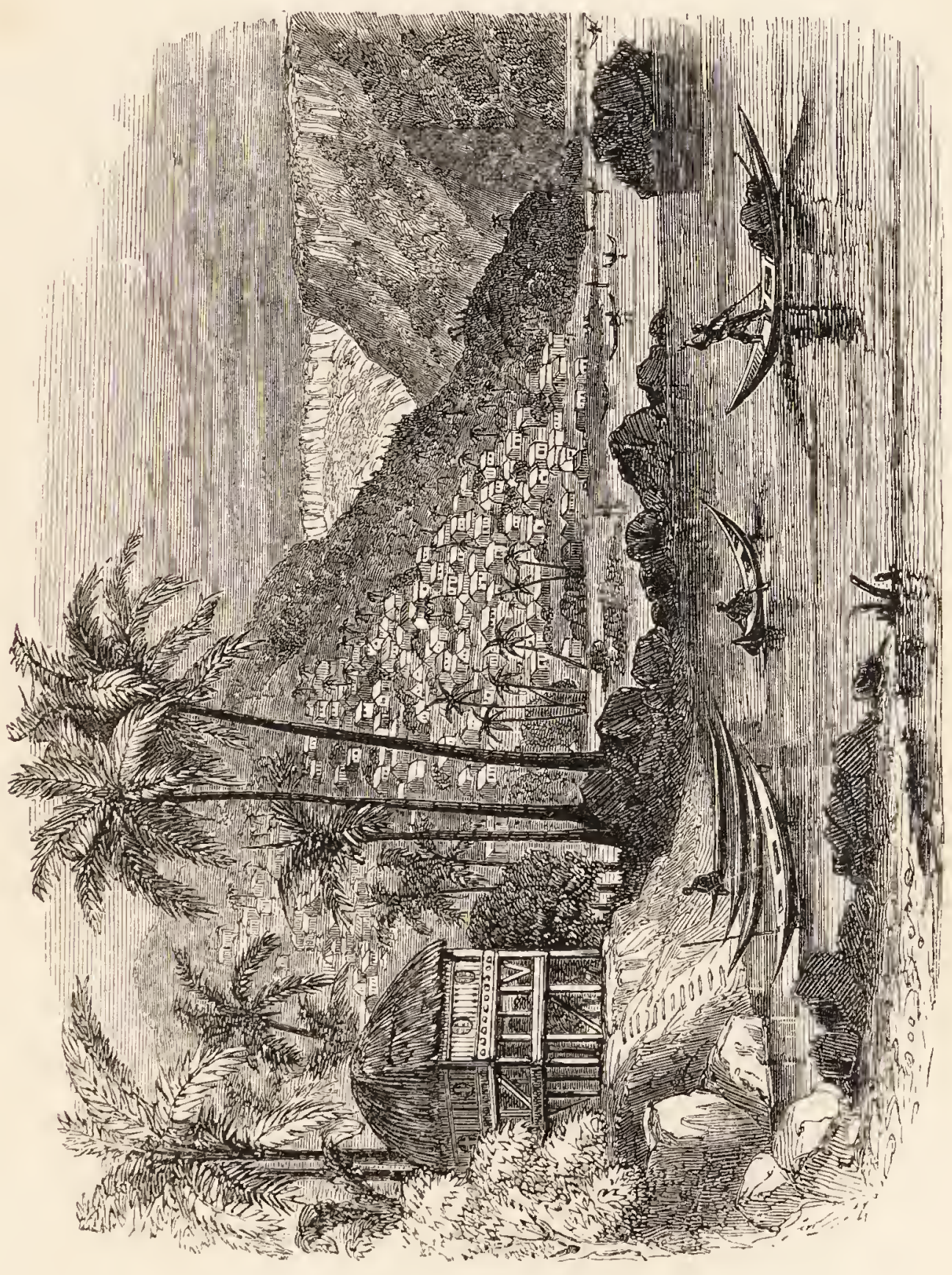


gorge. The view was a very striking one : owing to the steepness of the valley, the roofs alone of the cottages were visible, from which ascended the sounds and smells of a dense native population, and to which there appeared to be no way of descending. The opposite side rose precipitously in lofty table-topped mountains, and the river was studded with canoes.

The descent was fully 800 feet. The cottages were placed close together, each within a little bamboo enclosure, eight to ten yards deep; each was built against a perpendicular wall which supported a cutting in the bank behind; and a similar wall descended in front of it, forming the back of the compartment in which the cottage next below it was erected. The houses were often raised on platforms, and some had balconies in front, which overhung the cottage below. All were mere hollows of wattle or mud, with very high-pitched roofs: stone tanks resembling fonts, urns, coffins, and sarcophagi, were placed near the better houses, and blocks of stone were scattered everywhere.

We descended alternately along the gravelled flat of each enclosure, and perpendicularly down steps cut in the sandstone or let into the walls. I counted 800 houses from the river, and there must be many more; the inhabitants are Bengalees and Khasias, and perhaps amount to 3000 or 4000 ; but this is a very vague estimate.

We lodged in a curious house, consisting of one apartment, twenty feet long, and five high, raised thirty feet upon bamboos: the walls were of platted bamboo 
matting, fastened to strong wooden beams, and one side opened on a balcony that overhung the river. The entrance was an oval aperture reached by a ladder, and closed by folding doors that turned on wooden pivots. The roof was supported by tressels of great thickness, and like the rest of the woodwork, was morticed, no nails being used throughout the building. The floor was of split bamboos laid side by side.

After staying three days at Chela, we descended the stream in canoes, shooting over pebbly rapids, and amongst rocks of limestone, water-worn into fantastic shapes, till we at last found ourselves gliding gently along the still canals of the Jheels. Many of these rapids are so far artificial, that they are enclosed by gravel banks, six feet high, which, by confining the waters, give them depth; but Chela being hardly above the level of the sea, their fall is very trifling. We proceeded across the Jheels to Chattuc, and then north again to Pundua, and so to Churra.

Having pretty well exhausted the botany of Churra, Dr. Thomson and I started on the 13th of September for the eastern part of the Khasia and Jyntea mountains. On the Kala-panee road, which we followed, we passed crowds of market people, laden with dried fish in a half-putrid state, which scented the air for many yards: they were chiefly carp, caught and dried at the foot of the hills. Large parties were bringing down baskets of bird-cherries, cinnamon-bark, iron, pine planks, fire-wood, and potatos. Of these, the birdcherries (like damsons) are made into an excellent preserve by the English residents, who also make 
eapital cherry-brandy of them: the trade in cinnamon is of recent introduction, and is much encouraged by the Inglis family, to whose exertions these people are so greatly indebted; the cinnamon is the peeled bark of a small species, allied to that of Ceylon, and though inferior in flavour, and mucilaginous (like cassia), finds a ready market at Calcutta. It has been used to adulterate the Ceylon cinnamon; and an extensive fraud was attempted by some Europeans at Calcutta, who sent boxes of this, with a top layer of the genuine, to England. The smell of the cinnamon loads was as fragrant as that of the fish was offensive.

In the evening we arrived at Nonkreem, a large village in a broad marshy valley, where we procured accommodation with some difficulty, the people being by no means civil, and the Rajah holding himself independent of the British Government.

Atmospheric denudation and weathering have produced remarkable effects on the lower part of the Nonkreem valley, which is blocked up by a pine-crested hill, 200 feet high, entirely formed of round blocks of granite, heaped up so as to resemble an old moraine; but like the Nunklow boulders, these are not arranged as if by glacial action. The granite is very soft, decomposing into a coarse reddish sand, that colours the Boga-panee. To procure the iron sand, which is disseminated through it, the natives conduct water over the beds, and as the lighter particles are washed away, the remainder is removed to troughs, where the separation of the ore is completed. The smelting is very rudely carried on in charcoal fires, blown by enormous double- 
action bellows, worked by two persons, who stand on the machine, raising the flaps with their hands, and expanding them with their feet, as shown in the cut on the next page. There is neither furnace nor flux used in the reduction. The fire is kindled on one side of an

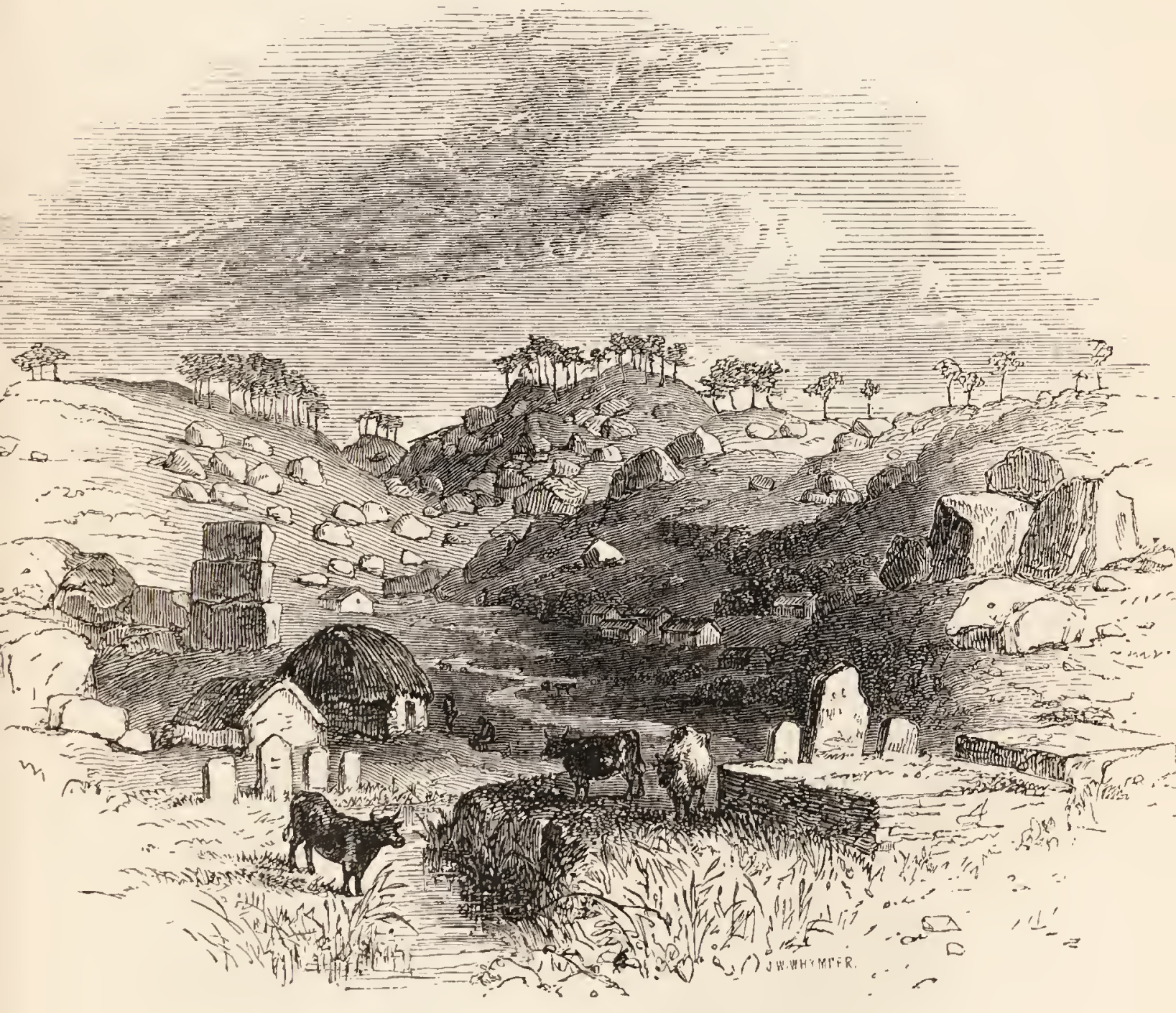

NONKREEM VILLAGE.

upright stone (like the head-stone of a grave), with a small arched hole close to the ground: near this hole the bellows are suspended; and a bamboo tube from each of its compartments, meet in a larger one, by which the draft is directed under the hole in the stone 
to the fire. The ore is run into lumps as large as two fists, with a rugged surface: these lumps are afterwards cleft nearly in two to show their purity.

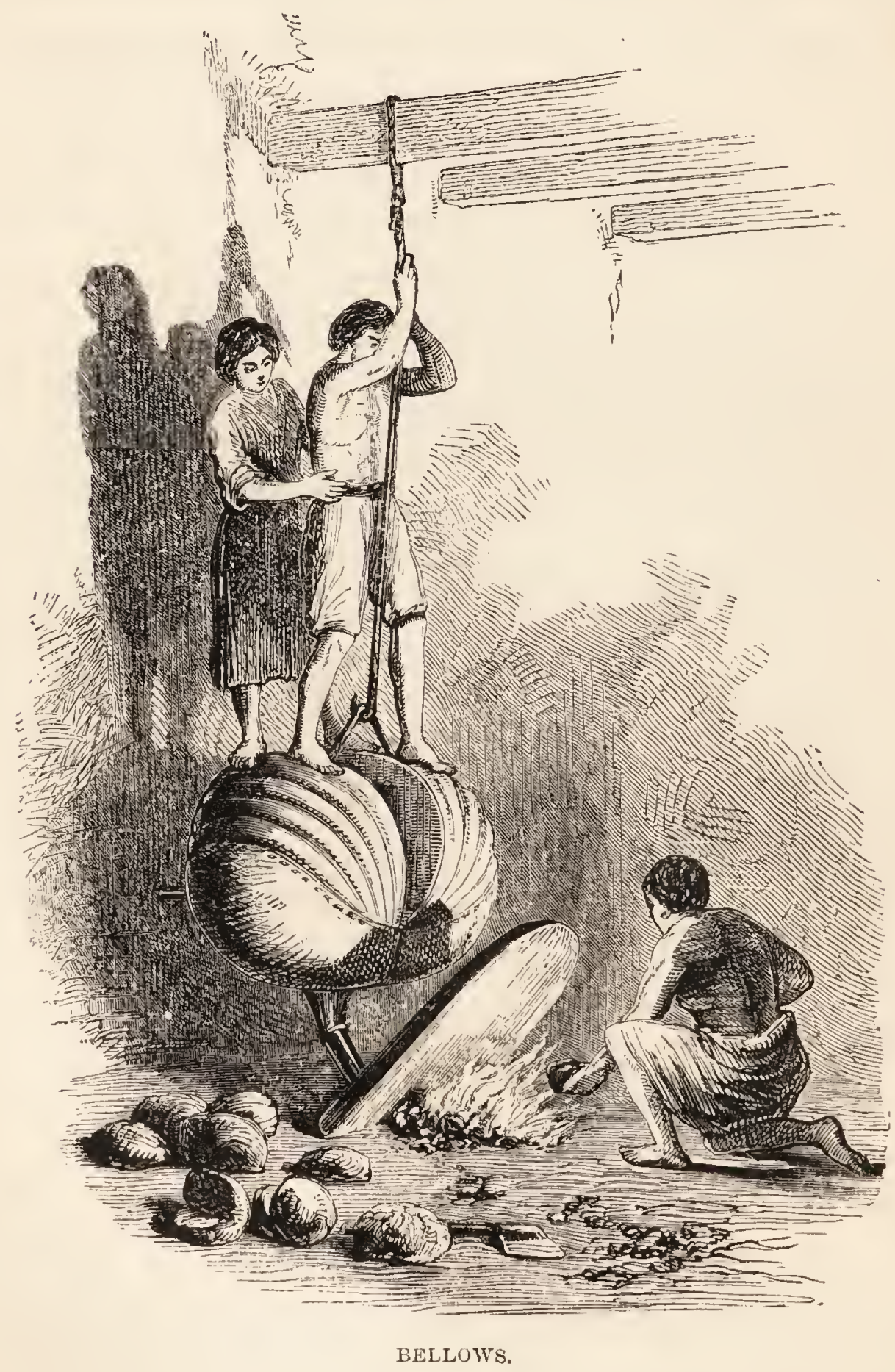

The scenery about Nonkreem village is extremely picturesque, and we procured many good plants on the rocks. The country is everywhere intersected with 
trenches for iron-washing, and some large marshes were dammed up for the same purpose: in these we found a diminutive water-lily, the flower of which is no larger than a half-crown; it proves to be the Nymphea pygmea of China and Siberia-a remarkable fact in the geographical distribution of plants.

From Nonkreem we proceeded easterly to Pomrang, where we took up our quarters in an excellent bungalow, built by Mr. Stainforth (Judge of Silhet). It occupied the eastern extremity of a lofty spur that overhangs the deep fir-clad valley of the Oongkot, dividing Khasia from Jyntea.

A beautiful view extends eastwards to the low Jyntea hills, backed by the blue mountains of Cachar, over the deep valley in front; to the northward, a few peaks of the Himalaya are seen, and westward is Chillong. We staid here till the 23rd September, and then proceeded south-eastwards to Mooshye. The path descends into the valley of the Oongkot, passing the village of Pomrang, and then through woods of pine and oak, the latter closely resembling the English, and infested with galls. The slopes are extensively cultivated with black awnless unirrigated rice, and poor crops of Coix, protected from the birds by scarecrows of lines stretched across the fields, bearing tassels and tufts of fern, shaken by boys.

We crossed the river twice, proceeding south-west to Mooshye, a village placed on an isolated, flat-topped, and very steep-sided hill, 4,863 feet above the sea. A very steep path led up to the top, where there is a stockaded guard-house, once occupied by British 
troops, of which we took possession. A Labiate plant (Mesona Wallichiana) grew on the ascent, whose bruised leaves smelt as strongly of patchouli, as do those of the plant producing that perfume, to which it is closely allied. The patchouli plant has been said to occur in these parts of India, but we never met with it, and doubt the accuracy of the statement. It is a native of the Malay peninsula, whence the leaves are imported into Bengal, and so to Europe.

On the 25th we left Mooshye for Amwee in Jyntea, which lies to the south-east. We descended by steps

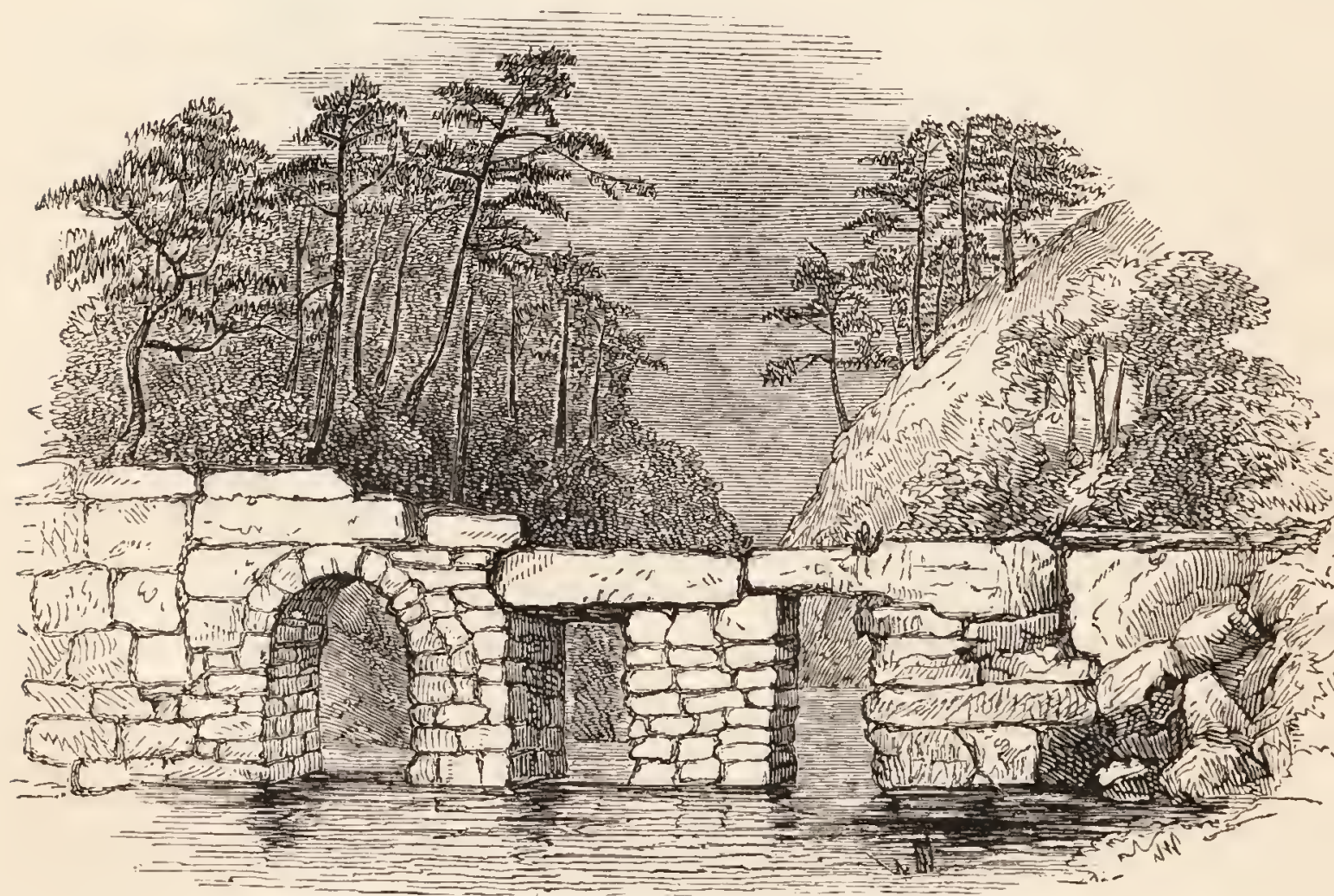

OLD BRIDGE AT AMWEE.

cut in the sandstone, and fording the Oongkot, climbed the hills on its east side, along the grassy tops of which we continued, at an elevation of 4000 feet. Marshy flats intersect the hills, to which wild elephants some- 
times ascend, doing much damage to the rice crops. The pitcher-plant (Nepenthes) grows on stony and grassy hills about Amwee, and crawls along the ground; its pitchers seldom contain insects in the wild state, nor can any special function be suggested for the wonderful organ it possesses.

About eight miles south of the village is a bridge, half of which is formed of slabs of stone (of which one is twenty-one feet long, seven broad, and two feet three and a half inches thick), supported on piers, and the rest is a well turned arch, such as I have not seen elsewhere among the hill tribes of India. It is fast crumbling away, and is covered with tropical plants, and a beautiful white-flowered orchis grew in the mossy crevices of its stones.

From Amwee our route lay north-east across the Jyntea hills to Joowye, the hill-capital of the district. The path gradually ascended, dipping into valleys occupied by fields of rice in which were placed gigantic images of men, dressed in rags, and armed with bows and arrows, to scare away the wild elephants!

The situation of Joowye is extremely beautiful: it occupies the broken wooded slope of a large open flat valley, dotted with pines; and consists of an immense number of low thatched cottages, scattered amongst groves of bamboo, and fields of plantain, tobacco, yams, sugar-cane, maize, and rice, surrounded by hedges of bamboo, Colquhounia and Erythrina. Narrow steep lanes lead amongst these, shaded with oak, birch, and Camellia, the larger trees being covered with orchids, climbing palms, pepper, and Gnetum; 
while masses of beautiful red and violet balsams grew under every hedge and rock.

We procured a good house after many delays, for the people were far from friendly to Europeans; it was a clean, very long cottage, with low thatched eaves almost touching the ground, and was surrounded by a high bamboo paling that enclosed out-houses built on a well-swept floor of beaten earth. Within, the woodwork was carved in curious patterns, and was particularly well fitted. The old lady to whom it belonged got tired of us before two days were over, and first tried to smoke us out by a large fire of green wood at that end of the cottage which she retained; and afterwards by inviting guests to a supper, with whom she kept up a racket all night. Her son, a tall, sulky fellow, came to receive the usual gratuity on our departure, which we made large to show we bore no ill-will: he, however, behaved so scornfully, pretending to despise it, that I had no choice but to pocket it again; a proceeding which was received with shouts of laughter, at his expense, from a large crowd of bystanders.

On the 30th of September we proceeded north-east from Joowye to Nurtiung, crossing the watershed of the Jyntea range, which is scarcely raised above the mean level of the hills; it is about 4,500 feet elevation. To the north the descent is rather abrupt to a considerable stream, beyond which is the village of Nurtiung.

The ascent to the village from the river is by steps cut in a narrow cleft of the rocks, to a flat, elevated 4,178 feet above the sea: we here procured a cottage, 
and found the people remarkably civil. The general appearance is the same as at Joowye, but there are here extensive and very unhealthy marshes, whose evil effects we experienced, in having the misfortune to lose one of our servants by fever. Except pines, there are few large trees; but the quantity of species of perennial woody plants contributing to form the jungles is quite extraordinary: we enumerated 140, of which 60 were trees or large shrubs above twenty feet high.

Nurtiung contains a most remarkable collection of those sepulchral and other monuments, which form so curious a feature in the scenery of these mountains, and in the habits of their native population. They are all placed in a fine grove of trees, occupying a hollow; where several acres are covered with gigantic, generally circular, slabs of stone, from ten to twentyfive feet broad, supported five feet above the ground upon other blocks. For the most part they are buried in brushwood of nettles and shrubs, but in one place there is an open area of fifty yards encircled by them, each with a gigantic headstone behind it. Of the latter the tallest was nearly thirty feet high, six broad, and two feet eight inches in thickness, and must have been sunk at least five feet, and perhaps much more, in the ground. They are erected by dint of sheer brute strength, the lever being the only aid.

Splendid trees of Bombax, fig and banyan, overshadowed them: the largest banyan had a trunk five feet in diameter, clear of the buttresses, and numerous small trees of Celtis grew out of it, and an immense flowering tuft of Vanda carulea (the rarest and most 


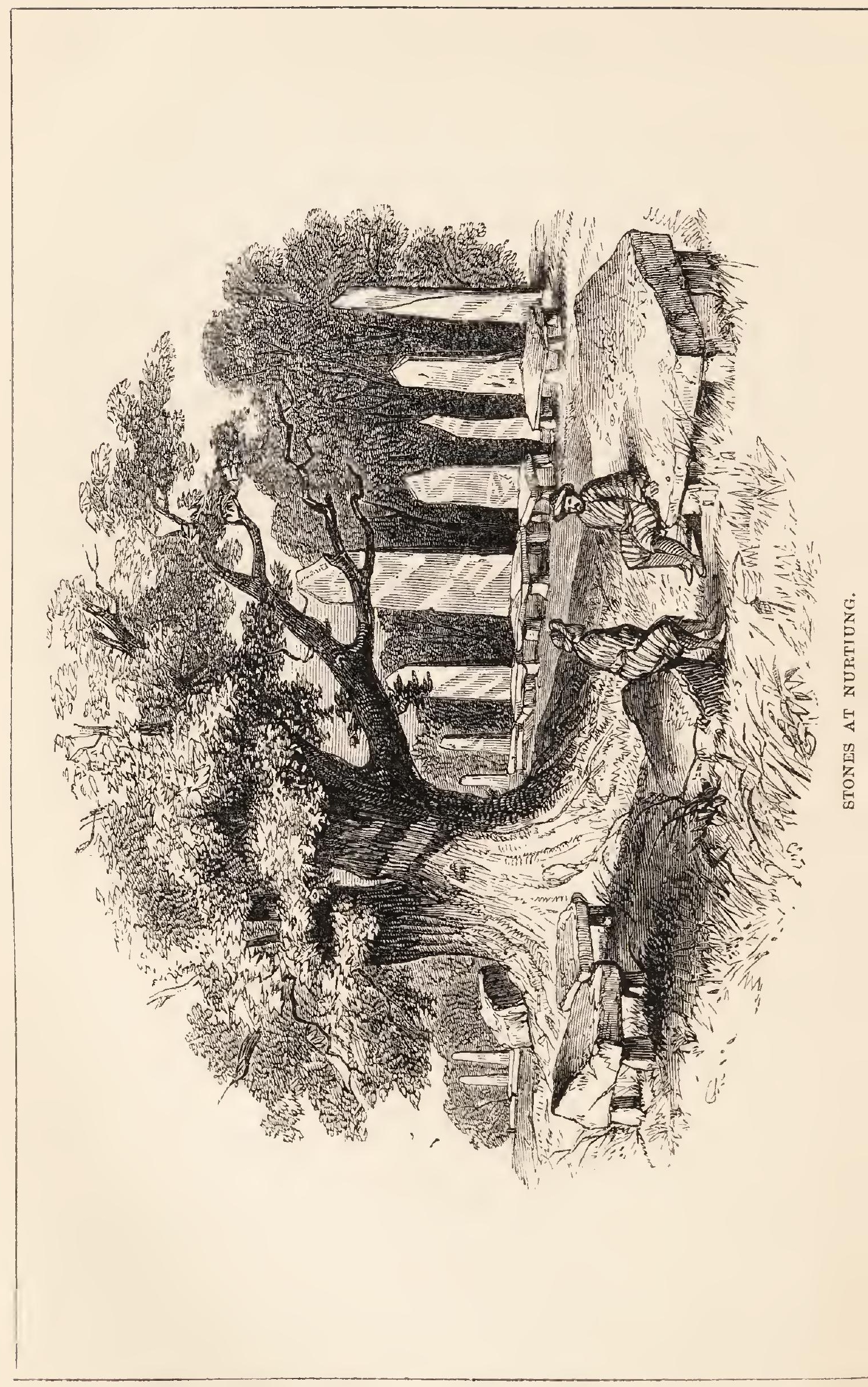


beautiful of Indian orchids) flourished on one of its limbs. A small plantain with austere woolly scarlet fruit, bearing ripe seeds, was planted in this sacred grove, where trees of the most tropical genera grew mixed with the pine, birch, Myrica, and Viburnum.

The Nurtiung Stonehenge is no doubt in part religious, as the grove suggests, and also designed for cremation, the bodies being burnt on the altars. In the Khasia these upright stones are generally raised simply as memorials of great events, or of men whose ashes are not necessarily, though frequently, buried or deposited in hollow stone sarcophagi near them, and sometimes in a clay urn placed inside a sarcophagus, or under horizontal slabs.

The usual arrangement is a row of five, seven, or more erect oblong blocks with round heads (the highest being placed in the middle), on which are often wooden discs and cones: more rarely pyramids are built. Broad slabs for seats are also common by the way. side. Mr. Yule, who first drew attention to these monuments, mentions one thirty-two feet by fifteen, and two in thickness; and states that the sarcophagi (which, however, are rare) formed of four slabs, resemble a drawing in Bell's Circassia, and descriptions in Irby and Mangles' Travels in Syria. He adds that many villages derive their names from these stones, "mau" signifying "stone:" thus "Mausmai" is "the stone of oath," because, as his native informant said, "there was war between Churra and Mausmai, and when they made peace, they swore to it, and placed a stone as a witness;" forcibly recalling the stone 
Jacob set up for a pillar, and other passages in the Old Testament. "Mamloo" is "the stone of salt," eating salt from a sword's point being the Khasia form of oath; "Mauflong" is "the grassy stone;" \&c. Returning from this grove, we crossed a stream by a single squared block, twenty-eight feet long, five broad, and two thick, of gray granite with large crystals of felspar.

We left Nurtiung on the 4th of October, and walked to Pomrang, a very long and fatiguing day's work. Near the village of Lernai oak woods are passed, in which Vanda ccrulea grows in profusion, waving its panicles of azure flowers in the wind. As this beautiful orchid is at present attracting great attention, from its high price, beauty, and difficulty of culture, I shall point out how totally at variance with its native habits, is the cultivation thought necessary for it in England.** The dry grassy hills which it inhabits are elevated 3000 to 4000 feet: the trees are small, gnarled, and very sparingly leafy, so that the Vanda which grows on their limbs is fully exposed to sun, rain, and wind. There is no moss or lichen on the branches with the Vanda, whose roots sprawl over the dry rough bark. The atmosphere is on the whole humid, and extremely

* We collected seven men's loads of this superb plant for the Royal Gardens at Kew ; but owing to unavoidable accidents and difficulties, few specimens reached England alive. A gentleman who sent his gardener with us to be shown the locality, was more successful : he sent one man's load to England on commission, and though it arrived in a very poor state, it sold for $300 l$., the individual plants fetching prices varying from $3 l$. to 10l. Had all arrived alive, they would have cleared 1000l. An active collector, with the facilities I possessed, might easily clear from 2000z. to $3000 l$, in one season, by the sale of Khasia orchids. 
so during the rains; but there is no damp heat, nor stagnation of the air, and at the flowering season the temperature ranges between $60^{\circ}$ and $80^{\circ}$, there is much sunshine, and both air and bark are dry during the day: in July and August, during the rains, the temperature is a little higher than above, but in winter it falls much lower, and hoar-frost forms on the ground. Now this winter's cold, summer's heat, and autumn's drought, and above all, this constant free exposure to fresh air and the winds of heaven, are what of all things we avoid exposing our orchids to in England: it is under these conditions, however, that all the finer Indian Orchidece grow.

On the following day we turned out our Vanda to dress the specimens for travelling, and to preserve the flowers for botanical purposes. Of the latter we had 360 panicles, each composed of from six to twenty-one broad pale-blue tesselated flowers, three and a half to four inches across; and they formed three piles on the floor of the verandah, each a yard high:-what would we not have given to have been able to transport a single panicle to a Chiswick fête!

On the 10th of October we sent twenty-four strong mountaineers to Churra, laden with the collections of the previous month; whilst we returned to Syong; whence we again crossed the range to Nunklow and the Bor-panee, returning to Churra towards the end of the month.

In November the vegetation above 4000 feet turns wintry and brown, the weather becomes chilly, and though the cold is never great, hoar-frost forms at 
Churra, and water freezes at Moflong. We prepared to leave as these signs of winter advanced: we had collected upwards of 2,500 species, and for the last few weeks all our diligence, and that of our collectors, had failed to be rewarded by a single novelty. We however procured many species in fruit, and made a collection of upwards of 300 kinds of woods, many of very curious structure. As, however, we projected a trip to Cachar before quitting the neighbourhood, we retained our collectors, giving orders for them to meet us at Chattuc on our way down the Soormah in December, with their collections, which amounted to 200 men's loads. 


\section{CHAPTER XXX.}

Boat voyage to Silhet-River-Palms-Fish weirs-Forests of Cachar-. Sandal-wood, \&c. - Porpoises - Alligators - Silchar-Tigers - Ricecrops - Cookies - Munniporees-Hockey-Dance-Nagas-Excursion to Munniporee frontiel-Elephant bogged-Climate, \&c. of CacharMosquitos-Fall of bank-Silhet-Tree-ferns-Chattuc-MegnaNoacolly-Salt-smuggling-Delta of Ganges and Megna-Westward progress of Megna-Tide-Waves-Dangerous navigation-Moonlight scenes-Mud island-Chittagong-Views-Trees-Coffee-PepperExcursions from Chittagong-Gurjun trees-Earthquake-BirdsPapaw-Poppy and sun fields-Seetakoond bungalow and hillPerpetual flame-Climate-Leave for Calcutta-Hattiah island-Plants-Sunderbunds-Steamer-Tides-Nipa fruicans--Crocodiles_Phonix paludosa-Fishing-Otters-Departure from India.

We left Churra on the 17th of November, and taking boats at Pundua, crossed the Jheels to the Soormah, which we ascended to Silhet. Thence we continued our voyage 120 miles up the river in canoes, to Silchar, the capital of the district of Cachar: the boats were such as I described at Chattuc, and though it was impossible to sit upright in them, they were paddled with great swiftness. The river at Silhet is 200 yards broad; it is muddy, and flows with a gentle current of two or three miles an hour, between banks six to twelve feet high. As we glided up its stream, villages became rarer, and eminences more frequent in the 
Jheels. The people are a tall, bold, athletic Mahometan race, who live much on the water, and cultivate rice, sesamum, and radishes, with betel-pepper in thatched enclosures, as in Sikkim: maize and sugar are rarer, bamboos abound, and a few palms are planted, but no date-palms.

A very long sedge grows by the water, and is used for thatching: boatloads of it are collected for the Calcutta market, for which also were destined many immense rafts of bamboo, 100 feet long. The people fish much, using square and triangular drop-nets stretched upon bamboos, and rude basket-work weirs, that retain the fish as the river falls. Near the villages we saw fragments of pottery three feet below the surface of the ground, showing that the bank, which is higher than the surrounding country, increases from the annual overflow.

About seventy miles up the river, the mountains on the north, which are east of Jyntea, rise 4000 feet high in forest-clad ranges like those of Sikkim. Swamps extend from the river to their base, and penetrate their valleys, which are extremely malarious: their forests are frequented by timber-cutters, who fell jarool, a magnificent tree with red wood, which, though soft, is durable under water, and therefore in universal use for boat building. The toon is also cut, with red sandalwood; also Nageesa, Mesua ferrea, which is highly valued for its weight, strength, and durability: the eagle-wood, a tree yielding uggur oil, is also much sought for its fragrant wood, which is carried to Silhet, where it is broken up and distilled. 
Porpoises, and both the long and the short-nosed alligator, ascend the Soormah for 120 miles, being found beyond Silchar; which place we reached on the 22nd; it is a small station about forty feet above the river, which however rises half that height in the rains. Long low spurs stretch from the Tippera hills for many miles north, through the swampy Jheels to the river; and there are also hills on the opposite or north side, but detached from the Cookie hills, as the lofty blue range twelve miles north of the Soormah is called. All these mountains swarm with tigers, wild buffalos, and boars, which also infest the long grass of the Jheels.

During the first Birmese war, a force was sent up to this remote corner of Bengal, when the country was an uninhabited jungle, so full of tigers that not a day passed without one or more of the grass or woodcutters being carried off. Now, thousands of acres are cultivated with rice, and during our stay we did not see a tiger. The quantity of land brought into cultivation in this part of Bengal, and indeed throughout the Gangetic delta, has probably been doubled during the last twenty years, and speaks volumes for the state of the peasant under the Indian Company's sway, as compared with his former condition. The Silchar rice is of admirable quality, and much is imported to Silhet, the Jheels not producing grain enough for the consumption of the people. Though Silchar grows enough for ten times its population, there was actually a famine six weeks before our arrival, the demand from Silhet being so great.

The villages of Cachar are peopled by Mahometans, 
Munniporees, Nagas, and Cookies; the Cacharies themselves being a poor and peaceful jungle tribe, confined to the mountains north of the Soormah. The Munniporees are emigrants from the kingdom of that name, which lies beyond the British possessions, and borders on Assam and Birmah. Low ranges of forestclad mountains separate it from Silchar, to the southeast of which are interminable jungles, peopled by the Cookies, a wild Indo-Chinese tribe, who live in a state of constant warfare, and possess the whole hill country from this, southward to beyond Chittagong. A few years ago they invaded and ravaged Cachar, carrying many of the inhabitants into slavery, and so frightening the people, that land previously worth six rupees a biggah, is now reduced to one and a half. A strong party was sent to rescue the captives, and marched for many days through their country without disturbing man or beast; penetrating deep forests of gigantic trees and tall bamboos, never seeing the sun above, or aught to the right and left, save an occasional clearance and a deserted village. The incursion, however, had its effects, and the better inclined near the frontier have since come forward, and been enrolled as the Cookie levy.

The Mumipore emigrants are industrious settlers for a time, but never remain long in one place: their religion is Hindoo, and they keep up a considerable trade with their own country, whence they import a large breed of buffalos, ponies, silks, and cotton cloths dyed with arnotto (Bixa), and universally used for turbans. They use bamboo blowing-tubes and arrows for shooting birds, make excellent shields of rhinoceros 
hide (imported from Assam), and play at hockey on horseback like the Western Tibetans.

One fine moonlight night we went to see a Munnipore dance. A large circular area was thatched with plantain leaves, growing on their trunks, which were stuck in the ground; and round the enclosure was a border neatly cut from the white leaf-sheaths of the same tree. A double enclosure of bamboo, similarly ornamented, left an inner circle for the performers, and an outer for the spectators: the whole was lighted with oil lamps and Chinese paper lanterns. The musicians sat on one side, with cymbals, tomtoms, and flutes, and sang choruses.

The performances began by a copper-coloured Cupid entering and calling the virgins with a flute; these appeared from a green-room, to the number of thirty or forty, of all ages and sizes. Each had her hair dressed in a topknot, and her head covered with a veil; a scarlet petticoat loaded with tinsel concealed her naked feet, and over this was a short red kirtle, and an enormous white shawl was swathed round the body from the armpits to the waist. A broad belt passed over the right shoulder and under the left arm, to which hung gold and silver chains, corals, \&c., with tinsel and small mirrors sewed on everywhere: the arms and hands were bare, and decorated with bangles and rings.

Many of the women were extremely tall, great stature being common amongst the Munniporees. They commenced with a prostration to Cupid, around whom they danced very slowly, with the arms 
stretched out, and the hands in motion; at each step the free foot was swung backwards and forwards. Cupid then chose a partner, and standing in the middle went through the same motions, a compliment the women acknowledged by curtseying and whirling round, making a sort of balloon with their petticoats, which, however, were too heavy to inflate properly.

The Nagas are another people found on this frontier, chiefly on the hills to the north: they are a wild, copper-coloured, uncouth jungle tribe, who have proved troublesome on the Assam frontier. Their features are more Tartar than those of the Munniporees, especially amongst the old men. They bury their dead under the threshold of their cottages. The men are all but naked, and stick plumes of hornbills' feathers in their hair, which is bound with strips of bamboo; tufts of small feathers are passed through their ears, and worn as shoulder lappets; and they also wear brass armlets, and necklaces of cowries, coral, amber, ivory, and boars' teeth. The women draw a fringed blue cloth tightly across the breast, and wear a checked or striped petticoat. They are less ornamented than the men, and are pleasing looking; their hair is straight, and cut short over the eyebrows.

The Naga dances are very different from those of the Munniporees; being quick, and performed in excellent time to harmonious music. The figures are regular, like quadrilles and country-dances: the men hold their knives erect during the performance, the women extend their arms only when turning partners, and then their hands are not given, but the palms are 
held opposite. The step is a sort of polka and balancez, very graceful and lively. A bar of music is always played first, and at the end the spectators applaud with two short shouts. Their ear for music, and the nature of their dance, are as Tibetan as their countenances, and different from those of the IndoChinese tribes of the frontier.

Had we had time, it was our intention to have visited Munnipore, but we were anxious to proceed to Chittagong. I however made a three days' excursion to the frontier, about thirty miles distant, proceeding along the north bank of the Soormah. On the way my elephant got bogged in crossing a deep muddy stream: this is sometimes an alarming position, as should the animal become terrified, he will seize his rider, or pad, or any other object (except his driver), to place under his knees to prevent his sinking. In this instance the driver in great alarm ordered me off, and I had to flounder out through the black mud. The elephant remained fast all night, and was released next morning by men with ropes.

The country continued a grassy level, with marshes and rice cultivation, to the first range of hills, beyond which the river is unnavigable; there also a forest commences, of oaks, figs, and the common trees of east Bengal. On the east side of the range, the road descends to a broad valley covered with gigantic scattered timber-trees rearing their enormous trunks above the bamboo jungle: immense rattan-canes wound through the forest, and in the gulleys were groves of two kinds of tree-fern, with palms, screw-pines, \&c. 
The climate of Cachar partakes of that of the Jheels in its damp equable character; the temperature seldom rising above $90^{\circ}$ in summer, nor sinking below $45^{\circ}$ in January: during our stay the weather was fine, and dense fogs formed in the morning.

There are few mosquitos, which is one of the most curious facts in the geographical distribution of these capricious blood-suckers; for the locality is surrounded by swamps, and they swarm at Silhet, and on the river lower down. Both on the passage up and down, we were tormented in our canoes by them for eighty or ninety miles above Silhet, and thence onwards to Cachar we were free.

On the 30th of November, we were preparing for our return to Silhet, and our canoes were loading, when we were surprised by a loud rushing noise, and saw a high wave coming down the river, swamping every boat that remained on its banks, whilst most of those that pushed out into the stream, escaped with a violent rocking. It was caused by a slip of the bank three quarters of a mile up the stream, of no great size, but which propagated a high wave. This appeared to move on at about the rate of a mile in three or four minutes, giving plenty of time for our boatmen to push out from the land on hearing the shouts of those first overtaken by the calamity; but they were too timid, and consequently one of our canoes, full of papers, instruments, and clothes, was swamped. Happily our dried collections were not embarked, and the hot sun repaired much of the damage.

On the 2nd of December we proceeded to Silhet, the 
capital of the district of the same name, occupying a slightly raised part of the Jheels, where many of the Teelas seemed joined together by beds of gravel and sand. In the rains it is surrounded by water; in winter Jynteapore and Pundua may be reached by land, crossing innumerable creeks on the way.

The most interesting botanical ramble about Silhet is to the tree-fern groves on the path to Jynteapore, following the bottoms of shallow valleys, and along clear streams, up whose beds we waded for some miles, under an arching canopy of tropical shrubs, trees, and climbers. In the narrower parts of the valleys tree-ferns are numerous on the slopes, rearing their slender brown trunks forty feet high, with feathery crowns of foliage, through which the sunbeams trembled on the broad shining foliage of the tropical herbage below.

Silhet, though hot and damp, is remarkably healthy, and does not materially differ in temperature from Silchar, though the climate is more equable and humid. We thence took large boats to navigate the Burrampooter and Megna, to their embouchure in the Bay of Bengal at Noacolly, a distance of 250 miles, whence we were to proceed across the head of the bay to Chittagong, about 100 miles further. We arrived at Chattuc on the 9th of December, where our Khasia collectors met us with large loads of plants, and we paid them off. The river was now low, and presented a busy scene, from the numerous trading boats being confined to its deeper channels.

On the 13th we entered the broad stream of the 
Megna. Rice is cultivated along the mud flats left by the annual floods, and the banks are lower and less defined than those of the Soormah, and support no long grasses or bushes. Enormous islets of living water-grasses and other plants floated past, and birds became more numerous, especially martins and egrets. The sun was hot, but the weather otherwise cool and pleasant; the mean temperature was nearly that of Calcutta, $69 \frac{3}{4}^{\circ}$, but the atmosphere was more humid.

On the following day we passed the Dacca river; below which the vegetation of the Sunderbunds commences: there is a narrow beach, and behind it a mud bank several feet high, supporting a luxuriant green jungle of palms, immense fig-trees, and tall betelpalms.

Towards the embouchure, the banks rise, the river expands into a muddy sea, and a long swell rolls in, to the disquiet of our fresh-water boatmen. Low islands of sand and mud stretch along the horizon; which, together with the ships, distorted by extraordinary refraction, flickered as if seen through smoke. We landed in a canal-like creek on the 17th, and walked to Noacolly,* over a flat of hard mud, covered with turf. Noacolly is a station for collecting the revenue and preventing the manufacture of salt, which, and opium, are the only monopolies now in the hands of the East India Company. The salt itself is imported from Arracan, Ceylon, and even Europe, and is stored in great wooden buildings here and elsewhere. The ground being impregnated with salt, the illicit manufac-

* "Colly" signifies a muddy creek, such as intersect the delta. 
ture by evaporation is not easily checked; but whereas the average number of cases brought to justice used to be twenty or thirty in a week, they are now reduced to two or three. It is remarkable that though the soil yields such an abundance of this mineral, the water of the Megna at Noacolly is only brackish, and it is therefore to repeated inundations and surface evaporations that the salt is due. Fresh water is everywhere found at the depth of a very few feet, but it is not good.

The total breadth of the delta is 260 miles, from Chittagong to the mouth of the Hoogly, and is divided longitudinally by the Megna : all to the west of that river presents a luxuriant vegetation, while to the east is a bare, muddy expanse, with no trees or shrubs but such as are planted. On the west coast the tide rises twelve or thirteen feet; on the east from forty to eighty. On the west the water is salt enough for mangroves to grow for fifty miles up the Hoogly; on the east the sea-coast is too fresh for that plant for ten miles south of Chittagong. On the west, 50 inches is the Cuttack annual rain-fall ; on the east, 90 to 120 at Noacolly and Chittagong, and 200 at Arracan. The east coast is annually visited by earthquakes, which are rare on the west; and, lastly, the majority of the trees and shrubs carried down from the Cuttack and Orissa forests, and deposited on the west coast of the delta, are not only different in species, but in Natural Orders, from those that the Fenny and Chittagong rivers bring down from the jungles.

At Noacolly we were glad to find that our observations on the progression westwards of the Burram- 
pooter were confirmed by the fact that the Megna also is gradually moving in that direction, leaving much dry land on the Noacolly side, and forming islands opposite that coast; whilst it encroaches on the Sunderbunds, and is cutting away the islands in that direction. The advance of the fresh water amongst the Sunderbunds is destructive to the vegetation of the latter, which requires salt; and if the Megna continues its slow course westwards, the obliteration of a very peculiar flora over thousands of square miles, and the extinction of many species of plants and animals that exist nowhere else, may ensue. In ordinary cases these plants, \&c., would take up their abode on the east coast, as they were driven from the west; but such might not be the case in this delta, for the sweeping tides of the east coast preverit any such vegetation establishing itself there, and the mud which the eastern rivers carry down becomes a caking dry soil, unsuited to the germination of seeds.

The main land of Noacolly is gradually extending seawards, and has advanced four miles within twenty. three years: this seems sufficiently accounted for by the recession of the Megna. The elevation of the land is caused by the overwhelming tides and south-west hurricanes in May and October; these extend for thirty miles north and south of Chittagong, and carry the waters of the Megna and Fenny back over the land, in a series of tremendous waves, that cover islands of many hundred acres, and roll three miles on to the main land.

We left Noacolly on the 19th for Chittagong, the 
distance to which place is only 100 miles; but the passage being considered angerous at this season (during the spring tides), we were provided with a large vessel and an experienced crew. The great object in this navigation is to make progress towards the top of the tide and during its flood, and to ground during the ebb in creeks where the bore (tidal wave) is not violent; for where the channels are broad and open, the height and force of this wave rolls the largest coasting craft over and swamps them.

Our boatmen pushed out at 3 A.M., and brought up at 5 , in a narrow muddy creek on the island of Sidhee. The waters retired along channels scooped several fathoms deep in black mud, leaving our vessel aground six or seven feet below the top of the bank, and soon afterwards no water was to be seen; as far as the eye could reach, all was a glistening oozy mud, except the bleak level surfaces of the islands, on which neither shrub nor tree grew. Soon after 2 p.r. a white line was seen on the low black horizon, which was the tide-wave, advancing at the rate of five miles an hour, with a hollow roar; it bore back the mud that was gradually slipping along the gentle slope, and we were afloat an hour after: at night we grounded again, opposite the mouth of the Fenny.

By moonlight the scene was oppressively solemin: on all sides the gurgling waters kept up a peculiar sound that filled the air with sullen murmurs; the moonbeams slept upon the shining surface of the mud, and made the dismal landscape more ghastly still. Silence followed the ebb, occasionally broken by the 
wild whistle of a bird like the curlew; till the harsh roar of the bore was heard, to which the sailors seemed to waken by instinct. The waters then closed in on every side, and the far end of the reflected moonbeam was broken into flashing light, that approached and soon danced beside the boat.

On the 21st we were ashore at daylight on the Chittagong coast far north of the station, and were greeted by the sight of hills on the horizon: we were lying fully 20 feet below high water mark, and the tide was out for several miles to the westward.

We were three days and nights on this short voyage, without losing sight of mud or land; and arrived at Chittagong on the 23rd of December.

Chittagong stands on the north shore of an extensive delta, formed by rivers from the lofty mountains separating this district from Birmah. It is large and beautifully situated, interspersed with trees and tanks: in the hollows around are native huts amidst vegetation of every hue, glossy green figs, broad plantains, feathery Acacias, dark Nageesa, red-purple Terminalia, leafless scarlet-flowered Bombax, and grey Casuarina. The hills about the station are not more than 150 or 200 feet high, and are surmounted by good European houses, surrounded by trees of Acacia and Crsalpinia.

Seaward the tide leaves immense flats, which stretch for many miles on either side the offing. Inland the views are beautiful, of the many-armed river, covered with sails, winding amongst groves of cocoa-nuts, palms, and yellow rice fields: while on the horizon, at the distance of 40 or 50 miles, rise mountains, 4,000 
to 8,000 feet high; they are clothed with woods, abounding with the splendid timber trees of the Cachar forests, though, like these, they are said to want teak, Sal, and Sissoo: they have, besides many others, magnificent Gurjun trees, the monarchs of the forests of these coasts. They are inhabited by turbulent races, who are coterminous with the Cookies of the Cachar and Tippera forests, if indeed they be not the same people. The natives of Chittagong are Mahometans and Mugs, a Birmese tribe who inhabit many parts of the Malay peninsula, and the coast to the northward of it; they are excellent shipbuilders and active traders, and export much rice and timber to Madras and Calcutta.

To the south, undulating dunes stretch along the coast, covered with low bushes, of which a red-flowered Melastoma is the most prevalent, and is called a rhododendron by many of the residents.

Coffee has been cultivated at Chittagong with great success: it is said to have been introduced by Sir W. Jones. Both Assam and Chinese teas flourish, but Chinamen are wanted to cure the leaves. Black pepper succeeds admirably, as do cinnamon, arrow-root, and ginger.

Early in January we started on an excursion to the north, following a valley separated from the coast by a range of wooded hills 1000 feet high. For several marches the bottom of this valley was broad, flat, and full of villages. At Sidhee, about twenty-five miles from Chittagong, it contracts, and spurs from the hills on either side project into the middle: they are 
200 to 300 feet high, formed of red clay, and covered with brushwood.

At Kajikehath, the most northern point we reached, we were quite amongst these hills, and in an extremely picturesque country, intersected by long winding flat valleys; some full of copse-wood, others presenting the most beautiful park-like scenery, and a third class expanding into grassy marshes or lake-beds, with wooded islets rising out of them. The hillsides are clothed with low jungle, above which tower magnificent Gurjun trees (wood-oil). This is the most superb tree we met with in the Indian forests; it is conspicuous for its gigantic size, and for the straightness and graceful form of its tall unbranched pale grey trunk, and small symmetrical crown: many individuals were upwards of 200 feet high, and fifteen in girth. Its leaves are broad, glossy, and beautiful; the flowers (then falling) are not conspicuous; the wood is hard, close-grained, and durable, and a fragrant oil exudes from the trunk, which is extremely valuable as pitch and varnish, \&c., besides being a useful medicine. The natives procure it by cutting transverse holes in the trunk, pointing downwards, and lighting fires in them, which causes the oil to flow.

On the 8th of January we experienced a sharp earthquake preceded by a dull thumping sound; it lasted about twenty seconds, and seemed to come up from the southward; the water of a tank by which we were seated was smartly agitated. The same shock was felt at Mymensing and at Dacca, 110 miles north-west of this place. 
We crossed the dividing ridge of the littoral range, on the 9th, and descended to Seetakoond bungalow, on the high road from Chittagong to Comilla. The forests at the foot of the range were very extensive, and

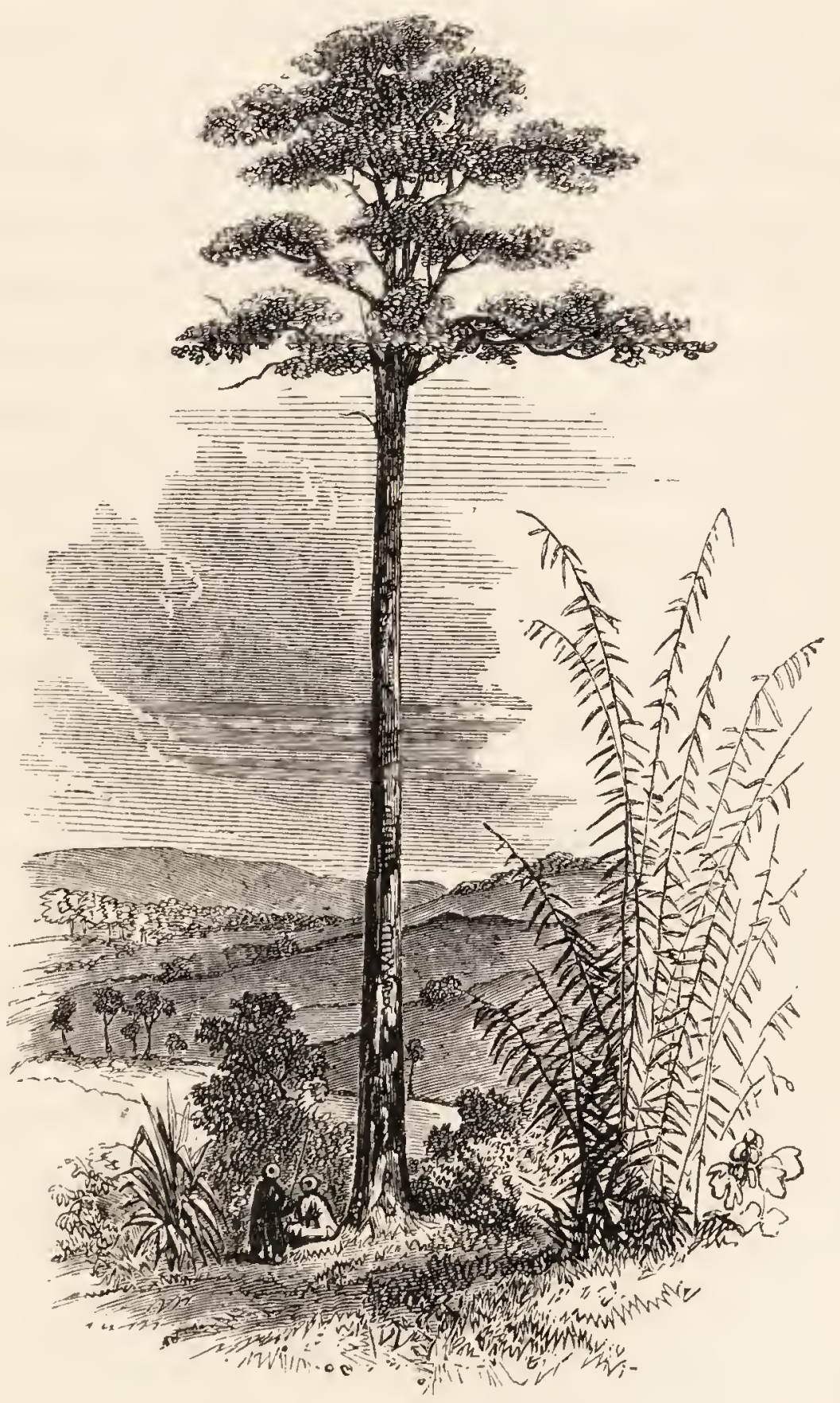

GURJUN TREE.

swarmed with large red ants that proved very irritating: they build immense pendulous nests of dead and living 
leaves at the ends of the branches of trees, and mat them with a white web. Tigers, leopards, wild dogs, and boars, are numerous; as are snipes, pheasants, peacocks, and jungle-fowl; the latter waking the morn with their shrill crows; and in strange association with these is the common English woodcock, which is occasionally found.

The trees are of little value, except the Gurjun, and "Kistooma," a species of Bradleia, which was stacked extensively, and used for building purposes. The papaw* is abundantly cultivated, and its great gourdlike fruit eaten; the flavour is that of a bad melon, and a white juice exudes from the rind. The Hodgsonia heteroclita, a magnificent climber, grows in these forests; with a climbing Apocyneous plant, the milk of which flows in a continuous stream, resembling caoutchouc (it is probably the Urceola elastica, which yields Indian-rubber).

The ascent of the hills, which are densely wooded, was along spurs, and over knolls of clay; the road was good, but always through bamboo jungle, and it wound amongst the low spurs, so that there was no defined crest or top of the pass, which is about 800 feet high. There were no tall palms, tree-ferns, or plantains, and altogether the forest was smaller and poorer in plants than we had expected.

From the summit we obtained a very extensive and singular view. At our feet was a broad, low, grassy,

* The Papaw tree is said to hare the curious property of rendering tough meat tender, when hung under its leaves, or touched with the juice; this hastening the process of decay. With this fact, well-known in the West Indies, I never found a person in the East acquainted. 
alluvial plain, intersected by creeks, bounding a black expanse of mud which (the tide being out) appeared to stretch almost continuously to Sundeep Island, 30 miles distant; while beyond, the blue hills of Tippera rose on the north-west horizon.

Descending, we rode several miles along an excellent road, to the bungalow of Seetakoond, twenty-five miles north of Chittagong. The west flank of the range we had crossed is much steeper than the east, often precipitous, and presents the appearance of a sea-worn cliff towards the Bay of Bengal. Near Seetakoond (which is on the plain), a hill on the range, bearing the same name, rises 1,136 feet high, and being damper and more luxuriantly wooded, we were anxious to explore it: we therefore spent some days at the bungalow. Fields of poppy and sun (Crotalaria juncea) formed most beautiful crops; the latter grows from four to six feet high, and bears masses of laburnum-like flowers, while the poppy fields resembled a carpet of dark-green velvet, sprinkled with white stars; or, as I have elsewhere remarked, a green lake studded with water-lilies.

The road to the top of Seetakoond leads along a most beautiful valley, and then winds up a cliff that is in many places almost precipitous, the ascent being partly by steps cut in the rock, of which there are 560 . The mountain is very sacred, and there is a large Brahmin temple on its flank; and near the base a perpetual flame bursts out of the rock. This we were anxious to examine, and were extremely disappointed to find it a small vertical hole in a slaty rock, with a lateral one below for a draught, and that it was daily 
supplied by pious pilgrims and Brahmins with such enormous quantities of ghee (liquid butter), that it was to all intents and purposes an artificial lamp; no trace of natural phenomena being discoverable.

On the dry but wooded west face of the mountain, grew many beautiful palms, with dwarf date-palm, and Gurjun trees. The east slope of the mountain is damper, and much more densely wooded; we there found two wild species of nutmeg trees, whose wood is full of a brown acrid oil, seven palms, tree-ferns, and many other kinds of ferns, several kinds of oak, Dracæna, and figs. The top is 1,136 feet above the sea, and commands an extensive view to all points of the compass; but the forests, in which the ashy bark of the Gurjun trees is conspicuous, and the beautiful valley on the west, are the only attractive features.

The weather on the east side of the range differs at this season remarkably from that on the west, where the vicinity of the sea keeps the atmosphere more humid and warm, and at the same time prevents the formation of the dense fogs that hang over the valleys to the eastward every morning at sunrise. We found the mean temperature at the bungalow, from January 9th till the 13 th, to be $70^{\circ}$.

We embarked again at Chittagong for Calcutta, on the 16th of January, at 10 P.Mr., in a very large vessel, rowed by twelve men: we made wretchedly slow progress, being for four days within sight of Chittagong! On the 20th we only reached Sidhee, and thence made a stretch to Hattiah, an island which may be said to be moving bodily to the westward, the Megna 
annually cutting many acres from the east side, and the tide-wave depositing mud on the west. The surface is flat, and raised four feet above mean highwater level; the tide rises about 14 feet up the bank, and then retires for miles; the total rise and fall is, however, much less here than in the Fenny, higher up the gulf. Two kinds of tamarisk, and some thorny shrubs, are the only bushes on the eastern islands; on the central ones a few dwarf mangroves appear, with the holly-leaved Dilivaria, dwarf screw-pine, and a curious fern, a variety of Acrostichum aureum. Towards the northern end of Hattiah, Talipot, cocoa-nut and date-palms appear.

On the 22nd we entered the Sunderbunds, rowing amongst narrow channels where the tide rises but a few feet. The banks were covered with a luxuriant vegetation, chiefly of small trees, above which rose stately palms. On the 25 th, we were overtaken by a steamer from Assam, a novel sight to us, and a very strange one in these creeks, which in some places seemed hardly broad enough for it to pass through. We jumped on board in haste, leaving our boat and luggage to follow us. She had left Dacca two days before, and this being the dry season, the route to Calcutta, which is but sixty miles in a straight line, involved a détour of three hundred.

From the masts of the steamer we obtained an excellent coup-d'ail of the Sunderbunds; its swamps clothed with verdure, and intersected by innumerable inosculating channels, with banks a foot or so high. The amount of tide, which never exceeds ten feet, VOL. II. 
diminishes in proceeding westwards into the heart of these swamps, and the epoch, direction, and duration of the ebb and flow vary so much in every canal, that at times, after stemming a powerful current, we found ourselves, without materially changing our course, suddenly swept along with a favouring stream. This is owing to the intricate ramifications of the creeks, the flow of whose waters is materially influenced by the most trifling accidents of direction.

Receding from the Megna, the water became salter, and Nipa fruticans appeared, throwing up pale yellowgreen tufts of feathery leaves, from a short thick creeping stem, and bearing at the base of the leaves its great head of nuts, of which millions were floating on the waters, and regetating in the mud. Marks of tigers were very frequent, and the footprints of deer, wild boars, and enormous crocodiles: these reptiles were extremely common, and glided down the mudbanks on the approach of the steamer, leaving between the footmarks a deep groove in the mud made by their tail. The Phonix paludosa, a dwarf slender-stemmed date-palm, from six to eight feet high, is the allprevalent feature, covering the whole landscape with a carpet of feathery fronds of the liveliest green. The species is eminently gregarious, more so than any other Indian palm, and presents so dense a mass of foliage, that when viewed from above, the stems are wholly hidden.

The water is very turbid, and only ten to twenty feet deep, which, we were assured by the captain, was not increased during the rains: it is loaded with 
vegetable matter, but the banks are always muddy, and we never saw any peat. Dense fogs prevented our progress in the morning, and we always anchored at dusk. We did not see a village or house in the heart of the Sunderbunds (though such do occur), but we saw canoes, with fishermen, who use the tame otter in fishing; and the banks were covered with piles of firewood, stacked for the Calcutta market. As we approached the Hoogly, the water became very salt and clear; the Nipa fruits were still most abundant, floating out to sea, but no more of the plant itself was seen. As the channels became broader, sand-flats appeared, with old salt factories, and clumps of planted Casuarina.

On the 28th of January we passed Saugor island, and entered the Hoogly, steamed past Diamond Harbour, and landed at the Botanic Garden Ghat, where we received a hearty welcome from Dr. Falconer. Ten days later we bade farewell to India, reaching England on the 25th of March, 1851. 



\section{N DEX.}

Acacia, i. 8 ; Catechu, i. 45.

Acorns, ii. 2.

Alligator, i. 44, 47.

Alpine vegetation, ii. 99, 106, 123, 137, 151.

Amlah, conference with, ii. 216.

Andromeda fastigiata, i. 321.

Aralia as fodder, i. 336.

Ararat, Mount, ii. 30.

Arums, food from, ii. $69,83$.

Arun river, ii. 148.

Atmosphere, pressure of, ii. 149.

Aurora borealis, i. 31 .

Balanophora, ii. 68.

Bamboos, i. 1.46, 149, 295.

Banyan, ii. 253.

Beejaghur, i. 49 .

Bees'-nests, i. 190 ; ii. 41.

Behar, hills of, i. 28.

Benares, ii. 65 ; observatory at, ii. 67.

Betel pepper, i. 90.

Bhagulpore, i. 81; Horticultural gardens of, i. 82.

Bhomsong, i. 280 ; ii. 35.

Bhomtso, ii. 132, 171 ; ascent of, ii. 179 .

Bhotan coolies, i. 171, 174, 263.

Bhoteas, i. 127, 205.

Birds, ii. 22, 168.

Boodhist monuments, i. 134, 137.

Boswellia thurifera, i. 25.

Boulders, i. 191.

Brick tea, i. 202.

Buckwheat, wild, ii. 54.

Burdwan, i. 5 ; coal-fields of, i. 7 ; palace of Rajah, i. 5.
Burrampooter, alteration of bed, ii. 259 ; course of, ii. 177.

Butea frondosa, i. 8.

Cachar, ii. 319.

Casalpinia paniculata, i. 22.

Calcutta Botanic garlens, i. 2, 3 ; ii. 250.

Calotropis, i. 26.

Camels, i. 10, 54.

Campbell, Dr., at Bhomsong, i. 280 ; at Tumloong, ii. 196 ; bad treatment of, ii. 209 ; interview with Rajah, i. 285 ; join him in prison, ii. 218 ; leaves Dorjiling, i. 266 ; ii. 152 ; released, ii. 244 ; removed from Tumloong, ii. 234 ; superintendent of Dorjiling, $i$. 107; taken prisoner, ii. 206; visits Siklim, ii. 154.

Cane bridge, i. 140 ; ii. 38 .

Catechu, i. 45.

Cathcartia, ii. 202.

Catsuperri lake, i. 339 ; temples, i. 341 .

Chait, i. 338.

Chakoong, vegetation of, ii. 43 .

Changachelling temples, i. 344.

Charcoal for gunpowder, i. 8.

Chattuc, ii. 267.

Chela village, ii. 300 .

Children's toys, i. 317.

Chillong hill, view from, ii. 288.

Chittagong, ii. 330 .

Cholamoo lake, ii. 132, 164.

Chola pass, ii. 203.

Cholera tree, i. 25.

Chooujer:ma pass, i. 250. 
Chumulari, ii. 172.

Chunar, i. 65.

Churra, ii. 269, 273, 278, 298 ; rain-fall of, 284 .

Cinnamon, ii. 304.

Coal-fields of Burdwan, i. 7.

Cochlospermum, i. 46.

Coles, i. 48.

Colgong, i. 85 .

Cooches, ii. 10.

Cosi river, i. 86.

Cowage plant, i. 11.

Cryptogramma crispa, i. 250.

Currant, Sikkim, ii. 156.

Cypress, funereal, i. 297, 314.

DACCA, ii. 260.

Dakoit, i. 59.

Damooda valley, i. 6.

Date palm, i. 30, 33.

Deodar, i. 245.

Dewan, Sikkim, i. 107, 281, 288 ; alarm of, ii. 240 ; arrival from Tibet, ii. 222 ; dinner with, ii. 238 ; disgraced, ii. 247 ; interview with, ii. 227.

Dhak, i. 45.

Digarchi, ii. 176.

Dinapore, ii. 75.

Dingpun, Tibetan, ii. 167.

Do-Mani stone, i. 278.

Donkia, ii. 129 ; pass, ii. 132, 184.

Doobdi convent, i. 316.

Dorjiling, i. 103, 104 ; climate of, i. 109 ; prospects of, ii. 256.

Dunwah pass, i. 26.

Dust storm, i. 44,74 .

Earthedake, ii. 4, 332.

East Nepal, scenery of, i. 196.

Edgeworthia Gardneri, i. 195, 312.

Elephants, ii. 8, 297 ; bogged, ii. 323 ; docility of, i. 9.

Eranoboas, i. 31.

Euryale ferox, ii. 261.

FAIR, i. 55.

False sunrise and sunset, i. 56, 179.

Ferns, edible, i. 277.

Fir-wood, ii. 66.

Flutes from Lhassa, ii. 242.
GANGES, features of, i. 72.

Gangetic delta, ii. 327 ; valley, ii. 6.

Gangtok Kajee, ii. 235.

Ghazeepore, i. 71.

Glaciers, ii. 76 .

Goats, shawl-wool, ii. 105.

Grasses, gigantic, ii. 11.

Great Rungeet, excursion to, i. 133 ;

valley of, i. 139.

Grouse, Himalayan, ii. 124.

Gum arabic, i. 54.

Gurjun trees, ii. 332.

Himalaya, view of snowy, i. $86,112,175$; ii. 70,286 , 295 ; vegetation of outer, i. 88 , 99.

Hodgsonia, ii. 33.

Hooli festival, ii. 12.

Horn-bills, i. 177.

Homet, ii. 49.

Hot baths, i. 289 ; ii. 126.

Hot springs, ii. 126, 140 ; Lepcha lad sleeps in, 188.

ILAM, i. 172.

Insects, i. 74, 143, 148, 264; ii. $42,50,84$.

Iron smelting, ii. 304.

Islumbo pass, i. 264 ; vegetation of, i. 265 .

JAIN sect, i. 15 .

Jeelpigoree, ii. 10; Rajah of, ii. 12 , 15.

Jews' harp, ii. 224.

Jheels, ii. 262 ; Flora and Fauna of, ii. 265.

Jigatzi, ii. 176.

Jongri, i. 331.

Jung Bahadoor, ii. 250.

Junnoo mountain, i. 251.

Kambachen village, i. 246.

Kangaroos, i. 6.

Kiang, ii. 178.

Kinchin-jhow glacier, ii. 140 .

Kinchin-junga, i. 322 ; circuit of, i. 327 ; glaciers, ii. 71 . 
Khasia, excessive rain-fall of, ii. 283 ; Flora, ii. 271, 282 ; mountains, ii. 267 ; mountains, expedition to, ii. 255 ; people, ii. 275 ; people, monuments of, ii. 311.

Kishengunj, ii. 256.

Kollong hill, ii. 290.

Kongra Lama, ii. 98.

Kulhait river, i. 265.

Kunker, i. 11.

Kus-kus, i. 36.

Kymore hills, i. 33, 46.

Lac, i. 8.

Lachen, ii. 39, 53 ; valley, vegetation of, ii. 60 .

Lachen-Lachoong, ii. 39.

Lachoong, ii. 39.

Lake beds, ancient, j. 234, 249, 337.

Lamas, dance of, i. 218 ; worship, i. 104, 294.

Land-slips, ii. 41, 45, 112, 125, 153.

Larch, Himalayan, i. 245.

Leaf-insect, ii. 300.

Leebong, i. 134.

Leeches, i. 98,157 ; ii. 42.

Lepchas, i. 117, 165; cups of, i. 123 ; dress of, i. 121 ; food of, i. 123 ; marriages of, i. 125 ; religion of, i. 126 .

Leucas, ii. 10.

Lhassa, i. 283.

Lichens, i. 329 ; ii. 179, 184.

Limboos, i. 128 ; customs of, i. 129. Lizard, i. 31.

Maddaobund, i. 14.

Magras, i. 130.

Mahanuddee river, i. 89, 92 ; ii. 257.

Mahowa, i. 13.

Mainom mountain, i. 291.

Maize, hermaphrodite, i. 148.

Maldah, ii. 258.

Mango, i. 55.

Manis, i. 201.

Mantis, ii. 300 .

Mechis, i. 92 ; fisherman, ii. 26.

Meepo, i. 189 ; ii. 37.
Megna river, ii. 326.

Mendongs, i. 201, 270.

Mesua ferrea, ii. 318.

Mirzapore, i. 57.

Moflong, ii. 287.

Momay Samdong, ii. 128, 185.

Monghyr, i. 79 .

Monkeys, ii. 59, 121.

Mon Lepcha, i. 320.

Monuments in Khasia, ii. 311.

Moormis, i. 130 .

Moraines, ancient, i. 221, 236, 246, 248 ; ii. $7,85,92,118,128$, $140,142$.

Morung, ii. 5, 8 .

Mosquitos, ii. 324.

Moxa, ii. 39.

Mudar, i. 26.

Mungeesa peak, i. 47.

Munnipore dance, ii. 321.

Murwa beer, i. 124, 164, 275.

Musk deer, i. 256 ; ii. 59.

Muslin manufacture, ii. 261.

Myong valley, scenery of, i. 173.

Mywa Guola, i. 186.

NAGAS, ii. 322.

Nageesa, ii. 318.

Nango mountain, i. 227, 241; pass,

i. 242 ; vegetation at, i. 243 .

Neongong, lake of, i. 290 ; temple of, i. 293.

Nepal, expedition to, i. 168.

Nettles, i. 173 ; ii. 192 ; uses of, i. 276.

Nicotiana rustica, ii. 239.

Nightingales, i. 310 ; ii. 153.

Nipa fruticans, i. 1 ; ii. 338.

Nitrate of lime, i. 37.

Nymphaca pygmeea, ii. 307.

Ourbanum, i. 25.

Opium, manufacture of, i. 75.

Orchidea, ii. 282.

Ortolan, i. 89.

Ovis Ammon, i. 234.

P 4 KEe travelling, i. 4.

Palung plains, ii. 101, 146.

Paper from Daphne, i. 181, 195. 
Parasnath, i. 11; ascent of, i. 13, 17; summit of, i. 19 ; temple on, i. 20 ; vegetation of, i. 21.

Patna, i. 75.

Pawn, i. 90.

Pemiongchi, speech of lama, ii. 231 ; temple, i. 309.

Perpetual snow, ii. 107, 136.

Pheasants, i. 244.

Phonix paludosa, ii. 338.

Phospliorescence, ii. 158.

Phud, ii. 190.

Picrorhiza, i. 259.

Pitcher plant, ii. 309.

Plain of Tibet, ii. 175.

Plants transported in ice, ii. 255.

Poisoners, i. 59.

Polygonum, ii. 54.

Praying cylinder, i. 161, 195 ; ii. 196.

Pundim, i. 323.

Punkabaree, vegetation of, i. 96.

RAGEU, ii. 112.

Rajah, Sikkim, i. 285, 287 ; house, ii. 195 ; seizure of Terai lands, ii. 247.

Rampore Bauleah, ii. 258.

Rangamally, ii. 17.

Ratong valley, i. 324, 335 .

Rhododendrons, i. 116, 239 ; ii.

77 ; honey poisoned by, i. 190.

Rhododendron leaves, curling of, ii. 203 ; poisoning of sheep by, ii. 158 .

Rhubarb, gigantic, ii. 77 .

Rice paper, i. 336.

Rivers, temperature of, i. 278 ; velocity of, ii. 113.

Rotasghur, i. 34.

Rose in plains of Bengal, ii. 261.

Roses, attar of, i. 71 .

Ryott valley, ii. 194.

Sakinizung, ridge of, i. 181.

Sakkya Sing, i. 305.

Salmon, ii. 187.

Salt-smuggling, i. 319, 327; ii. 326.

Sand waves, i. 32.

Saussurea gossypina, i. 215.

Scandent trees, i. 154.
Scorpions, i. 46.

Screw pine, i. 284.

Seetakoond, ii. 335 ; hot springs of, i. 80 .

Sheep, wild, i. 233.

Shigatzi-jong, ii. 176.

Sidingbah, i. 261.

Sikkim, i. 105 ; fruits of, i. 150 ; history of, i. 310 ; inhabitants of, i. 117 ; temples of, i. 301, 341 ; valleys of, i. 267.

Siligoree, i. 91.

Silhet, ii. 325.

Simonbong temple, i. 161.

Sinchul, i. 103, 115.

Singtam Soubah, ii. 40, 87, 155 , 205 ; disgraced, ii. 215.

Snakes, 49, 112, 300.

Soane river, i. 30 ; cross, i. 41, 46 ; valley, vegetation of, i. 42 .

Songboom, i. 338.

Soorujkoond, hot springs of, i. 23.

Sunderbunds, i. 1; ii. 337 ; Flora and Fauna of, ii. 265.

Sunrise and sunset, false, i. 56, 179.

TALLunt, vegetation of, ii. 86 .

Tamarisk, ii. 17.

Tambur river, i. 183, 190, 262.

Tassiding, convent of, i. 299.

Tchebu Lama, i. 286 ; ii. 32.

Tea plant, i. 134.

Teesta river, i. 145; exit from mountains, ii. 20.

Teeta, i. 259 .

Tendong mountain, ii. 30.

Terai, i. 91 ; ii. 3,5 ; vegetation of, i. 92.

Terraces, ancient, i. 231.

Thomson, Dr., arrival at Dorjiling, ii. 245 .

Thuggee, i. 58, 60 .

Tibet, i. 283 ; ii. $132,135,172$; animals of, ii. 108, 164, 179 ; frontier, ii. 64, 82, 98, 136.

Tibetans, i. 250 ; ii. 103 ; churns, ii. 95 ; Dingpun, ii. 204 ; dress of, i. 191 ; food of, i. 201 ; guard, ii. 204; guitar, i. 288 ; household, i. 201 ; mastiff, i. 193, 273 ; ponies, ii. 94 ; saddle, i. 279 ; salute, i. 192 ; ii. 47 ; 
sepoys, ii. 162, 167; tents, i. 206.

Tide wave, ii. 329 .

Tiger hunt, i. 50.

Titalya, i. 91 ; ii. 4 .

Tobacco, Chinese, ii. 239.

Toddy, i. 30, 33.

Tonglo, camp on, i. 159, 174; excursion to, i. 146 ; height of, i. 160 ; vegetation of, i. 152,157 ; view from summit, i. 175 .

Tree frog, i. 156.

Tumloong, ii. 195; gathering of Lamas at, ii. 230 .

Tungu, ii. 92.

Tunkra pass, ii. 122.

Tupgain Lama, i. 273.

Vanda ccerulea, ii. 314.

Vanda reared from seed, ii. 253.

Vegetation of temperate zone, i. 158 ; retardation of, ii. 185.
WALLANOHOON, i. 189, 196, 206 ; convents, i. 218 ; temperature of, 209.

pass, height of, i. 215 ; vegetation of, i. 210 ; visit to, $i$. 213.

Walnut, i. 313.

White ants' hills, i. 18.

Wormwood, ii. 44.

YAKS, i. 202.

Yalloong river, i. 257.

Yangma Guola, i. 219; lake, i. 226 ; valley, i. 221,238 ; convents of, i. 225 ; village, 228 ; village, cultivation at, 228, 230 .

Yaru river, ii. 177.

Yeumtso, ii. 169.

Yoksun, i. 314 ; lake, i. 337.

ZeMu Samdong, ii. 65, 81, 156.

THE END. 




7.

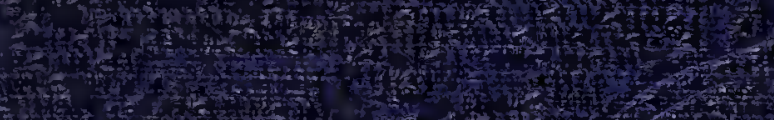

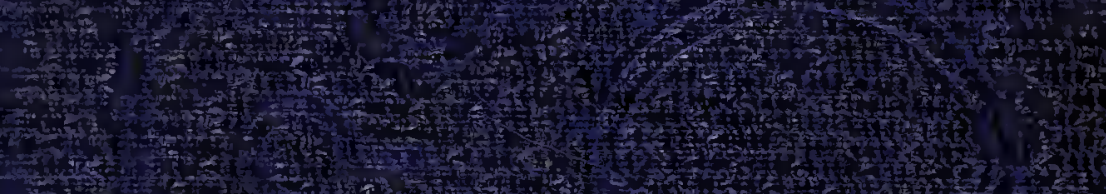

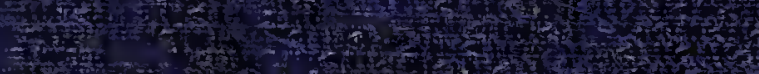

F.

(1)

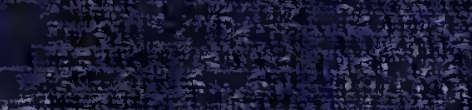

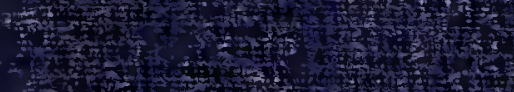

-

10
7

A

3.1.

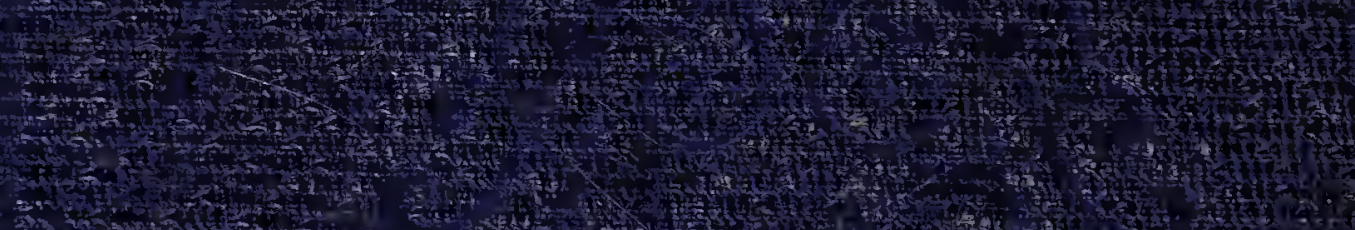

3
4

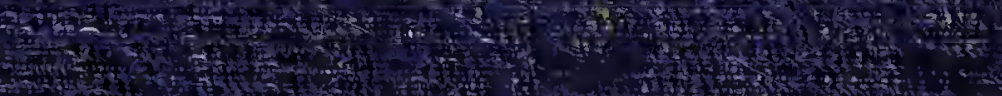

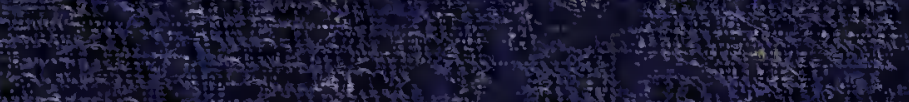

4.

7.t.

W.

7.

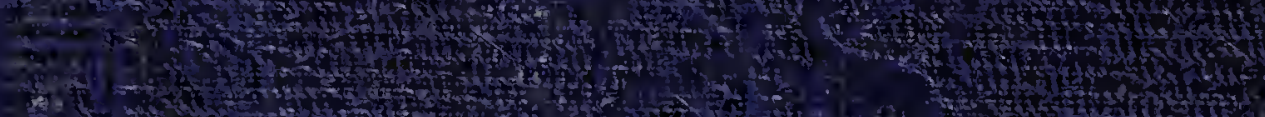

8.

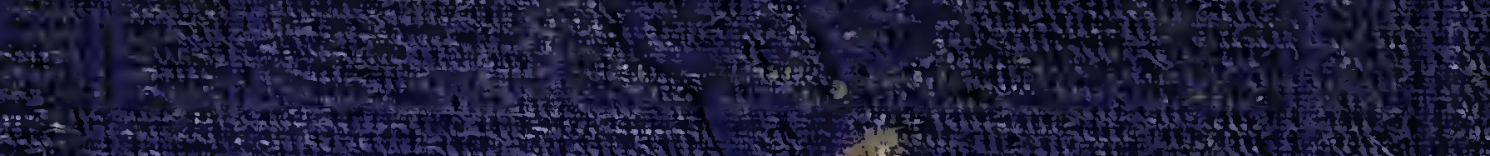

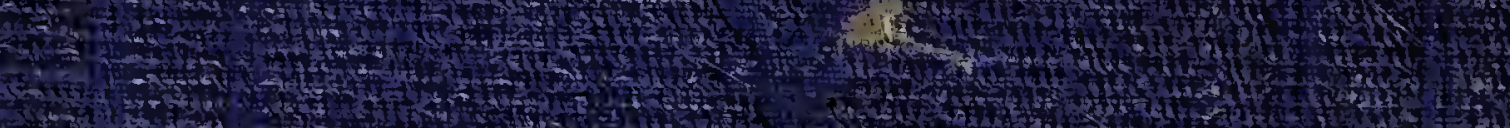

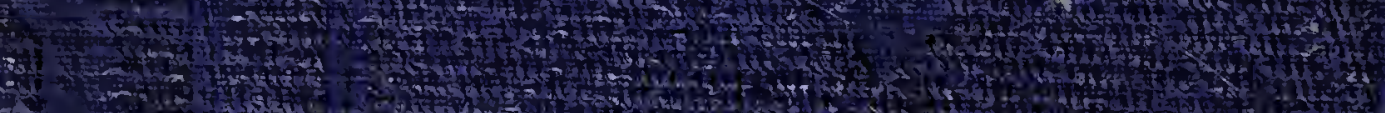

W.

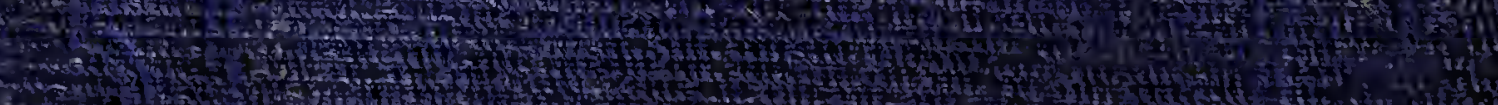

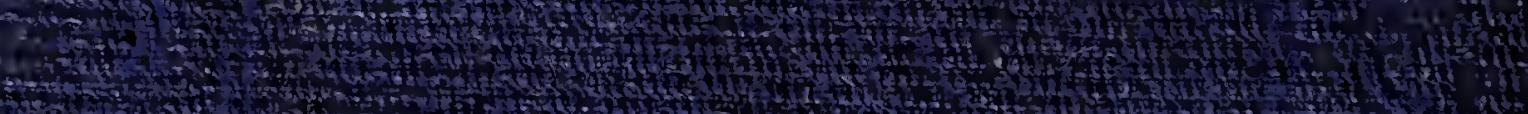

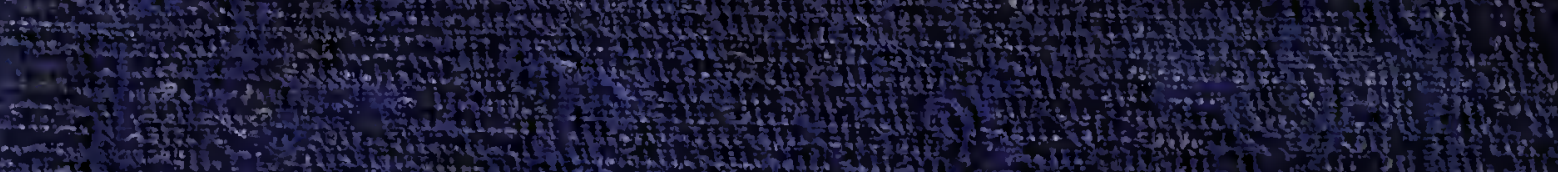

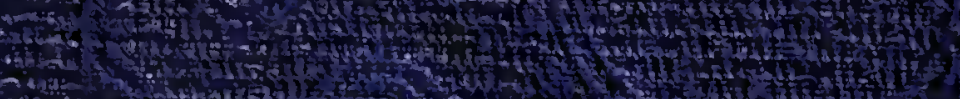

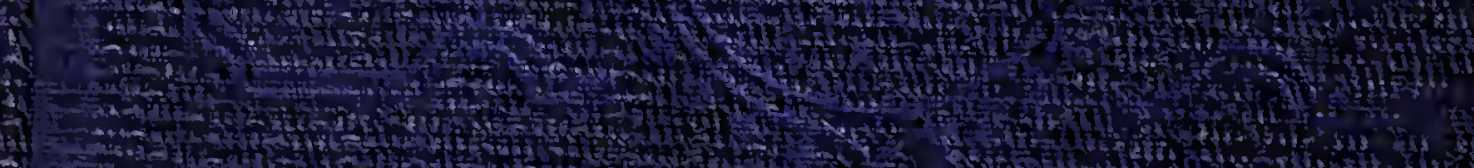

A.

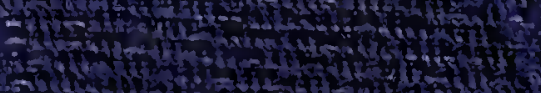

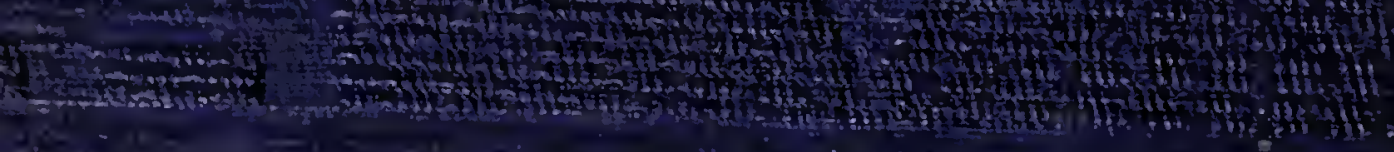

ate

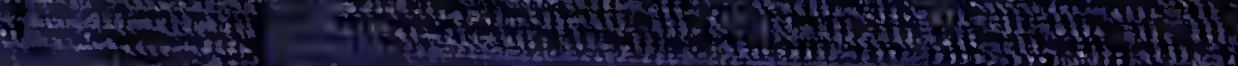

